\title{
Medicines for the developing world : innovation and economic policy
}

Citation for published version (APA):

Daems, R. (2008). Medicines for the developing world : innovation and economic policy. [Doctoral Thesis, Maastricht University]. Universitaire Pers Maastricht. https://doi.org/10.26481/dis.20081128rd

Document status and date:

Published: 01/01/2008

DOI:

10.26481/dis.20081128rd

Document Version:

Publisher's PDF, also known as Version of record

\section{Please check the document version of this publication:}

- A submitted manuscript is the version of the article upon submission and before peer-review. There can be important differences between the submitted version and the official published version of record.

People interested in the research are advised to contact the author for the final version of the publication, or visit the DOI to the publisher's website.

- The final author version and the galley proof are versions of the publication after peer review.

- The final published version features the final layout of the paper including the volume, issue and page numbers.

Link to publication

\footnotetext{
General rights rights.

- You may freely distribute the URL identifying the publication in the public portal. please follow below link for the End User Agreement:

www.umlib.nl/taverne-license

Take down policy

If you believe that this document breaches copyright please contact us at:

repository@maastrichtuniversity.nl

providing details and we will investigate your claim.
}

Copyright and moral rights for the publications made accessible in the public portal are retained by the authors and/or other copyright owners and it is a condition of accessing publications that users recognise and abide by the legal requirements associated with these

- Users may download and print one copy of any publication from the public portal for the purpose of private study or research.

- You may not further distribute the material or use it for any profit-making activity or commercial gain

If the publication is distributed under the terms of Article $25 \mathrm{fa}$ of the Dutch Copyright Act, indicated by the "Taverne" license above, 


\section{MEDICINES FOR THE DEVELOPING WORLD}

Innovation, Economics and Policy 
November 2008

Published by Universitaire Pers Maastricht

Printed in The Netherlands by Datawyse Maastricht

ISBN 9789052787862

Information about the commercial edition is available on www.globalstrategicmanagement.info

(C) 2008 by Rutger Daems

ALL RIGHTS RESERVED. NO PART OF THIS PUBLICATION MAY BE REPRODUCED OR TRANSMITTED IN ANY FORM OR BY ANY MEANS, ELECTRONIC OR MECHANICAL, INCLUDING PHOTOCOPY, RECORDING OR ANY INFORMATION STORAGE AND RETRIEVAL SYSTEM, WITHOUT PERMISSION IN WRITING FROM THE AUTHOR. 


\title{
MEDICINES FOR THE DEVELOPING WORLD
}

\section{Innovation, Economics and Policy}

\author{
Proefschrift \\ ter verkrijging van de graad van doctor aan de Universiteit Maastricht, \\ op gezag van de Rector Magnificus, Prof. mr. G.P.M.F. Mols, \\ volgens het besluit van het College van Decanen, \\ in het openbaar te verdedigen op \\ donderdag 27 november 2008 om 16.00 uur \\ door
}

Rutger Daems

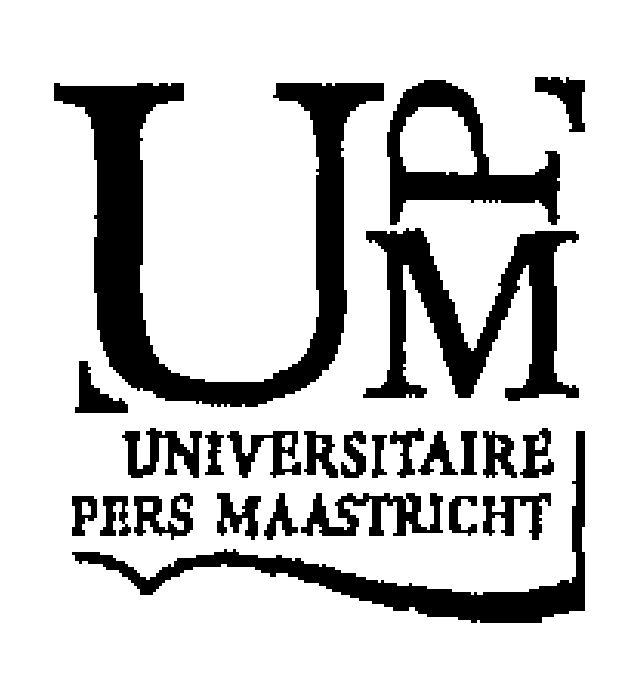




\section{Promotor}

Prof. dr. L.L.G. Soete

\section{Beoordelingscommissie}

Prof. dr. B. Verspagen (voorzitter)

Prof. dr. J.F. den Hertog

Prof. dr. F. van Merode 


\section{Table of contents}

Preface $\quad$ IX

Abstract XII

List of acronyms XIV

List of tables and figures $\quad$ XVII

$\begin{array}{ll}\text { Introduction } & 1\end{array}$

1 Challenges in poverty reduction: Health and economic growth 23

1.1 Introduction 24

1.2 The health and wealth relationship 24

1.3 A health crisis in the developing world 33

1.4 Access to existing and novel medicines 39

1.5 Conclusion 54

2 Innovation and diffusion: International trade, pricing and patents $\quad 57$

2.1 Introduction 58

2.2 Economic analysis of patents and 'market failure' 59

2.3 Differential pricing and international trade barriers $\quad 74$

$\begin{array}{ll}2.4 & \text { Economics of TRIPS options for access to medicines }\end{array}$

2.5 Conclusion 84

3 The supply and demand side of pharmaceutical product innovation $\quad \mathbf{8 7}$

3.1 Introduction 88

3.2 The demand for pharmaceutical and healthcare products 89

3.3 The supply of pharmaceutical and healthcare 95

3.4 The pharmaceutical and medical biotechnology industry 109

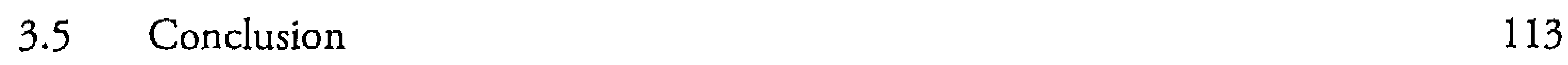

4 Product innovation and risk in the pharmaceutical $\begin{array}{ll}\text { and biotech industry . } & 117\end{array}$

$\begin{array}{lll}4.1 & \text { Introduction } & 118\end{array}$

4.2 Process for discovery and development of new medicines 119

4.3 Average costs and returns to new medicine introductions 128

4.4 R\&D on neglected diseases and public/private partnership 135

$\begin{array}{lll}4.5 & \text { Conclusion } & 143\end{array}$ 
5 Theoretical perspectives on risk-adjusted valuation of pharmaceutical R\&D $\quad 145$

5.1 Introduction 146

5.2 Payback, IRR, and NPV discounted cash flow analysis 147

5.3 Options pricing theory applied to valuation of $\mathrm{R} \& \mathrm{D}$ projects $\quad 150$

5.4 Risk-adjusted discount tates and the firm's cost of capital 155

5.5 Project-related technical risks and global market uncertainty 161

5.6 Use of decision-tree simulation in evaluating R\&D projects 165

$\begin{array}{lll}5.7 & \text { Conclusion } & 168\end{array}$

6 Pharmaceutical R\&D on developing world diseases:

$\begin{array}{ll}\text { A 'risk-investment-incentive' model } & 171\end{array}$

$\begin{array}{lll}6.1 & \text { Introduction } & 172\end{array}$

6.2 Building an integrated 'risk-investment-incentives' model 172

6.3 Risk and investment relationship in R\&D on developing world diseases $\quad 174$

6.4 Incentives-investment relationship in R\&D on developing world diseases 184

6.5 Calculating the impact of 'push' and 'pull' incentive mechanisms 190

$\begin{array}{ll}6.6 & \text { Conclusion } \\ & 195\end{array}$

7 Public incentive mechanisms for stimulating pharmaceutical $\begin{array}{ll}R \& D \text { on poverty-related diseases } & 197\end{array}$

$\begin{array}{ll}7.1 \text { Introduction } & 198\end{array}$

7.2 Overview of 'push' and 'pull' incentive systems for stimulating R\&D 200

7.3 Technology push systems to support R\&D on developing world diseases 206

7.4 Market pull systems for stimulating R\&D on developing world diseases 210

$\begin{array}{ll}7.5 \text { Conclusion } & 219\end{array}$

8 Calculating the size of incentives to accelerate pharmaceutical $\begin{array}{ll}R \& D \text { on poverty-related diseases. } & 221\end{array}$

$\begin{array}{lll}8.1 & \text { Introduction } & 222\end{array}$

8.2 Advance Market Commitments (AMCs) and critical success factors 224

8.3 Base scenario for a hypothetical new medicine development project 226

8.4 Sensitivity analysis and simulation of variations in model parameters 228

8.5 Case study: pneumococcal prophylaxis analysis results 245

$\begin{array}{ll}8.6 \text { Conclusion } & 249\end{array}$ 
9 Anticipating emerging global illnesses: Public health policy and industrial alignment

9.1 Introduction 252

9.2 Disease prevention strategies and industrial policy alignment 255

9.3 Public policy for stimulating new medicines R\&D and production 256

9.4 Pandemic influenza: how to mitigate the socio-economic consequences 266

$\begin{array}{ll}9.5 \text { Conclusion } & 271\end{array}$

10 Alternative innovation models for medicines discovery, $\begin{array}{ll}\text { development and risk sharing } & 273\end{array}$

$\begin{array}{lll}10.1 & \text { Introduction } & 274\end{array}$

10.2 Global Medical Research and Development Treaty (MRDT) 276

10.3 IPR buy-out/prizes, patent pooling, and open source innovation 283

10.4 New public-private partnerships in medical product development 302

$\begin{array}{ll}10.5 \text { Conclusion } & 312\end{array}$

Summary and conclusions

$\begin{array}{ll}\text { Key research findings and policy implications } & 317\end{array}$

$\begin{array}{ll}\text { Samenvatting en conclusies (Dutch version) } & 336\end{array}$

$\begin{array}{ll}\text { Bibliography } & 355\end{array}$ 


\section{PREFACE}

This dissertation is about the economics of developing new medicines that address current unmet medical needs, particularly in the developing world - and the implications for business and public policy. In the pursuit of achieving international economic development and equity in health, there are many obstacles to overcome, especially by the poor and marginalized populations in the world as they are disproportionately affected by disease. The structural improvement of health care systems, services and products, as well as ensuring access, is an important factor in the pursuit of these goals. This also means ensuring that good quality, safe and effective medicines are available and effective in addressing existing and unmet medical needs. But this is only one element of a larger puzzle. More attention beyond treatment and prevention of ill health is needed to create the environmental conditions for individuals, communities and countries to overcome poverty and to live together in prosperity and peace.

Scientific-medical research in academia and applied pharmaceutical product development in industry have a vital role to play in attaining the Millennium Development Goals (MDG) through improving health and as a result reducing poverty. But, to reconcile the different needs of patients, pharmaceutical companies and public health services is far from simple. Patients require quality treatment, pharmaceutical companies need an environment in which investment and innovation are rewarded, and public health services are constantly struggling to keep costs down. The development of innovative medicines for as yet unconquered diseases in the developing world poses an even greater challenge. But no single stakeholder is expected to accomplish all of the tasks required to invent these medicines, bring them successfully to market, and ensure they are within the reach of patients. Besides advanced science and engineering skills, an understanding of international business, industrial economics and financing systems is necessary, and a public policy must be developed to stimulate pharmaceutical research and development $(R \& D)$ on poverty-related diseases. Such endeavor necessitates a public private partnership and a series of concerted and wellmanagement activities between key entities comprising governments, health organizations, academia, industry, and non-governmental organizations. The efforts and resources mobilized in such a partnership must be sustainable as these projects will take many years and cost hundreds of millions of U.S. dollars. It is therefore crucial for these initiatives to receive long-term commitments at the highest political level.

There are a number of real and perceived risks concerning private-sector investment in the development of novel therapeutic treatments and prophylactic vaccines to combat diseases like HIV/Aids, tuberculosis and malaria that cause significant havoc, and thus negatively affect growth in the developing world. Many questions posed by different stakeholders have spawned controversial debate: What are the barriers to $R \& D$ in this therapeutic area? What 
is the role of private companies? And what is the role of government? Where to collaborate and where to compete? Are intellectual property rights (IPRs) a good or a bad thing? How much money should we spend on $R \& D$ projects? What about radically different methods of technical innovation? At last, can patients in poor countries afford these new medicines? To formulate an adequate answer to these questions we first need to thoroughly understand the medical technology innovation process.

This dissertation studies the association between risk and investment in often lengthy and complex pharmaceutical and biomedical R\&D projects, and how such risks can be mitigated. A private corporation's decision to invest, or not to invest, in such R\&D projects can be positively influenced by public incentive mechanisms that aim to accelerate the development of medicines for diseases prevalent in developing countries. One of the key proposals that recently captured the attention of world leaders is a novel international financing system termed Advance Market Commitment (AMC). Over the last three years, this socalled 'pull' incentive system has evolved from an academic concept to an ambitious pilot project that has the potential to save hundreds of thousands of lives in least developed countries (LDC). It is anticipated that, if the AMC pilot project shows positive results in 2008-2010, the G7/G8 together with other sponsors and philanthropists will show interest in applying this new economic mechanism to a broad range of neglected diseases.

The author has been an active member of various multi-disciplinary taskforces that were created under the auspices of the G7/G8 to study this area of innovation in technology financing. The author's task was facilitated not only by being a member of the World Bank's Global Advisory Group on Innovative Financing Systems, but also as a member of the GAVI Alliance Executive Committee, and as the former Chair of the Global Executive Committee for Biologicals and Vaccines at the International Federation of Pharmaceutical Manufacturers and Associations in Geneva (IFPMA). His professional experience and academic interests in globalization, strategy and innovation together with his educational background in economics, science and technology place him in a position to not only provide a holistic approach in examining these problems but to formulate solutions that are acceptable to all stakeholders. Additionally, the advantage of having been a member of various public private partnerships has facilitated direct access to the various stakeholder groups with the purpose of conducting in-depth interviews with members of public policy bodies, as well as corporate senior executives, many of whom are key decision makers in capital investment, resource allocation, and strategic portfolio management.

Therefore, the author would like to profoundly thank all members of the public and private sector with whom he has worked over the past five years, and in particular those colleagues from the World Bank, World Health Organization, The GAVI Alliance, The Bill \& Melinda Gates Foundation, The Center for Global Development in Washington DC, BIO 
Ventures for Global Health, and of course my colleagues from industry in both the industrialized and emerging economies. The results of our hard work, intense discussions and open collaboration, and the common drive to create an environment for sustainable international development and economic growth, have truly enriched my life. I am also very grateful for the support received from Prof. Luc Soete, Professor of International Economics and Director of the UNU-MERIT Institute, a renowned international research institute specialized in the economics and management of technology and innovation. UNUMERIT which is co-managed by the United Nations University and Maastricht University in the Netherlands, has provided a safe haven for me - particularly during my sabbatical leave from industry - where I could reflect and study, test new paradigms, and ultimately develop the concepts underpinning this book. Finally, this work could not have been completed without the professional editorial assistance of Dr. Edith Maes and Ms. Alia den Baars.

Although the individuals and institutes listed above have provided many constructive comments and suggestions, they were not asked to endorse the conclusions and recommendations expressed in this book. The responsibility for the final content of this publication rests entirely with the author. 


\begin{abstract}
Over the last decade, the public sector has recognized the need to develop new health technologies to address the problems of the poor in developing countries. It acknowledged that the only way to bring products successfully to the marketplace is to work in conjunction with the private sector, that is, the multinational and local pharmaceutical and biotechnology firms. This dissertation argues that the traditional paradigm in which the 'public crowd' and the 'private crowd' confront each other represents incomplete and counterproductive views of the world. It offers instead a unifying innovation framework that fosters public private partnership. In today's market economies, firms usually seek to obtain a high return on their investment particularly those that take the risk of investing in complex products. However, there is little incentive in developing drugs, diagnostics or vaccines if patient-consumers cannot access them. Poverty stricken countries have the most vulnerable populations, but are least capable of accessing the health services and products needed. In many cases, these countries are simply unable to afford prices that would cover investment costs in research and development $(R \& D)$. It is imperative to find innovative solutions that resolve this conundrum. This study provides new insights into the relations between corporate investment, and technical, market, and financial risks, as well as economic incentives including patent rights. An integrated model that characterizes and evaluates novel funding mechanisms to support medicines R\&D has been constructed, and the positive, as well as unintended negative consequences, of a number of 'push-pull' mechanisms are examined. We recommend that governments support only those systems that are likely to accelerate the development of medicines for neglected diseases, and thereby improve the welfare of the most deprived populations in the world.
\end{abstract}

Key words: International Economics, Public Policy, Corporate Strategy, Innovation Management, Pharmaceuticals. 


\section{ABSTRACT (Dutch version)}

De publieke sector heeft het laatste decennium ingezien dat er nood is aan nieuwe gezondheidstechnologie om de armoedeproblemen in derdewereldlanden te bestrijden. Het heeft ook erkend dat de snelste en efficiëntste manier om dit doel te bereiken ligt in een samenwerking met de private sector, namelijk de farmaceutische en biotechnologische bedrijven. In deze dissertatie zullen we dieper ingaan op de moeizame relatie tussen de publieke en de private sector al zien we tegenwoordig de creatie van meerdere samenwerkingsakkoorden. In de hedendaagse internationale markteconomie verwachten bedrijven om profijt te kunnen halen uit hun investeringen. $\mathrm{Zij}$ hebben namelijk tijd, moeite en geld geïnvesteerd in de ontwikkeling van hun product. Dit leidt automatisch tot de vraag: waarom investeren in de ontwikkeling van nieuwe medicijnen, behandelingen, en vaccins indien de patiëntklant geen toegang kan krijgen tot deze nieuwe producten? Armere landen hebben namelijk niet het budget om deze nieuwe producten aan te schaffen tegen kostprijs, laat staan tegen hogere prijzen. Nieuwe en innoverende oplossingen zijn vereist om dit probleem te verhelpen. In dit proefschrift hebben we een analytisch kader opgesteld, en dit kader zal gebruikt worden om nieuwe financieringsmethodes voor $R \& D$ te bespreken en te evalueren. De positieve effecten van 'push-pull' mechanismen zullen besproken worden, net als de ongewilde negatievere effecten ervan. Deze studie geeft nieuwe inzichten in de relatie tussen enerzijds bedrijfsinvesteringen en technische, marktgerelateerde en financiële risico's, en anderzijds economische stimuli inclusief octrooien die regeringen kunnen aanwenden om de ontwikkeling van nieuwe medicijnen tegen veronachtzaamde ziektes te steunen, en daardoor de internationale welvaart te bevorderen van de meest kwetsbare populaties in de wereld.

Kernwoorden: Internationale Economie, Publiek Beleid, Bedrijfsstrategie, Innovatie Management, Farmaceutica. 


\section{LIST OF ACRONYMS}

\begin{tabular}{|c|c|}
\hline ADIP & Accelerated Development and Introduction Planning \\
\hline AMC & Advance Market Commitment \\
\hline $\mathrm{APC}$ & Advance Purchase Commitment \\
\hline ARV & Anti-RetroViral drugs \\
\hline BCG & Boston Consulting Group \\
\hline BOP & Bottom of the Pyramid \\
\hline BVGH & BIO Ventures for Global Health \\
\hline CAPM & Capital Asset Pricing Model \\
\hline CBD & Convention on BioDiversity \\
\hline $\mathrm{CEO}$ & Chief Executive Officer \\
\hline CGD & Center for Global Development \\
\hline $\mathrm{CIPH}$ & Commission on Intellectual Property Rights, Innovation and Public Health \\
\hline CRADAs & Cooperative for Research and Development Agreements \\
\hline CSIS & Center for Strategic and International Studies \\
\hline CSR & Corporate Social Responsibility \\
\hline CVI & Children's Vaccine Initiative \\
\hline DALY & Disability-Adjusted Life Year \\
\hline $\mathrm{DBF}$ & Dedicated Biotechnology Firms \\
\hline EADS & The European Aeronautic Defence and Space Company \\
\hline ECG & Electrocardiogram \\
\hline EDCTP & European and Developing Countries Clinical Trials Partnership \\
\hline EFPIA & European Federation of Pharmaceutical Industry and Associations \\
\hline EIV & Expected Investment Value \\
\hline EME & Established Market Economies \\
\hline EMEA & European Medicines Evaluation Agency \\
\hline ENPV & Expected Net Present Value \\
\hline EVM & European Vaccine Manufacturers \\
\hline FDA & Food and Drug Administration \\
\hline FDI & Foreign Direct Investments \\
\hline FLOSS & Free/Libre/Open Source Software \\
\hline GATB & Global Alliance for TB Drug Development \\
\hline GATS & General Agreement on Trade in Services \\
\hline GAVI & Global Alliance for Vaccine Initiatives \\
\hline GCP & Good Clinical Practice \\
\hline GDP & Gross Domestic Product \\
\hline GFATM & Global Fund to fight AIDS, Tuberculosis, and Malaria \\
\hline GLP & Good Laboratory Practice \\
\hline GMP & Good Manufacturing Practice \\
\hline
\end{tabular}




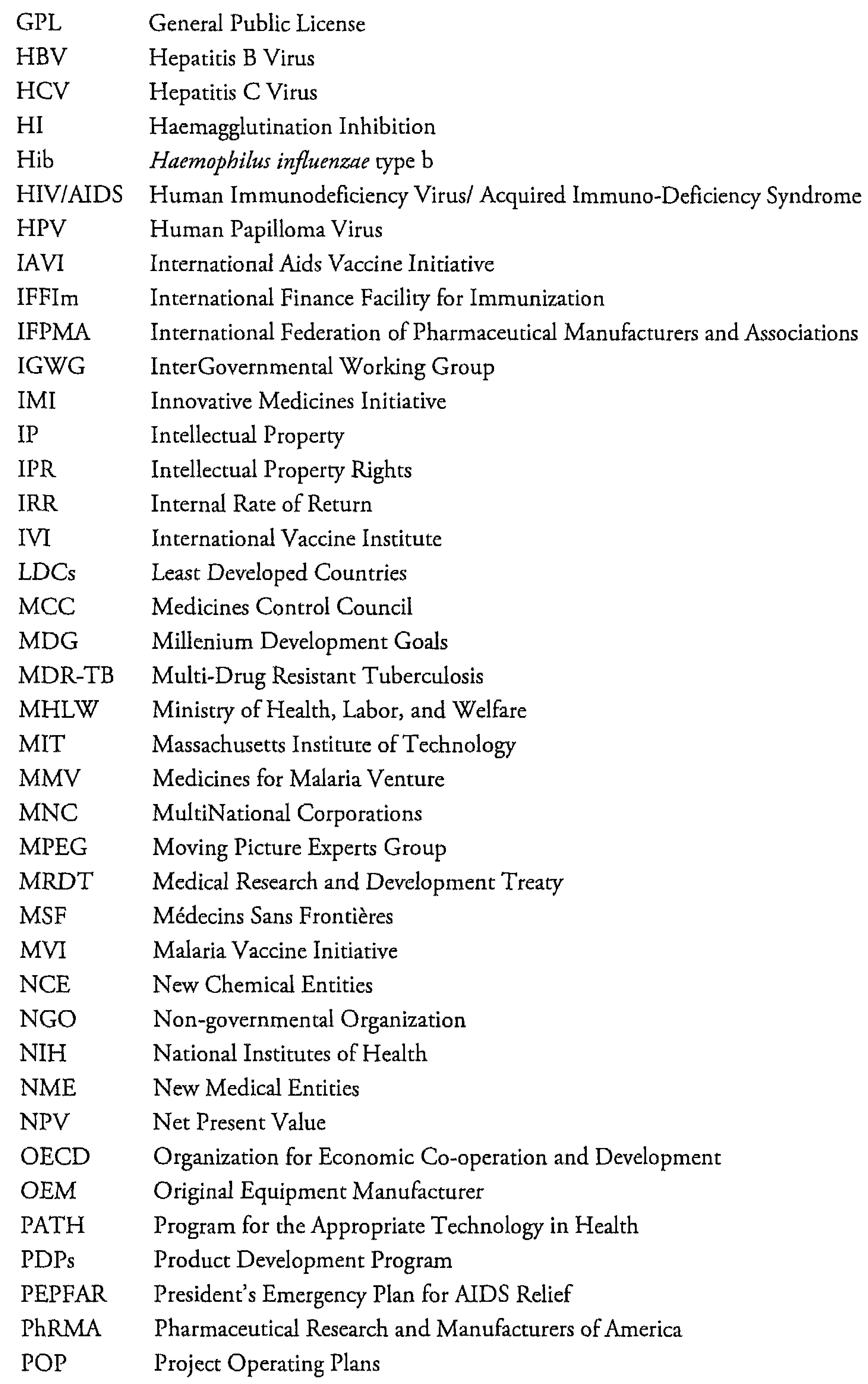




$\begin{array}{ll}\text { PPP } & \text { Public-Private Partnerships } \\ \text { PV } & \text { Present Value } \\ \text { PWC } & \text { PriceWaterhouseCooper } \\ \text { R\&D } & \text { Research and Development } \\ \text { ROE } & \text { Return on Equity } \\ \text { ROI } & \text { Return on Investment } \\ \text { SARS } & \text { Severe Acute Respiratory Syndrome } \\ \text { SME } & \text { Small and Medium Enterprise } \\ \text { SML } & \text { Security Market Line } \\ \text { S\&P } & \text { Standard \& Poor Index } \\ \text { SRA } & \text { Strategic Research Agenda } \\ \text { TAT } & \text { Therapeutic Area Teams } \\ \text { TB } & \text { Tuberculosis } \\ \text { TDR } & \text { WHO Special Program for Research and Training in Tropical Diseases } \\ \text { TNC } & \text { Trans-national Corporation } \\ \text { TRIPS } & \text { Agreement on Trade Related aspects of Intellectual Property rights } \\ \text { UNCTAD } & \text { United Nations Conference on Trade and Development } \\ \text { UNDP } & \text { United Nations Development Program } \\ \text { UNICEF } & \text { United Nations International Children's Fund } \\ \text { UNU } & \text { United Nations University } \\ \text { USAID } & \text { United States Agency for International Aid } \\ \text { WACC } & \text { Weighted Average Cost of Capital } \\ \text { WHA } & \text { World Health Assembly } \\ \text { WHO } & \text { World Health Organization } \\ \text { WIPO } & \text { World Intellectual Property Organization } \\ \text { WTA } & \text { World Trade Association } \\ \text { WTO } & \text { World Trade Organization } \\ \text { XDR-TB } & \text { Extensive Drug Resistant Tuberculosis } \\ & \end{array}$




\section{LIST OF TABLES AND FIGURES}

Table $1 \quad$ R\&D by the ten largest international sectors

Table 2 Estimated global health R\&D funding (in USD)

Table 3 Nominal and real cost-of-capital for the pharmaceutical industry

Table 4 Definition of the independent variables (X1, X2, X3)

Table 5 Definition of the dependent variable (Y)

Table 6 List of push and pull incentive mechanisms to stimulate pharmaceutical $\mathrm{R} \& \mathrm{D}$

Table 7 Summary of characteristics of push/ pull incentive systems

Figure 1 Areas influencing $R \& D$ investment in developing world medicines

Figure 2 Inequalities between OECD (richest) and LDCs (poorest) countries

Figure 3 Overview of the Millennium Development Goals (MDGs)

Figure 4 GDP/capita vs. percentage of deaths caused by infectious diseases; by WHO region and mortality stratum

Figure 5 Principle of identifying the optimal patent length

Figure 6 The particular need for patents for pharmaceuticals

Figure 7 The status of medicines: continuous need for product innovation

Figure 8 Standard drug development process and time (years)

Figure 9 Probability of clinically tested compounds entering various phases to gain approval

Figure $10 \quad$ Expenditures per prescription drug

Figure 11 New drug approvals have fallen steadily since 1996

Figure 12 Present values by deciles for 1990 to 1994 new drug introductions

Figure 13 Pharmaceutical product patent real timeline

Figure 14 Option to postpone corporate investment in R\&D on LDC diseases

Figure 15 The pharmaceutical product development 'stage-gate' process

Figure 16 Computer simulation supporting R\&D investment planning and risk assessment

Figure 17 Frequency distribution of discounted profit values for two hypothetical R\&D projects

Figure 18 Framework for an integrated 'risk-investment-incentive' model

Figure 19 Risk and investment framework for pharmaceutical $R \& D$

Figure 20 Real options methodology applied to pharmaceutical 'stage-gate' product development process

Figure 21 Two-stage model illustrating 'push' and 'pull' incentive systems

Figure 22 Real options methodology applied to medicines development for industrialized (EME) and/or developing (LDC) countries 
Figure 23 Push and pull mechanisms applied to three scenarios for the development of medicines for LDC countries

Figure 24A Pushing and pulling potential new medicines through development

Figure 24B Characteristics of push and pull options

Figure 25 Global disease category pipeline for vaccines

Figure 26 Calculating pharmaceutical / biotech R\&D investment options

Figure 27 Introduction of $\mathrm{HepB}$ and $\mathrm{Hib}$ vaccines into developing countries

Figure 28 Hypothetical new medicine project: sensitivity analysis

Figure 29 AMC two-stage pricing model for global equity

Figure 30 Minimum threshold level for appropriating returns on R\&D investment

Figure 31 Probabilities of success and failure in a competitive environment

Figure 32 Estimated probability of obtaining market licensure

Figure 33 Demand forecasting for AMC pilot project in LDCs

Figure 34 Pandemic vaccine development: alignment of public health and pharmaceutical policy

Figure 35 Push and pull systems: underpinning pandemic vaccine development

Figure 36 Influenza pandemic vaccines: production, global supply and distribution

Figure 37 Cross-reactivity to $\mathrm{H} 5 \mathrm{~N} 1$ viruses after vaccination with adjuvanted $\mathrm{H} 5$ vaccine 


\section{MTROMUTWON}

\section{Background}

No greater improvement in health has been attained in the last hundred years, than at any other time in the last three millennia. In the last twenty-five years, the pace of global health improvements has accelerated, as increasing numbers of people have gained access to new health services, health technologies, better household environments and to education - but not all have benefited equally from these gains. More than $90 \%$ of mother and child deaths continue to occur in developing countries. The poorest $20 \%$ of the world's population are roughly ten times more likely to die before the age of fourteen than the richest $20 \%$. Lower income countries - and sub-Saharan Africa in particular - share a disproportionate burden of mortality and disability, and the global threat of the (re)emergence of new killer pathogens in the presently highly connected world threatens to reverse and compromise social and economic development in many parts of the world, once again particularly in those countries that are struggling with poverty.

Tackling health issues in the least developed countries (LDC) has been recognized by United Nations organizations like the World Bank, World Health Organization (WHO), and the United Nations International Children's Fund (UNICEF) as a vital part of tackling poverty. Better health and living conditions can directly contribute to reducing poverty by improving the quality of life for its citizens, expanding opportunities and safeguarding livelihoods and productivity. A healthier population with a longer life-span is likely to invest more time and effort in developing its human capital (newborns, children, and adults)

${ }^{1}$ Human Development Reporc, 2005. 
- which contributes to the further creation of knowledge and an acceleration in the diffusion of technology and medical innovations. Existing medicines - that is drugs, vaccines and diagnostics - have the intrinsic power to save lives and improve health when they are of assured quality, properly used, and affordable to the end-user (patient-consumer). However, the lack of access to currently available medicines, let alone new and innovative medicines, remains one of the most serious global health problems. Although considerable progress has been made in the last twenty-five years since the WHO introduced its essential medicines list, the benefits have been unequally distributed across populations. The result is unnecessary human suffering and an economic slowdown that create and maintain the status quo in poverty-stricken nations. The problem may even worsen as viral and bacterial resistance to some key medicines develops, such as for malaria, tuberculosis, pneumonia and HIV/aids - and when new medicines are developed to replace those that are no longer effective, they are often more expensive and more strictly controlled to ensure proper implementation.

With respect to still to be invented medicines, the research and development (R\&D), delivery of and access to priority medicines ${ }^{2}$ in the developing world is a particularly complex policy area. On the one hand, improved access to prescription drugs, vaccines and medical diagnostics requires reliable health care and distribution systems, increased and sustainable financing, rational and evidence-based policies about prescription and use, and prices that are affordable to the end-user. On the other hand, much more substantial and sustained investments are needed in advanced technological $R \& D$ programs. Because of the particularly high incidence of infectious diseases in the developing world, novel and improved medicines that prevent, treat, or ultimately eradicate those diseases afflicting primarily the poorest populations are needed. They represent an important and cost-effective component of a package of tools necessary to break the circle of poverty. Recent advances in biomedical discovery have brought hopes for better drug treatments and preventative vaccines closer to reality, but the challenges remain enormous. Many countries in the developing world face the onslaught of human immunodeficiency virus/ acquired immunodeficiency syndrome (HIV/AIDS) combined with the impact of high-burden diseases such as tuberculosis ${ }^{3}$ (TB) and malaria; as well as tropical diseases such as trypanosomiasis (sleeping sickness), leishmaniasis, schistosomiasis, dengue fever, etc. The transmission of the HIV causing AIDS is in principle preventable through behavioral change and the disease can be treated but not cured with the support of anti-retroviral (ARV) medicines. A

\footnotetext{
${ }^{2}$ Priority medicines are defined as those medicines that are needed to meet the priority health care needs of the population.

${ }^{3}$ The epidemics of HIV and tuberculosis (TB) are closely intertwined. One-third of the population infected with HIV are also infected with TB, and as their immune systems are increasingly compromised, they have a heightened susceptibility to active TB, which, because of their HIV infection is harder to diagnose and treat.
} 
vaccine to prevent this viral infection and its transmission, and thus ultimately stop the disease from spreading, is very much needed ${ }^{4}$.

Leading scientists believe that developing an HIV/AIDS vaccine is feasible in principle, but this does not make its development a foregone conclusion. The research and development aspect of a safe and effective prophylactic AIDS vaccine poses more than a few scientific challenges. A successful vaccine must elicit immune responses capable of blocking infection either by sexual, intravenous, or mother-to-child transmission. It must be capable of stimulating immune responses like antibodies that neutralize free virus particles, as well as cellular immune responses that destroy incoming virus-infected cells. The problem is understanding which anti-HIV immune responses are required for generating protective immunity against HIV and which components of HIV are necessary for an effective AIDS vaccine. The tremendous geographic diversity of the subtypes of HIV worldwide suggests that mixtures or 'cocktails' of vaccines may be required to induce universal protective immunity. At the current pace, it is likely to be several decades before an effective prophylactic agent becomes available in OECD countries, let alone in the developing world. It is even less likely to become a reality if the private sector is left to address the existing uncertainties that impede sustained investment in complex $R \& D$ and entrepreneurial risk-taking.

The current resources for $R \& D$ in the private sector are insufficient to fund the development of more than just a small number of much needed new vaccines and second and third-generation medicines that prevent or cure diseases of poverty. Incentives for the private sector to engage fully their resources in this area are currently not in place. However, they are essential for research, development, and scaling-up of manufacturing. The consequence is industry's continued focus on diseases for the industrialized world (i.e. cardio-vascular, cancer, diabetes, asthma, etc) and slow progress of clinical trials for neglected diseases. Were it available, commercial funding on behalf of the LDC that are by definition lacking investment capital and buying power themselves, would increase the number of products under development and accelerate worldwide clinical trials, and thereby raise the possibility of success for improved next generation medicines. Encouraging these R\&D efforts over time is therefore particularly important. What is urgently

\footnotetext{
${ }^{4}$ Vaccines represent the best hope for large, rapid and affordable improvenents in health in the developing world. But vaccines to prorect against HIV/AIDS and malaria do not yet exist. The vaccine against TB (Bacille CalmetteGuerin, or BCG) is almost 80 years old and, although protective for children, does not effectively protect adults against TB. HIV/AIDS prevention focuses largely on promotion of safe sex, use of condoms, together with fewer sexual contacts. All of these measures face behavioral, cultural and religious barriers. Preventing HIV/AIDS is also important for $\mathrm{TB}$, as a weak immune system causes the emergence of latent $\mathrm{TB}$ infection, which then poses a risk to others.
} 
needed is new pathways for long-term financing of scientific-medical discovery and product development aimed at bringing novel medicines to developing country markets.

\section{Scoping the problem}

The reality today is that for many of the diseases that are less prevalent or non-existent in high-income countries, there has been a chronic lack of interest in funding $R \& D$ projects that result in pushing the science further, leading to the registration and availability of new products. The lack of novel medicines and health technology products (i.e. drugs, vaccines, and diagnostics) to fight diseases that lead to poverty in primarily developing countries, is one of most pressing social responsibilities this world faces. The debate, at core, concerns the promotion of the production of public goods, in this case, of the sustainable, effective creation of useful health products that can be ushered through an extensive development and regulatory approval process, to be accessible to the public as safe, effective and proven medicines that were not otherwise available to the public.

However, investing in state-of-the-art medicines and health technology products is a complex and risky proposition. Only a handful of pharmaceutical firms and several smaller biotech companies have historically developed the necessary drugs and vaccines for the protection or treatment of infectious and other diseases. Basic scientific advances often occur in university research laboratories, but these public institutions are generally unable to spend the large sums of money that are required to transform the fundamental scientific discoveries into safe and effective prophylactic vaccines or drug treatments that can be approved and licensed. The transition from the initial medical-scientific 'discovery' phase to the applied product-oriented 'development' phase is more likely to occur in pharmaceutical and biotech corporations. They have the financial capacity and the technological knowhow, combined with the human resources specialized in clinical testing, regulatory affairs, as well as engineering and manufacturing.

Today, the low-, middle-, and high-income countries depend for the majority of their new medicines on high-tech companies based primarily in the United States, Western Europe and Japan. In future, upcoming R\&D-driven firms located in the emerging economies like India are expected to convert their generic medicine businesses to research-driven organizations. For the moment, however, these firms have limited experience and capabilities in pharmaceutical and biomedical $R \& D$, and as yet have produced virtually no new medicines. The pattern of geographic locations for $\mathrm{R} \& \mathrm{D}$ centers skewed towards $\mathrm{OECD}$ countries is largely explained by the fact that the pharmaceutical and biotech industry is not only a highly research driven sector but also capital-intensive. Despite the fact that the public 
sector in OECD countries generally finances and subsidizes basic scientific-medical research in universities and biomedical institutes, it has limited resources and expertise in transforming the basic discoveries into tangible products. It is now commonly accepted that the later stages of product development and testing and the engineering technology for their largescale manufacture are better undertaken by a capital-intensive private sector. After all, private firms can design and run these processes more efficiently because they have the skills, experience, infrastructure and know-how to invest in and manage these projects (Batson, Ainsworth, 2001; Ainsworth, Batson, 1999).

Broadly speaking, the process of medicines discovery, development and production requires a sustained mobilization of highly skilled human and financial resources over a long period of time before any promising compound reaches its patients. It takes an average of 10-15 years after which the first revenues can be generated by a pharmaceutical company to recoup its preliminary $R \& D$ investments. The total cost of developing a new medicine up to the point of its commercial launch - including the many product failures along the way plus the innovator's cost of capital - is estimated to amount to US\$ 802 million (DiMasi, 2003). This high cost is a reflection of the complexity of pharmaceutical and biotechnological science and engineering, as well as the rigorous regulatory hurdles that must be overcome to run clinical trials in different populations to demonstrate the new medicine's quality, efficacy and safety. Moreover, studies published by micro-economists have demonstrated that only three out of ten pharmaceutical products brought to market produce revenues that match or exceed their original R\&D costs (Grabowki, Vernon, 2002). In other words, few new compounds are generating sufficient revenues to recover the continuously increasing cost of pharmaceutical R\&D.

As one might expect, the $\mathrm{R} \& \mathrm{D}$ 'risk-investment' challenge is compounded when dealing with projects focused on developing-country diseases. For many disease and therapeutic product areas, the public health interest and industry's investment priorities coincide. In other disease areas, such as tropical diseases that are predominantly confined to poor countries, there is the inherent inability to pay for the development costs. In these cases, internationally sponsored public funding mechanisms may have to be created to forcefully and effectively respond to this gap in new medicines $R \& D$. For those diseases that are globally spread, as for example HIV/AIDS, the health problems of developing countries could be shared with the richer countries. It is, however, not that simple. For example, the particular strain (clade) of the HIV virus that is most common in Africa (clade C) differs from the clades that are usually prevalent in industrialized countries. It is unclear therefore and commonly presumed unlikely - that a vaccine developed to fight the clades prevalent in industrialized countries would also be effective against clade $\mathrm{C}$ seen in the poorest countries of the world. Suppose the vaccine is effective against clade $C$ as well, neither households nor public sector health budgets in these low-income countries will be able to afford the 
purchase of the product in sufficient numbers to prevent and treat the disease. Although there is a considerable local 'need' for health products that tackle diseases that are essentially poverty-related, this does not manifest itself in an actual 'market' (effective demand) for these products. And without customers who have the purchasing power, the incentive for the industry to engage in $\mathrm{R} \& \mathrm{D}$ that leads to the production of novel medicines could be rather limited. Given the likelihood of significant social and economic distress to these societies, multilateral and bilateral OECD interventions to create a valuable market on behalf of developing countries are warranted.

The dilemma of new medicines R\&D being subject to 'time consistency' also needs to be addressed. This refers to the fact that, despite the high $R \& D$ expenses for new medicine development, it can often be manufactured at relatively low marginal cost once the product has been developed. Armed with this knowledge, governments and supra-national procurement agencies like UNICEF may choose to use their buying power (monopsony) to obtain these products at a price that covers only the (marginal) production cost, but not necessarily includes the $R \& D$ costs, nor the cost of bearing the risk that these $R \& D$ efforts might fail. As a result, the possibility that politicians, pressure groups or procurement agencies rightfully use this 'gaming strategy' ex-post, may in fact dramatically lower the incentive for firms to take on any risky $R \& D$ projects. This suggests that governments' or buyers' credibility could be at stake when negotiating a price that covers not only the cost of manufacturing, but also all costs associated with discovery, development and large-scale production. An advance purchase agreement could be one form of signaling this commitment.

Skeptics would argue however that creating an effective market on behalf of developing countries is in itself not enough. Research of new medicines is considered by some a public good in the sense that knowledge generated by research is virtually costless to disseminate and limitless in the number of beneficiaries. Since the first company that invests in new medicines R\&D can expect to quickly see the benefits of its knowledge shared by its competitors - unless its intellectual property is protected - there is little incentive for the company to carry out this research, even though society would benefit from the knowledge it produces. Nonetheless, there are those who claim that the health needs of the poor have been almost entirely neglected by private sector R\&D efforts. Some have called for redesigning the current $R \& D$ paradigm in order to ensure that more efforts and resources are dedicated to diseases of poverty. The latter may suggest establishing a global Kyoto-style Medical Research and Development Treaty (MRDT) through which biomedical R\&D on 
neglected diseases could be centrally directed towards perceived health priorities. We developed an approach, however, that does not require a complete overhaul of the current R\&D system but employs very specific economic and policy measures that promote collaboration between the private sector, governments and public institutions. Such collaboration is necessary to stimulate $R \& D$ but at the same time to avoid excessive rent seeking. Therefore, its implementation requires adequate governance and legal structures to oversee and manage the new entity, alliance or public private partnership.

The ultimate goal is to foster enhanced collaboration between the public and private sector partners and to formulate public policy and corporate strategy recommendations based on a range of options from which governments, supra-national agencies, and industrial organizations can select. The objective is to propose a robust and sustainable innovation framework, which includes an R\&D funding mechanism. This could prove as important to the private sector as to the public sector. For the early stages of the 'upstream' discovery process, universities and government-funded biomedical research institutes are likely to remain the primary sites of innovation, as maintaining a climate that supports new ideas and open source innovation will be essential in overcoming basic challenges in science. For the late(r) stages of what is often referred to as the product-oriented 'downstream' development process (comprised of applied research, engineering and large-scale production), the bulk of work can efficiently be carried out by the multinational and/or local pharmaceutical and biotech companies. The role the (smaller) usually private biotechnology companies play and in particular those that focus entirely on research is in translating the fruits of fundamental scientific research into more practical applications eventually leading to the delivery of new tangible (medical) products. To effectively support and enhance future private sector's investment in advanced product development, governments should continue to put in place measures that protect the innovator or firm's intellectual property rights during a limited period. The question is how to find an appropriate balance. This book will weigh the pros and cons of such intervention.

All things considered, perhaps the biggest challenge is to ensure access to the newly developed medicines. There is no point in designing innovative medical compounds if patients cannot access them. Thus, there is a need to balance the interests of inventors in protecting their discoveries and the benefits such protection provides and the needs of the public, who benefits from wider access to knowledge that may lead to more discoveries and lower prices as a result of competition (Stiglitz, 2006). These two objectives should ideally be met simultaneously if they are to substantially reward true innovators by allowing them to

\footnotetext{
${ }^{5}$ The MRDT proposal hinges around a global credit trading mechanism, with signatory countries' credits earned from spending on a wide variety of types of $\mathrm{R} \& \mathrm{D}$. This thinking is borrowed from the Kyoto Protocol which deals with the problem of environmental $\mathrm{CO} 2$ emissions trading.
} 
recoup their investment and make a profit as a reward for entering into risky ventures, and by the same token, to offer these inventions to patient/consumers at an affordable price. The question of how to best achieve these two objectives has stirred controversy over the concept of intellectual property rights. While a number of civil society critics argue that (excessively) strong intellectual property rights slow down innovation and induce high prices, industry advocates of (even) strong(er) intellectual property rights suggest the contrary, saying that intellectual property rights stimulate research and that the price reflects the value of these medicines. The industry argues that without strong intellectual property protection, there would be no incentive for $R \& D$, and without $R \& D$, generic imitations of these medicines would not exist or be produced in developing countries. For these reasons, intellectual property rights cannot be an end in itself but are rather a means to an end. Both are legitimate viewpoints. While patents enhance societal welfare by stimulating innovation, there is the belief that patents artificially raise prices of medicines, hence limiting access to high-income countries. In conclusion, a well-designed policy for intellectual property must balance the costs of monopolization and the benefits of innovation, by limiting the period of the patent and the ability to use patents for 'abusive' monopoly power, and requiring disclosure of the details so that others can build on them,.

\section{Conceptual framework and model}

The aim of this dissertation is to contribute to the discussion of the role public, private, and governmental sectors have in the development of medicines that are urgently needed in LDCs. More specifically, this study seeks to develop and propose conceptual frameworks for enhanced pharmaceutical and biomedical innovation in the area of infectious diseases that are prevalent in these poorer countries.

An integrated analytical model will be constructed to map the relationship between risk and investment, and how this affects the discovery, development and production of medicines for use primarily in developing countries. The various technical, market and financial risk factors that currently slow down the development of such medicines will be analyzed and their impact measured by means of a dynamic stochastic simulation model. This simulation

\footnotetext{
${ }^{6}$ Intellectual property rights give the owner of that property the exclusive rights to use it. It creates a temporal monopoly. The owner of the property can, of course, allow others to use it, usually for payment of a fee. Intellectual property rights have been designed to protect inventors who have invested money and time in innovation and allow them to receive a return on their investment. Patents give an inventor exclusive rights to market the innovation for a limited period of time, currently twenty years. No one else can sell the exact same product without the permission of the patent holder. But in return for the patent, the applicant must disclose the details of the invention which, in turn, spurs innovation.
} 
model will allow policy-makers to calculate and optimize the size of government subsidies needed to accelerate critical projects by disease area. Understanding the impact that governments and in particular public incentive schemes have on a private firm's ability and willingness to invest in risky projects will indirectly help develop equitable solutions for better health and greater prosperity for the neediest populations in the world.

\section{Objectives}

- To describe the pharmaceutical $R \& D$ process leading to the development of new medicines and to evaluate the pros and cons of alternative public and private sector innovation models that may achieve this more effectively than the current system and at a lower cost.

- To build a 'risk-adjusted' pharmaceutical $R \& D$ investment model to evaluate, optimize and accelerate the discovery and development of innovative medicines that have the potential to combat diseases disproportionately affecting people living in the developing world.

- To assess the impact of public policy and incentive mechanisms designed to employ economic devices that either reduce the cost of pharmaceutical R\&D (technology 'push' systems), or address the lack of viable markets in developing countries (market 'pull' systems).

\section{Approach and structure}

The innovation framework proposed in this dissertation is an attempt to add weight to the new medicines debate. It is in the interest of the poor that the fruits of innovative efforts be translated into life-enhancing benefits, in the shortest period of time. Therefore, the microeconomic considerations must be seen against a backdrop of macro-economic and health policy issues that global communities face in their quest to end poverty and human suffering. Given the complexity of these issues, it requires a holistic approach, that is, a broad understanding and involvement of various disciplines like international economics, public policy, corporate strategy, innovation management, health economics and financing.

The literature currently treats pharmaceutical and biotechnology R\&D on poverty-related diseases - and the corresponding investment decisions - as a 'black box'. To gain new insight, we must approach the issue from a different angle. The author therefore advocates analyzing and understanding the mechanisms through which corporate performance and motivation is affected. At first, the 'risk-investment-incentive' causation relationship will be 
explained by placing the internal resources and competencies of the firm at the center of the analysis. This focus is portrayed in the overlap of the three knowledge areas (circles) in figure 1:

- Pharmaceutical R\&D \& Risk Management,

- Corporate Financing \& Capital Investment,

- Public Health Policy \& Incentive Systems.

The dynamics between these key areas is expected to significantly affect, and positively or negatively influence, the outcome of a firm's decision to invest (or not) in the discovery and development of life-saving medicines for the developing world. The resulting 'riskinvestment-incentive' framework - supported by computer-guided simulation experiments involving identified key risk factors and investment decision parameters - is expected to fill a void in current understanding.

Before proceeding, however, it is worth clarifying that the purpose of this book is to share new insights in new medicines R\&D through the development of sustainable solutions that can be implemented relatively quickly given the urgent need. To frame the core corporate issues, however, additional areas must be analyzed which are shaping the environment leading indirectly to enhanced (or reduced) investment in R\&D on internationally neglected diseases. This is illustrated by the outer triangle in figure 1 :

- Economic Development \& Health Care,

- Access to Medicines \& Health Systems,

- Innovation Framework \& R\&D Models.

It is crucial in this context not to mix the public health priorities with a particular political or industrial agenda. To put it differently, the global health objectives must always prevail over any individual country gains or industrial concerns regardless of whether such policies would benefit multinational corporations (MNCs) or even the local manufacturers based in the developing and emerging economies. Unless, of course, this improves the new medicines development process, the health benefit-outcomes, and/or reduces the overall cost of the program. It is equally important to note that the methods that are used for calculating investments and subsidies must be accurate and transparent to avoid that evidence-based decision making is replaced by strategic gaming. If this were to happen, trust and goodwill between the public and private partners would quickly evaporate. Accordingly, instead of forging a fruitful partnership, the stakeholders will start to behave like adversaries. Such attitude is clearly counterproductive and given that it undermines our strategic intent this will hopefully not happen. 
Figure 1: Areas influencing R\&D investment in developing world medicines

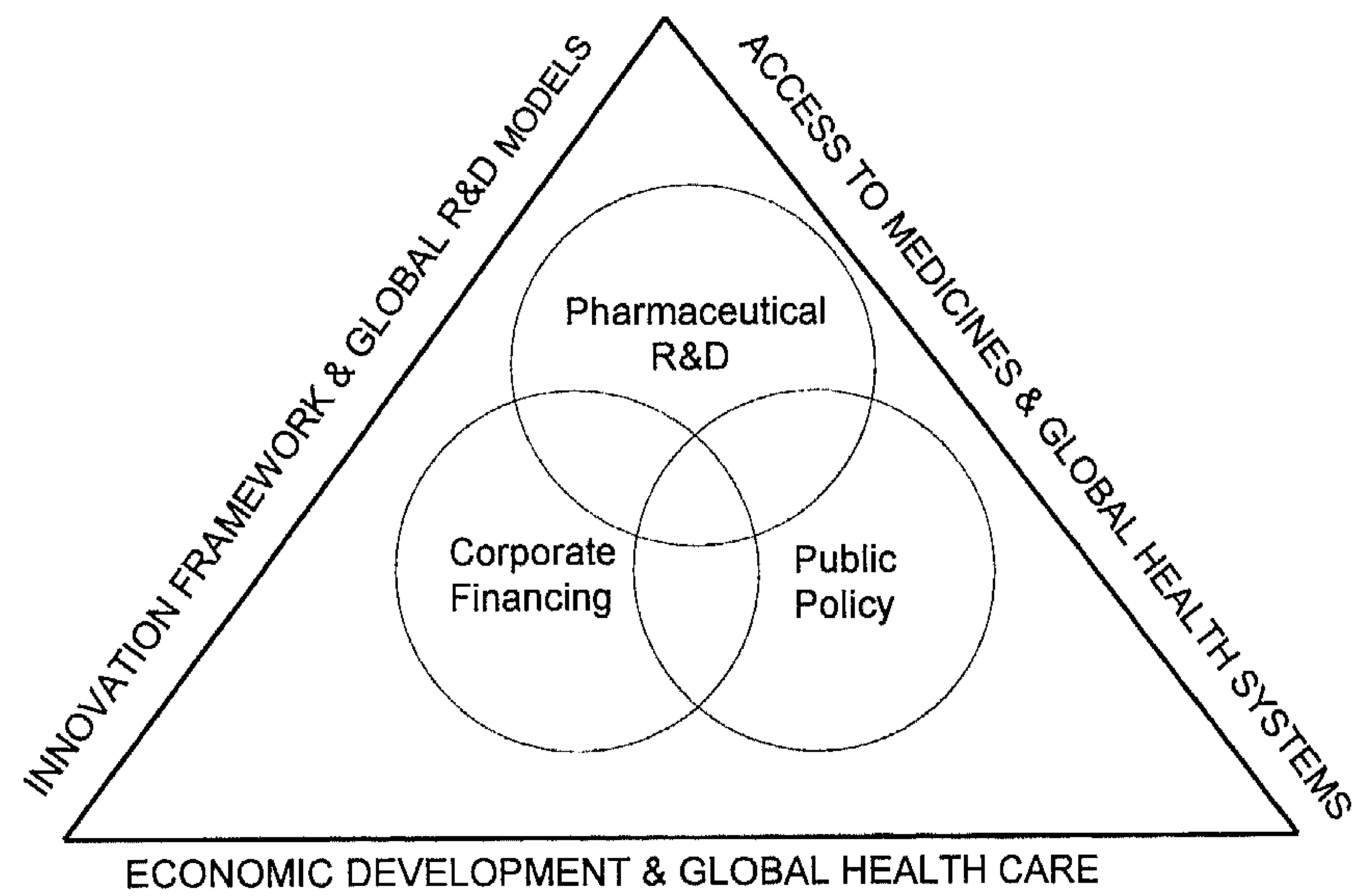

The six inter-related knowledge areas that will be examined are as follows:

\section{Economic development \& global health care}

Chapter 1 describes the association between Global Economic Development and Health Care. While it has long been recognized that increased national wealth is associated with improved health, it is only as of recently that the contribution of better health to economic growth has been acknowledged. Health is no longer seen as a mere by-product of international economic development but as one of several key determinants of economic development and poverty reduction. This has been demonstrated by the WHO's Commission on Macroeconomics and Health in their final report published in 2001. The Commission, chaired by Jeffrey Sachs, built a strong case for investing in health (World Health Organization, 2001).

Historically, the proposition that health represents a very important component of human capital equal to education was first most prominently defended by Grossman (1972) but is increasingly more widely accepted. Given the fact that human capital is a determinant in economic outcomes, and since health is an important component of human capital, it follows that health can be considered a determinant in obtaining economic outcomes as well. In recent years, important advances have been made in the understanding of the link between health and international economic development, especially in low-income countries. A recurring theme throughout the literature is the existence of feedback loops that 
demonstrate the existence of mutually reinforcing improvements in health and wealth. In the broader historical sense, studies exploring the role of health in a specific country over one or two centuries have shown that a large share of today's economic wealth is attributable to past achievements in health, sanitation and improved medical care. Typically measured as life expectancy, or child or adult mortality, the factor of health enters as a very robust and sizeable predictor of subsequent socio-economic growth in virtually all studies that have examined the differences in growth rates between poor and rich countries. These findings together with the extensive literature review done by the Commission on Macroeconomics and Health have helped bring about a shift in the prevailing paradigm that better economic performance is followed by improved health outcomes. Surely, this new evidence has paved the way for health to be included in national development strategies and policy frameworks that support poor countries.

The WHO Commission's report on communicable (infectious) diseases, as well as maternal and prenatal health, mainly focused on health intervention priorities for the poorest countries. Unsurprisingly, the majority of these countries are located in Africa. The report identifies key intervention targets as follows: HIV/AIDS, malaria, tuberculosis, maternal and prenatal conditions, other major causes of child mortality (including measles, tetanus, diphtheria, acute respiratory infection, and diarrhoeal disease), and particularly vaccinepreventable illnesses, as well as tobacco-related disease. We will demonstrate that fighting infectious diseases produces positive externalities that not only benefit the concerned individual but the entire community as well, and therefore should be given priority.

\section{Access to medicines \& global health systems}

Chapter 2 investigates the thorny subject of Access to Medicines and Global Health Systems. One of the biggest problems faced by low-income countries and even more so by LDCs is not only a lack of novel medicines, but the widespread inability to distribute existing, high-quality and off-patent medicines to the sick. Unfortunately, the majority of people in sub-Saharan Africa do not receive even basic drug treatments or other health technology products. This section of the book examines where the delivery of medicines to those who need them fails. The failures include, amongst other things, weak health care infrastructures, regulatory environments that are hostile to health insurance markets and other risk pooling mechanisms, compounded with needless taxes, tariffs and counterfeiting of live-saving medicines.

There are many circumstantial factors that seriously impede access to medicines, a series of which have been recently reviewed (Ahmed et al, 2007). The review revealed that a number of self-generated policy failures are responsible for the fact that up to $50 \%$ of people in areas of Africa and Asia have no access to essential medicines. Two-thirds of all African 
children who die under the age of five could have been saved by low cost treatments such as vitamin A supplements, oral re-hydration salts and existing combination-therapy drugs against malaria. In addition, the World Water Forum reported in 2006 that $40 \%$ of Africa's population - 300 million people - has no access to clean water. A dramatic side effect of contaminated water is the reduced effectiveness of prevention and treatment strategies for HIV/AIDS. One commonly implemented strategy to prevent mother to child transmission of HIV is making mothers switch from breastfeeding to infant formula. The question then is, what the fate is of children that do not have access to clean potable water? Another example is malaria control programs that through better water management could greatly reduce malaria mosquito breeding sites. These multiple failures in the delivery of public services in developing countries, along with the suboptimal distribution of prescription and over-the-counter medicines, are compounded with the fact that few commercial companies are willing to shoulder the risk of developing essential drugs and health technology products for poor populations. If a new medicine stands little chance of reaching its intended consumer, there is no point in risking large capital investments and in developing a product specifically designed for low-income markets. If the barriers to access were lifted, however, there would be far greater demand for existing as well as novel medicines, which in turn would make it a more enticing commercial proposition to R\&D-based companies and medical technology innovators.

A number of scholars argue that, in the long haul, the poorest countries in the developing world need to take responsibility to build and maintain self-sustaining, efficient health care systems that allow effective distribution of life saving drugs, vaccines and diagnostics, as well as the propagation of vital health education and training. Poverty and a weak health infrastructure in many of these countries nowadays share the same root causes: poor governance and corruption. Solve the latter and you solve the former. For that reason, the reform of governance structures must become a priority. That includes improving legal systems and entrenching the rule of law. This is necessary but may not be enough. Ultimately, by elevating these countries to a higher level of socio-economic growth may be the only way for them to be able to tackle ill-health on a sustainable basis.

\section{Pharmaceutical RerD and risk management}

Chapter 3 explains the Supply and Demand Side of Pharmaceutical Product Innovation and how this market operates; whereas chapter 4 describes the Pharmaceutical $R \& D$ Process with a focus on the present industrial model. Alternative and possibly complementary innovation models will be discussed in chapter 10 . This chapter further explains the premise that intellectual property is an important supply side factor which can be reconciled with the demand side and weak purchasing power of developing countries through a system of tiered pricing. 
Taken as a whole the pharmaceutical innovation process is undoubtedly a complex, expensive, lengthy and risky undertaking (Duetsch, 2002; Needleman, 2001; DiMasi, 1995). New product research and development requires testing thousands of compounds, of which ultimately only a few are developed into a potential and safe medicine (IFPMA, 2004; Epstein, 2003). Promising compounds make their way through the pipeline and, as the work progresses, the amount of resources required to support the new medicines' development increases. Candidate medicines are tested, first in small and later in larger clinical trials in order to meet the unequivocally high standards for safety and quality ${ }^{7}$. Regulatory approval must be obtained subsequently in each market separately because of the lack of harmonization of standards and procedures. Estimates of the total cost of developing a new medicine vary from hundreds of millions of dollars to well over one billion. Substantial investments are also needed beyond R\&D to build large-scale manufacturing and distribution capacity depending on the geographic scope of the project, the individual market demand forecasts, and the anticipated economies of scale.

A new compound's journey down the pharmaceutical $R \& D$ pipeline is by no means smooth. This book attempts to map the numerous bottlenecks and impasses, some of which come about because companies may not have enough people with a particular expertise, the necessary equipment, or facilities able to handle the technical problem. One of the most significant reasons for bottlenecks is that companies are developing a number of products simultaneously and these may be competing for the same resources. Hence, to manage its various $R \& D$ projects, the firm will review the status of its $R \& D$ portfolio at several points in the process and make decisions on whether to continue with the development or abandon some projects. The recommendation in this book is that companies adopt a so-called 'stage-and-gate' approach to help them manage these difficult project management decisions. This method defines the tasks, activities and accountabilities within each consecutive phase of the development process (Samuels, 1999; Sully, 1999). Every phase has a menu of deliverables, that is, a list of information items that executives need in order to make effective 'go/no-go' decisions in capital investment and human resource allocation.

For most new medicines available today, the investment is financed by a mixture of private capital and public money (by government, philanthropic and charitable giving). Nearly all

\footnotetext{
${ }^{7}$ Clinical testing of new compounds typically proceeds through three successive phases. In phase I, a small number of usually health volunteers are tested to establish safe dosages and to gather information on the absorption, distribution, and metabolic effects, excretion, and toxicity of the compound. Phase II trials are conducted with subjects who have the targeted disease or condition and are designed to obtain evidence on safety and preliminary data on efficacy. The number of subjects tested in this phase is larger than in phase I and may number in the hundreds The final pre-approval clinical testing phase, phase III, typically consists of a number of large-scale (often multi-center) trials that are designed to firmly establish efficacy and to uncover side-effects that occur infrequently. The number of subjects for a compound in phase III trials can total in the thousands.
} 
medicines depend to some extent on publicly funded basic science, while the private sector is the single largest investor of applied pharmaceutical $R \& D$, and typically takes on the challenge of converting basic scientific advances into usable products. These downstream stages of the development process, including clinical trials, manufacturing and marketing approval, account for more than two-thirds of the total costs of developing a new medicine. These costs are usually passed on to consumers and governments, directly or through insurance. Companies make these $R \& D$ investments with the expectation to sell the finished product for a profit and (at least) recover the investment they made while assuming the risks of failure. We will argue that performance based rewards and other market-led incentives to support industrial innovation are necessary to make sure that pharmaceutical R\&D is targeted at strategies that bring the best possible products to patients around the world as quickly as possible.

\section{Corporate financing \& capital investment}

Chapter 5 examines the methods used in Corporate Financing and Capital Investment that aim to appraise complex $R \& D$ projects individually and/or collectively. A key strategic issue within the pharmaceutical and biotech industry is portfolio management, which addresses the question of how corporations should allocate and optimize their scarce resources. The larger multinational pharmaceutical companies and the upper tier of midsize biotechnology have generally several project 'options' running simultaneously. The question that these companies must answer is whether their shareholders' money is being spent on the 'right' projects, but also whether the different stakeholders are best served knowing that there is a range of unmet medical needs to respond to nowadays ${ }^{8}$.

This section of the book analyzes the advantages and drawbacks of the different analytical methods through which pharmaceutical $R \& D$ investment projects can be evaluated. These include payback, internal rate of return (IRR), and net present value (NPV). Of these metrics, the payback calculation provides limited information and at times can be misleading. IRR, although a good and useful technique, has its limitations. NPV, on the other hand, has clear advantages and is predominately used by corporations for project appraisal and selection (Smart $e t a l, 2004$ ). Furthermore, recent findings have shown that more

\footnotetext{
${ }^{8}$ Pharmaceutical and biotech companies are bound to target their R\&D on products that will produce a commercial return. As things stand today, the markets for new medicines for diseases occurring mainly in developing countries are not sufficiently valuable to offer investment returns, and are on that basis unable to provide justification for triggering expensive and complex research and product development. Even where initial investment in medical research results in promising scientific leads, limited resources mean that many of those leads languish in the laboratory, with insufficient resources and few champions to bring more than a few of them through to the next stages of product formulation and development, clinical testing, registration, distribution and delivery.
} 
powerful valuation methods based on 'options' pricing theory are also able to capture the value of flexibility in complex and risky R\&D projects (Boer, 2003; McGrath, MacMillan, 2000). An increasing number of scholars acknowledge the similarity between a stock option and an R\&D project (Loch, Bode-Greuel, 2001; McGrath, MacMillan, 2000; Angelis, 2000; Faulkner, 1996). Economists and business managers alike are attracted by the concept that 'options' give the investor the opportunity to capitalize on future earnings while limiting potential losses. The value of this method lies in the fact that management always has the option to abandon the $R \& D$ project if interim results are not promising, thus limiting $R \& D$ project losses to the amount invested in past phases. Traditional NPV methodology fails to recognize this flexibility, and may therefore undervalue important opportunities in new medicines R\&D of interest to the developing world.

To date, the most widely accepted investment options model is the Black-Scholes, which a number of firms, including some early-adopter pharmaceutical companies, have applied to their development projects (Newton, 1994; Sender, 1994; Ross, 1991). However, the complexity of the formula means that the Black-Scholes method appears to most of its users as a 'black box'. The mathematical manipulations that occur are not always transparent or easily understood and the results are often counter-intuitive (Faulkner, 1996). It is recommended that instead of using this rather complex financial model, an alternative 'real options' method is used based on a binomial approach and decision tree analysis. Decision tree lattices are not only more user-friendly but equally accurate, and provide more transparency concerning the project's risks and investment value. Moreover, an 'optimal' roadmap visualizes the options available to managers at each critical stage of the product development trajectory (Morris, Teisberg and Kolbe, 1991). Unfortunately, for our purposes, the Real Options method also provides managers with the option to postpone or bail-out of investments or commitments if their pay-off appears uncertain. For LDC-markets in particular, this means that LDC-country purchase agreements will have to be made beforehand by local governments in collaboration with international donors and agencies.

\section{Public policy and R\&D incentive systems}

The Public Policy and Incentive Schemes aimed at stimulating R\&D on developing world diseases are examined in chapters $6,7,8$ and 9. A major market failure is the absence of incentives to develop medicines that potentially have important social benefits, but that are not currently being developed, in large part because pharmaceutical and biotech companies lack adequate incentives to engage in $R \& D$ to develop such socially beneficial products.

The prospects for projects leading to novel or better products for the prevention and treatment of diseases prevalent in developing countries have improved in recent years. This is mainly due to the recent establishment of OECD government donor funds and philan- 
thropic organizations such as the Bill \& Melinda Gates Foundation which have greatly increased the necessary resources. Nonetheless, more potent, sustainable and possibly complementary incentive mechanisms are needed to considerably accelerate $R \& D$ on poverty-related diseases. The merits of two new approaches that are expected to overcome the traditional poor return's barrier in $\mathrm{R} \& \mathrm{D}$ projects for developing-country medicines will be described in this chapter: (i) technology 'Push' incentive mechanisms, and (ii) market 'Pull' incentive mechanisms. Though different definitions have been offered, the simplest define 'push' systems, as those that reduce the risks and costs of new medicines development, and 'pull' systems as those that assure a future return in the event that a viable product is produced (Webber, Kremer, 2001; Sachs, 1999; Sachs, Kremer, 1999; Muraskin, 1999). It is generally believed that technology push systems exert greater influence early in the value chain, while market pull systems are stronger at a later stage (although they may indirectly encourage basic research in these therapeutic areas). To date, a great deal of high-level work has been completed in order to outline the possible approaches for public-private collaboration and the appropriate use of these new incentive mechanisms (Barder, Levine, Kremer, 2005; Glass, Batson, 2001; Ainsworth, Batson, 1999). Much work remains to be done in order to optimize these economic incentive models that aim to specifically accelerate $R \& D$ on neglected diseases, and to effectively translate the concepts of public funding into reality.

Much of the debate between public and private stakeholders revolves around designing appropriate incentives through an advance market commitment (AMC). The AMC concept aims to shorten the time lag between the development of new medicines and their use in places where they are needed. Poor nations usually lack the funds to acquire a new medicine until many years after its launch when it becomes available at price levels that are affordable in the neediest places. In the AMC proposal, international donors make legally binding pledges to pay for a new product on behalf of low income countries, if and when one is developed. This allows corporations to recoup their investments and ensure faster market adoption and diffusion. The concept attempts to imitate the market conditions that spur innovation in disease areas prevalent in the industrialized world.

The expectation is that this innovative incentive scheme creates the necessary market-driven impetus for firms to invest in identifying promising avenues for product $R \& D$. Since the AMC is a performance-based mechanism, firms have to compete with each other in bringing their best products to market as quickly as possible, and with a long-term commitment to supplying the poorest countries at 'affordable' prices throughout the process. Several issues must be first resolved before this becomes a reality. 


\section{Alternative models and R\&D partnerships}

Chapter 10 explores possible 'alternative' health technology innovation frameworks. In the 'classical' model patents play a strong role in encouraging R\&D-investment. Some critics though, have called for no less than a complete overhaul of the present paradigm. Opponents argue that the patent-driven system could be substitured by other mechanisms without jeopardizing the level of pharmaceutical $R \& D$ output. The fundamental nature of these alternative models is to radically alter the intellectual property rights scheme. If possible, patent protection for pharmaceutical and health technology products would thus be eliminated. The purpose is to put a medical invention in the public domain immediately after regulatory and marketing approval has been obtained and to have it produced by third parties in the hope that it is sold nearly instantly at generic prices.

This chapter investigates a number of alternative innovation models as presently proposed in the literature and at congresses: (i) Global Direct Funding - a system where R\&D is directly funded via a global tax-like mechanism to raise predetermined investment amounts; and (ii) Prize \& Awards - a system where successful innovation efforts are compensated with a prize or award upon completion of the innovation, which subsequently is put in the public domain; or (iii) Open Sourcel Patent Pools - a system that relies on collaboration through open re-source $R \& D$ from the beginning of the research and development process; (iv) New Product Development Partnerships - an eclectic array of novel collaborative mechanisms and structures based upon public and private partnership. We will demonstrate that getting the right balance between on the one hand openness of basic medical research and on the other hand maintaining incentives to ensure that possibilities discovered by such research are further developed and tested to the commercialization stage, is a big challenge under any system of incentives and rewards. This chapter will also illustrate that few - if any - of these models are able to replace the patent-based process wholesale, especially if it is used in conjunction with an AMC incentive mechanism and/or with internationally tiered or differential pricing.

One of the latest suggestions for reform is to create a Global Medical Research and Development Treaty (MRDT) through which $R \& D$ on medicines could be centrally directed towards global health priorities (Love and Hubbard, 2004). This treaty would consist of a multilateral agreement which sets up a state-driven mechanism according to which governments set aside a fixed percentage of their national output (GDP) to financing selected projects. Proponents of the MRDT system claim that many of today's problems could be overcome. This concept, however, poses a range of extremely challenging problems. It is not clear what credible and enforceable measures could be taken for those who deviate from the supposedly self-enforcing commitment upon which the treaty relies. The data required to discipline errant government signatories would be too poor to be useful and rent-seeking 
or other forms of inefficient gaming of the system would be impossible to police. This suggests that the system could result in many perverse effects and unintended consequences. The MRDT also takes an overly simplistic approach to the interface of the different components of the new medicine innovation process, with no explanation of how different modes of $R \& D$ and funding would coexist. To split the almost seamlessly connected stages of the contemporary product research, development and production process is not a trivial matter. The innovator ideally needs to be skilled in designing novel compounds and in carefully selecting and testing new product formulation that would lend itself to large-scale production. In practice, it will not be easy to play 'volleyball', that is, to coordinate back-and-forth between various technical teams and to effectively transfer projects and know-how between different departments if they do no longer belong to the same organization. Other scholars have independently acknowledged that there is an advantage for pharmaceutical and biotechnological companies to be vertically integrated (Arora, Fosfuri, and Gambardella, 2004).

An alternative model for stimulating $R \& D$ on tropical or neglected diseases is the awarding of prizes. This system has in principle the value of encouraging competition and thus increasing the number of potential product candidates (although only one can get the prize) (Love and Hubbard, 2007). It is relatively easy for the public sector to implement and for the private sector to benefit from the valuable positive public relations when winning the prize or tournament. Conversely, a prize or tournament may also have serious drawbacks, in that winning a prize does not guarantee that a viable, affordable medicine will eventually result. A serious disadvantage is that it must be given to the winner regardless of how enthusiastic the market reacts to its launch, that is, whether the invention is in fact adopted and used by the developing countries. What is more, the prize model does not reward second or third-generation entrants that may offer an improved safety, efficacy, or convenience profile, and therefore may stifle further innovation. It represents undoubtedly a bureaucratic system and requires setting up intermediate entities that act like clearinghouses. This unnecessarily complicates the system because an active medical technology market already exists between pharmaceutical companies, biotechnology research firms, universities and public institutions, and venture capitalists. These stakeholders ensure that compounds are progressively moving along the $R \& D$ value chain towards their market destination. They are also best placed to assess the intrinsic value of any breakthrough or incremental invention made along the way and to overcome the problem of asymmetric information.

The viewpoint in this book is that a voluntary prize may offer some limited incentives to solve well-defined parts of the pharmaceutical research and development process. For example, resolving those technical issues that are supporting the core product development process and that are common, may be of mutual benefit to all researchers. A prize could 
also be useful to researchers of developing countries in stimulating research in disease areas not currently the subject of substantial exploration. Overall, the prize model does not seem to be an effective replacement for the current IP-based $R \& D$ process. The fact that the innovator does not have direct contact with the ultimate user of the invented product puts prize systems in a category diametrically opposed to open innovation systems where consumers play a pivotal role in the design of technical innovation (Hippel von, 2004). Finally, the question is whether other appealing systems like 'open innovation' (Chesbrough, 2003) and 'open-source' innovation (Love, 2007; AEI-Brookings, 2005), which are fostering collaboration rather than competition, should not be investigated. We will show that it is worth examining the latter system particularly in upstream medical-scientific research and in those therapeutic areas where 'proof-of-concept' has not yet been established.

\section{Towards a better future}

The purpose of writing this book was to propose a structural solution for the development and supply of vital medicines that target developing world diseases on a much greater scale than what is currently the case. The research, development, production and distribution of new and improved medicines for developing world diseases is mainly accomplished on an ad-hoc basis and through programs of charity, fundraising and social benefit. While it is important to maintain these programs, it is also timely to establish a structural solution that is sustainable based on the efforts of private corporations in partnership with the public sector. The challenge, however, is to reconcile the private sector's criteria for profitability and maximization of shareholders wealth, as in any other industry, with its specific task to provide new and existing medicines to the world's rich and poor. Only then can we claim that global equity in health has been achieved?

This will require significant and sustained efforts from a variety of partners, ranging from governments of developing and industrialized countries, the World Bank, WHO, nongovernmental organizations (NGOs), foundations, and of course the industry itself. Within the broad spectrum of partners, there is an increasing consensus that an opportunity exists to break the historical pattern and move the discussions from rhetoric to action. Stakeholders nowadays do acknowledge the fact that private-sector $R \& D$ on diseases affecting primarily developing countries is limited in large part because the commercial value of the

\footnotetext{
${ }^{9}$ The concept of equity in health can be defined in several ways as its principles derive from the fields of philosophy, ethics, economics, medicine, public healthy, and others. Common to most definitions of health equity is the idea that certain health differences (most often called inequalities in health) are unfair or unjust (Macinko, Starfield, 2002).
} 
market prospect is small relative to the health and economic benefit these products would bring to the world. Although a number of international funding programs finance research on diseases endemic in third world countries, there is a benefit to complementing the existing 'push' programs with 'pull' initiatives. Therefore, over the last five years, under the auspices of the World Bank's Global Health Policy Research Network (GHPRN), the 'Pull Mechanisms' Working Group ${ }^{10}$ comprising experts with academic, public policy, industrial, and legal backgrounds have been brought together to develop innovative options for creating workable incentive mechanisms.

The multidisciplinary working group suggested in 2005 that an Advance Market Commitment (AMC) could complement in principle the existing public and philanthropic funding of R\&D, and "may significantly accelerate the development and availability of medicines for diseases occurring in the developing world". The novel system has the potential to stimulate the allocation of commercially driven research funds to neglected diseases thereby harnessing the energy, experience, and expertise of the private sector in partnership with the public sector. Without this funding commitment on behalf of poor countries, there will continue to be insufficient private sector funding to bring more than a few, if any, new candidate medicines to market. If structured correctly, pull-incentives like the AMCs may help to ensure a reliable future supply of innovative medical products. The G7/G8 Finance Ministers and other high-level politicians expressed a clear interest in further exploring the AMC framework. The main advantage perceived by the OECD donor governments sponsoring the AMC is the fact that the system bears no cost to them or payment until a new product has been developed by the private sector, and has been successfully launched and adopted by the patient-customers in developing countries.

The request to pilot an AMC project for a select number of future medicines of importance to developing countries was brought to the table at the July 2006 Summit of the G8 in St. Petersburg, Russia. This was the result of a one year preparation by the World Bank's Advisory Group which culminated in the pre-publication of the Italian Minister Tremonti Report (Tremonti, 2005). Meanwhile, the first donor pledges have been received ${ }^{11}$. Some observers, however, like those from the Department of Economics at the University of Oxford were at that time quick to point out that, in their opinion, important flaws are (still) present in the design and need to be urgently addressed. In order to resolve the remaining issues, an in-depth understanding is needed of the economic aspects of the

\footnotetext{
${ }^{10}$ The Pull Mechanisms Working Group was co-chaired by Michael Kremer of Harvard University, Ruth Levine of the Center for Global Development, and Alice Albright of the Vaccine Fund. Other selected members included representatives from the World Bank, GAVI, UNICEF, The Brookings Institution, the pharmaceutical and biotech industry, life sciences venture capital, top industry law firms, and the Bill and Melinda Gates Foundation. ${ }^{11}$ http:/blogs.cgdev.org/globalhealth/2007/02/launch-of-amcs.php
} 
medicines innovation process. The analysis carried out in this book and the solutions offered will hopefully benefit both the public and private stakeholders interested in the development of medicines for neglected diseases, and thereby contribute to enhancing the welfare of the most deprived populations in the world. 


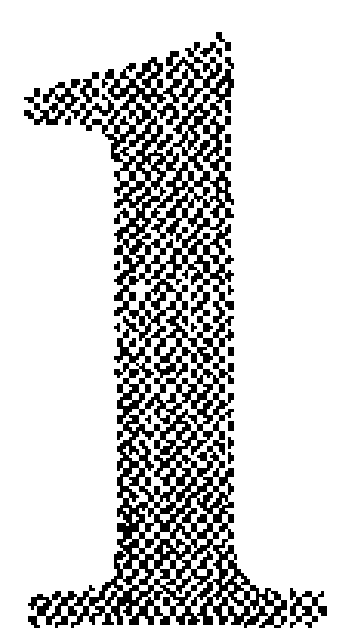

Challenges in poverty reduction: health and economic growth 


\subsection{Introduction}

Despite improvements in health care over the past century, a significant gap remains in health and life quality standards between the established market economies (EMEs) and the $\mathrm{LDCs}^{12}$. The poorer countries have a pattern of disease markedly different from the more affluent countries. About one third to one-half of healthy life years lost in the developing world is due to communicable diseases, such as malaria, tuberculosis and HIV/AIDS. In many of these nations, the process of socio-economic development is slowed down by the heavy burden of these endemic diseases because ailing people are temporarily or permanently kept out of the productive process and need to be supported instead of contributing to creating wealth for their families and nations. Improving the health status of LDCcitizens depends among other things on a better usage of existing and underutilized health technology tools to combat infectious diseases. In many cases, these countries urgently need new and improved pharmaceutical and medical products. The premise in this chapter is that preventive vaccines and novel therapeutic medicines that are able to address unmet medical needs and offset drug resistance, are an important and cost-effective component in the control and eradication of poverty-related diseases.

\subsection{The health and wealth relationship}

\section{The causal link between health and wealth}

There has been debate regarding whether health is a cause of poverty, a result of poverty, or both. For decades, scholars thought that the causality ran in only one direction - as incomes rose, health improved. Rich countries tend to have healthier populations than poorer countries. As populations become more affluent, mortality decreases and life expectancy increases (Goklany, 1999b; Pritchett, Summers, 1996; World Bank, 1993). Recent years have seen increased attention paid to assessing the reverse effects as health has come to be seen as a key driver of economic development.

\footnotetext{
${ }^{12}$ Throughout this document, LDCs refers to the set of countries in the lowest income categories with common health care problems that are disproportionately located in Africa, South Asia, Latin America and Eastern Europe. The EMEs category includes countries with GNP per capita of US\$ 9,266 or more (World Bank, Word Development Indicators, 2004; 1999 benchmark data). Defining the (sub)set of LDCs is more difficult. In the statistical tables, unless otherwise specified, the category of LDCs includes all countries in the low- and middle-income categories (a GNP per capita of less than US\$9,266). This without question is too broad a definition as it groups Cameroon and Ghana with the Czech Republic and Hungary. In terms of health care (and economic development in general) the latter two have more in common with the U.S. or EU than with Sub-Saharan Africa. It would be preferable to categorize by economic, health and geographic factors rather than by income.
} 
Bloom, Canning, Jamison (2004) and Bloom, Canning, Weston (2003) recently confirmed that better health can have strong effects on economic growth. Previously economists tended to ignore health as a relevant factor of production and an important determinant of economic growth. The widely observed positive relationship between health expenditures and economic growth was considered the result of a strong positive income effect. Gradually, more and more scholars came to recognize that health is an important determinant of macro-economic growth (Barro, 1997; Bloom, 1995; Fogel, 1995; World Bank, 1993; World Health Organisation, 1999). Over the past years this has been confirmed on the basis of empirical cross-country studies, starting for developing economies, and later covering western economies as well (Suhrcke, McKee, Sauto Arce, Tsolova, Mortensen, 2005). The wide-ranging report of the WHO Commission on Macroeconomics and Health under the auspices of the former Director-General, Gro Bruntlandt (World Health Organization, 2001) concluded that the causation runs strongly in both directions. In other words, poor health causes poverty and poverty contributes to poor health particularly in LDCs. The empirical literature remains somewhat mixed however with respect to the link between average income to population health. GDP per capita does not provide a full picture of the economic impact since improving healthcare has a knock on effect by reducing mortality rates, boosting national productivity and in the long-term increasing population size. When the value of the extra lives that result from health improvements is taken into account, the effect of health improvements on economies is much greater than the effect on per capita GDP alone (Bloom, Canning, Jamison, 2004; and Bloom, Canning, Weston, 2003). Thus, since GDP per capita is an average, it does not account for the greater economic benefits that may accrue to the poor population pockets in that country as compared to the rich, when population health improves.

According to neo-classical economic theory, economic growth depends on three factors: the stock of labor, the stock of capital, and productivity, the latter depending in turn on technological progress which, in neo-classical theory, was considered to be an exogenously given factor. More recently, researchers have tried to replace the assumption of exogenous technological progress by an explanation of just what is driving productivity. Hence, technological progress came to be seen as an endogenous process that could be driven in particular by investments in human capital, largely understood as skilled labor. Much of this research was rooted in the initial formalization of a theory of human capital formation (Becker, 1964). Becker's ideas were motivated by the evidence that the growth in physical capital and labor, at least as conventionally measured, explains a relatively small part of the growth of income in most countries. According to his human capital theory, investments in human capital raise an individual's productivity both in market and non-market activities. Thus, individuals have an incentive to invest in themselves through education, training and health in order to increase their future earnings. But these investments also have costs 
associated with the direct outlays on market goods and the opportunity costs of the time that must be diverted from competing uses.

The question then is how much healthcare provision a nation should provide to its citizens from a macro-economic perspective? An endogenous growth model has been developed by van Zon and Muysken (Zon van, Muysken,2003; 1997). Their model shows how the provision of health services influences an economy's rate of growth. Since growth is produced using labor services, increasing health activities might imply lowering output and possibly growth if these labor services can no longer be used elsewhere in the economy. At the same time good health is necessary to be at all productive. Hence, there is a direct tradeoff between the health state of the population and growth performance. The above econometric model has shown that the relation between growth performance and health activities is parabolic. For low levels of health activities growth increases with the size of the health sector, but then starts declining for further increases in the size of the healthcare sector. In other words, an increase in longevity as experienced by Western economies entails lower growth prospects for these economies, while for economies in the development stage, a positive relationship between health activities and growth is much more likely to exist. For the latter, a double health dividend may be realized from increasing health care spending, that is the population can attain both a higher health level and a higher growth rate of income and consumption per head. In this context, the WHO's recent call for four million additional health care workers to be added worldwide - with one million incremental staff needed for Africa alone - appears to be justified. ${ }^{13}$ For Western economies, however, such a double dividend will only be obtained by increasing the productivity of the health sector rather than by expanding nominally health activities, ceteris paribus.

Unfortunately, the poorest segment of the world's population is most vulnerable to the phenomena of ill health and the inadequate provision of healthcare services. These populations face tremendous personal and community problems in coping with ill health and have by definition the least means to address them. This 'vicious circle' between disease and poverty that is all too often seen in LDCs is illustrated in figure 2. The graph shows that the circular evolution is mutually reinforcing, and is in sharp contrast to the desired, opposite phenomena, that is, the 'virtuous circle' of improved health and economic development as experienced over the last decades by the more affluent, industrialized countries.

\footnotetext{
${ }^{13}$ (www.who.int/workforcealliance/forum).
} 
Least Developed Countries

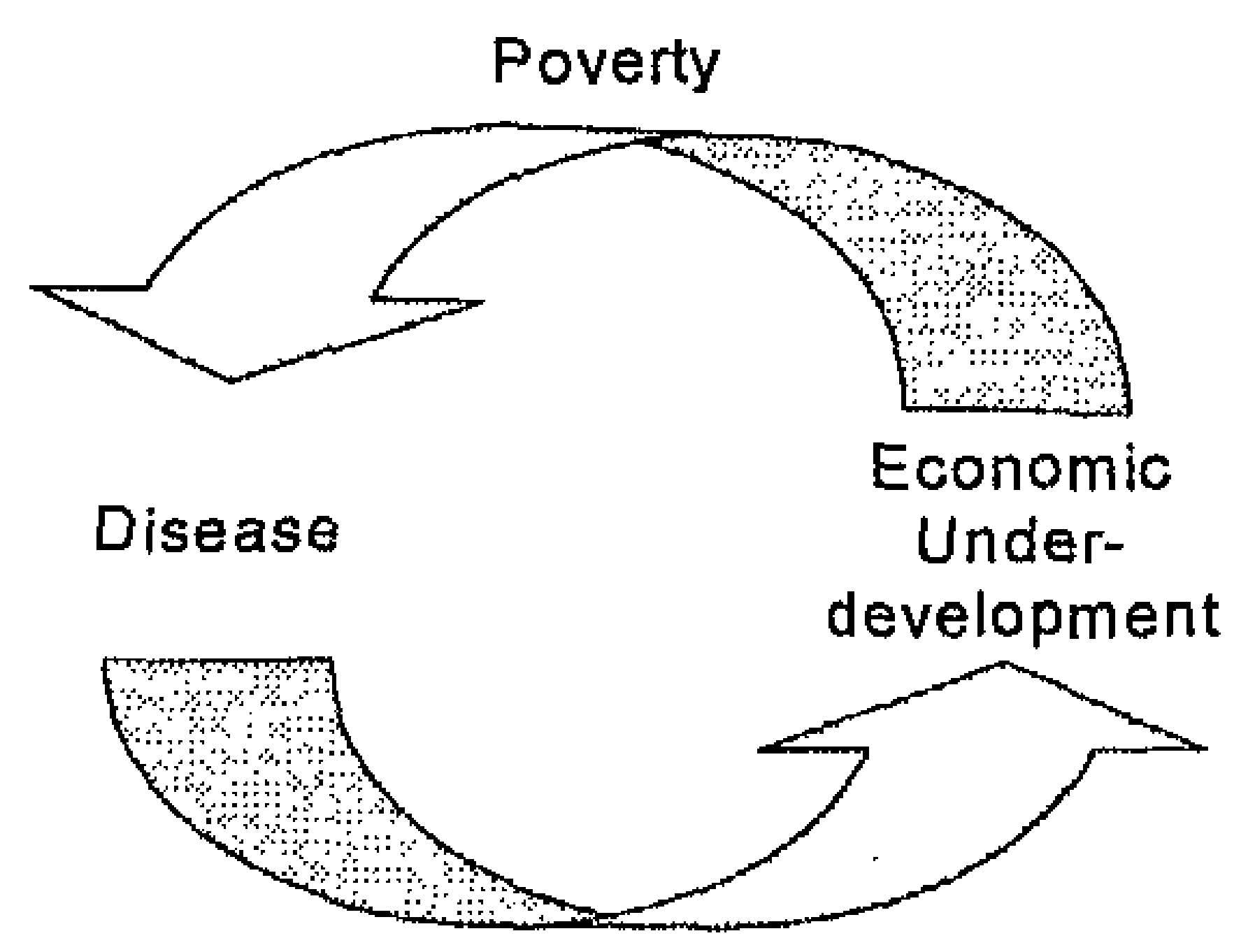

Industrialized Countries

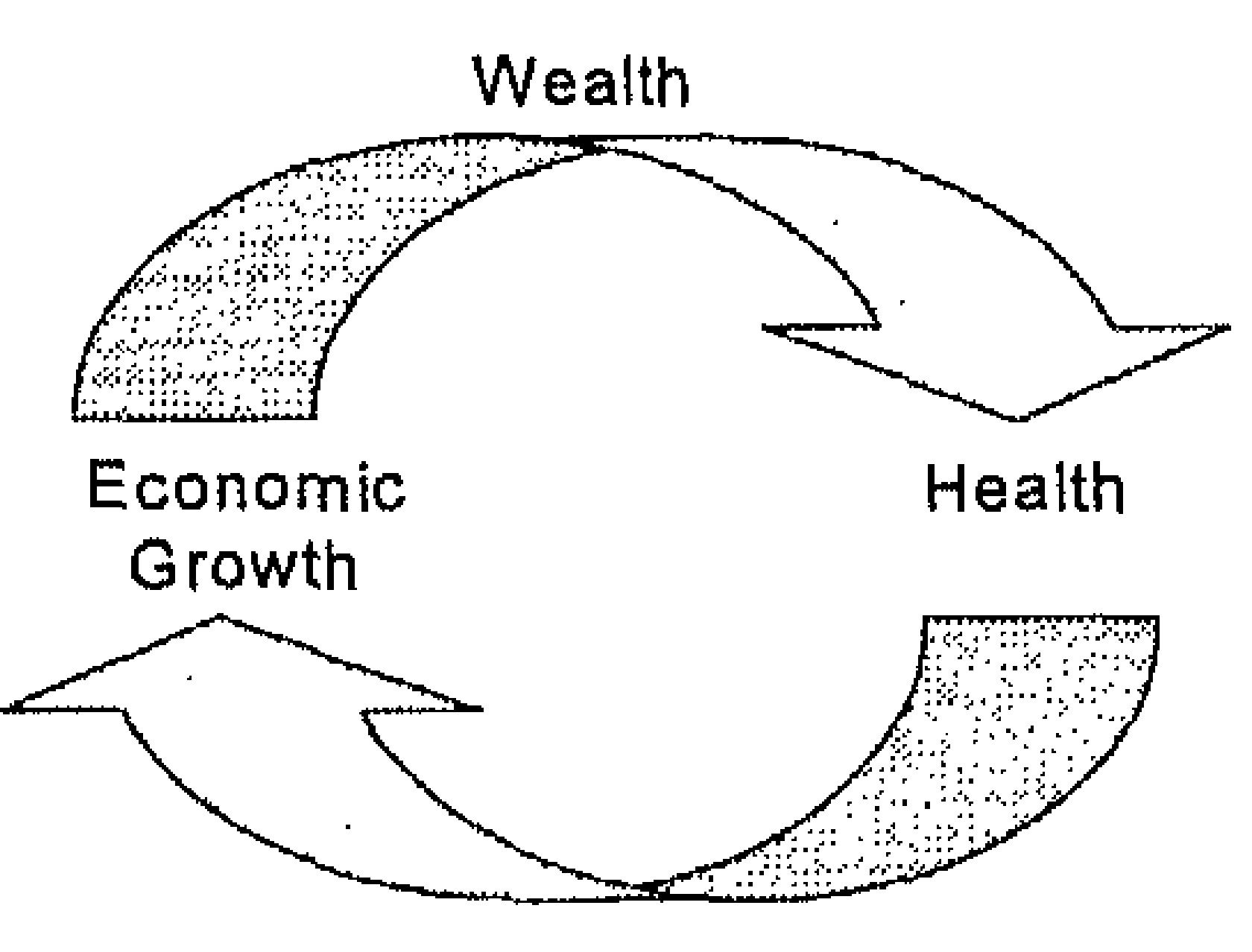

As a result of this interrelatedness, 189 governments from around the world signed the Millennium Declaration in September 2000 in which they committed to achieving sustainable reductions in all dimensions of extreme poverty. The Millennium Development Goals (MDGs) in support of developing countries have a strong focus on health outcomes, including the need to significantly improve maternal and child health outcomes, and to tackle the burden of HIV/AIDS and other major diseases affecting primarily (and often uniquely) citizens of the developing world. To track progress against this visionary global agreement, the MDGs comprise eight quantifiable and shared priorities to be achieved by 2015. They are summarized in figure 3. Although each of the MDGs is tracked separately, the reality is that they are strongly interlinked. Consequently, enhanced access to improved health services more broadly and to novel and essential medicines in particular, is now seen as key to tackling patterns of ill health, and in reducing the prevailing mortality and morbidity rates in the LDCs.

Figure 3: Overview of the Millennium Development Goals (MDGs)

Goal 1: Eradicate extreme poverty and hunger

Goal 2: Achieve universal primary education

Goal 3: Promote gender equality and empower women

Goal 4: Reduce child mortality

Goal 5: Improve maternal health

Goal 6: Combat HIV/AIDS, malaria and other diseases

Goal 7: Ensure environmental sustainability

Goal 8: Develop a global partnership for development 


\section{Epidemics are influencing the world's economy}

It is not a coincidence for the MDGs to focus on combating infectious discases. Several epidemics of infectious diseases are raging at any given time and are highly prevalent in developing countries. The emergence of new epidemics in the past fifteen years alone, such as, SARS, hantavirus and avian flu have hit the international headlines and the resurgence of old ones demands great agility and ingenuity from medical practitioners, developers of medicines, public health professionals and policymakers alike.

Epidemics are defined as a sudden, sharp increase in the incidence of a communicable disease, which afflicts a large number of people in a relatively short period of time (Bell and Lewis, 2005) ${ }^{14}$. They only occur when there is a sufficiently large pool of uninfected people to contract and transmit the disease, that is to say, there must be a large enough reservoir of potential victims (or 'susceptibles') for the disease to spread. They can be very debilitating and obstruct those aspiring to live in a more prosperous society by deterring overseas investment and international tourism, as well as, by changing expectations about how well their personal and nation's economy will function. Pathogens that cause epidemics of infectious diseases include viruses, bacteria and parasites. Most of them emerge from crossspecies transmission: smallpox and TB from cattle, malaria, HIV and yellow fever from primates, and measles from dogs or deer. Transmission to humans will occur if a human virus mutates when exposed to animal viruses of the same family (Hull, 1963; Diamond, 1997). SARS, which is caused by a corona virus, is believed to be transmitted via wild animals (e.g. masked palm civets and raccoon dogs). Other species of animals are also carriers, though they may be immune to the disease. The modes of transmission of the diseases themselves are diverse: airborne (influenza, diphtheria, whooping cough, SARS), contact with blood and other bodily fluids (HIV/AIDS, typhoid), the ingestion of pathogens (cholera), and insect bites (bubonic plague, malaria, yellow fever). While some infectious diseases, such as the common cold (which is not the same a influenza), normally do little more than make their sufferers a bit miserable for a few days, others may cause serious morbidity (illness) and increased mortality (death).

Even though far more people in the developing world die of TB and malaria combined, it is the worldwide HIV/AIDS epidemic that has focused attention on the disparity between the developed and developing world in terms of being affected by pandemics. Unlike the

\footnotetext{
${ }^{14}$ The definition of an epidemic is a surprisingly controversial matter. Originally reserved for communicable disease ourbreaks, epidemiologists now routinely apply the term to other health risk factors, like obesity, and have introduced multiple qualifiers, so muddying the definition. There are also no set rules as to when an outbreak becomes an epidemic. There is agreement on the term pandemic defined as an epidemic that has crossed national borders.
} 
massive pandemics of the past, such as the Black Death or the influenza outbreak of 1918 19, HIV/AIDS inflicts death very slowly. Twenty-five years after the first case of AIDS was identified, there are thirty-nine million people living with HIV and more than four million new HIV infections each year (Bloom, Ajay, 1997). Although expanded prevention programs have led to partial success in some countries, current preventative interventions have proved inadequate in slowing the spread of HIV at the global level ${ }^{15}$. As a result, the epidemic still causes 2.8 million deaths each year. Despite the fact that efforts continue to focus on scaling up prevention and developing new tools such as male circumcision, microbicides, and pre-exposure prophylaxis, controlling the AIDS pandemic will require all of these efforts, and much more. If no effective vaccine or cure is found within the next 20 years, areas of the world that are now witnessing explosive epidemics or are in their second or third wave of HIV infection may well find themselves harder hit - and more deeply transformed - than Europe was by the Black Death (Garrett, 2005).

Tuberculosis is a common and deadly infectious disease caused by mycobacteria, mainly Mycobacterium tuberculosis. TB most commonly attacks the lungs (as pulmonary TB) but can also affect the central nervous system, the lymphatic system, the circulatory system, the genitourinary system, bones, joints and even the skin. Diagnosing standard tuberculosis has always been difficult and this is one of the reasons why TB is making such a come back, because many people that needed treatment have been missed and have gone on to infect others $^{16}$. The emergence of drug-resistant strains nowadays, when the TB bacteria have become resistant to some of the medications, which are thus no longer effective, has considerably complicated the challenges. TB currently infects about a third of the world's population and kills from two to three million every year (Iademarco, Castro, 2003). Most cases are latent, meaning people have no symptoms and are not infectious to others. The really nasty part of this re-emerging disease is that the infection is likely to become active when people's immune systems are suppressed -- most notably by the AIDS virus, but also by malnutrition, cancer or other diseases. The most ordinary forms of TB take months to eradicate with antibiotic cocktails. Most worrisome is the fact that two dangerous new forms have recently emerged - the so-called multi-drug resistant tuberculosis, or MDR-TB,

\footnotetext{
${ }^{15}$ Smith and MacKellar (2007) argue that despite inflammatory thetoric heard at the beginning of the pandemic, HIVIAIDS has not proven to be a disease that spreads globally like SARS or pandemic influenza. Apart from $\mathrm{R} \& \mathrm{D}$ aspects, the problems associated with HIV/AIDS are regional at most, not global. Obvious cross-border aspects like transmission associated with long-haul truckers and migrant workers in Southern Africa call for a regional, not a global response.

${ }^{16}$ For patients with drug-resistant strains, health care providers need to know through drug sensitivity testing which drugs work and which ones do not. Otherwise, they run the risk of giving parients medication that simply does not treat them. Evidence has shown that the prognosis of patients with drug-resistant TB who had been treated inadequately with firsr-line medicines is worse than if they had been treated with the correct medicines from the start.
} 
and the extensively drug-resistant form, or XDR-TB. These strains are much harder, if not impossible, to cure. Therefore, the WHO has declared TB a global health emergency in 1993; and the Stop TB Partnership developed a global plan to Stop Tuberculosis to save 14 million lives between 2006 and 2015 (World Health Organization, 2006).

Finally, between 300 million and 500 million new cases of malaria occur every year, resulting in 1.5 to 1.7 million deaths annually (Gringle and Bahamon, 2003). Those most vulnerable to malarial infection ${ }^{17}$ include children less than five years of age (particularly in Africa), pregnant women, and individuals with little or no natural resistance to malaria (non-immune persons). In some areas, malaria is the leading cause of death in children under five. Complications from infection include anemia and increased susceptibility to other diseases. Thus, malaria represents a major public health challenge, particularly in many of the poorer tropical countries. Well over three-quarters of malaria cases and deaths occur in Africa. The disease inflicts severe economic losses on societies in the form of lost school days, low economic productivity, and long-term disability from severe illness. In some areas, as much as $25 \%$ of annual household income is spent on malaria-related costs. The total cost of the disease in sub-Saharan Africa has been estimated to be US $\$ 12$ billion per year with $40 \%$ of public health expenditures in high-burden countries going to malaria control and management. In some areas, gross domestic productivity is estimated to be $32 \%$ lower than it would be if malaria had been eradicated from Africa by 1960 (Gringle, Bahaman, 2003).

The magnitude of malaria's detrimental effects has prompted renewed global commitment to eradicating this disease. The 1992 Global Ministerial Conference on Malaria in Amsterdam, attended by representatives from 102 countries, released the World Declaration on the Control of Malaria, which urges early diagnosis of malaria, prompt treatment, and sustainable preventive measures. At the 2000 Summit on Roll Back Malaria in Abuja, Nigeria, African heads of state reaffirmed their commitment and called for "strengthened health systems to ensure that by the year 2005, at least 60 percent of those suffering from malaria will have prompt access to correct, affordable treatment and those at risk of malaria, particularly pregnant women and children under five years of age, will benefit from the most suitable combination of personal and community measures such as insecticide-treated mosquito nets and other materials to prevent infection and suffering". One of the biggest challenges however in controlling malaria is combating its drug resistance. Increasingly, one

\footnotetext{
${ }^{17}$ Malaria is normally transmitted through the bite of an infected female mosquito of the genus Anopheles. The female mosquitoes acquire the parasite when they feed on the blood of an individual infected with malaria, mainly between dusk and dawn. Malaria can also be transmitted through the transfusion of infected blood to a nonimmune individual (Finkel Michael, 2007; Malaria: Stopping a Global Killer, National Geographic, July, p.32-67).
} 
of the parasites that causes malaria (Plasmodium falciparum ${ }^{18}$ ) is becoming resistant to chloroquine, the most widely used malaria treatment since the 1940s. The most common replacement for chloroquine in Africa, sulfadoxine-pyrimethamine (SP), is also rapidly losing effectiveness. Continued use of such ineffective pharmaceuticals contributes to the spread of drug resistant strains and thereby causes a disturbing increase in malaria-related morbidity and mortality. A shift to effective first-line treatment could prevent a substantial percentage of deaths from malaria each year. It is clear that halting the spread of drugresistant malaria needs to be a global priority and resources must be focused on those areas of the world where the ever increasing burden of disease is greatest.

Other infectious and therefore communicable diseases, such as viral influenza ('flu'), were until recently qualified as less dangerous; however, they can take a huge toll as history tells us. Flu viruses are believed to mutate into dangerous-for-human forms about every forty years. In 1918, the world was hit by the epidemic known as Spanish flu - its origin was in Spain - and the loss of life is estimated between 25 million to 40 million (Sachs, 2005). The Spanish flu broke out before the end of World War I and the war situation was of course ideal for the rapid dissemination of these viruses - millions lived in crowded conditions, were short of good food and water, soldiers were physically weakened, and the weather was cold and windy. In a matter of weeks the virus spread all over Germany, France, Italy and a number of central European countries. After the hostilities came to an end, the homecoming soldiers spread the virus from Europe to the Americas, Africa, Australia, and Asia. Naturally, the recent emergence of avian influenza (bird flu), or H5N1, on the world scene has drawn renewed attention to viral influenza epidemics of global scale and is an example of the challenges posed by new pathogens. While the worldwide economic cost and consequences of a looming influenza pandemic that spreads among humans and animals are hard to predict with certainty, the potential scale of the disaster warrants broad and serious international cooperation now. A recent estimate of the possible economic consequences of a bird-become-human flu pandemic affecting humans suggests that, in a worst-case scenario, 142 million people could die and global economic losses could reach US\$4.4 trillion (McKibbin, Sidorenko, 2005). Preventive measures to keep this emerging disease from spreading from animals to humans are thus essential, as are preparations for mitigating the socio-economic impact by containing further spread of the disease through the development and production of antiviral drug treatments, pandemic and pandemic-like vaccines.

\footnotetext{
${ }^{18}$ Malaria is an infection caused by parasites of the genus Plasmodium. Human malaria is caused by four species: $P$. falciparum, $P$. vivax, $P$ malariae, and $P$. ovale. The first two species have the widest distribution, with $P$. falciparum causing the most serious illness and the majority of deaths, particularly in Africa. $P$. vivax is the most prevalent species in Asia (Finkel Michael, 2007; Malaria: Stopping a Global Killer, National Geographic, July, p.32-67).
} 
Dissemination of infections is traditionally fueled by social factors, such as migration, poor living conditions and civic riots; customs and diet of different nations; and specific qualities of microorganisms, such as resistance and a change in virulence and toxin-producing ability, not to mention global warming. Rampant epidemics may cross national borders and become worldwide epidemics, that is, pandemics. This poses further taxing challenges and economic means that few countries can afford. Dengue fever, for instance, had for years been confined to tropical regions only until it began spreading into temperate zones in more recent years, largely as a result of the increase in air travel and the shipping of used tires harboring dengue-carrying Aedes mosquitos. The territorial expansion of these mosquitos is expected to gradually increase with global warming. Perhaps the biggest test posed by epidemics caused by infectious agents is the propensity of the underlying disease agent to mutate. Success against one strain of a disease - either by natural resistance or medical intervention - can open a niche for the emergence of a new strain, and these new strains are likely to be virulent. Lastly, a large group of diseases has been confined, almost by default, by most researchers and policy makers alike to the 'other diseases' category, receiving much less political attention and financial support. These 'other diseases' include the viral, bacterial, parasitic and fungal infections of the tropics ${ }^{19}$, together with acute respiratory infections and diarrheal diseases of children. These diseases are sometimes referred to as the truly 'neglected' diseases and because they are rife primarily in the tropics they are affecting the most disadvantaged populations. Examples of these neglected diseases are Chagas disease, African trypanosomiasis, onchocerciasis, leishmaniasis, schistosomiasis, leprosy, lymphatic filariasis, Dengue fever, Guinea worm, and blinding trachoma. Many of these diseases lead to severe disfigurement and long-standing disability as well as present a particular social and economic burden to the populations concerned.

The best way of fighting these epidemics - as well as countering the increasing drugresistance micro-organisms have managed to build up over the past years, which makes currently available drugs obsolete - is to prevent them from happening altogether. And the best way of preventing the disease impact is to halt the spread of the disease, if possible, at the source through elimination of vectors, educational programs, vaccines, bed nets, etc. But today, effective malaria and HIV/AIDS vaccines or other ones do not exist. Meanwhile, to prevent these epidemics become pandemics, the WHO urges all countries to be constantly alert to the occurrence in neighboring and even far-off societies. Almost all countries worldwide participate in the WHO's global surveillance network aimed at actively monitoring outbreaks of old and new diseases. This includes the timely characteriza-

\footnotetext{
${ }^{19}$ For example, Chagas disease, African trypanosomiasis, onchocerciasis, leishmaniasis, schistosomiasis, leprosy, lymphatic filariasis, Dengue fever, Guinea worm, or blinding trachoma.
} 
tion of emerging pathogens through a worldwide network of laboratories (i.e. WHO Collaborating Reference Centers).

\subsection{A health crisis in the developing world}

\section{The gap between developed and developing countries}

The WHO Commission on Macro-Economics and Health (2001) has identified eight 'specific' top areas that account for a large proportion of the gap in disease burden between the poorest countries of the world and the affluent countries with established market economies. These are AIDS, malaria, TB, diarrheal disease, acute respiratory infection, vaccine-preventable disease, nutritional deficiencies, and unsafe childbirth. The disease burden attributable to these infections, maternal and prenatal conditions, as well as nutritional deficiencies represents roughly $60 \%$ of the entire disease burden in the world's poorest countries, most of which are located in Africa, Asia and Latin America, This is almost three times as much as in other developing countries, while in the upper tier of developed countries the combined burden of these diseases and conditions represents only a tiny fraction of the national disease burden.

As figure 4 illustrates, the share from infectious diseases is much higher in low income countries than in richer ones (Bloom, Canning, Jamison, 2004 and Bloom, Canning, Weston, 2003). Extra socio-economic considerations come into play when a disease is infectious to the community. The immediate consequence is the risk that one infection triggers a chain of infections that leads to a multiplication of costs, which magnitude depends not only on the damage the disease causes to each individual, but also on the probability that it will be transmitted. When that probability is positive, the illness is not a purely private matter for the infected individual, rather, the infection gets a certain public character. Any case of a communicable disease therefore generates, at least potentially, negative externalities. The very fact that the threat of transmission exists will itself cause costs to arise, to the extent that measures are taken to ward it off. Health scares may also deter potential investors and tourists from a country, as the SARS epidemic in China and South-east Asia has demonstrated. Foreign direct investment (FDI) in Hong Kong at the height of the SARS crisis fell by $62 \%$ in one quarter (Tam, 2003). 
Figure 4: GDP/capita vs. percentage of deaths caused by infectious diseases; by WHO Region and Mortality Stratum

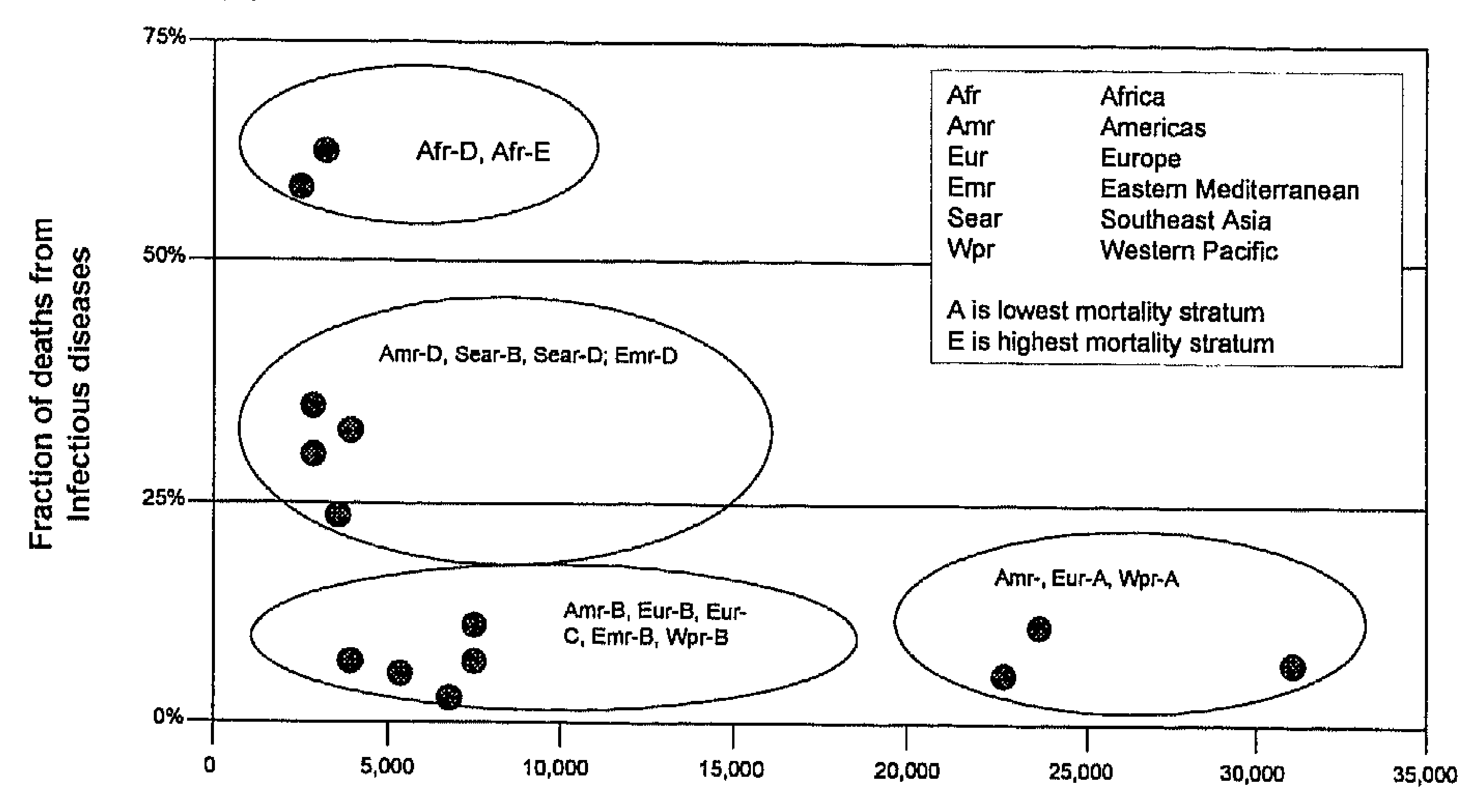

GDP/capita, PPP, constant 1995 US \$

With a few exceptions, data are for 2002.

Data are from WHO online database and World Bank,

World Development indicators 2004.

Unsurprisingly, epidemics of infectious diseases are likely to arise under conditions commonly created by poverty. Poor sanitation and hygiene allow bacteria, viruses, parasites and other vectors of transmission to thrive. These conditions for infectious diseases to spread include not only close and frequent contact between individuals, but also weak bodies that are more susceptible to infection and less able to ward off infections. Where populations are malnourished, left weak by other health setbacks, or have a high proportion of very young or very old members, epidemics have the potential to become endemic. It is therefore no surprise that epidemics tend to occur where health systems are weakest and incapable of detecting and responding to rapidly evolving health threats. Moreover, poverty conditions can lead individuals to engage in behaviors that facilitate disease transmission (e.g. sex workers). Preventing these epidemics from spreading throughout the developing world requires overcoming a range of obstacles, as responding to an epidemic once it begins at the household level. Although one might hope that long-term vulnerability to epidemics of infectious diseases may decrease as development standards rise, a more highly interconnected world may by contrast promote the occurrence of infectious disease epidemics even further (and most certainly faster).

The immediate socio-economic costs of epidemics are in many instances apparent, while the long-term costs are often unclear or hidden. Bloom, Canning, and Sevilla (2004) argue that when the 'value of life' is included in the cost, it becomes clear that epidemics are 
extremely costly. Several epidemics in the past have clearly caused negative income effects (King, 2006). The AIDS pandemic, while not yet significantly affecting GDP per capita, has already had major effects at the household level, particularly among the poor (Bloom, Ajay, 1997). Poor families hit by HIV/AIDS suffer disproportionately from lost earnings, and in most cases have to draw on savings or sell assets to pay for treatment. Relatives of infected individuals may have to take time off from work or withdraw prematurely from school to provide care. The immediate spending not only affects the family's wellbeing and quality of life, but also their economic outlook. Bell et al have modeled the long-term costs developing countries will have to bear as a result of the AIDS pandemic, and in particular the vast scale on which the social and economic effects are likely to be felt due to the decreased investment in human capital (Bell, Devarajan, Gersbach, 2003) ${ }^{20}$.Complications in evaluating the total impact of the AIDS pandemic lie in the long latency period of the HIV virus, the long-term course of the disease which is difficult to predict, and, therefore, the long-term economic effects (Bloom, 2006). But HIV/AIDS undoubtedly directly affects businesses and indirectly households in the developing world. In a survey among 8719 business leaders conducted by the World Economic Forum in 2004, business leaders expressed concerns about the current and future impact the HIV/AIDS pandemic will have on their respective workforces and other aspects of company operations (World Economic Forum Global Health Initiative, 2005).

Under 'normal' circumstances, that is, within a properly functioning health care system and a well developed infrastructure, including health education and prevention, and the provision of necessary treatment and care, the disease profile would be radically different But widespread poverty in HIV/AIDS affected countries significantly decreases the financial, physical, and human resources needed to establish such well-functioning healthcare systems (World Health Organization, 2001). This precarious situation is often exacerbated by the continuing political instability and lack of safety compounded by ongoing military conflicts, as well as the questionable government prioritization when it comes to health care budgeting.

\footnotetext{
${ }^{20}$ Clive Bell, Hans Gersbach and Shanta Devarajan modeled the impact of HIV/AIDS on human capital, the stock of knowledge and abilities in a population that fuel long-tem economic growth. The AIDS epidemic affects human capital in three ways. First, it kills society's most productive people, i.e. young adults. Secondly, it kills parents, and therefore noc only breaks the chain of transmission of knowledge from generation to generation, but also reduces household incomes, so that children are less likely to go to school. Additionally, the risk that children may become infected can reduce parents' interest in investing in their education. Thirdly, less-educated children in turn will have less knowledge to pass on to their own offspring.
} 


\section{Poor children are disproportionately affected}

While the issue of poverty has attracted a great deal of international attention, there has been less recognition of the problem of extreme poverty among children which is more pervasive and has pernicious long(er)-term consequences. The fact that poverty among children is an even greater problem than poverty in general should come as no surprise. It is in the world's poorest regions that children outnumber the older age groups. Nearly $50 \%$ in the least developed countries is under the age of 18 , compared with just $22 \%$ in the high-income OECD countries (Stiglitz, 2005). Extreme poverty denies these children access to such basic needs as safe drinking water, adequate food and health care. It is the main cause for under-five mortality in sub-Saharan Africa, the least developed region in the world, with rates twice the world's average and nearly 30 times higher than the average in high-income countries.

Stiglitz (2005) argued that "as an economist it is easy to say that we are not allocating resources in ways that maximize our own long-term interests. Lack of resources is however not, and cannot be, an excuse. Nor is this to say that we should view the eradication of poverty among children in the world as simply a matter of self-interest. It is a question of what is morally right". He asserts that the world can easily meet the expense of basic health care for the least developed countries if it were willing to do so. The average yearly cost of servicing sub-Saharan Africa's external debt is roughly US $\$ 80$ per household, almost half of the average amount that each local family spends on health and education combined (US\$173). Stiglitz observes that faster and deeper debt service relief for the poorest countries could free up additional resources for social expenditure that would go a long way to alleviating poverty. This he says can be illustrated with the example of UNICEF's projected cost of immunizing every child with vaccines that have a proven record of preventing childhood diseases (e.g. polio, diphtheria, tetanus, pertussis, hepatitis B, etc.). For the whole of 2004, this project amounted to approximately US\$187 million, and represents roughly $0.02 \%$ of global military spending (Stiglitz, 2005). He concludes that "armed with this data every society has the moral duty to mobilize its resources to reduce the level of deprivation that the poorest children in this world experience on a day-to-day basis".

Stiglitz also warns that the rich nations' self-interest is at stake. The greatest threat to this world is the social injustice and despair felt especially by younger generations, which may provide a fertile breeding ground for terrorism. Hence it can be argued that, in this era of global economic interdependence, the more affluent economies have a collective social responsibility to help the disadvantaged ones. 
One of the most effective strategies to reduce the effect of infectious diseases is active immunization that provides life-long immunity to disease causing agents. Vaccination is the cornerstone of public health. Immunization of 'at-risk' groups, or entire population cohorts, is known to be a cost effective and lifesaving intervention that prevents needless diseases, disabilities and deaths. To date, immunization has eradicated smallpox, substantially reduced morbidity and mortality from diphtheria, pertussis, tetanus and measles, and (until very recently) was thought to be on the verge of eradicating polio (until outbreaks occurred in some LDCs).

In the context of making globalization work for the 'haves-not', acting against vaccine preventable diseases and preparing for the possible emergence of pandemics, will significantly contribute to the enhancement of global health and security. Immunization programs offer both direct and indirect benefits by raising protection levels of all populations against infectious diseases, reducing the inequity gap, and providing an important contribution to development and poverty alleviation.. Because successfully vaccinated individuals do not contribute to further transmission of infectious agents, the vigor of the epidemic decreases. Non-vaccinated individuals benefit from the intervention as well as their chances of contracting the disease will also diminish ${ }^{21}$. Unfortunately, many developing countries are lagging behind in achieving high coverage rates for existing vaccines compared to more wealthy nations. Immunization is far from universal in LDCs and in some vaccination coverage levels are gradually sliding again. Measles for example, has immunization rates of over $90 \%$ in Europe, but below 70\% in South Asia and below 60\% in sub-Saharan Africa (Bloom et al, 2005). Ten developing countries reported cases of polio in June 2005, despite the massive (and largely successful) global effort to eradicate polio virus. Surveillance data from 2003 showed that $62 \%$ of countries had not achieved full routine immunization coverage. Bloom et al (2005) have reported that The Global Alliance for Vaccines and Immunization (GAVI) estimated that at least 9.2 million additional infants needed to be reached to achieve full coverage. The next pillar of achieving disease prevention is through ensuring access to an unprecedented array of new vaccines and technologies that are at an advanced stage of research and development for those at risk in all countries. This includes vaccines against major killers such as rotavirus, which is responsible for as many as onefourth of the 1.9 million child deaths annually as a consequence of acute diarrhea, and pneumococcal disease, which makes up a large proportion of the two million annual deaths from acute respiratory infections in the world.

\footnotetext{
${ }^{21}$ The greater the proportion of people in the population that is immune to a communicable disease through vaccination, the less likely it is that sustained disease transmission occurs; a concept referred to as herd immuniry.
} 
From an economist's perspective, vaccination is not purely a health sector issue. It resonates in wider socio-economic planning and long-term macro-economic progress. The assessment of the benefits of vaccines and immunization programs has traditionally focused on a specific range of health-related impacts. These are expressed as, for example, number of averted illnesses, hospitalizations and deaths; disability-adjusted life years (DALYs) gained; and the medical costs avoided. Cost-benefit and cost-effectiveness analyses are the most common assessment methods ${ }^{22}$. Bloom et al (2005) have demonstrated that this perspective is however too narrow. Neither cost-effectiveness nor cost-benefit analysis has so far taken full account of the broader economic impacts of immunization. The alleged wider socioeconomic impact stems from the fact that immunization protects individuals not only against getting an illness per se, but also against the long-term effects of that illness. A more thorough investigation of the impact vaccination has, should include not just direct medical costs saved and illness averted, but also the effects on cognitive development, educational attainment, labor productivity, income, savings, investment, and fertility.

Bloom, Canning and Weston (2005) have examined the reasons for the vaccination coverage rates in developing countries to go down in recent years. They attribute the current worldwide gap to logistical and infrastructure problems, political instability (e.g. war), difficulties in reaching the most remote populations; and changes in public perceptions about the safety of vaccination. Interestingly, there is an instance where industrialized nation politics had a hand in it too. In a report by the U.S. Institute of Medicine (1997), the U.S. vaccine industry was in 1982 forced to stop offering low-price vaccines to developing countries following congressional hearings that 'savaged' the industry for "allegedly subsidizing vaccines for the poor children of the world by charging high prices to American families and taxpayers". As the Institute of Medicine pointed out, this decision was based on a flawed premise that the vaccine would not be developed for the U.S. market. On the contrary, the vaccine manufacturer intended to protect American children and overseas travelers. The discussion in this book on why 'joint costs' of biomedical $R \& D$, and the welfare benefits offered by 'preferential or tiered pricing' practices, do not increase prices in affluent markets will be held in chapter 2 .

\footnotetext{
${ }^{22}$ Cost-effectiveness analysis looks at the cost of a health intervention per life saved (or per DALY gained, etc.); cost-benefit analysis takes into account the value of each life saved or the extra years of healthy life gained in monetary terms by comparing the total value of those benefits (costs of illness saved) to the cost of the intervention.
} 


\title{
1.4 Access to existing and novel medicines
}

\author{
Access barriers to medicines in developing countries
}

The backing of public policies and provision of public funds by public health authorities is not a guarantee that existing drugs and vaccines are effectively distributed. Many diseases that disproportionately affect low-income countries can easily be prevented or treated with existing medicines, as they appear on the WHO's Essential Drugs List. Nevertheless, these diseases continue to impose an important burden on the health of millions of people affected, proving that the biggest challenge that remains is getting the interventions to the people who need them. Any considerations regarding the need for novel interventions should therefore be made within the context of access to medicines. Otherwise, they may lead to unnecessarily wasted resources and create expectations that cannot be met.

Where people lack access to medicines, they cannot by definition, obtain the products they need to prevent or treat a medical condition. This might be because the product is not available, not being offered, or because it is unaffordable. No doubt, prices and ability to pay matter particularly to the poor and their governments in the poorest countries. In many countries in the developing world, patients pay for medicines out of pocket, which can account for $60-90 \%$ of what the household spends in total on healthcare (Stevens, 2007). As a result, the price of medicines, particularly for newer treatments such as those for HIV/AIDS, has in recent years become the focus of the international community. But the price of new and existing medicines is by no means the (only) barrier to access. Inadequate financing for health, poor priority setting, inappropriate drug selection and prescription, and weak health care and supply systems represent important hurdles that bar people from getting the care they need. This is exacerbated by the lack of general education, leaving individuals unaware of their own health needs, or of strategies that could protect their health, or health services and products that might already be available to them.

The widespread distribution of medicines is conditional to adequately functioning health care systems and well developed infrastructure. If health care systems are deprived of resources, it is unlikely that they will be able to procure the necessary medicines, or be able to employ sufficient numbers of staff that can prescribe and administer these products. The majority of low-income countries simply lack the basic infrastructure that is needed to distribute medicine successfully. In addition, roads are often badly maintained or nonexistent, making it difficult to ensure a constant supply of medicines to remote areas (Saleh, Ibrahim, 2005). Electricity supply is often erratic, which increases the cost and difficulty of running refrigeration systems in clinics and hospitals. As a result, heat-sensitive biological products like vaccines are often not stored at sufficiently low temperatures to ensure product stability. 
Even an intervention by multilateral public health authorities, like the WHO or UNICEF, and the provision of public funds either locally or through donations, are not a guarantee that existing medicines will be effectively distributed. Consider the case of malaria, where, despite the establishment of the WHO's prestigious 'Roll Back Malaria' initiative and the injection of donor funds specifically earmarked for malaria, the most modern and potent anti-malarial drug has not been correctly used six years after the initiative began (Attaran, 2004). It is known that well-equipped and properly staffed modern medical facilities are adept at disseminating the latest medical tools and drugs (Dussault, Dubois, 2003). The lessons learned are that where these conditions are not fulfilled, distribution and communication channels are inefficient and new medicines are slow to reach the patients, if they reach them at all (Gambardella, 2000). Finally, weak public healthcare systems do not simply result in a failure to distribute existing medicines and services. Stevens (2007) argues that they also have a knock-on effect on the demand for new drugs and act as a serious disincentive to would-be innovators of new medicines.

Deregulation and free trade have, over the past thirty years, been embraced by Western countries as tools for economic growth. Poor countries have yet to benefit from this finding. Many governments of low-income countries compound the problem of weak health systems by imposing taxes on medicines, ranging from port charges, central, regional and local taxation, as well as import tariffs and value added taxes (VAT). State-imposed price hikes, along with numerous and very burdensome bureaucratic barriers, strangle the developing world's access to medicines (Bate, Tren, 2006). Other government-imposed measures and regulations may include pre-shipment and inspection costs, and pharmacy board fees. Compiled, these add significantly to a drug's retail price which has a negative impact on access to medicines especially for the poorest. In a survey of nine countries, Danzon and Furukawa (2003) found that the costs resulting from local government policy and regulation added an average of $68.6 \%$ to the cost of imported pharmaceuticals.

The pleas for a greater commitment from OECD countries to tackle problems in the developing world ring hollow when the governments of LDCs maintain taxes, tariffs, and bureaucracies that impede decent healthcare for their own populations and cause their own citizens to die needlessly (Olcay, Laing, 2005). Although India is often hailed as a purveyor of cheap generic drugs abroad, high tariffs at home limit patient access to critical drugs made by foreign manufacturers. As a matter of fact, only $35 \%$ of Indians have access to essential medicines and far less have access to domestically produced copycat (generic or counterfeit) ARVs to fight HIV/AIDS. This is worrisome given that the Global Fund to Fight AIDS, TB and Malaria stated that as many as 8.5 million Indians are already HIV positive and the disease is spreading (UNAIDS, 2004). Bate and Tren (2006) therefore propose an alternative solution. The revenue lost to developing countries from tariff abandonment is generally small; instead, revenue can be raised in far less regressive ways, such as 
through domestic income taxes or sales taxes on nonessential goods. The WHO recently published a paper on this position: "It is vital that policy makers, both at a national and international level, address the issue of tariffs on medicines and recognize the regressive nature of these duties, which ultimately tax the sick without regard for their economic status or ability to afford these medicines. Pharmaceutical tariffs could be eliminated without adverse revenue or industrial policy impacts" (Olcay, Laing, 2005).

Beyond visible barriers such as tariffs, manufacturers exporting to overseas markets often face less visible, but nevertheless significant hurdles and complexity in registering their products. These tend to emanate from local drug approval agencies and are often designed rather to protect the local industry than achieving better outcomes for patients. A wellknown example is South Africa's Medicines Control Council (MCC). The MCC requires that all new medicines obtain its own regulatory approval before they can be marketed in the country - even if they have already been approved by reputable foreign regulatory bodies such as the American Food and Drug Administration (FDA). The inefficiency of the MCC means that new medicines that have already been registered for use in the United States, European Union, and Japan wait an average of thirty-nine months for approval in the South African system (Stevens, 2007). Another example comes from Namibia (Bate, 2005) which announced in 2002 that all medicines registered in the country prior to its independence (1990) should be re-registered. In the face of these non-tariff barriers, companies will often forego the regulatory complexity and expense of registering their products in these countries (and will instead invest their resources elsewhere). Especially since this is compounded by the already low purchasing power of the majority of the population in LDCs. Under these conditions these countries do not seem to constitute a significant market for foreign manufacturers. The result is that fewer medicines are getting approved, even when they are desperately needed. One would think that a higher level of competition in the marketplace would normally drive prices down and consequently increase access but this does not seem to be the case in these markets.

Lastly, there is the related issue of poorly functioning insurance markets in developing countries., Health insurance generally enables individuals to pool their financial resources and thereby hedge themselves against the risk of unexpected and expensive illnesses ${ }^{23}$. In return, an insurer agrees to compensate the individual for monetary payment in a specified way should defined, uncertain events actually happen. When health insurance systems function well, demand for healthcare increases due to the large number of people covered against the costs of ill health. Several studies have shown the (positive) link between greater

\footnotetext{
${ }^{23}$ Health insurance takes the form of a contract in which payment is made in advance of pay out by the insuring company.
} 
uptake of preventive and therapeutic medicines among poor and vulnerable populations and the availability of health insurance in the United States (Poisal and Chulkis, 2000). Despite the importance of this element in the healthcare system, many of the low-income countries do not have properly functioning health insurance schemes. In 1998, not one low-income country with a gross national product (GNP) per capita below US $\$ 761$ had a social health insurance scheme (Carrin, 2002). As a result, individuals not covered by insurance pay for healthcare out of their own resources (or are nominally provided such services by the state). Since these populations are already poor, their ability to purchase medicines - especially the newer, expensive ones - is likely to be very low indeed. The conclusion is that health insurance that is not available or affordable constitutes a major barrier to access to medicines and poses significant constraints on demand and usage despite the fact that many medicines are cost-effective from a healthcare system and societal perspective. A number of low-income countries have in recent years experimented with national insurance and social security to increase access to healthcare, but with corrupt and/or malfunctioning healthcare systems the poor and underserved are still deprived of essential medicines and basic healthcare services.

Stevens (2007) argues that one important reason for the low level of insurance coverage in poor countries is the lack of adequate court systems and an absence of the rule of law, which makes the enforcement of legal agreements difficult, lengthy and expensive. In an environment where contracts are difficult to enforce, it is not surprising that many people are unwilling to risk paying into an insurance plan. This then relates to a failure on the part of the government to create an adequate rule of law and supporting institutions. This is compounded by the absence of a functioning market economy. At the end, it keeps people poor and undermines access to and demand for medicines and other goods and services, like medical insurances; it also directly affects the supply of these goods. In addition, slow, expensive and corrupt court systems make it difficult to enforce contracts, which in turn discourage potential suppliers from entering into supply contracts.

The risk that trucks carrying medicines will be stopped and the cargo stolen or impounded, or a bribe levied by corrupt law enforcement officers further reduces the incentive of companies to supply medicines (Sherwood, 2000). A 2006 World Bank report estimated that about half of all funds donated to strengthen healthcare services in sub-Saharan Africa never reach the hospitals and clinics. According to the bank, money leaks in the form of payments to ghost employees, padded prices for transport and warehousing, the siphoning off of drugs to the black market, and the sale of counterfeit - often dangerous - medications. In Ghana, for example, where such corruption is particularly rampant, an amazing $80 \%$ of donor funds get diverted from their intended purposes (Garrett, 2007). The problem with bringing to market a trademark protected product in these countries, in reality means that these companies may face competition from cheaper, but typically less 
effective, ineffective or even harmful, counterfeit products. In summary, the empirical evidence suggests that dysfunctional judicial systems restrict the ability of inventors and innovators to commercialize their inventions, and this in turn impedes economic growth.

\section{Lack of innovation to address poor country diseases}

Some fifty years ago, at the time the World Bank and other multilateral development banks were established, it was thought that what distinguished developed from less developed countries was having more capital. Policymakers believed that what was needed in order to make less developed countries into more developed countries was basically to transfer capital. However, the key learning has been that other factors are equally important.

Hernando De Soto (2000) describes in his book 'The Mystery of Capital: Why Capitalism Triumphs in the West and Fails Everywhere Else' that what has successfully created capital in the West is a process deeply embedded in the legal structure of its property systems. De Soto argues that "every developed nation in the world at one time went through the transformation from predominantly extralegal property arrangements to a formal, unified legal property system". In his opinion, the lack of legal property explains why citizens of developing and former communist countries cannot make profitable contracts with strangers, cannot get credit, insurance, or utilities services. According to De Soto this is because "they have no property to lose"; because they have no property to lose, they are taken seriously as contracting parties only by their immediate family and neighbors. So long as the assets of the majority of people are not properly documented and tracked by a property bureaucracy, they are invisible and sterile in the marketplace. He concludes that "people with nothing to lose are trapped in the grubby basement of the pre-capitalist world". De Soto is aware of the fact that, like in all representative systems, property paper is seen by many intellectuals as an instrument of deceit and oppression. These negative attitudes towards representation have been powerful undercurrents in the formation of political ideas. De Soto clearly demonstrates the importance of legal property systems in industrialized countries by using the analogy with the plight of Bill Gates, the world's most successful and wealthiest entrepreneur. He wonders: "How many software inventions could Bill Gates have made without patents to protect them? How many deals and long-term projects could he have carried out without enforceable contracts? How many risks could he have taken at the beginning without limited liability systems and insurance policies? How much capital could he have accumulated without property records in which to fix and store that capital? How many resources could he have pooled without property representations? How many other people would he have made millionaires without being able to distribute stock options? How many economies of scale could he have benefited from if he had to operate based on dispersed cottage industries that could not be combined? How would he pass on the rights to his empire to his children and colleagues without hereditary succession? In sum, it is 
unlikely that Bill Gates, or any entrepreneur in the West, could have been successful without property rights systems based on a strong, well-integrated social contract.

A central idea that emerged over the last ten years has been that success is not only the result of closing the gap in capital between developed and less developed countries, but also of closing the gap in technology and knowledge. It is now widely acknowledged that what separates developed from less developed countries is precisely this gap in knowledge and technological innovation capacity. Stiglitz (2003) concurs with this view: "knowledge, innovation and technology are important elements on the path for growth and development". This emphasizes the crucial role of education and the importance of investment in human capital (Obstfeld, Rogoff, 1996). Studies indicate that, due to positive investment externalities, the investment in physical and human capital may contribute more to economic growth than the original neoclassical theory suggested (Gilpin, 2001). Although the investment is aimed at improving the productivity of the firm that invests, the technological and other spillovers can benefit other national firms and even the entire economy. Romer and Lucas incorporated these ideas in the new endogenous theory of economic growth. Many, if not most, of the central ideas in this growth theory had been set forth earlier by other economists, including Joseph Schumpeter, Kenneth Arrow, Christopher Freeman, Richard Nelson, and Sidney Winter ${ }^{24}$. In short, whereas the neoclassical model builds only on two factors of production (labor and capital) and treats technology or knowledge as an exogenous factor that assumes that progress in technology is produced by random scientific and technological breakthroughs, the new theory incorporates progress and advances in knowledge as endogenous factors within an economic growth model. In other words, where knowledge and technology just occurred in the neoclassical model, the new theory assumes that they result from conscious decisions taken by entrepreneurs and individual firms, and that technological advance is thus largely market-driven. Entrepreneurs are assumed to invest in research and development activities for the same reasons they invest in other factors of production, that is on the basis of the expected profitability of the investment.

Similarly, Gilpin (2001) explains in his book "Global Political Economy: Understanding the International Economic Order" why this concept of advanced knowledge and technology - as a separate factor of production - has important implications for understanding growth. The 'knowledge' of how to do things raises the productivity of the other factors. Investment in capital and advanced knowledge thus stimulate and reinforce one another in a 'virtuous circle' of cumulative causation so that acceleration in the rate of capital invest-

${ }^{24} \mathrm{~A}$ valuable history and critique of the theory is in Richard Nelson, "How New is New Growth Theory" Challenge 40, no. 5 (September/October 1997): 29-58. Nelson himself atrributes much of the new thinking about economic growth to Moses Abramovitz. 
ment can raise the long-term growth in per capita income. The endogenous growth theory also demonstrates that policy measures can have an impact on the long-run growth rate of an economy. For example, subsidies for education or research and development increase the growth rate in some endogenous growth models by increasing the incentive to innovate.

Jeffrey Sachs (2005) makes it clear in his book "The End of Poverty" that the "lack of innovation' is indeed one of the major problems that cause an emerging economy to stagnate or decline. The upside is that this gap in innovation capability can be resolved. The geographic region that not too long ago still belonged to the developing world, and that has been most successful in achieving and accelerating socio-economic development and macro-economic growth, is East Asia. It is often taken as an example for other regions in the world to follow, and may to a certain extent offer a template for economic growth in areas like, for instance, the BRICKS countries (Brazil, Russia, India, China, Korea, South Africa). Over the past thirty to thirty-five years, most of the once low-income countries in East Asia have seen their per capita incomes increase eightfold. As time goes by, the East Asia crisis (1997-1998) looks more or less like a blip, as countries like the Republic of Korea have returned to their strong and robust economic growth. When examining this country's progress over a long period of time, evidence shows that it has been enormously successful, not only in promoting economic growth, but also in reducing poverty. The key to that success is the closing of the technology gap. Until forty to fifty years ago, Korea's per capita income was roughly comparable with that of India, and so was its state of technology. Korea like so many other developing countries was an agrarian economy. Today, it has become a major producer of chips and of other electronics. It is engaged in a whole variety of product innovations and has a clear strategic intent.

There is still a huge difference between the world's richest and poorest countries in their tendency to innovate and this is particularly true for the pharmaceutical technology and medical services sector. As discussed in previous sections, one of the main reasons is that poor countries have inadequate healthcare systems and a poor infrastructure. Another is that wealthy countries generally have a large $(r)$ commercial market, which increases the incentive for innovation, brings new technologies to market, further raises productivity and expands the size of the market, and thereby creates new incentives for innovation. Achieving this kind of momentum creates, in effect, what Sachs calls a 'chain reaction' (which is synonymous to endogenous growth) - that is, innovation expands the market size, and in turn a larger market raises the incentives for innovation. Economic growth and innovation thus proceed in a mutually reinforcing process. This is the ideal situation. In stark contrast to the thriving innovator in industrialized countries is today's plight of the indigenous inventor in an impoverished country trying to make a living. Even if this inventor were able to develop new scientific approaches to meet local socio-economic needs, the chances of recouping the investment in $R \& D$ through sales in the local market are very low. The local 
purchasing power to buy a new pharmaceutical or medical product is small and the market price will not provide for sufficient profits if the invention is successfully brought to market, even despite state-of-the-art patent legislation. The problem is not only the property rights to the invention, but the size of the 'real' market directly related to the buying power as will be described later.

In sum, the more affluent countries of North America, Western Europe, and East Asia, all invest heavily in medical research and development because they are assured of both patent protection and access to large markets. This stands at the core of their business model and economic growth paradigm. The advanced economies are typically directly investing two percent or more of their gross national product into the research and development process, and sometimes more than three percent of GDP (Sachs, 2005). That type of capital investment is very sizable with hundreds of millions and - depending of the size of the corporation - even billions of U.S. dollars invested each year in R\&D activities. Moreover, these investments are not merely left to the market alone. Governments invest heavily too, especially in the earlier stages of innovation. However, these corporate investments in and the public funding of medical research projects in rich countries aim at rich-country diseases. Every year, the public and private sectors together spend more than US $\$ 70$ billion on health care R\&D. Regrettably, only an estimated $10 \%$ of this is allocated to research in disease areas that affect $90 \%$ of the world's population. This is known as 'the $10 / 90 \mathrm{gap}^{25}$. Between 1975 and 1999 , only 13 (1\% of the total) out of the 1,393 new drugs developed were to treat purely tropical diseases (e.g. Chagas disease, African trypanosomiasis, leishmaniasis, etc.) although, from a healthcare demand and global equity perspective these illnesses deserve more attention ${ }^{26}$.

\section{Positive relation between free trade and global bealth}

In most of the poorer countries, the process of pharmaceutical innovation simply never gets started. As described earlier, inventors do not invent because they know that they will not be able to recoup the large, fixed costs of developing a new compound. Impoverished governments cannot afford to back the natural and medical sciences in government labs and universities, and as a result, scientists do not stay - the infamous 'brain drain'. This inequality in innovation activity magnifies the inequality of global incomes. Academic researchers have observed that over the span of the last two centuries, this innovation gap is

${ }^{25}$ Global Forum for Health Research website: www.globalforumhealth.org

${ }^{26}$ See 'Fatal Imbalance' (2001) and other information on Médecins Sans Frontières' website: www.msf.org: it is important to note that, new medicines with high relevance to developing country needs and a market in richer countries were developed over this period - ARVs for HIV/AIDS are one example. Other medicines, such as new anti-malarials, have been developed as of 2000 . 
one of the most fundamental reasons why the richest and the poorest countries have diverged, and why the poorest of the poor have not been able to get a foothold on growth. The rich move from innovation to greater wealth, further to innovation; the poor do not.

The good news is that there are alternative ways to reap the rewards of innovation. Even when countries are not inventors of technology themselves, they can still be beneficiaries through the importation of innovative products and the global diffusion of advanced technology. Angus Deaton (2004) argues that the health of most people in the world depends mostly on their ability to adopt health knowledge and health technologies that were discovered elsewhere. Technical inventions can be imported directly through finished goods, capital imports in the form of machinery, or foreign direct investment through which a high-tech firm sets up a pharmaceutical factory in a rapidly developing country. Historically, many of the poorer East Asian countries were successful in raising local technology, not so much through homegrown innovation as through their success in attracting foreign investors who brought these new technologies with them (starting either as standalone companies or through joint-ventures with a local partners). The pharmaceutical and medical technology industry is a good example. An increasing number of companies have used this stepwise approach and start their foreign investment by first building local product packaging lines followed by upstream investment in aseptic filling, further expanding by building bulk producing facilities locally, and in some cases by developing expertise in new product research and development through training and through intra-company career secondments.

Economists of every persuasion are convinced that free trade is generally superior to trade protection (Gilpin, 2000). The most spectacular increases in economic growth all involve simultaneous increases in both exports and imports. Trade is the best way of tackling poverty in developing countries, and sustained economic growth and prosperity worldwide can only be achieved through continued widespread trade liberalization and integration. ${ }^{27}$ Furthermore, international trade allows developing countries to acquire vital knowledge. Before the late $19^{\text {th }}$ century, cross-border trade was restricted to a handful of nations. Today, all countries trade internationally and even lower-income countries are recently seeing their share of global trade significantly increased. Because of this growing international exchange of goods and services, the related knowledge itself - including advanced pharmaceutical and medical technology, most of which originated in rich countries - is gradually being disseminated to the rest of the world. This is not a new phenomenon. Already after World War II, the global spread of ethical drugs, such as penicillin - a medi-

\footnotetext{
${ }^{27}$ The theorems and analyses stating that market economics deliver benefits in the form of higher living standards and lower prices are all based on the assumption that there is effective competition in the market place (Stiglitz, 2002).
} 
cine discovered and developed in Britain - had a massive impact on mortality in many poor countries as well. Similarly, the spread of other important public health technologies developed in rich countries, such as the synthetic pesticide DDT, have significantly reduced the incidence of malaria in many parts of the world. However, in order for poor countries to maximize the benefits from international trade, they need a rules-based trading system that reduces the barriers to trade between the developing and developed countries, and vice versa. To benefit all players, international trade has to be free and fair, with the same transparent and mutually agreed rules applied to everyone.

The World Trade Organization (WTO) has laid down a set of rules to help open up global trade and ensure fair treatment of all participants. The system, although imperfect, offers a degree of transparency and legal certainty in the conduct of international trade. The most visible way to make trade free is to reduce, or remove altogether, import duties or quotas which countries apply to products. Suppliers, whether domestic or foreign, can then compete openly on price and quality. Nevertheless, there are also hidden or 'technical' barriers to trade whereby governments and companies try to gain an unfair advantage over others. According to the Permanent Delegation of the European Commission to the International Organizations in Geneva, these unfair trade practices include the following (European Commission, 2007):

- Selling goods on foreign markets below cost or domestic price in order, for example, to force producers in these countries out of their home market - so called 'dumping';

- Paying subsidies from the state budget to companies, including to 'national' champions', to give them an unfair advantage in export or domestic markets;

- Reserving public contracts for local firms, even though foreign bidders submit better offers;

- Disregarding intellectual property rights (trademarks, copyrights, and patents) by producing pirated or counterfeit goods that are sold cheaply to undercut the original manufacturer.

While proponents believe that the spread of science and technology, facilitated by free trade, is the most important reason why life expectancy has been steadily rising for the last fifty years in most parts of the world, opponents argue that trade liberalization and especially agreements such as those administered by the WTO are harmful to the poor. Regrettably, leaders in poor countries often receive ill advice and have come to believe that the trade system is unfair and hypocritical. They focus on other countries' protectionism and ignore their own. In his book "In Defense of Globalization", Jagdish Bhagwati (2007) explains why developing countries' protectionism - currently at average levels higher than in the rich countries - can only hurt their own prosperity. In his opinion, NGOs that advise governments, like Oxfam, that work on trade justice and are opposed to free trade, may not 
know enough about trade policy. While causing harm to the poorer countries cannot have been the intention of non-governmental organizations like Oxfam, Bhagwati contends that 'yet the road to hell is paved with good intentions ${ }^{28}$. That explains why history repeats itself. Take for example the recent WTO agreement - the General Agreement on Trade in Services (GATS) - which has been accused of undermining sovereignty of developing countries in the provision of health services. The reality is that the GATS health care services agreement allows signatories a great deal of flexibility. Like all trade agreements, the agreement is voluntary and relies on mutual recognition, not coercion (with WTO staff acting more as a broker). The GATS agreement is rather a significant spur to new technology transfer and knowledge exchange, as it encourages the adoption of internationally tradable service products such as telemedicine, medical tourism and proper standards for health insurance. It may even provide a framework to overcome the so-called 'brain drain' of medical personnel fleeing from South to North, by introducing more equity in career opportunities and salaries at home.

However, the trend is generally positive in that developing countries are party to a larger number of multilateral and bilateral investment agreements. As an upshot, investor confidence is rising and the spin-off is that these free trade agreements may become a powerful mechanism for improving the health of the world's poorest populations (Short, 2000). This will lead to an increase in foreign investment and competition, which drives improvements in products and processes that lead to economic growth and social welfare. In his paper "Free Trade for Better Health", Philip Stevens (2005) describes a series of examples demonstrating that free trade can indeed be a powerful mechanism for improving human health. Stevens believes this for two reasons: (i) On the one hand, liberating trade by reducing import taxes between individuals and countries is a proven method for increasing prosperity and wealth; (ii) On the other hand, open international trade enables effective technology transfer ensuring that advances made in one market rapidly become available elsewhere, positively affecting health of a nation. As a word of caution, Joseph Stiglitz and Andrew Charlton (2005) explain in their book 'Fair Trade for All: How Trade Can Promote Development' that this does not mean that liberalizing their trade within the WTO would benefit developing countries, irrespective of the actions taken by developed countries. If it were that easy, a pro-development trade agenda would not be needed, that is, developing countries should simply unilaterally open up their markets, and the faster they do so, the better. The authors contend however that a balanced pro-development agenda is more complex to resolve.

\footnotetext{
${ }^{28}$ Bhagwati's remarks are based on the much cired Oxfam report 'Rigged Rules and Double Standards: Trade, Globalization, and the Fight Against Poverty' (Oxford: Oxfam, 2002).
} 
The impact transnational corporations (TNCs) have on the process is another important factor in successfully harnessing the benefits of free trade. TNCs together with a growing number of small and medium enterprises (SMEs) have the ability to contribute significantly to globalization and the accompanying industrial and economic development in host countries. They can share advanced technologies, management processes, specialized skills, ability to organize and integrate production across countries, to establish marketing networks, and equipment on favorable terms. To reap the benefits from these transactions, developing countries need to create an environment that stimulates greater involvement of TNCs in the domestic economy. This can be done by encouraging collaboration with domestic suppliers and subcontractors, and promoting formal alliances and joint ventures as a way of building local capacity and acquiring technical skills. In return for lowering the barriers of entry into developing countries for advanced economy products and businesses, TNCs should develop adequate statutes at the global level. As a matter of fact, in a world of international production, domestic policies on finance, investment, competition and taxation, explicit and implicit rules need to be designed and integrated within an international framework. The United Nations Conference on Trade and Development (UNCTAD) emphasizes in its World Investment Reports that it is important for TNCs to also adhere to high standards of corporate social responsibility.

\section{Business strategy and corporate social responsibility}

Adam Smith famously argued that the pursuit of self-interest in a free market would benefit all in society. What is less well remembered, is that he also said that sympathy - by which he meant a concern for one's fellow man - was essential for the cohesion and stability of a society. Critics argue that businesses have eagerly embraced the self-interest part of the equation, ignoring the equally important aspect of maintaining sympathy for others. In recent years, businesses have increasingly been scrutinized and are more and more required by their shareholders (which in reality are all of us investing in private and pension funds, etc.) to not only deliver short-term financial results, but also act in a socially responsible manner. Overall, a growing number of citizens (and not only investors) expect to see a broader role and responsibility assumed by businesses in society. There is a growing need for more transparency and more pressure is being put on corporations and business to be more accountable in their actions to their stakeholders (and not only to their shareholders).

Corporate boundaries are expanding externally as society increasingly expects businesses to work with their partners and other stakeholders in a sustainable fashion in order to provide solutions to humanitarian crises and related problems facing the world. There are two contrasting, ideological positions in this sometimes vigorous debate on a corporation's social responsibility. On one side of the spectrum are those who argue that, to borrow Milton Friedman's phrase, 'the business-of-business-is-business'. This belief implies that 
social issues are peripheral to the challenges of corporate management. The sole legitimate purpose of business is to create shareholder value. On the other side of the spectrum are the proponents of corporate social responsibility (CSR). The latter is a rapidly growing movement. An increasing number of companies consequently claim that they already practice the principles of corporate social responsibility (CSR), but skeptical advocacy groups argue that they must go further in their commitments.

Alyson Warhurst (2005) has been tracing trends in strategic corporate thinking. In her opinion, a new multi-stakeholder governance framework is evolving that encourages businesses of the future to re-invent themselves as a 'force-for-positive-good' in society. This involves going well beyond the paradigm of simply 'doing-no-harm', and way beyond previous expectations of businesses as being only about 'shareholder value'. She believes that the challenges of expanding boundaries of responsibility are best addressed through 'strategic partnerships'. Likewise, Ian Davis (2005) contends that both extreme perspectives - the 'business-of-business-is-business' versus the 'CSR approach'- obscure, in different ways, the significance of social issues to business success. He believes that it is time for CEOs of especially larger corporations - because of their economic power - to recast the debate and recapture the intellectual and moral high ground from their critics. He therefore encourages especially the multinational companies to build issues of social interest into their corporate strategy. MNCs need to articulate their social contribution and define their ultimate purpose in a way that is more subtle than the 'business-of-business-is-business' approach - and less defensive than the current CSR approach.

The fundamental problem with the 'business-of-business-is-business' mind set is that it obscures two important realities:

Firstly, the 'business-of-business-is-business' philosophy should recognize that social issues are not so much tangential as fundamental to the business of business. From a corporate strategy perspective, but a defensive one, companies that ignore society's interest expose themselves to criticism. Companies that treat CSR as incongruent with the very nature and purpose of business, and indeed a hindrance to free trade, are turning a blind eye to impending forces that have the potential to alter their future in fundamental ways. Although the effects of social pressure triggered by these external forces are not always obvious or may not be immediate, that is not a reason for companies to delay preparing for them. Interestingly, from a strictly shareholder perspective, most stock market value depends on expectations of corporate cash flows beyond the next three years. This author believes that a strategic long-term corporate view needs to go well beyond the short-term profit goal. Large sums of shareholders' wealth have been put at stake as a result of social issues that ultimately feed into the fundamental drivers of corporate performance. Davis (2005) argues that if practiced as an unthinking mantra, the 'business-of-business-is- 
business' concept has gradually lead managers to focus excessively on improving the shortterm performance of their businesses, thus neglecting important longer-term opportunities and issues, including societal pressures, the trust of customers, investments in innovation and other global growth prospects. The past decade's storm of social pressures in the pharmaceutical sector,-stemming from issues such as the public perception of excessive prices charged for HIV/AIDS drugs in developing countries- have later on lead to a general (and sometimes seemingly indiscriminate) toughening of public policy, international trade regulations, and global political environment in regard to this industry.

It is envisaged that, in the case of the pharmaceutical and medical industry, the focus can shift and new markets created, particularly in emerging economies with fast-growing demand and vastly unmet medical needs. In his book 'The Fortune at the Bottom of the Pyramid', C.K. Prahalad (2006) challenges managers to re-evaluate their preconceived notions about the commercial opportunities in serving the relatively poor nations of the world. Drawing on a wealth of case studies, he argues that companies must revolutionize how they do business in developing countries if both sides are to prosper. So far, he claims, the large-scale private sector has only been marginally involved in dealing with the problems of $70-80 \%$ of the world's population. However, more and more corporations are seeing the economic potential that the rapidly emerging economies represent. Polish citizens in Warsaw quickly earned about US $\$ 800$ per month and this amount is soon to double. Projections for 2025 indicate there will be more people with an income above US $\$ 15,000$ in Brazil, China, Russia, and India than in Japan today. Prahalad wonders what would happen if we mobilized the resources, scale, and scope of large firms to co-create solutions to the problems at what he calls the bottom of the pyramid (BOP), those four billion who live on less US $\$ 2$ a day: "Why can't we mobilize the investment capacity of large firms with the knowledge and commitment of NGOs and the communities that need help? Why can't we co-create unique solutions?". He claims that collaboration between the poor, civil society organisations, governments, and large firms may create the largest and fastest growing market in the world based on innovative solutions. A recent example of this is the creation of microfinance institutions like the Grameen Bank of Bangladesh - the precursor of group liability lending - whose founder Muhammad Yunnus won the Nobel Peace Prize in 2006. The Grameen Bank's objective is to empower poorer communities by expanding individual lending products or in some cases, to shift from group liability to individual liability. This practice is expected to deepen outreach and provide more flexible microfinance products to the poorest in society (Microcredit Summit Campaign, 2005).

Secondly, an important fact why the pure 'business-of-business-is-business' outlook obscures many companies' reality is that there is a growing need to address questions about integrity, ethics and legitimacy. It is neither sufficient nor wise to say that it is for governments to set laws and for companies to (simply) operate within them. Nor is it 
acceptable to point out that many criticisms of business are unmerited or that those issuing these criticisms ought to acknowledge blame for their own practices and social responsibility. Irrespective of whether these criticisms are valid, their cumulative effect can and will shape the strategic context for corporations. It is therefore imperative that the business community seeks to lead the debate rather than merely reacting to it. Complicating the debate is the fact that in certain parts of the world-particularly in some poorer developing countries- the rule of law and basic public services are notable by their absence. This reality can render the 'business-of-business-is-business' mind set unhelpful as a guide for corporate action. If companies operating in these difficult environments focus too narrowly on ill-defined local legislation, or shy away from broad debates about their alleged 'bad' behavior, they are likely to face mounting criticism over their own activities as well as a greater risk of becoming embroiled in local political tensions.

As a result, corporate strategy experts like McKinsey, advise CEOs to introduce explicit processes to ensure that social issues and emerging social forces are discussed at the highest levels as part of overall strategic planning (Davis, 2005). This means that executives must educate and engage their boards of directors. To do so, companies can choose from a range of potential tactics, such as more transparent reporting, shifts in R\&D portfolio, or asset reorganization to capture expected future opportunities, to shed perceived liabilities, changes in approaches to regulation, and, at an industry aggregate level, the development and deployment of voluntary standards of behavior. Corporate leaders are well advised to shape the debate on social issues much more consciously by establishing ever higher (and appropriate) standards of integrity and transparency within their own companies, and by becoming much more actively involved in external debates (such as those in the media) on issues that shape the social context of business. A starting point may be for executives to articulate publicly the purpose of their business in terms less dry than shareholder value, although it should continue to remain the critical measure of business success.

In line with this thinking, Bonini et al (2006) advise corporate managers that it may be more accurate and motivating - and indeed more beneficial to the shareholder value over the long term - to describe the ultimate purpose of their business as the efficient provision of goods and services that society wants. This by itself is a hugely valuable, even noble, concept. It may actually form the basis of the contract between business and society, and the basis of most people's real interactions with businesses. Corporate managers could for instance point out that profit is not an end in itself but a signal to society that a company is succeeding in its mission of providing something people want-and in doing so acting in a way that uses resources more efficiently relative to other possible uses. From this perspective, the creation of shareholder value or profits is the measure and legitimate reward of success in delivering to society the goods and services we 'all' desire, and can be claimed as the more fundamental business objective. Thus, by moving away from a rigid 
focus on the term shareholder value, private sector business can make clear to broad audiences that it understands the trade-offs inherent in its social contract.

Joseph Stiglitz (2006), in his book "Making Globalization Work", endorses the views of those demanding that pharmaceutical and life sciences companies are held to higher standards by society in comparison to other industrial sectors. Klaus Leisinger, head of the non-profit Novartis Foundation for Sustainable Development, has sorted out the special nature of the healthcare business, which he believes is different from many other businesses in well-defined aspects. In an interview with Kumra (2006), he contends that "a sick patient does not have 'consumer sovereignty' to buy or reject a (medical) product; . . . if you are thinking about buying a car, you often have the alternative of using a bicycle or public transport; but if you are sick you need a medicine, and if it is lifesaving you have even less choice; . . conditions of poverty impose an additional corporate responsibility, especially with lifesaving drugs like for malaria or with medicines to cure a disease like leprosy". In addition, he proposes that corporations implement differential pricing meaning that they sell at the market price in rich, industrialised countries but provide the drug at cost or at highly subsidized prices to international organizations like the WHO.

\subsection{Conclusion}

The least developed countries are disproportionately exposed to infectious diseases that spread easily throughout the community. Three diseases alone - HIV/AIDS, TB and malaria - kill about five million people every year. They have a long-term debilitating effect on the 250 million people who suffer from them and have shown to reverse decades of development gains.

At the macro-economic level, this burden of ill health and death significantly reduces economic growth and undermines efforts to reduce poverty. For developing countries and emerging economies, better health has now been accepted as a central long-term driver of economic growth. For individual families and citizens that are living in these countries, better health means less suffering and less time and expense invested in caring for ill family members, improved physical and intellectual development, enhanced school attendance and learning, and higher productivity at work. Over the last decade, however, the global public and healthcare communities have turned their attention toward finding a structural remedy for combating internationally neglected diseases - those illnesses that disproportionately, and sometimes exclusively, affect the poorest populations living in low-income countries. 
As pointed out earlier in this chapter, there is a direct relationship between the multiple failures in the delivery of health care services, along with the sub-optimal distribution of prescription and over-the-counter medicines in developing countries and the fact that few commercial companies are willing to shoulder the risk of developing the drugs and health technology products needed by these countries, Still, industrialized country governments, NGOs, and pharmaceutical companies have an obligation to further raise the level of research and development on health problems typically affecting these populations. For example, preventing infectious and (re)-emerging diseases is best accomplished through immunization programs. Yet for many diseases that kill millions of people, drugs already exist and they should be made available today to the world's poor. Unfortunately, the health care systems in the developing world face severe capacity and financing constraints that further undermine domestic and international efforts to tackle these and other debilitating diseases and impede the swift roll out of new treatments when new medicines become available.

The private sector across all industries, and in particular the transnational pharmaceutical and medical product corporations, has a key role to play in making globalization work better for poor people. This is not only a matter of good citizenship or corporate social responsibility. It is in everyone's interest to help defeat the vast majority of communicable diseases prevalent in the developing world, as these diseases cannot be halted by geographical or political borders. There is an enlightened self-interest for politicians and public health authorities, and citizens of all countries in sponsoring such initiatives. International trade, frequent travel, conflict and migration, and global warming have proven to enhance the opportunities for cross-border transmission of infectious diseases, thus potentially threatening all economies in the world.

Finally, while the leaders of the poorest countries are happy to lobby for more aid and demand that companies offer their medicines at reasonable costs, they continue to levy taxes on these products until they are unaffordable to most. High import tariffs are intended to protect domestic industries as much as to raise revenue. Consequently, international drug manufacturers are less likely to sell to those markets. Manufacturers must also jump through numerous bureaucratic hoops before they can sell their products, even if they have already complied with drug safety standards in the US, the EU, and Japan. This evidence shows that there is little value to developing countries in maintaining regulatory barriers as they eventually stall imports and therefore limit access to essential medicines; tariffs on medical products can be eliminated without adverse revenue or industrial policy impacts. 


\section{Irnowation and diffusion: International trade, pricing and patents}

Building up a strong portfolio of products to prevent and treat diseases that disproportionately affect low-income countries requires a variety of policy measures. Encouraging private-sector investment in $R \& D$ with globally available and well-defined patent rights, together with greater financing through publicly-funded 'push' and 'pull' incentive mechanisms, is vitally important to rectify the lack of medicines developing countries need. The debate about patents and fair and affordable access to health care for all, is increasingly in the news today, even more so as worldwide attention focuses on the growing HIV/AIDS crisis. Implementing a differential/ tiered pricing system for pharmaceutical and health technology products for diseases with a worldwide prevalence would effectively permit companies to charge different prices in economically different markets. This practice, applied on condition that there is no parallel importation, allows corporations to simultaneously continue their pricing strategies in industrialized markets and sell at marginal production cost plus a margin to the poorest countries. We argue that intellectual property rights (IPR) and pricing mechanisms effectively implemented, offer a powerful means of improving affordability to existing life-saving products for the poor while not undermining incentives for firms to continue investing in $R \& D$. 


\subsection{Introduction}

This chapter will describe the relationship between pharmaceutical innovation, patents, and international trade. It will also try to reconcile some of the contrasting opinions that lead to improved access of innovative medicines in the developing world.

- First, the patent system fulfils a critical role in stimulating innovation and new product development. If patents do not exist, pharmaceutical and biotech companies would be forced to keep their innovations secret as they can be copied relatively easily. Such an industrial policy of non-disclosure may in effect last longer than the patent lifetime of the pharmaceutical compound itself. Therefore, contrary to popular belief, patents stimulate innovation by forcing companies to disclose their inventions and the knowledge behind them. This in turn serves as the basis for other inventions. However, in return these companies are allowed to appropriate the fruits of their labor by temporarily exercising monopolistic rights. This does not withhold other innovators from designing and building a better 'mousetrap' and to positively compete with the initial market leader or to actively gain the preference of patients/consumers who are beneficiaries in this process.

- Secondly, in the case of supplying new medicines to developing countries, the problem is not patents but affordability, pricing, and barriers to international trade. Differential pricing - sometimes called tiered- or preferential pricing - offers a viable solution particularly if the disease is prevalent in both the developing and developed world. This may apply to a number of diseases ranging from HIV to civilization illnesses such as cancer, diabetes, etc. because of changing food and lifestyle patterns. Today, the number one cause of death in India, China and Vietnam is not HIV/AIDS but heart disease, and cancer remains in the top ten. Recognizing this evolution, people in these countries will increasingly need clot-busting drugs, chemotherapy and electrocardiogram (ECG) machines just like in industrialized countries. MNCs and local manufacturers will need to make these life-saving technologies available to serve the poor and will be able to do this by applying differential pricing.

- Unfortunately, differential pricing cannot be applied to medicines and technologies that prevent or treat illnesses that mainly, if not exclusively, affect people living in tropical regions, often the poorest countries. Examples are malaria, leishmaniasis, trypanosomiasis, Chagas disease. Here, public tailor-made incentive mechanisms need to be created to support R\&D-driven companies in making the necessary investments and taking the risks of developing breakthrough drugs, vaccines and diagnostics that serve the populations in these endemic countries. Free product donations may alleviate the greatest need at a certain point in time but over time are economically not sustainable for the large quantities required. A structural solution must be found. A solution that establishes publicly funded 'push' and 'pull' incentive mechanisms to encourage 
private-sector investment in pharmaceutical and medical technology $\mathrm{R} \& \mathrm{D}$ is vitally important if we want to remedy the lack of essential products in this disease category.

- Finally, expanding access to medicines in developing countries requires considerable consideration of the broader societal context. The statements of 'too high' prices and 'too long' intellectual property rights are often cited with respect to access to new medicines, but they are just two 'pieces of the puzzle' that require further study. Other problems include the barriers to in-country distribution, underutilization of existing medicines, shortages in skilled labor, and the lack of adequate financing and insurance systems to support the adoption and diffusion of new medicines. The right approach would be to focus on strengthening the current healthcare infrastructure, delivery and procurement systems in these developing countries (as discussed in chapter 1).

\subsection{Economic analysis of patents and 'market failure'}

Do patents foster innovation and technological change?

Under standard economic theory, the purpose of a patent is to provide the patentee with an exclusive right (a monopoly) over the invention. The aim of the monopoly is to allow the patentee to generate monopoly profits, and thereby to reward the inventor and provide an incentive for $\mathrm{R} \& \mathrm{D}$. The reason why an incentive is required for research and development is because the knowledge embodied in an invention has 'public good' characteristics. This means that an invention may be the subject of 'free-riding' (i.e. unauthorized competitive use) by third parties, with the consequence that the inventor is unable to appropriate the full benefit of the invention. This leads to under-creation of inventions, to the detriment of society as a whole. To avoid this outcome, a patent is thus made available for inventions that satisfy certain thresholds of merit. But there are costs to granting patents. These costs include the loss associated with the monopolistic behavior of the patentee, and the loss created by the reduction in improvements on the patented invention made by competitors of the patentee (Christie, Rotstein, 2007).

In effect, a patent is a limited property right that governments offer to inventors in exchange for their agreement to share the details of their inventions with the public. A prominent concern shared by policy makers, academicians and industrialists is whether patent legislation indeed succeeds in preserving a balance between the interests of the public, i.e. knowledge disclosure, and those of inventors, i.e. monopoly over creative output, in order to maintain stable patterns for developing technologies. In some cases, however, patents fail to provide a sufficient degree of knowledge disclosure in return for monopoly rights. Then, the ability of second comers to review and to learn from prior 
inventions, and to build new inventions upon it, is restricted. Defining the duration of protection as well as the scope and height of the grant is no trivial matter.

What follows is a brief account of the evolution of economic thinking on patent protection. The neo-classical approach recognizes patents as legal mechanisms that are primarily geared at preventing market failure as a result of under-investment in R\&D. Firms are deterred from allocating financial resources for the development of new technologies unless their inventions are safe from reverse-engineering and duplication by rivals (Arrow, 1962). Consequently, the neo-classical studies of patent regimes that function as a means to economic growth typically aim at discovering the optimal design of the patent system. In other words, they look at how to best maximize social welfare (summing up the inventor's profits during the patent duration and the consumers' surplus in the following period), and minimize the social cost in terms of deadweight loss from monopoly rights and R\&D investments. In this scenario, deadweight loss also known as the excess burden of monopoly is triggered by the monopoly pricing approach the innovator is likely to use during the patent period. This may lead to artificial scarcity described as scarcity of items, even though the technology and production capacity exists to create abundance in supply. Enduring the application of even stronger patent regimes by increasing, for example, the patent length may increase the innovator's rewards for successfully commercialized inventions, but may hamper the pace of innovation in the long run by restricting the use of progressive techniques in the $R \& D$ of new products.

Nordhaus (1969) was the first to highlight the significance of the patent regime design by examining the links between the length (duration) of the patents (as a measure for the degree of protection granted to innovators) and the consequent incentives to innovate. His synopsis was later expanded (and criticized) in Scherer's work (1972). Recently, Christie and Rotstein (2007) have attempted to answer the question whether the current 'one size fits all' approach to duration of protection is optimal. Currently, all inventions are entitled to the same maximum period of grant, that is, 20 years. The original Nordhaus model is straightforward. Standard economic theory holds that the optimal patent length is modeled by equating the marginal social benefit of a patent over time with the marginal social cost of the patent over time. The marginal social benefit of a patent over time is the value of the incremental inventive activity generated by the patent in each time period. The marginal social cost of a patent is the value of the incremental harm to society resulting from the patent in each time period. The marginal social benefit curve is assumed to slope downwards, because the incentive effect of an additional period of monopoly protection falls over time. The marginal social cost curve is assumed to slope upwards, however, because the additional cost incurred by extending patent protection increases over time due to an absence of substitutable products (i.e. products that compete with the patented invention). In theory, the optimal patent length is found by identifying the time period in which the 
marginal social benefit in the period equals the marginal social cost in that period - that is, where the two curves cross. This principle is illustrated in figure 5.

Figure 5: Principle of identifying the optimal patent length

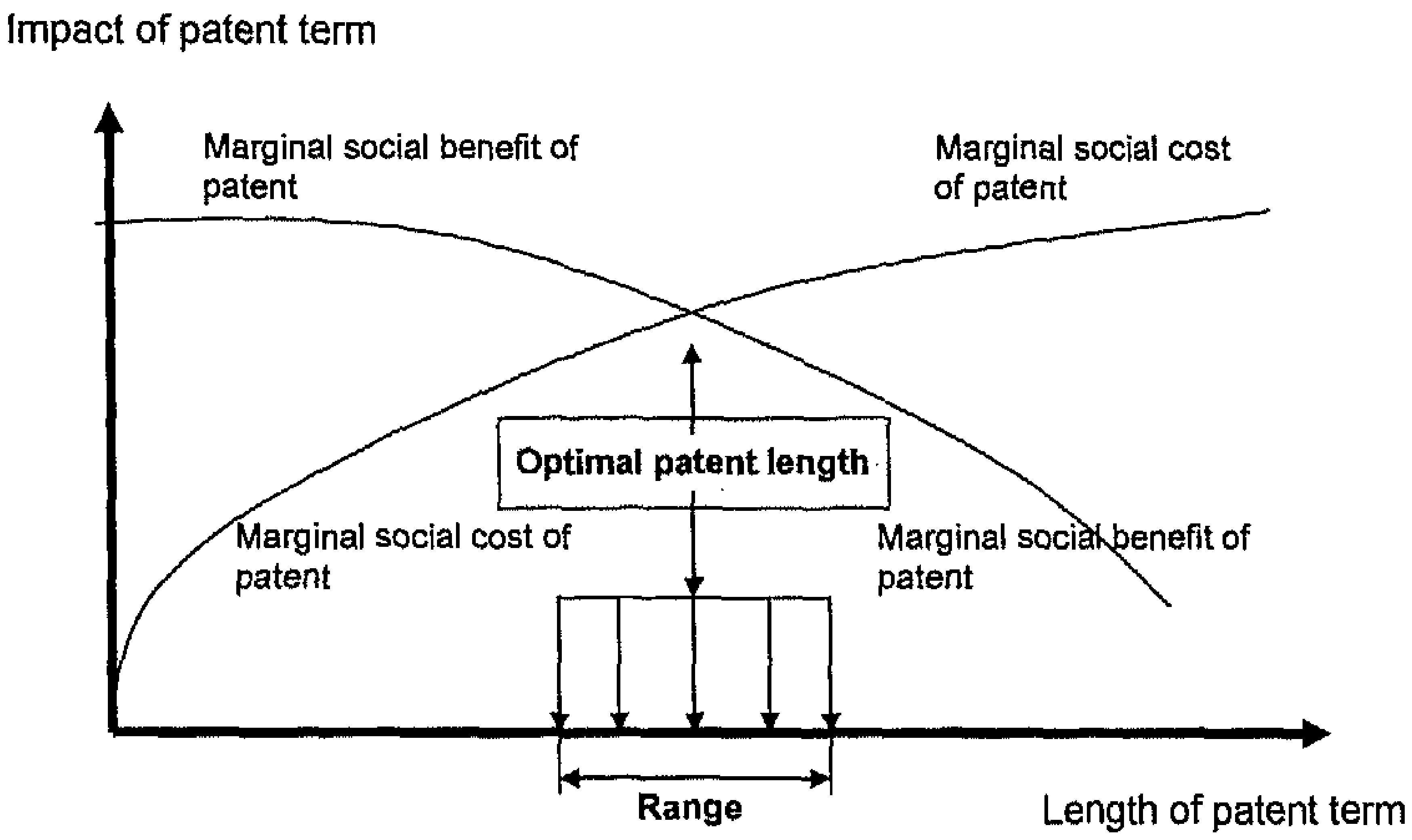

Identifying the range of the location of the optimal patent length

According to Nordhaus, once a patent life of six or ten years has been reached, the level of welfare generated by the patent system is very insensitive to the life of the patent. However, for 'small' inventions (i.e. with percentage cost reduction less than 5\%), the monopoly losses associated with the patent system are small (less than one-fifth of the gains from the invention). In a reply to Scherer, Nordhaus (1972) asserts that "if we were to err on one side, the analysis suggests too long a patent life is better than too short a patent life; for runof-the-mill inventions, the losses from monopoly are small compared to the gains from invention; and the best way to prevent abuse is to ensure that trivial inventions do not receive patents". The Nordhaus model thus demonstrates that the welfare loss of overly long patents is minimal, while the social cost of having too short a patent life is large. According to some commentators, this analysis provides the "main theoretical justification for the existing long and broad degree of patent protection" provided by the current patent system $^{29}$. Christie and Rotstein argue that the reality is that it is not possible to know how, exactly, to draw either the curve of marginal social benefit or the curve of marginal social cost. At the very best, it might be possible to ascertain the bounds of such curves - in which case, the range of the location of the optimal patent length could be identified. The authors found it helpful to turn to consider the real world practices of patentees when it comes to

${ }^{29}$ Given that inventions build on each other, an obvious limitation of the above literature is that it assumes the underlying environment is static. The most recent theoretical work considers the case of sequential innovators. This includes game-theoretical modeling of patent races among competitors. 
duration of patent protection i.e. when account is taken of patentees' practices regarding renewal of their patents and the legal features of the current system. By drawing together these observations made on the one hand on the basis of economic theory, and on the other hand the evidence of patentees' real world practices, they conclude that the system on duration of patent protection currently in operation matches closely to what would be considered optimal.

\section{The link between patents, innovation, international trade, and health}

Knowledge and innovative ideas have been a vital force in international development. While new technologies and ways of doing business are usually first developed in advanced economies, their transfer to other societies have been a key factor in the rapid modernization of the world's most successful developing nations, most notably the Asian Tigers and China (Shapiro, 2007).

The value of the intellectual property that embodies innovative ideas - from computer software and musical recordings to patented pharmaceuticals and information technologies - is enormous ${ }^{30}$. In essence, everyone has an interest in innovations regardless of where they happen to originate, because those who use them benefit most. There is no doubt that the benefit from using Windows by workers and corporations exceeds Microsoft's profits, or that HIV medications provide much greater economic benefits from an individual and societal perspective than the profits earned by the research-intensive firms that develop and patent them. The question is whether we really need this patent protection? Part of the answer lies in how people respond to normal economic incentives. While there are a few true altruists, most people will develop something that benefits others if doing so also benefits them. Moreover, as corporations have come to dominate the increasingly complex and costly development of technological innovations, the prospect of future gains as an essential incentive has become conclusive. The rest of the explanation lies in the economic nature of ideas, which make the prospect of earning returns profoundly dependent on property rights and legal protections. Unlike physical goods, such as a piece of equipment or real estate, an idea cannot be physically possessed, so its use by those who develop it does not preclude others from using it at the same time. As a result, the returns on innovations cannot be secured without legal protections of the new ideas that animate them. In a survey, American R\&D executives said that $60 \%$ of the projects that ultimately produced new discoveries would never have happened without patent protection (Shapiro, 2007).

\footnotetext{
${ }^{30} \mathrm{~A}$ World Bank study of patenting and growth in 92 countries over the same period, 1969 and 2000, found that a $20 \%$ increase in the annual number of patents granted, wherever the technologies originated, was associated with an increase of $3.8 \%$ in output, an unusually powerful finding (Shapiro, 2007).
} 
By contrast, many developing countries face different concerns because they have far less economically valuable intellectual property and therefore are significant importers of innovative technologies and expertise ${ }^{31}$. In the past, many of them were tempted to ignore foreign intellectual property rights, especially while patents were still in force and their owners could charge prices substantially higher than the marginal costs required to produce the goods. Therefore, weaker intellectual property rights hold the appeal of significantly reducing the cost of any given patented product. Additionally, governments of developing countries claim that in many instances the market for innovative products in low-income countries (the definition of which is often stretched to include middle-income countries for obvious political reasons) is too small to affect global investment in R\&D. They argue that developing countries should be allowed to ignore the intellectual property rights of foreign companies at almost no cost to the rest of the world.

Do patents help stimulate the development of medicines that are needed in developing countries? Or, are developing countries better off when they ignore intellectual property rights? If so, will this lead to better access to these medicines in LDCs? In economic theory, as in the design of public policies, welfare considerations are at the heart of the justification of patent systems. Coriat et al (2006) argues that any patent system as a set of institutional arrangements has to balance two opposing requirements: on one side (i) generation of innovation, and on the other side the (ii) diffusion of the innovative products thus generated on a large scale and at the lowest cost. In the case of pharmaceuticals and medical products, such welfare considerations are intuitively even stronger. These peculiarities explain why the design of the patent system in the pharmaceutical and biotechnology sector, the observation of its impact on the prices, and the availability of medicines attract special attention from policy- and lawmakers. As stated by Scherer and Watal (2001), "The public policy question is how to balance this desire to make new medicines affordable to all those who need them, and yet retain strong incentives for inventing and developing new and better treatments".

The Center for Strategic and International Studies (CSIS), a prominent think-tank in Washington DC, recently brought together a panel of high-level officials from key developing nations to discuss efforts that aim to foster good stewardship of intellectual property rights. Panelists acknowledge the link between IP protection and economic development (Shapiro, 2007). They also agree on the principle that as knowledge is not an excludable

${ }^{31}$ The situation is now gradually changing in the emerging economies. Although OECD countries hold as much as $95 \%$ of patents, Grossbacher (2007) found that since 2002, Mexico, India and China have shown a tremendous increase in patent applications. The number of patent applications filed could be linked to a level of development - for example, the number of post-graduate students in a given country. 
good, it makes sense to compensate for the resulting market failure through intellectual property rights. They are aware that patents provide the inventor with the right to prevent others from making, selling, distributing, importing or using his/her invention, generally for a period of twenty years (unless authorized through a licensing agreement). However, some commentators raised concern about the application of the existing global IP system in various high-tech domains. They fear that the minimum 20-year (nomina ${ }^{32}$ ) patent period under TRIPS implies higher costs for many products - the most notorious example being the anti-retrovirals for the treatment of HIV/AIDS - with the local creation of new products being very unlikely (at least in the short term).

The at times heated debate about the role of patents on medicines for developing countries is not new. In 1999, Dr. James Orbinski, President of the International Council of Médecins Sans Frontières (MSF), gave special meaning to the term 'market failure' by stating that "the market (he was obviously referring to industry) has failed; in fact, the pharmaceutical record is the clearest evidence of any form of market failure" ${ }^{\text {"33 }}$. Dr. Gro Harlem Brundtland, the former WHO Director General, then added: "let us be frank about it: essential and life-saving drugs exist while millions and millions of people cannot afford them; this amounts to a moral problem, a political problem and a problem of credibility for the global market system ${ }^{34 "}$. Regrettably, it is true that the history of AIDS drugs has not been uneventful. First, for almost a decade, the industrialized world ignored that antiretroviral drugs could be used in the developing world (U.S. government officials stated in 2001 that Africans could not learn to take the drugs on time because they did not have watches. Afterwards, under international pressure, pharmaceutical companies somehow agreed to discounts, but they were deemed as inadequate - a year's supply still exceeded US $\$ 1,000$ per patient. Only when an Indian generic manufacturer provided a 'reversed-engineered' copy at three-drugs-in-one combination regimen or antiretroviral cocktail for US $\$ 150$ per year, and also major donors stepped forward, did distribution effectively start to reach the needy populations.

Currently, we are witnessing another round of HIV/AIDS medication battles, this time over more advanced and even more expensive drug regimens from Merck and Abbott Laboratories. Once again, patents are considered the culprit. The Clinton Foundation has endorsed decisions by the governments of Thailand and Brazil to break companies' patents

\footnotetext{
${ }^{32}$ In Chapter 3, we will see that the actual patent period is significantly shorter, that is, after market authorization for the new compound has been obtained and the product is launched on the market.

${ }^{33}$ Closing comments, conference on 'Access to Essential Medicines in a Global Economy', 24-25 November 1999, qt http://www.haiweb.org/campaign/novseminar/orbinski.html.

34 Statement by the Director General to the Executive Board at its $105^{\text {th }}$ session, found at http://www.who.int/director-general/speeches/2000/200000124_eb.html.
} 
and purchase cheaper, copycat versions of the drugs elsewhere. Abbott Laboratories that saw this as an industrial 'policy coup' to support Thai industry retaliated by withholding seven new drugs from Thailand, including an antibiotic, a painkiller, and medication for high-blood pressure. The fight is vicious; however it is hard to see how this confrontation could have been avoided. The cost of developing a new medicine is rapidly approaching US $\$ 1$ billion (for more details - see chapter 4), and companies still need to show a profit in order to recoup the cost and encourage shareholders to invest in innovation. Especially in the case of infectious diseases like HIV/AIDS, etc. sustained innovation and second and third generation products is very much needed due to the growing resistance against today's drugs. The solution lies in engineering a system that respects patents to sustain innovation, but at the same time ensures access to these new medicines when they are licensed. In our view, a policy that abolishes today's patents would represent a pyrrhic victory over the longrunning battle waged to resolve the issues of access to the existing as well as still to be invented medicines.

In response to the continuing global crisis in medicines development and supply, the World Health Assembly (WHA) which is the governance body supervising the WHO created the Commission on "Intellectual Property Rights, Innovation and Public Health". This Commission was established pursuant to resolution WHA56.27, which was adopted by the Fifty-sixth World Health Assembly in May 2003. The resolution requested the WHO Director-General "To establish the terms of reference for an appropriate timelimited body to collect data and proposals from the different actors involved, and produce an analysis of intellectual property rights, innovation, and public health, including the question of appropriate funding and incentive mechanisms for the creation of new medicines and other products against diseases that disproportionately affect developing countries, and to submit a progress report to the Fifty-seventh World Health assembly and a final report with concrete proposals". It took however until the Fifty-ninth WHA of 2006 - described in resolution WHA59.24 on "public health, innovation, essential health research and intellectual property rights" - to define a global strategy and plan of action and to welcome the Commission's report, which contained some 60 recommendations. Moving forward, the WHA established an Intergovernmental Working Group (IGWG) whose commission it is to draw up a global plan of action and provide a framework based on the commission's first recommendations, with a particular focus on research and development relevant to diseases that disproportionately affect developing countries.

To the surprise of the vast majority attending the $60^{\text {th }}$ WHA in May 2007, conversation at the hearing organized by the IGWG on Public Health, Innovation and Intellectual Property did not go beyond discussing which procedure for multilateral consultation to follow. In addition, statements such as "no option should be off the table" were made along with assertions that "more dialogue leading to public private partnership between various stake- 
holders might be a good idea". This slow pace of bureaucratic progress after many years of deliberations together with the lack of direction of what needs to be done, and how things should proceed to achieve the next project milestones, triggered much criticism from conference delegates, including ministers of health of developing country member states. Of considerable concern to many is that the IGWG is lacking vision and leadership, and has complicated matters more than it has resolved issues. Clearly, the working group has been unable to reconcile innovation, public health and IPR. So far, it has only managed to cast doubt on patents by labeling them as the main culprit blocking access to medicines. This is short sighted and has lead activists to advocate for compulsory licensing rather than trying to foster public-private collaboration in combination with economic mechanisms like for example tiered pricing. We will focus on how specific incentive mechanisms that are not based on disincentives or penalties for innovators can be created and implemented (although they can be enforced if need be). These new mechanisms are developed to stimulate private-sector investment and to galvanize partnership through strategic alliances and joint ventures without losing sight of general welfare principles.

\section{Justification for the grant of pharmaceutical patent rights}

Figure 6 shows the particular importance of the patent system for stimulating pharmaceutical and medical innovation. Discovering and developing a new pharmaceutical compound typically costs far more than copying it. Without some protection, entry by imitators can quickly erode the profit available to the actual inventor and discourage potential investors from committing sizable sums to biomedical research. In other words, when inventors capture only part of the benefit to society from their innovations, private returns do not reflect social returns and the result is a decrease in $\mathrm{R} \& \mathrm{D}$ investments.

Once a pharmaceutical product exists, however, public welfare is best served by having it priced close to marginal production cost. (Lanjouw, 2002; Reekie, 2002). Intellectual property laws in all countries recognize this inherent tradeoff in a variety of ways. It forms the basis of statutory term limits in patent law. The longer patent protection lasts, the larger the incentive to invest in research: is, and based on this premise, one might want patent protection to be infinite (although this proposition could be challenged as chapters 3 and 4 will show). By contrast, the longer patent protection lasts, the longer consumers must wait for competitive entries at lower prices. At a certain point, the latter argumentation of delayed access to lower priced medicines is viewed as outweighing the former benefit of stimulating innovation. So, the patent term is limited. Most countries acknowledge this tradeoff in their choices to limit protection for certain types of inventions.

Figure 6: The particular need for patents for pharmaceuticals 
Figure 6: The particular need for patents for pharmaceuticals

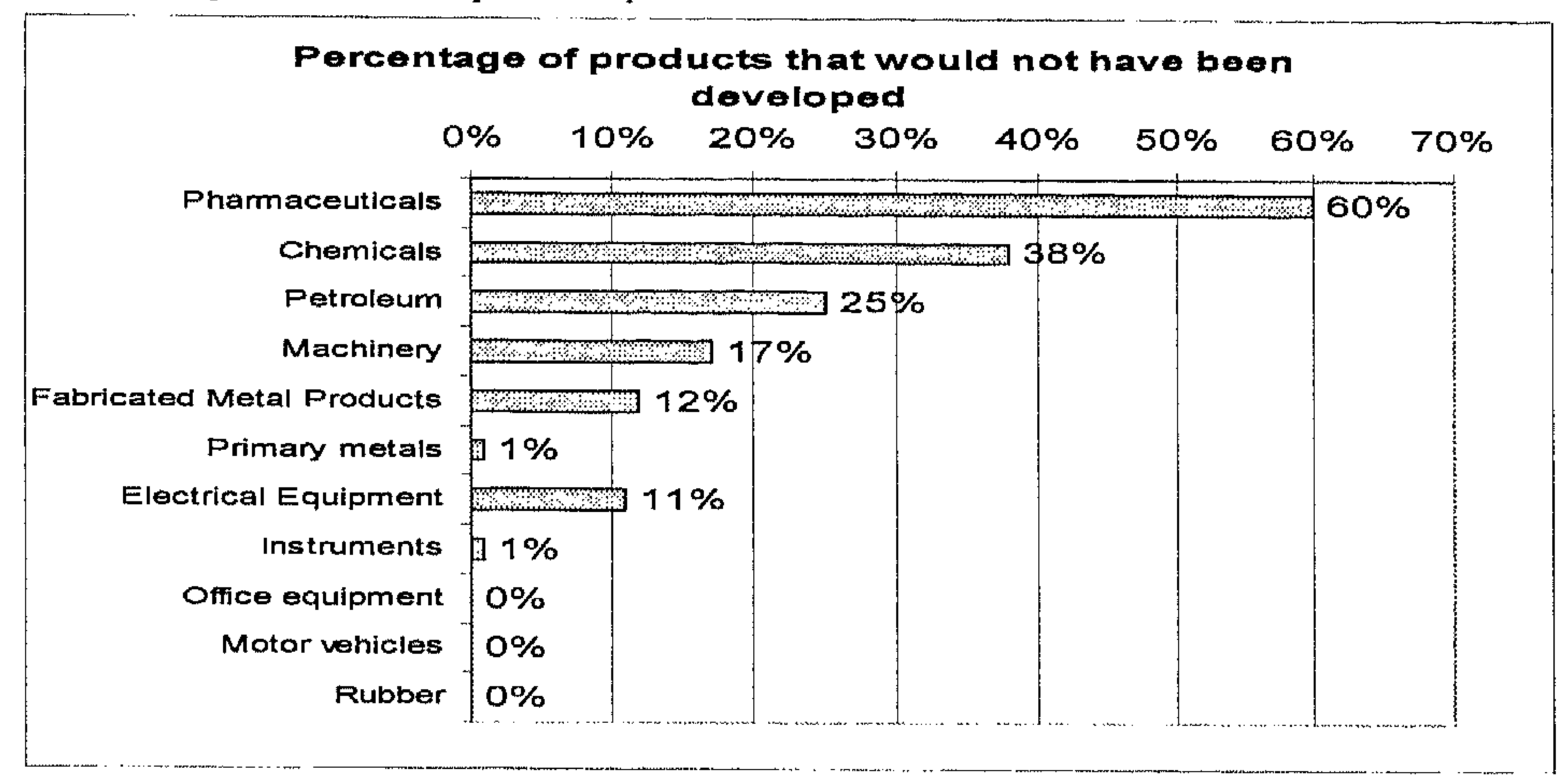

Source: Adapted from Mansfield E. Patents and Innovation: An Empirical Study. Management Science, February 1986.

For this reason, government granted patent rights are an important source of market exclusivity ${ }^{35}$. It is particularly true for the pharmaceutical industry because medicine innovations are relatively straightforward to imitate (when it concerns 'chemical' pills; 'biological' products are more complicated). Over the last century, the debate has revolved around the issue of defining the appropriate bounds on intellectual property rights for publicly funded research. It has been the focus of over forty U.S. congressional hearings and reports and four special commissions between 1940 and 1975 in the U.S. alone (Jaffe and Lerner, 2001). Since the early 1980s, the U.S. and other governments have taken the position that it is important to give private researchers relatively generous rights to inventions resulting from publicly-funded research programs in order to obtain the most benefit from public investments. With the Bayh-Dole Patent and Trademark Amendments Act of 1980, the U.S. federal government allowed small businesses and nonprofit organizations to retain ownership of patents on government-sponsored research results, and to license them on an exclusive basis to industrial firms for further development and production. Shortly thereafter, this right was extended to all government contractors, including large firms. According to Lanjouw (2002), there are advantages to this system. If public funding is only partial, perhaps limited to the basic research/ discovery phase, then it is important to allow firms to garner whatever profits are available in the market to cover further development, production, registration, distribution and marketing costs.

\footnotetext{
${ }^{35}$ Patents grant monopoly rights over a specific innovation, not over a therapeutic area. There may be intense competition between a patented product and alternative drugs or other medical treatments for a given disease (as well as competition with other non-health goods that a consumer might want to purchase). What is actually limited is direct imitation of the parented product.
} 
Just because patent rights are available, does not mean that the private sector controls the process of innovation. Nor does the establishment of clear property rights mean that they must be unconstrained. For example, the system of Cooperative Research and Development Agreements (CRADAs) uses formal contracts between government-operated laboratories and private firms allowing cost sharing, or industrial partners to own an exclusive license for any patented invention that results from collaborative research (Stiglitz, Wallsten, 1999). It should be noted that this right may be restricted and depends on the partner agreement on performance benchmarks. Another example of a specific Product Development Program (PDP) is the International AIDS Vaccine Initiative (IAVI), which seeks to coordinate research efforts between the public sector, academia and industry. In this instance, industrial partners hold the patent rights for the exclusive marketing of any HIV/AIDS vaccine developed, but are held to the condition that the patented product must be sold to governments of developing countries at 'affordable prices'. Failing adherence to these conditions, IAVI obtains the right to license the patent to an alternative producer, based on non-exclusivity for this purpose (IAVI, 2000). Similarly, under BayhDole, the U.S. federal government retains 'march-in' rights to revoke ownership and licensing privileges if an invention is not developed and made available on reasonable terms to the public.

Historically, many countries had restricted patent protection for pharmaceutical and agriculture-related innovations. The reasons for this were twofold. First, patent rights in other countries were available to stimulate research investment. Because some nations had a 'free ride' on products brought about by other countries' patents, the benefit of increasing protection in their own markets was relatively small. Second, since health and food are regarded as basic needs, higher prices due to patents were more acutely felt, particularly in LDC's. This made food and drug prices a politically sensitive subject. Over time, pharmaceutical and health technology products have been protected throughout the world, but only at a slow pace. Extension of patent rights to healthcare products for the developing world as required by the WTO, continues to generate widespread criticism. The difficulty lies in finding an acceptable system or balance. Positions tend towards two endpoints: At one end, there are those who support the current move toward a system where all countries have the same form of intellectual property laws and where the protection attributed to health product inventors is at the level currently available in developed countries. At the opposite end are those who view the higher prices sustained by pharmaceutical and related technology patents as too burdensome to poor(er) countries and advocate either no patents for medicines in the developing countries or expansive compulsory licensing provisions.

Lanjouw (2002) claims that any policy discussion in this area should start with the recognition that granting inventors intellectual property rights inevitably entails a tradeoff. The tradeoff should not be, as is sometimes cast, between corporate profits and public health, 
but rather between two equally important public health goals: (i) widespread access to existing drugs, and (ii) the maintenance of incentives to create new ones. Higher prices sustained by pharmaceutical patents finance the search for innovations, however, higher prices also mean that fewer consumers are able to purchase the goods based on those inventions. The question whether the extension of patent rights is desirable, therefore depends upon the extent to which the prospect of future profits leads firms to increase investments in research and development, and the degree to which each additional investment results in additional innovations. Societies that have adopted patent protection have judged that, on balance, the dynamic gains outweigh the short-term efficiency costs. Since both of these gains may decline at higher levels of $R \& D$ investment ${ }^{36}$, one can expect a relatively higher benefit from increasing protection where incentives are initially low.

The pharmaceutical industry claims that the availability of patent rights in LDCs would stimulate private investment in products tailored to the specific needs of these countries. The industry believes that it is hard to oppose its view that a pharmaceutical policy specifically targeting developing country diseases should focus primarily on attracting more research and manufacturing competencies - after all, they need to develop the products before they can make them available to those who need them. However, the argument used by the industry when advocating the adoption of strong patent systems in the developing world, raises two additional questions: Firstly, is it important that private firms are involved in the search for new products specific to LDC diseases? Secondly, if the answer is yes, should the availability of patent protection in the developing world be part of the incentives established to encourage the industry's involvement?

Most observers will agree that intellectual property protection in countries with incipient knowledge-based industries is likely to spur economic growth, which in turn increases the demand for products with high knowledge content like medicines. Conversely, weak legislation on IPRs could lead to the emergence of copy industries at the expense of innovator industries - with negative consequences for economic growth, as innovator industries generate more economic value added in comparison with copy industries (McArthur, 1999). Similarly, one could argue that developing countries have a social interest in providing intellectual property protection as a way of encouraging further investment, research and innovation from which they should benefit. The details of these IPR regimes must nevertheless be tailored to the particular circumstances of each individual country. The WTO set out the minimum standards for intellectual property protection by the agreement on Trade-Related Aspects of Intellectual Property Rights (TRIPS). Negotiated during the

${ }^{36}$ In a statistical srudy of pharmaceutical research programs, Henderson and Cockburn (1996) found sharply decreasing returns on greater investment in individual projects. They did however find advantages to size, but they only match the level of the overall research program. 
1986-94 Uruguay Round of WTO talks, TRIPS introduced for the first time intellectual property rules into the multilateral trading system. It allows WTO members flexibility in implementing domestic IPR regimes that take into account their national circumstances.

Where it may be in the interest of developed countries to grant their pharmaceutical firms patents, most developing countries that have no such firms and very limited resources, do not have the same interest. In their case, the local production of 'generic' drugs appears as the only way to lower the cost of medicines. And, historically a large number of countries in fact did so. Most developing countries had a very loose to no pharmaceutical patent system until the mid-1990s (Remiche and Desterbecq, 1996). In Coriat et al's view (2006), the vast majority of developing countries used their 'rights to learn by imitating' and by 'copying' - a right extensively used in the past by the current industrialized countries themselves - to establish local capacities to produce generic drugs at low costs. Developing countries that are only now in a process of extending protection to pharmaceuticals, are at a considerably lower level of income than those who adopted the practice earlier. In addition, the poorest of consumers are rarely insured and must pay for pharmaceuticals directly out of pocket when subsidized public supplies are not available. This makes the necessary policy changes particularly costly, since price increases have a greater impact on consumers in lowincome countries. Nonetheless, there is a rationale for developing countries to extend patent protection even though they do not face the same tradeoffs as the early adopters ${ }^{37}$. Unlike the early adopters, they may have specific pharmaceutical product needs that are not necessarily shared by other developing countries already offering patent protection. One can think of the following three reasons:

First, developing countries and in particular those located in the tropics have disease patterns that are quite distinct. For example, HIV/AIDS is estimated to have killed 2.3 million people in Africa alone (UNAIDS data for 2001). The A strain of the HIV virus is particularly widespread in low income countries but it is not in the developed world. For approximately twenty diseases, at least $99 \%$ of the global disease burden is concentrated in the very low- to middle-income countries (Lanjouw and Cockburn, 2001). Together, these twenty diseases are estimated to have caused the loss of almost two hundred million disability-adjusted life years (DALYs) in 1998 and over five million lives; a large share of them among children.

Secondly, the randomness of evolution provides another reason for patenting medicines for neglected diseases that afflict developing countries. Nature does not distinguish between the

\footnotetext{
${ }^{37}$ For a discussion of more formal models of some of the tradeoffs associated with the extension of patents to additional countries - see Deardorff, 1992; Chin and Grossman, 1990; and Diwan and Rodrik, 1991.
} 
biology of diseases of the poor and the rich. So, therapeutic molecules or pathways that are targeting neglected diseases might also be relevant for treating diseases that affect populations in more affluent regions.

Thirdly, even for diseases with a worldwide prevalence pattern, the products designed for the more developed markets may be unsuitable for many LDC countries. Tropical countries with a weak infrastructure need pharmaceutical products that for example can withstand interruptions in a distribution cold chain or have a long shelf life. Given the characteristics of the market, the preference of preventive vaccines over drug therapies in the control of HIV/AIDS is a good example. An HIV/AIDS vaccine would be by far easier to deliver in a low income country than the current drug treatment cocktails. However, efforts to develop a vaccine have been limited in comparison to the investment in treatment. Thus, even for a disease with global spread for which there are pharmaceutical and medical treatments, there may be only few options tailored to the specific needs of the developing world.

Finally, in addition to providing incentives to indigenous companies to invest in the research and development of innovative products, IP protection in LDCs may spur innovation through technology transfer by foreign companies and thereby generate interest in developing drugs and vaccines to treat and prevent tropical diseases (Lanjouw, 2002). By contrast, countries that exploit their weak intellectual property regimes by threatening to issue compulsory licenses for drugs and other advanced health technology products, dramatically reduce the incentives to invest in local research, development and production (Rozek, 2000).

Not a market failure but an affordability problem

Despite the rhetorical discourse on this subject, some observers including this author dispute the claim that $\mathrm{R} \& \mathrm{D}$ on medicines for diseases prevalent in the developing world represents a 'market failure'. The activists' disguised reasons behind this claim are to imply that the 'market-based R\&D incentive system' has failed and therefore needs to be replaced by a 'centrally planned system' in which the state should reduce regulations and take over research and development of a firm's innovation, especially in disease areas such as tropical diseases.

To define the term 'market failure', one must first define 'market success'. A standard definition of market success is that all gains from trade have been exhausted. Individuals have bought and sold a product to the point at which the marginal cost of production is equal to the marginal benefit of consumption. Any further production and consumption would not make the consumer better off without making the producer worse off. This 
allocation of resources is said to be 'Pareto efficient ${ }^{38}$. Thus, it is the efficiency of the market that defines whether it has succeeded or failed. A true 'market failure' can occur under a number of circumstances. First, an agent in a market can gain such market power that it allows him to block other mutually beneficial gains from trade. This can lead to inefficiency due to imperfect competition. This can take many different forms, such as monopolies, monopsonies, cartels, or monopolistic competition. Second, a deficiency in the market structure may systematically prevent a market from moving towards Pareto efficiency. The classical example is the presence of either a producer monopoly or a consumer monopsony. A period of monopoly that lasts too long stifles competition and prevents the efficient convergence of the marginal cost of production with the marginal benefit of consumption. A third source triggering market failure lies in external costs or benefits not being properly included in the price, thus leading to a misallocation of resources. The point to remember in this argumentation is that unmet demand in itself does not constitute a market failure. A market may still be efficient even if the cost of a product is unaffordable to many in society ${ }^{39}$.

The main question then becomes whether a patent represents a monopoly and thus potentially a source of market failure, or whether, by virtue of the exchange of disclosure for exclusivity, it represents an acceptable trade-off of short-term welfare loss for long-term dynamic gain. The key answer to this question lies in the definition of a 'monopoly'. Is it just the concentration of market power, or is it a condition of the market's structure preventing the free entry of new competitors? The standard reply by economists is that a true monopoly can only occur when there is an artificial barrier to market entry. Patents do not prevent new inventions from coming into the market to provide the same functional product use. A patent affords its holder with an opportunity - but only an opportunity - for charging a price above the marginal cost of production. Whereas a patent may incur a static welfare loss as a result of exclusivity, that loss is expected to be offset by dynamic market gains from the increased incentive to innovate, and to continuously invest, which may

\footnotetext{
${ }^{38}$ Pareto-efficient improvements to real-watld economic systems are extremely rare, and considered 'the holy grail' of economic improvements. In principle, Parcto efficiency also does not require an equitable distribution of wealth. An economy in which the wealthy hold the vast majority of resources can be Pareto efficient. This possibility is inherent in the definition of Pareto efficiency; by requiring that an allocation leaves no participant worse off, Pareto efficiency tends to favor outcomes that do not depart radically from the status quo. Amartya Sen has pointed out that under relatively plausible starting conditions, systems of social choice will converge to Pareto efficient, but inequitable, distributions. A simple example is the distribution of a pie among three people. The most equitable distribution would assign one third to each person. However the assignment of, say, a half section to each of two individuals and none to the third is also Pareto optimal despite not being equitable, because none of the recipients is left worse off than before (when none had pie).

${ }^{39}$ On the other hand, a welfare loss, which can apply to either a producer or a consumer, does not necessarily reflect on the efficiency of a market. The most common source of welfare losses is taxes that add a wedge to either the cost of making a product or of consuming it, or both.
} 
exceed the short term loss in the long haul. Hence, patents do not represent a market failure. However, they could present an ambiguous welfare loss in isolation if the intellectual property system systematically fails to stimulate innovation initiatives and related investment.

Even if patents do not create a market failure in the context of access to medicines in developing countries, the affordability of those medicines certainly remains a serious problem. The patient-consumers in these countries simply have too little purchasing power. The extension of patent protection to the developing world, by itself will not cause private investment to pour in for products specific to these markets. Industry executives have stated in various interviews and hearings, that firms usually do not patent their products in the poorest countries, even if the opportunity were available because there is so little prospect for profit, and patent registration and maintenance costs money. This claim has also been supported by an economist and a lawyer in a research report on the patent status of fifteen anti-retroviral (anti-aids) drugs in fifty-three African countries (Attaran, 2004; Attaran and Gillespie-White, 2001). These researchers found that, outside of South Africa, patenting in the rest of Sub-Saharan Africa was very limited. This finding stresses the fact that patents in poverty-stricken countries are not impeding access to drug treatments and vaccination. However, the reverse argument may also be true. Having patents in place in developing countries does not per se stimulate investment in research and development benefiting these countries.

Despite the likelihood that patents in poor countries may not be sufficient to elicit sizable investment in products addressing their specific needs, they are nevertheless desirable as part of a package of policies ${ }^{40}$. The real issue is unmistakably the need for more money to procure and distribute both newly developed and existing medicines. In addition, there is the need to strengthen the logistical and healthcare infrastructure as well. As it seems, affordability is one of the many problems developing countries face. Public funding therefore could be addressed directly or indirectly, and if possible, through a collaborative public/private partnership. Public incentive schemes intended to subsidize new medicines discovery and development for neglected diseases should be designed and implemented without delay. These $R \& D$ incentive systems are often characterized as either 'push' or 'pull' mechanisms (Morris, Stevens, Gelder van, 2005; Kremer, Glennerster, 2004; Webber, Kremer, 2001; Batson, Ainsworth, 2001; Kettler, 2000; Kremer, 2000; Kremer 1999a,

\footnotetext{
${ }^{40}$ Lanjouw (2002) proposes a rather simple change to patent rules within the OECD that might resolve some of the problems. Firms would be able to choose to patent drugs in either developed or developing countries, but not in both. However, even if this solution were to win the support of developed countries, it does nor provide new incentives to overcome the lack of attention by large pharmaceutical firms to doing research on neglected diseases in developing countries (Arundel, 2002).
} 
1999b; Muraskin, 1999). While 'push' incentive mechanisms aim at subsidizing scientific research inputs up-front, 'pull' mechanisms promise to pay for a specific product with defined characteristics only after it is developed.

\subsection{Differential pricing and international trade barriers}

\section{Welfare effects of international price differentials}

Patents in pharmaceutical $R \& D$ on developing world diseases function in association with differential pricing and 'pull' incentive mechanisms aimed at replicating a market. Differential pricing works particularly well for medicines, since the pharmaceutical $R \& D$ leading to a new product can be considered a 'global joint cost' that benefits consumers worldwide ${ }^{41}$. The economic theory of efficient pricing to cover joint costs - so-called Ramsey pricing concludes that charging different prices to different users is the most efficient means of covering joint $R \& D$ costs when users differ in their true price sensitivity/ elasticity ${ }^{42}$ (Plahte, 2005). Danzon (1998) of the Wharton School, University of Pennsylvania, argues that differential (tiered) pricing leads to more appropriate use of medicines and permits a higher level of R\&D than would otherwise occur under uniform pricing. Nonetheless, there is a threat to this robust system. International parallel trade is known to erode price differences across countries. If permitted, it undermines one of the most efficient pricing mechanisms for paying the joint $R \& D$ costs that benefit all countries.

The economic theory of Ramsey pricing resolves the problem of finding prices that provide the highest well-being to consumers, while generating revenue sufficient to cover all costs, including joint costs (Lafont et al 1993; Baumol W. et al, 1970; Ramsey F., 1927). Ramsey prices differ between users and, on average, must exceed short run marginal costs. Specifically, the mark-up of a price over its marginal cost should be greater for users who are relatively price-insensitive (i.e. inelastic demand) than for users who are more price-sensitive (i.e. elastic demand). These price differentials lead each group to reduce their demand by an equal percentage relative to the hypothetical demand at price equal to marginal cost. Conversely, if everyone is charged the same price, the price-sensitive users will reduce their

\footnotetext{
${ }^{41}$ Because this global joint cost is not causally attributable to particular patients or countries, the cost structure alone cannot determine how much each country should contribute. In addition to $R \& D$, joint costs also occur in primary production, where a single plant typically supplies several compounds to multiple countries, implying costs are shared across products and countries.

${ }^{42}$ In the context of pharmaceuticals, differential or tiered pricing means charging different prices to different countries for the same medicine in response to the different price sensitivity of demand in these countries.
} 
consumption more and thus experience a greater loss in welfare than the price-insensitive users. Users who are highly price-sensitive (e.g. low-income countries) may entirely drop out of the market, even though they might have been willing to pay a price sufficient to cover the marginal cost. This theory implies that global social welfare would be enhanced with a differential pricing strategy.

As a consequence, to meet the needs for medicines in the poorest countries of the world, it is critical that manufacturers are able to offer the poorest countries the lowest possible prices. At the same time, manufacturers must be able to recover their costs and earn a fair return on their investment, in order to support continued investment in medicine research and development and to maintain ample production capacity. To achieve this balance, expenses are amortized unequally across all countries, such that the poorest countries pay a relatively lower (but fair or equitable) share for these products compared to middle and high-income countries. Differential pricing can thus go a long way to improve access to medicines in LDCs, at least for those medicines for which there is a middle or high-income market elsewhere ${ }^{43}$.

Regrettably, there is the common perception that price differentials imply cost shifting from a low-price to a high-price market. This is often exemplified by public statements like for example: "a pharmaceutical company may only be willing to sell in a low-price country because it can recoup any losses it incurs there from sales in higher-priced countries" (Brittan, 1992). This viewpoint should be nuanced because the argument either ignores the so-called 'joint-ness of $\mathrm{R} \& \mathrm{D}$ costs', or mistakenly assumes that all users should contribute equally, contrary to welfare-maximization principles ${ }^{44}$.

\section{Perverse effect of international parallel import trade}

Generally, international trade increases economic welfare by permitting consumers in importing countries to benefit from low prices realized by more efficient or low(er)-cost producers in exporting countries. The criteria for sound international trade leading to increased consumer welfare are bound to the following assumptions: (i) the lower price in

\footnotetext{
${ }^{43}$ Other subsidy mechanisms will be needed to promote $R \& D$ for medicines that have no high-income market (Danzon, Towse, 2003). These will be described in chapters 7 and 8.

${ }^{44}$ It is indeed a widespread misconception that tiered pricing of medicines entails patient-consumers in the highprice markets 'subsidizing' the consumers in the low-price markets. Plahte (2005) illustrated, that tiered pricing is not a subsidy as the term subsidy suggests that medicine prices in the developed countries are higher than they would have been in the absence of low-price sales to developing countries. Using the term 'subsidy' to describe tiered prices on the international medicines market is therefore not only unhelpful, it can mislead politicians and decision makers into discouraging the use of a mechanism that is beneficial to all parties involved.
} 
the exporting country reflects the real lower costs of production due to either superior efficiency or low(er) input costs; and (ii) the consumers in the importing country are expected to benefit from these lower prices by increasing their consumption.

An investigation by Danzon $(2003,1998)$ revealed that parallel trade (arbitrage) in pharmaceuticals does not yield the efficiency gains that normally result from international trade. In the short term, the net distributive effect of international parallel trade mainly transfers revenues from manufacturers to intermediaries (distributors) who capture most of the margin between the low export price and the higher regulated price in the importing country. Hence, the standard free trade assumptions do not apply and are not followed in practice. Since pharmaceutical production must conform to regulated 'good manufacturing practice' (GMP) in all countries, production techniques are uniform. One of the few sources of savings is to lower labor cost, in particular the cost of packaging and processing, which is a relatively small fraction of total costs. Parallel trade for pharmaceuticals violates the necessary conditions for efficiency gains, as they are not achieved through superior production efficiency but from trade given that countries usually achieve low pharmaceutical prices and become parallel exporters through stringent price regulation or weak patent protection. Because international parallel trade exploits regulated price differences that do not reflect the real cost differences, it can actually increase societal costs due to the additional costs of transportation and administration, yet still be profitable for the trader. In that context, price regulation reduces efficiency, by distorting production efficiency and incentives for innovation (Thomas, 1996).

Furthermore, consumers may be potentially exposed to increased health risks as parallel imports can include counterfeit products of inferior quality, or repackaged products which make it difficult to trace in the event of a recall, or product labels that have not been adapted to the country and consumers misuse the product. In many of these cases the original brand-name manufacturer could be found liable or have its reputation damaged. In the long term, when the potential volume of international parallel trade exceeds a critical level, the original manufacturer's profit-maximizing strategy will be to attempt to set a single, uniform price in all connected markets. The greater the expected downward pressure on prices, the higher the manufacturer's launch price is likely to be. In any event, consumers in traditionally low-price countries are worst off. They will be charged higher prices and could possibly be denied access to the most innovative medicines, although they might have been willing to pay a price sufficient to cover their country-specific marginal cost under differential pricing. If a private company were solely concerned about short run revenues ignoring reputation and non-financial concerns - the rational policy would be to withhold launch in any of the low-price countries as long as the expected net revenue from that country would be less than the revenue loss in other potentially higher price market segments. Thus small, low-price countries are most at risk of losing access to medicines. 
Efforts to have the (fixed) $R \& D$ costs recouped by the original innovator or firm is furthermore exacerbated by the monopsony (buyer) power exerted by some governments - or supranational purchasing agencies - acting on behalf of developing countries. They may be strongly tempted to force prices down to the marginal cost of recipient developing countries. This is good for these countries. But knowing that the cost of inventing and developing a new compound is largely sunk by the time the end product is launched and the price is negotiated, manufacturers have no choice but to accept the price/reimbursement offered to them as long as marginal production costs are covered. This means that the initial R\&D costs are not necessarily recouped. As a consequence, recipient developing country governments are often free-riding on other governments in the world to pay for the joint costs of R\&D (Barder, Levine, Kremer, 2005; Towse, Danzon, 2003; Danzon, 1998). Where does it become harmful? A free-rider behavior in one country can export inadequate prices throughout the entire region (for example, Latin America), or even the rest of the world, and certainly in countries that use reference pricing as a measure of reimbursement. The original product manufacturer is therefore likely to set a uniform price that translates into a relatively high launch price for the new medicines to come (Plahte, 2005; Danzon, 1998). Under this scenario, consumers in low-income countries are worse off due to the higher drug prices and possibly further restrictions on access to innovative medicines. Less obvious is that consumers in the previously high-price countries will also be worse off as some medicines that consumers would have been willing to pay for may no longer be developed had differential pricing been correctly applied.

In synthesis, for pharmaceutical firms to develop innovative medicines, revenues must be sufficient to cover all costs, including the joint costs of $R \& D$. On the other hand, smaller market countries in the world have been able to pursue a free-rider strategy, attempting to drive the price they were paying down to their country specific marginal cost. This had initially a negligible impact on global industry revenues and hence on future supply of medicines. Now that a low price set in one particular country diffuses more broadly through parallel trade and reimbursement regulation benchmarked against foreign prices, free riding by one country can significantly erode global revenues and incentives for R\&D. The concern is that extremely low prices applied in the poorest countries will spill over to middle- and high-income countries where governments monitor prices and reimbursement relative to foreign countries. The impact of this economic price 'leakage' on a new pharmaceutical or health product's expected return-on-investment can be very significant, ultimately eroding the company's worldwide profit (thus not in developing countries only).

\section{Getting essential medicines to populations in need}

Many observers still think that the patent system is the main cause for medicines not getting to people in the developing world. As discussed in the previous chapter other 
logistical variables play a much larger role. The proof is that more than $95 \%$ of 325 drugs on a list of essential medicines produced by the WHO are not protected by patents. Amir Attaran et al (2004) found that patents only infrequently constrain access to WHOclassified 'essential medicines'. They reported that in sixty-five low- and middle-income countries, where four billion people live, there are few patented medicines on the WHO's Model List of Essential Medicines of 319 products. Actually, only 17 are patentable, but are generally not patented, so that overall patent incidence in these countries is low (1.4\%) and concentrated in larger markets. Nowadays, treatments for killer diseases such as malaria and TB can also be bought as generic medicines at very low cost to the patient. However, according to the WHO, one third of the world's population still cannot get hold of these drugs. The situation is even worse in the poorer parts of Africa and South-East Asia, where half of the population cannot get hold of these low-cost generic medicines. In 2003, there were an estimated 550000 AIDS patients in India, but only 13000 of them were taking antiretrovirals ${ }^{45}$ - still the most effective treatment for AIDS. Yet, these pharmaceutical medicines were not protected by patents. In India, companies make and sell generic antiretroviral drugs. Thus patents (alone) are not preventing these medicines from reaching patients. The fundamental reasons for the shortfall are lack of funding, poor healthcare systems, and finally yet importantly, absence of political will.

What needs revisiting is the context and framework of the health systems in developing countries (Stevens, 2007). Addressing the failures in public programs is critical to good governance and effective functioning of local health care systems. A first priority is ensuring greater local accountability. This comprises higher standards for healthcare staff, effective training and supervision of staff at all levels, routine audits of fiduciary transactions, and improved record keeping to systematically provide data to managers and administrators, etc. Professionalizing the leadership and management of hospitals, clinics and other points of service greatly improve the quality and productivity of service delivery, and increase access to care and patient satisfaction. These kinds of initiatives lead to the improvements in the system that investors and donors foster. Their funding and advice oil the wheels of progress and support the emergence of strong institutions. Finally, because good governance promotes effective public services and as cited before economic growth, the healthcare sector cannot afford to be on the sideline on this agenda.

\footnotetext{
${ }^{45}$ According to Subhash Hira, Director of Aids Research and Control (ARCON), Mumbai, India; http://www.wellcome.ac.uk/doc_WTD004333.html
} 


\title{
2.4 Economics of TRIPS options for access to medicines
}

\author{
Trade related aspects of intellectual property rights
}

Until 1995, protection of intellectual property was a matter of national legislation. Since then global minimum standards of intellectual property, including patents, are covered in the Agreement on TRIPS, to which all WTO member governments have committed themselves to comply with ${ }^{46}$. The main elements of the TRIPS Agreement that are relevant to the healthcare/access to medicines debate are explained in the WTO's TRIPS and Pharmaceuticals fact sheet ${ }^{4748}$. In addition to TRIPS' minimum requirements, individual WTO Member States are free to maintain and expand their existing IP regimes ${ }^{49}$. However, the system of intellectual property protection as represented by TRIPS has received a lot of criticism (Coriat et al, 2006, Morris, Stevens, Gelder van, 2005; Dyer, 2004; Webber, 2003; Lanjouw, 2002; Reekie, 2002; Arundel, 2002; Mitelka, 2002; Barton, 2001).

In reviewing the literature, two diametrically opposed positions can be identified. On the one hand, the argument is that copyright, trademarks and geographical indications may be useful and appropriate tools for developing countries, but not patents, except insofar as developing nations offer patent protection to attract foreign direct investment. The critics of the system claim that patents are harmful to developing countries because of the power that patents confer on their owners over markets and price. On the other hand, proponents including the World Intellectual Property Organization (WIPO) ${ }^{50}$ claim that this idea that patents are not relevant to developing nations, or are incompatible with their economic objectives - is inaccurate as they give the impression that it is possible to simply opt out of the international patent system, and yet still achieve economic development. This they believe is an error as patents are an essential component of economic strategy for all countries, regardless of their state of economic development ${ }^{51}$. Despite this rationale, many poor countries believe that the TRIPS Agreement gave them a raw deal. They find it difficult to

\footnotetext{
${ }^{46}$ Contrary to popular misconception, Trips does not create a single, universal patent system. Companies seeking protection round the world still depend on each country's patent office to grant those rights and their judicial, customs and police services to enforce them, although some European countries have got together to offer regionwide patents. Disputes on the application of the TRIPS agreement, are subject to WTO Dispute Sertlement. ${ }^{47} \mathrm{http}: / / \mathrm{www} . w t o . o r g / e n g l i s h /$ tratop_e/tripsfactsheet_pharma.pdf

${ }^{48}$ The period of exclusivity for the patent holder is specified as twenty years from the date at which the patent (not the pharmaceutical product) is registered. Given the length of time taken to develop and approve a new pharmaceutical product, this implies an exclusive marketing period of between 8 to 12 years on average.

${ }^{49}$ In particular less developed countries were exempr until 2006 - delayed at Doha in 2001 until 2016.

${ }^{50}$ The World Intellectual Property Organization (WIPO) is a specialized agency of the United Nations mandated with managing intellectual property issues and standards on an international level.

${ }^{51}$ Idris, K., 'Intellectual Property: A Power Tool for Economic Growth', WIPO publication No. 888.1, p. 16.
} 
assess how changes to their country's intellectual property regime are going to impact upon their trade prospects, particularly for those whose current comparative advantage is in imitating products. Once reverse engineering becomes inconsistent with their national legislation, there is an argument that they will no longer be able to continue the production of generic medicines, and to exploit this opportunity to 'catch-up' with developed economies $^{52}$.

In this polarizing debate around TRIPS, it is necessary to distinguish between what can be done to improve access to existing medicines and what would encourage the development of new medicines to support the developing world. While the first issue depends on the availability of adequate donor funding, strong patents are at the heart of the second problem. For the more advanced developing countries, such as India and Brazil, TRIPS will provide like elsewhere the incentive for able researchers to remain in their own countries rather than to relocate to highly industrialized countries, and build a research-based industry capable of developing medicines for the diseases of poverty ${ }^{53}$. A well-developed and successful local R\&D base and associated private sector industry would generate social, political and economic benefits for the countries concerned. Activists calling for TRIPS to be weakened, or even abandoned, fail to recognize that such a move would condemn most innovators and firms of a research-based industry that would otherwise be uniquely placed to produce medicines relevant to their developing country need ${ }^{54}$. The introduction of TRIPS has already encouraged Indian companies, including Ranbaxy, Dr. Reddy's Laboratories and Nicholas Piramal, to build up their research base and it would be sad if this impetus were to be lost (Dyer, 2004). Hence, a minimum protection of intellectual prop-

\footnotetext{
${ }^{52}$ Nonetheless, India's position as a generic medicine producer and provider will not be damaged and its pharmaceutical industry business may continue as usual, even after product patents are introduced, due to the nonretroactive nature of product patents under the Act. With regard to any generics of pharmaceutical products covered by the 'mailbox' that were in the market prior to January 1, 2005 and on the date the originator received a product patent the law specifies that those generics will be able to remain on the Indian market with only a payment of royalty to the innovator (IFPMA, 2005).

${ }^{53}$ Innovative Indian scientists are currently more likely to move abroad to jurisdictions in which their creativity can be better rewarded. The relative lack of patent protection also results in low levels of patenting by Indians inside India.

${ }^{54}$ At present, India contributes almost nothing to pharmaceutical $R \& D$ despite its population size, economic importance, disease burden, and chemical and biological manufacturing strengths. While India has strong 'world class' film and software industries - because of good copyright protection given to these industries - it lags far behind in developing new drugs even for the range of infectious diseases that burden its society (TB, malaria, AIDS, etc.) despite its relatively strong scientific tradition and the knowledge of biological manufacturing techniques. The most important element that is lacking in the development of its pharmaceutical and biotech industry is patent protection and related forms of intellectual property protection.
} 
erty (as specified in the TRIPS Agreement) remains a necessary condition for R\&D investments in much needed medicines ${ }^{55}$.

\section{Clarification of flexibilities relating to public bealth and TRIPS}

The Agreement on TRIPS allows countries to take measures to qualify for or limit IPRs, including for public health purposes. Some doubts have arisen, however, as to whether the Agreement was sufficiently flexible to support public health objectives. It was unclear whether it actually promoted access to affordable existing medicines while supporting $R \& D$ into new ones. The Doha Declaration on Public Health and the TRIPS Agreement tried to respond in a number of ways to these lingering concerns about the possible implications of the TRIPS Agreement for international public health, in particular with regard to access to patented medicines (Watal, 2007). First, it emphasizes that the TRIPS Agreement does not and should not prevent members from taking measures to protect public health. Second, it makes it clear that the TRIPS Agreement should be interpreted and implemented in a way that supports WTO members' rights to protect public health, and, in particular, to promote access to medicines for all. Third, it clarifies some of the flexibilities contained in the TRIPS Agreement. The Declaration makes it clear that each member is free to determine the grounds upon which for example compulsory licenses are granted and it clarifies that each member has the right to determine what constitutes a national emergency or other circumstances of extreme urgency. It states that public health crises, including those relating to HIV/AIDS, tuberculosis, malaria, and other epidemics, can represent such circumstances. With regard to the exhaustion of IPRs and a member's right to permit parallel imports, the Agreement stipulates that a member's practices in this area cannot be challenged under the WTO dispute settlement system. While emphasizing the flexibility in the TRIPS Agreement to take measures to promote access to medicines, the Declaration also recognizes the importance of IP protection for developing new medicines and reaffirms the commitments of WTO members in the TRIPS Agreement. With regard to the least developed countries, the Declaration agrees to provide them with an extension of their transition period until January 2016 for protecting and enforcing patents and rights in undisclosed information with respect to pharmaceutical products. This was given legal effect through decisions of the TRIPS Council and the General Council.

\footnotetext{
${ }^{55}$ Intellectual property protection needs to be sufficient to establish the right R\&D incentives. However, sufficient flexibilities should be retained to ensure that (patented) products are available and affordable in cases of national emergency and where market power is abused. Such flexibilities are contained in the TRIPS Agreement and Doha Declaration although there is a need for greater common international understanding on the interpretation of these flexibilities.
} 
Most importantly, the Doha Declaration recognizes the problem of countries - with insufficient or no manufacturing capacities in the pharmaceutical sector - in making effective use of compulsory licensing. On 30 August 2003, the WTO General Council adopted to that end a decision that waives, in certain circumstances, Article $31(\mathrm{f})$ and (h) of the TRIPS Agreement. The decision covers any patented pharmaceutical products, or pharmaceutical products manufactured through a patented process, needed to address public health problems recognized in Paragraph 1 of the Doha Declaration on the TRIPS Agreement and Public Health. This decision includes active ingredients as well as diagnostic kits.

Alternatives to Intellectual Property Rights Protection (IPR)

The topic of intellectual property protection for medicines has triggered much debate in the media and academic circles around finding alternative systems. The specifics of this topic will be discussed in full in chapter 10 . This section will only highlight the two most commonly proposed measures and their definition: IPR Buyouts and Compulsory Licensing. Recently, some newer concepts have been introduced, as there are the Global Medical Research and Development Treaty and Open-Source Innovation. For an in-depth review of these systems and a discussion of their advantages and drawbacks, we refer to the last chapter of this book.

\section{IPR buyouts}

This policy proposes to 'purchase' the patent or intellectual property, backed by promises of providing adequate compensation to the inventor for the research accomplished. The objective is to put the information (sooner) in the public domain, so that production would be competitive and 'generic' prices would be driven down to marginal cost. This option is similar to creating an advance purchase commitment or 'pull' mechanism for new products. It demonstrates a clear commitment by the sponsoring government to purchase the invention - thus enhancing the incentives to the inventor. With a patent buy-out, however, the patent is taken away from the innovator ${ }^{56}$. The national government(s) or international community signals it is prepared to pay for the research and can then either put the information in the public domain for competitive production, or auction the patent to any bidder.

\footnotetext{
${ }^{56}$ Taking away the patent from the innovator will not be necessary if a system of Advance Market Commitments (AMCs) is used - as we will see in chapters 7 and 8.
} 
The key issue is to determine what the right price is for a patent. From an economic viewpoint, an efficient price would be one that reflects the net social benefit resulting from the patent since this would produce the correct incentive for firms to invest in research. Where estimating these benefits is extremely difficult, one could look to the market to make such estimates. As suggested earlier, the value of the patent could also be determined by an auction among manufacturers. However, this could be considered collusion of the players to put in bids, knowing that the government is going to buy out the patent anyway (Kremer, Glennerster, 2004). Moreover, the reality is not as simple as one patent per endproduct as each product could be the output of a number of patented inputs. In practice, it is thus not one single patent that is being purchased, but rather one or more in a number of countries. The actual challenge for any sponsoring government is to determine whether it is this particular invention, or the yet to be seen outcome of other research, that it should buy. Certainly national politics will further complicate the decision making process.

As an alternative to $R \& D$ 'pull' mechanisms described above, 'push' mechanisms could also be used to encourage the development of novel treatments needed in developing countries. 'Push' incentives work by providing upfront financial support for R\&D in pre-determined therapeutic areas. Such funding might take the form of either tax breaks or subsidies for research and development carried out by private firms or of increased funds to public, nonprofit research organizations. Advocates of a more extreme direct funding approach argue that directly subsidized or even wholly nationalized $R \& D$ is the best way to produce safe and effective medicines for diseases of poverty (Hubbard, Love, 2005). Scholars specialized in medical innovation and experts in pharmaceutical R\&D like, for example, DiMasi and Grabowski (2004), have noticed serious drawbacks to this upfront funding of $R \& D$ because these subsidies may not necessarily lead to the development of useful medicines. Push strategies have in the past been found to be subject to potential principal-agent problems. Since these mechanisms subsidize research inputs rather than outputs they are facing problems of asymmetric information and moral hazard incentives.

\section{Compulsory licensing}

Compulsory licensing allows third parties to exploit a technology protected by a patent. Patent holders are compensated, albeit only partially, for the dilution of their exclusive rights through the payment of royalties.

Article 31 of the TRIPS Agreement allows compulsory licensing and governmental use of a patent without the authorization of its owner. This can only be done under a number of conditions aimed at protecting the legitimate interests of the right holder. It is generally not 
known that the authority applying for a license must first have attempted, unsuccessfully, to obtain a voluntary license ${ }^{57}$ from the right holder on reasonable commercial terms and payment of adequate remuneration. The eventual authorization granted under compulsory licensing must also meet certain requirements. One is that the license cannot be exclusive and as a rule is granted predominantly to supply the domestic market ${ }^{58}$. The Agreement also foresees that the negotiation clause can be waived in the case of national emergency, extreme urgency or for non-commercial public use. Although this clause has not been further outlined, many have applied it to issues of national public health. Compulsory licensing can be authorized under conditions that constitute an abuse of intellectual property rights having an adverse effect on competition in the relevant market. Such abuse may have to be determined to be anti-competitive after due judicial or administrative process ${ }^{59}$.

While WTO dispute resolution panels will have to determine more precisely the interpretation of the cited flexibilities, more should be done to come to a common understanding of the conditions that warrant use of the cited flexibilities under TRIPS, especially compulsory licensing. The science-based industry's view as expressed through its trade associations (IFPMA, PhRMA, EFPIA, BIO, etc.) is that broad-base use of compulsory licensing provisions is likely to undermine private sector incentives to conduct $R \& D$. They believe this will lead to problems in ensuring that the right incentives are in place to fund development work in the area of medicines for diseases prevalent in developing countries. For this reason, compulsory licensing is best reserved as a policy measure of last resort, that is, where other efforts to address affordability such as increased international sponsoring for product purchase, differential (preferential) pricing, and the voluntary licensing agreements have failed.

\subsection{Conclusion}

Despite advances in healthcare there are still many diseases for which there is no cure or for which treatments could be improved. Continued research and innovation is essential. This

\footnotetext{
${ }^{57}$ Under voluntary licensing, either an application is made to the patent holder to gain a license or the patent holder approaches potential licensees to produce the patented product. It does require agreement between the licensee and the patent holder without prejudice to the rights of the patent holder.

${ }^{58}$ The WTO TRIPS council and General Council recently defined the circumstances that justify export compulsory licensing. This can only be used in the event of a public health crisis in countries that truly lack pharmaceutical manufacturing capacity, and not to achieve industrial or commercial goals in exporting countries (IFPMA, 20052

${ }^{59}$ The most common ground under national patent laws permitting compulsory licensing is "non-working" i.e. when a rights holder is not supplying the patented product in the patent granting nation.
} 
chapter has provided evidence that protection of intellectual property rights in conjunction with tiered pricing arrangements are key elements in maintaining this commitment.

Patents are crucial to pharmaceutical innovation and without them, there would be no financial incentive to fund the cost of discovery and development of new products. The importance of patents to research-based pharmaceutical and medical biotechnology companies relates in large measure to the high costs, long development times and the ease of copying the final product. There is also the rationale for rich and poor countries to have patents in place to respond to developing country-specific needs, where the creation of stronger incentives leading to the discovery and development of new medicines, is of paramount importance. In the absence of a patent, the only way inventors can protect their inventions is through total secrecy, which is counter to furthering innovation, a fact often ignored by those who consider that patents prevent research. It is only when patents are used excessively to protect information to the extent that researchers cannot use a patentprotected invention in their studies that the system is a considerable barrier to further innovation. To prevent such abuse of patents, several countries have implemented the 'research exemption', which allows scientists to use patent-protected technology freely for their research provided they do not exploit it commercially. In light of these issues, the protection of intellectual property with patents is crucial for pharmaceutical companies to discover and develop new drugs for the developing world.

Further, it is important to strike a proper balance between public health concerns and the interest of the patent owner. This balance in principle exists within the patent system. Appropriate levels of IP protection encourage local firms in the developing world to invest in innovation without the fear of free riding by competitors. They encourage firms in the developed world to enter into partnerships and collaborations with indigenous companies elsewhere and to invest in their markets. To ensure that the poorest and medically most needy individuals in the developing world have access to the medicines they need, amendments to the WTO's TRIPS Agreement have been endorsed. TRIPS strikes a balance between IP protection for the companies that innovate and if needed the flexibility of compulsory licensing for developing countries to provide treatment to the needy in the face of a national emergency.

Differentiated (tiered or preferential) pricing should be common practice as it is economically efficient and equitable. The operation of a tiered pricing system is dependent upon the ability of the producer to segregate the markets in which different prices are charged. With assured market separation, originators can offer prices comparable to prices that a local generic firm would charge. Without segregating the markets, the lower priced products will tend to be traded at a mark up into higher price markets. This would erode the demand for higher priced products and erode the overall profits of the innovator. Under these circum- 
stances, companies have an incentive to adopt uniform pricing, which means higher prices for developing countries and a reduction in overall consumer welfare. Therefore, full support should be given to implementing a system of international differentiated pricing by putting a framework in place that allows (or rather tolerates) that low prices are charged to the poor without the low-priced products being re-imported into higher price markets. It is the responsibility of all governments to ensure that international trade regulations are endorsed and effective logistic systems are in place to prevent such parallel importation. In short, wealthier nations should not expect to pay the same low price as the poorer ones in the global market. Companies can simply not sustain the R\&D costs necessary to create safe and effective medicines if they have to deliver them at not-for-profit prices. On the one hand, a strong political will is needed in the industrialized world to accept that the less wealthy in developing countries pay less than the home market, and on the other hand, authorities in developing countries should ensure that low priced products effectively reach the poorest and are not sold in the high price market segments.

As a final point, this may be the time for governments and policymakers to consider alternative innovation models and incentive schemes for promoting research and development on developing world diseases. However, any such scheme should work in conjunction with the incentive mechanism contained in the patent system. Chapter 10 discusses the advantages and disadvantages of some alternative systems and their compatibility with patents and tiered pricing. 


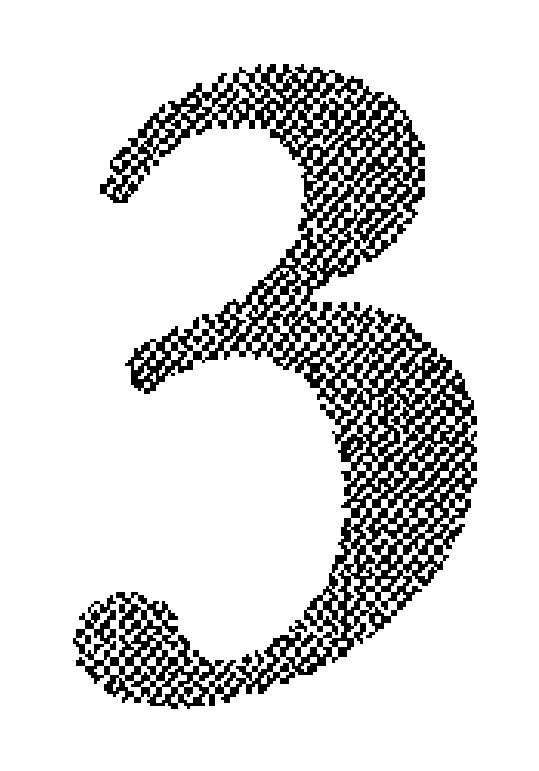

The supply and demand side of pharmaceutical product innovation 


\subsection{Introduction}

The demand for pharmaceutical and medical products derives from the general demand for health. Progress in addressing people's health needs over the past century has been nothing short of spectacular. Medical innovation is at the heart of this progress. New drugs, vaccines and medical tools have revolutionized healthcare practice, making many fatal ailments curable, treatable, or significantly improving the quality of life among patients suffering from disease. Indirectly, these advances have contributed to economic and social development by building healthier and more productive societies as discussed in chapter 1 .

Worldwide demographic changes lead to all populations suffering gradually from the combined burden of chronic, non-communicable ailments, and the rise of new infectious pathogens resistant to established therapies ${ }^{60}$, as illustrated in figure 7. Faced with these unmet and evolving global health needs, ensuring the continuity of innovation in medicines is in the best interest of mankind. Hence, the role that medical science and pharmaceutical product technology play in keeping patients one step ahead of the changing profile of disease burden, is critical. The need for additional innovation in healthcare is obvious. In 2002, the WHO estimated that out of more than 5,000 identified diseases, the number of disease genes discovered was 1,253 and the molecular characterization of clinical disorders existed for more than 1,700 diseases. Even for those diseases with relationship to disease genes, the molecular sequences needed to design a drug were largely unknown. Even today, that leaves a significant number of medical conditions for which the origins are unknown and which consequently lack appropriate treatments. Cardiovascular diseases are the leading cause of mortality in many developed as well as developing countries, and modern diseases like diabetes are gaining importance in all regions. Chronic conditions that disproportionately afflict the aged require substantial $R \& D$ efforts in order to provide satisfactory treatments and thereby reduce the cost of these diseases. Further, drug resistance is growing in developing countries plagued by infectious diseases such as malaria (Ridley, 2002) and TB (Zumla, Grange, 2001). Here, counterfeiting exacerbates the problem and is particularly dangerous for anti-retroviral therapies used to treat AIDS. In 2003, Nigeria was forced to temporarily suspend imports of a number of essential medicines after discovering that up to $80 \%$ of the imported supply was counterfeit (Authentication News, 2003).

\footnotetext{
${ }^{60}$ Even in Europe and the US, resistance of the HIV/AIDS virus to the latest anti-retroviral drugs (ARVs) is reaching as high as $30 \%$ in some populations (Gallo, Montagner, 2003).
} 
Figure 7: The status of medicines: Continuous need for product innovation

\begin{tabular}{|c|c|c|c|c|}
\hline & Vaccine & Prevention & Treatment & Cure \\
\hline HIV/AIDS & * & * & $\triangle$ & * \\
\hline Tuberculosis & * & * & * & * \\
\hline Malaria & * & * & $\Delta$ & $\triangle$ \\
\hline Childhood Diseases & $\triangle$ & $\triangle$ & $\triangle$ & $\triangle$ \\
\hline Respiratory Infections and Diseases & $\triangle$ & * & $\triangle$ & * \\
\hline Cancers & * & $*$ & $\triangle$ & * \\
\hline Neuropsychiatric Disorders & n.a. & * & $\triangle$ & * \\
\hline Cardiovascular Diseases & n.a. & $\triangle$ & $\triangle$ & * \\
\hline Diabetes & n.a. & * & $\triangle$ & * \\
\hline
\end{tabular}

Source: IFPMA (2007); The Pharmaceutical Innovation Platform

\subsection{The demand for pharmaceutical and healthcare products}

There is widespread variation in the utilization and diffusion of medical technology among (and within) countries. This may be due to different healthcare needs, economic conditions and health system features, but it can also indicate suboptimal use of technology and potential inequities in patient access. This in turn leads to unnecessary socio-economic costs, unnecessary suffering, reduced health outcomes, and negatively impacts a developing nation's growth.

\section{Pharmaceutical product prescriptions}

While most other markets have two participants, the producer and the consumer, demand for many health services and products, including the usage and prescription of pharmaceuticals, is determined by 'third-party intermediaries': the government and/or private insurers. In this healthcare market, the patient receives the service from a professional provider who charges a fee-for-service of which amount the third party pays a large proportion or the entire amount. This relationship, in which the professional provider (agent) acts in the patient-consumer's (principal's) best interest, has been the subject of intense debate for decades, because of the incentives built into the 'fee-for-service' medical care system. It is commonly known that national governments, private insurers and sick-funds, throughout the world, are facing increasing demands on their healthcare systems. Hence, the 'fee-forservice' system is changing along with the role of the physician. The latter is increasingly becoming an agent not only to the individual patient but also to third-party payers. Devising contractual incentives for healthcare providers to make the right trade-offs between the short-run desires of individual patients and the collective long-run insurer/policyholder 
interests is at the heart of the ongoing revolution in today's healthcare markets, both in terms of pricing, reimbursement and organizational structure.

In many countries, the price of medicines is being regulated, negotiated or simply capped. Payers are increasingly exerting pressure on health care providers (physicians, hospitals, etc.) to compare different treatment protocols and to pursue the most clinically effective and cost-effective options. Not surprisingly, given the mounting financial constraints in the healthcare market, new health technologies and medicines have become subject to health outcomes research and cost-effectiveness analysis ${ }^{61}$. Health Technology Assessment (HTA) is increasingly becoming a requirement by private and public health organizations and healthcare payers because it helps clarify the features and benefits a new technology may offer to them when made available. However, suppliers may be seeing it as an additional hurdle to making new and improved medicines available to patients. As was to be expected, the combination of increased demand for innovative health technologies in combination with limited national healthcare budgets has resulted in tensions between delivering costeffective health care and improving or sustaining a country's manufacturing and R\&D base. It is therefore increasingly important to strike a balance between affordable health care and the adoption of innovative health technologies. To meet this end, it is necessary to consider the value of a product (in medical, economic, legal and equity terms), and who in the population benefits most from the innovation, leading to the optimal usage, and the appropriate placement in the spectrum of care (Drummond, 2001).

The medicine or health technology that delivers the best value - in terms of medical advantages offered to the patient and cost savings to the health care system and indirectly to society - may command higher prices and expect reimbursement based on value for money. By the same token, new products that represent only marginal or no improvement over existing therapies will gain little respect in an increasingly demanding marketplace, and vice versa (Maes, 2002). Failure by corporations to adequately capture and demonstrate the intrinsic value of their innovations will result in a lower price setting and, therefore, generate lower profit margins. HTA can help meet these challenges by deciding which technologies are cost-effective and which ones are not, and by defining the most appropriate indications for their use (Drummond, 2001). HTA can be used to validate a new technology, define its role in a health care system, and empowers governments and patients that are privately insured to make evidence-based decisions based on value. In short, it supports

\footnotetext{
${ }^{61}$ Health outcomes research is the study of the efficacy of alternative therapeutic paths. The objective is to improve health care and achieve the optimum benefit from the resources available by assessing the outcomes of different treatment or preventative options by using established methodology from epidemiology, clinical research, psychometrics, health economics and health services research.
} 
innovation and gives patients and physicians the information they need to make the best treatment choices.

The goal of economic evaluations of healthcare interventions is thus to provide policy makers with guidance about how scarce resources can be allocated so that the social and economic benefits are maximized (Drummond, O'Brien, Stoddart, Torrance, 1997). As a result, governments may have to allow more funding and greater flexibility between budgets, so that spending levels are driven by value rather than arbitrary spending caps within various narrowly defined departmental 'silos'(Drummond, 2001). Silo-budgeting - the assessment of costs and benefits within a specific healthcare operational cost center - is inimical to the true objective of HTA, which is to help decision-makers obtain the maximum health gain and economic benefit from healthcare investments. Yet, this broader view - healthcare expenditure as an investment not a cost - is rarely taken by healthcare administrators. Consequently, more discussion of the wider macro-economic aspects of healthcare decision-making must be stimulated if 'silo budgeting' is not to put at risk the optimization of health gains.

To establish the 'full' value, various HTA assessment techniques are being used such as cost-benefit, cost-effectiveness, and cost-utility analysis. In-depth discussion of these methods is beyond the scope of this book. Assessments are almost always comparative - the product under review is evaluated against some specified standard of performance or other product or treatment. The results of a cost-effectiveness (CE) analysis are expressed as a $\mathrm{CE}$ ratio, which compares the incremental cost of an intervention with the corresponding incremental health improvement ${ }^{62}$. When health policymakers, authorities and purchasers need to decide whether a suggested price is fair and reasonable, the result of the analysis allows them to compare the various costs and benefits of a proposed treatment to other alternatives.

\section{Pricing of prescription pharmaceuticals}

The model of price setting in a perfectly competitive market suggests that prices are based upon marginal costs. However, this model does not apply to research-based medicines, for if they were priced according to their marginal cost, they would be relatively inexpensive and in the end no expenditures on $R \& D$ would be made ${ }^{63}$. While price-control policies

\footnotetext{
${ }^{62}$ The intervention under study and its alternative are denoted as 1 and 0 respectively. If $C_{1}$ and $C_{0}$ are the net present values of costs that result when the interventions and alternatives are used, and $\mathrm{E}_{1}$ and $\mathrm{E}_{0}$ their respective health outcomes, the incremental $C E$ ratio is simply: $C E$ ratio $=\left(C_{1}-C_{0}\right) /\left(E_{1}-E_{0}\right)$. This ratio, a cost per unit of incremental health effects is often used as a measure of value.

${ }^{63}$ The pharmaceutical industry's most differentiating characteristic is that it is particularly high in fixed costs.
} 
could lead to cheaper medications and reduce health expenditures in the short run, it is exactly the removal of the incentive to invest in $R \& D$ that could delay innovation and drive up healthcare cost in the long run. Moreover, alternatives to prevention and drug treatment, such as labor-intense hospitalization and surgery, generally tend to be a much more costly option than pharmaceuticals.

An efficient pricing framework that stimulates $R \& D$ would allow both the buyer and the seller to act more as in an oligopolistic market, with some control over price (Schweitzer, 1997). Here, prices could exceed marginal costs only if value can be proven to the consumers. This is in line with the HTA principle described above and the innovation profit theory' (Hirschy, Pappas, 1998). For such an interactive system to work, markets must be competitive and customer driven. Research has found that the market for pharmaceuticals is indeed competitive (Kettler, 1998). That is, the system is based on competition between new and existing products - and product differentiation is inferred from customer preferences for product attributes. So, new drugs that enjoy full patent protection compete with other products in the same drug class as well as older drugs that have a favorable reputation and product loyalty. This underscores the importance of effective market demand in pharmaceutical price determination. One may think that this appears at first to be counterintuitive because the cost of pharmaceutical development, a supply-side variable, is so often 'blamed' for the high price of medicines. The above reasoning confirms however that low or high prices are determined by the various demand factors that together constitute the marketplace (Schweitzer, 1997). This is not to say that producers do not have to look at the technical production and development cost structure (including failures), because these parameters determine the floor price under which they cannot compete in a sustainable fashion.

For the developing world, the majority of prescription drugs and vaccines are purchased by centralized 'third party' procurement agencies such as the United Nations Children's Fund (UNICEF). Nowhere is the external price pressure more evident than in the case of procurement organized by non-governmental agencies on behalf of low-income countries. From a business perspective, the arrangements that these procurement agencies use to buy new and existing medicines compound the problem of an already anemic market. Once firms have invested $R \& D$ resources in a newly developed medicine, these procurement agencies have an incentive to play their role as dominant purchasers, regulators and often arbiters of intellectual property rights, to negotiate the lowest possible price, in the interest of protecting scarce healthcare budgets. Given the limited funds available for international health - despite donor support for basic drug treatments and immunization programs achieving a low price is a legitimate way for authorities to buy valuable health products for as many people as possible. However, the result of continuously buying these products at very low prices means that firms receive little more than the cost of production, not enough 
to recover the fixed $R \& D$ costs, or the cost of maintaining, let alone further expanding, the current production capacity (Barder, Levine, Kremer, 2005).

\section{Profit margins of the pharmaceutical industry}

Historically, the pharmaceutical industry has been a leader in financial performance and value creation. In recent years, however, its stock-market record has raised doubts about the sustainability of these results along with fundamental questions about the industry's health. For decades there has been considerable disagreement concerning the rate of return pharmaceutical companies earn on their high fixed $R \& D$ costs. The persistently high profit returns reported in pharmaceutical company financial statements have provoked both debate and frontier-extending research on the limitations of accounting data. An often-used defense by industry against the claim about excess profits is that high average returns are necessary to induce investment in high-risk research and development projects. Some studies have revealed that in the past drug companies had higher cross-sectional variance in their profit returns for given years than companies operating in other industries. However, this explanation is not persuasive according to Clarkson (1996). Time series analyses have shown that pharmaceutical companies had more stable returns than the average for all manufacturing industries.

A more compelling rationale is that accounting data on pharmaceutical profits yield biased interpretations, given the special circumstances this type of high research-based industry faces. The relatively high share of $R \& D$ in this industry implies that accounting profits for the pharmaceutical and biotech industry may be overstated relative to other industries. Pharmaceutical and biomedical $R \& D$ is in essence an investment in intangible capital, but is treated as an expense rather than a capital investment in accounting statements. Hence, accounting measures of capital are downward biased, and estimates of return-on-capital are upward biased for the pharmaceutical industry. This bias fuels the perception that the pharmaceutical industry as a whole earns abnormally high profits, which not surprisingly leads to mounting pressure for lowering its prices. Clarkson (1996) has demonstrated that if the accounting rates of return are adjusted for intangible capital, the pharmaceutical industry is not out of line with other industries in terms of profits earned ${ }^{64}$. Other studies attempting to correct for the accounting bias have reached the same conclusion, that is, reported drug company returns on stockholders' equity (ROE) are overstated (U.S. Congress, Office of Technology Assessment, 1993). In 1993, the U.S. Office of Technology Assessment commissioned a study to investigate whether the allegedly supra-normal returns remain after the accounting biases have been purged. By using unusually rich cash flow and

${ }^{64}$ A more detailed example is provided by Scherer of Harvard's Kennedy School of Government (1993, p.104). 
expense data and conducting extensive sensitivity tests, a team of researchers found that the corrected average returns on investment for 88 drug companies between 1976 and 1987 exceeded benchmarks for two control groups by only two to three percentage points on average.

Today, the situation is reversed and financial analysts are rating the pharmaceutical industry as performing poorly ${ }^{65}$. Since 1998, the industry has seen its total shareholder returns (that is, stock value plus dividends) dramatically drop by over a quarter (Cortada, Fraser, 2005). From December 2000 to February 2008, the top 15 companies in the industry lost roughly US $\$ 850$ billion in shareholder value, and the price of their shares fell from 32 times earnings on average, to 13 (Garnier, 2008). The result of this evolution is that, despite a long history of successes in terms of new medicines discovery and commercialization, the majority of pharmaceutical companies have underperformed in the Standard \& Poor index (S\&P) over the past five years (Bate, 2007) ${ }^{66}$. In an industry that previously enjoyed double-digit growth, this new circumstance has proved profoundly disturbing to investors. It goes without saying that if profits continue to decline, investors at large may become less willing to pour their money into projects targeting developing world markets where they may be exposed to non-profit pricing and patent battles. If so, public health and patients in LDCs are likely to suffer from this downturn.

At the aggregate, the sudden decline in pharmaceutical industry revenues occurred due to two fundamental problems that have increased in size and severity over time. Firstly, the productivity in laboratories declined (i.e. referring to the lack of a sufficient number of new products emerging from $R \& D)^{67}$; and secondly, the increased therapeutic competition as a result of patent expirations, which permitted generic alternatives to enter in the marketplace leading to rapid declines in revenues and profits. These two problems that particularly affect research-driven companies have been compounded by increased external pressure from the fact that the so-called third party payers - governments and health insurance agencies - who are increasingly dictating the new terms and conditions for doing business with regard to procurement rules and use of medicines by influencing the kinds of treatments for which they are prepared to pay. Obviously, this trend for pharmaceuticals

\footnotetext{
65 "The big boys are running head first into a crisis as more than 70 major drugs lose their patent in the next few years; that could leave a potential hole of up to $\$ 100$ billion in lost sales by 2011". (Weintraub Arlene, Business Week, p. 116, March 26, 2007 'Biotech's unlikely new pal: can private equity manage its big risks and far-off returns?).

${ }^{66}$ For a graphical representation, see http://www.annerican.com.

${ }^{67}$ The revolution in the biomedical sciences that has taken place over the past few decades reached the public eye with the completion of a draft map of the human genome in 2000. Yet, the advances that have been made in the laboratory srill have to be translated into safe, effective and affordable new medicines.
} 
negatively affects the biotech sector. These two sectors are increasingly linked as we will see later.

With regard to the biotech sector, Pisano (2006) describes in his book 'Science Business' that the economic performance of this industry so far surprisingly has been disappointing by any objective standard. Pisano and colleagues assembled data on the financial performance of all publicly held biotechnology firms and rolled up an aggregate income statement (in essence treating the industry as if it were one firm). Plotted over twenty years, the researchers found that while revenues grew exponentially over time (as might be expected from an emerging industry), operating income (before depreciation) was essentially zero or slightly negative in most years. Once the industry's dominant firm - Amgen - was taken out of the sample, the picture got even bleaker. The conclusion is that the biotech industry, in aggregate, has lost money over its life span. Moreover, these were just publicly held companies, which were supposed to be in better shape than the hundreds of private companies, all of which almost certainly lost money. A chilling finding that explains why there are no easy alternatives in developing and commercializing medicines. The biotech industry will not simply replace the pharmaceutical industry.

Pisano argues that the uncertainty faced by a purely science-based industry like biotech differs in its very nature from that faced by other kinds of businesses. In biotechnology, the challenge of high risk and primary uncertainty are amplified by the long time horizon over which these risks and uncertainties are resolved. In science-based businesses the uncertainty and risks may linger for years, sometimes decades. Cancer or HIV/AIDS continues to prove a devilishly difficult disease to understand and treat, despite decades of massive investment in public and private research. And even when one finds a 'solution', it may not necessarily have commercial implications; rather, it may instead trigger a new round of basic research.

\subsection{The supply of pharmaceutical and healthcare innovations}

Some observers question whether the pharmaceutical industry is able to fix its $R \& D$ engine. Others believe that the emerging biotech firms will indeed overtake the established pharmaceutical companies and assume that these organizations are better at innovation. Industry leaders like Jean-Pierre Garnier - the recently retired President of GlaxoSmithKline - respond that the way to solve the industry's productivity problem is not to break up the pharmaceutical giants into smaller companies. He also argues that there are significant benefits to size: "it provides the critical mass needed for global clinical development and for acquiring crucial technology platforms". According to Garnier (2008), the solution is to return power to the scientists by reorganizing R\&D into small, highly focused groups 
headed by people who are leaders in their scientific fields, and who can guide and inspire their teams to achieve greatness: "their job) is to seek the best science wherever it resides, inside or outside a company; and to fix broken processes because of an increased bureaucracy built over the past years; and to promote a strong culture of innovation marked by a passion for excellence and awareness that results matter". But at the same time, pharmaceutical companies must forge alliances with academia and (smaller) biotech companies: "the model of even a very large pharmaceutical company concentrating its $R \& D$ resources inside its four walls has become obsolete; so, the 'Big Pharma' players can no longer hope to generate the absolutely best science in all areas on their own".

Garnier concludes with the observation that an open architecture has many advantages for pharmaceutical corporations. It forces competition between internal and external scientific teams as well as between different approaches to a common therapeutic solution. It makes the enterprise more flexible, allowing it to cancel programs without having to go through painful restructuring. The driving factor to enhanced $R \& D$ output is an improved understanding of science and medicine at the molecular level through a system of open innovation, and not to be forgotten a continuous investment in human capital by both the enterprise and society.

\section{Chandlerian firms versus network of agents}

The past two decades have seen a gradual but noticeable change in the economic organization of innovative activity. Until then, most firms used to integrate research and development with activities such as production, marketing, and distribution. Today firms are forming joint venture research and development alliances, licensing deals, and a variety of other outsourcing arrangements with universities, technology-based start-ups, and other established firms. In many industries, a division of innovative labor is indeed emerging, with a substantial increase in the licensing of existing and prospective technologies. (Arora, Fosfuri, and Gambardella, 2004) argue that technology and knowledge nowadays are becoming definable and tradable commodities. This is in contrast to Alfred Chandler's view.

Chandler (1990) argued that historically, the systematic application of modern science in the twentieth century took place within the more organized confines of the firm, where the production of new knowledge is combined with its application through mutually complementary investments in research, manufacturing, and marketing. Economists like Nelson and Winter (1982) and other scholars provided an economic justification for this pattern. The production of technology is a cumulative process based on tacit knowledge and expertise, requiring extensive interaction among the groups of individuals involved. These interactions can be realized more effectively when the individuals or groups belong to the 
same organization. It is therefore argued that, in essence, there are transaction costs, both static and dynamic, in the exchange of technological knowledge across various organizations, which may offset the advantages of a division of labor.

Arora, Fosfuri, and Gambardella (2004) claim that this vision of knowledge 'creation' integrated with knowledge 'use' has become inadequate for understanding economic growth in the twenty-first century. Over the past two decades, for example, several small $\mathrm{R} \& \mathrm{D}$-intensive biotech companies, the so-called Dedicated Biotechnology Firms (DBFs), as they are sometimes called, have entered the industry. These firms initially focused on discovering new therapies for a variety of ailments, as well as R\&D tools like, for example, high throughput screening. The research output and the competencies of the DBFs turned out to be important resources for the larger established pharmaceutical firms. Hence, the larger firms developed linkages through alliances, $R \& D$ joint ventures, and acquisitions. Some of the early biotech-companies, like Genentech, Amgen, Chiron and Genzyme, aimed to become full-fledged pharmaceutical companies, selling their products to final markets, and partly succeeded in this strategy. However, it soon became clear that the high costs and high failure rates of vertical product development and commercialization in pharmaceuticals were a serious barrier to the vast majority of the other biotech start-ups. The corollary is that the industry developed into one in which a large number of small DBFs, which specialized in the earlier research stages, became linked to the larger companies that were endowed with the necessary complementary resources largely in advanced product development and commercialization.

Accordingly, universities and biomedical research institutes became an additional source of new technologies and competencies for the industry. Innovations in biomedicine became the output of complex networks of relationships among the universities, the DBFs (which were frequently university spin-offs or linked to university research), and the larger companies (Pisano, Shan, and Teece, 1988; Orsenigo, 1989; Arora and Gambardella, 1990; Gambardella, 1995). The phenomenon we are seeing is thus a market for technology with well-defined division of innovative labor, involving DBFs as technology suppliers, and established pharmaceutical firms as buyers (Arora and Gambardella, 1994). Besides this evolution, the larger pharmaceutical firms typically establish relationships with many DBFs and universities in several areas simultaneously, thereby creating wider networks of linkages (Arora, Fosfuri, and Gambardella, 2004).

The notion that no industrial firm can go it alone in terms of harnessing the necessary resources for advanced technological innovation has been widely acknowledged in Henry Chesbrough's book, entitled: "Open innovation: The new imperative for creating and profiting from technology". According to Chesbrough, companies will increasingly have to explore new methods to exploit the innovation process. This culminates into an open stage 
process with the following characteristics: (a) the central $R \& D$ laboratory is no longer the privileged supplier of knowledge and/or ideas; knowledge and ideas are sought in universities, public research institutions, high tech start-ups and other companies; (b) in addition, an active search will be undertaken to commercialize technology via out-licensing, joint venture and spin-off routes outside the traditional product/markets of the company; and (c) it is presumed that knowledge and technology are difficult to protect and to have a 'first mover advantage' is considered more important than to set up defensive protection systems.

Likewise, Mytelka (2003) considers that innovation cannot be done in isolation but is part of a system. This innovation system can be defined as a network of 'economic agents' together with the institutions and policies that influence their innovative behavior and performance. An innovation system is conceptualized as an 'evolutionary system' in which learning takes place at both the firm and the systems level (Nelson, 1993; Nelson and Winter, 1982; and Lundvall, 1992). The starting point for many of these innovations lies in basic research. Transforming basic ideas into innovations involves several steps, requires many actors (both private and public) and is highly dependent on the incentives presented to universities and research organizations to pursue research that benefits users of research output in general. Therefore, there is a clear need for intensive collaboration between these actors.

Clark (1995), Nelson and Winter (1982) have documented how a number of features differentiated innovation systems from earlier equilibrium-based models of economic systems and of the notion of action and reaction (feedback) contained in the mechanical versions of systems thinking brought into the social sciences. Underlying the 'system of innovation' approach, is a new understanding of innovation as an interactive process through which enterprises in interaction which each other play a key role in bringing new products, new processes and new forms of organization into economic use. They are supported in this process by institutions and organizations such as industry associations, $R \& D$, innovation and productivity centers, standard setting bodies, universities and vocational training centers, information gathering and analysis services, as well as banking and other financing mechanisms. It follows from this reasoning that extensive, adaptable partnerships and clustering between firms, universities and research organizations is an essential feature of any dynamic research and development system.

\section{Building innovation capacity: The role of education}

The role of education systems in underpinning innovation systems and a country's human capital is considerable. Governments go to great lengths to improve the education systems, at all levels. However, the inequity in the education systems in developing countries provides an extra hurdle in the creation on knowledge that is supposed to underpin $R \& D$ in 
the pharmaceutical sector. With the exception of the least developed countries, most countries have achieved nearly universal primary education enrolment. But the enrolment ratio in secondary education in developing countries in 1995 averaged just 54\% compared with approximately $100 \%$ in OECD countries. For university education, which is at the heart of a national capacity to innovate, the respective enrolment ratios are $9 \%$ and $54 \%$ in developing countries and OECD countries, respectively, according to the Human Development Report (2001). This small basis of educated population is a huge challenge that developing countries need to address and overcome if they are to become self-sufficient in building local innovation systems.

The importance of high quality universities and research institutes is illustrated by the fact that for example the U.S. pharmaceutical and biotechnological centers are located in places with the strongest research capacities in the country. New York and Philadelphia boast eight of the ten largest U.S. pharmaceutical corporations, and Boston and San Francisco five of ten largest biotech companies. Between 1990 and 1999 these four centers produced 17,012 biotechnology-related patents (Cortright, Mayer, 2002). This may not be too surprising, as these centers received half of the National Institutes of Health (NIH) budget in grants in 2000 (i.e. US $\$ 7.5 \mathrm{bn}$ ) and investment in biotech start-ups reached US $\$ 2.9 \mathrm{bn}$ (i.e. six times the amount invested in Germany in the same period). Big academic centers or 'think-clusters' such as these may be considered a crucial factor in influencing biopharmaceutical companies' decisions in R\&D location. Lastly, it is not only size that matters, but above all quality and scientific significance in the related field. For example, when analyzed against the frequency and quality of scientific publications in biomedical sciences, the Boston area alone scored 21.0 (impact points), whereas the total score of all German universities was only 27.7 .

An interesting example of the impact of shifting a government's policy towards the area of education is Singapore. In the 1960s, when the city-state was struggling to attract foreign manufacturing companies, a massive national education program focusing on industrial training was initiated to increase the supply of technicians and engineers. With the development of the economy, focus shifted to expanding tertiary education that would provide much needed specialists in areas as engineering sciences, information technology, health sciences or natural sciences, and related technologies. Today, approximately $75 \%$ of the enrolments in polytechnics and approximately $62 \%$ in universities are in these areas. Education has long been a major item in public expenditure, accounting for some $22.4 \%$. There are currently thirteen high-quality research institutes and centers, and eight worldclass universities which have established a significant presence there (Mani, 2000). All these elements contribute to making Singapore the 'Boston of South East Asia'. Other East Asian 'tigers', such as South Korea, have followed Singapore's example and have substantially 
invested in education. This could serve as a model for other developing countries, which lack public resources to develop efficient education systems.

Another important aspect of educational systems is life-long learning or continuing education. It is widely recognized that one of the central characteristics of a knowledge economy lies in continuous technical development and innovation, that is, the necessity for individuals to learn continually new ideas and skills. Governments have taken on this challenge, with measures ranging from establishing well-equipped vocational training institutes and subsidized in-plant training programs in South Korea, to launching a series of training programs in Singapore, to providing almost US $\$ 1$ billion over five years in loans to postgraduate students in the Post-graduate Education Loans Scheme in Australia (Webber, 2003). Among the EU Member States, Sweden, United Kingdom, Denmark, Finland and the Netherlands have also made a strong commitment to post-graduate education and continuous learning.

\section{Fundamental research - The role of academia}

The role of government is to invest in 'pure' or 'basic' research in life sciences and other relevant areas, which produce data that are then considered a public good and are (in many cases) accessible to other parties anywhere in the world. This constitutes the innovation system that currently underpins the supply of new drugs, vaccines and diagnostics that can be used safely and effectively in diverse patient populations around the world. Research by universities and biomedical research institutions focuses on the discovery phase (upper stream process), and therefore can be defined as supportive and complementary to industry's $R \& D$, as this publicly funded research would otherwise not be actively pursued by industry (Suh, 2000).

There is a benefit to having a significant proportion of public research relevant to the pharmaceutical industry be carried out by universities, independent research institutions, and small 'start-up' companies. In such an innovation framework, a smooth interaction between public and private sector research is stimulated and seen as a critical element in technological innovation, industrial competitiveness, and growth (Polt, Rammer, Gassler, 2001). In this paradigm, academic research is not focused on anything as specific as new product discovery. Rather, scientists are free to range widely over the vast, complex puzzle of health and illnesses, helping expand the understanding of physiology and pathophysiology. With new biomedical tools and technologies, academic investigators carry their inquiries down to the molecular level and frequently make discoveries that open territories for others to explore. In the vast majority of cases, what these scientists produce is not a new medicine, nor even a substance that might become a drug. Rather, from their observations of biology, they generate ideas, hypotheses about the biochemistry of some disease 
state, which may offer a new inspiration for drug discovery. A good example is the NIH which works together with research-based pharmaceutical companies to promote basic development of new medicines ${ }^{68}$. Likewise, Singapore reported that 16 public research institutes have developed more than 70 new products and processes with industry; and helped commercialize more than 20 new products and processes and trained more than 580 researchers (Mani, 1999). Similar statistics can be found for other innovative economies, with other outstanding performers being Finland, Taiwan, Canada, and France ${ }^{69}$.

The private sector also undertakes basic biomedical research itself, but is able to access the pool of public research in the search of new ideas and potential biomedical products from which to make proprietary goods. In this integrated innovation framework, companies are primarily responsible for the process of developing, testing, producing, and bringing advanced products to the market, which is both time-consuming and expensive. The private sector's business model is performance-based and market-driven as it rewards results only after they have been achieved. The industrial $R \& D$ efforts are primarily financed from sales across many markets. A portion of the total cost of $R \& D$ cost is paid for by individual governments and their tax payers, which provides an effective de facto global mechanism for sharing $R \& D$ costs. The reward for investing in biomedical $R \& D$ and bringing new products to market is still the patent system. Protected by intellectual property rights and the flexibility of selling the final product above the cost of production, innovation-driven companies are able to recoup the cost of R\&D and deliver a return to their investors ${ }^{70}$. When the patent expires, the original medical product sales will get rapidly eroded by the introduction of generic products (Kettler, 1998).

This leads to the thorny issue of accessibility and appropriation with respect to knowledge generated in public institutions. While private companies have become more involved in basic science, universities and academic medical centers have become more involved in the business aspects of their science. Virtually all major research universities and teaching

\footnotetext{
${ }^{68}$ Policy makers recognize the importance of investment in basic biomedical research and advocate NIH funding others perceive the issue as contentious. Still industry invests significantly more in R\&D than the U.S. government does through NIH - US $\$ 45$ billion for industry in 2002 compared to NIH's total operating budget of US\$ 24 billion of which only a fraction is devoted to pharmaceutical R\&D, whereas the industry figures include pharmaceutical R\&D exclusively (PhRMA 2003, IFPMA, 2004). To put things into perspective, a report from the U.S. Congress found that (only) 4 of 47 drugs with sales of US $\$ 500$ million a year had been developed in part with technologies created with NIH funding (Jensen et al., 2001; NIH, 2001).

${ }^{69}$ Government Procurement of Advanced Technology Products Index - CGR 2001-2002.

${ }^{70}$ A patent is not a monopoly - it excludes others from practicing the invention for the specified time, but it does not exclude others from serving the market of the patented invention. That is, others are free to capitalize on these ideas to invent competing therapies for any given disease. The advantage of patents is also that it forces disclosure, otherwise innovators would prefer to keep their inventions secret.
} 
hospitals have industrial liaisons and technology licensing operations to both bring in research funding and to appropriate returns on intellectual property. The financial stakes are not trivial. However, Dosi et al (2006) dispelled the notion that universities can finance themselves in this newly created proprietary knowledge market. Or, as Nelson (2006) states: "the notion that universities can get rich from licensing revenue is, except few cases, misguided - dreams die hard". The controversy about patents on science (as practiced more and more by universities) is exemplified by the patent recently granted on a monoclonal antibody. Antibodies are usually natural substances that bind to a particular antigen and can neutralise the harmful effects of that antigen. Patents can be granted on laboratory engineered antibodies. The problem is that the patent on a specifically engineered antibody may include 'other antibodies' that can recognize and pick out that antigen (Bar-Sholam and Cook-Deegan, 2004). Nelson (2006) argues that the inclusion in the patent claim of 'other antibodies' means that the patent is unreasonably broad and should have been pruned back by the patent office and the courts. Although the patentee could well argue that the 'invention' was a method of recognizing a particular antigen and that the particular antibody actually used was just an exemplar, one can clearly see the blurry lines here between what can be classified as a human-made biomedical invention and the definition of a natural substance (to which free access should be given).

The worry is that if fundamental scientific discoveries become patented, this could impede the advance of science as well as the advance of technology. First, there is the fear that patents would block research conducted by and among universities in general; if not, at least complicate matters or make research more expensive. Therefore, Nelson (2006) suggested a possible solution by building a kind of explicit exemption for research not commercially oriented into patent law. In practice, this would limit the research exemption to non-commercial research organizations, perhaps just universities. This means that a university would have a de facto general research exemption if it adopted a policy of not patenting its research outputs. Second, given the argument that the 'Bayh-Dole Act' or 'University and Small Business Patent Procedures Act' of 1980 which gives U.S. universities, small businesses and non-profits intellectual property rights over the inventions that resulted from federal government-funded research, what would be the implications if the proposed actions are implemented? Again Nelson (2006) questions: "would not a cutting back of university patenting and strong pressures for broad non-exclusive licensing, interfere with technology transfer from universities to the biotechnology and pharmaceutical industry?"

To that end, the premise of the Bayh-Dole Act was and still is, that licenses using patented upstream research discoveries in order to develop downstream products will promote new product development by protecting licensees from free riders. The economic logic behind the Bayh-Dole Act is that these patents will facilitate technology transfer from universities 
to private firms (Hellman, 2005; Mowery et al, 2001). When university research generates knowledge that may be applied in commercial products or processes, private firms may be interested in this knowledge. However, when it comes to making additional investments in order to transform the university-generated knowledge into a commercial application, an additional incentive problem may pose itself. A firm that endeavors to undertake the additional $R \& D$ that is necessary to develop the commercial application will only consider this a useful undertaking when it has a prospect of deterring imitation by competitors. This is only possible if the firm that develops the applied knowledge to turn the university discovery into a commercial application has an exclusive right to do so. Otherwise, competitors may move in and use the freely available university knowledge to develop a competing application. This prospect is enough to discourage private investment following up university research. The only way in which the firm that wants to develop the university discovery may obtain exclusivity, is when the university patents its discovery, and grants an exclusive license to the firm (Crespi, Gevna, Verspagen, 2006).

Although this is a plausible assumption in some circumstances, there are times when patents on research discoveries will diminish incentives for further R\&D by allowing upstream patent owners to force downstream product developers to share expected rents. Consequently, Nelson (2006) challenges the nature and strategic intent of the Bayh-Dole Act and is sceptical how it is used in practice. Universities and their licensees have become increasingly aggressive about suing product-developing firms for patent infringement, sometimes recovering substantial damages through the awarded settlement. Eisenberg (2006) agrees that such forced rent-sharing is in conflict with the Bayh-Dole Act the aim of which is to promote industrial product development. Whether it also promotes social welfare depends in part on whether we are more concerned with the adequacy of incentives of upstream research performers, or of downstream product developers. Eisenberg infers that: "to the extent that rent-sharing is achieved through the creation of new exclusive rights that limit the dissemination of basic information that would otherwise be more broadly disseminated and used, it imposes welfare losses that may well exceed any welfare gains from enhanced incentives for upstream research".

In turn, Nelson (2006) shares this concern about the Bayh-Dole Act and reaches the same conclusion but for different reasons. In his view, the technology transfer from universities and research-driven biotechnology companies to pharmaceutical manufacturers does not wholly depend on patents as is commonly believed. He argues that this contention is based on historical evidence. Regrettably, he adds that "the biotech research firm is not a viable kind of enterprise anyhow - at least in the long run". Obviously, not everyone involved in biomedical and pharmaceutical research and policy-making as regards science and technology will share this viewpoint. With this comment, Nelson in fact sidelines the entire upcoming new biotech industry that is expected to play a vital role in underpinning the 
knowledge-based economy of the future. It is in our opinion better not to extrapolate the argumentation made for universities about ownership rights being nonessential to biotech research companies (because it is important). Nevertheless, Nelson is making a strong plea for wide-ranging reform of the Bayh-Dole Act. However, he realizes that in reality this may be difficult to achieve: "my preferred position would be to make it very hard for universities to patent, except in exceptional cases, but my belief is that the road to that reform is now too steep". For that reason, his second preferred strategy is not to try to eliminate university patenting altogether but to establish a presumption that university research results, patented or not, should as a general rule be made available to all who want to use them at very reasonable transaction and financial costs. This would not foreclose exclusive or narrow licensing in circumstances where it is necessary to gain an effective technology transfer, but would establish the presumption that such cases are the exception, not the rule.

The role of universities in the production of economically useful knowledge has received much recent attention in the policy debate in Europe. Specifically, most of the policy attention has focused on the need for European countries to enact a 'Bayh-Dole Act'-like legislation, which is expected to raise the number of patents owned by European universities. This lack of patenting by universities in Europe has been suggested as a problem behind the so-called European paradox (that Europe is strong in basic research but lags behind in technological applications in world markets). However, Crespi et al (2006) found that much of the university research that leads to patents $n$ Europe does not show up in the statistics, because private firms rather than universities themselves apply for the patent. As a result, the lack of university patents in Europe is really a lack of university-owned patents, not necessarily a lack of university-invented patents. The study concludes that no additional legislation is needed to make university patenting more attractive in Europe. Whether or not universities own commercially interesting patents resulting from their research, is taken care off by the market and no indication is found of market failure.

\section{The 'market driven' innovation model}

The private sector has created a successful, yet fragile, model for market-driven innovation and product development. Pharmaceutical and biotechnological innovation activities depend on entrepreneurial initiative, which in turn initiates the process of creative destruction as described by Schumpeter. This entrepreneurial process in which various companies compete with each other to deliver the first or next best generation of medicines has been very intense in the pharmaceutical sector (Teeling Smith, 1992). Whereas scientific-medical inventions in the field of molecular biology are the key drivers for bringing new products for the prevention, detection and treatment of disease to the market, there has been a drop over recent years in the number of new products actually being launched onto the market. This explains the concentration and consolidation of the industry over the last decade 
through merger and acquisitions, i.e. (i) the need to be able to turn round the temporarily decline in lab productivity, while meanwhile (ii) coping with tremendous pressure from expiring patents, as well as (iii) anticipating ever growing government efforts to rein in healthcare costs (Naik, Whalen, 2004).

As explained, the particular importance of patents to pharmaceutical companies relates in large part to the long development times and the relative ease of copying the final product. Without an effective and enforceable broad-based patent system, the current business model driving new medicines development is likely to collapse according to industry experts (PhRMA, 2003). The rationale backing this assertion is that if patent protection were to be reduced, there would no longer be marketing exclusivity, competitors would immediately enter any market with a successful product, driving prices down to the marginal cost. As a consequence, future $R \& D$ would never take place as there would be no way for firms to earn a yield on those investments in developing intellectual property. However, it must also be recognized that patent laws entail a social cost. Granting intellectual property through patent protection raises the cost of diffusion of knowledge and makes innovations too expensive for some populations that would otherwise benefit from their use. One part of this balancing act is to limit the duration of the patent. A very short patent life would imply a low level of appropriation such that the limited returns to innovative activity would imply low levels of innovation. A very long patent life would mean large losses in static efficiency, that is, most of the fruits of the innovation would accrue to the innovator, with little passed on to consumers (in the form of low prices) because the inventor would never be subjected to competitive pressure.

Eisenberg (2006) and Heller and Eisenberg (1998) argue that too much appropriation of knowledge particularly in the form of greater degrees of IPR protection may indeed deter innovation by yielding the possibility of multiple conflicting claims on complementary pieces of knowledge and by increasing litigation costs. This is likely to apply generally and in particular when the innovators are the very users according to von Hippel (2006). To take the example of open-source software, the creator of a piece of software does not retain exclusive rights but allows others to improve upon it (Ghosh and Soete, 2006). The person with the best skills or understanding of needs can innovate; innovation in this case is no longer limited to the original creator of the product. This implies the (near) elimination of search costs involved in identifying the best skills and resources to improve a work, as well as the elimination of transaction costs that would be required under an exclusive rights and royalty-licensing regime. In addition, Ghosh and Soete (2006) argue that in the 'old' R\&D model, developing countries are all (too) often treated as consumers who do not have the ability to innovate. They must therefore passively consume products of developed countries (with subsidies, if required), or if they are more industrially advanced they may imitate production methods developed elsewhere. Apart from being patronizing, this view does not 
fit with the new model of technological progress for development. Similarly, Mytelka (2003) contends that the problem faced by developing countries today in meeting their healthcare needs, is not simply one of securing cheaper medicines that can be supplied under negotiated conditions by MNCs at a discount. While this may be an expedient solution of the moment, it cannot provide the opportunities for learning and innovation upon which longer term development - and a narrowing of the fundamental inequalities that underlie the broader problem - are based. Open-source may well change this paradigm, and is described in more detail in chapter 10 together with other alternative innovation models.

Another option for developing countries is to directly participate in the search for new medicines based on their genetic resources and ensure that the benefits are shared equitably. The 1993 Convention on Biodiversity (CBD) attempted to link the conservation of biodiversity to the economic goals of sustainable development, and offered an opportunity for developing countries to actively participate in the innovation process. Several provisions of the CBD bear an impact on how bio-prospecting frameworks should be designed. Two of the most significant frameworks are Articles 15 and 8(j). Article 15 recognizes the rights of national governments to regulate access to genetic resources situated within their territories, while Article $8(j)$ recognizes the rights of indigenous and local communities on their traditional knowledge, innovation and practices (Sampath, 2005). Among these important topics is the access to genetic resources, and The Bonn Guideline made it clear that human genes are not included in this scope (Yamane, 2007). However, there is a difference whether the product is in the industrial or agricultural sector. One of the important factors in discussing the rules concerning IPRs and benefit-sharing in the agricultural seed sector is transaction costs. For agricultural seeds, the costs of establishing contracts between hundreds or thousands of farmers and breeders often outweigh the cost of limiting the scope of breeders' IPR. In the pharmaceutical and biotech corporate sector, by contrast, it may be more difficult to design a satisfactory contract between resource-owners and users. Whereas biological or genetic materials could in principle offer developing countries who invest heavily in science and technology some bargaining power, they can increasingly be substituted in drug research and development (R\&D). Sampath warns that bio-prospecting should not be seen as a cure-all innovation strategy and public policy; it is only one solution to the healthcare problems faced by developing countries.

\section{The 'government-controlled' innovation model}

Can a government-led pharmaceutical R\&D model offer a viable alternative? Experience in health technology and non-medical industries has shown that government-controlled R\&D is likely to suffer from an intrinsic set of problems resulting from tampering with marketbased dynamics. These may include a conflict of interest when, for example, a state or other 
procurement agency purchases products the government has developed itself. The result is often that superior products produced by foreign governments or pharmaceutical/ life sciences companies are more likely to be resisted, to the detriment of patients.

If governments were able to allocate funds to $R \& D$ without an increased cost to the public and were effective in discriminating between worthwhile and less worthwhile development projects, this strategy would dominate that of enhancing intellectual property rights, but this is not the case. This is why the U.S. government recently began an overhaul of its efforts to produce an AIDS vaccine after the failure of an important clinical trial in 2007. At a summit with AIDS scientists in early 2008, government officials pledged to prioritize spending on laboratory work and animal tests rather than expensive and disappointing clinical vaccine trials on humans: "We need to turn the knob in the direction of discovery... That is unambiguous", said Anthony Fauci, Director of the National Institute of Allergy and Infectious Diseases (Fauci, 2008). By contrast, the patent system that incentivizes private-sector entrepreneurs provides a more effective self-selection mechanism in picking new medicine development projects. Those who are convinced that they have a good idea about viable candidates invest their own money and the money of those they can persuade of the attractiveness of their idea. Such a selection mechanism may not only be more effective than, say, public officers attempting to assess a range of applications, because the cost of mistakes is borne by those making the misjudgment, not by the public at large. The patent system thus seem to provide strong incentives for individuals to pay due diligence to the merits of alternative research and development proposals. Because of these strong incentive and selection properties, the strategy of enhancing intellectual property rights is preferable to that of government subsidization.

In line with this thinking, Kremer (2000) considered a theoretical model of the relative cost of public versus private sector pharmaceutical $R \& D$. The study concluded that a biotech or pharmaceutical firm may find it profitable to take on a project as long as the probability of success times the net present value of the project exceeds the cost of undertaking the project. This implies that, if the government only funds worthwhile research projects and researchers focus all their energy on developing a product, the expected discounted cost of developing a product is likely to be similar in net present value terms. In most cases, private research is likely to be more cost-effective than government programs, because privatesector research organizations are more careful in selecting projects and focus more on developing products that are highly likely to receive profitable returns, as they are only rewarded if they succeed. In conclusion, design and production of pharmaceutical and medical products by the government tend to destroy the processes of market competition and product selection, although state selection of the best pharmaceuticals through fair regulation, procurement and reimbursement would increase competition and choice. 
No single government can realistically think in terms of complete self-sufficiency in the area of pharmaceutical and medical innovation and supply. It is a fact that the era of the protectionist go-it-alone state is becoming a thing of the past (Webber, 2003). Japan is one of the last highly industrialized nations that has tried to cling on to the system of state guided innovation and manufacturing of pharmaceuticals and vaccines. The result is striking in that today, Japan is a country that lags behind other countries by 20 years in terms of access to state-of-the-art pharmaceuticals and vaccines. The reason is that Japan has been notorious in shielding competition from abroad by forcing foreign manufacturers to conduct a wide range of additional studies on medicines following standards that oblige them to redesign product formulations and production processes, especially in the case of biological products. The fact is that, although many biological products and vaccines have been launched in Europe and the U.S. over the past 5 or 6 years due to the biotech revolution, none of these products have been introduced to Japan. During a visit to Japan in April $2008^{71}$, Peter Mendelson, EU Commissioner for Trade, highlighted the importance of foreign direct investment (FDI) and advocated competition between indigenous and foreign companies.

The following brief history illustrates the impact of Japan's policy on public health: Between 1995, when a viral hepatitis A vaccine was approved, and 2005, when a measlesrubella combination (MR) vaccine was approved, not a single new vaccine had been approved in Japan. During this ten year period, new vaccines and combination vaccines for children, adolescents and adults debuted one after another in Europe and the U.S., resulting in a huge 'vaccine gap' between Japan and Europe/U.S. Let us examine, for example, the case of Haemophilus influenzae type B (Hib) vaccine. The Hib vaccine protects against bacterial meningitis, a severe systemic infection that primarily affects infants and children under 5 years of age. About 500-600 Japanese patients develop Hib meningitis each year, of whom approximately twenty die, and the incidence of sequelae such as serious hearing impairment is high. Since its launch, the Hib vaccine has already been used in over 100 countries worldwide. These vaccines are known to be highly effective. Meanwhile, the number of meningitis patients has dramatically dropped to one hundredth. Academic societies in Japan submitted a written request to the authorities in the second half of 1990 s to seek early approval. The review process, however, took a very long time. The application finally passed the meeting of the Subcommittee of Pharmaceutical and Food Sanitation Council in November 2006 and market approval is anticipated to be granted in 2008.

Today, the Japanese government recognizes that the creation of a competitive market by removing barriers to enter the Japanese market holds the key to revitalizing its own indus-

\footnotetext{
${ }^{71} \mathrm{http}: / /$ ec.europe.eu/trade/issues/bilateral/countries/japan/pr210408_en.htm
} 
try. To do this effectively, the most important step consists in overhauling the Japanese 'convoy' system and its related policy. For a long time, the local pharmaceutical and medical products industry has been used to conducting business in an environment protected by the Ministry of Health, Labor and Welfare (MHLW). Products that were available for use anywhere in Europe, the U.S. and Asia could not gain entry into the Japanese market due to these regulations. One of the results of this longstanding business practice and lack of global competition is that the Japanese pharmaceutical and medical products market has been suffering from sluggish growth compared with Europe and the U.S.

\subsection{The pharmaceutical and medical biotechnology industry}

\section{Taxonomy of the global life sciences industry}

Few sectors are as transnational as the pharmaceutical industry. Each of the major firms has substantial manufacturing and commercial operations in many countries, making it sometimes difficult to tell where a firm's $R \& D$, manufacturing, or even strategic planning for a particular product occurred. Internationalization of $R \& D$ activities has also been growing. This is demonstrated by the number of laboratories located across the world, and by the rising number of international co-operation agreements or alliances, between either firms and government or university $R \& D$ institutions. At the same time, it is a reality that the number of countries that are substantially involved in pharmaceutical and biomedical research and development remains relatively low.

Sector concentration in the global life sciences industry has been particularly significant over the last decade. Many of the smaller firms have disappeared. Even leading players have merged and consolidated and worldwide research activity has gravitated towards a handful of multinational centers of excellence (Furman, Kyle, Cockburn, Henderson, 2005). These global centers are able to use revenues from selling products in numerous markets around the world and reinvest them in R\&D. The remarkable sums invested by the pharmaceutical and medical technology industry in $R \& D$ represent a transnational spreading of many countries' R\&D costs. This has been termed the 'finance-innovation cycle' (Webber, 2003).

Historically, the model of new medicines innovation was one of 'in-house' research, development, and manufacturing by vertically integrated pharmaceutical companies (Galambos, Sturchi, 1998). Although most major companies continue to undertake activity in each of 
these areas, this model has in recent decades been fundamentally changed. As explained, in large part, this is due to the rise of biotechnology companies ${ }^{72}$ and the shift of large pharmaceutical companies towards subcontracting an increasing part of their development and manufacturing activities (Kettler, Towse, 2002). By the mid 1990's, several thousands of biotechnology ventures had been launched, and several hundred survived to reach sufficient scale to become an important player in the health care industry. They were for the most part profit oriented and had much tighter and more explicit links to non-profit research institutions, with close personal, geographical, cultural, and contractual ties to universities, research institutes, and government labs. This provides them with a competitive edge. Academic scientists have played a significant role in founding several of the start-up biotech companies, either by moving out of academic employment, or participating actively in both worlds (Zucker, Darby, Brewer, 1998).

Quite a lot of biotechnology companies have entered the industry as direct horizontal competitors to established pharmaceutical firms, intending to realize profits by using their command of new techniques and insights from molecular biology to developing products that ultimately will be sold to end users. But the majority of the rather small-sized biotechnology companies focus on early stage research. When initial (pre)-clinical tests at these research-oriented companies are promising, their work is than either licensed to, or purchased by, larger pharmaceutical companies to complete the subsequent stages of development, manufacturing and marketing. Some of these biotech companies manage to develop and sell their own products in specialist areas, and a few do seek or expect to become large vertically integrated pharmaceutical companies. In general, however, the first model prevails. So, those who look to the biotech industry for an alternative product development and supply model (i.e. 'small is beautiful') tend to overlook the fact that very few biotech companies are robust, viable, independent companies. In reality, many of them largely depend on multinationals for their revenues. Failure of these global companies would lead to failure of many biotech companies as well.

\section{Pharmaceutical research \& development alliances}

The pharmaceutical industry is relative to other industries a very research-intensive sector ${ }^{73}$. Compared with other technology sectors such as the chemical industry, which allocates an

\footnotetext{
${ }^{72}$ In this book the term 'biotechnology' is understood to cover both biological technologies or tools (such as recombinant DNA techniques and technologies used in genomics and proteomics), and medicinal products with large molecular weight (e.g. insulin) - often biologically originated and produced. This contrasts with 'pharmaceuticals', which are small molecular weight chemicals, commonly produced by chemical synthesis.

${ }^{73}$ According to PriceWaterhouseCoopers (2001), this intensity is usually expressed as the ratio of R\&D expenditure to product sales.
} 
average research intensity of $5 \%$ of revenue on $R \& D$, the pharmaceutical industry has an average research intensity of $13 \%$ (see table 1), and the biotechnology firms typically spend even between $40-50 \%$ of their revenues on $\mathrm{R} \& \mathrm{D}$, although part of the reason for this is that many biotechnology companies have lower revenues. Overall, the sector's productivity is expected to increase through synergetic strategic alliances between the larger multinational pharmaceutical and the mostly smaller but more R\&D-focused biotechnology companies.

Danzon, Nicholson, and Pereira (2005) described the rich landscape of alliances between small and large firms at different stages of the medicines research and development process, and examined the impact of alliances on $R \& D$ success rates. They found, that for phase I trials in healthy volunteer individuals conducted by any particular firm, returns to experience were economically small; for the larger and more complex late-stage trials which focus on efficacy, they found evidence of large, positive and diminishing returns to a firm's overall experience (across all therapeutic categories). Nonetheless, they found no evidence that scale improves productivity beyond a certain threshold size, although economies of scale and scope in $R \& D$ were often a major reason for the recent horizontal mergers between the larger pharmaceutical firms. New medicines developed by firms whose experience is rather focused than broad (diseconomies of scope), are more likely to complete phase III trials successfully. These findings confirm the strategic notion that drugs developed in alliances are more likely to succeed in clinical trials, especially in phase II and III, when the licensee has more drug development experience than the originator. Thus any 'lemons' or moral hazard effects associated with out-licensing due to asymmetric information between smaller biotechnology companies trying to sell products to larger, multinational pharmaceutical firms, appear to be dominated by gains from trade, according to the investigators. As a result, the biotechnology sector is widely seen as one of the dominant forces of the $21^{\text {st }}$ century ${ }^{74,75}$.

In 1998, the public and private sectors (pharmaceutical and biotech industry) invested at the aggregate level at least US $\$ 73.5$ billion in worldwide health-related R\&D (Global Forum for Health Research, 2002). Of this, governments invested US $\$ 37.5$ billion in health-related R\&D, and the pharmaceutical and biotech industry US $\$ 30.5$ billion in specific pharmaceutical and life sciences R\&D. The remaining US $\$ 6.0$ billion was provided by private non-profit and university funds. For an overview, see table 2. Unsurprisingly, R\&D spending is highly concentrated in the OECD countries which account for $90 \%$ of the world's total R\&D expenditures. The trend is clear. The U.S. attracts the majority of

\footnotetext{
${ }^{74}$ Rinaldi A (2006). More than the sum of their parts? EMBO Reports; 7, 2: 133-136.

${ }^{75}$ DeVol R, Wong P, Ki J, Bedroussian A, Koepp R (2004). America's Biorech and Life Sciences Clusters: San Diego's Position and Economic Contributions. Santa Monica, CA, USA: Milken Institute.
} 
investment and resources, occupying a dominant position, and to a lesser degree the UK, Germany, France and Switzerland respectively. For low/middle-income countries like Argentina, Brazil, Mexico and other Latin American countries - in addition to India, Malaysia, the Philippines, Thailand and Turkey - the estimated outlay is (only) about US $\$ 2.5$ billion on health-related R\&D (1998 data). This trend for emerging economies may go upwards in the future although the US is likely to keep a dominant role.

During the 1990s, the United States already surpassed Europe as the leading site for pharmaceutical $R \& D$ and over the past ten years, $R \& D$ investments have steadily increased in the United States, at about twice the rate of R\&D growth in Europe. Even the pharmaceutical companies with headquarters in Europe have spent only $59 \%$ of their worldwide R\&D in the EU (1999 data), down from $73 \%$ in 1990 , the United States being the main beneficiary of this shift in R\&D expenditures (Global Forum for Health Research, 2002). The European Council regards pharmaceutical and biotechnological R\&D as the driving force behind economic growth and job creation, as well as improvements in healthcare. At the Lisbon Summit in 2000, the European council set a clear strategic objective to transform Europe into the world's most competitive and dynamic knowledge-based economy by 2010 - an economy characterized by a R\&D intensity of at least $3 \%$, with two-thirds of its total R\&D expenditure originating from the business enterprise sector ${ }^{76}$. Many other governments throughout the world are ranking biosciences prominently on the economic development agenda, as well.

Table 1: R\&D by the ten largest international sectors

\begin{tabular}{lll}
\hline Sector & Proportion of total R\&D & R\&D intensity \\
\hline 1. IT Hardware & $27.3 \%$ & $8.1 \%$ \\
2. Automotive & $17.7 \%$ & $4.0 \%$ \\
3. Phatmaceutícals & $\mathbf{1 5 . 7 \%}$ & $\mathbf{1 2 . 8} \%$ \\
4. Electronics \& Electrical & $9.6 \%$ & $5.8 \%$ \\
5. Chemicals & $5.0 \%$ & $4.1 \%$ \\
6. Software \& IT Services & $4.3 \%$ & $14.3 \%$ \\
7. Aerospace & $3.9 \%$ & $4.4 \%$ \\
8. Engineering & $2.8 \%$ & $2.8 \%$ \\
9. Telecoms & $2.2 \%$ & $1.8 \%$ \\
10. Health & $2.0 \%$ & $1.8 \%$ \\
\hline Source PriceWrate & \\
\hline
\end{tabular}

Source; PriceWaterhouseCoopers, 2001

\footnotetext{
${ }^{76}$ European Commission (2006). Europe in Figures, Eurostat Yearbook 2005, Luxembourg.
} 
Table 2: Estimated global health R\&D funding (in 1998 USD)

\begin{tabular}{lll}
\hline & Totals (billion US\$) & $\%$ of total \\
\hline $\begin{array}{l}\text { Public funding: } \\
\text { High income 5 }\end{array}$ & 34.5 & 47 \\
And transition countries & & \\
$\begin{array}{l}\text { Public funding: } \\
\text { Low and middle }\end{array}$ & 2.5 & 3 \\
Income countries & & \\
Private funding: & 30.5 & 42 \\
Pharmaceutical induscry & 6.0 & 8 \\
Private not-for-profit funding & & \\
\hline
\end{tabular}

Source: Global Forum for Health Research, 2002.

Unfortunately, recent data on the $R \& D$ intensity in the EU-25 suggest that the Lisbon objective may not be achieved without a significant injection of new $R \& D$ investment from both the private and public sector ${ }^{77}$. According to the European Federation of Pharmaceutical Industries and Associations (EFPIA) "the European pharmaceutical industry is losing competitiveness as compared to the U.S. industry, and there is an on-going concentration of R\&D in North America" (EFPIA, 2001). To observers there is no doubt that U.S. pharmaceutical companies have gained 'clear and growing leadership' in terms of worldwide sales generated by new chemical entities (NCEs) launched in the global marketplace during the last decade. This is according to a 2000 report on global competitiveness ordered by the Directorate General for Enterprise of the European Commission. The continuing concentration of $R \& D$ in the United States is reflected by the fact that 8 out of the top 10 prescription drugs by sales worldwide have originated in this country, compared to 2 from Europe. And the portfolio of products held by European multinationals tend to be older than that of U.S. firms, underlining once again the differences in research productivity in recent years (Gambardella et al, 2000).

\subsection{Conclusion}

Innovative pharmaceutical and health technology products are vital to improving and saving lives around the world. In the past century, novel drug treatments, vaccines and diagnostic tools have revolutionized medical practice, leading to incredible health im-

${ }^{77}$ Aho E, Comu J, Georghiou L, Subira (2006). Creating an Innovative Europe - Report of the Independent Expert Group on R\&D and Innovation Appointed Following the Hampton Court Summit, European Commission, Luxembourg. 
provements. These efforts need to be maintained as there is a continued need for new and improved medicines to fight the current, emerging, and evolving health challenges the world is facing.

By virtue of the critical resources, know-how, skills and capacities needed in the medicine development process, research-based private sector companies are a major contributor. Few if any other organizations are able to effectively support and manage this process from discovery, through development, manufacturing, testing and market approval, up to distribution and delivery. While academia and public research institutions are a valuable contributor in the discovery phase, the industry's expertise and experience in managing the product development process is hard to replace. The United States, Western Europe, Japan, and a handful of rapidly emerging economies account for the vast majority of innovative medicines developed through a system of intramural and extramural $R \& D$. In addition, there is also an active 'innovation market' through biotech firms that feed into the established pharmaceutical companies' downstream work.

Over the last two decades, the pharmaceutical industry has developed into a large network of small dedicated biotech enterprises, which specialize in the earlier research stages. Many have links with larger companies that are endowed with the necessary complementary resources for tesearch, product development and commercialization. In short, there has been a consolidation of companies in the sector which has created a structure for an upstream industry of specialized technology suppliers to become a stable source of new products and technologies. While some of the larger biotech firms have become suppliers in the final market as well, the vast majority of them are consciously becoming suppliers to the downstream producers of new and existing medicines.

At the core of a firm's decision to invest in R\&D is the expectation that intellectual property rights are respected by law. This depends on the willingness of governments to provide them with the monopolistic power of patents for a limited period. After all, patents are important since the key asset of any innovation-driven firm is the scientific knowledge underlying its new products. Unlike with the brick and mortar assets of many other businesses, there is nothing to keep competitors from using a pharmaceutical company's scientific knowledge unless the developer successfully keeps the discovery secret, or receives patent protection from the federal government. Since secrecy is difficult to maintain, firms have little incentive to take on the costs and risks associated with new drug $R \& D$ without some period of exclusive marketing that comes with a patent.

Regardless of supply-side considerations, it is market demand that actually sets prices for newly developed pharmaceuticals. Given the emphasis on cost containment in the healthcare sector worldwide, policy- and decision-makers will continue to request evidence of 
good value for the money for prescription drugs. Highly innovative medicines may command higher prices than less innovative products but their incremental value will have to be proven by health outcome and cost-benefit studies. Therefore, firms are likely to allocate their R\&D spending based on the expected market value for future products. Predictably, the research agenda for firms is directed toward alleviating disease-causing conditions in the more affluent parts of the world and particularly in those countries with established healthcare systems and sizeable markets. With no valuable investment market, the prospects for the development of medicines to prevent or mitigate the severity of diseases that are endemic in poor countries are not promising. For medicines developed specifically for developing country diseases, the problem is compounded by the fact that these countries have little purchasing power and largely depend on donor funds and supranational procurement agencies like UNICEF that exert monopsony or oligopsony powers which brings prices down below a reasonable price level to maintain innovation. 


\section{4 \\ Product innovation and risk in the pharmaceutical and biotech industry}

This chapter reviews the technical process and managerial aspects of pharmaceutical R\&D. It profiles the long and risky pathway of developing new medicines and details why this process has become more complicated, costly and time consuming. As will be demonstrated, it discovering a promising medicinal compound is not the only success factor. Success also depends on minimizing the time and associated costs to bring this compound forward from a scientific 'idea' to a fully developed product. This includes activities ranging from product formulation, clinical testing, production capacity building, to final regulatory approval and distribution. Over the last fifty years, the focus of the pharmaceutical and life sciences industry on creating medicines has resulted in the concentration in this industry of many skills essential to bringing new therapeutic and preventative products to the market. Intellectual leadership lies within industry in a host of scientific areas such as discovery chemistry, medicinal chemistry, informatics, functional genomics, high-throughput screening and computer modeling, pre-clinical testing and human trial management, regulatory dossier preparation and project management. Equally important are the control and managerial processes that these companies employ, and the investment decisions they must make to build $R \& D$ pipelines able to address and solve the various unmet medical needs in the world. 


\subsection{Introduction}

The earliest stages of medical-scientific discovery are often highly speculative and not directed towards a particular end. The early phases of 'discovery' are in many instances done by academia and public-sector research institutes, and different forms of national R\&D-programs. The fact that advancements in basic life sciences can be utilized by many parties simultaneously (non-rivalry in consumption), and are difficult to restrict access to (non-excludability), gives basic research the characteristics of a public good. The expense and large amounts of resources required to conduct clinical trials, however, discourages most public organizations from bringing new products to market on their own. As a result, public-sector scientist involvement tends to be in the very early phases of the R\&D process and it is private-sector companies that invest their money and resources in developing scientific ideas into what ultimately become marketable products. They also conduct inhouse biological and biochemical research, but their main expertise and infrastructure is geared towards advancing and supporting product development, large-scale manufacturing, and worldwide distribution and delivery.

Developments in the technologies employed in drug discovery have completely changed the nature of the research process in the pharmaceutical industry (Arora and Gambardella 1994, Henderson and Cockburn 1994, Nightingale 2000, Reiss and Hinze 2000). Traditionally, the discovery of a new compound has been the result of a trial-and-error process during which thousands of compounds were screened in order to find one with a specific biological profile, because the 'mechanism of action' of a compound was generally not clearly understood. This process required huge laboratories to conduct large-scale screening and extensive financial, human and technological resources. Each experiment produced knowledge that was very context-specific because these researchers were not able to associate the chemical structure and properties of the molecules with a particular disease. During the 1990 s, the introduction of what is known as enabling technologies, such as high-throughput screening, combinatorial chemistry, bio-informatics, and scientific advances in biomedical sciences transformed the experimental design and the drug discovery process although trial-and-error is still part of it. A new medicine is now the result of a more deductive science method and researchers understand better which biochemical and molecular pathways they want to block or stimulate, along with being aware of the basic features of the molecules that might serve this purpose. In particular, genomics and the development of functional models for diseases have provided an increasing number of potential drug targets, which can now be validated more easily using bio-informatics tools. Bio-informatics models biological pathways and simulates biological processes by using biological data and computational methods. Combinatorial chemistry has provided another new method of synthesizing a large variety of different molecules that can be screened more efficiently using high through-put screening systems. 


\title{
4.2 Process for discovery and development of new medicines
}

\author{
Research and development stages
}

The pharmaceutical new product development process can be divided into six stages (Criscuolo, 2004):

1. Target identification

2. Lead identification

3. Lead optimisation

4. Pre-clinical development (toxicology, pharmacology, drug metabolism in animals, formulation and chemical development)

5. Clinical development:

Phase I: tolerability in healthy volunteers

Phase II: controlled efficacy in patients and studies assessing the clinical proof of concept Phase III: large scale clinical trials to establish the efficacy of the drug

Phase IV: monitoring of the clinical trials to identify side effects

6. Registration with the health authorities

Stages 1,2 and 3 comprise the drug discovery phase (R), which aim to identify new compounds; and the remainder of the process comprises the development phase (D), where compounds are tested to assess their efficacy and tolerability. The division between $\mathrm{R}$ and $\mathrm{D}$ is not clear-cut and certain companies classify part of the clinical development up to the 'proof of concept' under $\mathrm{R}$. Broadly, in research (R), the work is done by empowering individuals or a small team of experts focusing on a particular disease area. Research organizations are being decentralized into networks of small, autonomous units to master complexity.

Discovery 'Research' process $(R)$

The discovery process starts with the search for promising chemical or biological molecules leading to the proof of concept for the development of potential prophylactic or therapeutic candidate products. This discovery phase is increasingly targeted, focusing on acquired know-how of the disease, or synthesized components under study in a particular therapeutic class, or focusing on models existing in nature for which improvements are sought. Thousands of molecules are sorted based on the properties sought, with the help of advanced computer programs and models. The fundamental objective of medicines discovery is to find a molecule that binds selectively to a target (receptor, enzyme, etc.) in the body to trigger a desired biological effect. The analogy of 'lock and key' is commonly used to 
describe the action of medicines in the body (Pisano, 2006). After a systematic process of elimination, only those compounds offering the best guarantees of quality, therapeutic efficiency and safe use are retained. A patent application is filed for the most promising molecules that will be subjected to pre-clinical studies and clinical trials in humans before being submitted to a rigorous registration approval process.

Once a company or research institute has selected a particular disease to be addressed, a usable or 'tractable' biological 'target' (usually a protein) involved with the disease is sought. Many targets are chosen on the basis of scientific hypotheses and do not lead to effective medicines because the initial hypotheses turn out to be wrong. Having selected a target, many compounds - potential medicines - are tested in the laboratory (in vitro) to see if they bind with it, in a process called 'lead identification'. With a potential lead identified, the next step is to see if the chemistry can be improved to give better potency, safety, solubility and other characteristics - this is lead 'optimization'. As soon as the lead compound has been identified in the laboratory, pre-clinical testing is undertaken in isolated cells and tissues, and in animal studies to assess the chemical, biological and toxicological properties of the compound.

\section{Product 'Development' process (D)}

If the laboratory and pre-clinical test results are favorable, clinical trials with human subjects may proceed. In phase I, the prospective medicine is tested on a few (perhaps 20 to 100) healthy volunteers to determine its basic pharmacokinetic and pharmacodynamic properties. In phase II, controlled trials are carried out on volunteer patients (perhaps 100 to 500) to gather information on the compound's safety and efficacy. If results justify it, more comprehensive studies are carried out in phase III (perhaps involving 1,000 to 5,000 voluntary patients in clinics and hospitals), particularly examining the long-term effects and making comparisons with other treatments already in use. If all of these steps are successful, the preparation of dossiers for registration with government licensing authorities may proceed. The next phase entails scaling-up manufacturing for the identified compound through an engineering-process that turns a few milligrams of the active ingredient into a finished product containing 20 or more ingredients to be produced in large volumes.

Before the approved medicine is made available to doctors, pharmacists and patients, the product must go through a final comprehensive administrative procedure including pricing and reimbursement. In total, the pharmaceutical development and approval process, including the administrative procedures, takes on average from 12 to 15 years, (IFPMA, 2004; Weber, 2003; Duetsch, 2002; Spilker 1990). After the product launch, the company is required to conduct post-marketing surveillance in close collaboration with authorities primarily to monitor the safety aspects of the new compound. 
The nature of uncertainty is quite distinctive in the pharmaceutical $R \& D$ process. In most industries, basic technical feasibility is not at stake in the $R \& D$ process. When Intel engineers set out to develop the next-generation microprocessor, they know with near certainty that they will end up with a device that works. In most contexts, fundamental technical uncertainty is resolved fairly early in the process. In the case of new medicines development the majority of $R \& D$ projects fail. What all of this implies is that, in aggregate, the vast majority of resources spent in pharmaceutical $R \& D$ goes toward projects that end up being 'losers'. According to Pisano (2006), such a relationship is not coincidental. R\&D investments in pharmaceuticals are largely focused on testing in order to generate information about a new medicine's potential safety, efficacy, and uses. Posed differently, R\&D in pharmaceuticals is fundamentally about successively reducing uncertainty through the acquisition and integration of information.

\section{New product development risks}

Think of a funnel, with the wide end representing the discovery stage and the narrow end representing the launch point of a new medical product. Thousands of compounds enter the $R \& D$ pipeline and begin to undergo testing. A large percentage fails in the early stages. More fail at each consecutive stage of development. This process of elimination of new compounds that are progressively moving through the $R \& D$ pipeline, often leads to the scrapping of compounds and projects, sometimes painfully at an advanced stage of product development. The reduction of the pool of new product candidates in this systematic selection process is known as 'attrition'. This is illustrated in figure 8.

Figure 8: Standard drug development process and time (years)

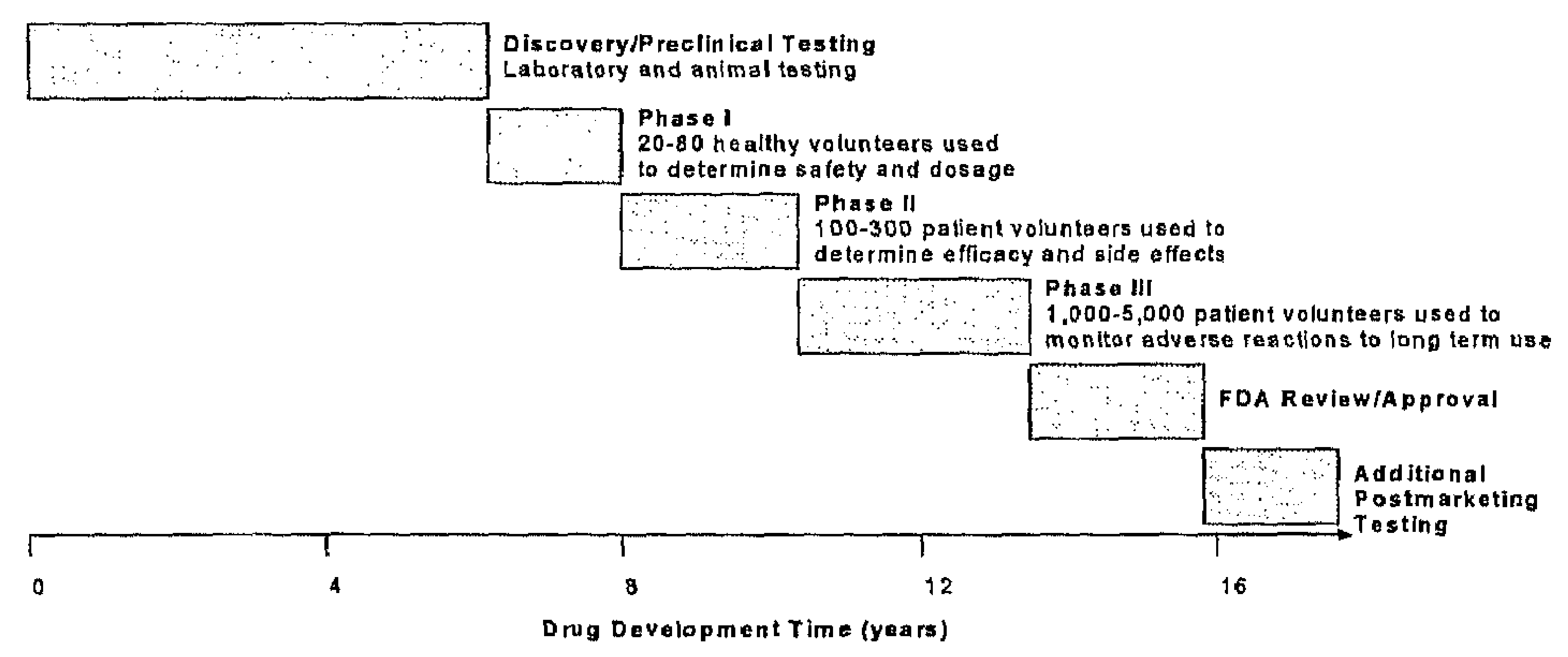


The $\mathrm{R} \& \mathrm{D}$ process is risky because of the uncertainty of whether a candidate will pass each development stage. The risk is very high early on - traditionally, 250 of 5,000-10,000 promising compounds screened, might enter pre-clinical testing, and of these, only five enter clinical testing in humans. And even at the later stages of the R\&D process, there is still no guarantee as failure or better 'attrition' rates remain relatively high in phase III clinical testing. On average, only one compound eventually receives approval in this example. Figure 9 shows the average failure rate of a representative new drug compound as it goes through the multi-stage clinical development phases toward regulatory and market approval. Of the full cohort of potential drugs beginning clinical testing in humans, $75 \%$ enter phase II, $36 \%$ survive to Phase III, and only $23 \%$ of all clinically tested compounds obtain approval (IFPMA, 2004). In sum, entering the final stages of clinical testing is no guarantee for success. The statistics show that even today approximately four to five compounds must be tested in man for each medicine that ultimately obtains market authorization after clinical testing.

Figure 9: Probability of clinically tested compounds entering various phases to gain approval

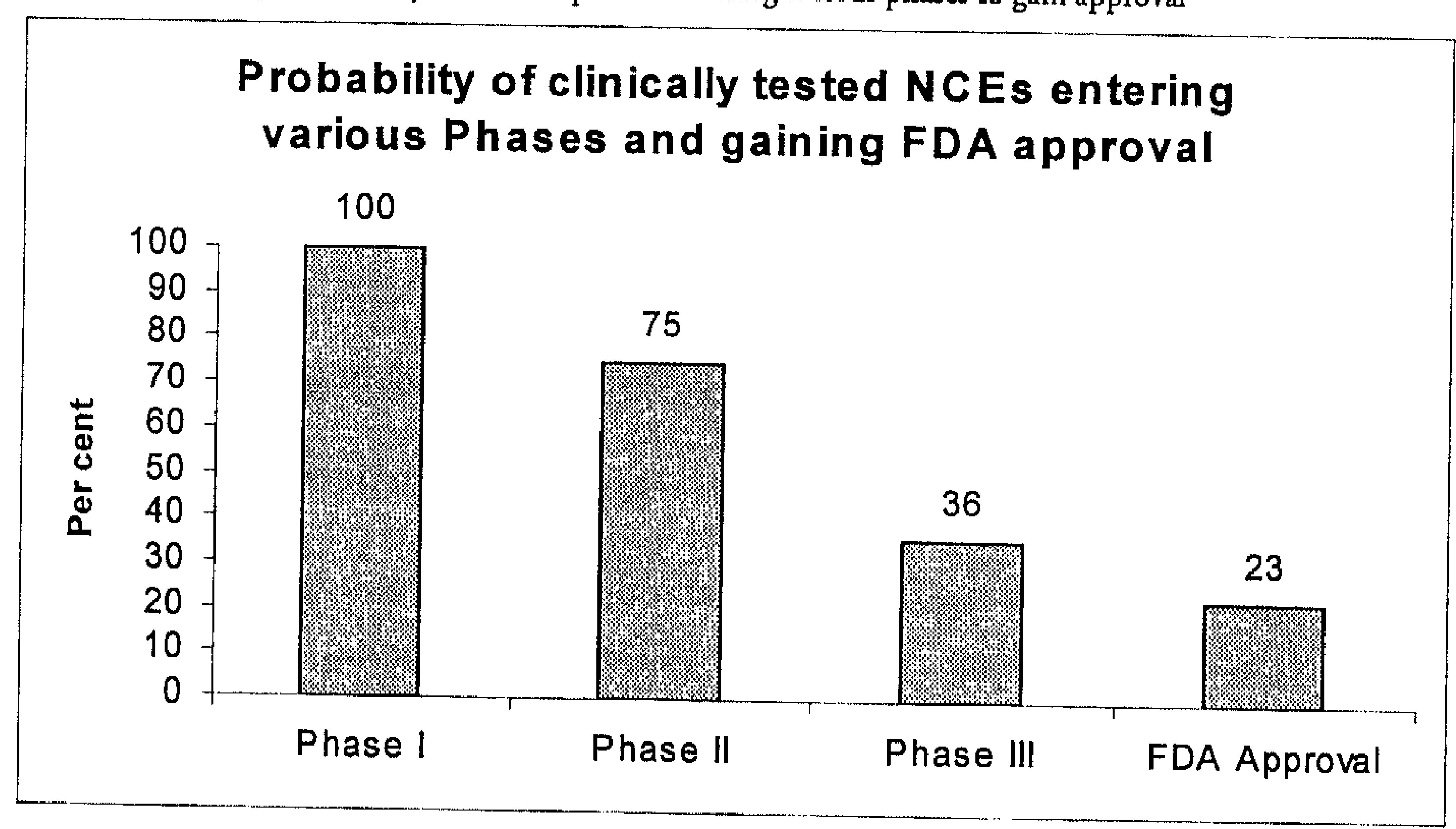

Source: PhRMA (2003)

\section{Pharmaceutical market authorization}

New products are approved when the national (or regional) regulatory authorities believe that the firm has demonstrated substantial evidence of the pharmaceutical product's safety and efficacy. Safety and efficacy are relative terms, despite the invention of biostatistics, the authorizing regulatory agency must consider the 'relative' efficacy and safety of alternative treatments in reaching a decision to approve a medicinal compound, or not. A new drug or vaccine that is less safe than existing therapeutic or preventative treatments would not be 
approved unless it offers a significant new advantage, at least for some patients. That new benefit would then have to outweigh the potential loss of safety. However, the benefit-torisk ratio cannot be reduced for new medicines allowed into the market. On the contrary, the standards of safety and efficacy required for granting approval of new pharmaceuticals to treat a specific disease or condition are becoming progressively higher. Regulatory authorities are inclined to insist on more and longer toxicity tests; to increase the number of subjects used; and to add new control tests as these become available - all to achieve the absolute assurance of safety. This tendency to make the process of drug approval more stringent contributes to the overall upsurge of $\mathrm{R} \& \mathrm{D}$ costs. DiMasi et al (2003) found that the inflation-adjusted annual growth rate for capitalized clinical costs to demonstrate safety and efficacy has become five times greater than the costs of pre-clinical work on new compounds. If this trend continues, it places an extraordinary burden on research-driven companies such that it may make future medicines development practically unaffordable ${ }^{78}$ (Rawlins, 2004).

In addition, national regulatory authorities not only impose technical guidelines related to research and development but also establish standards for handling and controlling pharmaceutical manufacturing processes (Good Manufacturing Practice (GMP), Good Laboratory Practice (GLP), and Good Clinical Practice (GCP)). In order to comply with these operational standards, companies have to validate all production facilities, equipment and processes (including software) they use by providing documented evidence that all these components perform in a reliable and consistent manner. In all of the discussions and debates between regulatory authorities and pharmaceutical and biotech companies, the regulatory agency has the final word. In a few cases the firm may attempt to discuss the request with the agency's inspectors, but rarely will it ever appeal or formally challenge these requests. Each of these conditions must be (re)-negotiated with the national authorities in each of the markets. Harmonization of requirements would therefore greatly facilitate the work and lower the operational costs.

Regulatory bodies such as the U.S. Food and Drug Administration (FDA), and the European Medicines Evaluation Agency (EMEA), or the newly established PMDA in Japan, are starting to recognize the need for worldwide harmonization in approval procedures (EMEA, 2004; Food and Drug Administration, 2004; Ministry of Health, Labor and Welfare, 2002). These agencies also have an important role in building future regulatory

\footnotetext{
${ }^{78}$ The risk is not unimaginable, as shown by the recent example of antibiotics. Because of the FDA's imposition of tighter requirements for approving antibacterial drugs, the industry's ability to provide a reliable pipeline of new antibiotics for treatment of serious infections has been impaired. Such unexpected and negative changes of regulatory guidelines create uncertaincy for companies that may have lasting impact on their investment decisions (Rawlins, 2004).
} 
capacities in developing countries and emerging economies that have to locally evaluate and approve file submissions. For the moment, this is based upon approval of the medicinal compound in Western countries. Regrettably, Western authorities such as the U.S. FDA and the pan-European EMEA will apply their risk-benefit calculations to the drug evaluations, which may be inappropriate for disease endemic countries. A good example of this is the withdrawal of the rotavirus vaccine (against severe diarrhea in young children) from the U.S. market in 1999, due to the alleged risk of patients developing intussusceptions (a temporary twist in the child's bowel) during the post-marketing surveillance period (Delage, 2001). This adverse risk, while significant according to U.S. standards for a U.S. target population - but which has very few deaths from viral diarrhea - could probably be accepted in high-burden developing countries where 1.8 million children die of diarrhea every year.

\section{Pharmaceutical and biotechnology production}

Pharmaceutical and biotech production as well as distribution are almost exclusively the responsibility of pharmaceutical companies and private distributors with the exception of specialized procurement and distribution networks like UNICEF and NGOs which are particularly active in the developing world. Licensure of both the product and the manufacturing plant, which for developing countries requires WHO pre-qualification, is required to commercialize a product.

Pharmaceutical production and in particular biological medicines production is a costly, rigidly controlled series of processes performed in facilities that meet GMP standards. The GMP regulations involve the manufacturing unit, equipment, and procedures and are designed to assure that medicines are as safe as possible. Compliance requires substantial investments over time. The plant is often built for a particular product; hence, the production processes involved determine its design. Since the end product of in particular biological production cannot be measured with chemical precision, the processes by which a biopharmaceutical product is made, are required to meet certain specifications. These are designed and validated by the manufacturer and approved by the regulatory authorities. The regulatory authorities measure progress at each step of the manufacturing process; for biological products like vaccines, for example, this comprises protein content, viral infectivity, bacterial contamination, and endotoxin content.

Pharmaceuticals are regulated throughout their entire lifetime. As explained, the inspectors and regulatory authorities have responsibility for assuring that licensed products are safe and effective. The responsible agency therefore reviews the safety and effectiveness of the product, as well as information on the production facility and processes. The agency also approves the labeling for a new medicine, including indications, contraindications, and precautions. Samples of each manufactured lot must be submitted to the national inspec- 
tors for approval before they can be sold. They monitor the production and distribution for licensed products with regular inspections of plants: this includes the evaluation of the production processes; the manufacturer's compliance with GMP; and testing of purity, potency, and absence of contaminants. The regulatory agency establishes criteria for release of the pharmaceutical product and has the authority to recall any of the products because of problems with safety or effectiveness. Changes subsequent to a medicine being put on the market such as change in production processes, change in packaging, change in address of the manufacturer etc. are handled according to a specific legislative framework. There are basically two types of so-called variations. The minor ones (Type I) are set out in a prescriptive list. If a variation is not on this list, it is by default considered to be a major variation. Major variations require a detailed scientific assessment (minimum delay of 90 days), with explicit approval needed, that is the authority must deliver a written approval before the change can be implemented. Biological products are explicitly excluded from being considered a minor variation, even when the same change for a chemical product would be a minor variation. As a result, the current system often creates significant and unnecessary bureaucracy, delays and costs for both industry and regulators, with no additional benefit to patient safety.

\section{Sequential and parallel development stages}

Although the new medicines research, development and production process is described as rigid and inflexible, in reality it is very dynamic. Many of the activities that go into making a new pharmaceutical product are not done step by step but often simultaneously. Clearly, this also significantly increases the project risk. As the work progresses, the resources that are needed have to follow. Consequently, the investment committed to the project over time takes the shape of an exponential curve demonstrating the gradual increase in capital outflows. At the beginning, few resources in terms of personnel, time, facilities and money are needed. As the new product moves through the pipeline with clinical evaluation and production scale-up to be carried out, the people and costs involved mushroom. It should be noted that, this journey down the pipeline is by no means smooth. Bottlenecks occur because a company may not have enough people with a specific expertise, equipment or facilities able to handle a technical problem. The most important reason for bottlenecks is that companies are developing a number of medicines at the same time where these are often competing for the same resources. Consequently, the long-term human resource and capital investments must be thoroughly evaluated not only at the beginning but at each intermediate stage of the $R \& D$ process.

To guide the entire process, many companies have adopted a so-called 'stage-and-gate' approach for managing their product development projects and driving new products to market (Samuels, 1999; Sully, 1999). This method defines the tasks, activities and account- 
abilities within each stage of the product development project. It allows corporate managers to review their investment options and decide the steps to be taken at regular intervals. The objective is of course to reduce the risk of failure by selecting the optimal pathway. In an attempt to shorten the research and development timings, and the pre-launch period for new compounds, companies often take significant financial risks, for example, by running the clinical trials and production scale-up programs in parallel (instead of sequentially). Such risk-taking in capital budgeting may have serious adverse consequences since these companies are making the commitment to already build a full-scale commercial plant before the new product is proven to adequately work in large patient populations. The degree of risk-taking is even compounded by the fact that these two stages (clinical testing and production scale up) are the largest budget allocation decisions in terms of nominal capital outlay in the course of the entire project.

While the objective is to speed up time to market, an inevitable consequence of the above increase in risk-taking has been the reduction in the number of pharmaceutical and biotech companies that are financially capable of participating in the successful development of novel therapeutic compounds. Even for those companies for whom this still represents a feasible strategy, cost escalation has placed a limit on the number of new chemical and/or biological entities that are submitted to the above decision-making process during any specific period of time. An important strategic question in this new pharmaceutical products race and $R \& D$ budget allocation process is: "How should my company most effectively invest its limited resources?" Several scholars have proposed strategic portfolio management as the solution (McDonough, 2003; Cooper, 2000; Comstock, 1999; Cooper, 1998).

\section{Corporate portfolio strategy and management decisions}

Portfolio decision-making applied to pharmaceutical $R \& D$ addresses a number of vital strategic questions each individual corporation must answer. Cooper (2000) defines portfolio decision-making as follows: "Portfolio management is about strategy, it is one method by which you operationalize your business strategy. . . . Portfolio management is about resource allocation, how your business spends its capital and people resources, and which development projects it invests in. ... Portfolio management is also about project selection, ensuring that you have a steady stream of big new-product winners". The result is that in recent years there has been a heightened interest in strategic portfolio management, not only in the scientific 'community but in the CEO's office as well. This raises another question: Who in fact (should) drive(s) the R\&D portfolio decision process in a corporation? Is it the general manager, senior functional executive, or the firm's middle management, or should operational taskforces be empowered? 
The decision to move from one project stage to the next is usually made by a multidisciplinary executive team comprised of representatives from $R \& D$, the division or business unit, and commercial development units that represent the regional blocks and interests (Comstock, 1999). Commercial development units in the larger corporations can also be an integral part of the corporate R\&D function, which brings into one team people with marketing, business development, and product development skills who help manage the transition of early-stage projects from the research to the business unit. These crossfunctional, often called Therapeutic Area Teams (TAT) own, manage and drive the stagegate process (Samuels, 1999; Sully, 1999). So, rather than operating in departmental 'silos' and different from a relay race where the baton is passed on to the next team, the TAT ensures that departments keep working together across the value chain; and in particular at the interfaces where there is overlap between functions and responsibilities. These TATs produce the Project Operating Plans (POPs), which define the project's research, development and market opportunities (Samuels, 1999). Scientific rationale drives of course the early stage $R \& D$ projects and this remains the case until one obtains proof of concept and proof in man. As of that moment, additional valuation methods and metrics based on, for example, the R\&D project's NPV become increasingly important, especially at the later stages of development. These measures become the key driver by the time clinical phase III is reached, which is also the moment the largest costs are incurred (Sully, 1999). In the larger corporations, different TATs compete with one another for corporate budget and resource allocation. POPs are reviewed frequently with senior management to ensure that, where teams have problems, the full experience of the organization is utilized to solve and remove them, and whenever necessary, adjustments or re-allocations to the budgets of the various $R \& D$ projects are made (Samuels, 1999).

McDonough et al (2003) found that companies with successful R\&D portfolios used a single senior executive to allocate resources. This result is surprising in light of the number of companies that utilize a cross-functional team to decide which projects go into the portfolio. The study findings were explained as a reflection of the fact that senior corporate managers typically possess a broader perspective than the $\mathrm{R} \& \mathrm{D}$ portfolio managers about issues that affect strategic allocation decisions. A corporate-wide perspective at the highest level is considered useful to ensure that appropriate tradeoff decisions are made across multiple product and disease areas in which the company is interested. In addition, the research showed that day-to-day management of the selected portfolio of $R \& D$ projects is critical to its success. On the other hand, some managerial practices are destructive no matter what the goals are, including switching team leaders and members in the course of a development project, as well as stretching people and financial resources across too many projects. 


\subsection{Average costs and returns to new medicines introductions}

\section{Pharmaceutical product development costs}

One consequence of the slide in productivity is the alarming rise in average $R \& D$ costs. International statistics show that $\mathrm{R} \& \mathrm{D}$ spending by companies and the average cost of developing a new compound, are both on the rise. In the last decade, the cost of new medicines development has been steadily increasing, primarily because of an increase in technical and regulatory attrition rates as well.

Figure 10: Expenditures per Prescription Drug

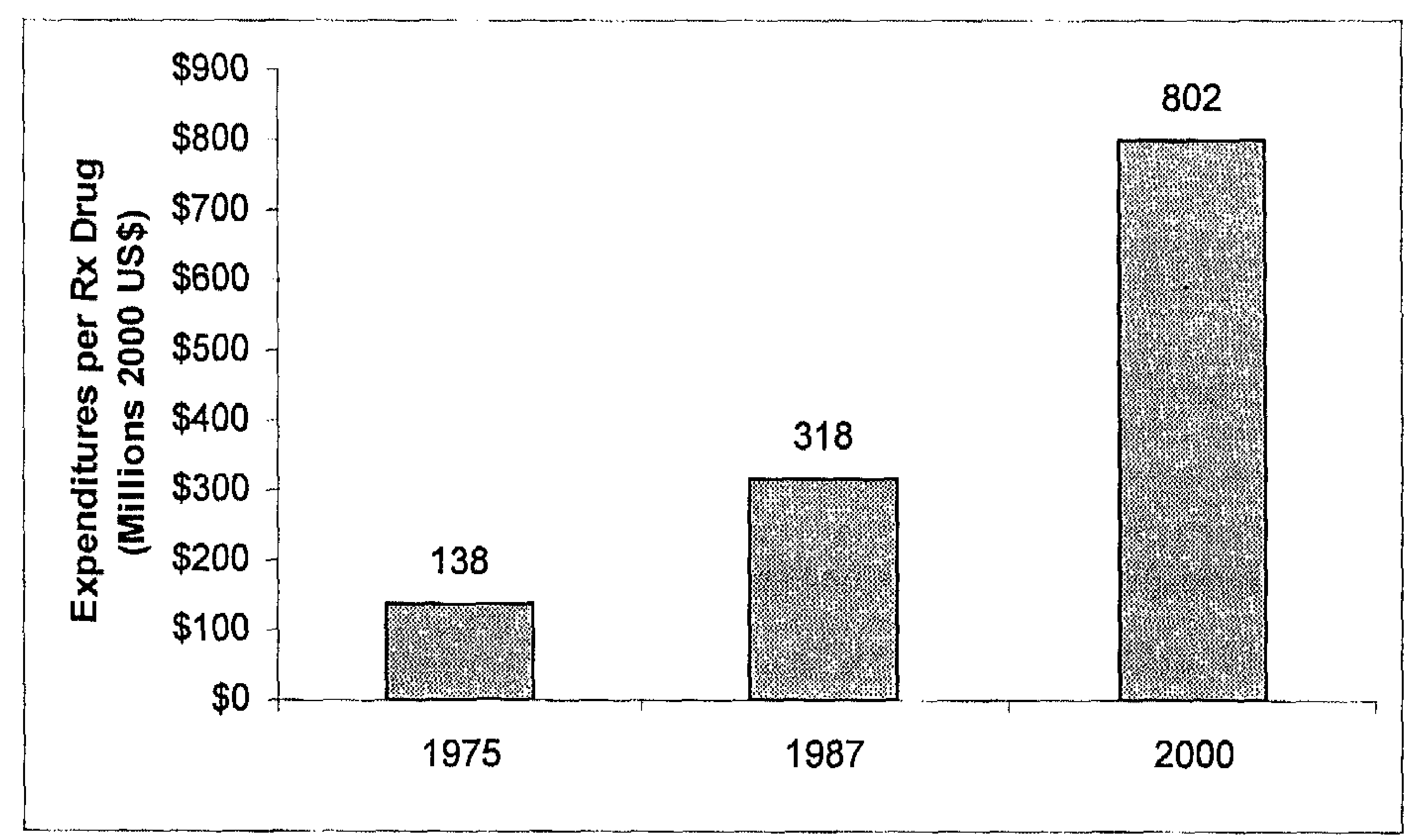

Source PhRMA (2004)

Economists at the Center for the Study of Drug Development of Tufts University, MA have calculated through a series of retrospective analyses ${ }^{79}$ that the average cost of developing a new prescription drug is nowadays about three and a half times more than it was 15 years ago, with the average cost reaching US\$802 million (in 2000) (DiMasi, 2003). This is illustrated in figure 10. Included in this cost analysis of bringing a new compound to market are expenses of project failures and the impact of long development times on investment costs. This explosion of costs in pharmaceutical research and development is

${ }^{79}$ The R\&D cost estimates in this study reflect an average cost across all diseases being researched in the industry. The figures were calculated using data covering 68 drugs from 10 multinational, foreign, and U.S.-owned pharmaceutical firms. 
mainly a result of the growing cost of clinical trials due to the increasing number of patients in each trial, the high rate of failure at each development stage, and the time required to achieve market authorization for the new product, where increasingly stringent regulations are applied before granting approval.

The swelling of $R \& D$ costs is unfortunately not accompanied by a similar increase in new product output ${ }^{80}$. Boosting the industry's investment in $R \& D$ has done nothing yet to increase the flow of chemical drug and biological approvals (Gilchrist, Fraser, Van Dyck, 2005). The number of (small) molecules approved by the FDA has fallen steadily since 1996. And as data from the Tufts Center for the Study of Drug Development show, the drugs that biotechnology has produced have not been enough to offset this decline (see figure 11) (Tufts, 2004). A study conducted on behalf of the U.K. Economic and Social Research Council is even more critical. It claims that over the past quarter-century, biotechnology has produced only 15 significant therapies (defined as medicines with sales of more than US\$500 million in 2002/2003 value). "The translation of this science into new technology is far more difficult, costly and time-consuming than many policy makers believe", the authors conclude (Nightingale, Paul, 2004).

Figure 11: New drug approvals have fallen steadily since 1996

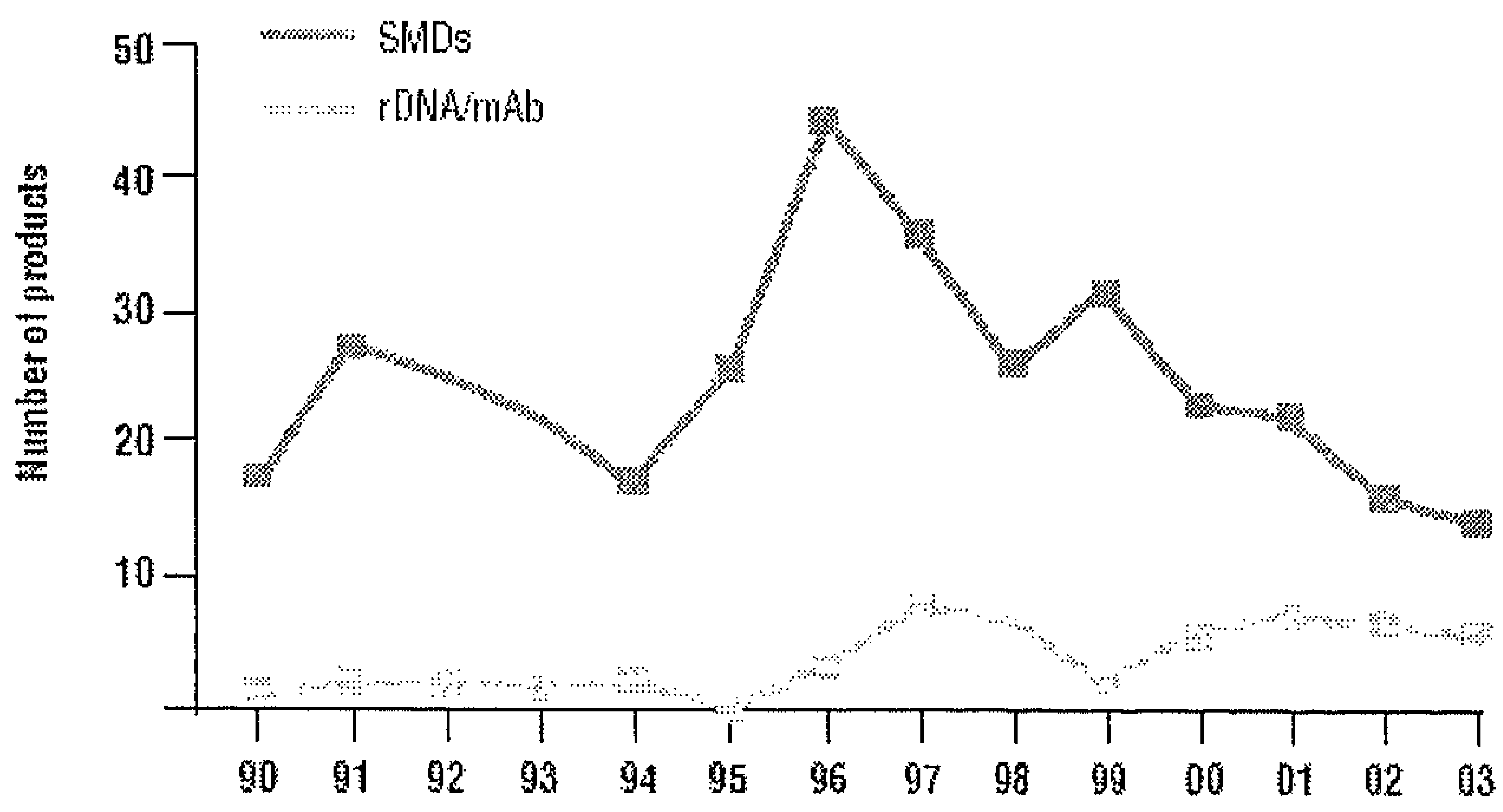

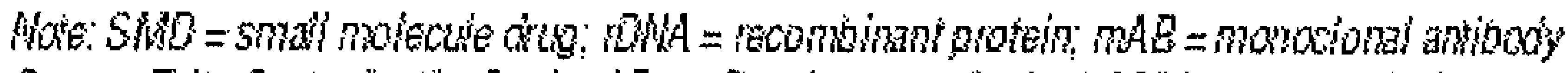

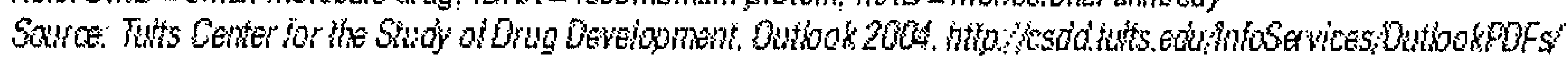
autook 20400 il

\footnotetext{
${ }^{80}$ At the same time, continued investment in pharmaceutical $R \& D$ is an imperative from an individual company perspective. There is strong evidence for a positive correlation between $R \& D$ intensity and sales growth (Research \& Development Scoreboard, 2002). A positive relationship exists between sales per employee and R\&D per employee. Companies with a higher than average percentage of sales from new products, show much higher sales growth than those with an average percentage of sales from new products.
} 
Even though the new biomedical science has not yet fulfilled its promise, the direction in which the industry is heading is indisputable. In a white paper entitled 'Pharma 2010: The Threshold of Innovation', IBM Business Consulting Services argues that a better understanding of the molecular sciences and massive advances in computing power will eventually enable the industry to make targeted treatment solutions - or healthcare packages for people with specific disease subtypes (Arlington, S., Barnett, S., Davies N., Palo J., 2004). Interviews with experts conducted by strategy consulting firms like the Boston Consulting Group and McKinsey Company concur with this view. Genomics ${ }^{81}$, genetics and proteomics - the study of proteins - will be transforming R\&D by identifying disease potential and highlighting new targets. Additionally, a broader revolution is underway, one that is driven by computing power (semiconductors, software, fiber optic networks, automation and robotics) (Tollman, Altshuler, Flanagan, Steiner, 2001). The possible advantages of genomics, genetics and informatics on the pharmaceutical R\&D process can be summarized as follows:

Genomics: The first advance in genomics is in high-throughput techniques with powerful new computing capabilities. These technologies are being actively applied throughout $\mathrm{R} \& \mathrm{D}$, particularly in the drug discovery stage, and promise to enhance productivity by boosting efficiency. By applying genomics technology, companies could theoretically realize savings of nearly US $\$ 300$ million and an average of two years development time per drug. This represents a $35 \%$ cost and $15 \%$ time saving (if the entire implementation is proven successful). From these findings, it is clear that if companies wish to stay competitive, they have no choice: they must (learn to) implement genomics technologies.

Genetics: Where the genomics wave is technology-driven, the genetics wave is data-driven, by exploiting the known details of the human genome and individual variations within it. The genetics wave proves its worth in both the earliest phase and the later phases of the value chain - target discovery and the clinic. Genetics can be applied to two tasks: identifying genes which carriers are susceptible to specific diseases (disease genetics); and subdividing patients in clinical trials according to variations in drug response (pharmacogenetics). These two approaches benefit $R \& D$ economics in several ways: Disease genetics will improve the efficiency of target discovery and will bring about improved success rates in validation and down-stream processes. Pharmacogenetics enables scientists to select patients more appropriately for clinical trials, which will not only help make the trials faster and

\footnotetext{
${ }^{81}$ Genomics in its narrow sense contrasts with genetics. Roughly, the former concerns itself with the common 'standard' genetic make-up, the latter with the distinctive genetic make-up of individuals.
} 
cheaper, but allow some drugs to pass that would otherwise have failed due to poor efficacy effects $^{82}$.

Informatics: The data explosion detonated by genome technology is creating vast amounts of genetic data, ready for sifting. Informatics is the process of manipulating and making sense of the obtained data sets. There are two basic approaches. First, significant development goes into organizing and connecting unconnected data. Here, the issues are around getting data properly structured and standardized. Second, specific developments around individual data sets are designed to improve access, and in visualization or identifying key elements. Here, the issue is about better mathematical methods and algorithms to mine the data.

The greatest proportion of information data is external, and using it within a company presents significant challenges. One example is the stream of DNA sequence data being produced as part of the Human Genome Project, where the volume of data being generated is staggering. It will be necessary to compare new sequence information with known sequences to see what it resembles. This involves more than just a straightforward database search. The program involved must know what constitutes a biologically meaningful resemblance, and must be able to deal with the errors that inevitably creep into the sequencing process. Devising new search algorithms requires extensive knowledge of computing theory, together with keen biological intuition. A familiar-looking gene sequence does not in and of itself reveal what the function is, or whether it codes for a disease-relevant and drug-tractable target.

Beyond these hurdles, other challenges will need to be addressed. Companies will need to decide exactly how to participate in these new developments - whether to invest in genetics approaches, and how deeply, consistent with their level of risk tolerance. Unprecedented coordination between marketing and R\&D will be necessary. The marketing department will need to have a say in deciding which markets and which genetic diseases $R \& D$ should concentrate on and whether they will need to become involved earlier in the process than in previous circumstances. Finally, careful thought will need to be given to ethical considerations. Companies will have to ensure privacy of genetic material and be prepared to address any concerns the public may have.

\footnotetext{
${ }^{82}$ In analyzing the economic implications of genetics, Tollman, Altshuler, Flanagan, and Steiner (2001) only considered the effect on pharmaceutical R\&D. Genetics is also likely to affect health care far beyond R\&D. In the short term, new market opportunities should arise in the diagnostics sector. In the longer term, generics will transform the delivery of health care. Increasingly, diseases will be redefined into various subtypes - a refinement that should facilitate more appropriate care and more 'rational' drug design. The combination of new diagnostics and tailored drugs may well usher in an era of individualized medicine.
} 


\section{Anticipating new product revenues}

In addition to the high risk of technical failure in pharmaceutical $R \& D$ due to the systematic elimination of candidates based on scientific criteria there is the commercial risk. Revenues generated by those medicines that in the end are successfully placed on the market must offset the R\&D costs. Obtaining the official authorization to market a new pharmaceutical product is by itself no guarantee of commercial success.

Historically, only $30 \%$ of all new drug compounds achieve commercial success, that is, when the current value of their net income generated is greater than or equal to their average R\&D costs (Grabowki, Vernon, 2002). In other words, only three out of ten drugs on the market produce revenues that match or exceed their $R \& D$ cost. Figure 12 shows the decile distribution of present value returns for new medical entities (NMEs) based on the Grabowski \& Vernon study from 1990 to 1994 . The deciles were constructed based on the ranking of 118 NMEs in terms of their individual NPVs of commercial returns. The graph in figure 12 illustrates that the revenue distribution is highly skewed. Products in the top decile bracket have an estimated present value of US $\$ 2.7$ billion. This is almost six times the present value of average $R \& D$ costs (US $\$ 480$ million). In other words, the top decile 'blockbuster' products alone account for about $52 \%$ of the total present value generated by all ten deciles. The second and third deciles still contain present values that exceed the average $\mathrm{R} \& \mathrm{D}$ costs, or US $\$ 1$ billion and US $\$ 0.6$ billion, respectively. However, the fourth deciles' present value is only US $\$ 433$ million in comparison with the average $R \& D$ cost of US $\$ 480$ million. All remaining deciles generate far less revenue. Taken together, 34\%, or about one-third, of NMEs have present values in excess of the estimated average $R \& D$ cost.

The fact that most medicines in the study sample have present values substantially below the fully allocated $R \& D$ cost does not mean that these drugs are economically insignificant. It is still worth obtaining the incremental revenues of the smaller selling products if they can cover their expected variable costs going forward. Whether a product will become a commercial success, is not always clear. Many of the uncertainties that exist for a new product are not known at the beginning of a project, that is its clinical profile in terms of risks and benefits, the introduction of substitute products, or the level of market demand are often not resolved until late in the $R \& D$ process. At that point, however, most of the $R \& D$ costs are sunk. So, over the long run, a firm must have its share of products in the top few deciles to have a viable corporate $\mathrm{R} \& \mathrm{D}$ portfolio. Sales of a few 'blockbuster' medicines are the primary source of financing for all other $R \& D$, and even these revenues fall sharply after the expiration of the patent. Thus, it is during the patent period of commercially profitable new products that a firm must recoup its costs in order to achieve profitability. Understandably, adequate protection of intellectual property is necessary to 
allow innovators to recoup the entirety of investments made in the past. Even then there is no guarantee this will happen.

Figure 12: Present values by decile for 1990 to 1994 new drug introductions

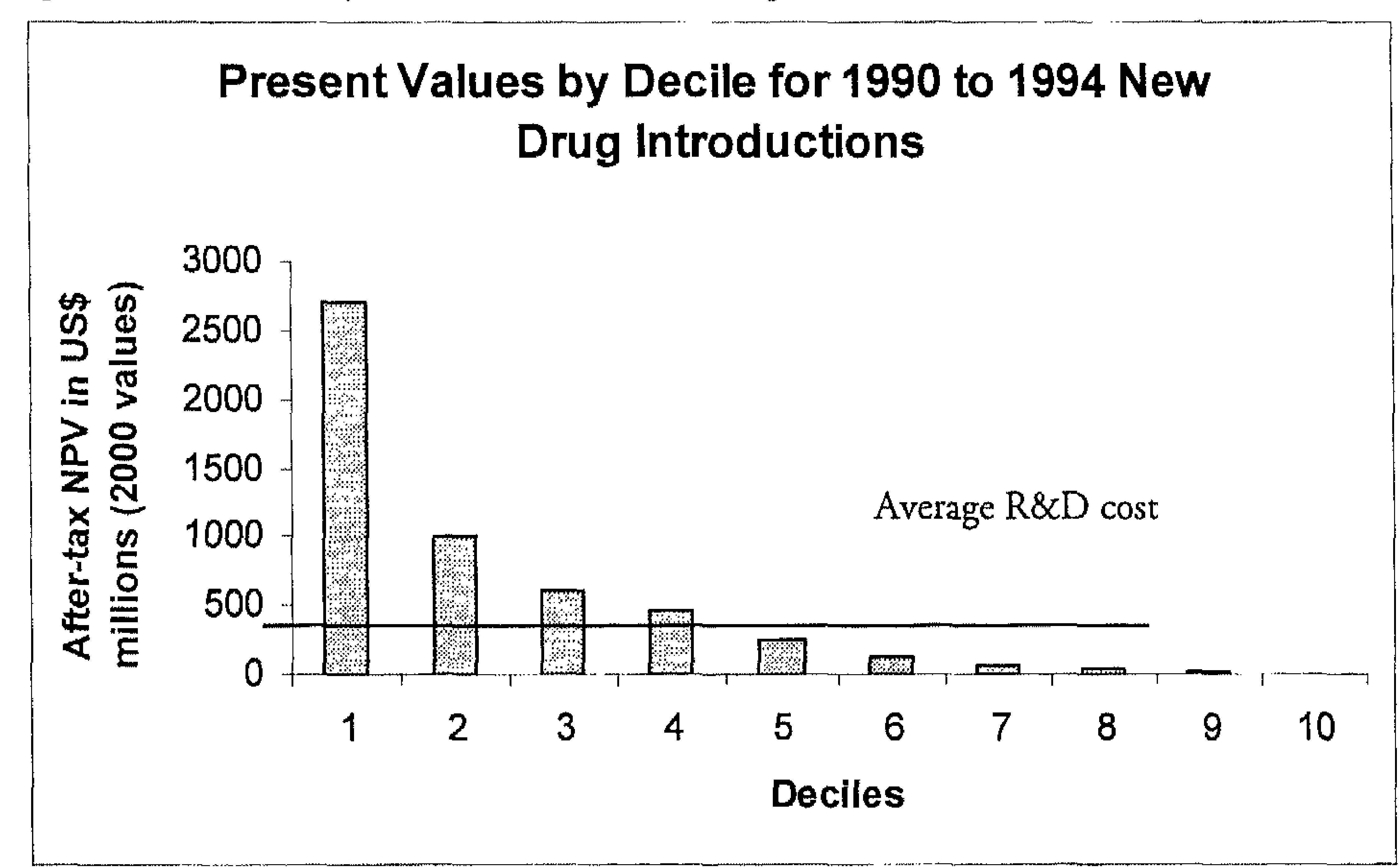

Source: Grabowski, Vernon (2002)

New products 'patent' timeline

Patent law lays down exacting requirements for approval. Patent holders must prove that their inventions are both novel and 'non-obvious', which means a skilled competitor could not derive a similar product from prior efforts. A patented drug must be proven to have a chemical or biological structure sufficiently different from others in its class, or it must provide new or unexpected therapeutic effects. Patented innovations may also include manufacturing improvements, or modifications or changes in the drug's ingredients that have a defined therapeutic or compliance benefit. A single medicine may warrant multiple patents if developers overcame significant hurdles that might have prevented its manufacture or safe or effective use. At the same time, a patent covering an improvement to an existing patented product does not prohibit generic competition against this existing or previous product once the patents protecting the original product have expired. For example, if a company develops a once-a-day dose for the original product and patents the new formulation, generic forms of the original formulation can be marketed so long as the patent on that drug has expired (BIAG, 2005). With this system of protections, products must prove that they are legitimately innovative, yet allow generic competitors to enter the market once patents expire. 
Patents are known to play an important role in the pharmaceutical industry as explained in the previous chapter ${ }^{83}$. The first tier of successful biotech firms (e.g. Genentech, Chiron, and Amgen) all relied on a strong patent base to develop proprietary technologies. The problem concerning pharmaceutical patents is that companies file for patents before the regulatory approval process is complete, effectively reducing the period of patent protection by nearly $50 \%$. This is illustrated in figure 13 . The effective patent life for medicines is estimated in practice to last no more than twelve years, largely because of the lengthy development time and rigorous filing system for a new drug (Grabowski, Vernon, 1996). Significant portions of a new product's patent life have thus passed before the new medicine is approved by FDA or EMEA authorities, and is ready to be launched on the market. It is only then that the company can recoup its investment.

In practice, the period of 'market exclusivity' due to patent protection is even shorter as a result of therapeutic competition due to the introduction of competing products in the same therapeutic class shordy after the launch of the first 'breakthrough' product. For example, major products launched in the late 1980s enjoyed market exclusivity of four to six years, while products launched a decade later could only benefit from six months to two years of market exclusivity (Sykes, 2000). The effective patent life of prescription pharmaceuticals is purposely cut by government policies designed to speed the entry of generics into the market. For example, the 'Bolar' provisions in some countries, allow generic companies to work on a patented substance and to perfect their manufacturing processes during the product's patent life. This has important implications for corporations, as their long-term financial projections are largely based on the expected exclusivity period. As discussed in chapter 3 , calls to forcibly break the related patents on behalf of developing countries, otherwise known as compulsory licensing, could also have serious negative effects on future innovation since they would deprive the patent holder of financial incentives to innovate in the future (Rozek, 2000).

\footnotetext{
${ }^{83}$ The role of patents and their importance to the research-based pharmaceutical industry has emerged in various academic studies. In many other research-oriented industries, like computers and semiconductors, factors such as lead-time and learning by doing were more important means for obtaining returns on R\&D than in pharmaceuticals. In a study by Levin et al. (1987) of 130 separate lines of business, pharmaceuticals ranked among the top few in terms of the importance of patents for appropriating R\&D returns. In a similar study, Mansfield (1986) examined the role of patents for $R \& D$ across different industries. He surveyed the chief research officers of 100 major U.S. corporations and found that $60 \%$ of the innovations commercialized in 1981-1983 by pharmaceutical firms would not have been developed without patent protection. The mean response for all firms across the various industries surveyed was $14 \%$.
} 
Figure 13: Pharmaceutical product patent 'real' timeline

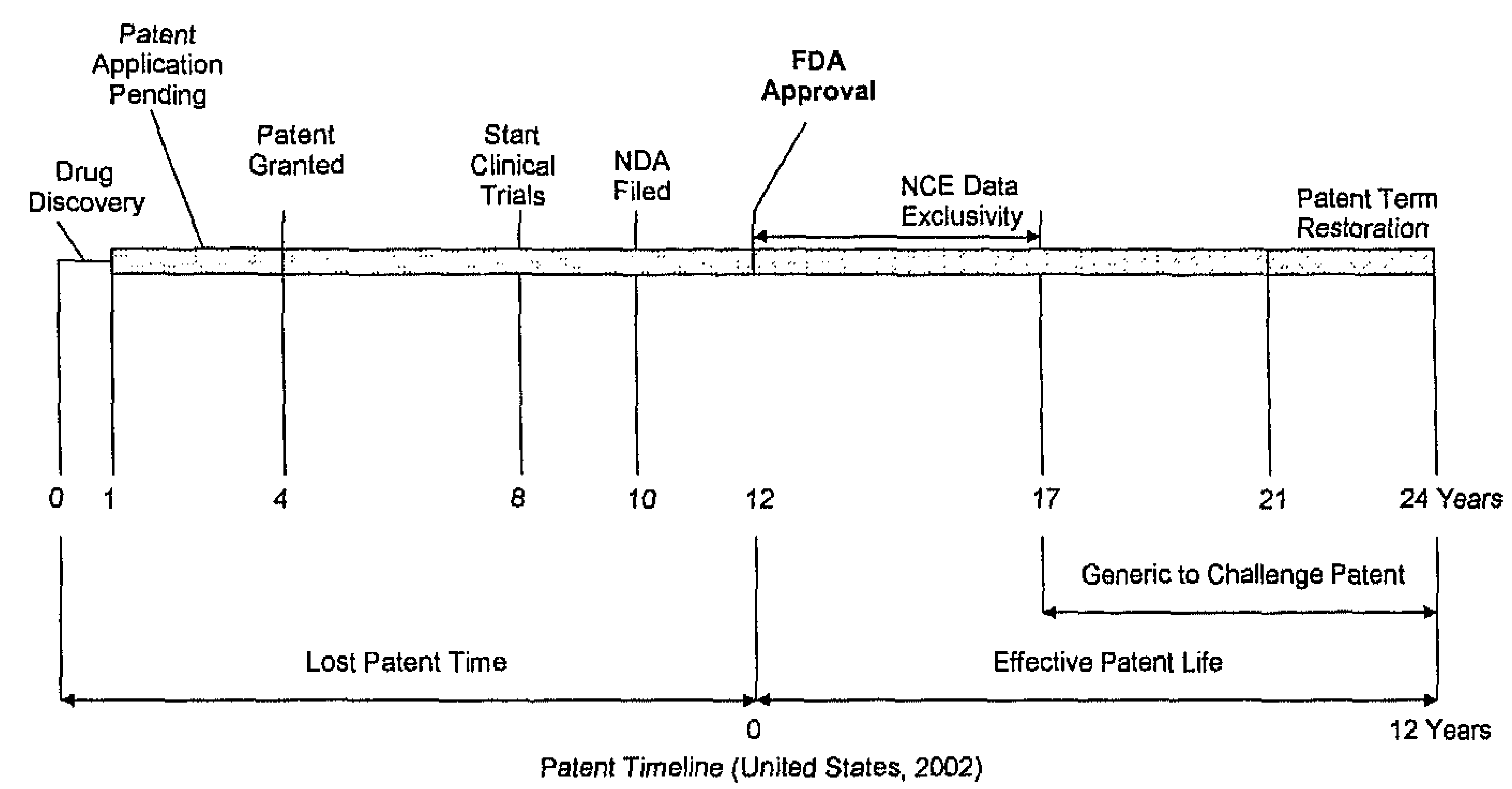

Source: PhRMA (2004)

\subsection{R\&D on neglected diseases through public/private partnership}

\section{Public private technology partnerships}

Funding for $\mathrm{R} \& \mathrm{D}$ can come from the public sector, from the commercial private sector or from foundations. Although the pharmaceutical R\&D model has generated many innovative medicines in the past, it seems to have difficulties taking care of diseases for which there are insufficient market incentives to trigger large private sector investment in $R \& D$ (Mrazek, 2003; Haffner, 2002; Trouiller, 2002; Trouiller, 2001). Corporations are likely to allocate their $R \& D$ spending based on the expected market value for future products ${ }^{84}$. Since market value and the ability of consumers to pay is predominantly from the United States, Europe and Japan, it is hardly surprising that the research agenda for these firms is directed toward alleviating disease-causing conditions in these countries. Diseases for which there is a small commercial potential and for which a market has been created do exist in the industrialized world. They are referred to as 'orphan' diseases and have a low prevalence in those parts of the world (e.g. cystic fibrosis). In the less developed countries, 'orphan'

\footnotetext{
${ }^{84}$ The functioning of the market for medicines in affluent countries depends on patents and regulatory protection, which grant a research-driven manufacturer a temporary period of market exclusivity. This means that manufacturers are able to charge consumers a price high enough not only to cover the cost of production but also the costs of R\&D. By offering the opportunity to charge temporarily higher prices for medicines, market exclusivity acts as a 'pull' mechanism, providing pharmaceutical companies with sufficient incentives to make risky investments, several of which have resulted in life-saving medicines of enormous social value.
} 
diseases are not rare diseases but actually affect millions of patients. They are sometimes referred to as tropical diseases, endemic diseases, neglected diseases, or diseases of the poor (Kettler et al, 2001; MSF, 2001; Reich, 2000), and refer to diseases such as malaria, HIV/Aids, tuberculosis, African trypanosomiasis (sleeping sickness), Chagas disease, dengue, leishmaniasis, schistosomiasis, onchocerciasis and lymphatic filariasis (Remme, 2002; Nossal, 2000; Yarney (2002).

A sustainable solution to alleviating the burden of these diseases in the developing world will only be possible with coordinated action from a broad range of stakeholders and influencers from both the public and private sectors. Public Private Partnerships (PPPs) have been proposed to develop new and improved medicines that are urgently needed in developing countries. Since 1975, the United Nations Development Program (UNDP)/ World Bank/ WHO Special Program for Research and Training in Tropical Diseases (TDR) have coordinated research on a number of neglected diseases. However, by the late 1990 's it became clear that there was a need for additional efforts by disease-focused partnerships, and in recent years we have seen the emergence of a new organizational concept for conducting $R \& D$, known as the 'virtual R\&D' organization (Nwaka, Ridley, 2003). Virtual $R \& D$ originally started in the private sector, as small biotech companies sought to move promising compounds beyond pre-clinical development, but were lacking the expertise and financial means. To address the specific product needs of developing countries, the virtual R\&D model is now being tried in the context of public-private collaboration for product development at the international level (Kettler, Towse, 2002; Nwaka, Ridley, 2003; IPPPH, 2002; Buse, 2000). The past few years have seen the acceleration of new partnerships with the creation of several disease-specific product development programs: The Medicines for Malaria Venture (MMV) and the Global Alliance for TB Drug Development (GATB) are often referred to as examples of the most promising R\&D organizations that have managed to raise the public profile of partnerships and initiate drug development pipelines for two major diseases previously lacking significant $R \& D$ efforts (Nwaka, Ridley, 2003; Wheeler, Berkley, 2001; MMV, 2003; GATB, 2002-2003).

As these few PPP initiatives for product development are still in their infancy, their achievements can be solely. based on the outcomes of intermediate success indicators. Unfortunately, only a small proportion of compounds have reached as yet the later stages of clinical development (i.e. Phases II and III). However, it may be too early to establish wherher this disease-specific product development approach has the potential to match the track record of the market-based model employed by industry, which so far is the only proven way to invent, test, develop and manufacture new compounds. A striking feature of the on-going PDPs is that they are, in effect, conducted in close collaboration with major pharmaceutical companies. For instance, four out of the five new products to be launched for malaria are developed by global pharmaceutical companies, and two of these projects are 
sponsored by MMV (Kettler, Towse, 2002; DND, 2001). This confirms that the most demanding part of drug $R \& D$ cannot be completed without the involvement of experienced companies. These companies have over the years built up a set of critical capacities, know-how and cross-disciplinary expertise in research and product development, regulatory and manufacturing processes that cannot be easily found elsewhere.

Further, when one examines the financial structures of these PDPs, it becomes apparent that these organizations face a major financing gap (Towse, Renowden, 2004). When it comes to addressing important neglected tropical diseases besides malaria and $\mathrm{TB}$, the situation is even worse, with PDPs so far unable to mobilize any of the needed funds. It seems that despite the generosity of a small group of donors and the growing involvement of the private sector, more funds need to be made available within the global health community, to secure, accelerate and sustain important $R \& D$ efforts that are showing promise.

The long-term cycle and statistical reality of new drug R\&D are such that, if these efforts are to succeed, many more projects will need to be initiated. The viewpoint in this book is that the current product development partnerships or PDPs are most relevant for medicines which have absolutely no market in their disease area by virtue of the following facts:

- Pharmaceutical and biotechnology firms that believe that they have identified projects with high expected revenues will be least inclined to seek public sector investments, which would dilute their equity stake and control over their $\mathrm{R} \& \mathrm{D}$ projects. In contrast, those that are least confident about their research prospects will be most inclined to seek outside equity investment and support (Webber, 2003). PDP money should not be directed to supporting these projects.

- Virtual public-private organizations are built on the premise that they are able to accomplish new product development tasks at significantly lower cost. Some organizations like IAVI initially claimed that they would 'dramatically shorten the time necessary from product design to global licensure by several years and at costs as much as $50 \%$ less than with the standard product development paradigms' (IAVI, 2000). These estimates were put forward on the premise that in the PDP concept, various product concepts are tested simultaneously and various stages of the product development process can be done in parallel instead of sequentially. As mentioned previously, shortening development times is an important initiative, but in practice, it will actually require more resources and money, and any short cut taken by the developer will significantly increase project costs and risks.

- Experience has shown that public private collaborations face human resource challenges. The experience of the Children's Vaccine Initiative (CVI) that was launched in 1990 by the WHO in response to the slowdown in development of new vaccines and the poor distribution of existing ones to children, has demonstrated that efforts to bring together public and private sector scientists and organizations to work towards a 
solution were unsuccessful. Muraskin reported ${ }^{85}$ that there was a "great gulf of distrust, often bordering on contempt" between public and private sectors. Public sector scientists viewed their private sector counterparts as being purely profit driven, while the latter saw the public sector as an untrustworthy partner. In 1999, the WHO closed down the CVI.

There is, of course, the alternative that governments themselves create greater drug and vaccine development and production capacities. As discussed before, a better option for governments is to offer the necessary financial incentives to pharmaceutical and biotech corporations in exchange for guaranteed increases in development efforts and the construction of production facilities. Innovative financing initiatives could help mitigate the scientific and commercial risks associated with new drugs and vaccines for diseases of the developing world, and in this way allow the private sector to contribute more to the development of these new technologies. Governments can also promote competition among companies for contracts of this type. This would mobilize the existing skills, expertise and resources within the multinational corporations, as well as in the mature, mid-size biotech companies $^{86}$. The fundamental piece of the puzzle, which is still missing, is the public and political commitment to buy these new medicines on behalf of low-income countries if and when they have been successfully developed by the private sector and/or PDPs. Another alternative is to build innovation systems in developing countries themselves, but this is likely to take time.

\section{Building developing country innovation systems}

To date pharmaceutical innovation is almost an exclusively first world phenomenon. In the period 1997-2001 only 4 out of 184 new molecular entities were developed outside of the European Union, the United States and Japan (IFPMA, 2004). However, together, India, Brazil, India and China account for more than $40 \%$ of the world's population and a substantial proportion of the global disease burden and deaths. Given the growing need for medicines worldwide, it seems reasonable to argue that establishing research-based pharmaceutical industries in emerging economies would benefit patients worldwide and generate important financial rewards for the host countries (Webber 2003, Mytelka 2003).

\footnotetext{
${ }^{85}$ See website of the Center for Global Development: Global Public Health Policy, Vaccines and Growth, October 16, 2005.

${ }^{86}$ Over the past decades, these research-driven companies have built the necessary know how in new medicines development, registration and production, and have invested heavily in infrastructure and training of their labor pool, as well as in state-of-the-arc biomedical equipment and facilities. In addition, Astrazeneca Plc. has a research institute for tuberculosis in Bangalore, India, while Novartis AG and GlaxoSmithKline Plc. are researching drugs for tropical diseases in Singapore and Spain, respectively.
} 
To achieve this, there are significant challenges to overcome. The disease profiles of the populations living in the developing countries are extremely heterogeneous, including diseases formerly only associated with developed countries such as cardiovascular diseases, cancers, diabetes, or neuropsychiatric disorders, as well as poverty related diseases like tuberculosis, dengue fever, Chagas disease, schistosomiasis and lymphatic filariasis. Despite the wider spectrum of diseases encountered in the developing world, these countries could perhaps meet their domestic health needs through improved local pharmaceutical $R \& D$, Some scholars argue that the process of 'endogenous' innovation is much more complex in a developing country context than in a developed country one (Soete, 2008). Likewise, the very process of building international innovation systems will require a re-conceptualization of the catch up process between North and South in more holistic terms (Mytelka, 2003). While the scale at which innovation systems building takes place can remain small, it will require a set of policies and programs to create system-wide knowledge competencies and $\mathrm{R} \& \mathrm{D}$ capabilities.

Mytelka (2003) argues that in science-based and patent-intensive industries there is a need to include broader innovation system properties that are largely absent from the literature on catching up in more traditional industries. Building a (bio)-pharmaceutical innovation system in developing countries requires more than simply learning how to produce a quality drug locally. Although such competences remain important in new wave technologies, they do not provide the stepping-stones to catching-up as they did in earlier periods of technological change. In traditional, engineering-based industries, like the textile, automobile and electronics industries, catching-up critically depended upon deepening production capabilities thereby ensuring that the clones, copies or original equipment manufacturer (OEM) goods were, at the very least, of similar quality and yet initially competitive because of their lower price. There was no need for more domestic $R \& D$ in the early phase of the industrialization process. Adaptation or modification, which led to productivity increase or capital stretching, could largely take place within the firm and through the strengthening of engineering capabilities ${ }^{87}$. In science-driven and patent intensive industries, this process of catching up differs from the traditional incremental process. Opportunities for building technological capabilities incrementally from a low-skill entry point are fewer in sciencebased industries such as (bio)-pharmaceuticals. For example, packaging does not provide a point of entry for catching-up. Reformulation, however, that involves combining an active ingredient with other chemical substances, such as adjuvants, preservatives and antioxidants that enable the product to reach its desired target and changing the form from syrups to

\footnotetext{
${ }^{87}$ The process of catching-up in these industries was thus an incremental one, in terms of the kinds of knowledgebases that were needed, the sequential way in which they would be acquired, and the gradual building up of the systern that enabled the imported rechnologies to function optimally in their new cnvironment (Mytelka, 1999a; Bell \& Pavitr, 1993; Katz, 1985,1976; Kim \& Yi, 1997; Lall, 1990; Pack, 2000).
} 
powders, tablets or capsules, does require new knowledge to ensure bio-equivalency (D'Este, 2002). There will be a period during the catching-up process in which a successful latecomer firm 'learns to learn', a skill that it can later apply to any product or process (Mytelka, 1999a). It also involves the building of problem solving capabilities that enable the firm to improve its productivity to imitate and to adapt products, processes and organizational technologies already developed elsewhere.

The domestic 'demand-side' will have to be brought into the system through the promotion of domestic 'user-producer' links and the development of channels for stakeholder involvement. Broad knowledge about biotechnology and life sciences will be needed in order for policy-makers to design adequate policies and support structures that encourage the promotion of collaborative relationships with partners at home, and to build the bargaining capabilities to negotiate equitable partnerships with those abroad. Collaborative relationships between universities, government research institutes and industry, were already a feature of the Korean innovation system from its earliest reverse engineering phase (Kim and Yi, 1997). Countries such as Korea and China have become models of bargaining from a strong, carefully constructed, knowledge base. Generally, however, LDCs have historically delivered less than $5 \%$ of new medicines. Notwithstanding this fact, a key group of emerging economies are increasingly well positioned to establish their own domestic pharmaceutical industries, and contribute to global pharmaceutical R\&D efforts over time. Countries such as India, China or Brazil are renowned for their human resources in natural sciences and technical disciplines, which provide a solid base for further industrial development. The same countries have also world-class research institutes and technological centers of excellence in such areas as informatics, biotechnology and chemistry; all core skills in pharmaceuticals. A number of these countries also have experience in quality manufacturing of generic drugs and vaccines, active ingredients production and to some extent in the synthesis of new pharmaceutical compounds and downstream clinical trials (Yuthavong, 2001).

Several biotech and pharmaceutical companies from China and South Korea ${ }^{88}$ already participate in joint R\&D partnerships with academic researchers and multinational pharmaceutical companies. Indian generic companies have publicly claimed that they could be financially competitive in new medicines development (Scrip, 2003). Business managers and public officials in developing countries see the key attractiveness of conducting R\&D

\footnotetext{
${ }^{88}$ By virtue of its outstanding human resources and government policies, Korea is emerging as a pharmaceutical innovator in the global arena. By 2002, the Korean pharmaceutical and biotech companies had 78 and 167 drug candidates in development, respectively. Significantly, the great majority of these projects focus on diseases such as cancer, neuropsychiatric diseases, but also osteoporosis, or ulcers and many of them have been already out-licensed to global pharmaceutical companies (Korea Drug Research Association, 2000-2001).
} 
locally as lower costs of manpower and infrastructure, cheaper maintenance of equipment, and availability of raw materials, as well as 'e-technical' scientists. Another important source of competitive advantage for countries like, for example, China may be their particular access to biodiversity and traditional knowledge resources. These resources could be used as a base for development of both a commercialized 'traditional medicines industry' (which is becoming more and more popular among patients in developed countries), and in parallel a 'modern pharmaceutical industry'. Using their natural resources as potentially valuable sources of novel biologically active molecules could facilitate this transition. Chang-Xiao (2002) reported that about 140 new drugs have originated directly or indirectly from Chinese medicinal plants by means of modern scientific methods.

Despite the apparent need for medicine innovation locally, a need that could contribute to finding new solutions to the problem of neglected diseases, not enough is being done fast enough to make it happen in reality. Instead of supporting the key elements required to build an R\&D-based industrial model, many developing countries still promote policies that benefit local, copy-based pharmaceutical industries at the expense of innovation. Switching faster from an industrial policy that promotes imitation to one that advances innovation could carry important social and economic benefits.

In essence, the issue is about the principle of adhering to the TRIPS agreement. Consequently, some corporations have expressed a preference for China over India (Nature, 2007). In terms of talent, India and China have equally brilliant people, but there are issues related to data and intellectual property protection in India that are not amenable to innovative $R \& D$. There is no data protection in India, which means that if one submits a dossier as part of an application for drug approval, it is immediately accessible to all competitor companies. But the biggest factor is the patent situation. When India brought in its Patent Act in 2005 it made its own amendments to the WTO's TRIPS agreement. These amendments essentially provide no patent protection for companies developing innovative drug products, because they do not allow the patenting of incremental improvements, which is often the way that science advances (although precautions have to be taken against 'evergreening': when companies patent several different uses or properties of the same medicine). By contrast, China has taken on board all of its obligations under the TRIPS agreement and it is now a matter of implementing these laws.

It is in this sense that UNDP acknowledged that innovative technological breakthroughs 'are pushing forward the frontiers of how people could use technology to eradicate poverty', as they 'are creating new possibilities for improving health and nutrition, expanding knowledge, [and] stimulating economic growth' (UNDP, 2001). Nevertheless, an important drawback is that pharmaceutical and biotech industries in emerging economies are likely to (first) concentrate their efforts on building future medical product portfolios targeting 
diseases prevalent in the wealthier countries because of the high(er) market value (on which to recoup their investments). This of course creates a disconnect, because the morbidity and mortality patterns seen in the industrialized countries are mainly due to chronic diseases and diseases often associated with lifestyle patterns like, diabetes. In contrast, the leading causes of morbidity and mortality in the developing countries are mainly communicable and perinatal diseases.

Consequently, the gap between market need and product demand, versus product supply experienced in precisely the therapeutic areas most relevant to developing countries will probably not change in the foreseeable future unless additional measures are taken. Firms, whether they are located in the developing or developed countries, are lacking sufficient incentives to enhance R\&D investment and mobilization of resources in R\&D aimed at fighting poverty-related diseases. Thus, for such products to be developed, the public sector or other donors should provide research-based companies with a framework in which there are clear incentives offered to invest in $R \& D$, and harness their invaluable assets for the benefit of the world's poorest populations. A similar problem has been successfully addressed in other disease areas. The incentives offered by governments to invest in 'rare diseases' (encountered in the industrialized world) ranges from tax credits and fast track approvals to extended market exclusivity for other products developed. In this way, both small biotech and large pharmaceutical companies are encouraged and urged to invest in $R \& D$ in what otherwise would have been labeled 'uneconomical' diseases. Arguably, similar frameworks could be created to address diseases that are epidemic or endemic in developing countries and for which new or improved medicines are needed. Of course, the measures employed in such case would have to be tailored to the context of developing country diseases. Instead of offering market exclusivity, for example, which is of little use in developing countries (because of the absence of a functioning market), schemes could include an option of 'transferable market exclusivity' ${ }^{89}$.

Yet, another perhaps even more powerful solution to encourage new medicines $R \& D$ into diseases of the poor is the establishment of a 'pull' mechanism in the form of a 'purchase fund'. This fund could cover a number of diseases concerned, thus creating a 'market' for future medicines developed (Kremer, 2000). Taken together, R\&D 'push' mechanisms like virtual public-private partnerships as well as performance-based 'pull' incentive mechanisms in the form of a 'purchase fund' offer prospects for an efficient way of incentivising the discovery and development of new medicines for poverty-related diseases. These two incentive options are not mutually exclusive as each of them presents a different set of

${ }^{89}$ A pharmaceutical company with, for example, a new Leishmaniasis drug could seek bids from other companies for its exclusive marketing extension right. Such a solution does not require direct public funding and the arising costs could be proportionally distribured among many developed and emerging markets (Bourgeois et al, 2001). 
challenges. The bottom line is that to be successful each will require a visible and sustained commitment from public and private stakeholders.

\subsection{Conclusion}

The process of pharmaceutical innovation is complex, lengthy and fragile in nature - the odds are sometimes overwhelmingly against bringing a new and successful medicine to patients. New product development can take an estimated seven to twenty years to conduct applied research and pre-clinical development, clinical testing, regulatory approval, production, distribution and delivery and at each of the stages, even the most promising candidates can fail to perform as hoped.

The investment costs are prohibitively high. Estimates of the total cost vary from several hundred million U.S. dollars to more than one billion, up to the point of regulatory approval. One reason these estimated costs are so high is that the investments are uncertain: of all the candidate products that enter development, only a small proportion will be successful, and far fewer will become 'blockbusters' that earn a significant return for the company. The decision to develop a pharmaceutical compound is, in effect, the outcome of a series of bets placed and options taken on emerging scientific pathways, based on an analysis of the competitive landscape and some reasonable estimates of the eventual market size and willingness to pay. For companies to stay in business, each successful product has to recover not only the costs of its own design and development, but also the costs of the unsuccessful candidates.

To develop a medicine designed for use in mainly the developing world remains a difficult decision when judged purely on business terms. The market value for medicines in the developing world is tiny compared to the industrialized world. Without an existing viable market to stimulate drug $R \& D$ into diseases of the poor, alternative arrangements are needed to ensure that products are developed, produced on a large scale, and made available affordably and reliably to developing countries. Governments have traditionally used many tools to promote science and technology. Involvement of external partners to share the costs and risks of pharmaceutical R\&D would be a constructive way to address the health problems of poor populations. Public private partnerships in product development (PDPs) led by NGOs have been proposed and tested as an alternative mechanism. But this mechanism does not seem to offer a general and sustainable alternative model. The PDP system necessarily relies heavily on the performance of the industrial partner. The latter could handle the work directly if appropriate incentive systems were created and subsequently applied in practice. To accelerate the development of new medicines for diseases concen- 
trated in developing countries, government donors could make a binding commitment to pay for a desired product if and when it is developed. A mechanism in the form of a purchase fund would create a 'market' for local and transnational corporations by mimicking the situation in the industrialized world.

Finally, new medicines development should not be seen as an industrial asset for rich countries only. A group of leading developing countries with for the moment limited R\&D capacities but a bright future is most likely to benefit from a policy mix supportive of product innovation. This would trigger foreign direct investment and expansion of the domestic pharmaceutical and biotech industry, and result in important social and economic benefits to the host nations. 


\section{Theoretical perspectives on risk-adjusted valuation of pharmaceutical $R \& D$}

This chapter examines theory relevant to the risk-adjusted valuation of $R \& D$ projects in the pharmaceutical and biotech industry. The author's viewpoint is that, in the case of medicines development (drugs, vaccines, and diagnostics), the classical investment analysis tools such as payback rates or discounted cash flow analysis, which are based on a new product's NPV, are not well suited for evaluating complex and risky projects. We describe the theoretical and practical advantages of applying 'real options' theory in evaluating the outcome of pharmaceutical $R \& D$ projects. Real options for advanced technology projects are based on the analogy between a financial stock option and a research-based product development project. Both options give the investor the opportunity to capitalize on future earnings while limiting potential losses. In pharmaceutical $R \& D$ projects, the investment in advanced product development usually depends on specific performance targets achieved at each consecutive stage of the development process. The option to abandon the project at any stage of the process is valuable in managerial decision-making because it allows investors the ability to make investments in stages rather than all up-front. This method fosters more balanced and informed risk-taking as it mitigates the adverse consequences of investing in complex, risky and lengthy projects with uncertain markets. 


\subsection{Introduction}

From the firm's shareholder's point of view, any business strategy should be judged by the returns it generates for the shareholders, as measured by the increase in the company's share price plus dividends. Applied to private sector $\mathrm{R} \& \mathrm{D}$, this means that only those development projects that forecasted discounted cash flows suggest financial returns above those of alternative investments of comparable risk should be funded. Thus, corporate executives working in the pharmaceutical and biotechnology industry are asked to analyze why they would consider investment into a particular research and development project, product portfolio or disease area cluster, profitable.

There are finance methods available to evaluate new research and product development projects. They include payback, internal rate of return (IRR), and net present value (NPV). Traditional valuation and strategy tools such as NPV ignore the importance of flexibility. Yet, pharmaceutical and biotechnology companies must allocate resources among competing opportunities and decide whether to invest in them now, take preliminary steps reserving the possibility for investment in the future, or do nothing. To adequately capture the probability of success as well as the volatility of pharmaceutical and biotechnology R\&D projects, the author proposes the decision analysis approach, which explicitly illustrates the project's technical, market and financial risks. With this method, a decision tree is constructed that fleshes out the entire development process and points out where managerial interventions are needed and options to proceed or abandon the project must be selected.

The advantage of using this methodology is that it will likely reduce investment risk since the option to abandon the new project before it reaches the end of its life is available at consecutive points in time during the entire process. It is therefore important to correctly identify and use the firm's 'risk-adjusted' discount rate of future cash flows. This methodology will provide the basis for developing a computer-assisted simulation program that supports managers in making investment decisions in pharmaceutical $R \& D$. The 'riskadjusted' investment model proposed in this book will provide a more accurate and dynamic managerial tool compared to other, more traditional valuation tools currently being used. 


\title{
5.2 Payback, IRR, and NPV discounted cash flow analysis
}

\author{
The payback decision rule
}

The payback method is the simplest of all capital budgeting decision tools. It enjoys widespread use, and is a recurring theme in textbooks on corporate finance (Smart, 2004; Hirschy, Pappas, 1999; McGuigan, Moyer, Harris, 1999). The payback method is defined as the amount of time it takes for a given project's cumulative net cash inflows to recoup the initial investment. If the individual/organization decides that it wants to avoid any investment that does not 'pay for itself' in, for example, three years or less, then the payback decision rule is to accept projects with a payback period of three years or less, and reject all other investments. If several development projects satisfy this condition, then firms prioritize their investments based on the ones that will achieve payback more rapidly. It should be noted, that the decision to use three years as the cutoff point is arbitrary, and there are no hard-and-fast guidelines that establish what the 'optimal' payback period should be.

The appeal of the payback method is strong. It sounds reasonable to expect a good investment to pay for itself in a fairly short period of time. Furthermore, by requiring projects to earn back the initial cash outlay within a few short years, the payback approach appears to take into account the time value of money, at least in a rough sense. However, despite its apparent virtues, the payback method suffers from several serious problems. First, the payback cutoff period is an arbitrary choice with little or no connection to stakeholder value maximization. How can we be sure that accepting projects that pay back within three years maximizes shareholder wealth rather than projects that pay back within two years or five years? Secondly, the way that the payback method accounts for the time value of money is crude in the extreme. The payback method assigns a $0 \%$ discount rate to cash flows that occur before the cutoff point. That is, if the payback period is three years, then cash flows that occur in years 1,2 , and 3 receive equal weight in the payback calculation. Beyond the cutoff point, the payback method implicitly assigns an infinite discount rate to all future cash flows. Thirdly, using this payback period as a way to control project risk is equally crude. If it is true, as is sometimes argued, that riskier projects have longer payback periods, then the payback rule simply rejects all such investments, whether or not they offer higher returns in the long run. Managers who naively follow the payback rule will tend to under-invest in long-term projects that could offer substantial rewards for the firm's stakeholders. 


\section{The internal rate of return}

The above payback method clearly suffers from a complete or partial failure to make adjustments for the time value of money and for risk. However, alternative methods that correct these shortcomings exist. Perhaps the most popular and most intuitive of these alternatives is known as the internal rate of return method. The IRR of an investment project is the compound annual return on the project, given its up-front costs and subsequent cash flows (Smart, 2004). Thus, a project's 'IRR' is the discount rate that makes the net present value of all project cash flows equal to zero. To find a project's IRR, one must begin by specifying the project's cash flows. Next, the discount rate that equates the present value of cash flows to zero can be found using a financial calculator, spreadsheet, or even trial and error. Once the IRR is calculated, it is compared to a pre-specified hurdle rate established by the firm. The hurdle rate represents the firm's minimum acceptable return for a given project, so the decision rule is to invest only if the project's IRR exceeds the hurdle rate.

How do firms decide whether to require projects that exceed a $10 \%$ or $20 \%$ hurdle? In principle, the company should set the hurdle rate at a level that reflects market returns on investments that are just as risky as the project under consideration. If the project at hand involves, for example, expanding a pharmaceutical or biotech firm's new product portfolio, then the hurdle rate should reflect what other companies offer investors in the market place. So, the IRR method establishes a hurdle rate or decision criterion that is market based, unlike the payback approach that establishes arbitrary thresholds for investment approval. The advantages of IRR over the payback method are actually threefold: (1) The method makes an appropriate adjustment for the time value of money. In other words, the value of money received in the first year is greater than the money received in the second year, and even cash flows that arrive several years in the future receive some weight in the analysis (unlike the payback approach, which totally ignores distant cash flows); (2) The hurdle rate is based on market returns obtainable on similar investments. This removes some of the subjectivity that creeps into analytical methods like the payback method where arbitrary threshold decisions must be made. In addition, it forces managers to make explicit, quantitative adjustments for the differences in risk as seen across projects; Lastly (3) since the 'answer' that arises from an IRR analysis is a rate of return, its meaning is easy for both financial and non-financial managers to grasp intuitively.

The innate appeal of the IRR technique does have its drawbacks, particularly when ranking investments with different IRRs. These intrinsic difficulties come into play when managers must discriminate between mutually exclusive new product investment projects. That is, how does the firm decide where to invest when several investments exceed the hurdle rate, but of which only a subset can be undertaken at any given time? Unfortunately, it turns out 
that selecting the projects with the highest IRR, can lead to bad decisions in certain cases. Prior research has shown that a naive reliance on the IRR method can lead to investment decisions that may favor investments with short-term payoffs over those that offer returns over a longer horizon (Lumby, Jones, 2001; Smart, 2004).

\section{The net present value}

A project is defined as having a positive NPV if the present value of the cash inflows (i.e. future profits) exceeds the present value of the cash outflows (i.e. today's investment). The advantage of the NPV method is that determining the present value of an investment project is relatively straightforward. First, one writes down the net cash flows that the investment will generate over its life; Second, the cash flows are discounted at an interest rate that reflects the degree of risk inherent in the project. The resulting sum of discounted cash flows equals the project's net present value. This NPV calculation is mathematically expressed by the equation:

$\mathrm{NPV}=\mathrm{CF}_{0}+\mathrm{CF}_{1} /(1+\mathrm{r})^{1}+\mathrm{CF}_{2} /(1+\mathrm{r})^{2}+\mathrm{CF}_{3} /(1+\mathrm{r})^{3}+\ldots \ldots+\mathrm{CF}_{\mathrm{N}} /(1+\mathrm{r})^{\mathrm{N}}$

In this expression, $\mathrm{CF}_{\mathrm{t}}$ represents net cash flow in year $t ; \mathrm{r}$ is the discount rate; and $\mathrm{N}$ represents the life of the R\&D project. The NPV decision rule says to invest in projects when the net present value expressed in monetary units is greater than zero, i.e.:

$$
\begin{aligned}
& \text { NPV }>\text { Euro } 0 \Rightarrow \text { Invest } \\
& N P V<\text { Euro } 0 \Rightarrow \text { Do not invest }
\end{aligned}
$$

This NPV rule generally leads to good investment decisions. Conceptually, the discount rate, $r$, in the NPV equation represents the opportunity cost, the highest rate of return that investors can obtain in the marketplace on an investment with risk equal to the risk of the specific project. So, when the NPV of a cash flow stream equals zero, that stream of cash flow provides a rate of return exactly equal to shareholders' required return. Hence, when a firm can find a project with a positive NPV, the project offers a return that exceeds shareholders' expectations. Therefore, the NPV method seems to resolve all the problems identified in relation to the internal rate of return method and the investment payback decision rule, such that:

- The NPV rule focuses on cash flow, not accounting earnings.

- When properly applied, this net present value method makes appropriate adjustments for the time value of money.

- The decision rule to invest when NPVs are positive and to refrain from investing when NPVs are negative reflects the firm's need to compete for funds in the marketplace rather than an arbitrary judgment of management. 
- The NPV approach offers a relatively straightforward way to control for differences in risk among alternative investments. Cash flows on riskier investments should be discounted at higher rates.

- The NPV method incorporates all the cash flows that a project generates over its life, not just those that occur in the project's early years.

- The NPV gives a direct estimate of the change in shareholder's wealth resulting from a given investment.

Consequently, scholars in finance and economics, as well as practicing managers have been enthusiastic supporters of the NPV approach (Lumby, Jones, 2001; Hirschy, Pappas, 1999; McGuigan, Moyer, Harris, 1999; Mansfield, 1999; Roberts, 1994). However, the NPV rule has also some significant weaknesses. An important drawback may result from its inability to incorporate the value of managerial flexibility when calculating a project's NPV (Boer, 2003; McGrath, MacMillan, 2000). Indeed, the NPV method (like every other method examined so far) does a relatively poor job of capturing the value of managerial flexibility, that is the value of options open to managers to improve the return on investments after they have been made. To incorporate this value into the investment analysis requires a more sophisticated approach that relies on the principles of options pricing theory.

\subsection{Options pricing theory applied to valuation of $R \& D$ projects}

Options pricing theory

The classical NPV method is considered to be the standard tool for evaluating capital investments. However, as stated previously, it can systematically understate the value of particularly risky investments in R\&D. These systematic errors occur because the NPV method is essentially static. That is, NPV calculations do not take into account actions by managers to increase the value of an investment once it has been made. When managers are able to react to changes in the environment in ways that alter an investment's value, we say that the investment has an embedded 'real option'. A real option is therefore similar to a financial option contract. It is a limited investment commitment with an uncertain payoff that conveys the right, but not the obligation, to make further project investments should the payoff look attractive. If the company decides not to make further investments, the option expires, but all that is lost is its price (McGrath, MacMillan, 2000) ${ }^{90}$. At any mo-

\footnotetext{
${ }^{90}$ Examples of what are commonly termed real options, in recognition of their formal equivalence to traded financial options, include: "(1) the option to defer the investment to a later date; (2) the option to abandon an
} 
ment, however, management can change the nature or the scope of the investment in response to information not known at the time of the original decision. Real options therefore enhance the original investment value because they give management the right, but not the obligation, to undertake future activities.

Various experts in new product innovation and strategic portfolio management have recognized the similarity between a stock option and an $\mathrm{R} \& \mathrm{D}$ project (Loch, Bode-Greuel, 2001; McGrath, MacMillan, 2000; DeAngelis, 2000; Faulkner, 1996). They are particularly attracted to the concept because both give the investor the opportunity to capitalize on future earnings while limiting the potential loss. $R \& D$ projects, like stock options, with a large variance in expected returns are more attractive than those with a small variance, given that both projects have equal average returns. Projects with a larger variance have the potential of a much larger payoff at no additional cost (and if they fail, the loss is limited to the R\&D investments made at that particular stage in the new product development process). Scholars therefore recommend using financial options theory wherever possible in $R \& D$ valuation.

\section{Black-scholes option model}

To date, the most widely accepted financial option model is the Black-Scholes model (1973). A number of industrial firms including pharmaceutical companies have applied it to their R\&D projects (Copeland, 2004; Nichols, 2000; Newton, 1994; Sender, 1994; Ross, 1991). Brealey and Myers were among the first to recommend using the BlackScholes formula for the valuation of proposed R\&D investments (Brealey, Myers, 1988).

The major advantage of Black-Scholes is that the computation of the value of the option is quick and easy. The formula itself is complex, but it can be programmed into a computer, and published tables exist in finance books to allow an easy 'look-up' of Black-Scholes values. However, the complexity of the formula means that Black-Scholes appears to be a 'black box' to most managers. The mathematical manipulations are not easily understood and the results are often counter-intuitive (Faulkner, 1996). This is considered a significant barrier to the acceptance of Black-Scholes variations. A second set of issues that arise are the assumptions made by the Black-Scholes approach. For example, the model assumes that the future value of the stock, or in the case of $R \& D$, the value of the cash flows received if the $\mathrm{R} \& \mathrm{D}$ results are implemented, is distributed lognormally and cannot be negative. How-

investment if cash flows do not meet expectations; (3) the option to modify the scale of operations as demand varies; (4) the option to alter the mix of inputs as raw material prices change; (5) and the option to make followon investments if the initial investment is deemed successful like in R\&D" (Higgins, 1998). 
ever, this may not be the case with every R\&D project. Trigeorgis $(1999,1993)$ discussed this problem of determining the value of the underlying asset for a real option. Essentially, if the underlying asset is not traded in the market (as is the case for $R \& D$ projects), it is difficult, if not impossible, to establish its value. In addition, the author emphasizes that the volatility in the Black-Scholes model is derived from the 'price relative' (final stock price divided by initial stock price), and obtained from historical data, which does not usually exist for $R \& D$ projects.

Rather than using a classical option model like Black-Scholes, several authors advocate using a decision tree analysis to approach the problem. Morris, Teisberg and Kolbe (1991) have described how investment projects with negative net present value can have a positive value when the option to abandon is incorporated in the model. They have illustrated this for projects where the net cash flows are normally distributed. Other authors have used similar approaches (Boer 2003; Faulkner, 1996; Dixit, 1995). The advantage of their binomial approach is that it may eliminate the need to make some of the possibly unrealistic assumptions required by the Black-Scholes model. However, it still requires management to estimate the distribution of the net cash flows. While this may look straightforward, it is more likely that management will have access to two separate estimates for calculating cash flows: (1) production and marketing costs; and (2) anticipated revenues. As a consequence, DeAngelis (2000) proposes a model based on the underlying distribution of costs and revenues rather than net cash flows. Furthermore, Morris, Teisberg and Kolbe (1991) have suggested combining the two uncertainties of costs and revenues into one probability model that then describes a project's net benefits (i.e. revenues minus costs).

Thus, there are situations in which options pricing theory may provide a better basis for the valuation of new product development projects than the traditional discounted cash flow techniques. Like a stock option, an R\&D project gives the owner the right, but not the obligation, to receive benefits in the future. While stock options allow the owner to buy stock in the future at some stated price (striking price), R\&D options would allow managers to implement the results of $R \& D$ some time in the future. Both options require the owner to make two separate types of decisions. The first decision is whether to buy or not to buy the option (or invest in the R\&D project). This depends on the value of the option (i.e. project) which is based on estimates of uncertain future benefits. And while the buyer may not know exactly what these future benefits will be, he/she can model the range and likelihood of these benefits using a probability density function. The second decision must be made some time in the future when the option expires or, in the case of R\&D, when the $R \& D$ project is completed. At that moment, the manager has the option to invest in production and marketing, or terminate the project if the results are not promising. 
Special features of the pharmaceutical $R \& D$ process include uncertainty due to the volatility encountered in developing country markets and delays in health policy decision-making influencing the adoption and diffusion of new technology in the marketplace, as well as irreversibility due to the large up-front sunk costs of research and development, and the flexibility to postpone if necessary further investments into advanced clinical testing and building of production capacity. These make standard investment rules relying on the NPV inappropriate because they treat investment opportunities as 'once-and-for-all' chances. As a consequence, the NPV method ignores the options involved in the sequence of managerial decisions to be made.

As an example, Pindyck (1993) presents a case where an investment of US $\$ 1$ is required at first, after which there is a probability of $50 \%$ that the project will be finished successfully. However, there is also the chance that another investment of US\$4 will be necessary to complete the project. The completed project will have a certain payoff of US $\$ 2.8$, so with an expected cost of US $\$ 3$ (i.e. US $\$ 1+0.50$ (US\$4)), the NPV is negative (-US\$0.2) and the traditional NPV rule would advise not to invest. More precisely, though, the investor would take into account that he has the option to abandon the project after phase one and so the NPV adjusted for the option value is 0.50 (US $\$ 2.8$ )-US $\$ 1=$ US $\$ 0.4$, which is greater than zero, so at least the first phase should be undertaken. The option value can then be calculated as the difference between the traditional and the adjusted NPV that is US $\$ 0.60$. It is important to note that the term 'option' in this context should not be understood as a synonym for choice or alternative. An option as it is meant here is the right, but not an obligation, to realize an investment opportunity.

Thus, the NPV calculation method not only undervalues investment in pharmaceutical $R \& D$ projects vis-à-vis Real Options, but it actually gives investors the opportunity to defer the next stage of an investment. The 'opportunity' to defer any further investment into the project as an 'option' means that one can assign a value to 'waiting'. In other words, investors may gain more information about the uncertainty that surrounds important economic decisions as time passes. For example, they may expect LDC governments to build up adequate health delivery systems and/or OECD donations and external funding to arrive over time. Therefore, staying flexible by postponing decisions has an option value to private investors if the degree of uncertainty faced is big enough. This value increases if the sunk cost that has to be incurred to launch the project is high, but also in times of larger uncertainty associated with future cost or revenues. Indeed, in this case, it pays off to wait and see how the conditions have changed, especially if they are expected to be rather stable afterwards. 
In order to demonstrate the principles of the approach, consider an investor who can postpone the decision to further invest in a particular project (which is the case for pharmaceutical $R \& D$ because it is largely a sequential process). Furthermore, the value of the investment is uncertain, and once committed, the cost of the investment cannot be recovered anymore. This implies that the investor can possibly gain by waiting until some of this uncertainty is resolved. Put differently, there is a so-called 'wedge' between the standard NPV of a project - i.e. the value of the project considering the investment as a 'once-andfor-all' opportunity - and the current value of the project to the investor taking into account the possibility of deferring the investment to a later point in time. Let us assume that $\mathrm{V}$ is the present value (PV) of the project to be undertaken and $\mathrm{C}$ is the cost of the investment made, where $\mathrm{V} \geq \mathrm{C}$. Subsequently, the expected PV of the option to invest can be maximized, and the option value is denoted by a function $F(V)$ (Pindyck, 1991):

$\mathrm{F}(\mathrm{V})=\max _{\mathrm{t}} \mathrm{E}\left\{\mathrm{e}^{\mathrm{r.t}} \cdot(\mathrm{V}-\mathrm{C})\right\}$

In this equation, $r$ is the discount rate, and Fuss (2008) recommends that time $(t)$ is chosen so as to maximize the expected value of the project. The expected return from postponing the investment is $E\{d F(V)\} / d t$, which has to be equal to the opportunity cost of postponing. This opportunity cost of postponing is the interest that could be earned on $F(V)$, which is received upon investment. This leads to the following arbitrage equation:

$E\{d F(V)\} / d t-r . F(V)=0$

Intuitively, this formula equates the marginal costs of waiting with the marginal benefits of doing so. To solve the equation, the $F(V)$ needs to be differentiated and the corresponding boundary conditions defined ${ }^{91}$. According to Fuss (2008) this leads to the conclusion that under uncertainty the value of the project at the exercise date must exceed the mere cost of the investment.

To illustrate the principles presented graphically, consider figure 14, where the value of the project increases with time (may be due to rising output prices subsidized by OECD countries). The option value, denoted by $\mathrm{F}(\mathrm{V}(\mathrm{t})$ ), starts out at zero because it can never be negative, as the investor can always choose not to exercise the option, i.e. $F(V(t)=0$. In contrast, the standard NPV can very well be negative, as long as the cost of exercising the option, $C$, exceeds the current value of the project, $V(t)$. Investment under the standard NPV rule therefore occurs where $(V(t)-C)$ crosses the $x$-axis, i.e. where $V(t)=C$. The option value $\mathrm{F}(\mathrm{V}(\mathrm{t}))$, however, is higher than the simple NPV, since the 'wedge' in the

91 To find the solution to the differential equation, we refer to Fuss (2008); p.30-35. 
equation exceeds 1 . The optimal exercise time therefore is at the point where the $F(V(t))$ curve crosses the $(\mathrm{V}(\mathrm{t})-\mathrm{C})$ schedule; which is much later than the optimal point in time where the NPV is applied. More precisely, what can be gained from waiting can be measured as the vertical difference between $F(V(t)$ and $(V(t)-C)$. At the point where $(V(t)-C)$ crosses the $x$-axis, $F(V(t)>(V(t)-C)$, the benefits of waiting are larger than zero. As $(V(t)$ $-C)$ continues to rise, however, these benefits diminish and it is optimal to invest when $F(V(t))=(V(t)-C)$.

Figure 14: Option to postpone corporate investment in R\&D on LDC diseases

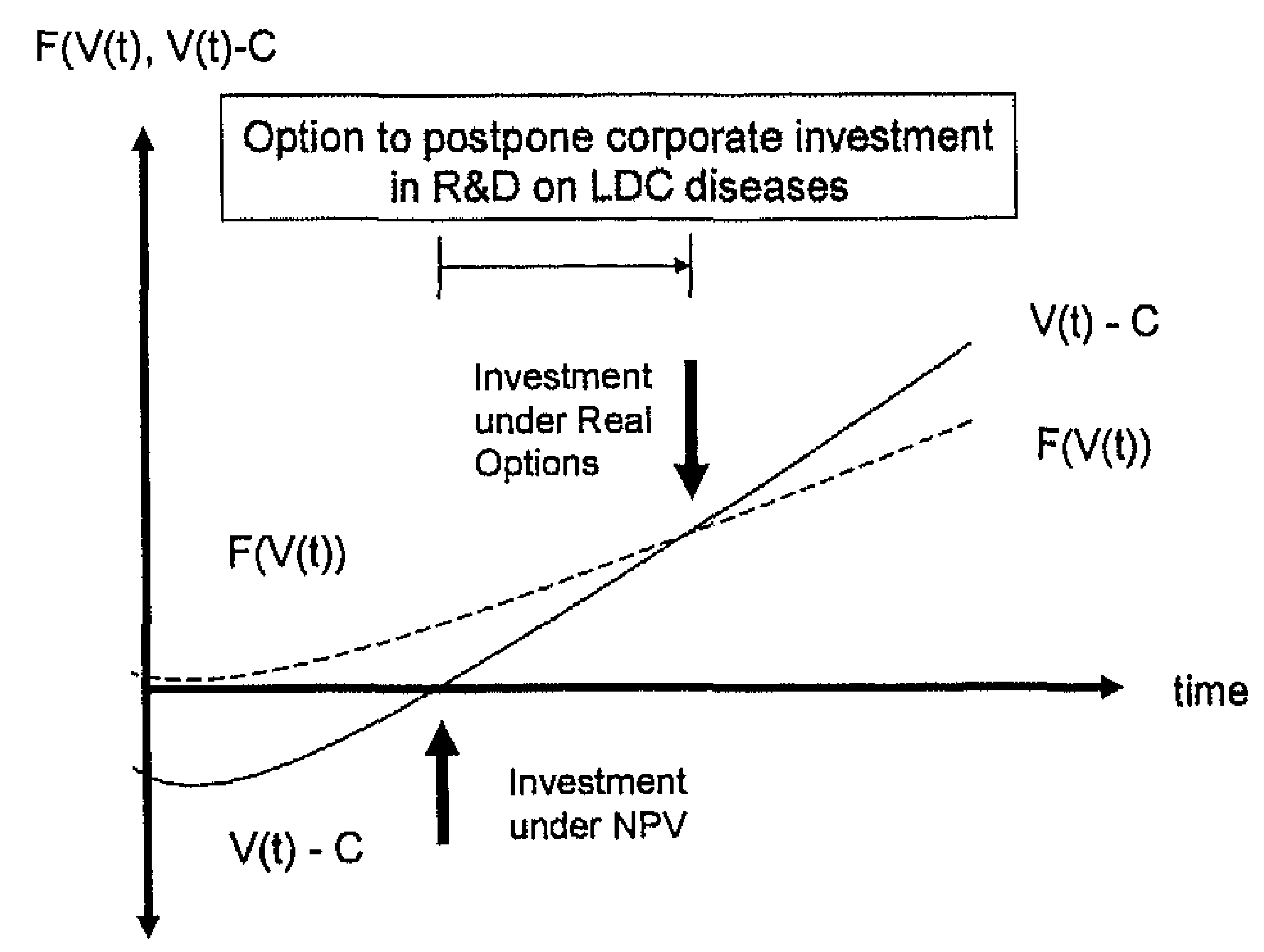

The optimal exercise time occurs later with an option value rule than with a standard NPV criterion

In conclusion, to avoid the wait-and-see situation in pharmaceutical $\mathrm{R} \& \mathrm{D}$ investment concerning developing world diseases, donor governments not only need to commit to sponsoring these projects but their commitment needs to be transparent, announced early and binding in order to create a climate for industrial investment in otherwise costly and uncertain projects. The alternative is that these projects may otherwise not be initiated or finished because firms may opt to bail out.

\subsection{Risk-adjusted discount rates and the firm's cost of capital}

\section{Risk-adjusted discount rates}

Determining the correct discount rate for the calculation of the present value of future cash flows usually poses a problem to managers regardless of whether they use the NPV or Real 
Options method. The minimum that a shareholder of, for example, a pharmaceutical company, expects from the business activities of the firm is to generate at least the same return as would be obtained by investing into a comparable stock. The return on a comparable stock can therefore be considered as a benchmark for the business activities of the respective industrial sector. Thus, from the shareholder's perspective, the discount rate represents the rewards they would expect from investing and accepting risk, whereas from the company's perspective the discount rate is the cost of capital with which the company's business investments are funded.

The most common way of calculating the 'risk-adjusted' discount rate is to add an increment to the basic rate, that is, discount the expected value of the risky cash flows at a discount rate that includes a premium for risk (Roberts, 1994). Generally, the greater the risk as perceived by its investors, the greater the return investors will require. It should be emphasized, however, that risk in this context means capital market risk, and not the technical and marketing risks related to a particular $R \& D$ project. As a result, the firm's cost of capital is determined in the capital market. And the capital market risk is defined as the volatility of a security's market value relative to the volatility of the market values of all securities. Finally, the expected return for a certain security with respect to its specific risk can be calculated by the capital asset pricing model (CAPM).

\section{Capital asset pricing model}

Historically, investments that have offered the highest average returns have displayed the greatest volatility (Higgins, 1998). This positive relationship between returns and volatility seen in historical data does make sense in a world populated by risk-averse investors ${ }^{22}$. If riskier investments did not offer the prospect of higher returns, they could not survive in the market. However, a measure of risk volatility (as measured by the variance or standard deviation of returns) has serious flaws, but investors can easily eliminate some of the assetreturn fluctuations through diversification ${ }^{93}$. Nevertheless, investors are particularly concerned by the systematic risk and the volatility that cannot be eliminated through diversification. Hence, asset pricing models attempt to quantify this systematic risk. Most importantly, these models attempt to determine the rate of return that investors may expect as a compensation for bearing this systematic risk.

\footnotetext{
${ }^{92}$ Risk aversion is defined as the desire to avoid or minimize uncertainty; risk-seeking on the other hand is a preference for speculation.

${ }^{93}$ Unsystematic or diversifiable risk is principally caused by company-specific factors (such as for example labor relations and management quality) which affect the performance of a company's cash flow. Such effects will be washed out in a well-diversified portfolio.
} 
'Beta' is the most popular metric for capturing an investment's systematic risk. It is a standardized measure of the risk of an individual asset; one that only captures the systematic component of its volatility. Beta (B) measures the sensitivity of an investment's return to fluctuations in the overall market. Investments with below-average levels of systematic risk have betas (slopes) below 1.0 and those with above-average systematic risk have beta's greater than 1.0. In other words, high-beta investments would increase the systematic risk exposure of a portfolio, while low-beta investments decrease it. Therefore, if investors concern themselves only with systematic risk and if beta measures that risk accurately, then we should anticipate a positive relationship between beta and returns $s^{94}$. The implication is that any measure of an asset's systematic risk exposure must capture how it covaries with the rest of the market (Smart, 2004). In other words, the higher the beta of a security, the greater the security's exposure to systematic risk and the higher the expected return it must offer to investors. According to the CAPM model, the equilibrium expected returns of all securities must plot on a straight line, called the security market line (SML). This is illustrated in figure 15. The linear equation illustrates that the expected return on a specific asset, $E(\mathrm{Ri})$, equals the risk-free rate (Rf) plus a premium that depends on the asset's beta, Bim, and the expected risk premium on the market portfolio, $E(\mathrm{Rm})-\mathrm{Rf}$.

$E(R i)=R f+B i m(E(R m)-R f)$

Where:

$E(R i)$ is the expected return on the capital asset

$\mathrm{Rf}$ is the risk-free rate of interest

B im (the beta coefficient) the sensitivity of the asset returns to market returns, or also

$\beta \mathrm{im}=\operatorname{Cov}(\mathrm{Ri}, \mathrm{Rm}) / \operatorname{Var}(\mathrm{Rm})$

$E(R m)$ is the expected return of the market

$E(R m)-R f$ is sometimes known as the market premium or risk premium (the difference between the expected market rate of return and the risk-free rate of return).

Note 1: the expected market rate of return is usually measured by looking at the arithmetic average of the historical returns on a market portfolio (i.e. S\&P500).

Note 2: the risk free rate of return used for determining the risk premium is usually the arithmetic average of historical risk free rates of return and not the current risk free rate of return.

In conclusion, the CAPM captures the essence of the relationship between risk and return on the stock market. Beta (B), representing equity risk, plays a central role in the calculation

\footnotetext{
${ }^{94}$ This is the crux of the capital asser pricing model (CAPM). The model predicts a positive, linear relationship between expected return and beta.
} 
of the expected return on equity. However, an R\&D project's value cannot be estimated the same way as a share's beta value. One possible approach to solving the problem is to use the beta value of the industry within which the project could be classified as a surrogate for the beta value of the project. This industry beta value would be an average of the firms within that industry. And beta values are regularly published for respective industry sectors ${ }^{95}$. Thus if the project under appraisal was expanding a pharmaceutical production facility for global use, the average beta value of the quoted companies in the pharmaceutical industry could be taken as an estimate of this project's beta. Some adjustments might need to be made to the $\beta$ value obtained in this way, if the project's systematic risk characteristics differ from those of the pharmaceutical industry. For example, Myers et al (1996) demonstrated that biotechnology companies have systematically higher betas than the more mature pharmaceutical companies, and in turn more immature biotechnology companies seem to have higher betas than the mature ones ${ }^{96}$. As such, 'pure play' R\&D biotechnology companies have a consistently higher risk for diversified investors compared to large, multinational pharmaceutical companies.

\section{Weighted average cost of capital}

Most companies are not only financed by equity but also by debt. Consequently, for investment decisions, the discount rate applied must represent the project's overall cost of capital rather than the cost of equity alone. Therefore, an extended equation must be applied, termed the weighted average cost of capital (WACC). It is the weighted average of the required rates of return on debt and equity, where the weights equal the percentage of each type of financing in the firm's overall capital structure:

$W A C C=\left(\frac{D}{D+E}\right) R_{d}+\left(\frac{E}{D+E}\right) R_{e}$

$\mathrm{D}$ and $\mathrm{E}$ represent the market value of the firm's debt and equity securities, respectively, and $R_{d}$ and $R_{e}$ represent the rate of return that investors require on bonds and shares. For most pharmaceutical firms, debt securities account for less than $10 \%$ of the market value,

\footnotetext{
${ }^{95}$ Estimares are regularly published by brokerage and advisory services. They are found by recording the change in the prices of stocks versus the changes of the average market on a monthly basis over four to seven years. A wellknown example is the Standard \& Poor's 500 guide in which the actual B values for companies traded on U.S. stock exchange markers are released in yearly intervals.

${ }^{96}$ Biotechnology companies were classified into three tiers. Tier one consisted of the mature biotechnology companies that have at least one drug in the market. Tier two comprises firms with medicine candidates close to or at an advanced stage of clinical testing. Tier three are firms that are only R\&D driven and are not yet close to having a product.
} 
so that the equity cost of the capital component is the dominant element of the weighted cost of capital for this industry (DiMasi et al, 2003).

Firms that use WACC to value real investments should be aware that a higher WACC value means that investments have to pass a higher hurdle before they generate shareholder wealth. DiMasi et al (2003) computed the appropriate WACC for the pharmaceutical industry based on a representative group of firms (in the USA). They found that between 1985 and 2000, the nominal cost of capital for these pharmaceutical firms had remained relatively stable ranging between $14-16 \%$, with a mean of approximately $15 \%$. In addition, DiMasi et al (2003) also undertook an informal survey among major pharmaceutical firms in mid-2001 to discover the hurdle rate used by companies in their $R \& D$ investment decisions. This survey comprised of six firms and yielded nominal hurdle rates from $13.5 \%$ to over $20 \%$. The authors concluded that a $15 \%$ nominal cost of capital rate is within the range of hurdle rates utilized by pharmaceutical firms for evaluating $R \& D$ investments. Ultimately, to obtain the real cost of capital, the expected inflation rate must be subtracted from the nominal cost of capital. Consequently, the real cost of capital for the pharmaceutical industry using the CAPM model, varies from $10.6 \%$ to $11.9 \%$, and the mean cost of capital is just over $11 \%$ - see table 3 . As a result, $11 \%$ can be used as the discount rate, or hurdle rate, in the valuation of pharmaceutical $R \& D$ projects.

Table 3: Nominal and real cost-of-capital for the pharmaceutical industry (1985-2000)

\begin{tabular}{lrrrr}
\hline & 1985 & 1990 & 1994 & 2000 \\
\hline Nominal COC (\%) & 16.1 & 15.1 & 14.2 & 15.0 \\
Inflation rate (\%) & 5.4 & 4.5 & 3.1 & 3.1 \\
Real COC (\%) & 10.8 & 10.6 & 11.1 & 11.9 \\
\hline
\end{tabular}

\section{Variable discount rates}

There remains a conceptual difficulty with the CAPM as it is a 'single-period return' model, whereas the discount rate required for an NPV calculation is a multi-time period rate of return. Myers $e t$ al argued that the cost of capital for R\&D projects should decline over the total development process as a step function (Myers and Shyam-Sunder, 1996; Myers and Howe, 1997). The authors termed the functional relationship a 'risk-return staircase' and assumed that this descending staircase phenomenon is not related to the usual notions of risk encountered during the scientific/technical development of risky products in new medicines $R \& D$. The descending 'staircase' relationship means that the cost of capital goes down as one moves from the basic research stages, through the late product development stages (e.g. clinical trials), and towards market introduction. This, however, has no bearing on the fact that a pharmaceutical company has to try thousands of compounds in 
order to achieve one successful outcome. The staircase concept has nothing to do with the risk of failing of new technology.

According to Myers (1996), it originates from what is called financial 'leverage'. Financial risk declines systematically through the consecutive new product discovery, development, manufacturing and product launch cycles. Thus, the R\&D costs could be viewed as a fixed obligation whereas the project revenues are less certain. As the investor in $R \& D$ goes through the product development process, he/she in effect pays off the mortgage and the residual value of the new medicine thereby becomes more certain. In other words, the present value of the future costs declines because the company is getting more and more of those costs behind it. At the same time, the present value of the net revenue increases, as it is closer to becoming a reality and the firm consequently has a higher probability of achieving it. As a result, the total value of the R\&D project itself increases. Myers (1996) explains this as follows: "If you think of leverage as a debt to equity ratio, or a debt to asset ratio, then the leverage goes down as you progress through the product development cycle. As the leverage goes down, the risk of your net position decreases and you get the descending staircase of the cost of capital".

Another way of looking at the evaluation of a hypothetical pharmaceutical $R \& D$ project is to treat it as a 'compound option pricing' problem (Myers and Howe, 1997). In that case, the firm effectively faces all options at decision points during the new product's development. This method reduces the informational requirements to two separate discount rates. One of these is the discount rate for net revenues on a marketed drug $\left(\mathrm{r}_{\mathrm{NR}}\right)$. The other is the discount rate on future costs $\left(\mathrm{r}_{\mathrm{FC}}\right)$. According to the authors, the discount rate for net revenues should be somewhat less than the overall company cost of capital. It is important to note that the discount rate for future costs, being an expected return on what is nearly a fixed debt obligation, is likely to be even lower. Myers and Howe have shown that this twodiscount rate method generally yields the same results as the more complex compound options valuation (Myers and Howe, 1997). However, other experts view this approach to discounting as too experimental for evaluating pharmaceutical and biomedical $R \& D$ projects (DiMasi, Hansen and Grabowski (2003). Their argument is that currently no pharmaceutical and/or biotechnology firm is using this approach for its project evaluations. These scholars recommend using the WACC method for the pharmaceutical industry, and thus employ a fixed discount rate as suggested in the previous chapter. 


\title{
5.5 Project-related technical risks and global market uncertainty
}

\author{
Modeling technical risks
}

Thus far, when considering capital budgeting analysis, the only consideration we have examined with regard to risk, has been selecting the right discount rate. We suggested in the previous section to use the WACC value for the pharmaceutical industry as a fixed discount factor during the investment analysis. In that case, we should be using a decisiontree method that incorporates the option to abandon a project at critical stages of the new product development process. It is too simple to believe that, once an analysis of a set of project cash flows has a positive discounted cash flow and the NPV is calculated, the work is done. Managers want to know more about a project than just its NPV. They want to know the source of related technical risks (e.g. project duration and costs) and market uncertainties after the new product has been launched (e.g. price, volume, market share) ${ }^{97}$.

Technical risks in pharmaceutical $R \& D$ are those risks that are directly related to the completion of the product development plan, including the registration of the new medicine. Specifically, new medicine development risks refer to the success, or failure, of laboratory and clinical studies and other technical development activities e.g. product formulation, production scale-up and registration. When all development risks relevant to the project have been identified, it is possible to design a model that captures these risks. Many companies have therefore adopted a 'stage-and-gate' approach that helps them manage new product projects as well as driving these products to market. The technical risks encountered at each stage of the sequential development process can be modeled with discrete probability distributions. Details of this 'stage-and-gate' model are illustrated by the clinical trial decision-tree in figure 15. This clinical testing stage has become an important step in a new drug's risk assessment. Expenditures on new medicines development have risen dramatically over the last decade in the realm of thorough clinical evaluation, driven by the need to demonstrate safety and effectiveness to pass the increasingly more stringent regulatory criteria. The cost of doing pre-clinical trials and full-scale clinical trials in men explains nearly half of the growing real expenditure in pharmaceutical $R \& D^{98}$ (IFPMA, 2003).

\footnotetext{
${ }^{97}$ In the analysis of handling uncertainty in investment decisions, the author uses the terms 'risk' and 'uncertainty' interchangeably. Although it is in theory possible to discinguish between the two terms, there is little purpose in doing so for our R\&D investment appraisal needs. Nevertheless, the term risk would be better in decision-tree analysis because it is based on expert assessment of the probability of events occurring (and bearing in mind that not all events can be foreseen leading to a degree of uncertainty that cannot always be quantified).

${ }^{98}$ As explained in chapter 4, clinical testing of new compounds typically proceeds through three successive phases. In phase I, a small number of usually health volunteers are tested to establish safe dosages and to garher information on the absorption, distribution, and metabolic effects, excretion, and toxicity of the compound. Phase II trials
} 
Risks in pharmaceutical product development cannot always be measured objectively. We suggest adopting the same position as Morgan and Henrion (1990) who consider risk from a 'personal' perspective. According to this perspective, the probability of an event is the degree of belief that a decision-maker has that this event will occur. According to this definition, probabilities can be based on judgments by a person, an expert or expert committee. Since this personal perspective is influenced by the experience and personality of the evaluator, the opinion of a group of experts concerning the degree of risk of a given project may differ. A widely used approach for reaching consensus among a group of experts is the 'Delphi' technique. This technique is based on the discussion of differing opinions among members until a consensus is reached regarding input data and the likelihood of events.

\section{Modeling market and sales risks}

Market and sales risks are defined as those risks that are related to the commercial exploitation of a new medicine. These risks have a direct influence on the anticipated market share for the newly launched compound. Depending on the time of launch and on the clinical activity profile that result from a certain product development scenario, the market and sales risks may vary a lot. Factors such as the performance of potential competitive compounds, or the attitudes and preferences of physicians, patients, health care payers, and governments may influence the outcome. To build a compound's market and sales forecast, formal and judgmental model building approaches can be used (Winston, Albright, 2001). The 'formal model' building approach consists of extrapolations of past data and is predominantly used for the short-term perspective. The 'judgmental model' building approach is more appropriate for the long-term perspective and consists of qualitative techniques such as expert judgment.

\footnotetext{
are conducted with subjects who have the targered disease or condition and are designed to obtain evidence on safety and preliminary data on efficacy. The number of subject tested in this phase is larger than in phase I and may number in the hundreds The final pre-approval clinical testing phase, phase III, typically consists of a number of large-scale (often multi-center) trials that are designed to establish efficacy and to uncover side-effects that occur infrequently. The number of patients in phase III trials for a compound can total in the thousands (Winslade, Hutchinson, 1993).
} 


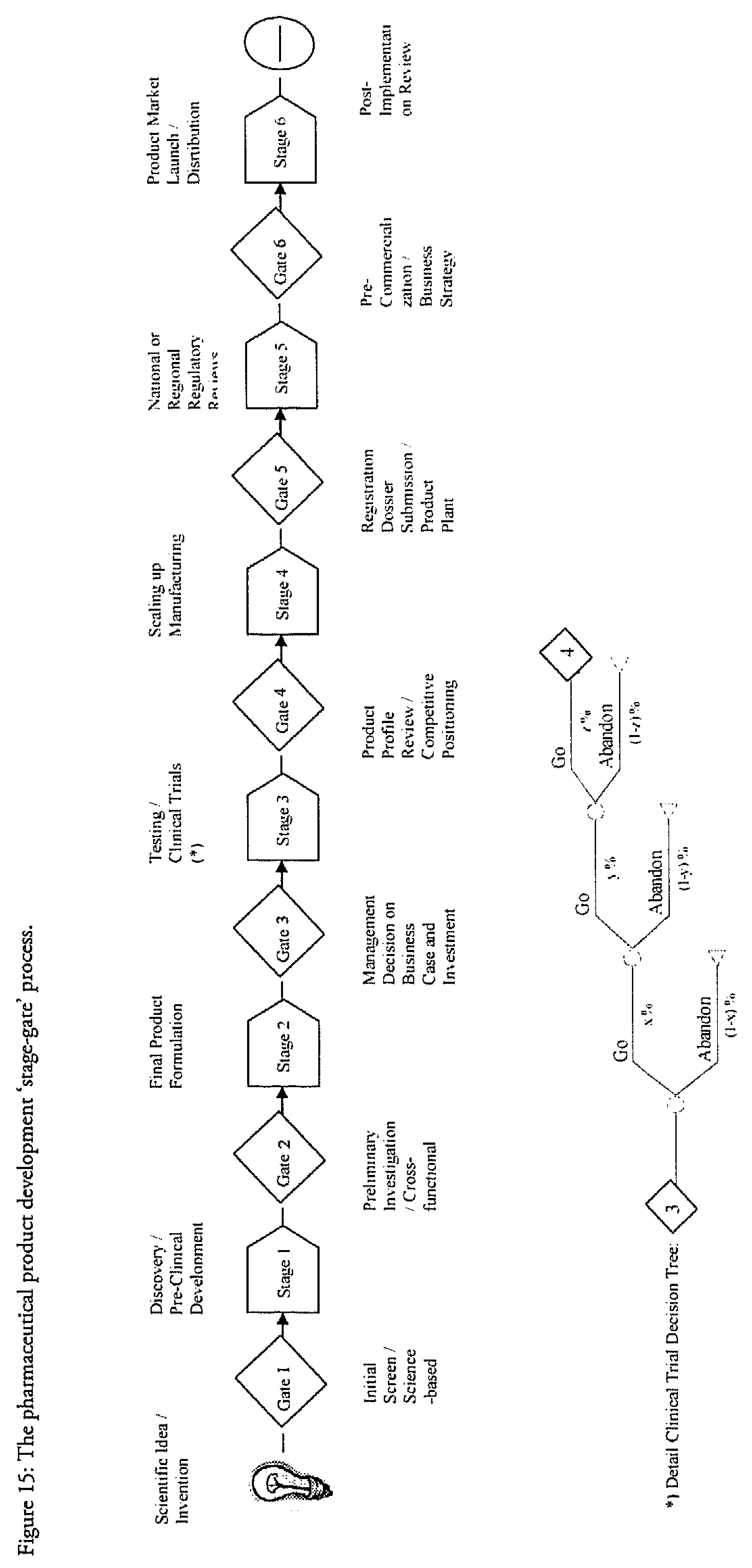


In most firms, various optimistic and pessimistic market scenarios are designed to reflect a selection of sales forecast conditions (Mansfield, 1999, McGuigan, 1999, Hirschy, 1998). The present value of the R\&D project's revenues is calculated several times depending on the number of market scenarios yielding more than one value per development project. Alternatively, only one (usually the optimistic) market situation is considered when calculating the new project value. Neither of these approaches is satisfactory, because the decision-maker is left with open questions. First, it is unclear which of these scenarios is best suited to evaluate a project in comparison to the other projects in the portfolio, or which mathematical approach could be applied to consider all net present values of the respective projects. Secondly, the final decision-maker (i.e. CEO or senior executive committee) is usually skeptical about the provided (optimistic) present value calculation and will probably make his/her own, mostly uneducated risk assessment when portfolio investment decisions are pending.

Instead of considering several discrete market scenarios, it is better to apply continuous probability distributions reflecting the range of sales figures that can occur when calculating marketing and sales risks (Eppen G, 1998). A well-known example of continuous probability distributions is the Normal or Gaussian distribution (Winston W, 2001). There is no scientific evidence suggesting that the market penetration of a new product follows the Normal or any other statistical distribution. Therefore, in such situations it is suggested to apply triangular distribution analysis (Winston W, 2001). In this approach, three scenarios of market uptake figures (i.e. optimistic, pessimistic, and most likely) must be defined for each forecast year. The yearly estimates written as triangular distributions can be entered into a spreadsheet by means of advanced software programs (e.g. Risk ${ }^{\mathrm{TM}}$ and Crystal Ball ${ }^{\mathrm{TM}}$ ). Each possible range of values within this triangular function may occur in reality. Rather than calculating a project's net worth based on forecasting separately pessimistic, optimistic and most probable values of sales, yielding three different NPVs, it is possible to run a simulation over the triangular distribution values resulting in a distribution of NPVs. This stochastic simulation, called the 'Monte Carlo' process, is widely acknowledged as a valid quantitative method for risk analysis" (Winston W, 2001).

The market conditions and sales forecasts may alter due to the (un)expected competitive response that occurs in a dynamic marketplace. During a pharmaceutical product's patent period, competition from a new medicine usually comes from developers of differentiated products that are offering comparable or superior safety and/or clinical efficacy (Kettler, 1998; Danzon, 1997). In the post-launch phase, other brand-name competitors are chal-

\footnotetext{
${ }^{99}$ Monte Carlo simulation allows one to conduct a random sampling of each probability distribution within the project model. The project model is repeatedly calculated choosing one value out of the respective distributions for each run (called iterations). The simulation result can be graphed as histograms or cumulative frequency plots.
} 
lenging the original company's product position and market share. Success depends upon which company best meets the needs of the market. Therefore, the main questions all companies are faced with are: (1) which combination of product attributes do customers want or prefer most? (2) And if any of the companies create new offerings, how are competitors likely to react to this market change? To analyze customer preferences among different competitors/ brands, an advanced market analysis technique called conjoint analysis, is often used (Day, Reibstein, 1997). The central idea of conjoint analysis is that products can be described by a set of attributes. New medicines for example can be described in terms of safety, efficacy, convenience, price, and so on. Physicians and patient/ consumers will attach different values to the levels of these attributes. They will make individual trade-offs among the attribute levels that characterize the various competitive offerings. Answers must be provided to questions like: Is a lower price more important than a higher efficacy? How important is a once daily medication regimen versus a twice daily? Across all attributes, respondents will choose the offering with the highest total value (or utility) to them. Since different people have different attribute-level values, called partworths, their trade-offs may vary ${ }^{100}$. As a result, different brands may appeal to different customers, leading to market segmentation. Software packages are available to analyze these 'conjoint or trade-off market research data ${ }^{101}$.

\subsection{Use of decision-tree simulation in $\mathrm{R} \& \mathrm{D}$ project evaluation}

\section{Simulating a project's expected npv and volatility}

In their R\&D investment appraisals, investors have to cope with the fact that the future is largely unknown and that decision-making has to be carried out based on 'expectations'. In a world where the future is uncertain, decision-making involves taking a risk: the risk that the actual outcomes may differ from what is expected. While the project's expected value, or average, of future profits is of obvious interest, the range of possible outcomes, or variability, is similarly important as a useful indicator of risk. In this respect, the actual outcome can either be better (the upside potential), or worse (the downside risk), than the expected outcome. A 'gambling' investor will likely focus most of his/her attention on the

\footnotetext{
${ }^{100}$ Conjoint analysis measures the part-worths through highly fractioned factorial designs (Hair $e t$ al., 1998). It tests these choices with respondents using a small fraction of the total possible combinations of attribure levels. An important marketing innovation has been the development of new product customer choice simulators, which allows to forecast buyer adoption rates and market shares for new and existing products (Day, Reibstein, 1997). ${ }^{101}$ (1) Bretton-Clark's package of Conjoint Designer, Conjoint Analyzer, SIMGRAF, LINMAP, and bridger, (2) Sawtooth Software's Adaptive Conjoint Analysis, and (3) SPSS also introduced a PC software package that is virtually identical in design to Bretton-Clark's.
} 
upside potential, but a 'risk' averse investor will be more concerned with the expected outcome and the downside risk.

The concept of Expected NPV (ENPV) is useful for new project appraisal in an uncertain world since it provides an average value of the project's performance ${ }^{102}$ (Lumby, Jones, 2001; Hirschy, Pappas, 1998). However, it cannot take into account 'risk', because the ENPV calculation is a measure of the investment's 'expected' performance, whereas risk is concerned with the likelihood that the 'actual' performance may indeed diverge from what is expected. The idea is therefore to create a computer-based simulation model that not only allows for the variables in the investment model to be related to each other but also to be varied on their own, or together, in almost infinite combinations. This technique is called a 'Monte Carlo' simulation. It requires probability distribution estimates for a number of variables, such as investment outlays, input costs, unit sales, product prices, etc. The algorithm is illustrated in figure 16. In a full-scale simulation, the software program will pick values at random from the probability distributions for each parameter in the model. Based on these values, the expected net present cash flows for the $R \& D$ project are calculated. These computer simulations allow managers to make precise judgments concerning the variability of various investment choices. Alternatively, instead of using complete probability distributions for each variable included in the problem, results can also be simulated based on best-guess estimates for each variable. Using this simulation technique, one can ask a variety of hypothetical 'what if questions. Typically, returns are highly sensitive to some variables and less to others. Attention is then focused on the variables to which investment outcomes are most sensitive. This technique known as computer-aided 'sensitivity analysis' again provides valuable insight for management decision-making purposes.

\footnotetext{
${ }^{102}$ The expected value is the anticipated realization from the investment's payoff matrix. In other words, it is the weighted-average payoff, where the weights are defined by the probability distribution. In this calculation, each possible outcome is multiplied by its probability and then summed. The weighted average outcome, or expected investment value, is expressed by the following equation:

Expected Value $=E(V)=\mu=\Sigma V_{i} \times p_{1}$; where i varies between 1 and $N$

$V$ is the profit level associated with the ith outcome, $p_{1}$ is the probability that outcome $i$ will occur, and $N$ is the number of possible outcomes, or states of nature. Thus, $E(V)$ is a weighted average of possible outcomes with each outcome's weight equal to its probability of occurrence. The expected value and profit distribution is specific for each investment project.
} 
Figure 16: Computer simulation supporting $R \& D$ investment planning and risk assessment

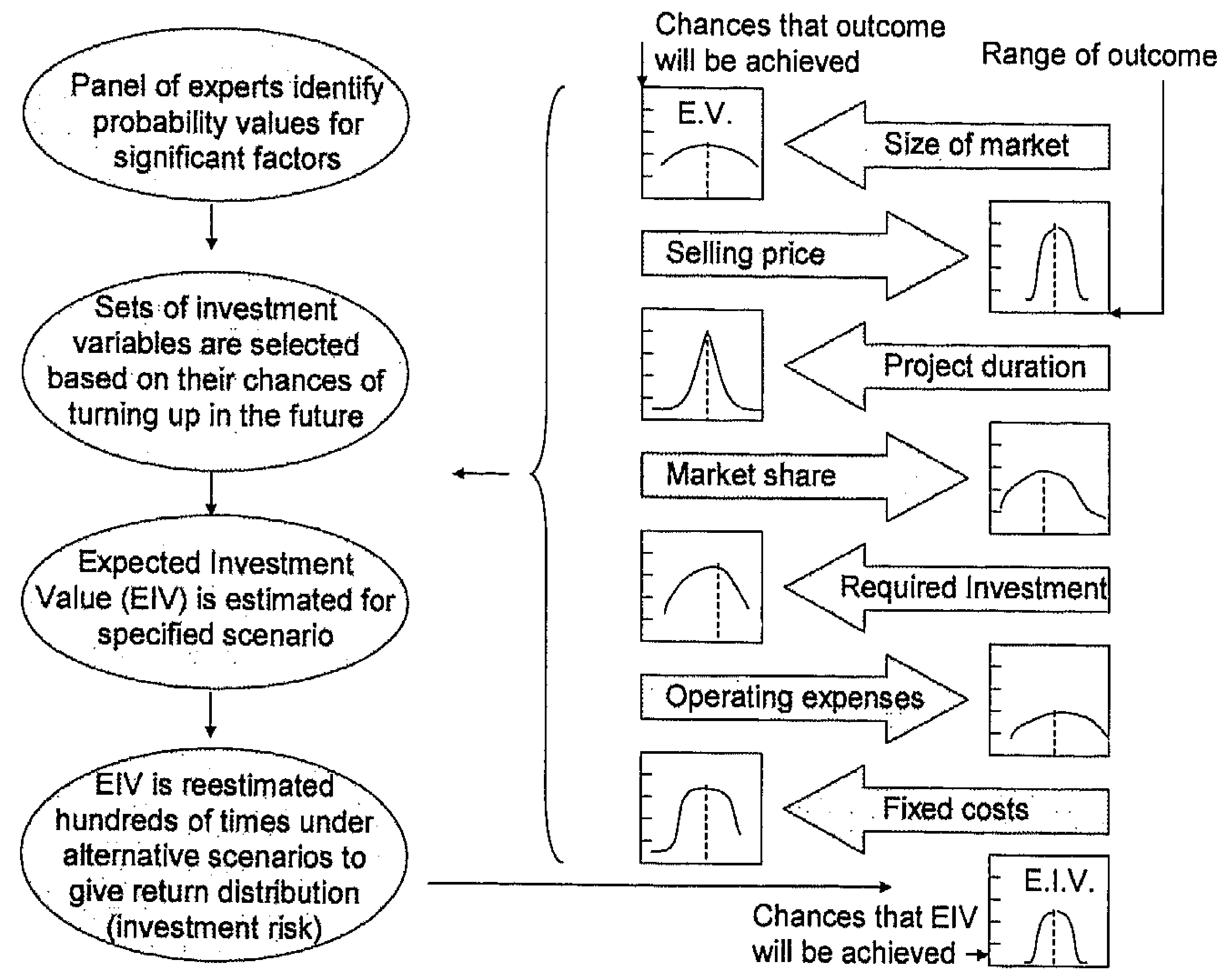

Source: Adapted from Hirschy, Pappas (1998)

\section{Evaluating multiple projects in the RerD portfolio}

In practice, to capture the volatility of a pharmaceutical or biotech R\&D project, a decision tree simulation model is constructed that describes the decision points where managerial interventions in the project are needed and real options to proceed (or not) must be reviewed. Furthermore, the project's expected value and volatility (i.e. risk) for each decision alternative must be calculated to arrive at an appropriate managerial decision. The investment outcome for two hypothetical pharmaceutical $R \& D$ projects ( $A$ and $B$ ) is graphically shown in figure 17. The assumption is that the two projects are mutually exclusive but happen to have identical ENPVs. Hence, based on the ENPV decision rule, management should be indifferent between the two projects as they are both expected to make a positive NPV of 50 million Euro. But figure 17 also shows that the two investments have different distributions of returns around their expected values. The first project (A) has a larger 'spread' (volatility), in other words, it has a lower downside but also a larger upside. On the basis of this distribution, it appears that the probability of a loss is much higher with the first project (A) than with the second project (B). Depending on the investor's attitude towards risk, he or she will make different investment decisions. Some individuals prefer 
high-risk projects and the corresponding potential for substantial returns, especially when relatively small sums of money are involved. However, both logic and empirical observations suggest that managers and investors are predominantly risk averse, especially when substantial capital amounts are involved. As a result, the probability of loss may be perceived too high in this example so that most decision-makers will decide to reject the first project $(\mathrm{A})$ in favor of the second project $(\mathrm{B})$.

Figure 17: Frequency distribution of discounted profit values for two hypothetical $R \& D$ projects

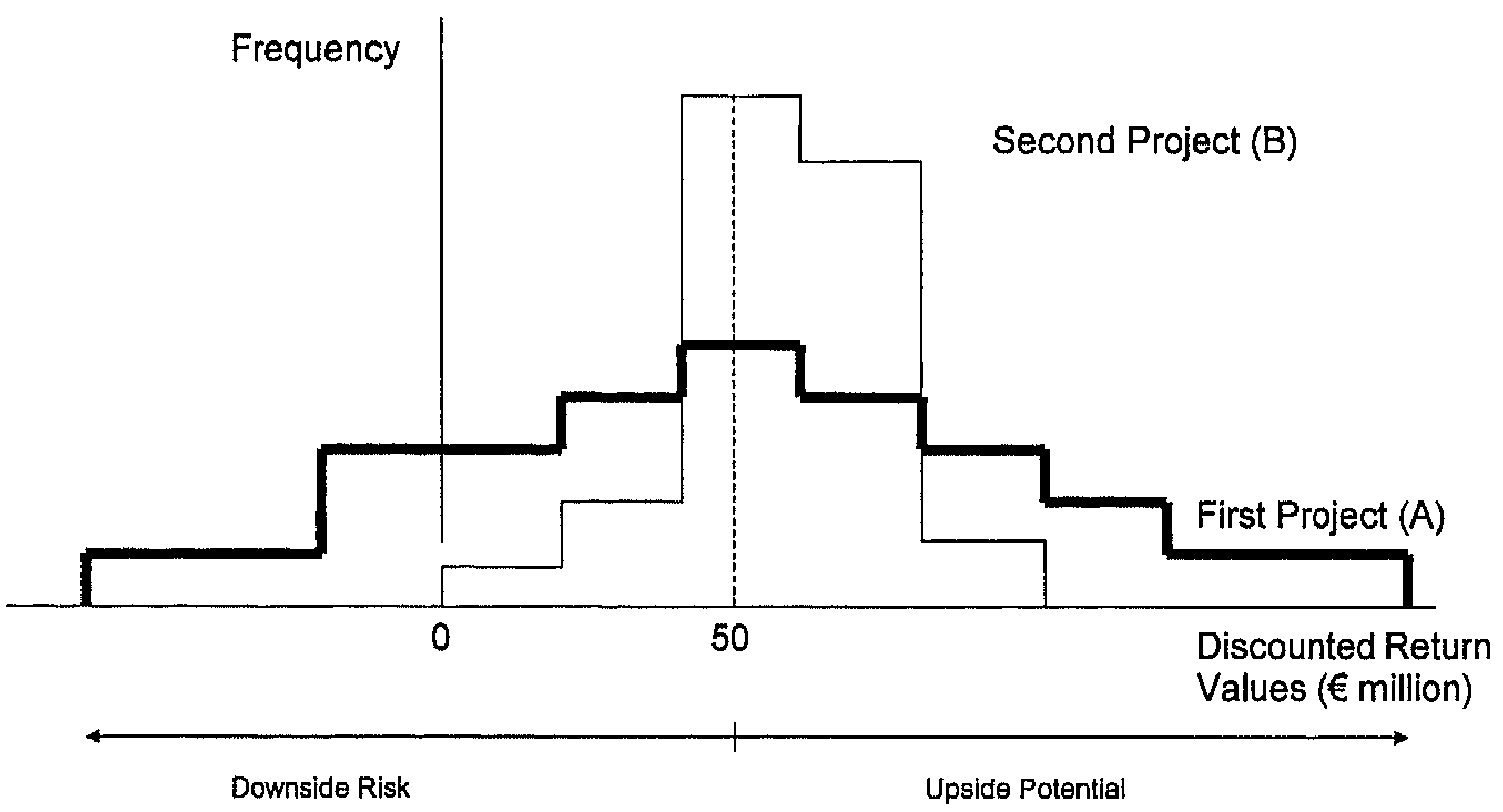

In summary, the 'real options' decision tree approach provides transparency about a project's real value to managers at each stage of the new product development project. In addition one should conduct a number of sensitivity analyses in order to see how much the project risk profiles and expected return distributions change when key parameters (e.g. probability of technical success, new product adoption in the marketplace, etc.) are varied. If the project's expected investment value (EIV) profile is sensitive to a particular parameter, it may be possible to monitor or specifically address this parameter in such a way as to reduce the investment downside. For example, in the case of new medicines development for predominantly developing-world use, various publicly funded 'push' and 'pull' incentive mechanisms can be applied to stimulate private sector investment in this particular disease area.

\subsection{Conclusion}

Several financial methods exist by which $R \& D$ projects can be evaluated. They include project payback, internal rate of return, and net present value. Of these, the payback 
calculation method provides limited information and at times can be misleading. It should therefore not be used for project assessment. IRR, although a good and useful technique, also has its limitations. On the other hand, NPV has clear advantages and is currently most commonly used by corporate managers and financial experts for $\mathrm{R} \& \mathrm{D}$ project appraisal and selection.

Literature research and empirical evidence have shown that 'option pricing theory' enables managers to capture the value of flexibility in risky $R \& D$ projects. The advantage of the 'real options' method in complex $R \& D$ valuation lies in the fact that management always has the option to abandon the project if the results are not promising at a certain stage, thus limiting losses to the amount invested up to that moment. The traditional NPV method fails to recognize this flexibility, and may therefore undervalue important opportunities in new medicines R\&D that corporations otherwise would have liked to pursue. Developing a 'real options' decision tree for pharmaceutical $R \& D$ project valuation requires an assessment of various key risk factors: (1) The firm's cost of capital; (2) The scientific-technical risks related to product research and development; (3) The market uncertainties and competitive pressure that gradually or abruptly may erode the new product's market share over time. All of the technical, market and financial risk factors can be integrated into one 'risk-adjusted' computer-assisted simulation model.

As a result, the expected investment value of any product development project can be calculated. Assuming that probability distributions can be developed for key parameters based on expert estimates for each cost and revenue category, the program is able to simulate the pattern of future events. By using standard Monte Carlo simulation software, the computer will randomly select cost levels from each relevant parameter distribution and will use this information to estimate the project's future return on investment. This process is repeated a large number of times to identify the central tendency of the projected returns and the corresponding expected values. When the simulation is completed, the frequency pattern and range of future returns for that particular project is plotted on a graph. The range of possible outcomes (distribution of EIV returns) is an important indicator of the project's investment risk. 


\section{Pharmaceutical R\&D on developing world diseases: á 'risll-investment-incentive' model.}

The computer-based simulation model proposed in this chapter focuses on the cause-effect relationship between a pharmaceutical $R \& D$ project's independent variables (technical, market, and financial risk factors), and the dependent variable's outcome (a firm's decision 'to invest', or 'to not invest', in a particular R\&D project). This methodology of risk assessment and investment appraisal through modeling can be applied to any new medicines development project, including projects aimed at established market economies, as well as those targeting developing countries. The managerial decision-support model proposed in this chapter compares a number of geographic investment strategies with their respective risk factors and investment outcomes. To gain further insight into the dynamics of these interactions, the key risk factors are being examined. Although these risk factors are considered independently, in combination they predict a firm's decision to investment (or not invest) in pharmaceutical $R \& D$. Most importantly, the integrated framework incorporates into a single model the influence and impact that publicly funded incentive mechanisms - termed 'push' and 'pull' mechanisms - may have on a firm's decision to invest in risky, complex and expensive projects. Incentive mechanisms are currently being examined to stimulate greater private sector involvement in $R \& D$ on diseases of the developing world. 


\subsection{Introduction}

Risk assessment, capital and human resource investment in pharmaceutical $R \& D$ on diseases of endemic or epidemic nature in primarily developing countries is often treated as a 'black box'. To gain insight into this decision-making process, this chapter will explore the mechanisms through which corporate performance is affected and stimulated. Further, the LDC-investment problem will be examined through the lens of industry, which is both an investor and producer of these medicines and the 'risk-investment' causation will be explained placing resources and competencies of the firm at the center of the analysis. Modeling is useful when making decisions under uncertainty. The ultimate goal is to incorporate into the corporate risk-investment model the influence that various external incentive systems (acting as anti-risks) may have on a firm's decision to invest in what are reportedly lengthy, risky and often expensive R\&D projects. The expected benefit of such an integrated 'risk-investment-incentive' model is that it can serve as a tool through which public and private managers can evaluate, optimize and accelerate the discovery and development of medicines for the developing world.

\subsection{Building an integrated 'risk-investment-incentive' model}

The proposed 'risk-investment-incentive' model is built in three distinct but interrelated stages:

1. First, a quantitative computer-based simulation sub-model is developed that focuses on the R\&D risk and investment relationship. To build such a 'risk-adjusted' investment model, it is important to understand the cause-effect relationship between a pharmaceutical $R \& D$ project's independent variables (i.e. technical, market, and financial risk factors), and the dependent variable (the firm's decision to invest, or not, in that particular project).

2. Secondly, in parallel, another simulation sub-model is developed, similar in nature to the above. The purpose of this model is to investigate the relationship between public incentives and private investment; and to assess the influence and impact of the external incentive systems that employ economic devices to reduce the costs and risks of pharmaceutical R\&D ('push' systems), or address the lack of viable markets in developing countries ('pull' systems). 
3. Finally, the two sub-models are seamlessly brought together into a single computerbased model ${ }^{103}$ that is able to respond to variations in external incentives (anti-risks) on the firm's ability and willingness to invest in these $R \& D$ projects. The impact of the push and pull incentives is described in a qualitative and quantitative manner via simulation and sensitivity analysis. The overall framework and its two sub-models are illustrated in figure 18.

Figure 18: Framework for an integrated 'risk-investment-incentive' model

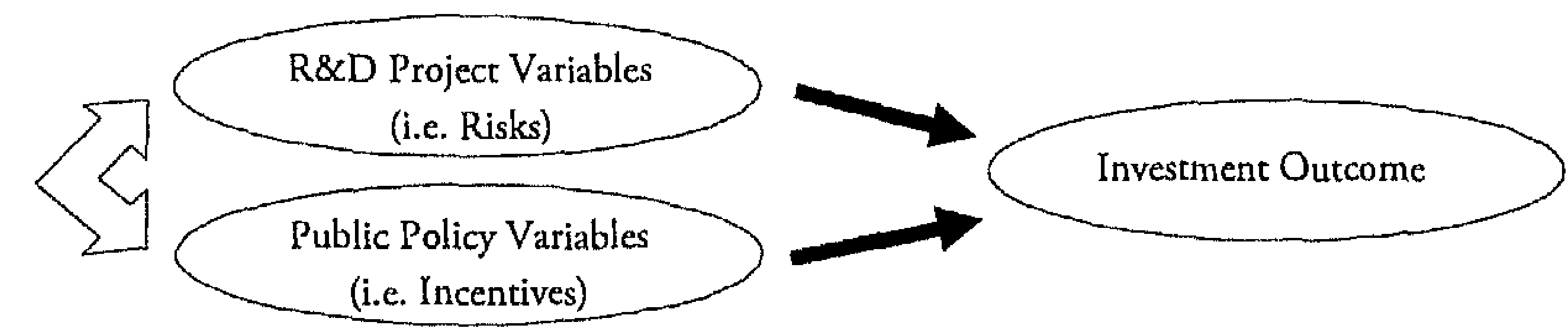

(a) Steps for building the 'risk-investment' sub-Model: Determine the technical, market and financial risk factors that are playing a key role in influencing a pharmaceutical corporation's 'Expected Investment Value'. This EIV is an indicator that suggests whether the $R \& D$ project should be selected and prioritized by the firm (or put on the R\&D investment backburner). The EIV and the shape of its distribution curve is specific for each $R \& D$ project and reflects the variability or volatility of a particular $R \& D$ project (see chapter 6). A key tenet of bringing all of the variables into one model is that it makes internal calibration possible. As such, corporations can compare different $R \& D$ projects in their portfolio despite the fact that some of these projects focus on different therapeutic areas or geographic regions. Therefore, the resulting 'risk-adjusted' EIV outcome measure represents a universal tool for ranking, selecting and prioritizing pharmaceutical $R \& D$ projects. In addition, it also allows for direct comparisons between $R \& D$ projects aimed at serving the established market economies and those targeting the least developed countries.

(b) Steps for building the 'incentive-investment' sub-model: Formalize the link between the two sets of public policy mechanisms (termed 'push' and 'pull') and the firm's decision to invest (or not invest) resources in R\&D concerning developing-country diseases. Arguably, the described public finance and incentive systems, alone or in combination, act as a catalyst for accelerating private sector investment in the development of new medicines on poverty-related diseases. These 'push-pull' systems will become operational only after an enabling (or disabling) signal has been received, triggered by backwards induction. For

${ }^{103}$ The two sub-models are inter-linked by means of their principal parameter, which is 'risks'in the first submodel and 'incentives' in the second. In this context, the 'incentive' variable in the integrated model is considered to function as 'anti-risk'. 
example, injecting public funds into the $R \& D$ process is only possible if the feedback obtained (through simulation) indicates that a negative EIV outcome is likely (given the R\&D project is carried out). Conversely, the same feedback mechanism will attenuate, or even freeze, the delivery of public funding if the project is deemed self-supporting, that is, if a positive EIV outcome can be obtained.

\subsection{Risk and investment relationship for R\&D on developing world diseases}

\section{The risk-investment relationship}

The risk-investment equation focuses on the association between the internal and external risk factors, and the firm's decision to invest (or to not invest) in new product development. This cause-effect relationship between the model's independent variables (technical, market and financial risk factors) and the dependent variable (the R\&D project's EIV) triggers the managerial decision to invest - or alternatively, postpone the decision to invest ${ }^{104}$. This is graphically illustrated in figure 19 . To better understand the various interactions, it would be helpful to examine the dimensions of each of the key parameters in the model and put each of the variables under the microscope.

\footnotetext{
${ }^{104}$ Of course, this risk-investment problem exists against a general political and healthcare background that may pose additional constraints on the firm. Clearly, the firm cannot always control these environmental influences meaning that these may impact the decision outcome as well. However, most predictable events are incorporated in the described risk factor clusters.
} 


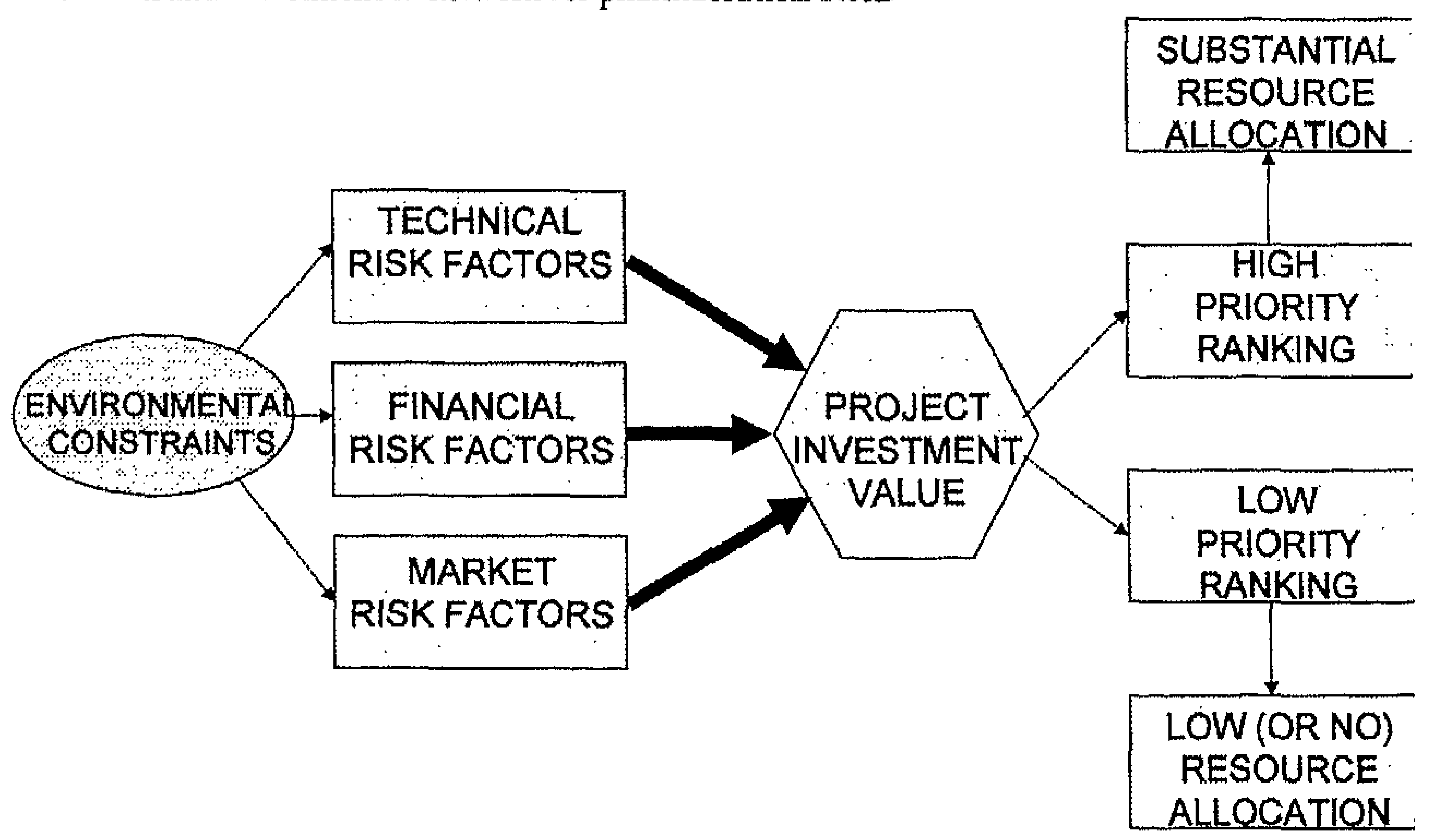

\section{Definition of technical, market and financial risk variables}

The components that sum up to the model's key independent variables (technical, market and financial risk factors) are summarized in table 4. Although these parameters are considered independently, in combination they are expected to (closely) predict the $\mathrm{R} \& \mathrm{CD}$ investment's outcome.

Technical Risk Factors: These are risk factors directly related to the completion of the new product development plan, including the registration of the final medicine. They can be modeled at each stage of the development project by means of discrete probability distributions. In order to do that, it is necessary to estimate the attrition rate at each stage of the work in progress, as well as the increase in development costs in expected value terms per stage and cumulative for the project to date. 
Table 4: Definition of the independent variables $(\mathrm{X} 1, \mathrm{X} 2, \mathrm{X} 3)$

\begin{tabular}{llll}
\hline \multicolumn{2}{l}{ The Independent Variables $(\mathrm{X} 1, \mathrm{X} 2, \mathrm{X} 3)$} & \multicolumn{2}{l}{ Dimension/scale } \\
\hline X1 & Technical Risk Factors & Simple & Complex \\
& A1. Project Duration; 'Time' (Years) & Short & Long \\
& A2. Project Costs; 'Costs' (US\$) & Cheap & Expensive \\
& A3. Artrition Rate; 'Attrition' (\%) & Low & High \\
X2 & Market Risk Factors & Low & High \\
& B1. Popularion Coverage; 'Volume'(doses) & Mass & Niche \\
& B2. Product Preference; 'Share' (MS\%) & High & Low \\
& B3. Differential Prices; 'Pricing'(US\$) & Premium & Discount \\
X3 & Financial Risk Factors & Low & High \\
& B1. Cost of Capital; 'Hurdle'(COC\%) & Low & High \\
& B2. R\&D Budget; 'Resources' (US\$) & Large & Small \\
\hline
\end{tabular}

To estimate the probability that an investigational compound will indeed enter the next development phase - and the duration and mean costs incurred for that period - a team of experts (internal, external or mixed) must be consulted ${ }^{105}$. Empirical evidence has shown that an expert judgmental approach is feasible and appropriate for new medicines evaluation. Since it is not certain that the development of the new compound will proceed to a given phase in the sequential development process, the costs at each phase should be viewed as the realization of a tandom variable. For example, the expected costs for clinical testing of a new pharmaceutical compound can be defined as:

$\mathrm{C}=\mathrm{E}_{\mathrm{c}}=\mu_{\mathrm{A} / \mathrm{c}}+\mathrm{p}_{\mathrm{I}} \mu_{\mathrm{I} / \mathrm{c}}+\mathrm{p}_{\mathrm{II}} \mu_{\mathrm{II} / \mathrm{c}}+\mathrm{p}_{\mathrm{III}} \mu_{\mathrm{III} / \mathrm{c}}$; where $\mathrm{PI}_{\mathrm{II}} \mathrm{p}_{\mathrm{III}}$, and $\mathrm{p}_{\mathrm{III}}$, are the probabilities that a randomly selected investigational drug candidate will enter phases I-III, and $\mu$ is the conditional expectation. Thus, $\mu \mathrm{A} / \mathrm{e}$, and $\mu \mathrm{I} / \mathrm{e}, \mu \mathrm{II} / \mathrm{e}, \mu \mathrm{III} / \mathrm{e}$, are the mean costs for a compound that enters the pre-clinical and clinical phases I-III, respectively (DiMasi, Hansen, Grabowski, 2003).

Precisely because pharmaceutical $R \& D$ is a multi-pronged, sequential process, decision-tree models can be used. At each stage of the process, decision nodes reflect the 'real options' available to managers in completing or abandoning the pharmaceutical $R \& D$ project ${ }^{106}$. This is illustrated in figure 20.

\footnotetext{
${ }^{105}$ Managerial decision-making processes under uncertainty have been described in the literature (see for example Russo, Schoemaker, 1990). It is beyond the scope of this study to describe the process on how a consensus is reached between the various committee members with different backgrounds (Delphi technique). Group dynamics will certainly play a role, although experts could be consulted anonymously via compurer. The process needs to be repeared for each new compound within a defined therapeuric area.

${ }^{106}$ Real options theory for advanced technology projects is based on the analogy between a financial stock option and a research-based product development project. Both options give the investor the opportunity to capiralize on future earnings while limiting potential losses. Chapter 5 describes the theoretical background of this methodology.
} 


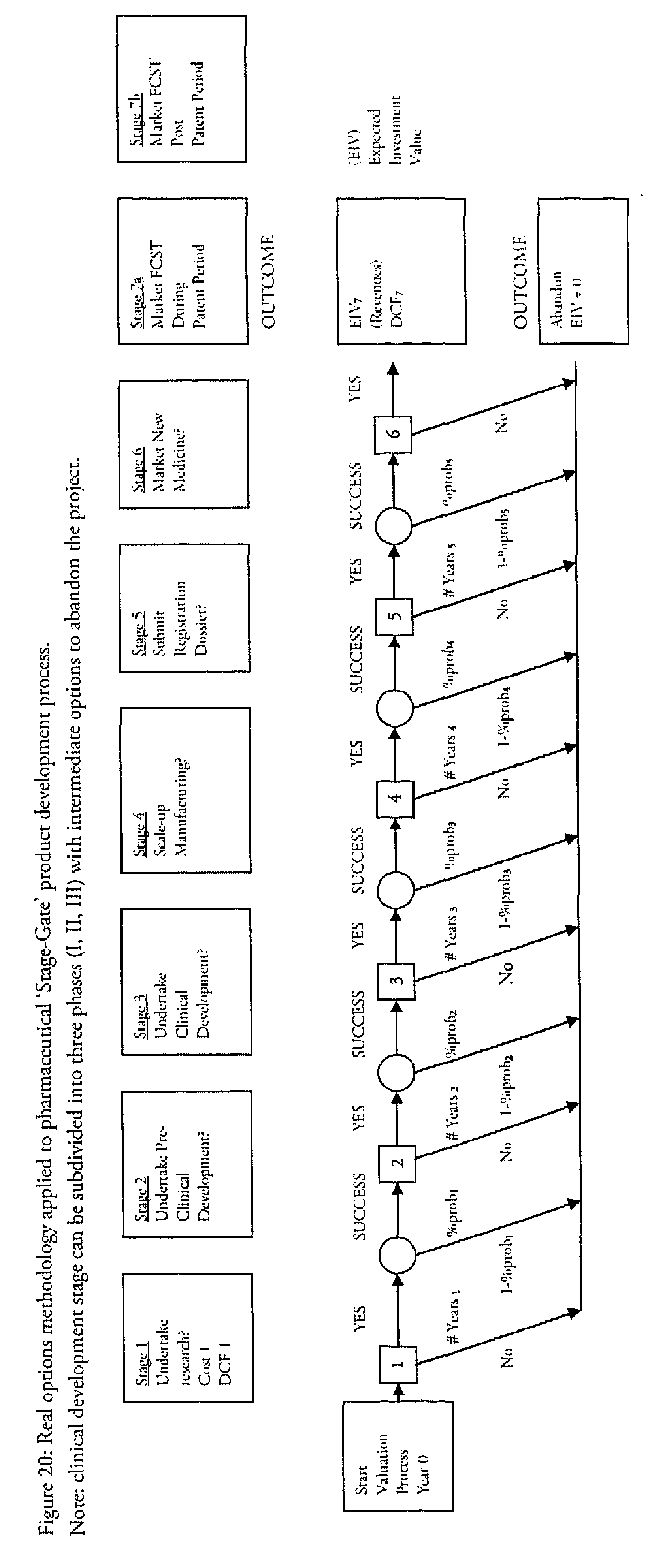


Market Risk Factors: A prospective analysis is conducted to estimate (future) market demand and related uncertainty. The data will be collected using an expert (Delphi) technique. The reason for this is that evaluators (often a great number with different backgrounds) have to cope with development times of more than a decade during which disease epidemiology patterns, healthcare systems and competition are likely to change. Therefore, future market demand for a new medicine is more accurate when based on an external expert panel's judgment and consensus. Judgments produced by a multi-disciplinary team can be transformed into quantitative estimates and processed statistically (Winston, Albright, 2001). A (simple) triangular distribution is able to effectively capture the range of expert estimates and scenarios, to reflect the optimistic, conservative and most likely product demand figures over a period of 10 to 20 years. A continuous probability distribution is preferred over discrete market scenarios (traditionally labeled as optimistic, realistic and conservative) when describing the range of product demand. The Monte Carlo technique can be employed for random sampling of each probability distribution. Again, advanced software programs are available to analyze and process this data (e.g. Treeage ${ }^{\mathrm{TM}}$ (Data), Risk ${ }^{\mathrm{TM}}$ (Palisade), Crystalball ${ }^{\mathrm{TM}}$ (Decisioneering) ${ }^{107}$.

The prospective market demand is calculated as the result of a new medicine's future price (per dose) multiplied by the total distribution volume (number of doses for the disease category), multiplied by its markets share (expressed in \%). The respective volume is derived from the rate of market adoption and diffusion the new product will be experiencing in various population groups and throughout various healthcare systems in the world. The corresponding price and reimbursement levels are determined by the national governments, private insurers or 'third-party' payers. Market conditions and in particular the monopolistic position that innovative compounds may initially enjoy change over time due to competitive responses. New products that are successful in the marketplace will undoubtedly attract competition and enlarge the circle of potential suppliers. During the new product's patent period, price competition will come from other developers offering differentiated products with comparable or superior safety, efficacy or tolerance. These competitors will challenge the original brand's position and market share. Thus, commercial success depends upon which company best meets the needs of its customers. Brand preferences among patients, physicians and buyers can be measured by means of conjoint analysis from which market shares can be inferred ${ }^{108}$ (Day, Reibstein, 1997).

\footnotetext{
107 Guidance on how to use these computer-based simulation programs can be found in books describing managerial decision analysis (for example, see Winston, Albright, 2001).

${ }^{108}$ The preference for a particular brand, product caregory or pharmaceutical company can be measured through trade-off or conjoint analysis. Sensitivity analysis can be applied to simulate the impact that changes in competitive market share may have on the expected investment value. Of course, a number of differentiated competitors is likely to emerge during the new medicine's parent period. What is more, a plethora of generic competitors will
} 
Financial Risk Factors: The opportunity cost of capital, also known as the required rate of return or hurdle rate is used to discount future cash flows for a particular project venture. Myers and Shyam-Sunder of the Massachusetts Institute of Technology (MIT) have estimated the cost of capital for the pharmaceutical industry by applying a standard capital asset pricing model (Myers, Howe, 1997, Myers, 1996). This study was commissioned by the U.S. Office of Technology Assessment as part of a larger study on R\&D costs, risks and rewards (U.S. Congress/OTA, 1993). The MIT researchers found that the real after tax cost of capital on equity plus debt varied between 10 and $11 \%$ in the $1980 \mathrm{~s}^{109}$. Later, Di Masi from Tufts University, MA, together with Hansen from the University of Rochester, NY, and Grabowski from Duke University, NC, determined the real cost of capital for the period of 1994 to 2000. They concluded that the pharmaceutical industry's weighted average cost of capital for that period, using the capital asset pricing model approach, was again around 11\% (DiMasi, Hansen, Grabowski, 2003). For the details, see chapter 5.

Consequently, the $11 \%$ cost of capital based on the above research data obtained for the pharmaceutical industry will be used as the 'discount' factor for our risk-adjusted $R \& D$ investment calculations. Using a decision-tree methodology in our valuation of pharmaceutical $R \& D$ projects, the same cost of capital rate can be applied to all $R \& D$ projects in the portfolio ${ }^{110}$ (Myers, Howe, 1997). It is reasonable to use the WACC of the firm, division or industry for that purpose. This reasoning only holds if R\&D funds are not scarce. If $\mathrm{R} \& \mathrm{D}$ funds are strictly limited and projects compete for scarce corporate resources, undertaking one project would incur opportunity costs to the firm, that is, the value from another, displaced, project would be lost. In that case, the discount rate will have to reflect the average return on investment from the alternative $R \& D$ projects, and these could be higher than the WACC. Reportedly, within the pharmaceutical industry, internal hurdle rates and risk premiums are higher and vary between 20 and 30\% (Loch, Bode-Greuel, 2001). However, the 11\% WACC will be used for calculating pharmaceutical R\&D project riskadjusted returns because we are interested in finding the corporate threshold level to invest in R\&D on medicines for neglected diseases. In other words, in our investment analysis and risk assessment calculations we are prepared to err in favor of developing countries and/or the international donor community.

almost certainly step into the arena at the moment the original product's patent has expired. These dynamics can be modeled by simulating the entrance of a random number of new companies into the marketplace at the beginning of any given year after patent expiry. The number of new entries is Poisson probability distributed resulting in a random shift in market share among all comperitors. Consequently, all competitors lose a random percentage of their market share to other entranes (Anderson, Sweeney, Williams, 2003).

109 To obtain the real cost of capital, the rate of inflation has been subtracted from the nominal cost of capital data based on a survey among pharmaceutical firms (see chapter 5).

${ }^{110}$ If applying real options to pharmaceutical R\&D projects by means of decision trees - providing an option to abandon at each stage these projects -- there is no need to add an additional risk premium to specific projects. 


\section{Definition of the investment's outcome variable}

A proxy measure for the anticipated investment value of a pharmaceutical $R \& D$ project, and, therefore, a firm's willingness and ability to invest (or to not invest) in a particular project, can be obtained by combining elements of value to investors into a single decision outcome measure. The assumption is that a pharmaceutical firm's investment decision is composed of a combination of three key decision criteria: (1) the project's risk-adjusted return on investment; (2) the company's strategic portfolio composition and product fit; and (3) the corporation's citizenship value (which is a rather intangible variable but can tilt the balance in the decision-making process).

The combination of these criteria into a single parameter will determine the project's investment value and priority to the firm. This is illustrated in table 5. The academic literature and historical precedents suggest that these criteria are all important to corporations and are used by many in guiding them through their R\&D investment and strategic portfolio decisions (Mc Donough, Spital, 2003; Cooper, 2000, 1898. 1997).

Table 5: Definition of the dependent variable (Y)

\begin{tabular}{|c|c|c|c|}
\hline $\mathbf{Y}$ & The Dependent Variable & Dimensio & a/scale \\
\hline Y. & Expected Investment Value & Low & High \\
\hline Y1. & $\begin{array}{l}\text { Return on Investment (high weight factor); } \\
\text { Financial Return of Project to Corporation; } \\
\text { 'Return on Investment' (US\$) }\end{array}$ & Negative & Positive \\
\hline Y2. & $\begin{array}{l}\text { Strategic Fit (medium weight factor); } \\
\text { Therapeutic Focus \& Life-cycle Management; } \\
\text { 'Strategic Fit' (\%) }\end{array}$ & Low & High \\
\hline Y3. & $\begin{array}{l}\text { Citizenship/ Goodwill (low weight factor); } \\
\text { 'Goodwill' (US\$) }\end{array}$ & Low & High \\
\hline
\end{tabular}

The first criterion, 'risk-adjusted return', is a variant of the net present value of the cash flow method. In a large survey comprised of 205 corporations across various industries, $\mathrm{McDonough}$ and Spital (2003) discovered that the majority of companies surveyed were using a formal system for their $\mathrm{R} \& \mathrm{D}$ portfolio selections. The other companies were using an informal system or no system at all. The great majority of the top corporations, however, were positively correlated with having a preference for formal systems. This includes various profitability and financial return- metrics, such as NPV, ROI, or payback period. Most often, these methods are used to rank projects against each other; that is, a particular $R \& D$ project's expected economic value is determined, and that value is used to rank-order projects against each other in the portfolio. The authors warn that just because a particular method is proven to be popular it is no reason to assume that it is the correct method, or even that it yields better performance. Cooper $e t$ al (1998) argue that it is better to use a hybrid, or combined, approach, which incorporates not only the pure financial payoff, but 
other elements, such as: (i) the corporation's strategic fit and ability to leverage core competencies; (ii) the R\&D project's technical risks and probabilities of success, and (iii) the ability to achieve sustainable competitive advantage through patents or proprietary knowledge.

Although deciding which projects to include in the firm's portfolio is already a difficult decision to make based on ROI, an equally difficult decision is deciding which R\&D projects to terminate and remove from the portfolio if resources are scarce. Since no company has an unlimited budget to conduct $\mathrm{R} \& \mathrm{D}$, focus in scanning the possible projects by disease category is critical (Needleman, 2001). Managers may be tempted to sidestep the decision made and add another project. Yet doing so can have disastrous results for the corporation. Cooper $(2000,1997)$ found that consistency helps to prevent the $R \& D$ pipeline from becoming overloaded. Stuffing the $R \& D$ portfolio with more projects would mean that fewer resources are available for each project, that experts are stretched, and that project leaders and members are switched or shared among several projects. McDonough and Spital (2003) found that clear project selection and termination criteria help to ensure that projects that remain in the portfolio fit with the company's strategic orientation and are not simply the pet projects of some managers. The second parameter, 'strategic fit', therefore deals with the important question of whether an $R \& D$ project is consistent with the company's business strategy. Here, the concept of product life-cycle management plays an important role. If, for example, a company has defined certain technologies or markets as key areas to focus on, will the new project under evaluation fit into this strategic area? A pharmaceutical company that is traditionally strong in one or more therapeutic areas will try to leverage its know-how and experience by searching for new compounds that may reinforce or replace its current franchise. The goal for that firm is to develop second or third-generation medicines, or innovative 'breakthrough' medicines to prevent or treat diseases that are related to each other in some way.

The third parameter, 'corporate citizenship/goodwill', refers to the firm's responsibility to act as a good corporate citizen regardless of profits made, or the lack thereof. Arguably, only a minority of $R \& D$ projects with an anticipated negative, risk-adjusted return will, or can be supported by private companies based on social responsibility arguments alone. The reason for this limitation is the average cost of developing new medicines, including the project failures and cost of capital (DiMasi, 2003). As industry R\&D budgets range between US $\$ 10$ to US $\$ 100$ million per annum for the mature biotech firms, to a few billion US dollars for the largest multinational corporations, it is clear that only a few companies are able to spend money on 'goodwill' projects leading to negative returns. This is not to say that health technology companies do not, or should not, have programs of corporate 
social responsibility. The list of donations and charity programs in this sector is actually quite long and may even exceed that of other industries" ${ }^{11}$. The definition of 'goodwill projects' used in this book specifically refers to contributions made by the pharmaceutical and biotech industry over and above social projects that they have already committed to. As such, it refers to the industry's ability and willingness to absorb the financial losses that occur when products are developed in support of resource-strapped nations. Some observers may consider this a political and public policy issue, and not an industry issue ${ }^{112}$. Proponents of the shareholder-value perspective claim that society would be best served by an economic rationale of profit-motivated corporations ${ }^{113}$. This study actually intends to test the limits of what is 'in principle' feasible in order to maximally stretch the firm's ability to invest in neglected diseases without making excess profit, but without making losses either, as that could not be a sustainable solution in the long run.

\section{Porffolio risk assessment and investment prioritization}

The key purpose of this book is to have poor countries pay a minimum contribution to future new medicines development despite the fact that they will be the principal benefactors. In other words, the large fixed costs of medicines discovery and development should be paid for by the industrialized nations and/or emerging economies (the degree of which varies depending on the global disease prevalence). LDCs would only pay for the variable cost of production of medicines, along with some of the related fixed costs to recoup clinical studies and manufacturing scale-up. Critics could argue that this approach favors developing countries as they already pay prices for medicines that largely correspond to their GDP. This is in contrast to the higher price industrialized nations pay for medicines. Perhaps in the near future, developing countries should be asked to make a higher contribution than only paying for the amount sufficient to cover the marginal cost of doses manufactured. A more appropriate contribution level might then be based on the value these new medicines deliver to their national health and economic systems. Knowing,

\footnotetext{
"II Since the United Nations announced its MDGs in 2000, the pharmaceutical industry has made available drugs, vaccines, equipment, health education and manpower worth US $\$ 4.38$ billion, with the cost of donated medicines valued conservatively at their wholesale price (Willis, 2005).

${ }^{112}$ Ethan Kapstein - Professor of Economics and Political Science at INSEAD - notes the following in an article: 'The Corporate Ethics Crusade: the demands that industry bears the main part of the heavy cost of subsidizing drug deliveries to developing countries represents cynical posturing and cheap talk on the part of the world's politicians and activists; the public health policies of many developing countries are a shameful mess, and industrialized nations put up no more than a pittance to help them" (Kapstein, 2001).

${ }^{113}$ Responsibility for local communities, employment, the environment, consumer welfare and social developments are not an organizational matter, but issues for individuals and governments. By pursuing enlightened selfinterest and maintaining market-based relationships berween the firm and all stakeholders, societal wealth will be maximized (Davis, Useem, 2000; Friedman, 1970).
} 
however, that the poorest countries spend on average US $\$ 10$ per capita on healthcare per year, any additional healthcare expense or savings made elsewhere in the system will not compensate for development costs. The objective is thus to focus ours effort on finding the 'zero-sum' EIV threshold level that triggers the necessary private sector investment in R\&D on neglected diseases without placing the burden on poor countries.

It could also be argued that the world should de facto prioritize $\mathrm{R} \& \mathrm{D}$ projects beneficial to developing countries based on the enormous burden posed by diseases on these countries. Notwithstanding the fact that there is merit in this idea from a global social responsibility perspective, this may trigger a controversial debate between industrialized and developing nations. The public debate would revolve around the perception that 'modern society' diseases affecting predominantly the industrialized countries - whose populations are growing older and suffer from illnesses like Alzheimer, cancer, diabetes, obesity, respiratory and cardiovascular disease - are perceived to be of less importance than the infectious diseases causing havoc in the developing world. The controversy might be heightened by the fact that industrialized nations are asked to not only pay for pharmaceutical R\&D that underpins their own medicines but also to pay for the developing-country medicines as well. Another complicating factor is that recent worldwide epidemiological studies have demonstrated that developing countries are increasingly seeing similar disease patterns as observed in the more developed countries. Consequently, LDC countries will also benefit from new medicines developed in these therapeutic categories ${ }^{114}$.

In conclusion, the filter by which $R \& D$ projects will have to pass in order to receive internal corporate funding is the risk-adjusted return value. Failure to screen potential projects on this parameter could result in corporations spending huge sums of money on developing products that eventually result in losses. Unsurprisingly, corporations will find it difficult to justify continuing investment in projects that have a negative return, unless of course the corporation makes a conscious decision that developing country-projects are entitled to systematically receive long-term internal funding based on the benefits offered by the other two decision parameters (i.e. 'strategic fit' and 'goodwill'). However, this is unlikely to happen in the majority of cases. Companies would expect the recipient-developing countries, or supranational agencies, to (at least) make up for the incremental costs of new product development, if and when this is needed. This would allow firms to formulate the medical compound such that broader protection is achieved across continents, or to conduct multi-country patient studies, or to secure local registration, or to arrange for crosscountry distribution for delivering medicines to remote areas. These incremental costs can also include scaling up primary and secondary manufacturing facilities to supply the larger

14 The world's greatest number of diabetes cases is now found in China and India. 
volumes needed to serve global needs. For example, if a vaccine against HIV/AIDS is successfully developed, companies must be ready to produce sufficient doses to cover approximately 10 million newborns in high-income countries, 40 million in middleincome countries, and 70 million in low-income countries per annum. If the assumption is that, to confer life-long protection, a full vaccination course consists of three doses, a total of 360 million doses per year would have to be produced to cover only the birth cohort. Ultimately, many more doses would have to be produced to protect young schoolchildren, teenagers, and adults living in these areas. Whereas the developing world needs billions of doses, by contrast, the industrialized nations need a few ten or hundred million doses to cover specific at- risk groups vulnerable to the disease.

The 'zero-sum' EIV method represents the (minimum) threshold level for private corporations to consider investing in lengthy, complex, risky and thus expensive $R \& D$ projects. In practice, corporations will try to invest in $R \& D$ projects that deliver results well above the zero-sum return level. If they do not, firms would never make gains above the cost of capital and their investors would simply move their investment elsewhere. It is important to realize that the 'zero-sum' EIV cutoff value is based on a preferential low price setting that can only be applied in an effort to supply medicines to the poorest countries. If the same 'rock bottom' concessionary prices were to be used in middle- and high-income countries, the differential pricing system would likely collapse. In other words, if the proposed method triggers a moral hazard or 'free rider' attitude among other nations but the poorest, it may render the implementation of a system based on differential pricing and corporate internal funding prohibitively expensive and risky to execute. Lastly, calculating the 'zerosum' EIV threshold level will have to be done carefully. For example, if billions of doses of HIV/AIDS vaccine must be produced at minimal cost, any downward deviation from the above 'zero-sum' base scenario would push corporations rapidly below the marginal cost of production and into negative earnings.

\subsection{Incentive and investment relationship in $\mathrm{R} \& \mathrm{D}$ on developing world diseases}

\section{The incentive-investment relationship}

Under the current rules, pharmaceutical and biotech companies lack the incentive to invest in pharmaceutical and medical technology $R \& D$ underpinning the supply of medicines to combat poverty-related diseases. This section will examine the investment-incentive link by constructing the causal relationship between a corporation's $R \& D$ investment and a number of external public-funded incentive mechanisms. 


\section{Public private partnerships to combat $L D C$ diseases}

Currently, the World Bank, European Commission, National Governments and NGOs are investigating the costs, benefits, and implementation issues of a menu of incentives to raise private-sector investment in the development of new medicines for developing countries. They have expressed a special interest in developing vaccines for HIV/AIDS, TB and malaria. The major dilemma still is how to appropriately reward private investment and risk-taking in $R \& D$, while at the same time keeping access barriers and prices for the forthcoming medicines low in the poorest countries. Policy makers are afraid that without public intervention, mature and efficient markets will price products at their (normal) full development costs and risks. This rationale is based on the fact that investment in new products carries a high scientific risk and market uncertainty that has to be balanced by a higher price for the finished product. Conversely, the result of investment in low-risk products where the science is known, product development is straightforward, and the market is guaranteed, will be lower prices. In practice, producing a new medicine always carries some degree of risk; the question is how large is this risk, what drives this risk, and who takes or pays for it.

If the public sector were to carry little or no risk in the development of new medicines, all the risk would be left to private firms. Firms may choose to minimize the risk by slowing down or even halting investment in the development of a particular new product. If the firm does decide to go forward, it may translate the risk it encounters into higher prices once the product becomes available. Both of these responses - slow development and high prices - have in the past affected the availability of medicines that are important to the developing world. On the other extreme, the public sector could carry all the risk by mobilizing, for example, their national biomedical institutes that could be made responsible for the development, production and commercialization of these medicines. In practice, this approach has rarely proven successful. Public sector institutes involved in biomedical $R \& D$ are focused on basic science and knowledge diffusion, rather than single-mindedly solving applied research and development problems or ensuring large-scale, consistent production according to (international) customer needs. However, by engaging in a carefully structured partnership relying on each partner's strengths, the above R\&D riskinvestment equation could be changed. The public sector may consider sharing the risks with the private sector and thereby change the latter's behavior. This could be accomplished, for example, by guaranteeing a minimum purchase price and volume, which would reduce the uncertainty regarding demand, lower the risks to firms, and lead to lower costs. 
There is consensus among stakeholders that if the availability of medicines for developing countries is to be expanded, powerful 'push' and 'pull' incentive mechanisms to engage firms in R\&D on poverty-related diseases must be identified. But controversy still exists over what type of 'push-pull' mechanisms should be used, and what their likely impact will be, in combination or alone, on the private sector's investment decisions.

\section{Technology 'Push' incentive mechanisms}

Push mechanisms are aimed at encouraging the development of disease prevention and treatments by providing upfront financial support for $R \& D$ into preferred therapeutic areas. This funding might take the form of either subsidies for $R \& D$ carried out by private firms, or of increased funds to public, non-profit research organizations. Advocates of the direct funding approach argue that subsidized or even wholly nationalized $R \& D$ is the best way to produce safe and effective medicines for diseases of poverty (Hubbard, Love, 2005). However, there are drawbacks to the upfront funding of $R \& D$ as these subsidies may not necessarily lead to the development of useful medicines. Push strategies are subject to potential principal-agent problems. In particular, push mechanisms that subsidize research inputs are subject to problems of asymmetric information and moral hazard incentives (Grabowski, 2005). First, at the outset, it is extremely difficult to determine the exact amount of funding that will be required. Second, there is a risk of overspend as the project may encounter previously unknown obstacles or avenues of research. Third, project leaders may be tempted to exaggerate the likely cost of the research in order to secure as much funding as possible. Lastly, the involvement of public stakeholders may skew research objectives, as their demands may reflect political preferences rather than clinical or public health priorities. In addition to inefficiency and waste, there is no guarantee that government subsidies will produce any of the specified outcomes.

An alternative 'push' methodology for stimulating $R \& D$ on poverty-related diseases is to create a modified form of orphan drug legislation. Such modified form would define eligible drug candidates in terms of target diseases rather than disease prevalence and, for example, could include tax credits for clinical trial expenditure carried out in developing countries, or fast-track regulatory approval. Such grant funding may also include work on epidemiology and disease burden evaluation, and the exploration of the most cost-effective strategies to cure or prevent diseases in the target population. The European Commission seems to be a proponent of the 'push' mechanisms that indirectly reduce the cost of R\&D to the private sector in a non-competitive manner (Commission of the European Communities, 2003). This commitment is shown in the establishment of the European and Developing Countries Clinical Trials Partnership (EDCTP) aimed at building local capacity for 
the organization, conduct and analysis of clinical trials leading to new medicines. The EDCTP network is geared to provide services for clinical Phases II and III in the development and testing process. By its very existence, it assumes that there are sufficient new compounds to be tested. Unfortunately, the pipelines for HIV/AIDS, TB and malaria drugs and vaccines, as well as other medicines for neglected diseases, are far from robust (Kaplan, Laing, 2004) ${ }^{115}$. Other incentives will thus be needed to bring promising new entities from the discovery stage to the point where clinical trials are conducted, and back up larger-scale testing, (re)-engineering, and production scale up. It is known that, when new compounds successfully move through the R\&D pipeline, the costs of development mushroom in the latter phase.

\section{Market 'Pull' incentive mechanisms}

While push mechanisms require upfront funding for research activities in the hope that they will yield a useful medicine for neglected diseases, 'pull' mechanisms act at the other end of the spectrum, providing funding or other pecuniary incentives only when a specific, predetermined outcome has been achieved. Pull interventions are thus performance-based strategies and include among others, a guaranteed purchase fund, or a roaming (transferable) exclusivity clause (Morris, Stevens, Gelder, 2005; Kremer, Glennerster, 2004; Kremer, 1999a, 1999b).

The 'roaming exclusivity' clause system allows companies that market an approved medicine in less developed countries at low prices, to extend market exclusivity for an existing and approved product, in a different therapeutic area in the more wealthy countries. In practice, pharmaceutical companies that are based in wealthy markets such as Europe, the U.S. and Japan will receive a patent extension for one of their existing products, in return for inventing a drug or vaccine for a poverty-related disease on a pre-determined list. The net effect of this incentive mechanism, were it to be employed, is to transfer the financial burden of developing new medicines for the developing world onto the medicines consumption of patient-consumers living in OECD countries (Morris, Stevens, Gelder, 2005). The question is whether diabetes, cancer, or cardiac parients - and their insurers - will accept to carry the extra financial burden for LDC-medicines on top of their own healthcare bills. Moreover, the market exclusivity clause might lead to price distortions in the therapeutic categories where the patent life of the beneficiary brand is extended. If no viable alternative medicine is available in that therapeutic category, this may prove politically difficult for governments, or third-party payers, that wish to control the spiraling healthcare

\footnotetext{
${ }^{115}$ In other words, if new chemical or biological entities are not available to be tested in clinical studies, the
} EDCTP will be underutilized. 
costs in their nations. A roaming exclusivity incentive system would also favor industrialized country manufacturers over developing country manufacturers who have little blockbusters in their commercial portfolio.

The other alternative system to creating a 'guaranteed' purchase fund entails that a visible pool of money is committed in advance by industrialized nations or supranational organizations (e.g. The World Bank). Under this proposal, a guaranteed purchase fund based on pledges from rich $(O E C D)$ governments or private charity organizations (Bill \& Melinda Gates Foundation) is established in order to purchase drugs and vaccines with pre-specified requirements. The money committed by these organizations could be earmarked so that it will only be spent on products resulting from the successful research and development of medicines for diseases of significance to the developing world. This approach has a number of attractive features originally described in two working papers published by Kremer at Harvard University, MA (Kremer, 1999a, 1999b). The concept has been further explored by the Center for Global Development (CGD) - an independent not-for-profit think tank on poverty related issues - and by other scholars (Barder, Levine, Kremer, 2005; Batson, 2005; Berndt, Horvitz, 2005; Danzon P., Pereira N., 2005; Grabowski, 2005; Hinman, 2005; Lieu, McGuire, 2005; Pauly, 2005; Barder, Levine, Kremer, 2004 Batson, Ainsworth, 2001). The benefit of what these researchers have termed an advance market commitment (AMC) is that it rewards successful $R \& D$ outputs rather than granting upfront support and funding of $R \& D$ that may not succeed. Public sector purchasers and taxpayers run relatively little risk because the technical development cost and investment risks are absorbed by the private sector. Transaction costs are expected to be minimal because managerial interventions are left to research-based companies and partners, in other words, to the invisible hand of market and competitive forces.

\section{Backwards induction as control mechanism for funding}

The effect of any of the above 'push-pull' incentive systems on the private sector's investment decision-making process can be simulated by employing the risk-adjusted investment model developed in the previous section. As explained, pharmaceutical and biotech $\mathrm{R} \& \mathrm{D}$ projects with a low EIV run the risk of being categorized as low priority to the individual firm, and will thus receive little internal funding during budget allocation. These projects may not fully benefit either from the resources that are available to the firm (e.g. sharing inhouse expertise and scientific knowledge, process know-how, technology platforms, laboratory and engineering infrastructure, managerial competencies and skills). As a result, technical and economic spillovers from other important and well-resourced research and development projects are not exploited although they are available in the company. 
To illustrate the effect of the proposed external incentives on an individual firm's decision process, an overlay to the original 'risk-investment' framework has been constructed see figure 21. The 'push-pull' incentive levers are represented by a double 'feedback/control' loop (one for push and one for pull as shown by the dotted line). The backward induction originates from the firm's likely decision to 'not invest' in a particular R\&D project for LCD countries. If simulation experiments demonstrate that the anticipated EIV-outcome is negative for a particular project of high importance to the developing world, the feedback/control loop will activate the 'push' and/or 'pull' incentive systems. The impact of these systems can be assessed quantitatively by using our integrated 'risk-incentiveinvestment' model ${ }^{116}$, which allows for calculating the external funds needed to overcome the internal hurdle of corporate investment and resource mobilization.

Figure 21: Two-stage model illustraring 'push' and 'pull' incentive systems

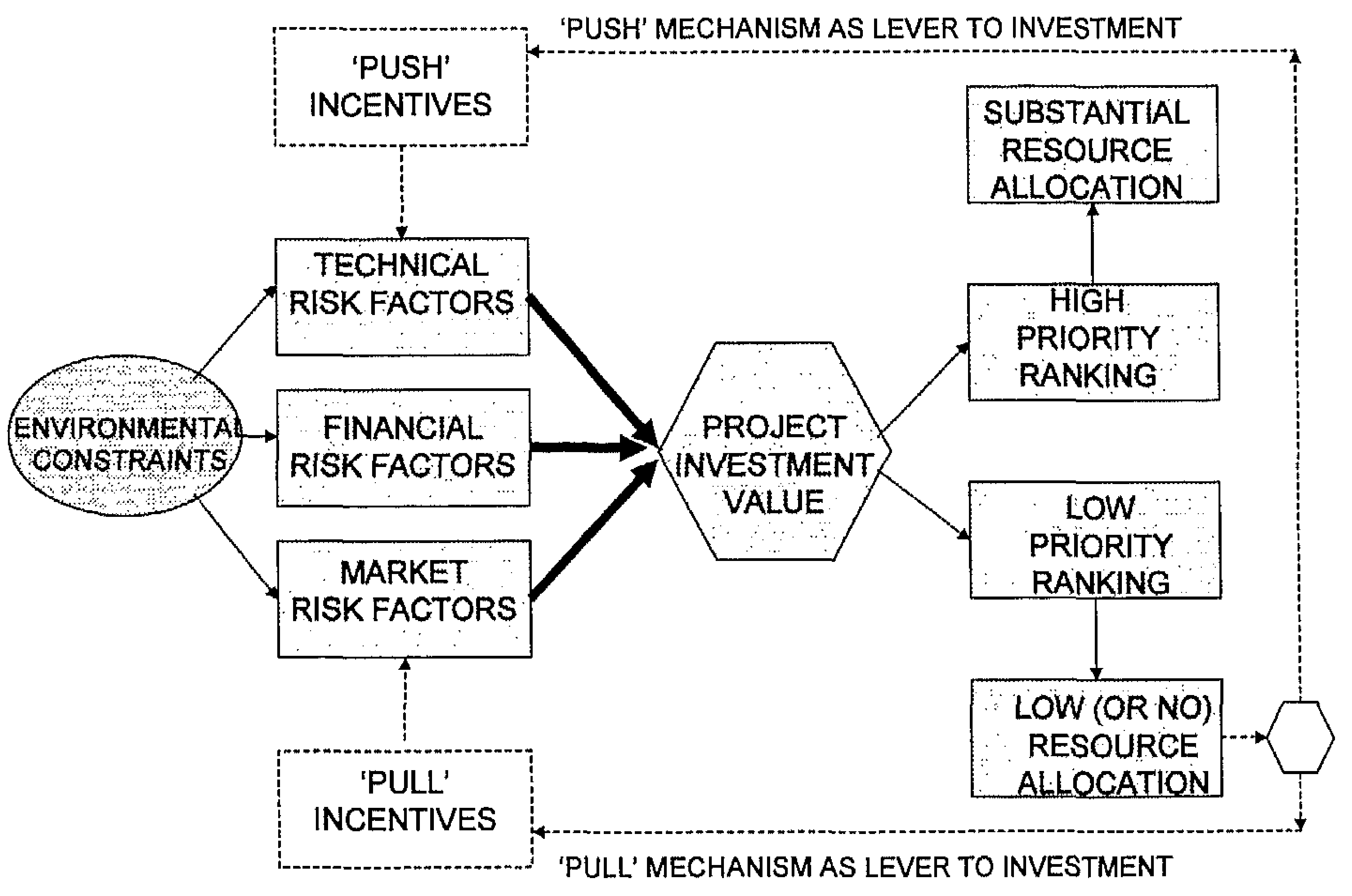

\footnotetext{
${ }^{116}$ From the ourset, the objective has been to calculate the minimum EIV threshold level needed to reverse a firm's 'no go' into a 'go ahead' decision for a particular R\&D project. Thus, the 'push and pull' incentive mechanism acrs as a moderator for stimulating private sector investment in developing country diseases. These incentives should however not be used to support other more lucrative projects. They should only be activated if the EIV of the developing-country R\&D investment branch turns negative. In other words, they should not be used to sponsor R\&D programs for high or middle-income markets as these projects should be financially self-supporting.
} 


\title{
6.5 Calculating the impact of 'Push' and 'Pull' incentive mechanisms
}

\author{
Advance market commitments for stimulating R\& $D$ on $L D C$ diseases
}

A new and potentially powerful incentive system, which is currently being debated in the international arena, would support $\mathrm{R} \& \mathrm{D}$ addressing unmet medical needs encountered in the developing world. The system is based on government donors pledging funding for new medicines that have been developed by the private sector (i.e. biotech companies, multinational pharmaceutical firms, and emerging market suppliers). The world's affluent countries represented by the G-8 have already welcomed the principle of this incentive system termed 'Advance Market Commitments' or AMCs ${ }^{17}$. At recent summits, the AMC mechanism has been considered, a powerful, market-based mechanism alongside direct funding, aimed at stimulating private-sector $\mathrm{R} \& \mathrm{D}$ on vaccines for diseases that predominately affect the poorest countries' (Di Leo, Clark, 2005). The G-7 finance ministers and central bankers decided that in principle they would like to launch a pilot program of AMCs for the purchase of new vaccines ${ }^{118}$. However, several issues need to be dealt with first before such an economic incentive mechanism could be applied. 'This includes estimating the 'right' size of external funds needed by the developing world in each of the therapeutic categories as well as the conditions for long-term supply and demand.

AMCs are expected to facilitate the critical review of corporations' $R \& D$ portfolios. It also has the potential to devise an investment policy in new medicines development that works for all countries in the world, independent of their GDPs and historical buying patterns. At the beginning of each $R \& D$ project, biotech and pharmaceutical corporations must decide

\footnotetext{
${ }^{117}$ The AMC structure would consist of a binding agreement between companies and donors, either from governments or private foundations. The donors would pledge to purchase an effective new medicine/ vaccine against a disease selected by an independent committee in order to treat or immunize a pre-determined number of people at a set premium price, high enough to generate revenues similar to those for other products (size to be determined). Donors/sponsors would only be required to pay after an effective product has been developed by the private secror. In the long run, companies are 'obliged' under this agreement to sell the medicine/ vaccine to eligible developing countries at an affordable price after the AMC period (when the above AMC fund offer has been depleted). An AMC commitment would apply to the lowest-income countries only, leaving companies free to sell their product at higher prices to the more affluent countries. In return, developing countries themselves should be making efforts that evolve beyond setting an affordable price if, and when, a new medical product becomes available. Particularly of concern to corporate and public investors are infrastructure problems in many geographic areas of the developing world. This could adversely affect the diffusion and delivery of new medicines even when there is a high medical need and prices have fallen down close to production cost.

${ }^{118}$ The G8 ministers acknowledged that immunization is the best way to fight global diseases. It saves lives in a cost-effective manner as it fosters development through its beneficial impact on human capital. The potential impact of effective vaccines on quality of life and economic development in the developing countries as well as their contribution to achieving the MDGs are hard to exaggerate. For more details, see chapter 1.
} 
which geographic strategies and investment options to pursue. This selection of geographic scope has an immediate implication on the choice of new product formulation (e.g. the inclusion of multiple bacterial/viral strains encountered in different regions around the globe), the level of scaling-up manufacturing (e.g. size and number of biofermentors), and the number of multi-country clinical trials and product registrations ${ }^{119}$. It should be no surprise that scarce $R \& D$ resources will first be invested in the development of compounds destined for use in the EME. Secondly, a mixed geography option may be considered in which companies address the type of unmet medical needs encountered in both the developed and developing world. Thirdly, compounds that are developed for exclusive use in poor countries are considered. Unfortunately this option may not be a priority. But thanks to the AMC scheme corporations will have the opportunity to consider investing in the above three-pronged approach based on equal footing from the beginning of the $R \& D$ projects onwards. A 'zero-sum' based calculation method is therefore advocated for the LCD-country R\&D project investment branch but not for the other two branches that are comprised of the more affluent countries which are deemed to be self-supporting.

The various strategic options are illustrated in figure 22. Depending on the global prevalence of a particular disease, the biotech or pharmaceutical company has the choice to target and launch its new compound in the following geographic areas: (i) $\mathrm{L}+\mathrm{M}+\mathrm{H}$ countries; (ii) $L+M$ countries; or (iii) $L$ countries only ${ }^{120}$.

In the first scenario, fixed development costs are absorbed by the high and middle-income countries. In the second scenario, only middle-income countries are in a position to cope with expenses and therefore absorb the fixed R\&D costs. And in the third scenario, which is dealing with diseases exclusively seen in the poorest areas, project costs need to be written off and be directly absorbed by the low-income countries themselves (or their sponsors). The result of employing the respective cost distributions is that varying degrees of external funding will be needed. The scale of funding will range from $R \& D$ projects that are deemed to be self-supporting (with the joint costs paid for by rich countries) to projects where almost $100 \%$ of the R\&D costs must be taken care of by local developing country governments and/or international donors. This is illustrated in figure 23.

\footnotetext{
${ }^{119}$ A number of national and international agencies will have to approve the multi-country clinical trial plan and will inspect the production facilities before marketing licensure is granted. The worldwide supply efforc also entails building, maintaining and controlling local manufacturing facilities for bulk production, filling and packaging. This could be done through a system of technology transfer and licensing agreements or joint ventures with partners in the developing countries.

${ }^{120} \mathrm{~L}=$ Low income country; $\mathrm{M}=$ Middle income country; $\mathrm{H}=$ High income country. In this analysis, we are nor interested in diseases confined to high and/or middle-income countries but rather diseases that are predominantly affecting low-income countries.
} 


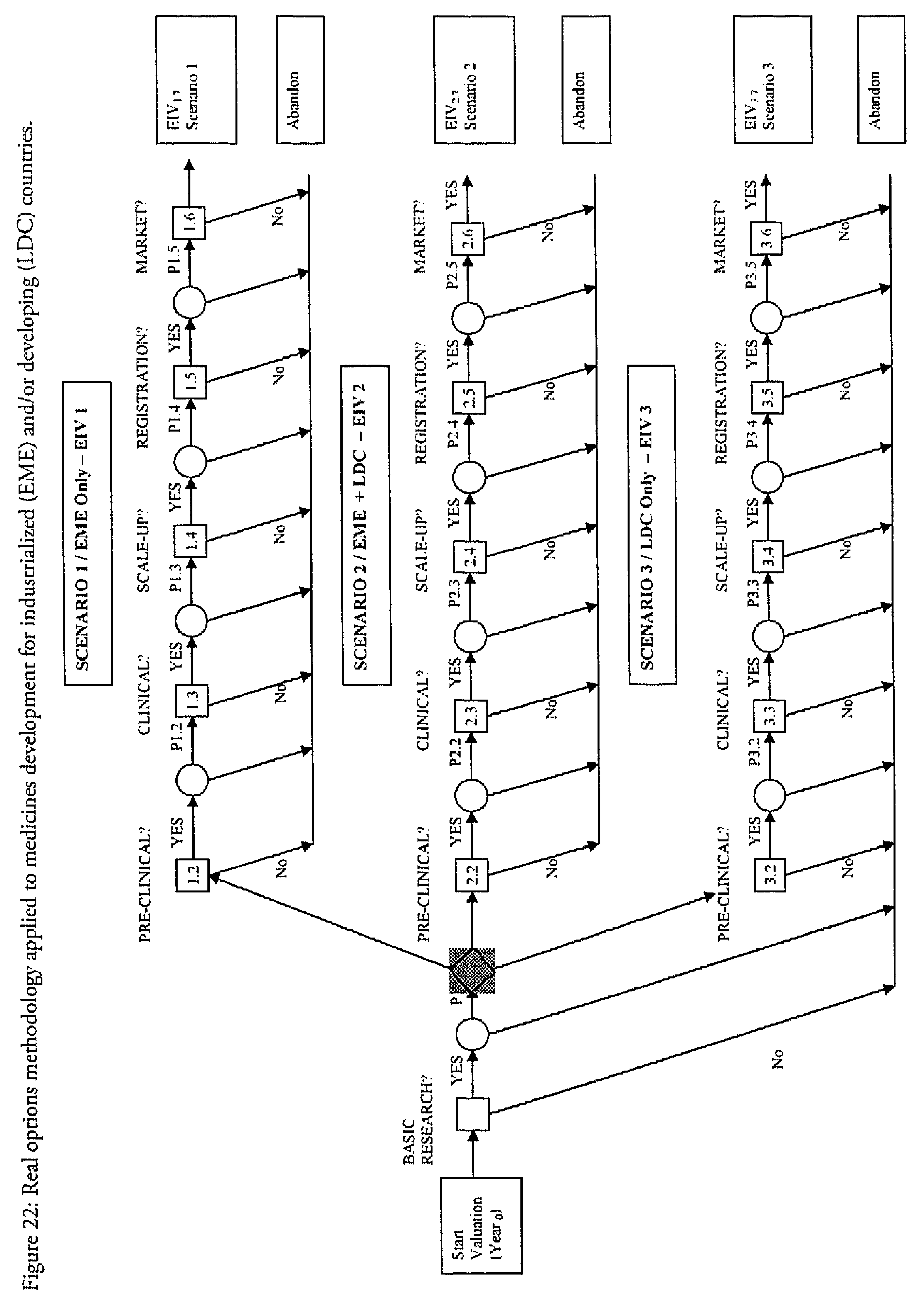


One of the greatest challenges in developing an AMC-based incentive mechanism is determining the 'right' market size needed to trigger an efficient pharmaceutical $R \& D$ response. The Center for Global Development recommends that external sponsors should aim at: i) setting the guaranteed market revenue high enough in order to accelerate $R \& D$ in the identified and preferred disease area; and ii) setting the size of the commitment below the social value of the medicine, so that sponsors do not commit themselves to paying more for a new product than it is worth to society (Barder, Levine, Kremer, 2005). The CGD has estimated that in terms of a firm's opportunity cost, the creation of an AMC worth US\$3.1 billion NPV (expressed in 2004 U.S. dollars) is comparable to the value of the lifetime sales of an average pharmaceutical product ${ }^{121}$. This assertion is based on the reasoning that the level of historic sales obtained from existing pharmaceutical products in the industrialized world has been sufficient to attract commercial investment from pharmaceutical firms. Therefore, CGD has therefore recommended establishing an AMC of a value around US\$3 billion for each disease category.

Academic researchers and industry managers alike have contested this approach. The fact that an AMC should aim at creating a 'market' comprised of several product brands and that the historic sales database used by CGD refers to revenues represented by only one commercial blockbuster in a given year, means that employing a standard opportunity cost across the board does not take into account the technical complexity of $R \& D$ projects nor the variation in disease burden among therapeutic categories. In addition, this omission in the original incentive model impedes the possibility of applying tiered or preferential pricing, which is known to be another mechanism for bringing new medicines to developing countries at affordable prices (while recovering the fixed $R \& D$ investment costs from industrialized nations). Further research is needed to assess the conditions under which AMCs would be most effective and how much funding would be needed to make this mechanism work in conjunction with a system of tiered pricing. Chapter 8 will propose an improved AMC calculation method..

\footnotetext{
${ }^{121}$ These recommendations are not based on the projected costs of conducting research and development but on the realized sales revenues of existing - commercially available - pharmaceutical products.
} 


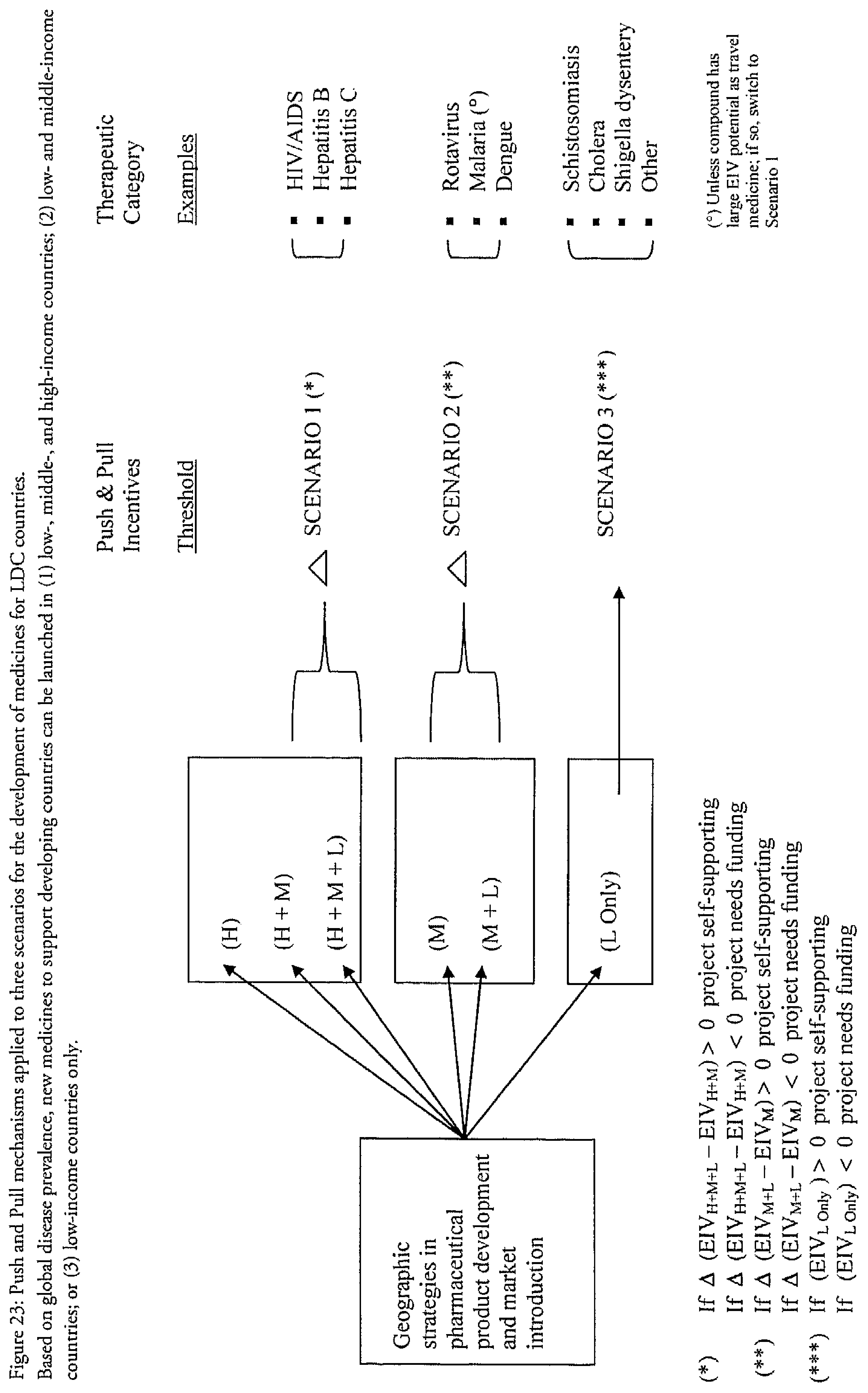




\subsection{Conclusion}

In addition to the significant scientific risks inherent to the development of a new medicine, market considerations play an important role at each stage of the pharmaceutical $R \& D$ process during which candidate medicines move from discovery to testing, licensing, production, distribution, and delivery. This chapter proposed a managerial decisionsupport model that compares a number of investment strategies with their respective risk factors and return-on-investment outcomes under uncertainty.

A firm's decision to invest in research, development and supply of new medicines, although tied to scientific-medical progress, is based on economic forecasts including in particular the costs and risks of investment, as well as the expected return on future sales in various market segments. The market value for medicines in the developing world is unfortunately small compared to markets in the industrialized world. This is in stark contrast to their medical need. Consequently, for new and complex medicines to be invented and produced for the developing world, governments and donors of rich countries should provide research-driven manufacturers with a framework in which there are clear incentives to invest in $R \& D$. As such, they will harness their invaluable assets for the benefit of the world's poorest populations.

New incentive systems that are often categorized as technology 'push' mechanisms and market-oriented 'pull' mechanisms offer prospects for efficient ways to support the development of new medicines with the potential to combat diseases concentrated in LDCs. As a general rule, 'push' incentive mechanisms are subsidizing costs, while 'pull' mechanisms will increase demand. These two options are not mutually exclusive and can be used when appropriate for stimulating R\&D into specific therapeutic areas. Each of them presents a different set of challenges, but the bottom line is that to be successful each requires a visible and sustained commitment from governments and donors of the more affluent countries. This comprises countries with GDPs in the category of middle to high-income brackets. Depending on the prevalence of the disease the usually high fixed costs of pharmaceutical $\mathrm{R} \& \mathrm{D}$ can be written of on the affluent customer base. This provides de facto an advantage to the poorest countries but does not necessarily increase the price in affluent markets compared to the base case scenario.

If such a political commitment were present, sponsors could make a binding commitment to pay for a desired novel medicine if and when it is developed. By establishing so-called advance market commitments firms can then invest in developing new products for developing country markets with the confidence that, if they succeed, there would indeed be a real market. In short, AMCs provide a valuable incentive system through which innovative companies can recoup the investments they made in building research, development and 
production capacity. The computer simulation model proposed in this chapter makes it possible for donors and policy-makers to calculate the size of external funds needed in order to successfully implement this novel economic incentive scheme. 


\section{Public incentive mechanisms for stimulating pharmaceutical $R \& D$ on poverty-related diseases}

The question of how to provide economic incentives for $R \& D$ on medicines for use in developing countries has intrigued economists, policy makers, public health specialists, and industry executives for a long time. The debate about the best use of private and donor resources in the fight against AIDS, TB and malaria has become increasingly intense. This chapter will explore a range of public policy measures beyond the classical R\&D tax credits. The publicly funded policy measures that support pharmaceutical $R \& D$ can be broadly classified into two categories: 'push' and 'pull' mechanisms. Push measures aim to stimulate private and public sector R\&D activity from an early stage onwards in the new product development process through a mechanism of direct project funding. By contrast, pull measures aim to enhance the incentive for conducting pharmaceutical $R \& D$ by improving the prospective value of the market for producers of new and improved medicines for use in developing countries through a credible commitment to purchase these products if they become available. This chapter will analyze the advantages, risks and drawbacks of these various incentive mechanisms. 


\subsection{Introduction}

Pharmaceutical $R \& D$ is a long-term, risky and expensive business. It can take up to 20 years to develop and produce a new product and costs hundreds of millions of U.S. dollars. Private sector companies will only invest substantial funds in $R \& D$ if they are confident that a market will exist for a future product.

The classical incentives to stimulate corporate $R \& D$ like tax credits are by themselves not enough to trigger interest from pharmaceutical and biotech producers in developing products for low-income countries. This chapter will explore public policy mechanisms beyond the common $R \& D$ tax breaks that could strengthen investment in products needed in the developing world. Such policy measures have been classified as 'push' and 'pull' incentive mechanisms. Push mechanisms aim to stimulate public and private sector activity from an early stage in the product development cycle through direct funding of selected projects. On the other side of the spectrum, pull measures are aimed at strengthening market incentives by improving the value of the prospective market for producers of new and/or improved medicines for use in primarily the developing world.

It is often argued that technology 'push' mechanisms exert greater influence early in the value chain of product development, while market 'pull' mechanisms are stronger later in the process. However, the latter system may also indirectly encourage investment into basic research program ('discovery') in select therapeutic areas. A schematic overview of the various 'push' and 'pull' systems is provided in figure $24 \mathrm{~A}$ and table 6.

Figure 24A: Pushing and Pulling Potential New Medicines through Development

Push mechanisms exert greater influence early in the value chain

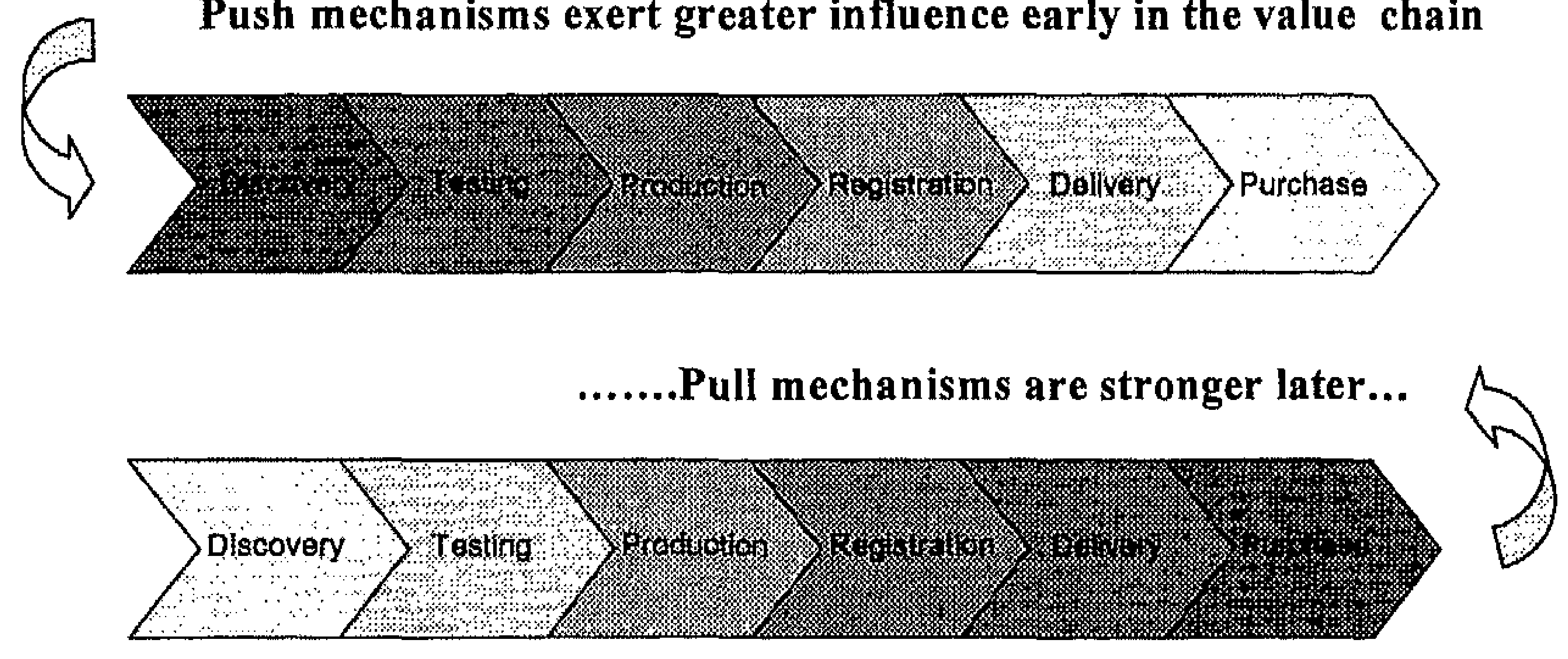

Level of Influence

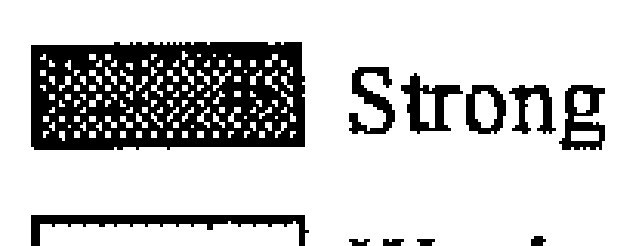

Weak 
Table 6: List of Push and Pull incentive mechanisms to stimulate pharmaceutical R\&D
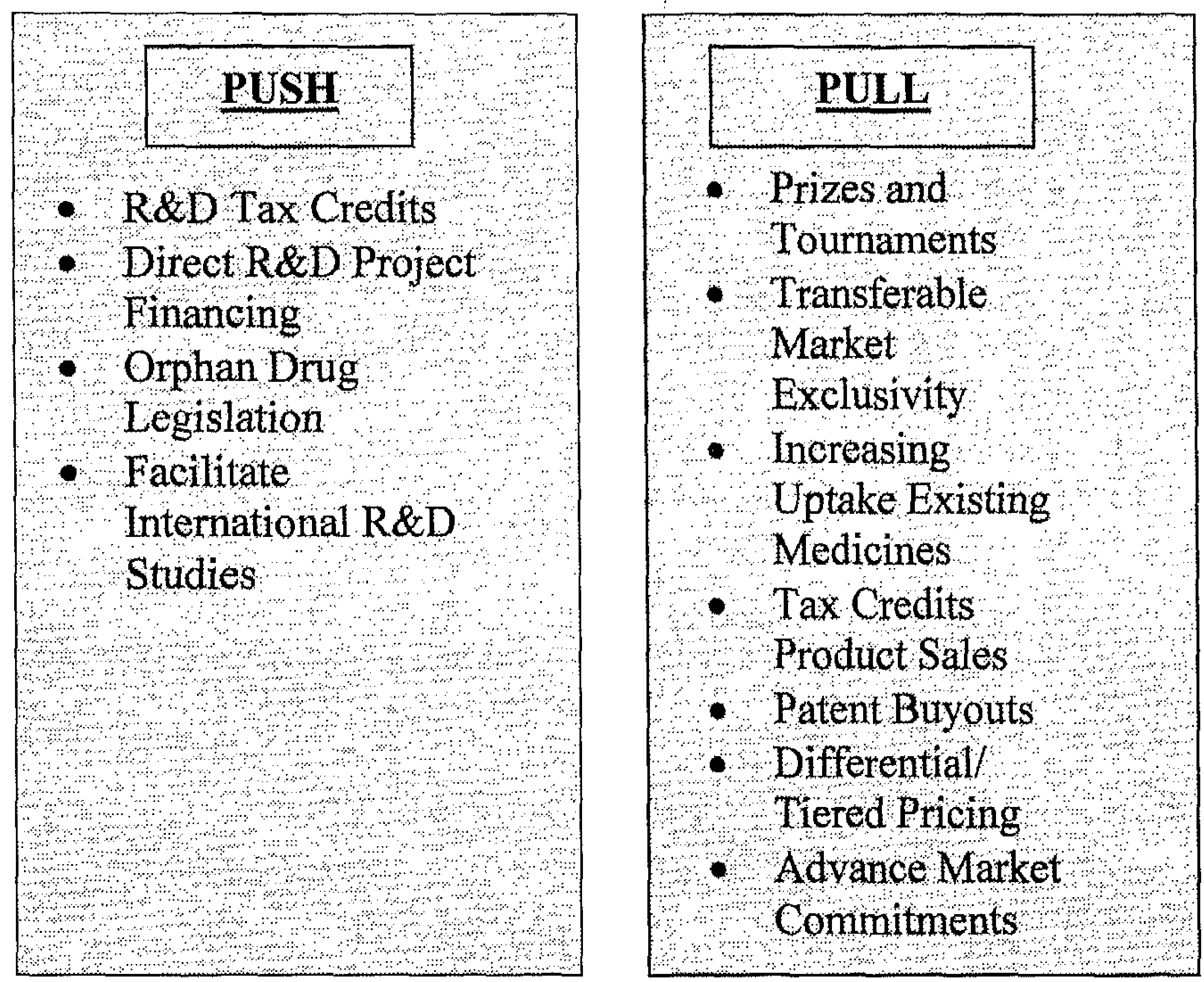

For many scholars and practitioners, it is becoming increasingly clear that there is no 'silver bullet'. No incentive mechanism, neither 'push' nor 'pull', will single-handedly solve the lack of new drugs, vaccines and diagnostics urgently needed in developing countries. The issue is that while the goal of the public 'buyer' and the private 'supplier' may be similar; the definitions of incentive and ideal situation are diametrically opposed. For a publicsector procurement agency, the ideal scenario would be to avoid all risk by only purchasing a product once it is fully developed, the demand is present, and the product is available at a very reasonable price. The opposite is true for the private sector supplier for whom the ideal situation is one in which the innovator's risk is reduced through some sort of upfront agreement that 'locks' the public sector into purchasing the final product, if possible at a specific price and quantity, before it is developed. Each of these systems has specific benefits, risks and drawbacks, the most important of which are set out in the following chapters. 


\subsection{Overview of 'Push' and 'Pull' systems for stimulating R\&D}

The computer-assisted simulation model proposed in this book allows policy-makers and donors to calculate the minimum amount of external funds needed to successfully implement these 'push $\&$ pull' incentive mechanisms, alone or in combination. The details of this analytical model and the interactions between the various key parameters of the resulting 'risk-investment-incentive' framework are described in chapter 6. The impact of 'push \& pull' mechanisms in reducing the risk to the firm's capital and human resource investment decisions in R\&D - and their ability to positively influence the company's decisionmaking process - is illustrated in figure $24 \mathrm{~B}$. An overview of the main characteristics of the various $R \& D$ incentive-mechanisms is provided in table 7 . 


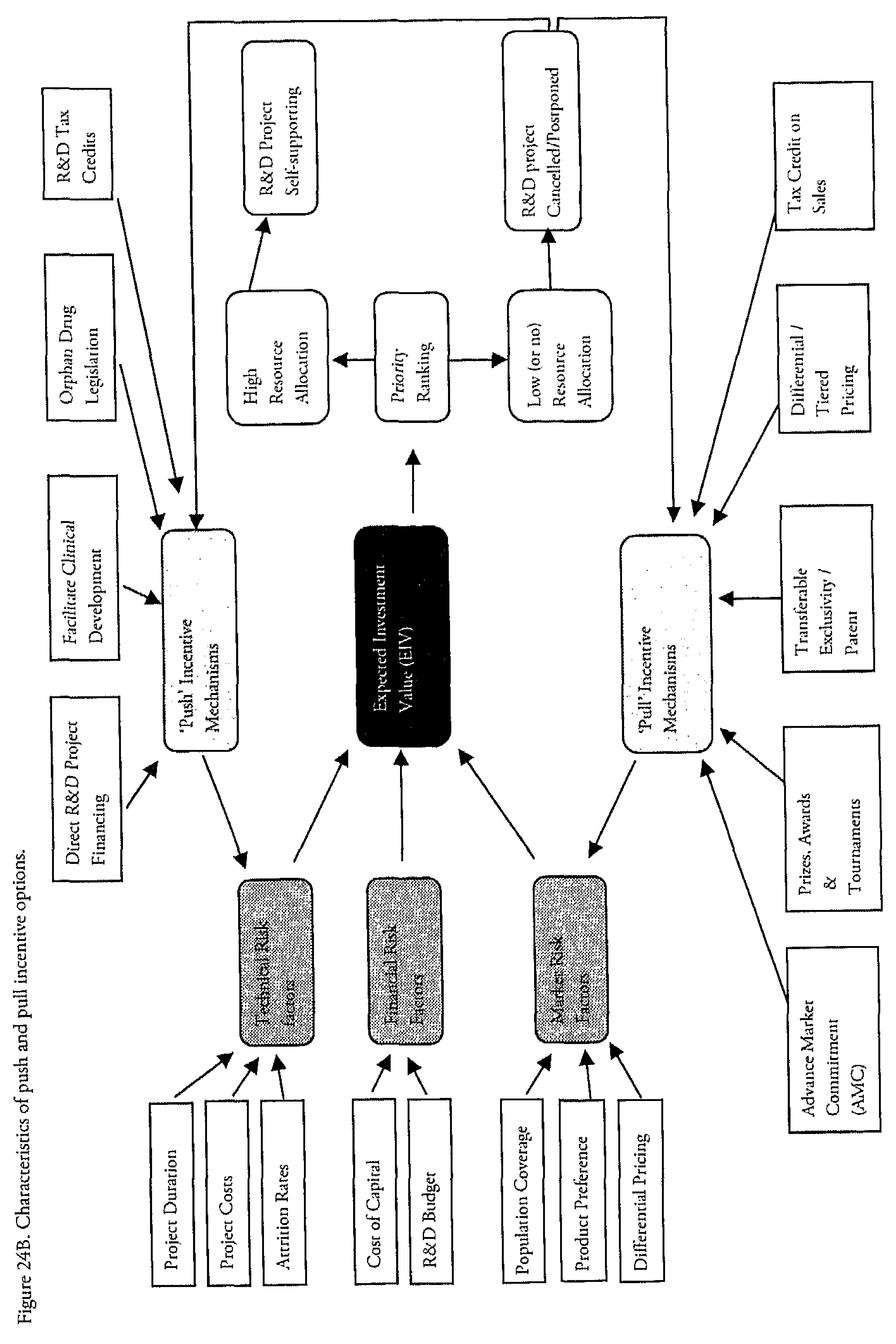




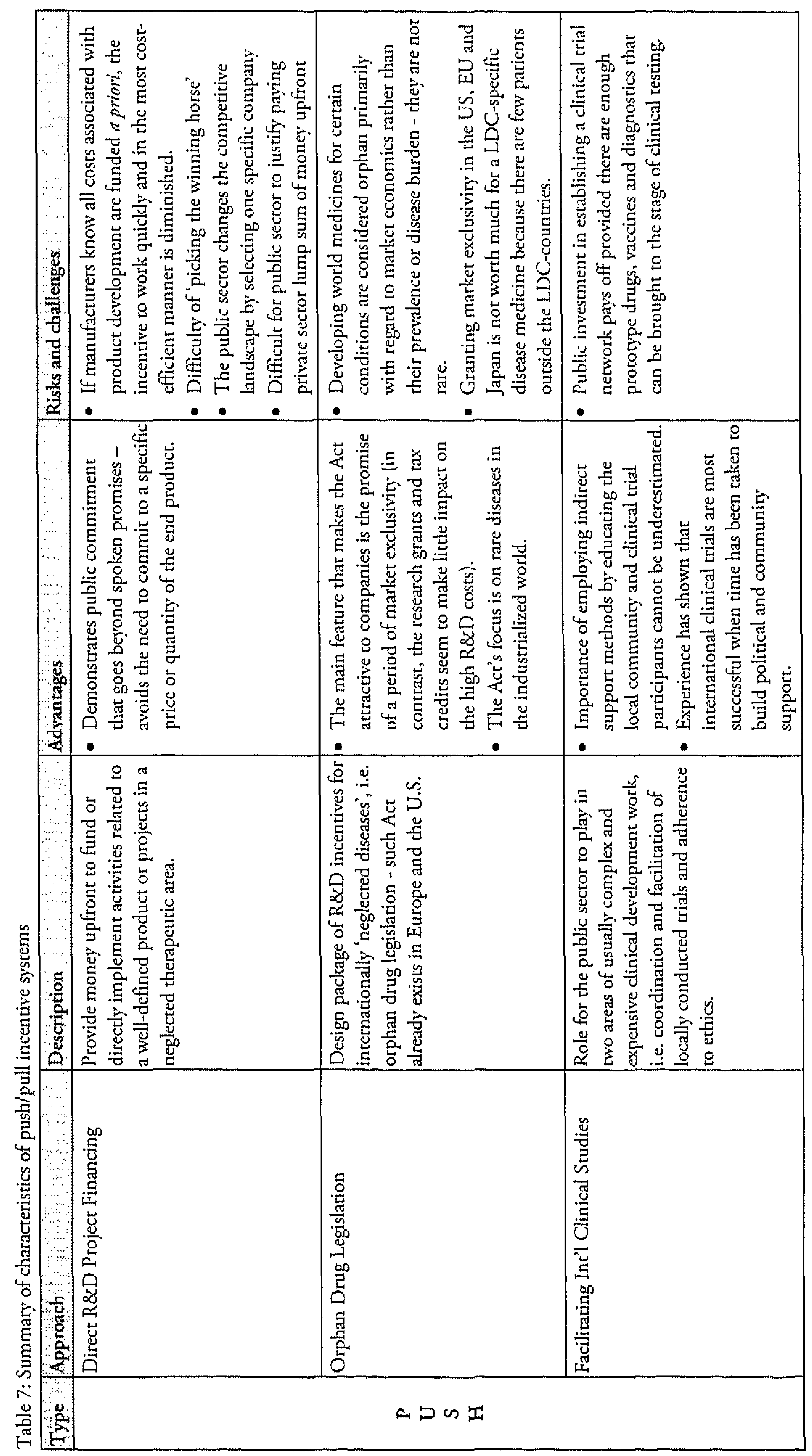




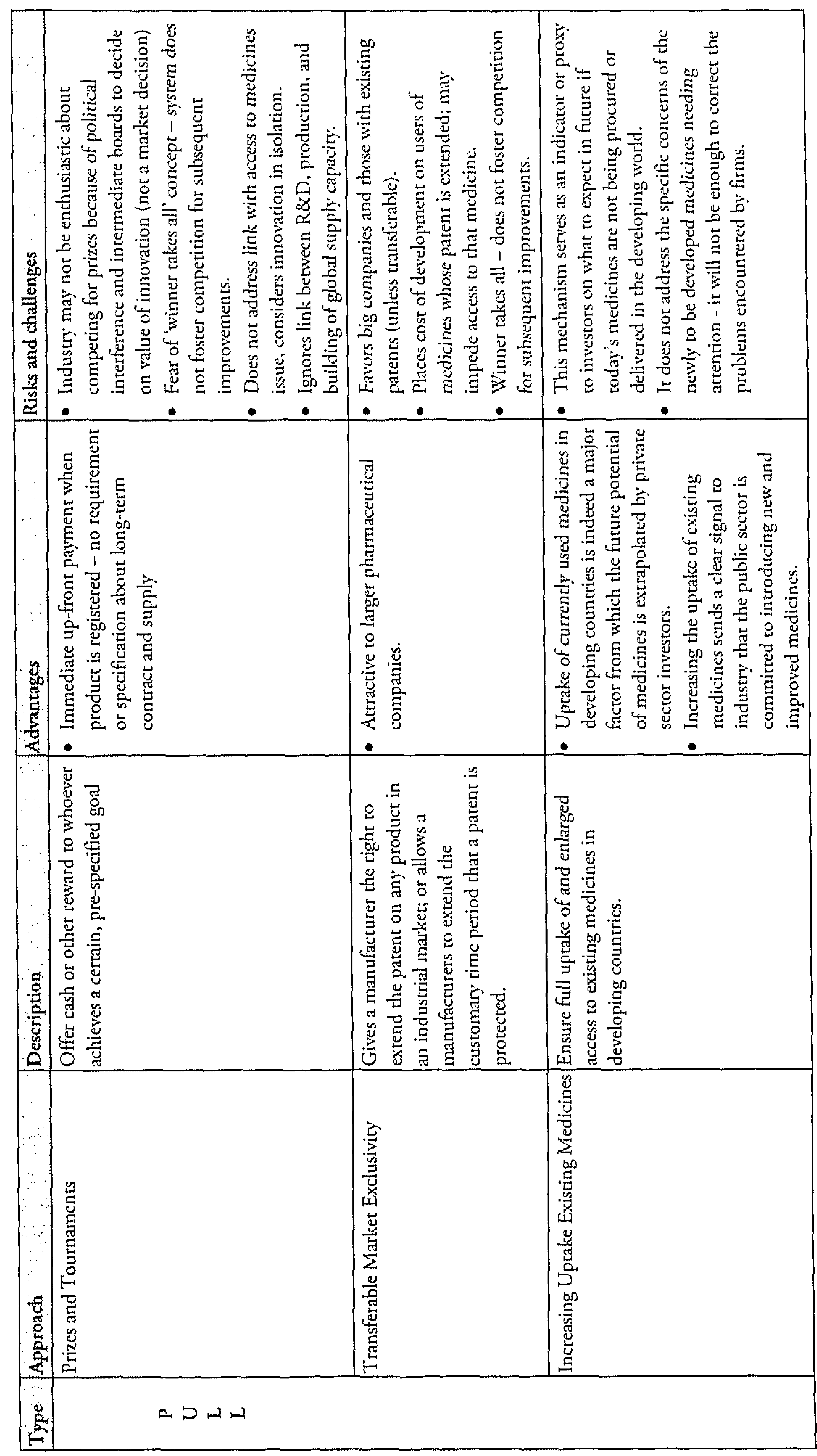




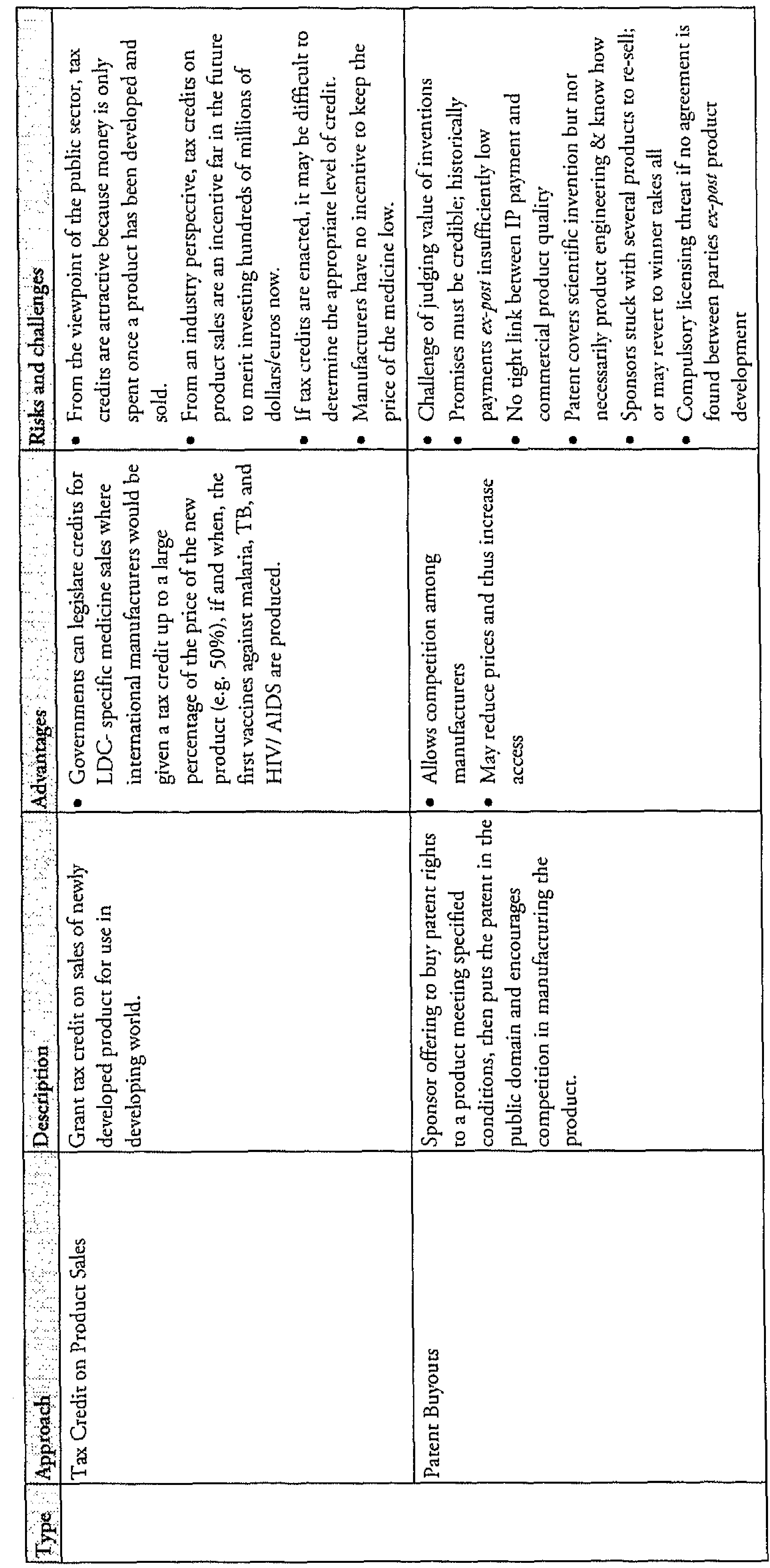




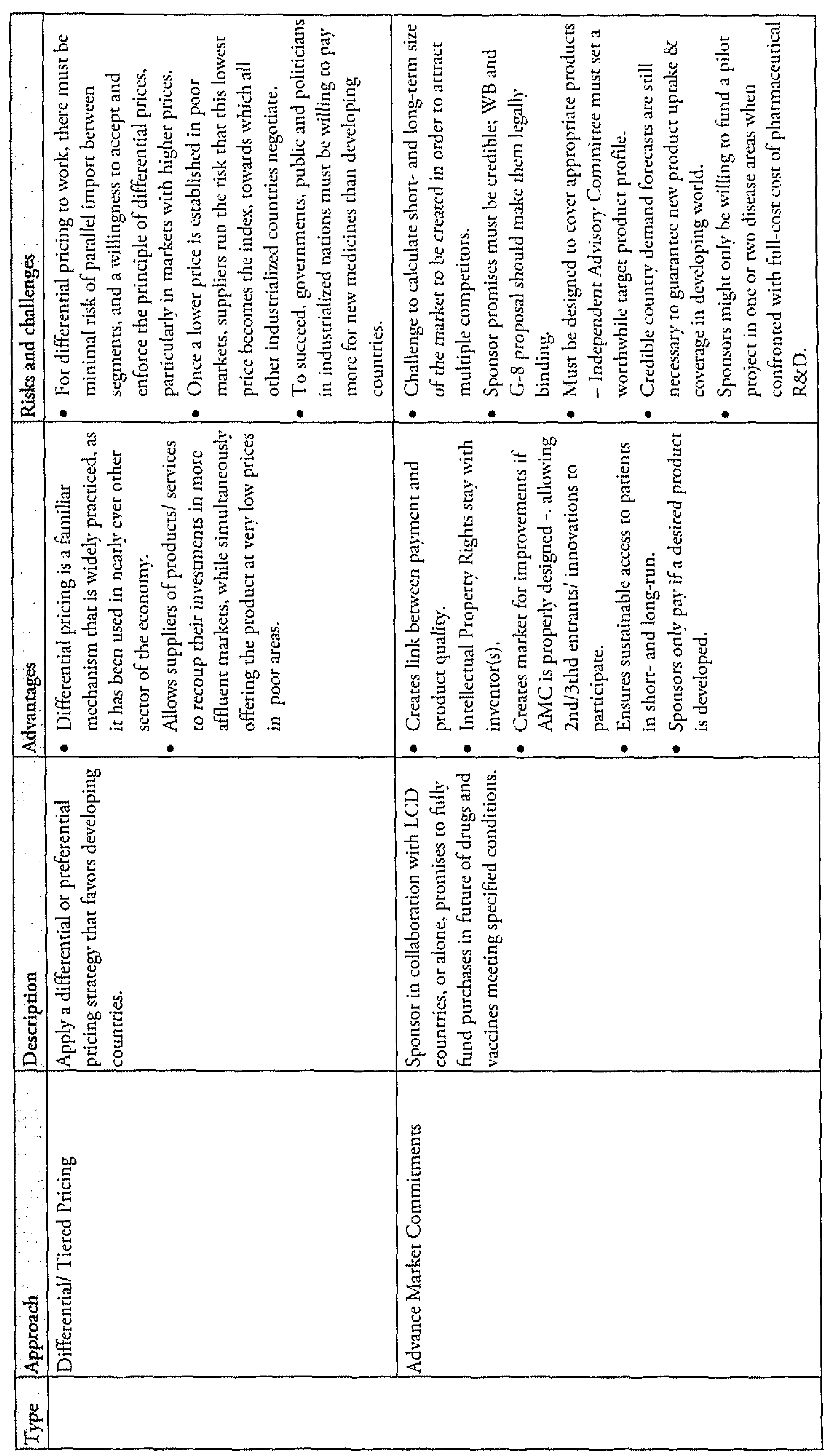




\subsection{Technology push systems to support R\&D on developing world diseases}

Conceptual framework for technology 'Push' options

Historically, the public sector has invested substantially in 'push' mechanisms, particularly basic biomedical research and some early product development. Technology 'push' options offer a number of benefits, of which the most important is reducing the risk to the product innovator and developer. The familiarity with and proven track record of this type of publicly-funded intervention are therefore considered important. However, these push mechanisms necessitate specifying and picking one prototype, or candidate product, over another. This entails sponsoring the R\&D of a particular innovator or company and as a consequence an amount of erosion or loss must also be taken into account since 'picking a winner' early in the process means that some $R \& D$ projects may eventually fail. It is quite possible that better options emerge at a later date.

Consequently, the public sector prefers to employ push mechanisms that are more generally defined, like providing funding to help develop animal models to better understand and explore a certain disease area; or developing laboratory assays and in-vitro surrogate markers that are needed to measure the impact of new medicines. This could include providing logistical and infrastructural support to companies that would like to conduct international field epidemiology studies, including clinical studies of natural exposure and resistance to disease, or health economic and cost-benefit studies to support the worldwide introduction of a newly developed medicine. These sets of activities are purposely broadly defined to support all products and prototypes that are developed in a certain therapeutic class and are thus not brand specific.

Finally, it should be remembered that push incentive mechanisms do not commit to an outcome, even though substantial money is being spent. Inevitably, some of the supported R\&D projects will fail whereas the money will already have been spent, and in most cases will be irrecoverable.

The following section will discuss the specific advantages and drawbacks of a number of key 'push' incentive mechanisms: 


\section{Push mechanisms - R\&D project funding}

Using direct funding as a push option entails providing money to finance or directly implement activities related to a well-defined product or a variety of $R \& D$ projects in a neglected therapeutic area. The main goal of this type of intervention is to increase the number of medicine candidates, provide data required for market introduction, and in general accelerate the process towards the selection and usage of the best, most efficacious product. Public 'push' funds may go toward financing either non-product specific activities, or product specific activities. In the category of non-product specific activities, the public sector can exert influence in a number of areas. Governments may fund fundamental research on scientific-medical issues like the pathogenesis of a particular disease, disease burden studies or the development of diagnostics to identify disease. The sponsors could also reward product formulations and presentations that, for example, can be conveniently used by children, or be adapted for use in resource-strapped settings. Finally, sponsors also play a role in helping the private sector navigate through the maze of international regulatory requirements and foster a climate of cooperation among authorities leading to the harmonization of the medicines approval process.

As a result, direct funding of $R \& D$ can be a powerful mechanism since it demonstrates public commitment that goes beyond spoken promises. The advantage is also that there is no need to commit upfront to a specific price or quantity of medicines. On the other hand, direct financing runs the risk of alternating the incentives in a way that works against the objectives of timeliness and efficiency. If manufacturers know that all costs associated with new product development are funded a priori, the incentive to work quickly and in the most cost-efficient manner may diminish. Most problematic perhaps is the fact that the public sector, by selecting to fund one specific innovator or company, changes the competitive landscape in a way that does not encourage competition, therefore reducing the number of candidate products and the possibility of 'picking the winning horse.' Finally, it will continue to be difficult for the public sector to justify paying the private sector a lump sum of money before any tangible progress has been shown, or a viable commercial product has been developed that is ready to be launched on the worldwide market.

\section{Push mechanisms - orphan drug legislation}

Designing a package of $R \& D$ incentives for a number of internationally neglected diseases in line with the 'orphan drug' legislation, which already exists in the U.S. and the European 
Union for domestic use - could be envisaged as a model ${ }^{122}$. The perceived economic market failure of medicines development for rare diseases in industrialized countries (i.e. diseases with a low prevalence rate like, for example, cystic fybrosis) has lead to the creation of incentives for the development of so-called 'orphan drugs' in the domestic market. By contrast, medicines for health conditions that are often highly prevalent in developing countries and cause a high socio-economic disease burden, may be considered as 'orphan' from an economic viewpoint. Private sector investment in $R \& D$ related to these types of conditions is constrained, primarily due to the low expected market opportunities that should develop from such investments. In other words, in the developing world, medicines for certain conditions are considered 'orphans' primarily based on market economics rather than their prevalence or disease burden.

Historically, there has been considerable discussion about possible mechanisms of public interventions like the orphan drug legislation. The U.S. Orphan Drug Act of 1983 uses market exclusivity and other mechanisms to enhance the market attractiveness, and thereby stimulate R\&D on products for diseases that are statistically rate in the United States defined as those diseases that afflict fewer than 200,000 Americans. The Orphan Drug Act provides the following incentives:

- Seven years of marketing exclusivity on FDA approval, i.e. the FDA cannot approve the 'same' drug for the same orphan indication from another company for seven years without the manufacturer's consent. Only if the new drug demonstrates clinical superiority can it be authorized for the same orphan disease.

- A tax credit for related clinical research, up to $50 \%$ of clinical testing expenses.

- Grant support for investigation of treatments for rare diseases.

The Orphan Drug Act has reportedly increased R\&D for rare (orphan) diseases. According to the FDA, more than 200 drugs and biological products for rare diseases have been brought to market since 1983, up from fewer than ten in the previous decade (Lichtenberg and Waldfogel, 2003). The main feature that makes the Act attractive to pharmaceutical companies is the promise of a period of market exclusivity (Henkel, 1999; Peabody. 1995). By contrast, the promise of research grants and tax credits taken together seem to have little impact on the high $R \& D$ costs involved. The greatest difficulty in applying the orphan drug incentive package to diseases prevalent in developing countries lies in the fact that granting market exclusivity for an LDC-specific disease medicine in OECD countries is not

\footnotetext{
${ }^{122}$ Regulation 141/2000 of EU Parliament and Council on orphan medicinal products created a procedure for the designation of medicinal products as orphan medicinal products. Orphan medicines are those "that without incentives it is unlikely that the marketing of the medicinal product... would generate sufficient return to justify the necessary investment" (Article 3, Regulation, 141/2000). In other words, orphan diseases apply so infrequently that the cost of developing and bringing to market a medicinal product would not be recovered by expected sales.
} 
worth much, because there are few patients outside the LDC-countries. As a result, companies are unable to sell LDC-specific products at high enough prices in the developed world to recoup their investments.

\section{Push mechanisms - Facilitating clinical trials}

Aside from providing funding for international research and development work, the public sector can play an important managerial role in two other areas of often complex and expensive clinical development work: coordination and facilitation of locally conducted trials and monitoring adherence to ethics (Glass, Batson, Levine, 2001). Experience has shown that international clinical trials are most successful when the investigator has taken the time to build political and community support. Potential roles for the public sector in this area may include working with local officials to inform and educate country participants of the need for and importance of these clinical trials and assist them in handling any problems that arise during the investigation. The role of education is extremely important; particularly for diseases like HIV/AIDS, TB and malaria. Clinical trial enrollees need to understand that participating in the trial will not necessarily protect them against the disease and equally importantly, that if they do contract the disease, that their participation in the trial is not necessarily the cause. Additionally, the public sector could help manufacturers of new medicines ensure clarity around issues of follow-on access. It is not uncommon for clinical trial participants to assume that their community will have guaranteed timely access to the new medicine once it becomes available. Since the time between a clinical trial and licensure of the new medicine is often longer in developing countries, this expectation needs to be addressed.

In developing countries, the importance of indirect support methods like educating the local community and clinical trial participants cannot be underestimated. Recognizing the need for this approach in the broader context of concerted actions around HIV/AIDS, malaria and tuberculosis and in the context of poverty reduction, the European Commission established a European Developing Country Clinical Trials Partnership (EDCTP) to accelerate the development of new and improved medicinal products. The EDCTP platform facilitates networking and co-ordination of international clinical research and development, strengthens clinical trials infrastructure in developing countries, and leverages funds to sponsor trials. The investment in establishing a clinical trial network will pay off provided there are enough prototype drugs, vaccines and diagnostics that can be brought to the (expensive) stages of testing in humans. Nevertheless, it is unlikely that by itself, this mechanism will be viewed as sufficiently valuable to alter private sector investment decisions and risk-taking behavior. 


\subsection{Market 'pull' systems for Stimulating R\&D on developing world diseases}

Conceptual framework for market 'pull' options

Pull mechanisms for the public sector are likely to be a safer form of intervention if structured so that money is given only in the event a desirable, affordable or specified product becomes available. However, the method has drawbacks when commitments to specific products are made early. The major problem of pull mechanisms is the difficulty of being specific about desired outcomes and returns far in advance of having an actual product. As previously discussed under push mechanisms, it is very difficult for the public sector to choose a 'winner' and justify that choice to the public (and also to members of the private sector) before an actual product exists. Similarly, it is difficult to agree to price and volume before a product is invented and licensed. If a 'winner' is ultimately chosen and a price is agreed, the public sector runs the risk of being 'locked-in' to an outcome that may or may not be the best option.

Conversely, the private sector may perceive pull mechanisms as being at the mercy of political 'changes of heart'. For companies that must invest early and heavily, future changes to political coalitions may have serious financial implications for investment decisions made earlier in the development process. To avoid that promises are broken, a legally binding guarantee will be required from sponsors preventing them to renege the original contract.

\section{Pull mechanisms - prizes and tournaments}

Prizes and tournaments are each structured slightly differently, but both have similar advantages and risks. Prizes are generally offered to whoever achieves a certain pre-specified goal or product, while tournaments generally offer a reward to whoever has progressed farthest towards the target by a given date.

The value of the 'pull' reward system is that it encourages competition and increases the number of potential therapeutic and preventative product candidates. It is relatively easy for the public sector to implement, whereas winning a prize or tournament has a valuable positive effect on public relations for the private sector. However, industry has never been enthusiastic about the idea of competing for prizes or in tournaments. The old Soviet Union used prizes in lieu of patents as a standard method for motivating individuals. It is well known that the Soviet experience was characterized by low levels of monetary compen- 
sation and poor innovative performance (Scherer, 1980; Artemiev, 1974; Hughes, 1946; Hughes, 1945). Overall, there is much less international experience with prizes as a means of encouraging innovation than with patents or research contracts.

For the system to succeed, the size of the prize awarded must correspond to the size of the investment required to win plus a premium. Historically, the awards that had been granted were miserly; they certainly were not what Schumpeter had in mind in describing "spectacular prizes . . thrown to a small minority of winners" (Scherer 1980). It is therefore doubtful that a generalized reward system administered in this conservative tradition would motivate as much risk bearing as the patent system presently does. It is doubtful that a central 'prize' committee, that may have the tendency to be conservative, would know the true market value of the medicine or technology it is hoping to create. In practice, there are two contrasting approaches leading to the following dilemma: if the prize is too low, companies will be reluctant to compete for future prizes which leads to fewer new medicines; and if the prize is too high, the new system will squander taxpayers' money and divert efforts from other areas of research.

Another even more serious drawback of employing prizes and tournaments is that these mechanisms not necessarily guarantee a viable, affordable new product at the end. After all, the prize, or tournament prize must be given to the winner, no matter what is being developed. Moreover, such a system does not reward second- or third generation entrants that are capable of offering enhanced product safery, efficacy or convenience. As such, prizes could potentially stifle innovation, especially in the long run.

\section{Pull mechanisms - transferable market exclusivity}

'Roaming' market exclusivity allows companies to transfer the market exclusivity awarded to them in the orphan drug package from the eligible LDC-specific drug to another product of their choosing. The possibility of transferring this exclusivity from one pharmaceutical product to another can be accomplished by employing either one of two specific mechanisms: a transferable patent extension or transferable market exclusivity. In each case, the innovator would benefit from some exclusivity awarded to an entirely different medical product marketed in countries with high(er) income(s), compared to the one destined to be used in the developing countries. In practice, transferable market exclusivities would have the effect of endowing any pharmaceutical or biotech firm's chosen product with an extra period of exclusivity in the more affluent (OECD) market.

Transferable patents could be a powerful mechanism to corporations because it could in principle extend the revenue stream of blockbuster products. Some of these blockbuster medicines generate revenues in excess of US\$500 million per annum. The prospect of 
extending exclusivity for these products will therefore create an incentive, which is hardly ever to be matched. Given the significance of the incentive, strict limits will undoubtedly be determined within a new legislative framework. Furthermore, any such incentive is likely to be linked by donors to a requirement for preferential pricing, and a commitment from the manufacturer to apply the lowest possible prices in countries where the LDC-medicine will be used. The problem, however, is that transferable patents disrupt the competitive playing field because it is generally the large pharmaceutical companies that have the 'blockbuster' products in their portfolio.

In an attempt to address the aversion of the public sector to extending pharmaceutical patents, a slightly different concept has been introduced. In 2006, Ridley, Grabowski and Moe proposed the U.S. FDA grants transferable 'priority review vouchers' to companies that successfully obtain approval for a drug or vaccine against neglected diseases, which can then be used to jump the queue for the review of another of the company's FDA applications. This could shave up to 6-12 months off the time to market for a potential blockbuster product. The gains of this accelerated approval process could be worth hundreds of millions of US dollars to major pharmaceutical companies; moreover, this would also benefit smaller biotechnology companies (that could sell such the voucher to a larger company) and generic firms (that could enter the market sooner given the earlier patent expiration). All in all, awarding a transferable 'priority review voucher' to any company that obtains approval for a treatment for a neglected tropical disease could act as a pull mechanism. The idea is that this procedure does not delay the approval process of other important medicines.

\section{Pull mechanisms - increase uptake existing medicines}

Private sector investors extrapolate the commercial 'potential' of still to be developed medicines from the uptake of existing (or under-utilized) medicines in developing countries. Increasing the actual allocation of real funds for existing medicines would therefore send a positive signal to the industry that the public sector in that country or region is committed to introducing new and improved medicines and enhance its credibility when calling for increased future investment from private sector investors. Where it constitutes a necessary but insufficient condition for enhanced private sector investment in $R \& D$ on developing world diseases, it forms at the same time a fundamental building block in creating trust between the private and public sectors. Increasing uptake of existing medicines in the developing world certainly serves as a good indicator that suggests to potential investors what to expect in the future. 


\section{Calculating the sine of incentives to accelerate pharmaceutical R\&D on poverty-related diseases.}

The World Bank, G8 governments, and other international community leaders have endorsed the concept of an 'Advance Market Commitment' to harness the creativity of private sector $\mathrm{R} \& \mathrm{D}$. The system is expected to accelerate development of medicines against diseases disproportionately affecting least developed countries. An AMC is an official commitment by donor countries to subsidize the purchase of a new product once it has obtained regulatory approval and developing countries have confirmed the demand for it. The objective is to help innovation-driven firms overcome the major investment barriers encountered in the creation and development of medicines against diseases afflicting poor nations. To address the remaining issues surrounding the AMC design, an in-depth understanding of how these investment decisions are made, is required. Running the simulation model proposed in the previous chapter will enable researchers and decision-makers to calculate the 'risk-adjusted' investment required by disease category. The calculation method is evidence-based and underpins the necessary R\&D investment decisions based on a public-private partnership. Here, we argue that a 'zero-sum' methodology is the optimal approach when determining the 'minimal' size required for AMC funds. 


\subsection{Introduction}

A number of pharmaceutical and biotech companies are pursuing products that have the potential to address diseases of the developing world but the level of effort pales when compared with the overwhelming need for new and improved drugs, vaccines, and medical diagnostics. To attract capital, companies must show shareholders and investors that their risk will be rewarded if the product succeeds. Unfortunately, the lack of a viable market for these neglected diseases makes it extremely difficult for private companies to fund internal $\mathrm{R} \& \mathrm{D}$ projects and in some cases keeps players entirely out of the field. Historically there have been delays of up to 15 years between the moment a new product is launched in industrial countries and becomes available in developing countries. To change this paradigm, greater market opportunities must arise in developing world countries to compete with all other R\&D demands companies face.

The G8 governments have commissioned the urgent development of new proposals for creating incentives and reducing the perceived risks of investments in the discovery and production of preventive medicines to combat diseases prevalent in the developing world. The challenge in particular is to ensure that the next generation of preventive vaccines becomes available to developing countries as quickly as possible. The prospects in this field are illustrated in figure 25.

Figure 25: Global disease category pipeline for vaccines

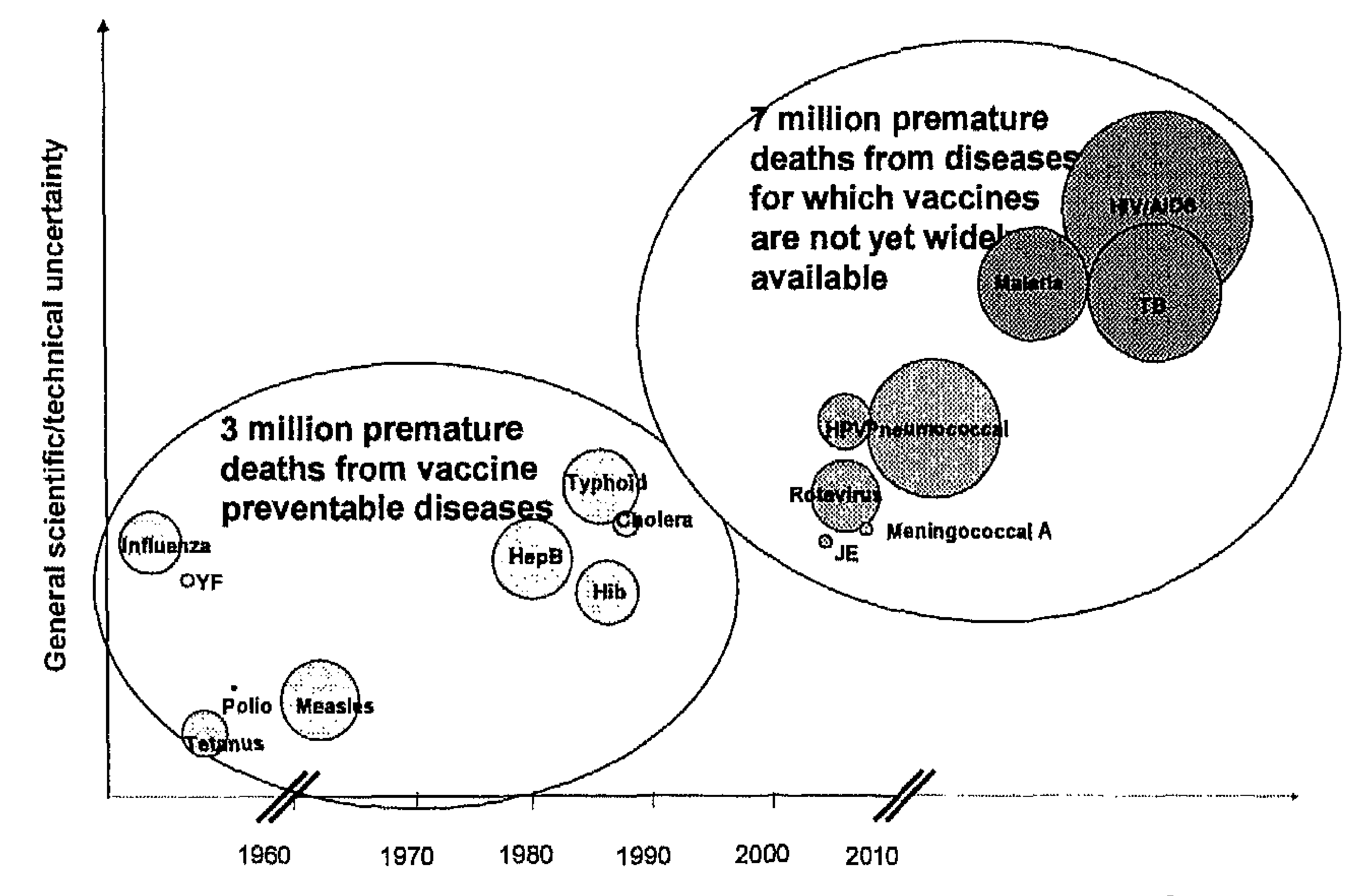


A novel micro-economic incentive system termed Advance Market Commitment may represent a powerful tool to stimulate industry investment in global health product development. At the summits held in 2005 and 2006 in Scotland and Russia, the Ministers of Finance of the G8, embraced the concept of AMCs - calling it a "potentially powerful mechanism to incentivize research, development, and the supply of new vaccines against developing world diseases". An incentive system based on AMCs and backed by a global donor fund was viewed as building on the best aspects of market-guided $R \& D$, while deploying public resources responsibly to accelerate biomedical innovation. The ministers' expectations were that, if AMCs are properly designed and implemented, corporate internal investment funds to support $R \& D$ together with other private-sector technical resources would shift, or be substantially increased, to include diseases currently de-prioritised in pharmaceutical and biotech R\&D.

Consequently, this would lead to an improved climate for industrial investment in the development of new compounds previously considered unattractive because of the absence of a viable market for them. AMCs are deemed complementary to other interventions, such as public-private partnerships (PPPs) in product development and public (basic) research underpinning the development of new medicines. AMCs would actually enhance their effectiveness. It is also important to highlight that AMCs complement and do not substitute for other policies that support $R \& D$ on neglected diseases. They increase the probability that the results of public research will be picked up and translated into products that are actually used ${ }^{125}$.

Trying to close the gap in medicines $R \& D$ from the standpoint of market-based incentives is a significant shift in international development and public policy thinking. Under an AMC funding proposal, the promise of public money available tomorrow would 'pull' today's private sector research and development along. The AMC incentive approach would imitate market forces (as close as possible) because it only makes money available if companies succeed in producing the desired medicines. As in any other business, these companies will have to decide if they are willing to take the risk of making the large investments needed to take a promising candidate medicine through all of the required research and development stages, satisfy the many regulatory requirements, and ultimately

\footnotetext{
${ }^{125}$ AMCs should not aim to replace or interfere with 'push' incentive systems for stimulating R\&D on neglected diseases that predominantly affect the developing world. Their aim is to fill a void and they should be complementary to already existing incentive systems, such as R\&D tax breaks, and technological collaboration through Public Private Partnerships and Strategic Alliances in specific disease areas (e.g. The Malaria Vaccine Initiative (MVI), The International Aids Vaccine Initiative (IAVI), AERAS and the Wellcome Trust Fund which supports R\&D efforts for tuberculosis vaccines. These 'PPPs' usually concentrate on the earlier stages of product development, and if possible 'translational research' leading to a scientific 'proof of concept' in that therapeutic area.
} 
deliver a safe and effective product that in the following years generates enough revenue to justify the outlay at the outset of the project. The journey can take several years or more than a decade, depending on the state of science and technology in the disease area under consideration. Hopes are high that this battle can be won.

Various public and private sector stakeholders, including the International Federation of Pharmaceutical Manufacturers and Associations (IFPMA), in principle support the AMC and issued public statements to encourage further exploration of other novel financing incentive systems like IFFIm. ${ }^{126}$ The IFPMA states that "it welcomes the launch of the inaugural bond for the International Finance Facility for Immunization (IFFIm), to improve developing countries' access to under-used and newly developed vaccines;... the IFFIm and other innovative finance mechanisms recognize the importance of disease prevention in general and vaccines in particular to preserve public healt". It concludes that "both the AMC and IFFIm AMC funding approaches are a courageous effort by industrialized country governments to use their financial muscle in an intelligent way to bring market forces to bear on major health care problems that are inextricably linked to poverty' (Press release, IFPMA 06 November 2006).

\subsection{Advance Market Commitment (AMC): Critical success factors}

Estimating the right 'size' of a market that does not exist and has to be created is arguably the most important challenge in the design and successful implementation of any AMC system, for both potential donors and industry participants. National government officials representing OECD donor countries will want to tender the minimum amount necessary to attract private industry participants, and thus avoid supporting an industry windfall for developing world products. By contrast, the more experienced research-driven pharmaceutical and biotechnology companies, that understand the challenges of operating in third world markets and the risk of relying on a promising but untested economic incentive mechanism, believe that they deserve and need a premium above the anticipated market returns.

\footnotetext{
${ }^{126}$ IFFIm is another innovative financing system for the procurement of preventative products for use in the developing world. IFFIm stands for the International Finance Facility for Immunization. The money raised by the sale of OECD government bonds provides an additional guaranteed source of funding for the acquisition of existing vaccines and the improvement of the immunization infrastructure in developing countries. IFFIm funds, which could amount to as much as US $\$ 4$ billion, would enable the GAVI Alliance to help developing countries immunize children against vaccine-preventable diseases ranging from Heparitis B, Hib and measles to polio, tetanus and yellow fever, potentially saving the lives of an estimated 5 million children between 2006 and 2015.
} 
A 'trade-off method that is acceptable to all stakeholders will have to be conceived. An initial proposal formulated by the Center for Global Development in Washington DC suggested that for pharmaceutical products in relatively early stages of development, a public AMC of approximately US $\$ 3$ billion should be made for each priority disease ${ }^{127}$. They assumed that this sum would be sufficient regardless of the disease category under consideration (without using a reference year or inflation adjustment). This token sum was claimed to be comparable to sales generated in the past for medicines sold in industrialized countries. Given that these sales were sufficient to attract commercial investments from private firms, it was recommended to create an AMC fund worth US $\$ 3$ billion. The proposed 'one-size-fits-all' approach was quickly criticized by academic researchers and industry representatives in the Advisory Group to the World Bank (Farlow, 2006). They argued that an AMC is supposed to create a viable - although artificially created 'market' that is comprised of several brands competing in a given disease category. Moreover, the historic sales revenue database employed by the Center for Global Development refers to the value of one particular commercial 'blockbuster' in a given year (Zocor(B) of Merck \& Co., Inc.). If the suggested amount becomes the 'standard opportunity cost' for assessing future R\&D projects, the calculation method will fail to adequately forecast the size of the fund needed (which may vary by project).

Global R\&D project costs vary between low and high extremes depending on the disease prevalence. If a disease causes a relatively high degree of morbidity and mortality in both the affluent and least developed countries, a system of differential (or tiered) pricing can be used. Based on the Ramsey pricing theory, differential pricing in the international market is considered an efficient way of paying for the joint costs of global pharmaceutical R\&D (see chapter 2). Assuming that market demand elasticities are related to income, differential pricing is consistent with standard norms of equity ${ }^{128}$ (Plahte, 2005; Danzon, Towse, 2003; Danzon, 1998). Some infectious diseases are ubiquitous; some are predominantly, if not exclusively, found in the world's poorest regions. In this case, applying a tiered pricing system that puts the burden of fixed R\&D costs on rich countries will not work. The specific R\&D project costs must (in theory) be absorbed by the LDC population represented in the product demand forecast branch of the geographic investment options. This is likely to be the case of the malaria vaccine, if the type of vaccine developed is only for use in the poorest countries of the world, it cannot be sold to the more affluent market segment.

\footnotetext{
${ }^{127}$ CGD researchers (hrtp://www.cgdev.org/) estimated that in terms of a firm's opportunity cost, creating a market commitment worth US\$ 3.1 billion (expressed in 2004 U.S. dollars) is comparable to the lifetime sales of an average pharmaceutical product.

${ }^{128}$ For price differentiation to be sustainable, either higher-income countries forego trying to 'import' low drug prices from low-income countries through international parallel trade and external referencing, or tighter regulations and stricter law enforcement make such practices less feasible.
} 
Improvements have been made to the above proposal by the Working Group on the Tremonti Report to the G8 Ministers of Finance (Tremonti, 2005). Still the model does not entirely incorporate all possible variations in key parameters, as fluctuations are hard to predict in, for example, product demand forecasts for developing countries. This often leads to a delay in new product adoption and diffusion. A more refined and long-term supply model is needed which calculates from the bottom up the 'risk-adjusted' R\&D project investments that are needed, and accordingly the rewards that investors may expect in each of the selected disease categories. Such a method will have to reflect closely how industry executives evaluate new $R \& D$ projects before deciding to invest in them. We propose to make use of the 'zero-sum' quantitative approach developed in chapter 6 . This calculation method provides a better way of determining the minimum size of AMC funds that are needed to support pharmaceutical R\&D projects on poverty-related diseases.

\subsection{Base scenario: Hypothetical new medicine development project}

As discussed in chapter 4, developing a new medicine takes on average 7 to 20 years, depending on the type of disease category and assuming success at each stage of the development process; and cumulatively costs hundreds of millions of dollars. This is illustrated in figure 26. Against this backdrop and process of continuously staggered capital investments made over a long time period, the expectation of future market returns determines today's decision to invest (or to not invest), and thus the availability of tomorrow's new medicines on the market.

In the proposal, each AMC must be sized to offset the project-specific risks, costs and estimated market timing of the newly developed medicine. Companies will evaluate each major investment based on a risk-adjusted assessment (including probability of technical and market adoption success) and net-present values (discounting revenues and costs to today's monetary value) - which together captures the risks of the $R \& D$ project vis-à-vis its probable return. The AMC intervention must trigger a neutral or positive return if it is to provide an incentive to industrial investors. In other words, if the simulated project review indicates a positive return to the company, it becomes a higher priority. If not, it may be more closely examined or may be dropped all together ${ }^{129}$.

\footnotetext{
${ }^{129}$ Some managers might be tempted to declare the R\&D project "strategic" (not based on evidence) and invest in order to preserve the opportunity to explore further the market potential and additional ways of funding later on. This would however mean sacrificing the auchority and discipline of managers who are required to use quantitative methods, and thus defeat the purpose of having any kind of rigorous analysis, which most companies and their investors would not tolerate.
} 


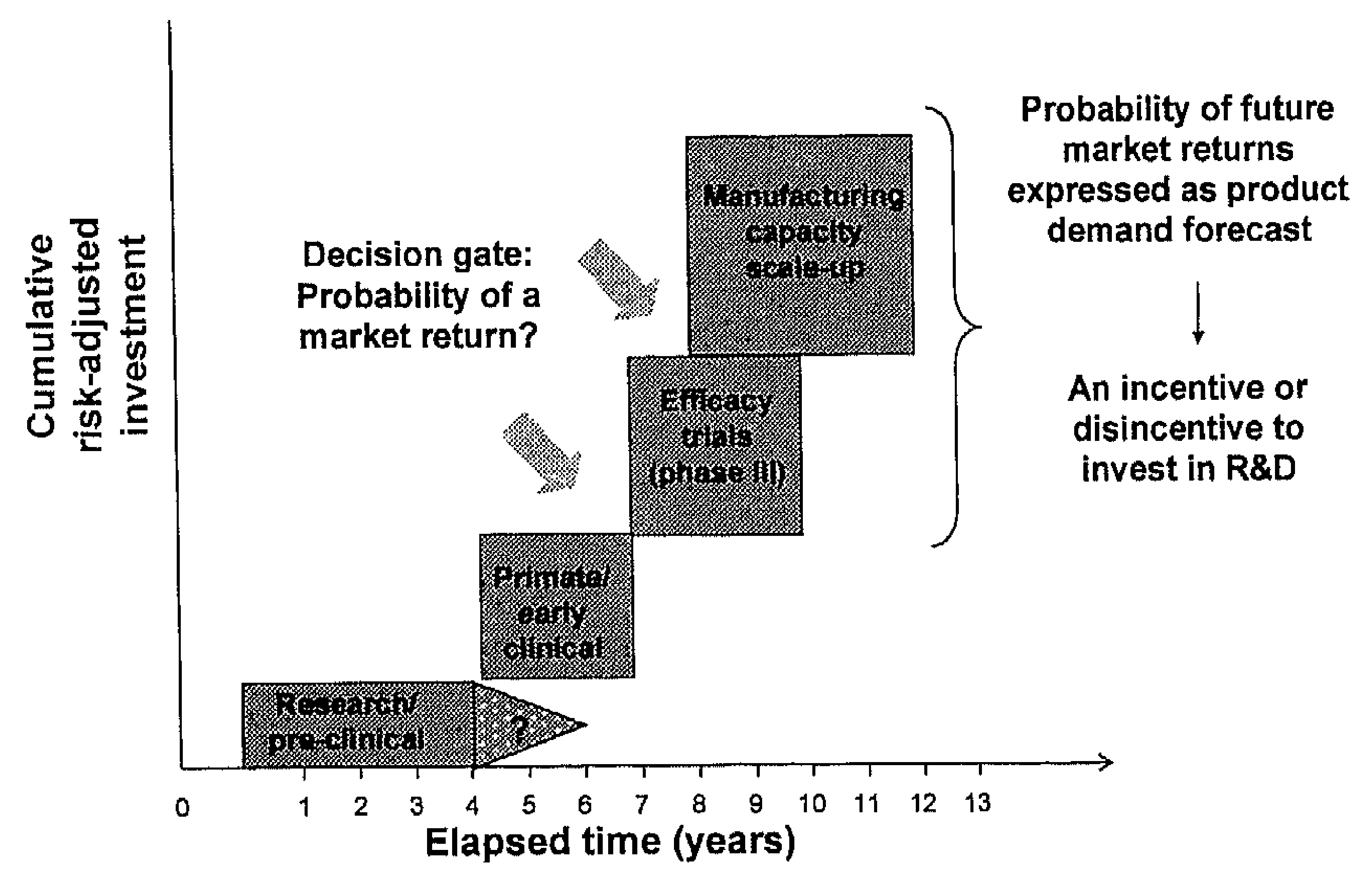

The 'zero-sum' options-based model proposed in this book enables one to capture productspecific estimates of the capital investment needed, as well as to assess the technological risks and market demands. The model calculates the estimated size of the AMC fund for each vaccine-preventable disease. Estimating the required funding remains challenging and even more so for products at an early stage of development. For compounds that have not (yet) delivered 'proof of concept', there is little information (or certainty) on the total investment that needs to be made, including the time it will take to market and the cost of producing the goods in mass quantities.

As with any other investment option, each potential supplier will have to individually evaluate the future AMC incentives offered based on the information available at the time of the investment decision. These internal assessments need to be updated at regular intervals. Figure 26 shows the 'go/no go' schematic development process for a hypothetical new medicine. Besides the internal cost estimates and likelihood of technological success, firms may need to take into account the likelihood that their competitors develop a more successful product that may out-compete them in terms of development speed (time to market) and/or customer preference (market share). Policymakers need to consider the number of firms that are potentially capable of developing such a product within a reasonable period (e.g. 10 years) in order for the AMC to be 'right-sized' and support more than 
one firm ${ }^{130}$. The advantage of mathematical scenario simulations is that the various scenarios envisaged offer strategic insight into the question whether the AMC size provides adequate economic incentives to motivate investments by multiple firms. The current model does not capture other intangible motivations, however, such as a firm's desire to be a good corporate citizen, or the desire to be affiliated with the researchers who crack the science for a killer disease (for now, this is out of our remit of research). However, these intangibles could tip the scales for firms to engage in the proposed projects.

The baseline scenario of the hypothetical pharmaceutical $R \& D$ project-calculation uses 'standard' values that have been released by industry albeit in an aggregated fashion. ${ }^{131}$ By using the 'most likely' set of input data, figure 28 (Table A) shows a positive return value to the firm for the base case (EIV of +US\$117 million). Based on this scenario a more comprehensive sensitivity analysis can be run to investigate variances in key parameters of the model. This includes testing variances in country demand forecasts, fluctuations in longterm pricing (for the post-AMC period), and possible risk aversion often shown by firms when confronted with a series of large consecutive investment decisions under greater uncertainty. The plausible scenarios as explored in the following section, and include case study simulations like 'what if the new product demand in developing countries is slower than originally estimated (with 1,3 , or even 10 year delay), or 'what if the cost-of-goods ex post is higher than estimated ex ante, and so forth.

\subsection{Sensitivity analysis: Simulation of variations in model parameters}

\section{Demand forecasting}

While uptake varies by country, the overall uptake rate for resource-poor countries has historically been disappointing (Wagstaff et al, 2004). Developing country governments could do more to make medicines accessible to the poorest as discussed in chapter 1. All too often primary health care is chronically under-funded. The real danger is that, even if new, safe, and effective medicines are developed, they will not be purchased nor made available to those who need them. In many parts of the developing world history has shown that even medicines that are given for free do not reach those who need them most, hampered by product distribution and health infrastructure problems. This weakness in healthcare infrastructure and staffing means that some patients may never see a healthcare provider or

\footnotetext{
${ }^{130}$ Chapter 6 provides more detailed information about the various parameters in the AMC model and how the model's input values can be estimated, leading to the $R \& D$ project's economic expected value outcome (EVI).

${ }^{131}$ BIAG - Biomedical Industry Advisory Group; http://biag.org./index.htm
} 
receive a medical diagnosis or prescription, let alone the care necessary to make effective use of newer and often more complex medicines. Significant investments are still needed in cold chain transport and storage of medicines, as well as improved formal education and practical training of health care professionals.

Health technology companies' major challenge is developing new product demand forecasts for lower-income markets and this because of the existing social, political and economic uncertainties in these nations. Historically, while these challenges exist in both developing and industrialized countries, the higher profit margins in the affluent countries have allowed manufacturers to use responsive, more expensive supply chains along with some excess inventory to buffer against market uncertainties (FutureCast, 2004; Supply Chain Management, 2005). High-income markets are also characterized by relatively good market research and information, and by purchasers and suppliers with established relationships and balanced market power. By contrast, product demand forecasting in developing countries is more difficult because of limited market research data and tools to estimate future demand. The cost of doing business is therefore higher than in developed markets. Well known hurdles include the multiple national and international approval processes, supply chain bottlenecks, especially in remote areas, and the country specific packaging requirements in multiple languages. Moreover, increased regulatory requirements imposed on manufacturers by the $\mathrm{WHO}$, as well as developing country regulatory officials have led to redundancy in clinical trials and an excessive number of plant inspections. Hence, the urgent need for harmonization of regulatory requirements for product registration in a large number of developing countries.

Demand forecasting for new medicines in developing countries is often misunderstood. It is important to clarify the difference between predicting unmet medical needs and forecasting (real) product demand. Medical needs are evaluated based on epidemiology studies that project how many people will need treatment, or preventive medical interventions like for example vaccination. These data do not automatically translate into adequate product demand forecasts relevant for the manufacturer. Demand forecasting is often hampered by the many physical barriers to supply and distribution of much needed medicines (e.g. people living in remote or war-torn areas), and by lapses in the local healthcare system. Additional factors include the number of patients who may seek treatment and their personal ability to pay or their insurer's willingness to reimburse. Therefore, any product demand forecast should be backed by a real commitment by the government to procure and distribute the new medicine at pre-defined volumes and prices prior to their supply. Obtaining certainty about the country's internal and/or external funding, as well as the timing and processing of product orders would allow suppliers to invest in building production capacity. Suppliers must pre-finance raw materials and intermediate products and - if surge capacity is required - make additional capital investment in (bio)pharmaceutical 
production facilities. This can easily take up three to five years to build, and to become validated and approved by regulatory authorities.

As discussed in an earlier section, the Center for Global Development developed an assessment and improvement process to address the problem of poor demand forecasting for developing world markets. A series of workshops were organized between public and private sector stakeholders to identify possible solutions. Participants ultimately agreed that shortcomings in forecasting at the country-level substantially increase the risks for suppliers, resulting in higher costs, supply shortages and concerns about the long-term viability of investing in health technology products for the developing world. This fear was substantiated by empirical evidence gathered by those who have been observing the history of new medicines launched in the developing world. A recent case that illustrates the problem acutely is that of malaria treatment,. In 2005, the demand from GFATM's countryrecipients for artemisinin based combination therapy (Coartem(B) alone - the most widely used pre-qualified anti-malaria drug by the WHO - was (initially) expected to reach 50 million treatments (UNICEF, 2005). To meet that demand, a concerted effort by international agencies, donors and most importantly the manufacturer, Novartis International AG, rapidly scaled up production to 30 million doses. However, the real demand measured by the actual uptake registered in 2005 was only 14 million treatments. By the end of 2005, this had led to a large oversupply at a significant cost to the manufacturer.

Another well known example is the introduction of the first genetically engineered vaccine produced by GlaxoSmithKline (previously SmithKline Beecham) and Merck (previously Merck Sharp \& Dohme) in the fight against viral hepatitis B (HBV) in the nineties. Contrary to popular belief, it was not the high market price that led to a difference of more than ten years in new product adoption between the industrialized and developing world. This may have been the case in the initial years, but even after all manufacturers dropped their prices below the US\$1 mark - and new competitors from Korea later pushed it to an even lower level - there was no dramatic improvement in the situation. The impetus in market uptake only came in 2000 when The GAVI Alliance was founded, which not only raised funds to support developing countries but in addition set up a managerial and leadership structure for coordinating the introduction and roll-out of existing, underutilized and new medical products in developing countries. Concerted efforts included long-term strategic planning and middle management education, training of health care workers and, in this case, vaccination program managers, as well as supply chain managers in order to secure cold storage logistics.

Despite the key learnings from the introduction of the hepatitis B vaccine, the same phenomenon and time lag is about to occur with another important new vaccine to prevent infection from Haemophilus influenzae type b (Hib), a leading cause of childhood bacterial meningitis and an important cause of pneumonia in developing countries. Figure 27 
illustrates the time lag between the developed and developing countries in access to the Hib vaccine. This observation prompted The GAVI Alliance to establish a taskforce that would be responsible for the Accelerated Development and Introduction Planning (ADIP) of new vaccines. Since then, the activities of the ADIP taskforce have been extended to include the supervision and roll-out of important vaccines like those against Streptococcus pneumoniae, Rotavirus, Human Papilloma Virus (HPV, causing cervical cancer), and eventually Hepatitis $\mathrm{C}$ virus ( $\mathrm{HCV}$, causing viral hepatitis $\mathrm{C}$ induced liver cancer).

Figure 27: Introduction of Hep B and Hib vaccines into developing countries

Introduction of Hep B and Hib vaccines into developing countries is occurring $10-15$ years after initial availability

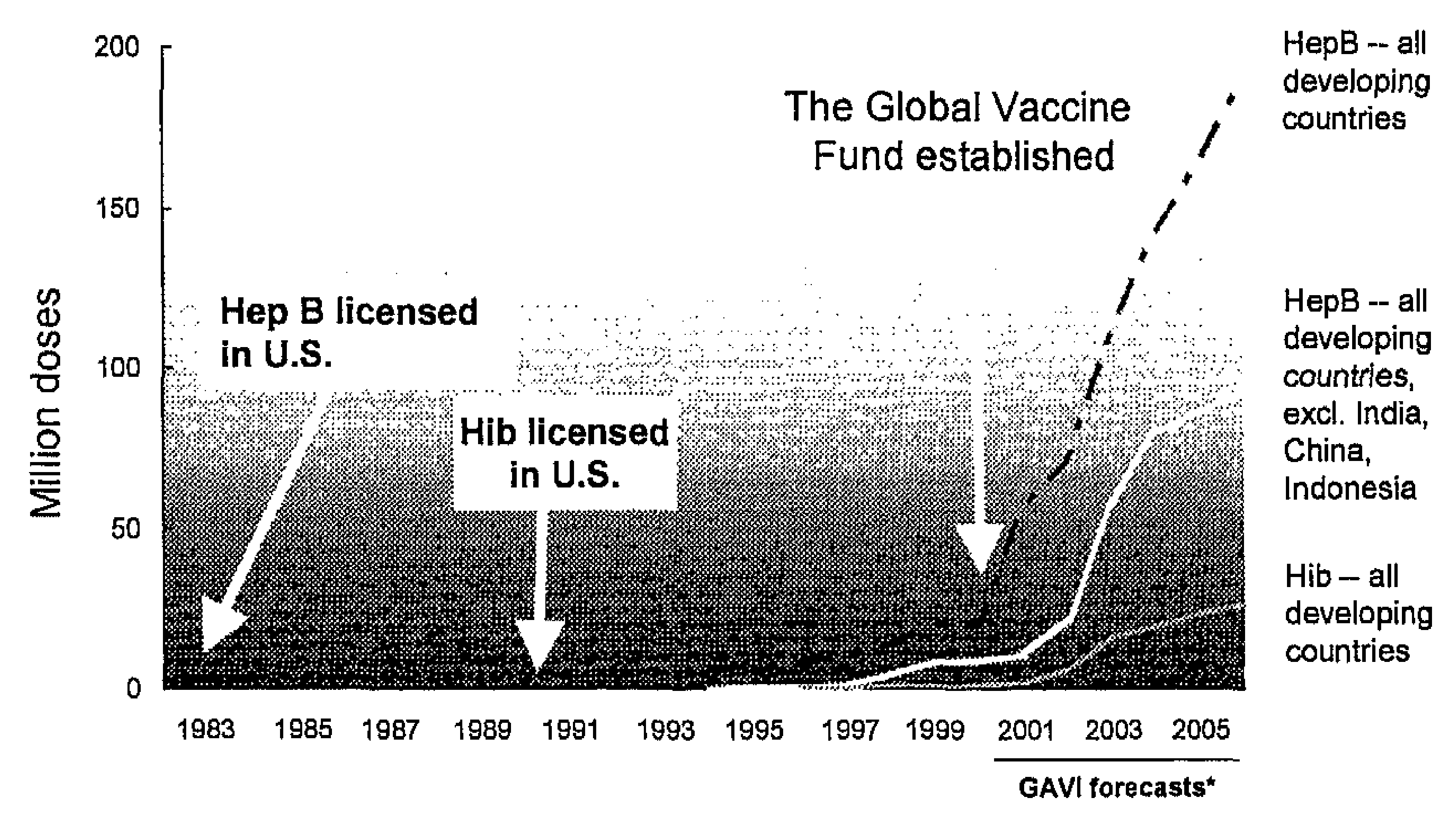

As the calculation in figure 28 and Table B illustrates, any significant delay(s) between the real uptake of a new medicine in the marketplace and its original forecast has negative financial consequences on a firm's return on investment. The results obtained from the simulation using the hypothetical new medicines development scenario show a dramatic decrease in estimated project income (EIV), well below the initial positive gain worth US $\$+117$ million in the base case scenario. After a modest increase, the value gradually decreases to very big losses ranging from US\$+13 million, over US\$-109 million, to US\$234 million. These negative values are the result of a shift of the demand forecast curve to the right following uptake delays in the marketplace ranging from 1 year up to 3 , or even 7 years beyond forecast. This shows that the EIV outcome is clearly sensitive to the product market uptake relative to the base scenario, ceteris paribus, although the negative impact is somewhat attenuated due to the de facto large time gap between sales and investment in 
pharmaceutical R\&D projects. This minor positive gain is then offset because the innovating firm rapidly loses its competitive advantage of being first on the market, and the original manufacturer is no longer in a position to capture the lion share of the promised AMC fund. Under a 'worst case' scenario, that is, of extreme delays in market uptake, the first mover company may even lose out not only to the full list of its direct competitors but also to those who had opted to follow a slower pathway from the beginning of the new product development. This could lead to a situation where the latter companies gain the largest market share by waiting to invest and opting to launch their products deliberately later but with an improved profile instead of trying to be first on the market. 

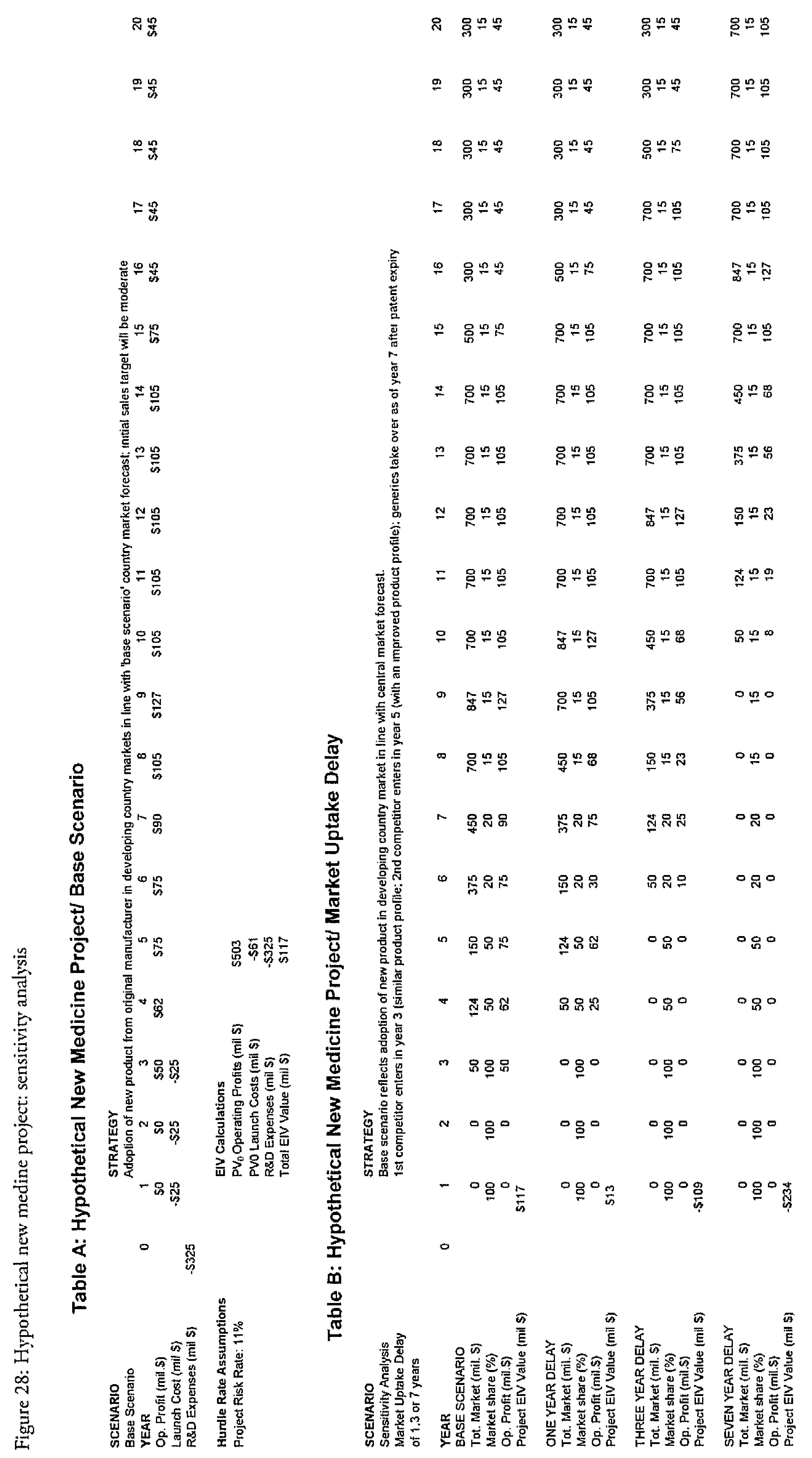


\section{Long-term pricing}

The AMC creates an incentive analogous to the incentives for $R \& D$ on medicines for diseases common in affluent countries. The medicines market for diseases prevalent in poor countries should be large enough to create stimuli for accelerating the development of such products, while the system provides excellent value for money to donors. It must be acknowledged, however, that donors have little to lose under the current scheme: if no innovative product is developed, the AMC commitments are simply not disbursed. This is regardless of any possible intermediate or incremental scientific progress that the innovator may have made and that directly or indirectly supports the design of a 'better mousetrap' in the future. More efforts are needed to reward intermediate stages of the new product development process (but currently this falls outside the scope of our model).

A salient question remains regarding the AMC set up. Currently, the AMC scheme resembles a time-limited financial 'bolus injection'. In the long haul, however, will the AMC ensure product supply after the initial funding period has ended? Because donor funds are supposed to dry up over time, the AMC concept uses a differential between the initial price needed to reward the company for the R\&D completed (and this cost is absorbed by OECD countries), and the long-term lower price that is needed to ensure continued access to the new medical product (and this cost should mainly if not entirely be absorbed by the developing countries themselves at that particular moment i.e. in the post-AMC period). Unsurprisingly, there are issues with defining these long-term prices in advance and how to pay for long-term supply. The AMC proposal, as originally envisaged, called for fixing the 'guaranteed' long-term prices at the moment donors and sponsors sign the initial AMC contract. This binding contract would set the long-term product price at a 'near-marginalcost-production' level, and stipulate the obligation for guaranteed supply in the long-run at that this fixed price in return for firms having had the advantage of initial sales at subsidized prices during the AMC period. The paradox is that this AMC concept of setting legally binding long-term prices upfront was designed to protect new medicine innovators and manufacturers from monopsony powers exerted by sole-buyer institutions that act on behalf of third world countries, such as UNICEF. Experience of the past has proven that a single buyer system drives prices down to the bare minimum and this during the entire lifecycle of the product, often leaving no room to recoup $R \& D$ investments.

Conceptually, the two-stage AMC model comprises two different prices that are used over time as represented by the stepped down pricing curve (figure 29). Initially, a premium price is offered during the AMC period; this means that afterwards, in the post-AMC era, the intial price decreases (with the objective to closely match marginal cost of production plus a relatively small mark-up covering transaction costs). This author's viewpoint, however, is that such legally binding commitments are not needed to ensure long-term low 
prices in developing country markets. This legal requirement would unnecessarily complicate matters. Nor would a mark-up pricing mechanism work in the end - even if the production costs could be determined or at least fairly-accurately estimated upfront. In our view, it would be much better to apply a competitive pricing model during the post-AMC era. A competitive mechanism hat would be able to drive prices down without having to know or second-guess production costs. In a competitive market-driven model, a number of innovators would be competing for market-share during (what is left of the patent period and will be joined by a plethora of generic producers at the time the original patent has expired. After all, the remaining real-patent lifetime is likely to come to an end just a few years after the AMC subsidy has elapsed - as discussed in chapter 4. Figure 29 illustrates this situation. The hyperbolic (dotted) pricing line shows how companies will, in the long run, that is, in the post-AMC period, compete on both price and product differentiation. The proposed alternative pricing system takes into account fluctuations that might occur in the marketplace in the long term and enables manufacturers to absorb these unforeseen costs. Thus, the system acts as if were a 'buffer' that absorbs changes that are hard to predict with any certainty beforehand by any of the stakeholders. Therefore, they cannot be defined at the outset of the $R \& D$ project.

Figure 29: AMC two-stage pricing model for global equity

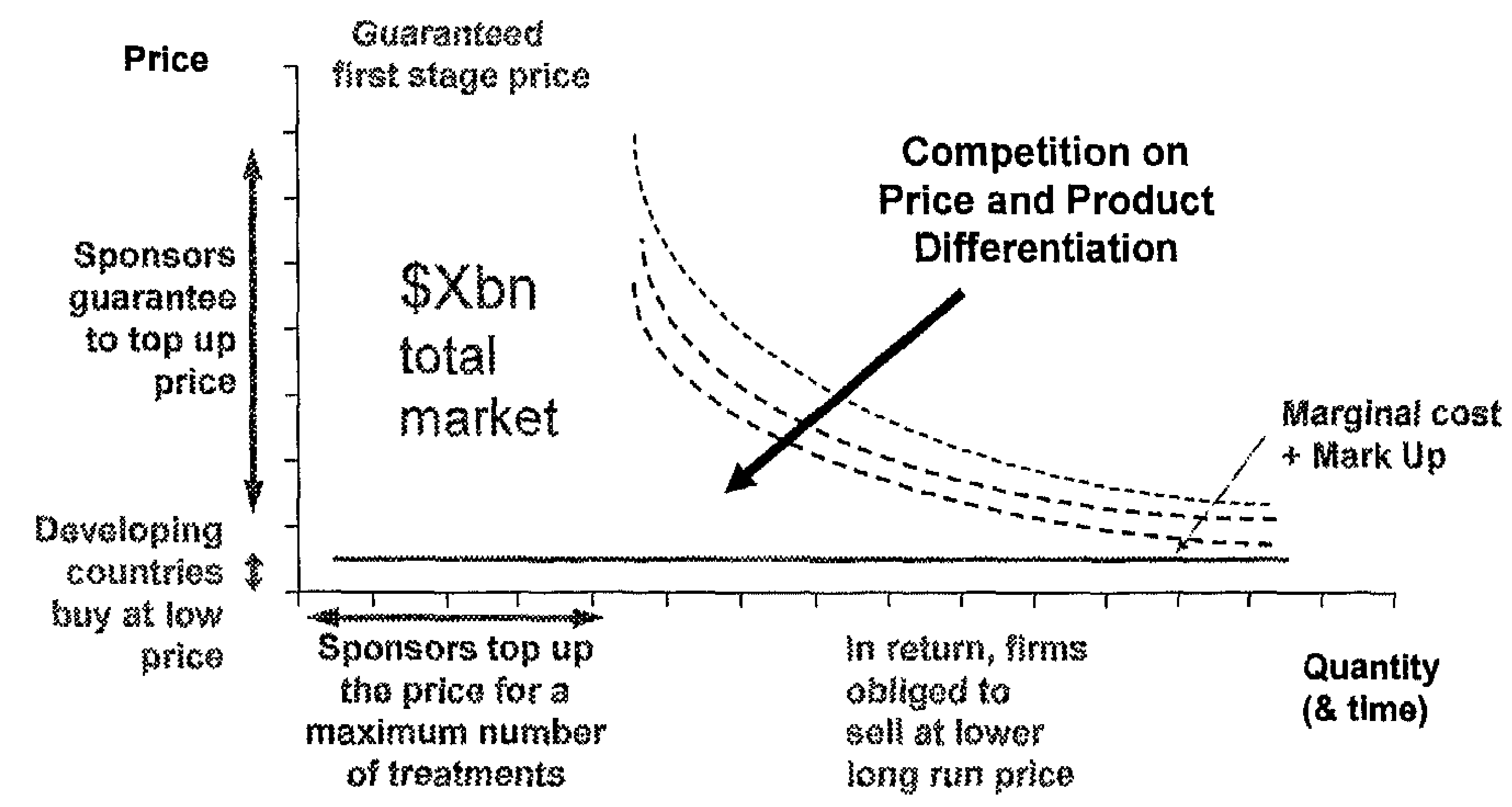

Government sponsors may also be afraid that companies would no longer be interested in supplying LCDs after the AMC period - during which rather heavily subsidized prices apply. This author believes that an alleged corporate 'hit \& run' strategy is not likely to happen. To test this hypothesis, let us consider a firm that, as soon as it has successfully completed its investment in discovery, development and manufacturing of a new product, is looking to supply developing markets for the long haul, at least 20-30 years: 
First, by the time an innovation-driven company has reached the market launch stage, it will have constructed fixed assets for mass-production of the specific product with the AMC incentive mechanism as a back up. From a sheer business perspective, the firm has the desire to pursue its original business objective, that is, to supply developing country markets in the long haul, and make a reasonable profit on this transaction. The situation would become far worse if the same company decided not to go through with its long-term commitment to producing large volumes for developing country markets, since the firm must write off all of the capacity investments it has made in anticipation of eventually serving these markets. Besides facing the negative financial consequences there are considerations of corporate social responsibility and reputation damage. External sponsors among which many governments would consider 'their' AMC money wasted. It is therefore a safe bet for sponsors and authorities to assume that companies will stand by their commitments. Renowned industrial corporations will do everything possible to avoid having their name attached to a very visible public-private project that ultimately fails and bestows a bad image on participants, especially if high-level national government officials and supranational agencies are involved.

Second, if a company's senior management has decided to be in it for the long haul - and shirking is anyway made difficult for them - it comes down to creating an environment conducive to sustainable supply over time. The original proposal by the Center for Global Development requires that innovation-driven companies submit their long-term supply price beforehand, at the latest, when the AMC contract with sponsors is signed (Berndt, Hurvitz, 2005). How is any company supposed to know its marginal production costs for a totally new product ten or more years beforehand? This parameter is impossible to determine ex ante. Berndt (2005) therefore suggests 'coupling' the long-term 'tail' price (post$\mathrm{AMC}$ ) to the initial country 'co-pay' (during the AMC period), that is, the small contribution developing countries have to make within the initial (premium) price paid by OECD to innovators. For instance, if the AMC subsidized price is US\$15 per dose, developing countries will be asked to contribute a co-pay of, for example, US\$1 per dose used. This seems fair, since the objective is to build commitment by developing countries to make them (co)-responsible for buying the product that best suits their needs. According to Berndt, by coupling the tail price to the country's initial co-pay, the model ensures LCDs are set an affordable price level from the beginning onwards and throughout the next 20-30 years. This does not seem to be the preferred route. As previously cited, these prices are determined in a guided fashion instead of being influenced by market forces. Even if companies were free to set the level of the 'co-pay', who can tell the marginal production cost on which the co-pay is based will match the developing countries' ability to pay in the end? 
The proposal to link the long-term (tail) price to the country's initial co-pay is justified to force companies not to sign into an AMC contract with too high a long-term price. The rationale is that keeping the co-pay low for developing countries is in the company's interest in order to become selected as the preferred supplier during and after the AMC period because its product offers the 'cheaper' alternative. For this reason, companies may be encouraged to set the new product's co-pay level at levels lower than the magic threshold of US\$1 per dose in the above example. As previously mentioned the expectation is that developing countries ultimately become self-sufficient and are able to pay for the long-term supply instead of being sponsored by external donors. However, this would only work within the proposed AMC framework if the real marginal production cost is no higher than the original country's co-pay (which at that time has become the long-term supply price for the next 20-30 years). The GAVI Alliance, World Bank and others assume that the poorest countries' ability to pay is likely to remain limited, situated in the range of pennies per dose instead of a number of dollars, and will likely remain so in the foreseeable future ${ }^{132}$. Consequently, having signed a binding contract to supply at prices below marginal production cost over a long period would expose companies to an enormous liability. This disastrous situation can be partially avoided if the company manages to persuade the developing countries to accept a higher 'co-pay' by quoting an artificially high marginal production cost, for example, well above the US\$3-5 per dose mark. Regrettably, the current AMC method forces company managers into a behavior of shirking.

The above scenario demonstrates that a company is bound to assume significant risks if it subscribes too early to a contract for the long term supply of a newly developed product at a tail price equal to the co-pay. The developing country's level of co-pay may have underestimated the real marginal production cost by a margin of error ranging, for example, from 5 to $50 \%$ (the range used in the simulation exercise). The impact on the project's EIV can be calculated by means of sensitivity analyses with the computer-assisted simulation model described in chapter 6 . The results obtained for the respective scenarios prove that the expected reduction in corporate income from the initially estimated positive gain worth US $\$ 117$ million rapidly turns into losses - the magnitude of which depends on how much volume must be contractually supplied below the marginal production cost. For instance, if 100 million doses are needed in the developing countries in a given year, and the 'real' cost of goods later turns out to be US $\$ 1.5$ per dose, whereas the co-pay was fixed at US\$1 per

\footnotetext{
${ }^{132}$ Linking the country's co-pay to the long-term production cost may become even more difficult because different co-pays are likely to be used in future. The GAVI Alliance decided at the beginning of 2007 to apply four levels of co-pay to facilitate the adoption of $\mathrm{Hib}$ vaccine in GAV-eligible countries. Despite the fact that all earn less than 1000 USD/capita, a distinction is made between poor, poorer, poorest, and fragile states (often in state of war). If this method is applied to the launch of future vaccines, any possible association or linkage with marginal production costs becomes an untenable proposition.
} 
dose dispensed, the nominal loss for that year (which must be deducted from any profits made during the AMC period) would amount to US\$7.5, US\$15, US\$37.5, and even US\$75 million per year, respectively. Again, in this exercise the cost of goods produced had been underestimated vis-à-vis the 'tail' price defined upfront with a factor varying between $5 \%,-10 \%,-25 \%$, and $-50 \%$. These losses will rapidly accumulate over the years in the post-AMC era and are sensitive to the size of the population to be served, ceteris paribus. The gap magnifies depending on the variance between 'real' and 'fictive' project cost estimates, as well as the nominal price level employed in any particular scenario used to simulate the risk-adjusted ROI.

The above rationale backed by mathematical simulation of possible scenarios reinforces the point raised earlier by Andrew Farlow from the Department of Economics at Oxford University's Oriel College. He claims that we may have ended up with an AMC instrument that is (too) complicated, in particular because it is trying to install pre-set subsidy schemes run by a central committee according to a fixed set of rules (Farlow et al, 2005, 2006). However, the World Bank's Advisory Group who has thoroughly revised the original proposal issued by the Center for Global Development managed to resolved, many of the points of criticism previously raised and subsequently made adaptations to the framework. But the issue remains contentious, in particular for the period after the AMC fund has come to an end and the described process of price (over)-regulation remains in effect. Any attempt to determine upfront the long-term (post)-AMC price - and to link this to future mass-production in a legally binding contract between stakeholders - remains controversial. Private sector contractors would not only find it inappropriate to fix long-term prices early on, but believe it would also be unfair because the public sponsored subsidy scheme will no longer exist at that point in time. Therefore, regular 'market forces' should take over at the end of the AMC subsidy.

Other issues need to be resolved as well. Mitigating demand risk remains a core challenge when fulfilling long-term supply contracts. The current AMC proposal does not address demand risk or provides sufficient returns to make a compelling business case for the nonsubsidized (post-AMC) period. Some form of purchase commitment, which guarantees purchase long term, would be a more efficient mechanism to convince suppliers to accelerate the scale up of production capacity. Moreover, this would facilitate entry of generic suppliers and emerging suppliers from the developing countries. It is likely that the disincentive of an otherwise low 'tail' price would prevent new producers to enter the market. Therefore, the public sector should set up a bidding, or tender process toward the end of the subsidized AMC period. The resulting contractual supply agreements would be strengthened considerably by the inclusion of a mechanism for a rolling multi year volume agreement and supply forecast (of at least 3-5 years). Such a commitment would give manufacturers the confidence and the lead-time required to invest in building the necessary 
manufacturing capacity. It is essential that prices remain at levels that are reasonable and sufficient to give returns that ensure continued investment into maintaining this manufacturing capacity, and regularly upgrade the production plant to required GMP standards. At the very least, the prices stipulated in the long-term contractual supply agreement must be adjusted to inflation. Ideally, the supply contract should also include a sunset clause limiting liability over time.

As a final point, it has been suggested in ad-hoc working groups and public debates that part of the solution lays in applying a straightforward technology transfer from the innovating companies to the developing country manufacturers before or towards the end of the AMC period. Many public sector participants see this as the ultimate solution for lowering production costs especially in the post-AMC period. Despite its intrinsic difficulties, we share the viewpoint that this is a plausible scenario, but only if the so-called 'technology transfer' is done on a voluntary basis, and only in those cases where it is appropriate. Moreover, some developing nations' ventures already obtain their technology through licensing and strategic alliances with developed-nation firms (Barton, 2006). Any attempt to use compulsory licensing however will be perceived by innovators and firms to conflict with the AMC concept and the intention to keep its 'additionality' characteristic with other incentive mechanisms, including patents. As discussed in chapter 2, firms that sell at a differentiated, higher price in the more affluent markets that are not covered by the AMC mechanism - i.e. outside the 75 poorest GAVI/ Vaccine Fund eligible countries - will have to keep a tight hold of their IP and know-how, in order to be able to grant preferential prices (read: sharp discounts) to the poorest countries.

Technology joint ventures are increasingly becoming part of any transnational corporation's business planning. Their objective is either to collect royalties from production for developing-world and/or emerging economy markets (which together include by far the largest portion of the world's population), or to produce offshore to decrease costs and increase access for products in these markets. From a strategic perspective, it is important that the local partner is committed to GMP, that good human resources be available, that the national regulatory process be solid, that there be access to local capital, and there be a favorable business culture in the country. If these conditions are indeed fulfilled, it is in the private sector's own interest to invest in locations where it can produce at the least cost and with reasonable market potential. It remains to be seen, however, whether the idea of lowcost off shore production and possibly low-cost scientific human resources is applicable to the biopharmaceutical and vaccine context. The fact is that the production of biological products, including vaccines, is complex, with manipulation of live micro-organisms and multiple steps to extract, purify and formulate the active substance or antigen - far more sensitive and sophisticated than the production of small molecule chemical pharmaceuticals. Production plants using biological materials are known to carry a high fixed cost and 
the factor of know-how and skills in biomedical engineering is crucial in the decision of where to build production facilities, and whether any transfer of technology between production units can be successfully accomplished. This is another reason why compulsory licensing of IP would be an artificial solution. Technology transfer does not work unless any internal or external transfer is done in a mutually beneficial cooperation, otherwise the essential know-how, training and support is lost.

\section{Risk aversion}

Pharmaceutical and biotech corporations are from an economist's standpoint 'risk averse' when it comes to large sums of money that are at stake in the development and manufacturing of novel medicines. In this context, risk averse does not mean that companies are unwilling to invest in complex high-technology projects but that they are likely to require a premium on risky or uncertain project investments.

This element is not always easy to incorporate in $\mathrm{R} \& \mathrm{D}$ project calculations especially when a 'zero-sum' return-on-investment method is applied that aims to support the least developed countries. Finding a balance between a new project's spectrum of risks and the firm's willingness to invest will largely depend on the corporation's financial abilities and its senior management team's perception of risk. Generally, there are three types of attitudes concerning 'risk' in capital investment decisions: (1) aversion to risk, (2) indifference to risk, and (3) preference for risk. Some executives prefer high-risk projects and the corresponding potential for substantial returns, especially when relatively small sums of money are involved. Both logic and observation suggest, however, that business managers and investors are predominantly risk averse (that is, cautious), especially when substantial sums of capital are involved. An entire spectrum of possibilities and scenario outcomes can be simulated and the range of corresponding return values plotted. This is illustrated in figure 30 where a firm's attempt to recover the full $100 \%$ of a risk-adjusted investment is demonstrated, or alternatively, to see its chances diminished only to recover respectively $99 \%$, $95 \%, 68 \%$ or $50 \%$. We assume in this scenario analysis that few - if any - pharmaceutical or biotech firms are willing to take a higher than $50 \%$ chance of loosing money on any pharmaceutical $R \& D$ project given the sizeable capital investments that are at stake.

The need to plan for unexpected and unforeseeable events (with any particular likelihood of occurrence) cannot be done with $100 \%$ accuracy, and therefore is difficult to incorporate into the model. This is one reason for private firms to aim for a $95 \%$ success rate in order to appropriate a return on investment and in defining the minimum profit threshold levels. However, the level of environmental uncertainty - in contrast with technical project risks that can be modeled by means of probability analysis - cannot be ruled out in the business of biomedical and pharmaceutical product development and supply, particularly in a 
developing country setting. For instance, every new product that has been introduced over the last decades has had to deal with claims of alleged and sometimes even real adverse effects despite extensive testing in clinical trials prior to market launch. During the postlaunch phase of a new compound, negative pressure may be exerted by public opinion despite a vast track record accumulated regarding the product's quality, safety and efficacy (François, 2005). Each time allegations regarding adverse events are expressed (regrettably often without documented evidence), enormous efforts from industry and public agencies are launched to investigate the claim and in the event of unproven causality, dispel the notion that, for example, childhood vaccines like polio, measles, mumps, rubella, or hepatitis $B$ are the cause of diseases as diverse as multiple sclerosis, Alzheimer, and so forth. Nor are these technologies the cause of the very disease they are meant to fight, this because the bacterium or virus used in the development process has been completely inactivated or the product cleverly engineered without the causative agent being involved in the production process. Nonetheless, it seems inevitable that at regular intervals environmental factors, such as public outbursts some of which trigger large-scale panic, may affect a firm's ROI, especially when, for instance, large cohorts of children, adolescents or adults are involved in the health program.

Companies have learned to hedge against evolving and often unexpected regulatory requirements. For example, there is the recent obligation to mass-produce childhood vaccines without using thiomersal in the manufacturing process - a classical mercury-containing preservative allowing for aseptic filling. Despite the fact that this additive has been proven to be safe, the recent abrupt changes in the ever-increasing safety requirements as demanded by public authorities together with additional requirements for improved production techniques have led to a massive (compulsory) investment in aseptic filling lines and the development of newly formulated products that must be clinically tested all over again. The uncertainty created by a firm's socio-political environment is usually exacerbated if it decides to operate in a developing country setting. In industrialized countries, an early warning system exists between regulatory authorities, manufacturers and healthcare professionals to alert parties in the most expeditious way about any (alleged) adverse events. This usually leads to rapid interventions, ranging from stopping production or temporary suspension for inspection, to recalls from the commercial distribution channel. The adverse event reporting systems are based on electronically and/or manually filled out case reports, and include field surveys conducted by the public as well as industry experts. Often such control systems are missing in the developing world and, if present, tackling the remaining hurdles is usually weak or lacking managerial and operational capacity to rapidly address and control the problem.

Another uncertainty is the gap between perceived need and effective demand in developing countries. In efficiently functioning markets both purchasers and suppliers carry the finan- 
cial risk of sub-optimal market demand forecasting and untimely supply. Contracts between suppliers and purchasers usually specify explicit incentives and/or penalties for poor forecasting and delivery. Measures include penalties to suppliers for delays in delivery, or conversely, incentives to suppliers in the form of minimum purchase guarantees from buyers. In many developing country markets, however, the separation between those who pay for the new products (i.e. OECD donor countries and other sponsors), and those who buy or ultimately consume them (i.e. developing country citizens) diffuses these risks. This raises problems of accountability and in practice any errors in forecasting are absorbed by the supplier (with no adverse consequences or penalties to the buyer). For example, within the context of the AMC system, it is suggested that risk and uncertainty within the legally binding supply contract is predominantly assumed by those firms acting as innovator, developer and supplier. Hence, a science-driven company is in a way forced into a strict price corridor for a duration up to 20-30 years despite the volatility seen in this type of market. What is currently missing in this partnership contract is a formal and explicit commitment from developing countries themselves guaranteeing the usage of products upon delivery. Knowing that a large supply of medicines is developed for them, the legitimate question is whether developing countries have the willingness and capacity to roll out products they previously committed to and have ordered from manufacturers (albeit not in a binding fashion). To that end, the country forecasts and sometimes rather vague promises will have to be translated into contractual obligations for the AMC to work to its full potential and satisfaction of all stakeholders. We recommend that a balanced agreement is brokered and negotiated by donor governments, but the developing countries themselves have to comply with the terms.

Another challenge related to corporate risk-taking in pharmaceutical $R \& D$ on neglected diseases is the pressure politicians and the public in general may exert on innovative firms in the event a new medicine is developed for a disease endemic disease in poor countries. In several in-depth interviews and roundtable discussions (anti-trust lawyers being present), industry CEOs went as far as to say that they fear the day their company announces it has developed, for example, the world's first vaccine against HIV/AIDS. Learning from recent experience in related global health areas, they anticipate the fact that the pressure from politicians and the public may lead to situations where companies have to lower the price of for instance antiviral drugs against HIV down to the point where they must sell the product at, or even below, marginal production costs; or decide to give the product for free all together. Another recent example is the case of malaria, where the Swiss drug maker Novartis announced on October 2, 2006 that it would cut the price of its malaria treatment Coartem $\otimes$ by more than a third to help the medicine become more affordable to African 
countries, but most likely at a loss to the company ${ }^{133}$ (Whalen, 2006). Daniel Vasella, CEO of Novartis, stated in a related press interview "that nevertheless the price wasn't the obstacle preventing his malaria treatment from reaching enough African patients . . . (rather) government bureaucracy, a lack of doctors and nurses in many African villages and difficulties distributing the drug to rural areas are the biggest stumbling blocks to Coartem ${ }^{\circledR}$ 's use". As this example illustrates, the pharma/biotech industry's concern is that affordability is not the only stumbling block in LDCs, but that capacity and infrastructure in-country are equally important. Therefore, the challenge for all stakeholders is, through concerted efforts internationally and locally, to create a political and economic environment that spurs R\&D on neglected diseases while simultaneously strengthening global health care systems.

Figure 30: Minimum threshold level for appropriating returns on $R \& D$ investment

\section{Risk-Adjusted "Zero Based" Expected Investment Value}

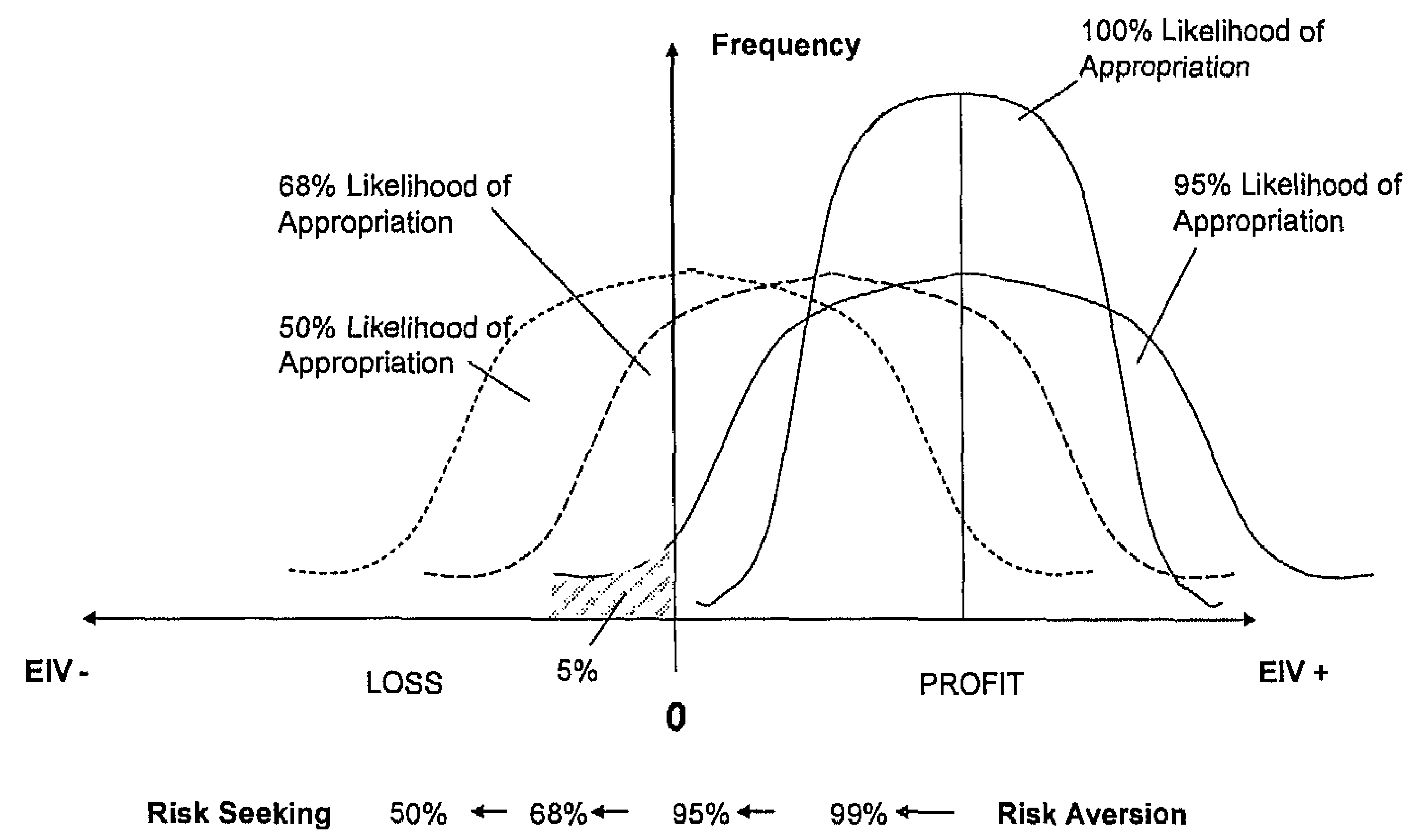

In summary, the concept of closely mimicking market forces to the maximum extent possible, rather than having donors or politicians determine what R\&D capital investments must be made and what type of technologies and organizational structures employed,

${ }^{133}$ As stated in the Wall Street Journal, Coartem $®$ will as of 2007 cost US $\$ 1$ per treatment, down from US $\$ 1.57$, and hence cost less than what it costs the company to produce it. Novartis, a large pharmaceutical company, is willing to temporarily absorb these losses; but unfortunately few other companies will be able to do so. 
creates greater incentives for innovation-driven firms. The successful implementation of new and innovative economic mechanisms like AMCs is necessary to break the conundrum of ill investment in the field of poverty-related diseases. What attracts willing industry investors is that most of the risk can be contained by correctly sizing the AMC market. In this context, it is also safe for donors to assume that the larger the financial commitment, the more players this will engage. The key issue is, however, to strike the right balance between maximizing the social value of this public funding system while ensuring broad private sector participation in the program, particularly from industry's more capable players. Finally, this indicates how important it is to employ a calculation method that takes into account the volatility of developing country markets. The size of the AMC-led market to be created is best based on a 'zero-sum' methodology, which gives an indication of the minimum size of external funds needed to make companies invest in complex and risky $R \& D$ projects that benefit of $L D C s$.

A cumbersome aspect of the current AMC framework proposal is the long-term pricing issue. The viewpoint initially was not to involve international sponsors and developing country governments in the post-AMC market follow-up and shift the responsibility of long-term supply contract obligations entirely to corporations. In the absence of accurate demand forecast data, production costs and market revenues, we recommend however, to determine the post-AMC price at a later stage, that is, at the end of the AMC period. Allowing market forces and price competition among multiple suppliers to come into play at the right time will lead to better price setting than legally binding price setting as determined ex ante. The aim of having binding contracts in the first place was not so much to keep suppliers in a price corridor as to make sure that sponsors and politicians could not renege on their promises to pay if, and when, a new product has been successfully developed and launched in developing countries. Hence, the preferred approach is to determine the long-term price when more data is available about potential manufacturing costs, since prices are reduced over time due to economies of scale and competitive pressure (like in any other market). Any upfront legally binding commitment to apply long-term prices seems to be unrealistic and limits price reductions due to competition. In addition, these ex ante arrangements do not allow for absorbing any unexpected production problems that might occur in the future, and/or coping with new regulations, or addressing allegations of medicine-induced adverse events, or making additional investments needed to maintain and continuously upgrade production facilities. 


\subsection{Case study: Pneumococcal prophylaxis analysis results}

This section outlines the recommended AMC market size and how the OECD subsidy has been calculated for a pilot project that meanwhile has been endorsed by several of the G-8 members. The World Bank, The GAVI Alliance and Industry Working Group has spearheaded the preparation of the case study describing the pilot AMC for pneumoccocal vaccines and presented the results at the second Donor Working Group meeting on 9 November 2006 in London ${ }^{134}$. This calculation pertains to the period during the AMC subsidy, and does not take into account the remarks made in the preceding section concerning issues faced in the post-AMC period, and specifically how to address risk aversion seen with private investors, as well as the economic methods that can be employed to resolve the long-term supply issues by means of market competition between suppliers of both the highly industrialized nations and the emerging economies.

Pneumococcal disease is the leading cause of child pneumonia deaths, as well as the second leading cause of childhood meningitis deaths. Pneumonia is the leading infectious cause of child mortality worldwide, causing an estimated 1.9 million (or 19\%) of the estimated 10 million child deaths that occur each year (Williams, 2002). Corporate investments in the development and production of pneumococcal vaccines have been stimulated to date by the potential of large markets in high and middle-income countries. The pneumococcal vaccine pipeline includes one licensed product and more than 20 candidate vaccines in varying stages of development. Up till now more than 30 million children in industrial countries, have been safely and effectively vaccinated by the licensed vaccine. Capacity is, however, inadequate and the vaccine is not considered suitable for widespread introduction in developing countries. Therefore, two new vaccines, that extend protection to populations in both developing and industrialized countries by adding more serotypes may be licensed by 2010 . Other vaccines, including from emerging country manufacturers may come to the market in the following 5 to 10 years. Given the risks associated with low-income country markets and the costs of scaling-up capacity, these incremental investments will not occur without external financial incentives.

The recommended size of the external donor contribution to the AMC is US $\$ 1.5$ billion in nominal terms with an NPV of US\$860 million. The price per dose is still to be determined, but is estimated to be within the range of US\$5-7 per dose with developing countries responsible for an affordable co-payment per dose of roughly US $\$ 1$. The first payments are anticipated to begin in 2010 and last for 9 to 10 years. Once the AMC is depleted, each participating firm will continue to supply the vaccine at a pre-determined low

${ }^{134}$ http://www.vaccineamc.org/files/Framework\%20Pneumo\%20AMC\%20Pilot.pdf 
price for an established period (however, the issue of how to determine this tail-price has not yet been resolved as explained earlier). The AMC fund would support the first three firms that come to the market with a pneumococcal vaccine of which the product profile suits developing countries (as determined by an independent expert panel), providing each investor with a neutral or positive risk-adjusted NPV. Overall, it is anticipated that the AMC intervention will result in 70 to 100 million infants becoming immunized over the life of the AMC project. This will prevent between 500,000-700,000 deaths during the AMC itself. However, the impact of the AMC goes beyond the contact period, as it assures a long-term sustainable supply and price (again, this is not yet defined). The impact also goes beyond the children immunized, as herd immunity will act as a multiplier, expanding the benefits of immunization to un-immunized children and older populations.

As explained, the AMC model is based on the valuation methodology commonly used by the industry to compare returns across alternative investments and cost of capital (see details in chapter 6). If the investment under review has a positive return, then it is prioritized; if not, it is more closely examined and may be dropped. Like other investment opportunities, each potential product supplier will evaluate the AMC subsidy based on the information available at the time of the investment decision. In addition to their own success or failure, each supplier must account for the possibility of other new suppliers successfully reaching the market as shown schematically in the 'market value and competition relationship' of figure 31 and figure 32 . Thus, the 'dynamic' analysis looks at the likelihood of competitors developing a successful product that will compete for market share. Given the goal of the AMC to encourage competition and continued innovation, the strategic analysis needs to consider the number of firms likely to develop a product within a reasonable AMC duration (e.g. 7-11 years) so that the AMC might be sized to support more than one firm. In the case of below pilot project, the threshold level selected allows the first three innovative firms to receive a neutral or better return on their investments. 
Figure 31: Probabilities of success and failure in a competitive environment

Valuation of new product development based on

probabilities of success and failure in a competitive environment

Potential market scenarios in the case of three innovation driven companies entering

the market for supplying novel medicines to LDC countries in return for a variable share of the AMC subsidy:

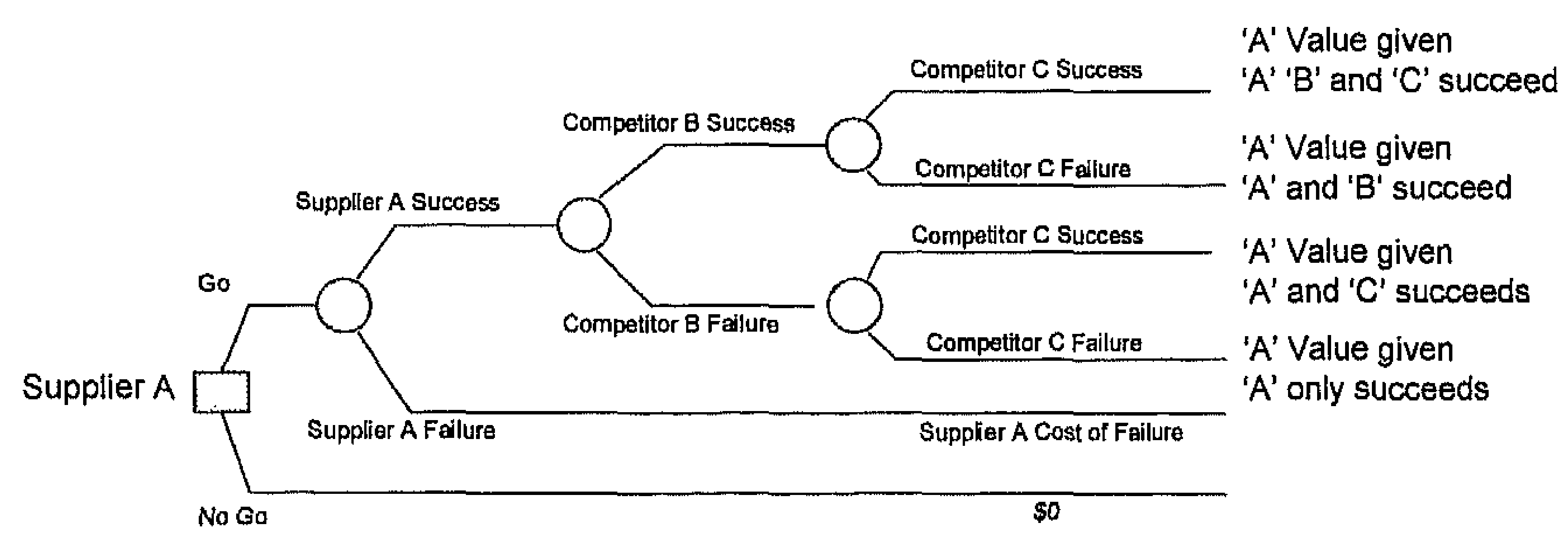

Figure 32: Escimated probability of obtaining market licensure

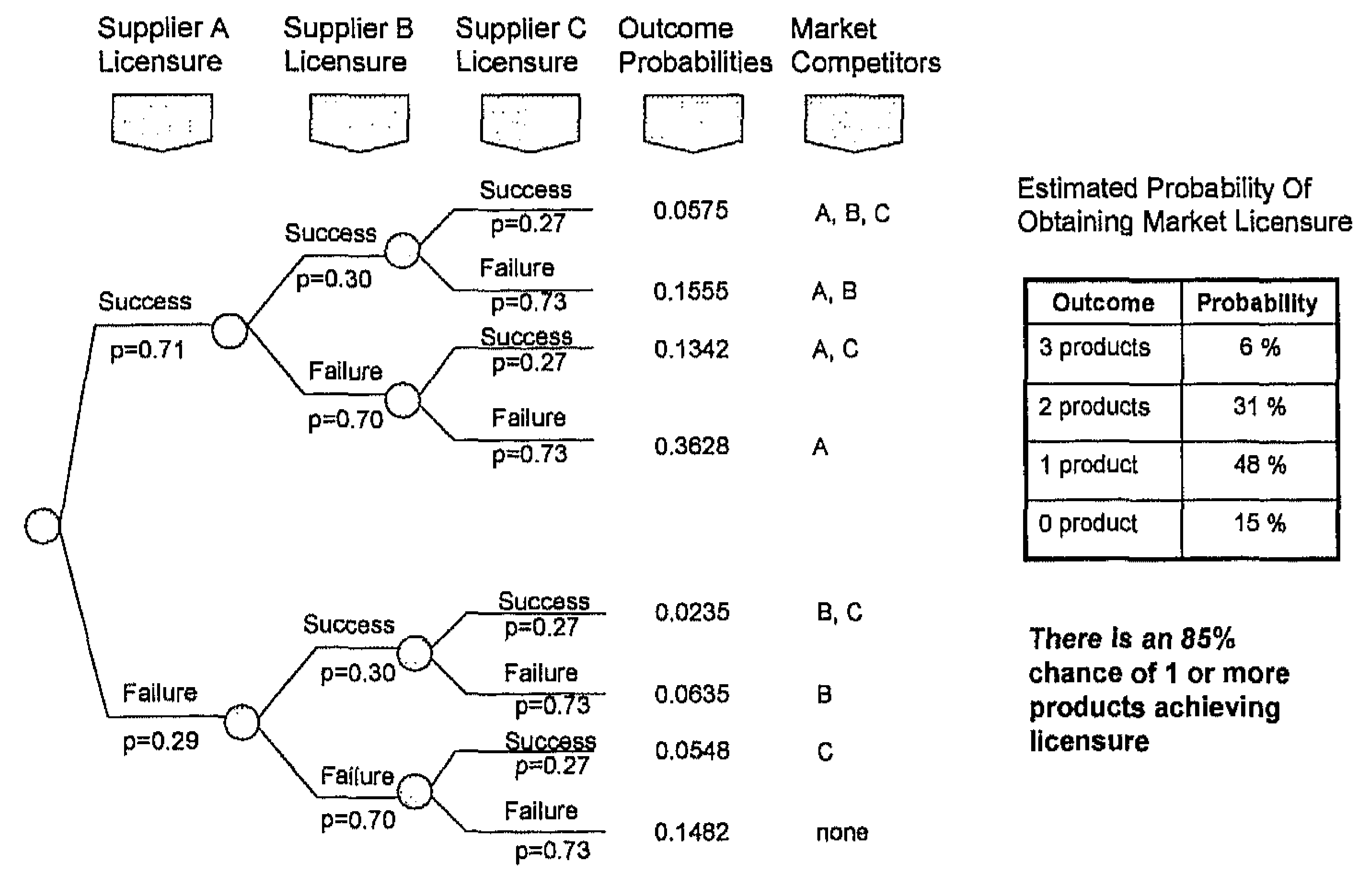


The model as described builds on internal and external data that are critical to a firm's response to an AMC, including on the demand forecast data for pneumococcal vaccines in LDC countries. Reliable estimates of country demand that accurately predict uptake of this new vaccine are the basis on which industry estimates the available market size. Forecasts clearly vary from disease to disease and are based on the timing of uptake (year of introduction) and volume (a function of the target population and the expected coverage levels). For the above therapeutic area, low-income country demand is expected to be about 178 million doses a year, as shown in Figure 33. The forecast model uses demand predictions for the 72 poorest developing countries currently eligible for GAVI funding.

Figure 33: Demand forecasting for AMC pilot project in LDCs

Demand Forecasting (Million Doses $* /$ Year)
For the 72 Poorest Developing Countries
Eligible for Funding

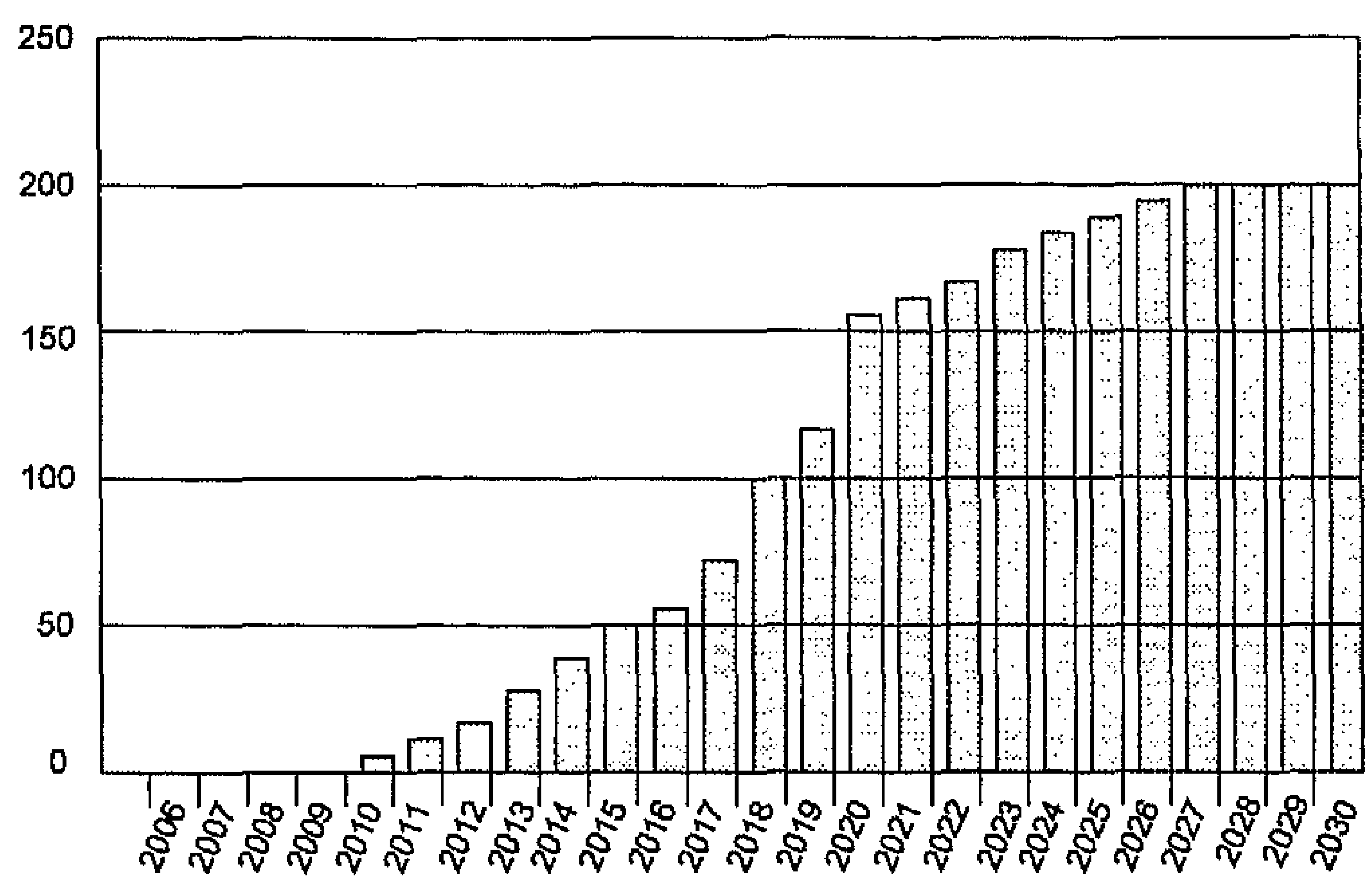

${ }^{*}$ Novel Anti-Pneumococcal Infection Vaccines

If the demand forecasts are inaccurate, for example, in assuming a more rapid uptake by countries than actually materializes - a pharmaceutical or biotech firm will not receive revenues and will be left with inventory that typically expires after 24 months. To date, forecasts of new medical product uptake in developing countries have been quite inaccurate. This contributes to industry's unwillingness to invest in these unpredictable markets. By definition, demand forecasting in these countries is difficult and often unreliable, especially as optimistic thinking about what 'should' occur has at times delivered forecasts exceeding actual product use in LDCs. 


\subsection{Conclusion}

Over the past few years significant progress has been made by both the public and private sector stakeholders on how to make work a novel funding framework called Advance Market Commitments (AMCs) - a mechanism aimed at stimulating pharmaceutical and biotechnology $R \& D$ on diseases afflicting primarily the developing world. AMC is a financial commitment by donor countries to subsidize the future purchase of a new medical product, not yet available, if and when such a product is developed, and if it is demanded by the poorest developing countries. The AMC creates an economic incentive for developers of health products analogous to that of doing research and development on products for diseases prevalent in affluent countries like, for example, cancer, diabetes, etc.

This chapter described how a quantitative computer-assisted model was designed that enables policymakers and corporate executives to calculate the minimum threshold-level of the AMC subsidy. This approach is based on 'risk-adjusted' capital investments to be made in each of the disease categories selected by experts as priorities for the developing world. The integrated 'risk-investment-incentive' model provides an evidence-based method to determine the minimum size of external donor funds needed to adequately compensate private sector investment in diseases that affect millions of people in the developing world each year. Ideally, the model uses triangular market estimates and takes into account the impact of variations in project costs, as well as in $R \& D$ project timelines. The method can be applied to new medical compounds in early-stages of development, as well as to those that have progressed further downstream the R\&D pipeline. The method is most accurate when the scientific 'proof of concept' has been reached, that is, when new and promising medical compounds are just beyond the stage of pre-clinical development, and an early indication of efficacy in humans has been obtained.

We advocate that AMC has the potential of becoming a powerful novel incentive system for promoting the development of products in hitherto neglected or under-resourced therapeutic areas. Despite its great potential, the AMC incentive mechanism may not be the one magic bullet to solve all problems limiting industry investment in global health products. Nonetheless, AMC is viewed as a critical component of a package of incentives needed to progressively attract more investment and involvement of the private sector in neglected diseases. The prerequisite is that modifications to the current system are implemented as suggested. Interviews and debates with different stakeholders including senior executives of leading companies have delivered proof that a more accurate design of the program will be essential for its future success. The current calculation technique at best determines the minimum level of funds needed. In true markets, however, the transaction price is agreed through a purchase negotiation and typically reflects the value of the product or service; it usually is a function of the quantities purchased and the duration of the 
agreement. Ultimately, the subsidized price should relate not only to the complexity and cost of manufacturing, but also to the economic and public health value of the new therapy or preventative tool, relative to other interventions. This external value factor must be incorporated in future AMC models; and this may require exploring health technology assessment techniques and valuation methods. 


\section{Anticipating emerging global illnesses: Public heal th policy and industrial alignment}

In anticipation of the world's next influenza pandemic (worldwide flu epidemic), this chapter will examine the public health policy decisions and industrial sector alignment that is needed to off-set this emerging threat. The WHO together with national government authorities are preparing for such a pandemic that is likely to affect all citizens around the world regardless of whether they live in poor or affluent countries. Influenza pandemics have occurred in the past at irregular and unpredictable intervals, and have been associated with substantial human suffering, mortality and socio-economic costs. For the moment, the new virus $(\mathrm{H} 5 \mathrm{~N} 1)$ is predominantly killing birds. However, it is widely seen as a candidate virus able to trigger the next influenza pandemic in humans. Pharmaceutical and vaccine manufacturers face investment decisions for an uncertain event. To manage the associated risks and uncertainties we argue that a public-private partnership is necessary for stimulating $R \& D$ in this 'neglected' therapeutic area. This would require 'push' and 'pull' incentive mechanisms able to stimulate innovation. Strategies based on the use of preventive medicines offering cross-protection against multiple pandemic-like strains may avert the worse effect of this looming threat to society. 


\subsection{Introduction}

The pandemic 'avian' flu threat

During the last century, influenza (flu) pandemics have caused millions of deaths, social disruption and profound economic losses worldwide. The recent outbreaks of highly pathogenic avian influenza, caused by the $\mathrm{H} 5 \mathrm{~N} 1$ strain, have raised concern that the world may be moving towards another flu pandemic (Ungchusak et al, 2005). Whereas all experts agree that another pandemic is likely to happen, they are unable to predict when. It has been estimated that in industrialized countries, the next pandemic may result in up to 130 million outpatient visits, 2 million hospital admissions and 650000 deaths over two years. However, the impact is likely to be the greatest in developing countries, and deaths caused by pandemic influenza could total many millions and cost hundreds of billions of dollars in economic disruption (World Health Organization, 2004).

The pandemic will be triggered by the emergence of a novel virus subtype to which the general population will have little or no immunity. And because this natural immunity is lacking, the virus will spread rapidly throughout the entire population. Avian influenza, or bird flu, does not normally infect humans, but if the virus acquires the ability to transmit readily from person to person it could spread across the globe within months or even weeks due to the extent and frequency of international air travel. Since the late 1990 's, several cases of $\mathrm{H} 5 \mathrm{~N} 1$ and $\mathrm{H} 7 \mathrm{~N} 7$ have occurred in humans from infected poultry, but there has not yet been a mutation that has allowed these viruses to spread efficiently in man (Katz, 2004). The formation of such hybrid viruses through re-assortment of an avian virus with a human virus combining characteristics of both strains is a stochastic event. The wider the distribution of avian viruses and the greater the contact infected animals have with man, the more likely the event is to occur. These conditions are mostly seen in the Far East, and recorded pandemics also appear to have originated in this region.

Therefore, the WHO has clearly stated that a pandemic will occur at some point in the future. It is no longer a matter of if, but rather of when as evidence strongly suggests that the $\mathrm{H} 5 \mathrm{~N} 1$ strain is now endemic in many parts of Asia, having established a permanent niche in poultry. Moreover, the $\mathrm{H} 5 \mathrm{N1}$ strain has established itself in healthy domestic ducks, and is expanding its mammalian host range. Recent analysis of ducks in Asia has shown that the $\mathrm{H} 5 \mathrm{~N} 1$ strain is much less dangerous to these birds, allowing them to be a reservoir for the disease (Hulse-Post et al, 2005). Ducks are therefore the 'Trojan horse' for the $\mathrm{H} 5 \mathrm{~N} 1$ viruses as they are unaffected by the infection, yet continue to circulate the pathogenic viruses. The H5N1 strain has also been identified in pigs in China, a worrisome finding as pigs can serve as hosts to human influenza viruses as well (World Health Organization, 2004). This prevalence of the pathogenic strain increases the likelihood that it 
might one day adapt to people through either re-assortment in a non-human mammalian species, co-infection within a human host or through spontaneous mutation, making $\mathrm{H} 5 \mathrm{~N} 1$ a likely candidate for the next pandemic. After the discovery of the $\mathrm{H} 5 \mathrm{~N} 1$ virus in Siberia in July 2005, the lethal flu strain killed more than 60 people in South-east Asia that year and ravaged the region's poultry industry, and would continue to spread across the Ural-mountains into Europe and other parts of the world (McLauchlin, 2005).

\section{Public health interventions to mitigate consequences}

Although predicting precisely when, where, or how the next flu pandemic will occur is near impossible, planning for it is essential. A pandemic outbreak will undoubtedly provoke high levels of social disruption and increased mortality and morbidity. The severe health and socio-economic consequences have prompted the WHO to assume leadership in galvanizing global planning efforts (World Health Organization, 2004; 2005). At the national level, an increasing number of countries have drafted national pandemic preparedness and emergency plans, while 'real life' simulation exercises are also being run to test the robustness of these plans.

An adequate surveillance system is the cornerstone of any pandemic preparedness and response. The WHO Global Influenza Surveillance network has been established in order to act as an early warning system with the intention of picking up the first human cases related to the emergence of a novel influenza virus, and to signal the first instances of human-to-human transmission. Experts agree that once a pandemic is fully underway, mass use of an effective vaccine in conjunction with antivirals in the early phases will be central to strategies for reducing morbidity and mortality (Salinsky,2004; Osterholm, 2005; Fedson, 2005; Fauci, 2005; Check, 2005; Stoehr, 2005). Experience with previous flu pandemics has shown that a pandemic spreads in 2-3 waves (the first being less intense than the second one) over a total period of 13 to 23 months. Vaccines are therefore a primary means of preventing and controlling pandemic influenza since they can be used as a prophylaxis and provide long-term immunity. Even the consequences of a severe pandemic may be reduced if large numbers of doses of effective pandemic vaccines can be quickly produced and equitably distributed to countries that need them. Many observers believe, however, that vaccines may not be available in large enough quantities before the pandemic has had its full impact. They claim that large-scale production of pandemic influenza vaccine may take up to six months after the pandemic strain has been declared, and cannot be initiated earlier because the novel virus has not been identified and isolated. Hence no country would have adequate supplies to protect its population at the start of the pandemic. This reasoning explains why so few countries have included vaccines and vaccination programs in their preparedness planning. 
To adequately prepare for the pandemic, measures for accelerating the development of a pandemic flu vaccine and increasing vaccine production capacity, are required. Measures can already be taken pro-actively, and part of the preliminary technical development work finished, in the pre-pandemic period. However, planning ways to control the inevitable pressure that healthcare professionals, pharmaceutical and biotech companies will come under from the public and politicians, if a pandemic does take place, will be much more difficult. Large-scale supply of vaccine quantities to cover the general population cannot be immediately achieved, and the production of millions of doses will take several months. It is argued that antivirals may be used at the onset of the pandemic while a strain-specific pandemic vaccine is being produced. However, there are several constraints and hurdles to overcome in this respect, making antivirals by no means a panacea. Hence, it is important to draft public health recommendations that determine upfront who will receive pandemic vaccines and/or antivirals, and how production and distribution of these products can be organized before and during the pandemic. It will not be easy to resolve these questions, while ensuring equitable delivery within and between countries since the demand for pandemic vaccines will be sudden and supplies will only become available progressively. Moreover, most of the manufacturing capacity is concentrated in Europe $(+/-65 \%)$. North America, Australia and Japan, along with producing countries can be expected to reserve scarce supplies for their own population (European Vaccine Manufacturers, 20005). The corollary of this concentration is that non-producing countries are likely to face the most acute shortages of anti-pandemic products and incur the greatest impact of the pandemic.

This chapter will examine the key issues that influence pandemic flu prevention and vaccine development, production, distribution and usage. Specifically, we will investigate how this process can be accelerated by the development of a public health strategy that defines ex ante anti-pandemic product utilization, and a pharmaceutical policy that is aligned with these public market-needs. These two complementary policies will be examined individually, and their complementary interactions discussed. This is graphically illustrated in figure 34. A successful policy for pandemic vaccine development and introduction is predicated on successfully designing and implementing so-called 'push-pull' incentive systems. The aim of these systems is to encourage an industrial policy and environment that is conducive to increased investment by industry in this therapeutic area. The coordination of these pandemic vaccine development activities could be embedded in a PPP.

While recent publications have focused on the problems and constraints presented by the timely and cost effective production of vaccines in the event of a pandemic, this chapter proposes tangible and achievable solutions for handling this major public health challenge. 
Figure 34: Pandemic vaccine development: alignment of public health and pharmaceurical policy

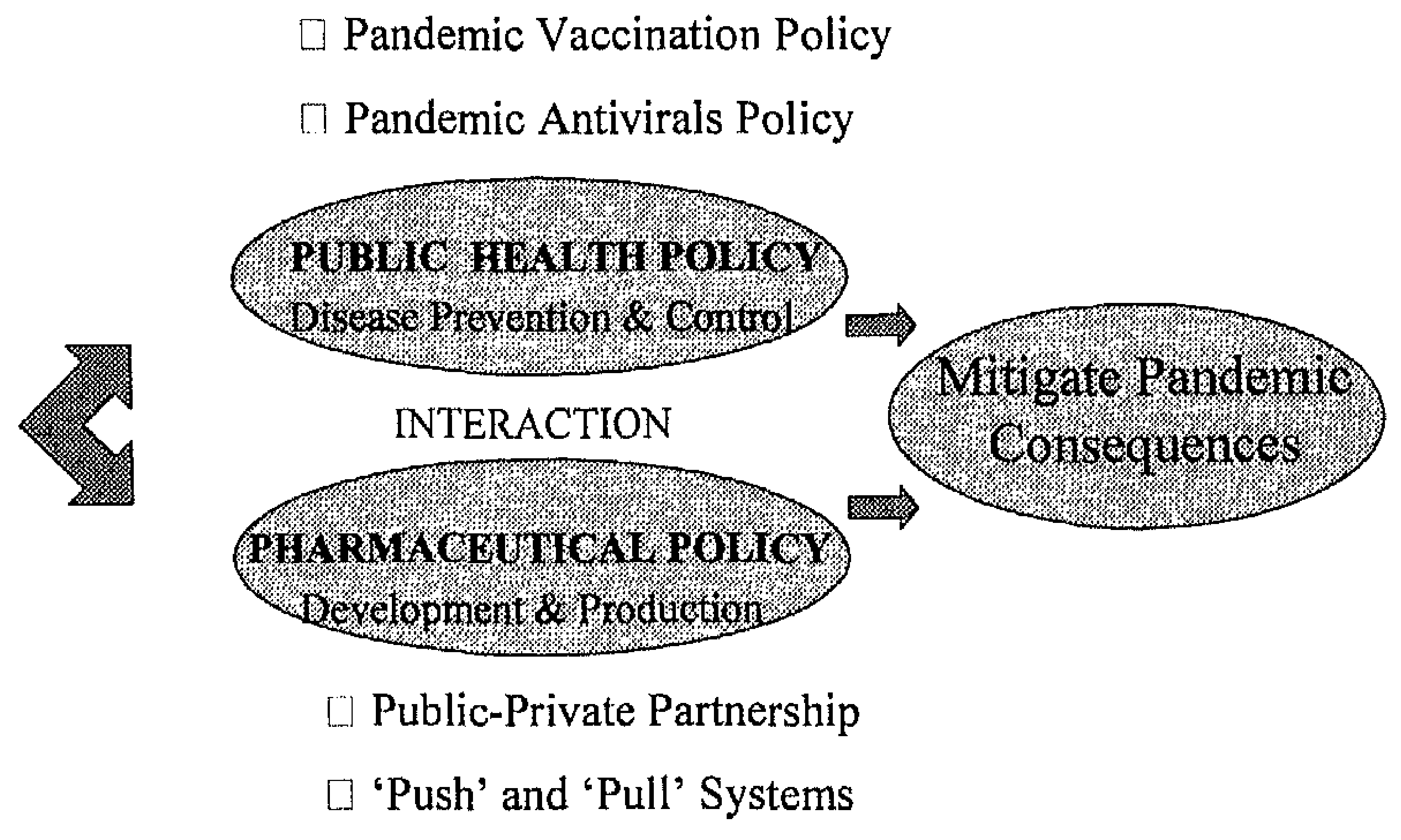

\subsection{Disease prevention strategies and industrial policy alignment}

Prevention through vaccination could offer one of the best opportunities to prevent disease and death caused by a flu pandemic, but there are limitations on the timeliness and availability of a vaccine for a number of reasons that need to be resolved. Presently, the industrial capacity for influenza antigen is believed to be far lower than the amount that will be required. In the event of a pandemic outbreak, strain-specific pandemic flu vaccines must be developed rapidly and produced in extremely large quantities. Consequently, pandemic preparedness efforts have so far focused on shortening the time frame between the emergence of the pandemic virus and the availability of vaccine for worldwide distribution (Fedson, 2005).

Increasing world production capacity for flu vaccine and deciding upon the scale to which this is necessary, depends on the type of public health strategies envisaged prior to and after the pandemic has been declared. If vaccine capacity is left unchanged at current production levels, supply will most probably be the major constraint determining future public health success. Conversely, if no clear public commitments are made today on how pandemic vaccine should be used, how much is needed and who will pay for it, supply capacity will fail to meet the public health needs. To resolve this conundrum and given the seriousness of the situation, the public health strategy to prepare for a pandemic and the industrial policy underpinning vaccine development must be aligned. An increasing number of governments have their preparedness and emergency plans already in place, and some have started stockpiling $\mathrm{H} 5 \mathrm{~N} 1$ vaccine. However, major barriers still exist around stockpiling, or 
pre-emptive vaccination with $\mathrm{H} 5 \mathrm{N1}$, and this reluctance can be associated with the uncertainty as to when the next pandemic might occur, whether it will be caused by $\mathrm{H} 5$ or some other influenza subtype, and whether the stockpiled vaccine would be a good match for the pandemic strain.

Some observers urge strategic planners to think bold: "Extraordinary threats call for consideration of innovative strategies that, in less-threatening circumstances, might be dismissed" (Schwartz, Gellin, 2005). Imagine, for example, that a pandemic 'prototype' vaccine could be developed, licensed and made available before the pandemic strikes, and that it would offer protection (at least partially) against various $\mathrm{H} 5$ strains with antigenic drifts so that, after having primed naïve individuals, it may prevent the worst adverse consequences of pandemic disease. The question is whether we would, as a society, consider using this candidate vaccine, and if yes, when, for whom and under which conditions.

\subsection{Public policy for stimulating new medicines r\&d and production}

\section{Barriers to development, production and licensing of pandemic vaccines}

The provision of pandemic vaccination depends almost entirely on the production facilities of those companies that are, every year, producing the 'regular', and inter-pandemic flu vaccine. These companies, supported by laboratories in the WHO's Global Influenza Surveillance Network, have gained considerable experience in the production of flu vaccines to match each year's circulating strains. Currently, vaccines are prepared as an antigen fraction from the virus (i.e. split virion vaccines and subunit vaccines). All companies produce their vaccine by growing the virus in embryonated eggs (Gerdil, 2003). In anticipation of the flu pandemic, some companies have moved forward in pursuit of a diversity of technical solutions and manufacturing options. Steps to improve industry's pandemic preparedness range from the construction of new production plants - meeting higher biosafety standards - through investigation of adjuvanted vaccines as an antigen-sparing technology, to the development of libraries of candidate vaccine prototypes. Some companies are investing in newer manufacturing plants and technologies, including cell-culture vaccines using cell lines. These newer technologies represent the way forward for industry in the production of both seasonal and pandemic vaccines. In the short term, reliance on existing technologies, backed by experience, is considered the best way to develop as many candidate vaccines as possible, as quickly as possible, in compliance with existing regulatory requirements. 
Annual flu vaccine production is directed to each flu season's vaccine demand (one dose regimen containing 45 microgram of trivalent viral strains) with no reserve capacity. Pandemic flu vaccine will need to contain only the pandemic virus; in other words, it will be a monovalent, not trivalent vaccine. Given the global production capacity of approximately 300 million doses of trivalent vaccine, it is theoretically possible that up to 900 million doses of a same-strength vaccine (monovalent, 15 microgram) could be produced (Fedson, 2005). As most people will be immunologically naïve to the new virus strain, they will require two doses of vaccine to be fully protected (Fedson, 2003). This means that only 450 million people could be vaccinated with two doses of a same-strength pandemic vaccine. In many countries, public health officials will want to vaccinate everyone in their population. This means that supply based on current capacity would only cover $20 \%$ of the possible pandemic vaccine demand. To meet global demand requires companies to dramatically scale up their flu vaccine production capacity with a factor of approximately 3-5 times their current output. However, the uncertainty related to the timing of the next pandemic and the possible indecisions as to how to respond to it - including which pandemic vaccine to develop and manufacture - leaves little incentive to industry to build additional production capacity.

Companies must make long-term investment decisions for an event that occurs only rarely and unpredictably. A key issue is the lead-time to build and validate a new biological manufacturing plant. This takes about four years of engineering work and the additional capacity has to be in place before a pandemic in order to provide the required number of doses. There are several barriers to manufacturing pandemic vaccines, in addition to the limited number of specialized production facilities. Several emergent strains are highly pathogenic both for the embryonated chicken eggs and for the people involved in vaccine production. This issue requires both the use of biocontainment facilities and the introduction of genetic manipulation techniques known as reverse genetics to remove the gene that makes the virus deadly. Only a few facilities are presently equipped to meet the enhanced biosafety level 3 conditions needed in most countries for the safe manufacturing of flu pandemic vaccines. Finally, R\&D work needs to be conducted and investments made in new product formulations to reduce antigen content with the aim of boosting the total output of pandemic vaccine production. These formulations require the use of adjuvants for improved immunogenicity and conduct of clinical trials with various dose-sparing formulations (MacKenzie, 2005).

Despite these technical hurdles, industry has the knowledge, experience, and capabilities for acquiring the necessary skills and know-how to develop and manufacture pandemic vaccines (Jack A., 2005). However, given the unpredictability of flu pandemics, private companies will need strong incentives to invest in developing a new product that may never be needed, or that nobody is willing to pay for unless the pandemic occurs. Therefore, a gap 
exists mainly due to a lack of public and political commitment towards pandemic vaccination preparedness, and insufficient economic incentives for supporting the private sector in building capacity. This has led the WHO to state at a meeting with all stakeholders in Geneva in November 2004, that: "slow progress of influenza vaccine development is no longer caused by insurmountable technical hurdles; the hurdles are political and economic in nature" (Stohr, 2005). Governments and supranational organizations should regard pandemic vaccine research, development and production as a 'public good' as the benefits would spill over to many individuals in the population, as well as many nations. This consideration would justify the use of targeted public incentive mechanisms for encouraging the development of products for which there is no readily available market, but that are important from a public health and consumer protection perspective. Mechanisms for stimulating pandemic vaccines development can be broadly classified as 'push' programs, which subsidize inputs, or 'pull' programs, which reward developers for actually creating the desired product.

\section{Push and pull systems for stimulating pandemic vaccine development}

Literature on incentives for pharmaceutical and vaccine development for diseases where an economic market failure exists, for example, orphan drugs or medicines for poverty related diseases, distinguishes between 'push' and 'pull' approaches (Kremer, Glennerster, 2004). Push programs subsidize research inputs through means, such as grants to academics, public equity investment in product development, tax credits for R\&D investment, and outlays for government laboratories. Pull programs on the other hand increase the rewards for developing specific products by committing to reward success by, for example, guaranteeing to purchase a certain quantity or guaranteeing to pay a minimum price for the product once it has been developed. The distinction, then, is roughly between paying for new product development inputs and paying for new product development outputs.

As discussed in chapter 3, research and development leading to breakthrough pharmaceutical and vaccine innovations, usually involves a combination of these push and pull mechanisms. Government organizations such as the NIH in the U.S. focus on supporting basic research, and the private sector is stimulated to turn this biomedical research into usable products by the promise of a market protected by patents for a limited time period. The incentive for corporations to invest is the prospect of future sales through which they can appropriate a return on their $\mathrm{R} \& \mathrm{D}$ investment, production and time-to-market efforts, as well as financial risk-taking. Applying this principle to developing a pandemic flu vaccine suggests using push programs for basic research and pull programs for encouraging biotech and pharmaceutical firms to turn this research into viable products. However, corporate funding may not be available for the development of a product that has no clear demand or market prospects. Capacity may also be strained if seasonal-flu shots and the avian-flu 
pandemic vaccine both need to be produced around the same time. As they are produced in the same facilities, companies will be required to make a trade-off decision between producing a vaccine for a pandemic threat and producing seasonal flu vaccine.

Given the nature of these risks and uncertainties, pandemic vaccine development will not happen spontaneously in the absence of market forces. But a well-designed pull program could efficiently align the necessary incentives, with governments defining the problem while private developers compete to find the best solution. A clear benefit to governments of using a pull program is that money changes hands only when a successful product is developed. Thus authorities need not worry that they will have invested millions in a project that ultimately fails. They can safely proceed with making 'advance purchase commitments' even if scientific opinion is divided about the feasibility of the innovative product to be developed. Ultimately, scientists and private firms working on the problem are best placed to judge the prospects of their own technology and inventions. If they judge these prospects worthwhile they will invest time and resources into pursuing these projects, knowing there will be a market for their product if they are successful. They are also free to explore the most promising research avenues and to pursue only those development programs that take into account requirements that fit their production processes. A pull program also creates a level playing field among all companies as it incentivizes many innovative technologies across the board. Pull programs do, however, have a number of limitations. Governments (buyers) must specify the desired development output beforehand, and coming up with the right specifications and eligibility requirements may be difficult. For example, what should the minimum protective efficacy level be for a flu pandemic vaccine? Finally, a pull program may potentially lead to duplication of research and development activities. However, in view of the limited flu vaccine technology in the world, it seems appropriate to pursue as many different leads simultaneously in searching for solutions.

A conceptual model for strategic product development of pandemic flu vaccine is illustrated in figure 35, including how push and pull incentive mechanisms can be applied. The effect of these publicly-funded incentive mechanisms depends on the financial support provided by governments, and the in-kind contributions made by public health institutions. This will be further discussed in the next section. The most straightforward objective is to produce a prototype vaccine with a single strain ${ }^{135}$ and the most likely candidate pandemic

\footnotetext{
135 Use of tetravalent vaccine has definitely appeal as the ultimate solution to a threat that may loom for many years to come. Production of tetravalent vaccine would not, however, solve current problems with production capacity. Moreover, if a pandemic-like strain is included in the inter-pandemic 'seasonal' vaccine, only the current at-risk groups will be reached. A 'one shot' vaccine is also unlikely to be effective, but probably will if boosted
} 
strain is H5N1. When the pandemic is declared and the final strain identified by the WHO, a 'fast-track' registration procedure can then be applied. Hence, there is no need to submit a mock-up file for each possible pandemic strain because most development steps and production processes are similar. The research-based pharmaceutical and biotechnology industry has the ability to complete the required core product development steps, which include: vaccine formulation(s), clinical lot production, pre clinical testing, clinical testing (3 phases), mock-up registration filing, production scale-up, shipment and delivery.

Figure 35: Push and Pull systems: underpinning pandemic vaccine development

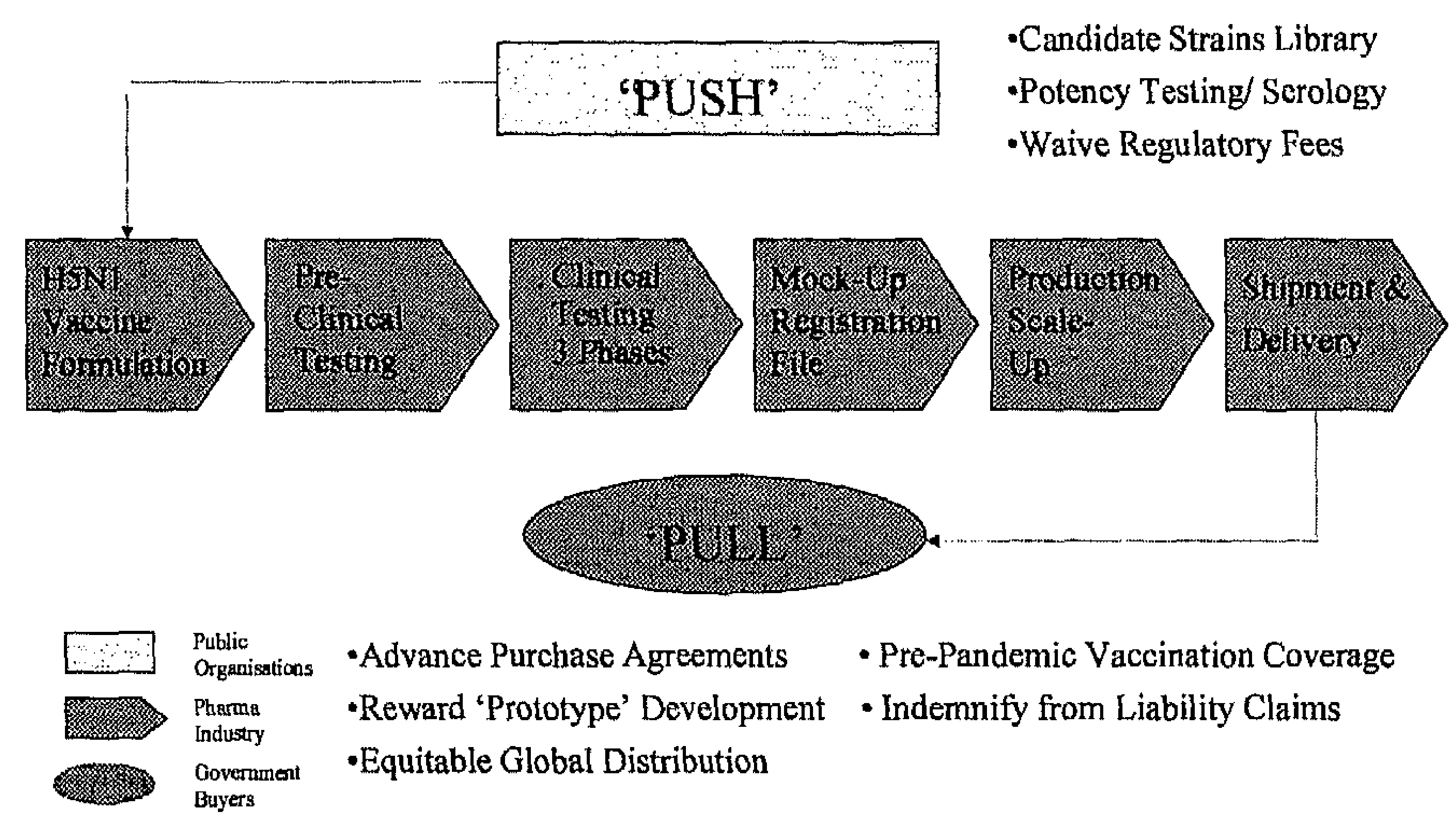

\section{Public private partnership to coordinate development activities}

Development of a pandemic vaccine that potentially may never be used, together with the fact that this type of one-off event is difficult to prepare for, particularly in the absence of advance purchase commitments to compensate producers for developing such a product, means that it will be difficult for companies to undertake production of pandemic vaccines without government support. Therefore, in the interest of public health, pandemic vaccine development, including tailor-made 'push-pull' incentive systems should be coordinated through a PPP. To be successful, such alliances should rely on each partner's strengths and competencies.

later. The same short-term limitations may apply to a trivalent vaccine containing the H5N1 component replacing one of the strains currently used in the seasonal vaccines. 
Since developing an adequate response to pandemic flu represents an immediate challenge to policymakers, the National Public Health Agencies of several governments have already prepared 'Influenza Pandemic Contingency Plans' for their nations. These can be consulted on their respective national websites e.g. United States, UK, France, Germany, Netherlands, etc. In addition, the European Commission has published a 'Working Paper on Community Influenza Pandemic Preparedness and Response Planning' (European Commission, 2005), and a draft proposal 'Towards Sufficiency of Pandemic Influenza Vaccines in the EU' (European Commission, 2005). The latter document summarizes the Commission's view on establishing a PPP between public bodies of the European Union and the vaccine industry to deliver vaccines in the shortest possible time in the event of a flu pandemic. In the U.S., the NIH are conducting basic research on viral pathogenicity and molecular evolution. The NIH also carries out research to identify drug targets and new technologies for vaccine production, as well as clinical research to test the safety and efficacy of new vaccines, diagnostics, and antivirals. A new U.S. bill, the 'Biopreparedness Act' of 2005, aims at eliminating barriers and building incentives for biotech and pharmaceutical companies to create better and more vaccines to bolster the nation's biodefenses (Pomerance, Bioshield, 2005). This would include vaccines against threats posed by possible natural catastrophes like avian flu. The backdrop to this bill is the bioshield law of 2004 against terrorist attacks with biological and chemical agents, which turned out to be a good start for biodefenses, but did little to improve the incentives, and reduce the disincentives, that companies face as they prepare vaccines and drugs that would become obsolete if governments choose to shift their priorities at the moment these products become available.

What follows is an analysis of those 'push' and 'pull' mechanisms that we believe are important for stimulating the development and production of pandemic flu vaccines. Incentives can be financial and non-financial, such as in-kind contributions by public institutions (Daems, 2005). For a graphical representation, see figure 35.

(a) 'Push' mechanisms:

A library of reference strains - The first step in vaccine preparation requires the generation of a 'reference virus' - generally a time consuming process. Reverse genetics can be used to generate reference viruses that precisely match a target flu strain, while removing the biosafety risks of high virulent pandemic virus strains and their virulence for embryonated eggs. Using this technique, an $\mathrm{H} 5 \mathrm{~N} 1$ reference virus can be produced, and be used to develop an inactivated H5N1 vaccine. Development of a seed stock library by the public sector to a stage suitable to manufacturers for production as a master seed lot may signifcantly expedite vaccine production when a pandemic strain emerges. The first phase of vaccine production would then be completed in advance of the pandemic, reducing the production time by approximately two months. This procedure mimics the annual process 
employed by the $\mathrm{WHO}$ and its collaborating centers to provide manufacturers with a vaccine reference strain that contains the antigens most likely to give protection during that particular influenza season. Manufacturers use this strain to produce their own working virus seed adapted to their production process in order to increase production yields.

Serological and potency testing - The immunogenicity of candidate vaccines will be assessed in animal models first and subsequently in clinical trials by measuring the antibody response using conventional haemagglutination inhibition (HI) assays, or other serological assays (e.g. microneutralization), when $\mathrm{HI}$ assays are not useful. Studies are required to validate and refine the current understanding of this 'immune correlate' of protection. For a new pandemic strain like $\mathrm{H} 5 \mathrm{~N} 1$, there will be little immunity from previous exposure in the population, and one dose may not be satisfactory. The contribution made by antibodies to a shared neuraminidase antigen in reducing severity of the disease may however be relevant. Experiments could be set up to determine the effect of different previous exposures (e.g. to $\mathrm{H} 1 \mathrm{~N} 1$ ), when combined with vaccination by a one or two-shot regimen of a new pandemic vaccine (e.g. H5N1). In addition, cross-protection provided by selected candidate vaccines against various wild type viruses could also be tested. It would allow for determining the protective efficacy of stockpiled vaccine, e.g. $\mathrm{H} 5 \mathrm{~N} 1$, against new strains of the same main type when they emerge, either giving reassurance to use the stockpile, or prompting work on developing a new vaccine seed.

Waive regulatory licensing fees - Another potential obstacle to pandemic vaccine availability, which could be addressed by governments and regulatory authorities in advance of any pandemic threat, is to waive the various national and supranational licensing fees that are usually paid for vaccine registration.

(b) 'Pull' mechanisms:

Inter-pandemic vaccination coverage - Flu vaccine manufacturing capacity is driven by the demand for product during the inter-pandemic years. Increased demand for seasonal flu vaccine would therefore increase capacity to manufacture pandemic vaccines. Increased flu vaccine usage during the inter-pandemic years would also give countries experience in the logistics of vaccine administration. After all, increased coverage in the pre-pandemic period may prove to be an important, but long-term, strategy that depends on the higher positioning of influenza among the many other infectious diseases that compete for attention and funds from governments. The World Health Assembly (WHA) agreed in 2003 on vaccination coverage targets for seasonal influenza for countries with vaccination policies in place (WHA, 2003). The objective of the WHA is to attain a coverage rate for high-risk populations of at least $75 \%$ by 2010 . Recommendations for universal flu vaccination of people aged 50 years and over were already adopted in the U.S. in 2000, while other countries 
decreased their age cut-off for universal influenza vaccination from 65 to 60 years of age. However, EU Member States and the European Commission indicated that changes in recommendations for adults younger than the age limits 60/65, or for children, were not being considered at that stage (European Commission, 2005). A pandemic preparedness strategy based on increasing the population coverage for annual flu vaccination, albeit very useful from a public health perspective, may only be slowly implemented by countries, and thus gradually increase production capacity over a longer period.

Advance purchase agreements - The WHO has stated that governments may wish to consider strategic stockpiling of a $\mathrm{H} 5 \mathrm{N1}$ vaccine. Some countries are actively pursuing this option with the objective of deploying this (limited) strategic stockpile to at-risk groups at the moment the pandemic takes hold. In addition, a number of countries are in the process of concluding 'advance purchase commitments' (APCs) for the supply of strain-specific pandemic vaccine at the moment the pandemic is declared. These APCs usually take the form of bilateral agreements between a country (buyer) and a selected manufacturer (supplier). The advantage of APCs is that it provides a strong pull system for underpinning private-sector investment in new vaccines development (Kremer, Glennerster, 2005). However, in the case of developing and producing pandemic flu vaccine, supply may never happen, and therefore payments through an APC mechanism may never take place. The result is that companies will have to write off their sunk development costs, as well as the costs incurred for expanding production capacity prior to the pandemic event. Whereas certain provisions can be made in these APC contracts, it seems appropriate to include milestone payments regardless of whether the ordered pandemic product is used by the purchaser or not; or in other words, whether the pandemic occurs or not.

Award for licensing prototype vaccines - What is missing, is an incentive mechanism for industry to substantially invest upfront in the research and development of various pandemic flu vaccines knowing that these products may potentially never be acquired or used . The question therefore focuses on how to share these financial risks in a balanced way between the public-sector buyer and the private-sector provider, preferably by using an incentive system that rewards output rather than input. A system that may suit both parties would comprise an interim milestone payment at the moment of obtaining regulatory approval, that is after successfully completing the 'prototype' development process for pandemic-like flu vaccines according to buyer specifications (e.g. H5N1 vaccine). The development of 'prototype' vaccines represents a substantial investment, and is estimated by the EVM to be several million US dollars per manufacturer per product (European Vaccine Manufacturers, 2005).

Indemnification from liability claims - Exposure to liability claims associated with usage of flu pandemic vaccine differs from normal marketed vaccines, mainly due to the tight 
deadlines that will have to be met in case of a pandemic outbreak. Vaccine safety is always of prime importance, but the need for extensive safety testing of the pandemic vaccine will have to be balanced against the need for rapid mass production. Liability claims triggered by consumers are likely to arise with mass immunization using a pandemic vaccine that has been submitted to an abbreviated clinical testing program. This may lead to unknown side effects when used at large in various populations, or may offer incomplete protection during a pandemic. This could occur despite usage of the pandemic reference strain for vaccine development following the WHO recommendations. Such litigation would potentially cost billions of dollars to producers and must therefore be addressed by the legislator beforehand. Hence, a legal instrument should be put in place that would temporarily waive manufacturers' liability for pandemic vaccine at the time of licensure and approval of production batches by authorities.

Equitable global distribution - Presently, flu vaccines are produced in a limited number of industrialized countries. However, developing countries may find themselves at the epicenter of the emerging pandemic wave. Governments will therefore need to develop a rational and evidence-based pandemic response plan and find solutions to equitable vaccine distribution and financing to meet the needs of humankind during and possibly before the pandemic outbreak. The WHO is already building a strategic stockpile of antiviral drugs that could be used to 'ring fence' the outbreak in developing countries (Abbott, 2005). Building a similar centrally managed stockpiling of pathogenic pandemic-like vaccines (e.g. $\mathrm{H} 5 \mathrm{~N} 1$ ) is being considered. A public-private partnership between the WHO, World Bank, UNICEF, Governments, NGOs, Foundations, and Industry is therefore needed. Procurement and distribution of pandemic vaccines for the world's poorest countries could be done through The GAVI Alliance. Funding could be realized through one of the so-called innovative financing systems, e.g. The International Finance Facility for Immunization (IFFIm), or UNITAID ${ }^{136}$, which raises money outside the traditional government budgets through a solidarity levy on airline tickets.

In the case of developing countries, the problem is compounded by the fact that the majority of the population does not use annual (seasonal) flu vaccines of which the regular manufacturing could be switched to strain-specific pandemic vaccine at the time the pandemic is declared by the WHO. These citizens are at risk if a new and lethal pandemic flu virus sweeps around the globe. Hence, there is a strong moral justification for fair

${ }^{136}$ In 2006, France, Brazil, Chile, Norway and the United Kingdom decided to create an international drug purchase facility called UNITAID to be financed with sustainable, predictable resources. As an economically neutral tool, the tax on air tickets was considered as the most suitable instrument. This mechanism seeks to fill a critical gap in the global health financing landscape: the need for sustained strategic market intervention to drive price reduction and increases in supply. 
distribution of pandemic vaccines from a global perspective, which justifies the mobilization of external support from OECD countries (Gostin, 2006). Even from a less altruistic perspective, there are supplementary reasons for investing in poor regions. Improved global surveillance and response can help in the early detection and containment of outbreaks in developing countries threatening the industrialized world, which thus leads to benefits universally. There is no time to waste in putting procurement and distribution systems in place because the timing of the event cannot be predicted. In addition, counterfeiting may exacerbate the situation. In February 2006, the WHO convened a meeting of dozens of non-governmental organizations (NGOs) and representatives from some 60 countries to discuss a related man-made plague in supplying medicines to developing countries namely, counterfeit drugs. The phenomenon of counterfeiting is now being practiced on a large scale and threatens to make a nonsense of every attempt to fight disease. Although precise and detailed data on counterfeit medicines is difficult to obtain, estimates range from around $1 \%$ of sales in developed countries to over $10 \%$ in developing countries, depending on the geographical area ${ }^{137}$ (WHO, 2008). It is already undermining resistance to HIV and malaria. Furthermore, the counterfeit risk brings about what everyone now dreads, a mutation of the deadly $\mathrm{H} 5 \mathrm{~N} 1$ (bird flu) virus into a new, drug-resistant strain which could render the best currently existing treatment, Tamiflu®, redundant.

Counterfeiting has become big business. The US based Centre for Medicines in the Public Interest predicts that counterfeit drug sales will reach US $\$ 75$ billion globally in 2010, an

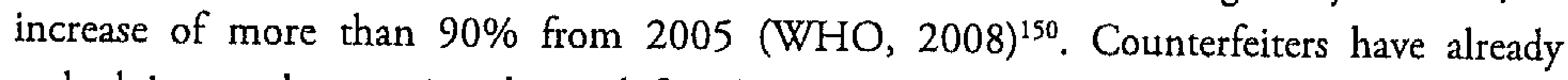
cashed in on the massive demand for the latest and most effective anti-malarial drug, artemisinin. More than half the drugs sold in South-East Asia now contain incorrect levels of the active ingredient, resulting in an estimated 100,000 unnecessary deaths each year (Stevens, 2006). The same holds true for the antiretroviral drugs used to treat HIV/AIDS which are being undermined by drug-resistant forms of HIV, again largely as a result of counterfeits (Stevens, 2006). The auguries in the case of bird flu are not good. The internet is awash with spurious Tamiflu®, consignments being discovered as far a field as New York and Beijing. Counterfeiters thrive anywhere the judicial system is weak, making it easy to persuade or bribe the authorities to turn a blind eye. As for appeal in the courts, in most poor countries cases take years to advance through corrupt and under-resourced courts.

\footnotetext{
${ }^{137}$ Source http://www.who.int/impact/resources/en/
} 


\subsection{Pandemic influenza: How to mitigate the socio-economic consequences}

\section{Towards an antivirals policy for pandemic disease control}

Given the difficulty of rapidly producing an effective vaccine, antiviral drugs are expected to be the first line of pandemic defense. For prophylaxis, antivirals have indeed the advantage, relative to vaccines, of providing rapid onset of protection. Unlike vaccine, however, this protection is short lived (unless taken for a very long period). There is also a lot of uncertainty, and nobody knows for certain the answers to several related questions: How many deaths could antiviral drugs prevent? To what extent would they slow the spread of a pandemic? Could they, as some mathematical modelers claim, even stamp out the disease as it emerges (Ferguson et al, 2005; Longini et al, 2005) ?

Four antiviral agents have been documented as effective for both prevention (chemoprophylaxis) and early treatment of seasonal influenza. However, they do not eliminate the virus, but reduce its release from infected cells by blocking a key viral enzyme. They are known to limit the severity of symptoms in non-pandemic flu and reduce suffering from acute bronchitis or pneumonia. For prophylactic purposes, antiviral agents must be taken daily for the entire period influenza is active in a community. For treatment purposes, antivirals should be taken within two days of illness onset in order to be effective (Salinsky, 2004). Unfortunately the efficacy of these neuraminidase inhibitors is low.

Limitations of antivirals may include inadequate availability and limited production surge capacity (Salinsky, 2004). In practice, stockpiling of antiviral drugs in advance will be the only strategy for ensuring sufficient supplies. However, the logistics are formidable. To be effective, a mobile stockpile of the drug would have to exist and be made available in the affected country (Monto, 2005). Even with this stockpile in place, strategic decisions will have to be made regarding the use of antivirals. Using antivirals for prophylactic purposes would require a prohibitively large stockpile. Hence, early treatment is considered to be a more efficient use of resources than prophylaxis. At the early onset of a pandemic, when limited human-to-human transmission of the virus has been confirmed, the use of antivirals would therefore be driven by a cluster of cases with the objective to reduce further human cases, and prevent, or at least delay further spread. In this early phase, treatment of suspected cases, prophylaxis of contacts, including health care workers and intense usage of antivirals in a limited number of well-defined clusters is recommended. However, once the pandemic is fully under way, tracing and management of individual cases may no longer be feasible. It is appropriate to question how patients will be diagnosed and antivirals supplied, prescribed and dispensed when the healthcare system itself will be in crisis. A priori- 
tized national and international distribution, supported by public education, at that stage would be the likely strategy with the objective to reduce morbidity and mortality in patients and buy time for the augmentation of vaccine stocks.

\section{Towards a vaccination policy for pandemic disease prevention}

While the use of antiviral drugs is a very important measure during the development period of pandemic vaccine, the most effective and perhaps only practical intervention to protect the population at large is vaccination.

It is often argued that a vaccine offering protection in the case of a pandemic cannot be made available until the precise strain of pandemic virus is known. However, this seems to be in contradiction with the WHO recommendation that stockpiling of $\mathrm{H} 5 \mathrm{~N} 1$ vaccine is necessary. A principal argument for strategic stockpiling prior to the start of a pandemic is that it will provide at least some capacity to reduce the morbidity and mortality in targeted populations at the very start of the pandemic. Assuming that the pandemic vaccine is safe and able to confer immunity to the individual, and thus prevent (at least partially) disease or alleviate morbidity and mortality in the population, the forward deployment of this stockpile should be considered ahead of the spread of disease.

Figure 36: Influenza pandemic vaccines: production, global supply and distribution




In addition to stockpiling, Daems et al (2005) advocates vaccinating individuals at risk with pandemic-like vaccines $(\mathrm{H} 5 \mathrm{N1})$ with the ultimate aim of preventing full-blown pandemics. The advantage of launching a 'pre-emptive' vaccination program is that it emphasizes disease prevention and not treatment as the key strategy for saving lives. Most importantly, 'pre-vaccination' of at-risk groups would closely resemble 'normal' vaccination programs and their implementation can be spread over time (i.e. months or years instead of weeks). It would therefore pose fewer constraints on flu vaccine production, distribution and pandemic program logistics (see figure 36). The seasonal flu vaccine production does not need to be interrupted, or halted, as is the case in other scenarios where a public health trade-off must be made. Most importantly, such a pre-emptive strategy mitigates the risk encountered by all other vaccination strategies that may become impossible to implement if poultry is wiped out and eggs for vaccine production are not available. While high-risk groups eligible to receive 'pre-vaccination' still have to be defined, healthcare workers and key emergency personnel will probably be part of it. Many others will be state employees like, for example, the police, fire brigade, the military, pandemic coordinators, etc. At the international level, vaccinating people with a high occupational hazard should be envisaged, like for example, those working or living in close proximity to poultry in Asia.

Arguments that this pre-emptive or pre-vaccination strategy may prove to be futile in case the pandemic never occurs - and therefore money has been wasted - do not correspond with statements made by the WHO describing this as the world's largest health threat that may kill thousands, if not millions of people, and have an economic impact running into billions of dollars. In terms of cost-effectiveness, a pre-emptive vaccination program is likely to protect people vaccinated for about ten years, while a stockpile would expire after one or two years and hence must be replenished each time with newly produced pandemic vaccine.

For such innovative vaccination strategy to work, the vaccine should ideally offer crossprotection against multiple pandemic sub-strains to avert the worst effects of an influenza infection. Some vaccine manufacturers are in the process of developing and testing such pandemic prototype vaccines. Three key questions about designing and producing pandemic-like ( $\mathrm{H} 5 \mathrm{~N} 1)$ vaccines must be answered:

- Can total pandemic flu vaccine supply be expanded by adjuvantation of the vaccine and thus reduce the antigen dose required?

- Will a pandemic-like vaccine generate antibodies to protect against a variety of mutating (drifted) flu virus strains in the future other than the one on which the vaccine was originally made?

- While egg cultivation is the standard today, are there any other production methods that could prove less subject to infection and possibly be more rapid? 
A pioneering biotech company named Chiron was one of the first innovators in this domain. The company started its pandemic preparedness program in 1998, soon after pathogenic avian influenza $\mathrm{A} /$ HongKong/97 (H5N1) viruses emerged as a pandemic threat to human beings. Since $\mathrm{H} 5 \mathrm{~N} 1$ virus strains tend to be pathogenic for embryonated eggs, a non-pathogenic variant strain, A/Duck/Singapore/97 (H5N3), was identified for vaccine production. Clinical trials were conducted to assess the safety, tolerability, and immunogenicity of various doses of this vaccine given either alone or formulated with the firm's oilin-water adjuvant MF59 (Podda, Del Giudice, 2004). Results have shown that 2 doses of the non-adjuvanted version, given 3 weeks apart and containing $7.5,15$, or 30 microgram of antigen, were not enough to induce protection. However, one shot of the MF59adjuvanted vaccine formulation was enough to elicit protective antibody levels even at the lowest dose used, i.e. 7.5 micrograms (Nicholson et al, 2001). These results teach us that it is extremely likely that, unlike most of the seasonal vaccines which are given to immunologically primed individuals, pandemic vaccines will need strong adjuvants and probably two doses to confer protection. This is in line with results obtained by others using plain whole-virus (Stephenson et al, 2003) or recombinant subunit HA vaccines given at doses as high as 90 micrograms (Treanor et al, 2001), showing poor seroconversion in the absence of adjuvants. In addition, researchers at GlaxoSmithKline Biologicals have shown that only adjuvanted vaccine allows dose sparing which is of paramount importance to guarantee wide vaccine availability (Hehme et al, 2002).

Like seasonal epidemic influenza virus strains, $\mathrm{H} 5$ avian strains are also able to recombine and to exhibit antigenic drifts. Indeed, H5 strains isolated in 2003 and 2004 in Thailand and Vietnam exhibit higher virulence as compared to the parent strain isolated during the 1997-1998 outbreak in Hong Kong, and also exhibit some changes in the amino acid sequences of their proteins, including HA. It is, thus, of extreme importance that a pandemic vaccine not only protects against the homologous strains with which it was prepared, but also against heterovariants which may have originated in the meantime (see figure 37).

Taken together, the data obtained in clinical trials provide a potential answer to the first two questions raised above, because they clearly show that dose sparing and crossprotection are feasible despite their evolution in the past eight years. The implication of the answers to these questions is that a pre-emptive vaccination strategy to prevent or at least contain a pandemic is highly feasible even using a virus strain not fully matched with the circulating strains, provided a strong adjuvant is used. 
Figure 37: Cross-reactivity to $\mathrm{H} 5 \mathrm{~N} 1$ viruses after vaccination with adjuvnted $\mathrm{H} 5$ vaccine



The third question can be answered by referring to efforts made by various manufacturers to produce flu vaccine in cell culture. For example, Chiron (now wholly owned by Novartis) pursues the development of a cell culture based subunit vaccine using the MDCK cell line (World Health Organization, 2004). This approach does not rely on fertilized hens' eggs for manufacture, allowing rapid scale-up, and offers the potential to work with pandemic strains of influenza that would be lethal to eggs without genetic modification. Both of these factors may expedite production in a pandemic situation, making vaccine available potentially weeks before conventional manufacture.

In synthesis, future evaluation of seroconversion to heterologous $\mathrm{H} 5$ antigens and the assessment of whether priming with a different $\mathrm{H} 5$ vaccine improves immunogenicity are also important investigations to undertake. These findings may contribute to the further development of novel vaccination strategies. This author has argued and advocated as one of the first at WHO meetings (Daems et al, 2005) that it may be possible to prime individuals at high risk (e.g. health care workers and poultry workers) during the early stages, or even before an emerging $\mathrm{H} 5$ pandemic with an adjuvanted vaccine produced from a previously prepared $\mathrm{H} 5$ strain (even if it is antigenically distinct), while waiting for an optimally matched vaccine that uses the pandemic strain. 


\subsection{Conclusion}

Global health experts have warned that the current bird flu virus could spark a worldwide pandemic in humans if it develops the ability to spread quickly from person to person. In this chapter, we presented the rationale and consequential policies for improved planning for pandemic vaccine development, production and global distribution. We recommend that a number of important policy measures are taken in the pre-pandemic era in order to significantly accelerate our preparedness. This requires a two-step approach:

- Designing and implementing a 'Public Health Strategy' for the prevention and control of pandemic illness with the aim to dramatically improve the general population's health and socio-economic outcomes through the optimal use of antiviral drugs and vaccines.

- Developing a 'Pharmaceutical Policy Strategy' for pandemic flu vaccine research, development and production based on public-private partnership (PPP), using 'push' and 'pull' incentive mechanisms to support the creation of medicinal products that could potentially never be used.

The fight against pandemic influenza faces limitations of science and technology. Only a few companies have the capacity to develop and produce human vaccines on a large scale to curb the spread in the population at large. Using currently available production methods and processes, they are unlikely to be able to deliver enough, and in particular quickly enough, vaccines to stop the pandemic outbreak once it occurs. But, companies face riskinvestment decisions for an uncertain event. A pandemic vaccine will take several months to develop after the initial pandemic outbreak despite all preparatory work being done. In the interim, antivirals can in principle be used to treat patients and reduce the chances that the disease continues to spread at a fast rate in a population that in principle is immunologically naïve to the pandemic virus.

It is recommended that stockpiling and a 'pre-emptive' or 'pre-vaccination' policy is implemented; both strategies are likely to dramatically alleviate, or prevent suffering and the loss of life. This requires research, development and manufacturing of pandemic-like vaccines that make use of innovative cross-protective formulations. These can then be used for strategic stockpiling and/or the protection of high-risk populations 'in advance', that is, in anticipation of the next influenza pandemic. Both strategies can almost immediately be implemented and activities scaled up over a period of several months/years, so that production speed and capacity becomes far less a constraint. An important advantage of the proposed policy is that it does not require establishing an AMC fund because investments for new product development and production capacity building can be recouped on 
product sales in the pre-pandemic era. In other words, real markets - particularly efficient markets - are great levers for corporate investment.

Governments around the globe should support stockpiling and pre-emptive immunization programs. Since developing countries will be most hit by the pandemic - and since the virus cannot be halted at borders - a donor fund must be created preferably by the United Nations for the stockpiling of pre-pandemic products to protect developing countries. 


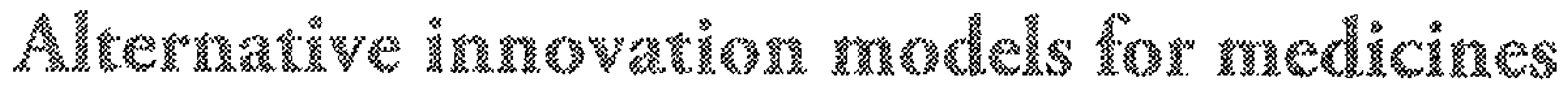 discovery, develoument and rish sharing}

This chapter will examine 'alternative' economic frameworks that have the potential to expand the innovation ecosystem beyond the traditional pharmaceutical R\&D model. A number of scholars believe that results can be obtained more effectively and possibly at a lower cost through alternative innovation systems rather than the current 'traditional' system. Critics of the 'traditional' market-driven system refer to the alleged inefficiencies associated with the monopoly of power in the use of medical-scientific knowledge. The fear is that in the case of (too) powerful biomedical patents being granted, intellectual property claims result in a lose-lose situation: the economy loses in the short run, as the higher prices of a monopoly lower welfare, and in the long term, innovation declines because of lack of competition. We will analyze the benefits and drawbacks of some newly proposed approaches: (i) A Global Medical Research and Development Treaty, ii) IPR Buy-out and Prize Systems, (iii) Patent Pooling and Open-Source Innovation, and (iv) Novel PublicPrivate Partnerships. 


\subsection{Introduction}

In his recent book 'Making Globalisation Work', Stiglitz (2006) notes that innovation is important; that it has transformed the lives of everyone in the world. He also claims that "intellectual property laws can and should play a role in stimulating innovation" . . but quickly adds "that the contention that stronger intellectual property rights always boost economic performance is not in general correct". There will always be a need for society to balance the desire of inventors to protect their discoveries - and the incentives to which such protection gives rise - with the needs of the public - which benefits from a wider access to knowledge - resulting in an increase in the pace of discovery and the lower prices that come from competition.

Stiglitz observes a growing movement of people that are dissatisfied with the 'traditional' market-driven system, including how it handles IPR. He advocates a better intellectual property regime be designed. His argumentation is based on the premise that monopolization may not only result in static inefficiency because the higher prices resulting from a monopoly on new medicines not only lower welfare, but also reduce innovation: "Monopolies insulated from competition are not subject to the intensive pressures that drive innovation", he says. He proposes that innovation models of the future not only need to lower the barriers for entry in order to enhance dynamism in innovation at the expense of static efficiency; they must also take into account the different needs of the developed and developing countries.

Similarly, Soete (2008) observed at a recently held UNU/UNESCO conference, that at the international level the evolution and trends in the field of technological innovation are as follows:

- In a high income country context, the challenge in developing innovation policies may increasingly address issues about the non-sustainability of current processes of 'creative destruction' within environments that provide premiums to insiders, and reward security and risk aversion;

- By contrast, in an emerging, developing country context, innovation policy challenges appear more to address 'backing winners' through industrial science and technology policies, and to further broaden an emerging national technological expertise in the direction of international competitiveness and specialization. Such broadening often involves a much stronger recognition on the part of policy makers of the importance of engineering and design skills and of accumulating 'experience' rather than just investing in research and development (R\&D).

Against this backdrop, concepts like 'open innovation' and 'open-source innovation' have in recent years flourished and became buzzwords in information technology, education and 
communication circles. A novel form of collaborative research, development and production of software is known as the Free/Libre/Open Source software (FLOSS) (Ghosh, Glott, 2005; Ghosh, 2005; Ghosh, Glott, Krieger, Robles, 2002). FLOSS has successfully built an ecosystem that relies on sharing knowledge, not on monopolizing ideas. The underlying notion of producing 'free software' originated in 1984 when Richard Stallman used the term for the first time, and later set up the Free Software Foundation. In this context, 'free' refers to freedom, not to price. So, the notion of 'free software' refers to the freedom users of the software should have: (1) to run the program, for any purpose; (2) to study how the program works, and adapt it to their needs; (3) to redistribute copies; (4) to improve the program, and release their improvements to the public, so that the whole community benefits. The free software paradigm and its definition - and its most common legal embodiment - the General Public License (GPL) - in principle, does not prevent charging for the software the developers distribute. Although the developers can indeed charge for their software ${ }^{138}$, they must provide recipients of the software with the source code and the four freedoms, including the right to redistribute the software to others without restriction. Because of the collaboration between individual volunteers and innovator-users, this practice has seen tremendous success, both in terms of the commercial and technical strengths of the produced software itself and as a model of organization and development. Unsurprisingly, it has received a great deal of attention from developing countries for two reasons: the software itself may be cheaper to use and support than proprietary software applications; and free software may be a novel way for developing countries to leap-frog into the global information economy (Ghosh, Soete, 2006).

It remains to be seen whether the healthcare sector and in particular the pharmaceutical and biotechnology industry will follow the same trend other industry sectors have. They both claim that intellectual property protection is the key driver of both economic growth and the advancement of science and technology in the life sciences industries that produce pharmaceuticals, vaccines, diagnostics, medical devices, and nutraceuticals. The trade associations therefore advocate using a strong and effective global intellectual property system. In the industry's opinion, the advantages of strong IPRs are clear. Enticed by the prospect of market exclusivity (for a limited period) afforded by patent protection, entrepreneurs and biomedical scientists expend great resources in developing and producing cutting edge pharmaceutical and medical technology products. They spend hundreds of

\footnotetext{
${ }^{138}$ At the 18-19 April 2007 event co-organized by the European Patent Office and the European Commission, 'open source' became a hot topic, important both to those with a patent-friendly view and to those favoring less patenting. Representatives form the YBM and Philips technology companies told Intellectual Property Watch that sometimes companies provide a software program for free, because they earn money from licensing related rechnologies and solutions: "Open source is like a free highway where the revenues are generated by other means, such as fees or toll booths" (Intellectual Property Watch, May 2007, Vol.4, No.5, P.5).
} 
millions of dollars and dedicate sometimes decades to develop a new product. Moreover, the vast majority of biotechnology companies and in particular the smaller start-ups, have no products (yet) on the market. While several of these biotech companies rely heavily on public-private partnerships to support their $R \& D$ initiatives, the majority of the funding is provided by the private sector and private equity donors. These entrepreneurial companies can only rely on their patent assets to generate R\&D financing. In this business model, patents provide the assurance investors need to risk the capital necessary in the long and costly research and development process - with the assurance that investments made are not only recouped but also generate a profit.

It is important for 'alternative' innovation concepts and systems that have the purpose of either being complementary to, or replacing the 'traditional' model of pharma and biotech $R \& D$, not to kill the golden goose of innovation unless their superiority has been demonstrated. To-date, research-based pharmaceutical and biotech companies have discovered and developed the great majority of existing medicines. The pharmaceutical industry has thus far been the most important single source of investment in health research. In 2002, the estimated total $R \& D$ expenditure of pharmaceutical companies worldwide exceeded US $\$ 45$ billion per year (IFPMA, 2007). With this background in mind, this chapter will critically examine a series of novel proposals that recently have been published and presented at conferences. Some have captured the attention of high-level working groups such as the WHO's Intergovernmental Working Group (IGWG) on "Innovation, Intellectual Property, and Public Health".

\subsection{Global Medical Research and Development Treaty (MRDT)}

\section{The structure of the proposed MRDT}

A paper published by Love and Hubbard (2004) questions the merits of market-based incentive systems as mechanisms for public funding of private-sector $R \& D$ on new pharmaceuticals and medical products relative to a number of other innovation frameworks. The authors suggest that current levels of pharmaceutical and medical product innovation can be maintained along with lower costs for medicines if one or all of the alternative statedriven mechanisms that they promulgate replace the current industrial patent system. They present a radical new scheme that would eliminate patent protection in order for new pharmaceutical and medical products to be sold at generic prices at the time of launch, immediately after regulatory authorities would have granted marketing approval that the the new compound is safe and effective. Pharmaceutical and medical R\&D would be financed via a tax or tax-like mechanism that would raise predetermined funds at the 
national level. The national R\&D budgets would be determined according to a treaty and would be a fixed percentage of a nation's GDP.

If adopted, the MRDT requires countries - rich and poor - to pledge to spend a fixed percentage of their GDP on medical $R \& D$. Different $R \& D$ areas would be targeted as special spending priorities. The concerned country would then increase the tax pressure and the burden would fall directly on the general taxpayer. This treaty therefore implies that measured spending would generate credits that would count toward a country's overall obligation. Since some countries like the USA have a comparative advantage in conducting R\&D, the credits would have to be tradable internationally in a similar fashion as the Kyoto Protocol deals with environmental emissions. Those countries that exceeded their benchmark obligations via domestically-performed R\&D would be able to sell credits to those countries that chose not to meet their obligations through domestic R\&D. Love and Hubbard believe that, through a global market for pricing and trading in these credits and the international flows of resources thus engendered, $R \& D$ would gravitate to countries that have a comparative advantage in doing it. However, given current patterns of R\&D spending, assuming the credit trading aspect of the mechanism actually works, and the U.S. agrees to join, the risk is that poor countries would on the whole (have to) become large net purchasers of these credits.

\section{Measurement, evaluation and implementation issues}

In the original concept of the MDRT, the notion was to eliminate altogether patents on new medicines, so that medicines could be sold at generic prices immediately after regulatory approval. The reasoning was that the $R \& D$ outlay for creating the new medicines would be paid for through taxes and tax-like instruments gathered and distributed through the MRDT. However, an increasing number of scholars raised questions and concerns with this concept. Fowler (2007), DiMasi, Grabowski (2004), and van Ypersele (2001) argue that pharmaceutical $R \& D$ contracts through a worldwide consortium are subject to principal-agent problems and flawed decision-making based on available information. As Love and Hubbard suggested, in international R\&D programs there would be political pressure, to shift research expenditures to particular countries. Involvement of protagonists could lead to moral hazard and adverse selection bias. Adverse selection could occur both in terms of what disease categories are funded and what (national) organizations are selected to undertake the various $R \& D$ projects.

Farlow (2007) thoroughly reviewed the wide range of measurement biases and intrinsic valuation limitations that the MRDT mandated executives would face in case the MRDT is approved, sponsored, and launched. It would be difficult, he argues, to measure the participating countries' sheer innovation performance and to assess the 'value' of their scientific- 
medical R\&D activity from just looking at spending flows alone (provided they can be correctly identified and retrieved from these countries). Emphasizing spending measures only obviously encourages waste. Therefore, the ability of the MRDT Executive Secretariat to use these data to reward or punish innovative countries accordingly, would be limited. Farlow contends that the value of risk-bearing activities needs to be correctly factored in (just as it has been done in AMC 'pull' funding calculations - see chapter 8). Again, there is a real danger with the MRDT approach of protectionist pressures from politicians to favor local medical and pharmaceutical R\&D.

DiMasi and Grabowski (2004) identified the compulsory termination of the patent system as their main concern with the MRDT proposal. So does Farlow (2007), who believes that, in an attempt to allay this fear, more recent versions suggest that countries would be allowed to 'experiment' and keep patent protection if they so desire as one of a range of $\mathrm{R} \& \mathrm{D}$ funding mechanisms that would qualify under the MRDT. How would these mechanisms work? Countries could earn credits by spending on public sector R\&D (i) on the creation of open source databases which is modelled in part on the Human Genome Project, an alliance of organizations that successfully mapped the three billion chemical pairs that comprise the human genetic code; (ii) on research explicitly targeted at neglected disease therapies; (iii) on projects that involve technology transfer to developing countries and capacity building in such countries; (iv) the preservation and dissemination of traditional medical knowledge; (v) public private partnerships/ product development partnerships; (vi) tax credits for companies that invest in R\&D; (vii) philanthropic expenditures, and so forth. Taken together, this would pose some extremely difficult challenges for measurement and evaluation, as well as raise the question of who would be responsible for making these judgements and weighing the value of each of these contributions on fostering innovation. In other words, what is this R\&D worth and does it deliver results? Clearly, this would require a centralized bureaucracy to judge. Farlow (2007) argues that similar measurement problems exist in other mechanisms such as the Kyoto Protocol, but at least there, the basic unit of measurement - tons of $\mathrm{CO}_{2}$ emissions - is the same everywhere in the world. In the case of the MRDT, converting the above scientific-medical innovation activities and contributions into a common denominator would be extremely difficult.

Summing up, MRDT program administrators and their sponsors are likely to have difficulties in assessing which scientific-technical opportunities are the most promising and what groups are best at carrying out the selected $R \& D$ projects. There is a risk of adverse selection because of the possibility of political rent seeking and related considerations. Under a centralized inter-governmental system of research expenditures, lobbying by those groups that are better organized politically will distort the direction of research to better suit their particular needs. In such an environment, governments and other sponsors may end up funding programs with very low chances of success, or alternatively, fail to fund promising 
programs because they do not conform to established theories and paradigms. Having pharmaceutical $R \& D$ projects supervised by a central bureaucracy runs counter to empowering modern development teams. Garnier (2008) recommends putting in place a flexible and innovative private sector $R \& D$ structure that allows a concentration of resources for maximum impact and more benefit to patients. These 'Centers of Excellence for Drug Discovery' would focus on specific disease areas and because of their small size they can make quick and informed decisions on whether to proceed with a promising compound as it reaches different stages of development.

\section{Alignment, management and coordination challenges}

The handicap of governments that are actively involved in the management of hightechnology and product-development consortia, as proposed by Hubbard and Love, is the lack of common vision, work coordination, flexibility, and integration of multi-disciplinary teams. This is in particular difficult if these expert teams are located at the various 'centersof excellence' around the world.

The model for the organization of pharmaceutical and medical technology innovation that has prevailed in the last century is one where, as described in chapter $3, R \& D$ and the complementary assets required for innovation are largely integrated inside the firm. It has been held up as part of a recipe for lasting commercial success (Chandler, 1990). Several authors examined the theoretical underpinnings of it. For instance, Nelson and Winter (1982) argue that the development of technology and innovation is based on organizational routines that are difficult to transfer across organizational boundaries. In addition, Teece (1988) has highlighted the transaction costs involved in transferring knowledge and technological information through arm's length market-mediated contracts. However, Arora et al (2004) argue that in the past two decades or so, there has been rapid growth in a variety of arrangements for the exchange of technologies or technological services, ranging from $R \& D$ joint ventures and partnerships, to licensing and cross-licensing agreements, to contract R\&D. This explains the symbiosis between 'Big Pharma' and the biotech industry.

Teece (1988) believes that, regardless of the size of the company, the best way of appropriating the rents from technology is by directly embodying it into goods and products (instead of licensing the technology to others). He acknowledges however that the formation of new markets for technology might ultimately change this view. Nonetheless, in a recent paper (Grindley and Teece, 1997), he reaffirms his earlier position by stating that: "becoming a pure licensing company not directly involved in the production market and increasingly remote from the manufacture and design of the product itself can be a risky strategy". Arora, Fosfuri, Gambardella (2004) agree that this is in essence probably correct. However, they argue that under some conditions the risk is worth the additional reward. In 
sum, licensing remains an important option, not mutually exclusive with own production. Therefore, a firm operating in a market of technology clearly needs to recognize what core, non-tradable and tradable competencies are. Having done so, it can then decide whether a given discovery or technological competency is to be exploited in-house or through licensing. In the case of pharmaceutical and biotech $R \& D$, we concur with this viewpoint.

We believe it is important in the development of chemical pharmaceuticals and even more so of biotechnological products to maintain a link between $\mathrm{R} \& \mathrm{D}$ and production. The objective is to use the original innovator's skills not only in designing molecules, but also in carefully selecting and testing product formulations that lend itself to large-scale production. It will not be easy to coordinate back-and-forth and to transfer projects and knowhow between different departments if they no longer belong to the same organization or operate under the same command. This is especially true in the field of bio-pharmaceuticals and vaccines. Here, the know-how factor and the 'art' of successfully preparing production batches scores highest given the somewhat unpredictable nature of working with biological materials - which are either composed of large, complex proteins, or sub-components of viruses and bacteria, or of different strains that are likely to interact with one another. In other words, contrary to popular belief, the state-of-the-art medicines research and development process is not a one-way linear activity process. Scientific researchers working in the laboratory will have to keep in mind what production engineers need, and vice versa. Close collaboration and if possible common accountability for the end result are strong incentives, if not prerequisites, for successful new medical product development and manufacturing. It is therefore important to maintain a close link during the entire innovation process. Afterwards, when the individual processes have been optimized and it has been proven that scaling up of production is feasible, one could spin-off or tech-transfer these processes to interested parties. Even then the technology transfer process requires a close collaboration between interested parties.

The danger inherent in the lack of unison in managerial decision-making and integration of project command leading to better control of multi-disciplinary and multi-country subprojects, can be illustrated by the faith that underwent the Airbus A380 'superjumbo'. In 2006, Airbus and its parent company, European Aeronautic Defense and Space (EADS), announced a major delay in the development of their flagship A380 'superjumbo'. The multi-billion Euro bungle threw the management of these European companies into turmoil and lit a firestorm of cross-border recrimination that still today infects many working relationships, from the executive suite to the shop floor. The crux of the problem was that employees of Airbus had to shed their national identities - not a small matter for French, German, British and Spanish employees - in order to form a cohesive collaborative team. The newly appointed Airbus CEO clearly was surprised by the limited progress that had been made on organizational integration over the last ten years. For almost 30 years, 
each country had been designated as a 'center of excellence' for different parts of the aircraft manufacturing process - a system of fiefdoms that allocates avionics work, for example, to the French, while Germans specialize in cabin design and installation, wings are done in Britain and aircraft tail sections are built in Spain. But when rear fuselage sections of A380s built in Hamburg began arriving in Toulouse in 2004, without the requisite electrical wiring for the planes' in-flight entertainment systems, the ensuing bottlenecks revealed that the computer modeling software used by the company's German and French sites was incompatible. Worse, the engineers scrambling to fix the problem in each country did so in different ways, while top managers and union leaders on both sides sought to place blame on the other. The result was a devastating two-year delay that was expected to erase more than Euro 4.8 billion of profit over the next three years for EADS, the parent of Airbus.

Shortly after his appointment in 2007 as CEO of EADS, Louis Gallois, announced his determination to make sure this would never happen again. One of his early edicts was to ban the use of national symbols in company PowerPoint ${ }^{\otimes}$ presentations. In an interview, he said "I don't want to see any flags on slides, because when you have a flag you always have an issue of national identity; ... I want when I am in Hamburg to feel home like in Toulouse; . . it is because of national pride that we have the problem of the A380" (Clark, 2007). He also planned to overhaul the organizational structure of the company. His intention was not only to unify administrative functions like human resources, information technology, and procurement, but also to integrate all aspects of aircraft design and manufacturing. For instance, instead of having a German team in Hamburg in charge of installing wiring according to a scheme designed by French engineers in Toulouse, there would be one transnational team working together, using the same tools and computer programs. Gallois recognized that this change would involve a revolution in thinking - and it meant transferring certain jobs to different locations within Europe. The planned reorganization also marked a cost-cutting phase that foresaw the loss of 10,000 jobs across Europe over the next four years and the sale of up to six factories. Airbus workers in France and Germany did stage huge strikes to protest these moves, and politicians on all sides fought fiercely to minimize the impact in their constituencies.

The resemblance between the Airbus 'Superjumbo' experience and the proposed 'MRDT' innovation concept that aims to set up a consortium of international collaborative $R \& D$ on neglected diseases is striking. Besides the organizational challenges, the MRDT faces a series of political problems, macro-economic budgeting issues and resource allocation hurdles as described above that are hard to overcome. Given the many questionable assumptions in the MRDT proposal, we wonder whether it is wise to support a radical overhaul of the current innovation system, for a system that is unlikely to work. 
The private sector will undertake $R \& D$ in whatever country it feels it can achieve the best results. These independent $R \& D$ organizations are not only likely to have better information about scientific opportunities, but may also possess different motives and agendas than politicians and program administrators. The commercial nature of pharmaceutical and biotech companies drives the careful selection of $R \& D$ projects and decisions to develop viable projects that are managed at a multinational scale. Senior management in these companies will focus on providing strong incentives to researchers and engineers to concentrate their efforts on the rapid and efficient development of novel products that are customer oriented. By contrast, under the Love and Hubbard system of grant-financed research, it can be difficult to monitor what priorities researchers are actually focusing on. There is also the intrinsic risk that medical technology researchers working on a particular line of technological research have an interest in exaggerating the promise of their own lines of research. As a result, scientific administrators may have trouble deciding which diseases are worth working on, and which technical approaches, if any, are worth pursuing. They may end up financing ideas with only a low probability of success, or worse, failing to fund promising research.

History has shown that under a system of grant-financed research, advocates for particular diseases and scientists working on these diseases have an interest in exaggerating the opportunities. Desowitz (1991) chronicles the classic story of the U.S. Agency for International Development (USAID) 1980s program to develop a malaria vaccine: a catalogue of malpractice, political interference, poor judgment, over optimism, lack of oversight and waste, and even corruption characterized the result of this effort. More recently, a less dramatic but similar controversial debate took place about centrally programmed clinical trials on an experimental HIV/AIDS vaccine. In early 2004, 22 prominent medical researchers published an article in a leading scientific journal stating that a large U.S. government-funded clinical trial was doomed to fail. The trial was scheduled to be conducted in Thailand and would use a prototype vaccine with funds received from the United States amounting to US\$119 million dollars (Burton, 2004). Despite these warnings, the trial went ahead and failed completely.

The advantage of making the private sector responsible for developing innovative pharmaceutical products is that it transfers the $R \& D$ risks and project selection process to an entity whose very existence depends on success (Webber, 2003). Pharmaceutical or biotech firms contemplating pursuing a line of research, and scientists contemplating joining biotech ventures in exchange for stock options, will invest their money and time only if they believe the scientific prospects are promising. This is true both at the level of selecting individual $R \& D$ projects, and at determining whether a major research effort on any given disease area is scientifically warranted. Even if government directed research committees manage initially to select appropriate research projects, they may fail to revise these judgments in 
light of later evidence. If the result of an $R \& D$ project that initially appears promising later turns out to be disappointing, a private firm is likely to shut the project down. For public sector institutions this is usually more difficult. Moreover, when governments control $\mathrm{R} \& \mathrm{D}$ spending directly, they may base decisions on political, rather than scientific considerations.

Why then do many government scientists argue that their programs are cheaper than industry's? The USAID experience cited above shows that researchers are prone to underestimate their costs and overestimate their chances of success. Of course, scientists in, for example, the pharmaceutical sector may display the same behavior. The difference here is that in the industry executives and investors anticipate this over-optimism, and correct for it by establishing high projected hurdle rates before approving $R \& D$ projects or investing funds (see chapter 5). The net effect is that industry executives and biotech investors wind up approving $R \& D$ projects that are likely to have a positive NPV after correcting for the over-optimism of project proponents. It is therefore misleading to compare the funds government scientists claim they need to develop a product with the markets pharmaceutical executives claim they need to justify the upfront investments. While the above assertions may reflect negatively on the state undertaking or dictating $R \& D$, this does not mean that the state does not, or should not, have anything other than a major role in setting the right conditions for stimulating technological innovation. This is particularly true in areas where there is a perceived market failure as is the case of new medicines for diseases disproportionately affecting the poorest countries. Besides directly stimulating basic research in public institutions and academia, public incentive systems that would support and accelerate private sector $R \& D$ can be implemented as described in chapters 7 and 8 .

\subsection{IPR buy-out/prizes, patent pooling, open source innovation}

IPR buy-out \& prize systems

Another possible alternative framework for funding $R \& D$ is a prize or award system. Essentially, the objective here is to buy out the intellectual property or patent from the innovator. Instead of paying for $R \& D$ inputs, governments or buyers could pay an innovator a lump sum for their innovation which is then placed in the public domain. Generally, the size of the prize corresponds to the size of the investment required to win. Prizes are usually offered to whoever achieves a certain pre-specified goal or product, while tournaments generally offer a reward to whoever has progressed farthest towards the target by a given date. While structured slightly differently, both prizes and tournaments have similar advantages and risks. 
A recent paper from Love and Hubbard (2007) strongly promotes this idea. The authors assert that "the (current) system for financing new drug development can be radically improved and could reduce spending overall, align investment incentives more efficiently, while making drugs available to everyone at generic prices". According to the authors, reforming the way society pays for R\&D on new medicines involves a "simple but powerful idea", that is, "rather than give drug developers the exclusive rights to sell products, the government would award innovators money: large monetary 'prizes' tied to the actual impact of the invention on improvements in health care outcomes that actually deliver successful products". Thus, the idea is that by attempting to divorce the incentive for innovation from the product's price to consumers, knowledge goods, including the R\&D for a new medicine, could be placed in the public domain almost immediately after it has been 'invented'. Moreover, the new product could be made available at prices that approach the marginal production cost of the medicine, knowing that the government prize system has already paid for the $R \& D$ fraction of the total investment equation.

The idea of IPR buy-outs and prizes is not entirely new. Prizes have been used in the past in other areas of scientific endeavor where one solution was needed. Prizes for solving mathematical problems, such as for example Fermat's Last Theorem, have been useful incentives. Perhaps the best known case of a prize award is described in Dava Sobel's famous book 'Longitude'. The book tells the true story of John Harrison, an English clockmaker, who revolutionized and extended the possibility of safe long distance sea travel in the Age of Sail by inventing a long-sought and critically-needed key piece in solving the problem of accurately establishing the East-West position, or longitude of a ship at sea. On such voyages, cumulative errors in dead reckoning frequently led to shipwrecks and lives lost. The problem was so intractable that the British Parliament offered a huge fortune ( $£ 20,000$, roughly $£ 6$ million in 2007 terms), for a solution. After steadfastly pursuing various methods during thirty years of experimentation, Harrison finally designed and built the world's first successful marine chronometer, a highly accurate and robust maritime time-keeping instrument which for the first time allowed a navigator to accurately assess the ship's position in longitude.

Today's biomedical problems seem to be of a more highly complex nature. Tackling critical issues and problems like for instance cancer requires a multidisciplinary approach. This can no longer be addressed by one person, but has to involve teams of experts in various disciplines. In addition, modern pharmaceutical product development requires major capital investments. Pharmaceutical discovery, testing and product development can cost in the order of hundreds of millions of US dollars. Thus, in order to make a prize attractive 
for major producers, very substantial sums of money need to be offered ${ }^{139}$. Even a prize of hundreds of millions of US dollars may not be enough to incentivize major inventors and producers to take part, given the high probability that products under research and development may actually not succeed and thus the entire investments would be lost. Nevertheless, a smaller company from an emerging market that has lower $R \& D$ costs may perhaps be attracted by a prize of hundreds of millions of US dollars. Even so, these examples illustrate that prizes may not constitute the right economic incentive system.

There are well known systematic and practical problems with a system based on prizes and tournaments. For example, governments are unlikely to properly value innovations. The reason is that, in practice, individual firms and innovators are better informed about how consumers and providers value their innovations. It is therefore inevitable that divergence arises between governments and companies on the evaluation of the consumer's perception of these innovations. This leads to scenarios where innovations attractive to consumer segments may not be funded. As a consequence, innovators become subject to what economists have termed the 'hold-up' problem (DiMasi, Grabowski, 2004) because the temptation is great for the award granting authority to offer prizes that are much lower than the true value of the innovation. Since the innovator's costs by the time of launch are sunk, the innovator has little choice but to accede to the expropriation of value. Clearly, such behavior by the award granting authorities would greatly diminish the incentives for innovators to engage in future $R \& D$ activities. This was the case of John Harrison who ultimately appealed to the King to receive (his part of) the promised award. To whom would one turn to in modern times, especially when stakeholders such as governments, companies, politicians and civil society representatives are involved?

Yet, in recent times, prestigious prizes have been awarded for high-tech inventions. For instance, the first X PRIZE competition, the famous Ansari X PRIZE for the Suborbital Spaceflight, successfully challenged teams to build private spaceships to open the space frontier. Burt Rutan, financed by Microsoft's co-founder Paul Allen, won the Ansari X PRIZE on 4 October 2004 with his spacecraft SpaceShipOne. As a result, US\$10 million was awarded to the winner, whereas more than US $\$ 100$ million had been invested in new technologies in pursuit of the prize. Today, Sir Richard Branson and others are actively involved in creating a personal spaceflight industry. Thus, besides the prestige of having won the X PRIZE there is a commercial spillover effect. This positive business effect is unfortunately missing when the same principle is applied to tropical diseases endemic in primarily the poorest countries of the world. In our view, a medical prize addressing

\footnotetext{
${ }^{139}$ Stevens (2007) argues that removing, or omitting to offer commercial incentives will make companies retreat from the difficult and expensive work on cures for cancer, HIV/AIDS and the like, and try to regain lost profits in politically safe "lifestyle" ailments.
} 
poverty-related diseases will have to be more than symbolic. It should compensate the investments made for the entire project, and support not one but several innovators that meet the product profile criteria. In reality, it will be very hard though for governments and the public sector to choose one 'winner' and justify that choice to the public (and to other members of the private sector). If the proposed medical $R \& D$ contracts have a high degree of specificity built in at the very beginning, they are likely to discourage thinking out of the box. If prizes are determined at a later stage, the innovator will already have invested in the development of the innovation.

Additional problems anticipated from the viewpoint of the innovator include the fact that prizes and awards place them at the mercy of political 'changes of heart'. After all, firms invest early and heavily; politically driven 'changes of heart' over time may therefore have serious financial implications. If a 'winner' is ultimately chosen - the medical prize being agreed to beforehand - the public sector runs the risk of being 'locked-in' an outcome that may or may not be the best one. Since the effectiveness of medical-scientific $R \& D$ activities is difficult to measure in early stages of development, some shirking is likely to result through reduced efforts and collusion. Moreover, as discussed previously, there is more to developing a medical compound and proof that it is safe and effective from a clinical point of view. The new compound's manufacturing process will have to be scaled up to deliver the high yields that are necessary to produce hundreds of millions of doses in a relatively short period. These considerations are especially important in the case of products with a high unmet medical need where time to market is critical. Take, for example, a new vaccine candidate against malaria, where the expectation is that it will be administered relatively quickly to all healthy individuals living in an endemic country shortly after its licensure. Where Sir Richard Branson can wait for customers that can afford to buy tickets for a trip with his space ship, there is no point in inventing and launching a life saving new medical product if the supply eventually falls short, and as a result people die.

Especially in the case of biological materials (biopharmaceuticals and vaccines) it is important to maintain the link between $R \& D$ and production. This has been illustrated by a biotech company in search of the (first) malaria vaccine. The company, called Sanaria Inc. (meaning 'healthy air', a play on the Italian 'mal'aria' or 'bad air'), finds itself at the heart of one of the most controversial scientific ideas. It is making a prototype vaccine the oldfashioned way, more or less as Louis Pasteur did. It is breeding mosquitoes that carry the malaria parasite in an unassuming biotech park in the suburbs of Washington D.C. Avoiding modern recombinant DNA technology that injects tiny fragments of parasite protein to prime an immune response, Sanaria actually uses the whole parasite, extracted by hand from the mosquito's salivary glands, and weakened so it cannot multiply. The technique used is radiation-weakened parasites, which has protected lab mice and a handful of humans, but developing a vaccine that can be mass produced is another ball game. "We've got 
a lot of work to do, and we're extremely mindful of the fact that the road to success is filled with potholes," said Stephen L. Hoffman, founder of Sanaria and a former chief of malaria research in the U.S. Navy, in an interview with the New York Times (2007). Sanaria has to work out how to raise sterile mosquitoes, to supercharge them with far more parasites than nature does, to dissolve saliva proteins to avoid allergic reactions and to freeze and thaw parasites without exploding them. Some scientists are troubled that the mosquitoes have to be raised on human blood, which cannot be sterilized. Besides the sterilization problem, there is also the risk that under-irradiated parasites would cause malaria or that weakened parasites would not reach the liver. Cryogenically frozen vaccines are also not practical at sites with poor refrigeration, a situation typically encountered in developing countries. It is unclear how the company is able to supply the world market if and when its product becomes licensed; unless a better match is found between the 'science' and 'engineering' aspects of its new compound.

Returning to the idea of prizes, other fundamental concerns should be resolved before disconnecting 'inventors' from 'producers' of medical products. There is also no reason for Love and Hubbard to assume that 'generic' manufacturers are by definition more able and efficient at producing medicines at a lower cost than 'innovation-driven' manufacturers. The output for any of the contenders must be of the same quality and in the case of medicines this is highly regulated through the national and international pharmacopoeia references. If the argument of the authors is that producers can be found in countries with developing and emerging economies - which is already the case for 'generic' medicines then there is nothing that can stop transnational innovators from moving to technology transfer, joint ventures, or strategic alliances if this were to significantly reduce production costs in the long run. This is an option if a system of advance market commitments is used as will be explained at the end of this chapter. The advantage of an AMC mechanism is that, if governments and consumers in developing country see no benefit in the innovation, they have the option to not adopt it, and if they do, they only pay a small fee. If an improved product comes on the market under an AMC, the purchasers are allowed to switch to the new product almost immediately if they wish to do so. Towards the end of the AMC external funding period, the original medical product is likely to be in the end phase of its patent life anyhow. The moment generic competition kicks in, consumer prices and access barriers will be kept low for the following 20 to 30 years.

We do, however, agree with Love and Hubbard that attempts should be made to link the size of a hypothetical prize fund not only to $R \& D$ input but also to healthcare outcomes and eventually the societal benefits produced by the new medicine. Two difficulties need to be overcome when applying this method. The first one is related to quantifying healthcare outcomes as QALYs. Hollis (2006) and Pogge (2005) propose a strictly proportional link to QALYs as the standard for measuring benefits and allocating prize fund awards. This 
proposal has shortcomings in that it over-rewards products with very large QALYs creating inequity between North and South at the expense of other valuable products with lower QALYs. Essentially, higher QALYs are associated with both the efficacy of the product and the number of patients who use it. This is the case of diseases like breast cancer, heart disease, diabetes, and asthma that affect large numbers of people. Our recommendation is that rewards should partly but not exclusively be linked to QALYs to ensure the development of a broader range of products and to address $R \& D$ objectives. The second difficulty that needs to be overcome relates to the timing of the award. Innovators should be rewarded the moment they obtain market approval from regulatory authorities and their product is purchased. By that time their product has been tested in large cohorts of patients, health outcomes studies have been performed, and the new product's public health impact has been simulated. However, there are limits. Innovators cannot be held responsible for the (un)successful implementation of a new medicine, once rolled out in the various markets. As we know, there are many external factors over which corporations have no control and that can obstruct a new product's adoption rate. Controlling the environmental factors should be the responsibility of the public health authorities (at least, under an IPR Buy-out or Prize incentive system). In addition, should a company only receive payment for its R\&D efforts 'ex-post? The model in chapter 8 has illustrated that, if this payment is spread over, let us assume, a 10-year period post-launch, the impact on the project's ROI would be greatly reduced. The forgone return needs to be compensated and will likely require a doubling or tripling of the prize. Such a fair compensation can be calculated with the integrated 'risk-investment-incentive' simulation model as demonstrated in chapter 8.

The assertion that new product adoption in developing countries is beyond the scope of what corporations can handle, is best illustrated by the experience of the Bill \& Melinda Gates Foundation with its flagship project in Botswana. In August 2000, the Gates Foundation, the pharmaceutical companies Merck and Bristol-Myers Squibb, and the Harvard University's AIDS Initiative, announced the launch of an HIV/AIDS treatment program in collaboration with the government of Botswana. According to Garrett (2007), Botswana had at the time the highest HIV infection rate in the world, estimated to exceed $37 \%$ of the population between the ages of 15 and 40 . The goal of the new program was to enroll every single infected citizen of Botswana in the treatment program and to give ARVs to all who were at an advanced stage of the disease. Merck donated its anti-HIV drugs, Bristol-Myers Squibb discounted its, Merck and the Gates Foundation subsidized the effort to the tune of US\$100 million, and Harvard University helped the Botswana government design the program. At the time the collaboration was announced, the target looked easily attainable, thanks to Botswana's top-level political support, the funds that would come from the donors and the country's diamond industry, the free medicines, and the sage guidance of Merck and Harvard University. Unlike most of its neighbors, Botswana had an excellent highway system, a sound general infrastructure, and a growing middle class. Furthermore, 
Botswana's population of 1.5 million was concentrated in the capital city of Gaborone. The conditions looked so propitious, in fact, that some activists charged that the parties involved had picked an overly easy target and that the entire scheme was little more than a publicity stunt, concocted by the drug companies in the hopes of deflecting criticism over their global pricing policies for AIDS drugs.

However, it soon became apparent that even relatively wealthy Botswana lacked sufficient health-care workers and a sound enough medical infrastructure to implement the program. The country had no medical school: all its physicians were foreign trained or immigrants. And although Botswana did have a nursing school, it still suffered an acute nursing shortage because of brain drain to South Africa and the United Kingdom. In that period, the country was losing up to $60 \%$ of its newly trained health-care workers to emigration annually. By 2002, the once-starry-eyed foreigners and their counterparts in Botswana's government had realized that before they could start handing out ARVs, they would have to build laboratories and clinics, recruit doctors from abroad, and train other health-care personnel. Former President Festus Mogae asked the U.S. Peace Corps to send doctors and nurses. Late in 2004, the American PEPFAR program got involved and started building a network of HIV testing sites and working on the provision of blood supplies to local hospitals. The rollout of HIV treatment commenced in 2005 after five years of preparation. By early 2006, the program had reached its goal of treating 55,000 people with ARVs (out of an estimated HIV-positive population of 280,000). The program is now the largest chroniccare operation - at least per capita - in the world. And if it works, Botswana's government will be saddled with the care of AIDS patients for decades to come - something that is expected to be sustainable as long as the soil continues to yield diamonds and the number of people newly infected with HIV continues to drop dramatically.

Although companies cannot solely be held responsible for the adoption of their product in developing country markets, they could ensure that the product is successfully adopted, meets the needs of the market, and is aligned with the public health interest, if a marketbased incentive system like the AMC system was used. In their comparison of the Prize Fund approach to the AMC approach, Love and Hubbard (2007) admit that "the most appealing argument in favor of the AMC approach is that it links the $R \& D$ incentive to the delivery of the products to patients". They mean by this the accomplishment of the entire research, development and supply process up to the point where market authorization is successfully obtained, and product delivered. The question that potential sponsors, however, will face if a Prize Fund approach is instead adopted, is once again: who will select a winner if there is no market mechanism involved to make such a selection? Love and Hubbard (2007) proposed the idea to build in the notion of 'competitive intermediaries'. These 'intermediate' entities would make the choices and allocate the funds to different modes of R\&D, and somehow - it has never been explained - succeed, or fail, on the basis 
of a 'market judgment' of their performances. These intermediary organizations would hopefully act as venture capital funds, and as stated by the authors "target investments in projects that yield scientific rather than financial returns". One may still wonder whether venture capitalists would be willing to invest in projects that basically generate no, or very low, future cash-flows. Nor is it clear how a central body would be better at setting priorities than the thousands of scientists, engineers and experienced business entrepreneurs whose livelihoods depend on getting these decisions right. In the opinion of this author, the concept of 'competitive intermediaries' and 'venture capitalism' to drive efficiency, was introduced at some point to soften the notion of a centralized bureaucratic mechanism using a 'competitive financing and allocation scheme' that would work through capital investment and allocation bureaus.

Lastly, the IPR Buy-out/ Prize system as an incentive model for stimulating R\&D does not reward second- or third-generation entrants that offer an improved safety, efficacy, and/or convenience profile and may stifle long-term innovation. Experience has shown that the 'first in class' new medicine is not always the best treatment. Thus, while the prize may reward the first medicine to be invented for a particular condition, a 'runner up' product coming later may actually be more effective. By contrast, the current market system of patenting each product allows the market to reward the most effective product, no matter where and when it has been invented. As noted earlier, a market system offers greater incentives for new product development and eventually for the most effective product than a prize system. History has shown that in countries where granting patents was not permitted and innovation was rewarded only by prizes, as in the Soviet Union, pharmaceutical R\&D did not advance. Therefore, it is important that any prize-like system complement, not replace, the current IP-based market system of $R \& D$. If researchers voluntarily choose to renounce patent rights on their products in exchange for a set prize, that is their right, but they should not be forced to do so. This recommendation is in line with the findings presented by the U.S. National Research Council to the Board on Science, Technology, and Economic Policy: "The government should not own, control or influence the disposition of intellectual property developed by (innovation inducement prize) contestants in the course of competing for a prize, with the exception of the winner who declines to put the winning innovation into the commercial practice or to license it within a reasonable time may be required to enter into good faith negotiations with a willing licensee" (National Academy of Sciences, 2007).

\section{Open source}

The concept of 'open (re)source' is commonly known in software development and refers to a situation where developers share intellectual property with one another and develop new technologies collaboratively. The major advantage of 'open source' is that any decen- 
tralized research project can draw on scientific expertise from various participants without worrying about intellectual property issues. As a result, open source has been suggested as a way of limiting the cost incurred by any individual company or research agency during the lengthy process of new product development. Given today's low cost and remarkable ease of communicating over the internet, the possibilities for collaboration have expanded dramatically. In addition, having a team of scientists working together instead of in direct competition may reduce the risk of duplicative research and limit the errors made during isolated research efforts. Advocates of this model point to its success in the software industry and envision that the same results can be achieved in new medicines discovery and development. Some have suggested that new medicines development should therefore take place - at least in part - in an 'open source' environment (Love, 2007; AEI-Brookings, 2005). At the 2007 conference co-organized by the European Patent Office and the European Commission to discuss scenarios for the future of intellectual property, James Love, Director of the non-governmental organization Knowledge Ecology International, said that he believed that collective management of IP would spread in the future with patents no longer being necessary (Iren and Gerhardsen, 2007).

Collaboration in an open source environment comes in many shapes and forms. While IBM's chip alliances involve deep, formal collaborations between ten or so partners, other innovation networks work very differently. An example is the software community Eclipse Foundation ${ }^{140}$, which oversees an open-source software initiative where people from 162 companies contribute software codes to a platform that is used for building business applications. Bitter rivals such as Oracle and BEA Systems collaborate on common technology, but compete when they use it in their own products. Since being established in 2001 by IBM and eight companies, Eclipse has emerged as the No. 2 software applications programming platform, trailing only Microsoft. However, while the benefits of collaborative innovation are easy to recognize, so are the pitfalls. From an organizational perspective, think how hard it is to get people in a single corporation to work together with a common vision. The risk in networks is that this complexity factor is increased three to five fold. Questions may rise about responsibility, ownership, or intellectual property when an innovation eventually turns into a viable product. Or, in the event the collaboration, alliance or network happens to break up, the community members have to be prepared to work through the divorce.

Despite these hurdles, many corporations like IBM have shown that the future probably lies in pursuing open innovation, and to a certain extent open-source innovation. Many

${ }^{140}$ www.Eclipse.org. Eclipse is an open source community whose projects are focused on building an open development platform comprised of extensible frameworks, tools and runtimes for building, deploying and managing software across the lifecycle. 
corporations, including those in the pharmaceutical sector, are therefore contemplating 'reinventing the way they innovate'. Even the 'old' model of giants like Merck, known to be a true believer of go-it-alone R\&D, is being reconsidered. Just a few years ago, the culture in these corporations still was that, if a technology was not invented within IBM or Merck, it was not good. Now, in particular the computer pioneer realizes that no matter how big an organization is, more smart people are going to be working outside its walls than inside. To avoid conflicts, companies specifically target fundamental research activities they are willing to share. In the pharmaceutical industry, some of the drug makers have teamed up to identify 'biomarkers', that is substances that indicate the presence of a disease. With that research in hand, each firm can then separately develop drugs and vaccines to combat these diseases. Perhaps here the notion of awarding Prizes might be useful, because we are dealing with a limited and well defined aspect of the research, development or production process $^{141}$. The role of the private and public sectors in public-private partnerships will be discussed at the end of this chapter; how they can work together in exploring those aspects of the pharmaceutical $R \& D$ process that are non-competitive in nature. It is our hope that such PPPs will also provide an open source model that gives scientific researchers more freedom to explore more options to find cures for diseases that are prevalent in poorer countries.

The difficulty with this model is identifying areas where to compete and where to collaborate as often the boundaries are blurred. Any judgment requires an in-depth understanding of the pharmaceutical R\&D process. Open source, in the context of pharmaceutical R\&D, could in principle apply to different stages of the new product research and development process. Most plausibly it would apply to the upper-stream level (of basic research) where researchers share knowledge about the theoretical uses of specific chemicals and biologicals, and test hypotheses using sophisticated computer models (Morris, Stevens, Gelder van, 2005). Such collaboration relies on an electronic network of scientific researchers from a host of different corporations, organizations and universities who work together for a common cause - in this case to research and select the most promising chemical or biological candidate compounds for a specific disease, to eventually develop new treatments or preventive products. Once a set of potentially useful chemicals or biologicals has been identified to treat or prevent a particular disease, it is necessary to carry out more rigorous testing, which at some stage would entail conducting clinical trials in humans while scaling

\footnotetext{
${ }^{141}$ This is illustrated by the InnoCentive Open Innovation community where cash awards up to US\$1 million for creative solutions can be won. Its open innovation marketplace for the life sciences ('Prize $4 \mathrm{Life}$ ') has been calling, for example, for a biomarker for measuring disease progress in Amyotrophic Lateral Sclerosis (ALS or Lou Gehring's Disease) and has also awards for specific improvements in well defined parts of the pharmaceutical production process. However, they would not venture into far more ambitious projects like a full blown new medicine development from $A$ to $Z$ (http://www.innocentive.com/).
} 
up the manufacturing process. Setting up large-scale field trials and building production units requires substantial resources including technical and academically skilled and trained personnel, as well as the disposition of expensive and complex equipment. So, the question arises by whom and how these investments would be funded, which indirectly brings the discussion back to intellectual property rights.

As discussed in chapter 3, over time a binary system has emerged in the new medicines industry that distinguishes between for profit and non-profit oriented activities. Historically, the vertical structure of the pharmaceutical innovation-driven industry has been moving into a pronounced binary dichotomy, with a clear distinction between the upstream 'open' science led by academia, and a downstream commercial sector dominated by large, highly integrated firms. Since the early 1980s, this innovation structure has become considerably more complex as an intermediate sector emerged between the academic research institutions and so-called 'Big Pharma'. Biotechnology companies and research institutions straddled the historical divide between the for-profit and not-for-profit research (Cockburn, 2005a). This brought much of the molecular biology and the life sciences within the ambit of the patent system. Patents are now routinely awarded based on fundamental scientific knowledge such as genetic sequence information, cell receptors, and fundamental metabolic pathways. The extension of exclusion-based intellectual property into the domain of basic medical science means that market competition based on proprietary rights over biomedical knowledge nowadays plays a significant role in determining the overall rate and direction of technological progress. In other words, while (large) pharmaceutical and (small or mid-size) biotechnology companies have become important participants in biomedical research, in parallel, universities and other non-profit entities have become enthusiastic participants in the patent system for new products.

Nelson (2006) and Cockburn (2005a) warn against this growing influence of expanding exclusionary intellectual property rights into the domain of academic and basic scientific research. Under the old bipartite structure, academic research reflected a world in which most exchanges of scientific knowledge were not explicitly priced, and patents excluded industry participants only from the final product market. Stiglitz (2007) characterizes this scientifically acquired common 'knowledge' as an example of a public good. Public goods, he claims, have two characteristics: one being 'nonrivalrous consumption' (the consumption of one individual does not detract from that of another e.g. knowledge of a mathematical theorem); and another being 'nonexcludability' (it is difficult, if not impossible, to exclude an individual from enjoying the good, e.g. military expenditure or a park in the city). Hence, a university's exchange concerning the use of the scientific knowledge it produces, became governed by an active market for licenses and partnership deals. This was the rationale behind the passage of the Bayh-Dole Act. Politicians argued that if private firms could not expect to earn money from licensing fees for innovations based on publicly 
available knowledge, they would not develop and market them; and the knowledge accumulated in academia and government institutions would not benefit the public. As a consequence, under the Bayh-Dole Act, publicly funded research that would formerly have gone into the 'medical-scientific commons' had to be patented.

As in any other market, prices in the 'patent' market are playing an important role in the allocation of resources across the medicines $R \& D$ process. The performance relies critically on the market for upstream research generating the 'right' signals for downstream resource allocation, and for further investment in upstream knowledge creation. To some it is far from clear that these conditions prevail in fundamental biomedical discovery. High levels of uncertainty and high transaction costs imply serious contracting problems. Additionally, there are ethical issues related to the more extreme case of gene patents which may slow down the pace of medical advancement on deadly diseases. Critics nowadays argue that gene patents are granted to halt medical research, prevent medical testing and keep vital information from patients and their doctors. In the public opinion, this raises costs exorbitantly. Newspapers regularly report on incidents and consumer complaints. This raises the question, for example, whether somebody else could make a cheaper diagnostic test. The answer is ,certainly, but in many cases the patent holder may block usage of the competitor's test. If an innovator owns the gene, no other research firm can test for it, unless they are willing to pay a price. Some argue that this unrealistic situation has stemmed from a mistake made by an underfinanced and understaffed government agency. Occasionally, broad and imprecise patents are issued because patent offices are under-funded, the patent examiners inadequately trained and lacking the necessary capabilities to search for the prior art (Arora, Fosfuri, Gambardella, 2002). Several years ago, to the surprise of many, including scientists decoding the human genome, the United States Patent Office misinterpreted previous Supreme Court rulings and began to issue patents on genes. However, humans share mostly the same genes. These genes are also found in animals. Our genetic makeup represents the common heritage of all life on earth. Just as snow, eagles or gravity cannot be patented, it should not be allowed to patent genes. Yet, by now about one-fifth of the genes in the human body are privately owned.

Overall, Cockburn (2005b) contends that the consequences have been disastrous for upstream, basic medical-scientific research. "Ordinarily, we imagine patents promote innovation, but that is because most patents are granted for human inventions. . but genes are not human inventions since they are features of the natural world". As a result of this steady trend in fundamental medical research, patents can now be used to block further medical-scientific innovation and ultimately hurt patient care. Yet, "in at least one important area of biomedical research - the burgeoning new discipline of computational biology 
or bioinformatics ${ }^{142}$ - open science appears to be alive and well" (Cockburn, 2005b). Here, academic researchers appear to have effectively limited the incursion of exclusionary IP through aggressive use of the public domain and open resource licensing. Accordingly, bioinformatics is perhaps the area in biomedicine where 'open source' innovation will prove to be most useful. We may see cross-fertilization within rapidly emerging economies that are already strong in software development like, for example, India and have the ambition to become leaders in biomedical research and development in addition to pharmaceutical production.

PriceWaterhouseCoopers (PWC, 2007) have conducted 185 interviews with MNC and domestic pharmaceutical companies across nine territories. The report provides insight into how the center of gravity of the global pharmaceutical industry is shifting in particular towards Asia. They conclude that, not only is Asia set to become the largest pharmaceutical market in the world, many Asian territories will be powerhouses of the industry. The shift started as economies grew and low cost manufacturing in the region expanded. Now companies are increasingly seeking to establish sites for research and development in Asian territories, beyond the clinical trial activity and (generic) manufacturing, which they already relocated in past years. The survey not only revealed trends of increased capability in the region, but also a changing business model in MNC. The majority of companies thought that the industry still does not see outsourcing as a sufficiently dynamic approach and is missing opportunities for shared development, learning and improvement. The survey also revealed that IPR uncertainty is perceived by pharmaceutical MNCs to be the biggest threat to growth. Interestingly, these concerns were shared by domestic pharmaceutical companies. While many are optimistic that improvements to protection are happening, none of them expect such moves will resolve the issue.

In this environment, PWC recommends that companies reduce their dependence on conventional IP mechanisms by complementing it with an IP strategy in the broader context of value creation and business strategy. PWC concludes by stating that "this is not to say that companies should give up on pressing for improvements to IP laws". While this may be a prudent statement from a top management consultancy, it concurs with the views of academics in the field of software and open source who argue that the latter does not provide evidence against the fundamental role of IPRs protection driving core innovations.

\footnotetext{
142 Bioinformarics and computational biology involve the use of techniques including applied mathematics, informatics, statistics, computer science, artificial intelligence, chemistry, and biochemistry to solve biological problems, usually ar the molecular level. Research in computational biology often overlaps with systems biology. Major research efforts in the field include sequence alignment, gene finding, genome assembly, protein structure alignment, protein structure prediction, prediction of gene expression and procein-protein interactions, and the modeling of evolution.
} 
Etro (2007) believes that the current coexistence of open source software and proprietary software may even exert, within certain limits, a positive impact on innovation on both sides. This, he says is illustrated by a different sort of open source activity. Wikipedia, for example, is a famous and successful online encyclopedia where anybody can post a new entry or edit an existing one. While it contains a lot of useful and constantly updated information, it often includes unmotivated and misleading references or mistakes that are the normal consequence of overlapping additions by heterogeneous contributors whose preparation is not properly controlled and whose effort is not rewarded ${ }^{143}$. Traditional encyclopedias, based on rewarded contributions by selected experts, are not as constantly updated as Wikipedia, but they provide a standard of quality and a balanced unifying structure that Wikipedia lacks. The trade-offs for the end users are clear and coexistence appears natural.

Can pharmaceutical R\&D become less dependent on IPR as demonstrated in the software industry? Etro (2007) warns that in the field of software, innovation and related business, interactions are complex because any product can include many inventions, some of which are licensed as proprietary software and others as open source software. This creates a fundamental asymmetry between companies. On one side, open source companies can use proprietary software within their products and freely distribute them while covering license expenditures through fees for their customer support services. On the other hand, other commercial companies cannot pursue their business model when including open source software within their software product, because they would infringe the copyright of the open source software if they charge a price for the license of their products. This asymmetry can create substantial problems for the conventional business model, and may inhibit or bias innovation by traditional commercial companies. It is currently unclear how this model can be extrapolated to the sector of biomedical innovation.

\section{Patent pooling}

The concept of a patent pool is a straightforward one. In industries where critical patents are held by a variety of owners, firms have two options if patents are not available: either large-scale and multilateral patent infringement, or an agreement that the groups will share their patents. If the infringement were to be prosecuted, counter accusations would fly and

\footnotetext{
${ }^{143}$ It remains surprising that such a large innovative process can take place, at least in part, through directly unrewarded efforts. Some economist have provided a few explanations for the incentives of these individual programmers: career concern, ego gratification and signaling activity are quite powerful and effective in this field. Unfortunately, the same nature of these incentives shows the possible limit of the innovative activity in the open source community: it is limited by the usual free riding problems emerging in the private provision of public goods.
} 
long, destructive periods of litigation would ensue. Therefore, almost inevitably, the second option is generally pursued, either tacitly or overtly. Pools are created for a diversity of reasons by governments or the private sector and can take many forms. The pool may involve simple cross-licensing among two or more competitors, in order to share a handful of patents necessary for the manufacture and sale of a particular product, or it may involve a large industry-wide pool open to anyone, encompassing hundreds of manufacturers and thousands of patents, as well as other intellectual property, such as rights to use data, knowhow or trademarks.

Patent pools have been around for over 150 years. One of the first patent pools was formed in 1856 by manufacturers Grover, Baker, Singer, Wheeler, and Wilson; all involved in accusations of patent infringement. The group first met in Albany, New York, to pursue their suits. Orlando Potter, a lawyer and president of the Grover and Baker Company, proposed that rather than sue their profits out of existence, they pool their patents ${ }^{144}$. As in that example, many industries could not function without patent pools since the coordination costs (risk, negotiation, etc.) would otherwise be too high. Patent pools are only one example of cases where members of an otherwise competitive industry join in a common cause to create some resource that is to their collective benefit. For example, the insurance industry pools claims data to collectively reduce risk; the catalog sales industry polls sales data to better model their customers; the auto industry collaborates to standardize components; and in the software industry we see open source collaboration. Today, patent pools are frequently utilized in technology fields that require common 'industry standards'. Examples in the entertainment industry alone are numerous, such as: radio, DVD-video, DVD-ROM and the compression technology developed by the Moving Picture Experts Group (MPEG) including the most well known, MPEG-2 Standard ${ }^{145}$. All these are examples of pooling with the common goal to reduce risk and lower coordination costs.

The rationale for patent pooling in biotechnology is intricately linked to the concept of the anti-commons in biomedical research, identified by Heller and Eisenberg (1998). Their argument echoes earlier concerns about university patenting and the patentability of genomic sequences. Both scholars contend that the cost of patents in the early stages of biomedical research stem not only from the standard restrictions that patents place on use

\footnotetext{
${ }^{144}$ See 'Singer'; Wikipedia.

${ }^{145}$ MPEG-2 includes the fundamental technology for the efficient transmission, storage and display of digitized moving images and sound tracks on which high definition television (HDTV), Digital Video Broadcasting (DVB), direct broadcast by satellite (DBS), digital cable television systems, multi-channel and multipoint distribution services (MMDS), personal computer video, digital versatile discs (DVD), interactive media and other forms of digital video delivery, storage, transport and display are based. The technology in MPEG-2 compresses digital information by reducing spatial and remporal redundancies in the binary data streams, thereby conserving transmission resources and storage spaces.
} 
but also from the specific problems of fragmented IP rights. They suggest that when the development of a commercial product requires access to multiple patents, negotiating access with different patent owners may be prohibitively difficult and costly. Too many property rights lead to the under-use of valuable resources, which Heller and Eisenberg consider "the tragedy of the anti-commons", a mirror image of the tragedy of (unregulated) commons. The 'Tragedy of the Commons' is a type of social trap, often economic, that involves a conflict over resources between individual interests and the common (not privately owned) good. The metaphor refers to a structural relationship between free access to, and unrestricted demand for, a finite resource. As a means of illustrating this, Garrett Hardin introduced in 1968 the hypothetical example of a pasture shared by local herders. The herders are assumed to maximize their yield, and by doing so to increase their herd size whenever possible. The metaphor illustrates how free access and unrestricted demand for a finite resource ultimately structurally dooms the resource through over-exploitation (in this case because of overgrazing). This occurs because the benefits of exploitation accrue to individuals or groups, each of whom is motivated to maximize the use of the resource to the point where they become reliant on it, while the costs of the exploitation are distributed among all those to whom the resource is available. This, in turn, causes the demand for the resource to increase, which causes the problem to snowball to the point where the resource is exhausted. The situation opposite to the tragedy of the commons is referred to as the tragedy of the anti-commons: a situation where rational individuals (acting separately) collectively waste a given resource by under-utilizing it (for example, in the case of overly relying on patents).

To complicate matters, the concept of patent pooling has often been controversial and misunderstood, and is spotted with instances of mandated patent pools. The 'compulsory pooling' scenario, developed during World War I for breaking a licensing deadlock in aircraft manufacturing, has provided inspiration to a wide range of industries (Dykman, 1964). Similar pooling arrangements have been advocated to fight contemporary medical crises. Following the outbreak of SARS many research institutes and private firms rushed to sequence the SARS genome and apply for patents. The WHO SARS Consultation Group and key SARS intellectual property owners created the "SARS IP Working Group" which found that R\&D would be delayed and constricted by the multiplicity of patents and that this could adversely affect the development of a vaccine. In 2005, the group suggested to create an 'upstream' patent pool to promote the development of a treatment or vaccine against SARS (Simon et al, 2005). The WHO 2006 Report of the Commission on Intellectual Property Rights, Innovation and Public Health (CIPH) outlines in detail the potential barriers to access affordable essential medicines, and concludes that patent pools could offer a way to overcome (some of the) the patent barriers to access essential medicines. Later, its proponents go as far as to assume that "a patent pool offers very practical ways to overcome the current patent barriers to access essential medicines, enable sustainable scale up of the 
production of essential medicines, expansion of access and creation of needed technologies developed for country specific conditions" (Knowledge Ecology International, 2007).

However, the kind of mandatory patent pools for medicines that are currently being discussed in the IGWG-context have not been used before. According to Moore (2007), they are essentially a glorified compulsory license. The scheme would allow a grouping of countries to pool patents from a variety of different owners simultaneously, avoiding "pressure that can accompany the decision to issue a compulsory license through regular channels". However, the problems of 'mandatory patent pooling' are the same as those for 'standard compulsory licensing'; the deterrent effect on innovative activity. Thus, it is inaccurate to assume that existing patent pools in other non-medical technological areas are the same as the compulsory patent pools proposed in the IGWG process. Moreover, the TRIPS agreement states that compulsory licenses should be issued on a case-by-case basis. A patent pool would consist of many compulsory licenses and thus cannot be implemented on a case-by-case basis if medicines for treatment of a certain disease have to automatically become part of a patent pool. In sum, compulsory licenses and mandatory patent pooling under which certain categories of inventions automatically become eligible would violate Article 31 of the TRIPS-agreement.

In addition, it is important to consider the issues that arise when a large consortium of firms is formed, which may be the case in patent pooling. Critics have stated that patent pools have anticompetitive effects and that they inflate the cost of competitively priced goods. As a result, antitrust laws and patents have often been in conflict, especially where patent pooling or patent cross licensing is concerned, although ironically both antitrust law and patent law are aimed at encouraging innovation, industry and competition. ${ }^{146}$ Meanwhile, antitrust laws, such as the Sherman Act in the U.S. have been designed to prevent the creation of monopolies and restraints on interstate commerce. It is recognized that in principle patent pools can have significant pro-competitive effects and may improve a business' ability to survive the era of rapid technological innovation in a global economy. However, anticompetitive effects may occur if the pooling arrangement deters or discourages participants from engaging in research and development, which is more likely when the arrangement includes a large fraction of the potential research and development in an innovation market. Therefore, justice departments developed a set of guidelines for them to follow when considering and approving patent pools, including for biotechnology patent pooling. The U.S. Patent and Trademark Office, for example, has issued a document entitled "Patent pools: A solution to the problem of access in biotechnology patents?" The document analyzes the potential benefits of forming patent pools in the biotechnology

\footnotetext{
${ }^{146}$ See Atari Games Corp. v. Nintendo of America, Inc., 897 F.2d. 1572, 14 USPQ2d 1034 (Fed. Cir. 1990).
} 
industry to both commercial entities and the public at large (Clark et al, 2005). The premise is that the social and economic benefits of patent pool arrangements should outweigh their costs.

The following paragraphs summarize the various benefits of patent pooling in the biotech arena, as well as some of their costs:

The first benefit associated with the pooling of patents is the elimination of problems caused by 'blocking' patents or 'stacking' licenses ${ }^{147}$. In the biotechnology field, the granting of patents to nucleic acids may create blocking patents or lead to stacking licenses ${ }^{148}$. Corporations that hold patents on an industry's basic building blocks, can prevent others from bringing commercial products to the market (Dykman, 1964). But by creating a patent pool of these basic patents, businesses can easily obtain all the necessary licenses required to practice that particular technology concurrently from a single entity (Merges, 1999).This, in turn, can facilitate rapid development of new technology, since it opens the playing field to all members and licensees of the patent pool (Carlson, 1999). Patent pools can therefore eliminate the problems associated with blocking patents or stacking licenses in the field of biotechnology, while at the same time encouraging the cooperative efforts needed to realize the true economic and social benefits of genomic inventions (Sung, Pelto, 1998). Since each party in a patent pool would benefit from the work of others, the members will be focusing on their core competencies, thus spurring innovation at a faster rate.

A second benefit is that patent pools have the potential to significantly reduce several aspects of licensing transaction costs (Merges, 1999). First, patent pools can reduce or eliminate the need for litigation over patent rights, because such disputes can be easily settled or avoided by the creation of a patent pool. A reduction in patent litigation would save businesses time and money, and also avoid the uncertainty of patent rights following litigation (Carlson, 1999). Small businesses, which cannot usually endure the costs of litigation, are more likely to survive and prosper if they are free from legal suits over patent rights.

Second, a patent pool creates an efficient mechanism for obtaining rights to a patented technology (Merges, 1999). Parties interested in a certain technology covered by a patent pool can, in one step, license all the patents essential to a core technology. Without a patent

\footnotetext{
${ }^{147} \mathrm{~A}$ 'blocking' patent is defined as patenes that have claims that overlap, in a manner that the invention claimed in one patent cannot be practiced without infringing the claims of the other patent and vice versa. A 'stacking' license gives the owner of a patented invention used in upstream research rights in subsequent downstream innovations (M. Heller et al., 1998).

${ }^{148}$ See Carlson S. (1999). "Patent Pools and the Antitrust Dilemma", 16 Yale J. ON REG. 359, 373.
} 
pool, a company would have to obtain licenses separately from each holder of the essential patent. Not only does the process of individual licensing require more time, money and resources, it also establishes a motivation for some patent owners to hold out on licensing their patent so that they can demand a substantially higher royalty, because the value of all the other licenses that the consumer already purchased depends on obtaining this last license (Brunetti, 1997). Patent pools are thus a solution to this anticompetitive 'hold out' problem, by providing a means by which most, if not all, necessary licenses are obtained at once. A reduction in transaction costs is deemed particularly important to biotechnology firms, where a significant portion of their research and development funds are being diverted to cover transaction costs, thus slowing down further innovation.

A third major benefit from patent pooling is the distribution of risks. Like an insurance policy, a patent pool can provide incentives for further innovation by enabling its members to share the risks associated with research and development (Carlson, 1999). The pooling of patents can indeed increase the likelihood that a company will recover some, if not all, of its research and development costs. Depending on the structure of the pool, all members may receive a set income based upon a percentage of the pool's royalty regardless of the 'economic' value of their individual patent. This arrangement evenly distributes the wealth of the pool to all its members. In addition, all members of a patent pool have equal access to the technology in the pool, which may enhance the commercial potential of the patented invention to an individual member. A mechanism that distributes risks and provides greater access to related technology should be extremely attractive to biotechnology businesses that have to fund the high research and development costs inherent in their area of innovation.

Finally, a fourth benefit of patent pooling is an institutionalized exchange of technical information not covered by patents (Merges, 1999). A patent pool provides a mechanism for free sharing of technical information related to patented technology among its contributing members and its licensees. By fostering lines of communication between the members, trade secrets become less prevalent. Instead, the members of the pool have an incentive to avoid overlapping efforts, especially in the field of biotechnology. Competitive success in the market place depends upon access to information in order to use limited resources efficiently, and patent pools would provide greater access to information to their members. This is particularly important in biotechnology, where the potential for commercial development is staggeringly high, especially if limited resources are used effectively and efficiently (Sung, Pelto, 1998).

In conclusion, the U.S. Patent and Trademark Office, other regulators, and stakeholders believe that the use of patent pools in the field of biotechnology could serve the interest of both the public- and private-industry, a win-win situation if streamlined licensing conditions are in place. The public sector would be served by having ready access to a greater 
amount of proprietary subject matter. Patent holders would be served by greater access to licenses of proprietary subject matter of other patent holders. The end result is that patent pools, especially in the biotechnology area, can provide for greater innovation, parallel research and development, removal of patent bottlenecks, and faster product development.

\title{
10.4 New public-private partnerships in medical product development
}

\author{
A new public private partnership
}

A public-private partnership is a system in which a government service or private business venture is funded and operated through a partnership of government and one or more private sector companies. These schemes are sometimes referred to as PPP or P3. In some types of triple Ps, the government uses tax revenue to provide capital for investment, with operations run jointly with the private sector or under contract. In other types, capital investments are made by the private sector on the strength of a contract with the government to provide agreed services.

Thus, PPPs offer another innovative approach to reducing health inequality, stimulate research in less lucrative areas, and facilitate access for new drugs and vaccines for people without the purchasing capacity to obtain these products on their own. PPPs are generally based on mutual confidence between the three main actors in the innovation triangle: (i) pharmaceutical and biotech corporations; (2) governments and NGOs/charitable foundations; and (3) academia and public research institutions. The relationship is established on the premise that each partner can share its own knowledge, skills and resources to create unique and flexible approaches to solving global health issues. Clearly, the more intertwined the operational activities become, the larger the need for one or more oversight committees at the danger of significantly increasing the level of bureaucracy and possible conflicts of interest between stakeholders.

In recent years, the number of PPPs in product development has expanded. In the vaccines field alone, there is a vast array of PDP agencies involved in efforts to generate new preventive (and sometimes also therapeutic) vaccines, including the Global Alliance for Tuberculosis Drug Development (GATB), the International AIDS Vaccine Initiative (IAVI), the International Vaccine Institute (IVI), the Malaria Vaccine Initiative (MVI) of the Program for the Appropriate Technology in Health (PATH), and others. These organizations often originated in the public sector or were backed by charities. They have been facing a series of challenges beyond the scientific hurdles, including $R \& D$ management, IPR management, regulatory considerations, access to manufacturing facilities, and many other ones. They are 
therefore keen on sharing resources and expertise with the private sector. Hence, there is a broad spectrum of organizational structures that can be employed in setting up PDP consortiums, despite the variances in project scope, objectives and activities. Most of the above examples are focusing on a particular disease e.g. HIV/AIDS, malaria, TB, etc.

Other medical product development initiatives have been taken recently. They strive for sustainable solutions by establishing durable organizational structures aimed at addressing the challenges encountered in the area of neglected diseases (important to both developing and developed countries). Two such organizations are the Global HIV Vaccine Enterprise and the Innovative Medicines Initiative (IMI). The former is an example of an organization that focuses on neglected diseases mainly prevalent in developing countries; the latter focuses on diseases that are important to the developed world (and given the changes in epidemiology increasingly the developing world as well). There is the system of AMC, which basically employs the operational machinery of the pharmaceutical and biotech companies. Governments and donors are remotely involved in product development, but have an active role in fundraising and providing financial incentives for private sector work under conditions of pre-agreed output and delivery. We start with the latter incentive system.

\section{Advance market commitments}

As defined in chapter 7, an AMC for a new drug or vaccine is a financial commitment by donors to subsidize the future purchase (up to a pre-agreed price), of a medicine not yet available, if appropriate medicines are developed and if they are demanded by developing countries.

AMCs aim to engage the dynamism and energy of the private sector. Decisions about which avenues to pursue and which to abandon are made by those with the highest stake, that is biotech to multinational firms, and with the best knowledge about the prospects for success. AMCs thereby reproduce the market-based incentives for developing country diseases that, together with public and philanthropic funding of $R \& D$, have contributed to tremendous progress in pharmaceutical $R \& D$ for the industrialized countries. It particularly rewards those firms that move fastest toward the objective of developing, producing and supplying these valuable new medical products. AMCs are even more effective when combined with push interventions - such as the public and philanthropic funding of research through academia, public-private partnerships and other bodies - because of the network effect of the increased number of scientific researchers working on the target diseases, as well as the enhanced probability that scientific research swiftly translates into the production of effective and safe medicines. 
In AMCs, public officials and philanthropic donors are requested to stay at arm's length of complex technical-scientific choices and tradeoffs. By clearly defining the objectives they wish to achieve with public funds, the sponsors can create the necessary conditions for trying a variety of different approaches, promoting competition, and allowing different firms to make their own judgments about the scientific feasibility and risks of alternative strategies. The AMC system is a performance-based funding mechanism that only provides sponsors with the assurance that large-scale funding will be provided if, and only if, an effective and safe product that is appropriate for the developing world is manufactured in large enough quantities to meet demand. This is consistent with innovations in international development assistance, in which donors seek to pay for results rather than inputs (Clinton 2007).

Thus, an AMC is not a general commitment to buy new medicines; it is a specific commitment to subsidize the purchase of new drugs and vaccines that meet pre-agreed standards. The total volume of medicines and the price per dose are established before industry makes significant investments in the development process, so that each firm has clear assurances of the size of the potential market. By the same token, the AMC incentive system establishes a market that the biotechnology and pharmaceutical industry currently perceives to be too small and too unpredictable. By creating incentives for investment in specific medicines for low-income countries, AMCs establish a market similar to one that prevails for medicines in affluent countries. Evidence suggests that the prospect of a valuable market indeed increases investment in innovative medicines.

Since AMCs are open to all firms, they can be designed not only to accelerate the development of new and effective medicines, but also to develop second and possibly even third generation products that improve on the first and ensure a competitive market. The AMC can also provide incentives for firms to invest in more efficient, large volume production facilities, thus allowing firms to have lower costs per dose that can be passed on through the provision of medicines at lower prices in the long term. Without an AMC system in place, developing country markets will continue to be seen as small and risky. Evidence has shown that when faced with choices, firms give priority to products and markets that provide greater certainty of high returns. The result is long delays in the development and availability of priority medicines - even when technical hurdles have been overcome. However, implementing AMCs can be associated with risk. These risks differ dependent on the stakeholders: the affluent (OECD) country donors, the public health community, the developing countries, and the industry. The design of the AMC can help mitigate some of these risks but some of these risks will remain unless more work is done:

- The first risk is that the AMC will be unsuccessful at changing industry's perception of PPPs. The perception might be that, although no funds will have been spent (just an economic 'opportunity cost' incurred), a complete failure might cause the donors to 
entirely drop the concept of $\mathrm{AMCs}$ and retreat from other innovative financing mechanisms aimed at accelerating access to priority health technologies.

- The second risk is that firms will engage in an AMC in good faith, but discover that they are locked into long-term agreements that are not economically viable either because the prices were set too low or because demand does not materialize despite the financial guarantees.

- The third risk is that the AMC will be successful while being publicly funded, but the commitment by corporations to ensure a long-term sustainable and affordable supply of the new medicine to developing countries will not materialize.

- The fourth risk is that an AMC will succeed, but its success for one disease area will be, at least partially, at the expense of another discase area in the same period.

- The fifth risk is that one product-winner takes it all, that is, despite the built in competition for market share, developing countries may all switch to the best product almost overnight (since price is no longer a differentiator). This is not necessarily a bad thing from a country's welfare perspective.

\section{Global HIV vaccine enterprise}

The Global HIV Vaccine Enterprise ${ }^{149}$ is another newcomer in the ecosystem of biomedical innovation models. It consists of an alliance of independent public and private organizations around the world dedicated to accelerating the development of a preventive HIV vaccine ${ }^{150}$. The HIV virus was identified more than two decades ago. Ever since, scientists have been working to develop a vaccine. Progress has been far too slow because of the higher than expected hurdles. Although researchers have made important strides in understanding the fundamental biology of HIV, there remains major scientific-technical and organizational challenges to translating this knowledge into an effective vaccine that could benefit millions.

In June 2003, an international group of scientists proposed the creation of the Global HIV Vaccine Enterprise (Klausner, Fauci, Corey, Nabel, Gayle, 2003). The authors invited comments on their initial proposal and challenged a number of scientists to identify new strategies and mechanisms to accelerate the global effort to develop a safe and effective vaccine. Their motivation was the recognition that the development of an HIV vaccine remains one of the most difficult challenges confronting biomedical research today (Fauci,

\footnotetext{
${ }^{149}$ Global HIV Vaccine Enterprise. Accessed Sept. 2007, http://www.hivvaccineneterprise.org/about/index/html.

${ }^{150}$ With nearly 5 million new HIV infections in 2005, and nearly 40 million people living with HIV/AIDS, the development of an HIV vaccine is the world's best long-term hope to bringing the global HIV/AIDS epidemic under control.
} 
2003; Desrosiers, 2004). Therefore, in its science-based strategic plan, the HIV Vaccine Enterprise presents itself as a global endeavor and emphasizes the need for integration and capacity building around the world. It is not supposed to be "a discrete organization with a pool of money" but a "coordinating group of individual funding agencies that will support specific areas of research using their own mechanisms, according to their own practices and policies, and following the Enterprise's principles"151.

The HIV Vaccine Enterprise completed and published its scientific strategic plan in February 2005. In April 2005, the Bill \& Melinda Gates Foundation pledged up to US $\$ 300$ million over five years for HIV vaccine research consistent with the Enterprise's scientific strategic plan. The initial grants under this program would focus on vaccine discovery and laboratory standardization priority areas of the plan. However, the ambition of Enterprise goes much further in that the envisaged plan covers the entire research, development and manufacturing process. The focus is not only on specific scientific roadblocks that need to be overcome, but includes building capacity for product manufacturing, field clinical trials, and addressing regulatory issues. Some observers find these noble goals, and the fact that they have been underwritten by many of the leaders in the field, will undoubtedly generate excitement and expectations. Others believe that the focus should be on scientific research only because that is where the largest bottlenecks are. The wide scope of the organization's strategic intent may cause confusion, as the Enterprise might be seen as competing in (R)esearch on the one hand with prestigious institutes like the American NIH, and on the other hand with industrial pharmaceutical or biotechnology companies, that master the (D)evelopment aspects, comprising all of the so-called downstream processes.

In terms of organizational structure, the original Enterprise plan stresses collaboration and coordination, and concerted efforts clearly provide benefits. Some observers wonder, however, whether some degree of competition, rather than collaboration would be healthy, and, if so, at what level would competition work best (Cohen and Yamey, 2005)? The Enterprise members seem to have wrestled with that question as well. The plan does mention that an "appropriate balance between productive competition and effective collaboration" should be pursued, and suggests that certain incentives are provided by "the funders with the greatest flexibility". David $\mathrm{Ho}^{152}$ argues that as long as it remains unclear where scientific breakthroughs will come from, diversity and flexibility should be encouraged and not stifled. He points to the danger of 'group think', and warns the Enterprise not to fall into that trap. Currently, HIV vaccine research may need the structure of cumulative

\footnotetext{
${ }^{151}$ These principles include collaboration, standardization, and coordination among international researchers and agencies.

${ }^{152}$ See comments of David Ho on Global HIV Vaccine Enterprise; DOI: 10.1371/journal.pmed.0020036.
} 
and reflexive research, not the linear unidirectional research presumed in many of the traditional models. In other words, a process where 'trial-and-error' discovered knowledge links back to basic knowledge and helps to uncover other trial-and-error discovered knowledge, and so on. This is illustrated by the following observation:

"A lack of knowledge about protective immunity has hindered HIV vaccine development. This obstacle is to some extent offset by the knowledge researchers in the field have gained about HIV diversity, the structure of some key HIV proteins, the events surrounding HIV entry into its target cells, and host responses to HIV antigens. Even though many of these scientific gains have been and will continue to be translated into HIV vaccine designs, it should be recognized that it will only be possible through clinical trials to evaluate the effectiveness of an intended immune response that is elicited by a candidate vaccine. HIV vaccine development therefore needs to be an empirical process, involving repeated rounds of clinical testing of a large array of candidate HIV vaccines ${ }^{153}$.

The main problem in our opinion with the Global HIV Vaccine Enterprise's strategic plan and accompanying organizational structure is that its scope is too broad. The remit of the original plan was not to prescribe specific research but "to stimulate both researchers and funders to explore new, more collaborative, cooperative, and transparent approaches ... in addition to continuing the productive, high-quality approaches already underway". Today, the objective still stands as nobody knows whether it is actually possible to develop a safe and effective HIV/AIDS vaccine. Moreover, provided it can be done, it is impossible to predict when the necessary scientific advances will happen. Therefore, should the Enterprise during all this time of research and development receive funding for an undetermined period, regardless of results obtained or milestones achieved? Why does the Enterprise propose to do all the necessary activities in an integrated fashion from $A$ to $Z$, while many of the core tasks can be done faster and more efficiently by the private sector? To illustrate the fact that the Enterprise's strategic plan is overly ambitious, let us examine the section in the plan that deals with new product development and manufacturing.

As described in chapter 4 , it is a fact that to meet eventual worldwide demand the manufacture of medicine candidates for large clinical trials (including potential HIV vaccine candidates) requires the development of processes for producing consistent, active product batches on a large scale. Development of these (bio)-processes further involves analytical work (e.g., toxicity and stability testing), and validated assays. These processes must be applicable to the manufacture of sufficient product to meet global needs after licensure.

${ }^{153}$ Lee, T-H. and Novitsky "HIV Vaccines: Design and Development" Chapter 39 in "AIDS in Africa" Second Edition, Ed, Essex, M. et al. p596. 
The argument for the creators of Enterprise to step in and - by and large - take over, or at least supervise, most of the key activities includes:

- "Worldwide expertise and capacity for the bioprocess development work is already limited and exists almost exclusively in the private sector. As more HIV candidate vaccines enter the $R \& D$ pipeline current capacity will be rapidly exhausted. However, this assertion can be refuted as private companies will invest in the development and manufacture, as soon as the largest impediment, the scientific 'proof of concept' has been resolved, and a market-based incentive mechanism like AMC has been put in place".

- "The initial priority is to identify or establish one or more dedicated HIV vaccine bioprocesses and analytical development groups that bring together the skill set and capacity to manufacture different promising candidates for clinical trials" - However, the aforementioned necessary skill set exists in both the public and private sectors which are already working in tandem with regulatory authorities.

- "The bioprocess development groups would also help train people and transfer manufacturing skills in whole or in part to manufacturing sites around the world. This training program would address the acute shortage of bioprocess experts. At a later stage, building, acquiring, or contracting facilities to carry out bioprocess and analytical work and to produce several different types of candidate vaccines should be considered" However, what type of know-how will be transferred and from whom, by whom, and under which conditions? How will intellectual property issues be handled? How will local manufacturing for international markets be reconciled?

- "Such facilities would further assist in transferring manufacturing technology to other production facilities, preferably in one or more developing countries. Decisions about which candidates a facility undertakes would be made through a well-defined, comprehensive evaluation process. The facilities could eventually be expanded to provide production capacity to launch a vaccine for public health use, should no manufacturer be available to produce the vaccine quickly upon licensure" - However, who will determine or prove that manufacturers are not quick enough, and that the Enterprise's chances of success are higher in building, maintaining and supervising these facilities over the coming decades?

In summary, the example of Entreprise shows that there are a number of fundamental issues that cannot be easily resolved when using 'open source' innovation in the upstream as well as downstream processes, and to centrally manage all of these collaborative, highly cumulative, backwards-and-forwards iterative activities through a PPP consortium. In 
addition, this innovation model demands that those drawn into late-stage collaborative clinical development trials would involve sharing confidential information - well before a product is even near to being developed. This could mean that 'the' successful medicine may not be the one being worked on by a firm or may be a combination medicine that does not include the firm's medicine in its formulation, precisely because of some information the firm revealed during this collaborative process. Hence, the tendency to not openly share both good and bad information in ways that risk undermining one's own research, will increase as the sunk capital costs rise towards the later stages of the overall process.

\section{Innovative Medicines Initiative (IMI)}

The Innovative Medicines Initiative ${ }^{154}$ is a recently proposed partnership between the European Commission and the federation EFPIA. The objective of IMI is to remove bottlenecks in R\&D and spur the discovery and development of better medicines with fewer side effects that reach patients faster. Surely, this is a noble goal. It must be said, however, that part of the vision is to simultaneously boost Europe's biomedical R\&D base by helping to correct for the relarive under-funding of biomedical R\&D in Europe compared to other regions in the world that stimulate $\mathrm{R} \& \mathrm{D}$.

The bottlenecks that have been identifies in the current biomedical R\&D process, have been identified through literature search and extensive consultations with stakeholders. For instance, data on product attrition rates indicate that the probability of a drug candidate passing from pre-clinical stages to market is very low. Factors most commonly resulting in project failure are either a lack of efficacy, clinical safety concerns, or toxicological findings in pre-clinical evaluation. It is felt that reducing the risks associated with these project failures is dependent upon a concerted and collaborative effort to address the bottlenecks in the drug development process. The biopharmaceutical industry's greatest priority is indeed developing capacity to predict failure at the earliest possible stage of the drug development process. Advances in basic biomedical science within the entire European research community therefore could, potentially, make a significant contribution to improving the predictability of the biomedical R\&D process. The vision for the future would thus be to possess the ability to identify the lack of efficacy as soon as possible, even when a drug has promising pre-clinical data, and the drug's potential for adverse drug reactions and pre-clinical toxicity.

The goal and objectives of the IMI public- and private sector collaboration are captured in a Strategic Research Agenda (SRA), which allows for updates at regular intervals based on

\footnotetext{
${ }^{154}$ The Innovative Medicines Initiative (IMI); http://www.imi-europe.org
} 
scientific advances. The envisaged collaboration encompasses pre-competitive research projects, that is research where companies are not adverse to their competitors having equal access to the results. An example of such a pre-competitive research project would be research that is not aimed at producing products, but rather at providing the tools, information and data that would enable every competing company to develop and register its own future products and services. The major pre-competitive barriers and bottlenecks in the current biomedical innovation process are the lack of predictivity of pre-clinical studies to anticipate clinical safety and efficacy, as well as the overall assessment of patient benefits and risks with regulatory authorities. Regulatory processes need to reflect new knowledge and incorporate this new knowledge into an improved regulatory framework that supports the faster discovery and development of better medicines. This will increase patient access to new medicines and decrease the escalating cost of drug discovery and development.

Altogether, leveraging the scientific and technological advances surrounding these bottlenecks could, potentially, boost the biomedical innovation and pharmaceutical R\&D base, and thus accelerate the discovery and development of better innovative medicines. This holistic approach also favors cross-functional collaboration between pre-clinical and clinical scientists, and consequently promotes the development of translational medicine. In addition, the main focus of the IMI is to change the way the different stakeholders work together, establishing a new type of collaboration between industry, academia, clinicians, patients and regulators, which would represent a true paradigm shift in culture. The organizational challenge that this poses is illustrated by the following quote:

"Perhaps the biggest sociological divide in pharmaceutical sciences is the gap between academic and industry scientists. Put bluntly, the sooner academic and industry scientists destroy the stereotypes they hold for each other, the more likely that drug discovery and development will truly evolve to succeed in the 21 st century"155.

In order to successfully implement the IMI, the European Commission and EFPIA intend to hold joint responsibility for creating and operating this new non-profit international organization. The organization will have a legal mandate to award research grants to European public-private collaborations that are conducting innovative research projects focused on four strategic areas (referred to as the 'Four-Pillars') that address the principal causes of delay in the current medicines $R \& D$ process, as summarised below:

- 'Predictivity of Safety Evaluation' (Pillar I): Nine recommendations are presented. These include the creation of a European Centre for Drug Safety Research and estab-

${ }^{155}$ http://ec.europa.eu/enterprise/epaa/index_en.htm 
lishment of a framework to develop biomarkers that will have human relevance and regulatory utility ${ }^{156}$;

- 'Predictivity of Efficacy Evaluation' (Pillar II): Five recommendations are presented, related to each of the five disease areas that have been identified as priorities for Europe, based on unmet medical needs. These recommendations include creating disease-specific European Imaging Networks, developing regional centers of excellence, creating disease-specific European centers for the validation of new biomarkers and enhancing collaborations with patients and regulatory authorities;

- 'Knowledge Management' (Pillar III): Fifteen recommendations are presented that include establishing a Translational Knowledge Management team to support Pillar I and Pillar II projects and creating a Knowledge Management Platform to develop effective data integration and analysis tools;

- 'Education and Training' (Pillar IV): Five recommendations are presented that include establishing a European Medicines Research Academy, and the implementation of multi-disciplinary programs to develop skills in integrating biology and medicine expertise.

As part of the European Union's 7th Research Framework Programme, the IMI has been proposed for Joint Technology Initiative status by the European Commission, subject to approval by Member States. In order to fully implement the recommendations of the Strategic Research Agenda, an investment of approximately Euro 460 million per year, or more than Euro 3 billion across seven years will be required, starting in 2007. The European Commission and the biopharmaceutical companies will contribute equally in this investment. The European Commission will fund academic participants in research collaborations, and support small and medium-sized enterprises, while the multinational biopharmaceutical company participants in research collaborations will completely fund their own contributions to the Initiative.

In synthesis, the IMI employs a transparent structure and disburses public money to exclusively boost the R\&D capabilities of the public sector and small biotech companies. The larger pharmaceutical companies are partners and will match the funds from the European Union's $7^{\text {th }}$ Research Framework Programme with R\&D resources such as staff,

\footnotetext{
${ }^{156}$ A biomarker is any type of chemical or physiological 'tell tale' that shows a certain kind of biological process is taking place and that other processes or outcomes will likely follow. The concept is not new, think for example of blood sugar levels as a biomarker for diabetes, or cholesterol levels as a marker for heart disease. Bur for the vast majority of diseases, there are no such indicators.
} 
laboratories, materials and clinical research capabilities. Benefits and synergies include the common development of surrogate markers in disease areas that predict clinical efficacy, or safety issues. This would not only improve and accelerate the current $R \& D$ process, it would also promote the reduction of animal models in $R \& D$ in the long-term. This can be achieved, not only through more predictive animal tests with measures that provide more meaningful data, but also by decreasing the number of compounds tested as a result of earlier detection of unsuitable candidates. Using animals and particularly primates in $R \& D$ is a sensitive issue where industry and public institutions are often attacked (verbally and sometimes physically) by animal right activists, which may lead to blockage of biomedical research activities. For all of these reasons, it is imperative to focus on developing common tools that are underpinning biomedical $R \& D$ in a non-competitive manner. Due to its general nature, the IMI is complementary to other $R \& D$ incentive systems like, for instance, AMCs.

\subsection{Conclusion}

This chapter examined four recently proposed biomedical innovation models and incentive systems for stimulating and accelerating pharmaceutical and biotechnology R\&D on diseases primarily affecting developing countries:

(i) Direct funding - a system where $\mathrm{R} \& \mathrm{D}$ is directly funded via global tax-like mechanisms to raise predetermined investment amounts; and (ii) Prizelaward - a system where successful innovation efforts are compensated with a prize or award upon completion of the innovation, which subsequently is placed in the public domain for free; or (ii) Open Source/patent pools - are systems that rely on collaboration through open resource R\&D from product research and development onwards; (iv) Product development partnerships includes systems that are encompassing various collaborative mechanisms and organizational structures based on public-private partnership.

(i) Direct funding - The Global Medical Research and Development Treaty (MRDT) as proposed is based on multilateral agreements for collective R\&D between government institutions. It requires that every government sets aside a fixed percentage of its national output to finance globally defined pharmaceutical R\&D. MRDT proponents claim that this can be accomplished through a global treaty. They believe that countries would be better off funding national $R \& D$ budgets of comparable magnitude as a quid pro quo for abolishing patents and gaining access to drugs at generic prices. For this to work, all or nearly all, countries must agree to tax their constituents (directly or indirectly) year-in and year-out to fund the system in order to contribute to the fixed costs of R\&D in an amount 
that is proportional to their GDP. We do not believe that the MRDT is a valid mechanism, and found the proposal plagued with issues of moral hazard and asymmetric information. A huge bureaucracy would need to be created to deal with issues of measurement and evaluation. Further, it is unlikely that the international market for credits will work. If the bulk of R\&D continues to be performed in the U.S., Europe and Japan, this could even represent a huge tax transfer from the poor to the affluent countries via the flows of the credit trading system. Even if all R\&D contributions can be measured and assessed, we will only measure the cost and not the efficiency, or value of R\&D flows under this system.

(ii) Prizelaward - Prizes and awards have the value of encouraging competition and thus increasing the number of potential product candidates. They are also relatively easy for the public sector to implement, and for the private sector to gain valuable positive public relations. A serious drawback to prizes and tournaments is that holding them does not guarantee that a viable, affordable medicine will result. The prize or tournament prize, must be given to the winner, no matter what has been developed and regardless of whether it will actually be used in developing countries or not. What is more, this incentive model does not reward second- or third-generation entrants that may offer an improved safety, efficacy, and/or convenience profile, and therefore may stifle further innovation. A voluntary prize could however offer some limited incentives to certain parts of the research and development process. It could also be useful in stimulating research of neglected diseases in emerging markets not currently the subject of substantial research. Nevertheless, such a model would not be an effective replacement for the current, IP-based R\&D system. At best, it could be a useful complement to it. Many of the practical and systematic considerations of the prize system are addressed in the AMC, and are currently being piloted with support from the G8. In our view, the AMC-system offers a more efficacious market 'pull' incentive mechanism for stimulating and accelerating private sector $\mathrm{R} \& \mathrm{D}$, and is complementary to other innovation 'push' programs.

(iii) Open source/ patent pooling

A patent pool is created when a number of patent rights, held by different patent owners are brought together (pooled) and collectively managed. The existence of a patent pool eliminates the need for constant renegotiating of licensing rights as new innovations are made by one or more members of the pool. This entails a welcome reduction in coordinating costs. Corporate risks are mitigated by the use of patent pools although this could raise concerns about antitrust. On the other hand, if patent pools become mandatory, they will lead to legal uncertainty among private sector investors that will not promote - but rather discourage - investments in $R \& D$. Thus, mandatory patent pools are not likely to promote innovation and $\mathrm{R} \& \mathrm{D}$ for new medicines. A more interesting template for collaborative innovation may be provided by the Free/Libre/Open Software (FLOSS) model of knowl- 
edge management. FLOSS is produced by a worldwide community of developers, who do not directly gain any monetary reward from their activity, but nonetheless keep producing new software and diffusing it on the internet for free. More research is needed to examine the possible pathways for using these open source networks in the field of bioinformatics and biomedical research, which is beyond the scope of this book. The opportunity to create and add value in a dynamic fashion provided by open source is particularly important for developing countries and rapidly emerging economies. Access alone limits them to the role of passive consumers in the knowledge economy; the ability to create will transform them into active participants.

\section{(iv) Novel product development partnerships}

New PPPs such as, the IMI require the public and private sectors to actively co-operate together, each focusing on its competencies. The IMI as proposed would be a unique public and private sector collaboration between patient organizations, universities, hospitals, regulatory authorities, as well as small and large biopharmaceutical and health technology companies. It is important to appreciate that IMI will not - and is not expected to deliver new medicines per se. However, it is expected to deliver powerful new multidisciplinary tools to improve the innovation process and as such establishes a new medicines development paradigm. In addition, AMCs will harness the managerial and operational capacity and infrastructure of the research-based industry in order to develop innovative products rapidly and efficiently while governments limit their interventions to funding projects (on behalf of developing countries and only if the $\mathrm{R} \& \mathrm{D}$ output is successful). Properly designed, AMCs ensure almost immediate access to newly developed medicines (upon completion of the R\&D work) by purchasing medicines at subsidized prices through international assistance. The subsidized prices are set sufficiently high to recoup the participating firms' risk-adjusted investment costs. In the long run, that is in the post-AMC period, these firms will have to ensure a sustainable supply to developing countries at affordable prices. By establishing such a quasi-market, the AMC mechanism provides an incentive for enhanced private investment in the development of new and improved medicines against diseases that kill millions of people every year in developing countries.

On the whole, we have provided evidence that an AMC system not only increases the incentive for $R \& D$ into diseases of the poor, but also acts as a supplementary incentive system to patents and research grants. In addition, we have demonstrated that patent buyouts are ineffective as a solution for creating new incentives for firms to develop new medicines for neglected diseases. In contrast to the alternative systems to an AMC, the concept of 'patent pooling' warrants further theoretical and practical research by both scholars and practitioners interested in promoting innovation in the area of neglected diseases. We found that 'open source' innovation fostering collaboration rather than 
competition should be encouraged in upstream medical-scientific research, and particularly in those therapeutic areas where a 'proof-of-concept' has not been established. 


\section{SUMWMRV AND CONCLUSONS}

The lack of novel medicines and health technology products (drugs, vaccines, and diagnostic tests) for diseases that cause poverty primarily in developing countries, is one of the most pressing socio-economic issues the world faces. Both the public and private sectors are increasingly involved in innovative $R \& D$ on poverty-related or 'neglected' diseases. Because of the often huge technical-scientific hurdles, however, and the low purchasing power of the poverty stricken population in the world, the private sector has little incentives to engage in these high risk projects. To develop novel and improved medicines basic scientific challenges need to be addressed first. Even if these efforts are successful, it can still take ten to twenty years before the final medicine becomes available. By the time a viable pharmacological product has been fully developed, and has been registered in each of the countries where the new product should come to market, the company has gone through a series of large investments. In the 'traditional' market-based innovation model, the costs incurred at each of the various research and development stages can be recouped through sales once the new product has been launched on the market. But would-be innovators and firms have no assurance of recouping these sunk-investment costs that need to be made beforehand, regardless of market success or failure. In addition, poor countries may not be able to afford prices high enough to cover the investment costs. Even when financial resources are available, the demand for any given medicine in these countries is unpredictable as institutional and administrative factors may delay decision-making and constrain actual uptake.

Empirical evidence suggests that both multinational and local pharmaceutical and biotechnology firms view developing-country medicines market as small, fragile, and risky. These companies do not expect a significant enough return on the products sold in these markets in order for them to warrant the hundreds of millions of investment that would be desirable 
from a public health point of view. Private investment is further discouraged because of the possibility of political pressure exerted on producers to sell their newly developed drugs, vaccines, or diagnostic tests at very low prices. As a result, many of the children and adults living in the developing countries only have access to these new health technology tools, at best 10 to 15 years after the initial licensure has been obtained in the industrialized countries. In short, the discovery, development, and delivery of new medicines predominantly targeted at developing countries and emerging economies is either undeveloped, or on a much slower track, compared to the pipeline of pharmaceutical and other health technology products for more profitable markets. This is a major challenge and a solution needs to be found. This dissertation has demonstrated that 'win-win' solutions, that are sustainable from a socio-economic perspective and that are not solely depended on corporate goodwill and philanthropy, can be created.

Improving the supply and at the same time guaranteeing access to novel and existing medicines in developing countries poses indeed an enormous challenge. The scale of the problem, as well as the technical innovation challenge, is simply too large for any stakeholder to act on, while expecting to succeed in any other projects. We have demonstrated that only a holistic approach and a concerted effort will work. All stakeholders have a role to play: (i) Pharmaceutical companies must actively invest in research of neglected diseases, as better preventive tools and treatments are urgently needed, and seek to make these medicines as affordable as possible to the world's poorest countries in a sustainable manner; (ii) Wealthy nations must provide more development aid and keep their promise of allocating $0.7 \%$ of their GDP to international development - new funding sources and mechanisms are coming through but funds are still inadequate; (iii) Developing countries themselves must show genuine political commitment to prioritizing health in their national budgets - this includes addressing stigma and improving affordability by removing import tariffs on medicines and harmonize regulatory requirements. While national governments have the primary responsibility for delivering healthcare, supported by intergovernmental agencies, and non-governmental organizations (NGOs), the pharmaceutical and biotech industry can play a significant role. Access to new and existing medicines for people at the bottom of the pyramid should be firmly integrated into corporate policy and become one of the cornerstones of business strategy.

In this thesis, we have endeavored to gain a much deeper insight into the R\&D 'riskinvestment-incentive' relationship by focusing on the association between a number of risk factors (technical, market and financial) and the decision to invest in the discovery, development and production of medicines holding great potential benefit for developing countries. We have been closely involved in the design, development, and testing of new economic incentive systems that have the potential to stimulate, accelerate and complement R\&D in the field of neglected diseases such as malaria, tuberculosis, HIV/AIDS, and other 
tropical diseases. To achieve this ambitious goal of developing medicines for developing country diseases and accelerate access to them, the national governments of industrialized and developing countries, together with supranational agencies, academia and public medical research institutes, as well as the research-based pharmaceutical and biotech industry, must work together to create even stronger partnerships and funding to support these grand projects. This may in the first place require a paradigm shift for both the private and public sectors. Issues can be resolved through an improved mutual understanding of each other's viewpoint and the willingness to reach a consensus. For instance, in the debate about stimulating the availability and use of either innovative pharmaceuticals or generic medicines, the fact simply is that we need them both. Hence, we must encourage qualitycontrolled local manufacturing of generic versions of critical medicines, like antiretroviral agents to treat HIV infection, since this has proven to be the most efficient way to provide large-scale treatment at hugely discounted prices. However, without the development of novel and dramatically improved medicines that address either existing or unmet medical needs, there will be no follow-on generic medicines. It is, therefore, equally important to provide incentives to firms to continue developing second and third generation products to secure both the short and long-term benefits of treatment of HIV-infected people globally, and to overcome resistance against the first-generation medicines.

This book proposes a conceptual framework and practical model of how constructive collaboration can be achieved in pharmaceutical and biotech R\&D between the public and private sector. We also developed an integrated analytical decision model that calculates the resources that are needed to fund this endeavor. Furthermore, we have argued that patents are crucial to pharmaceutical innovation and that without them there would be no financial incentive to fund the cost of discovery and development. Protection of intellectual property rights in conjunction with tiered pricing arrangements are key elements in maintaining the commitment to develop medicines for diseases that are prevalent in developing countries. Tiered or differential pricing is the commercial practice of using different price levels that take into account the purchasing power of the customer (or country) and the size and timeframe of orders. Although - at the nominal level - prices appear unequal, the system is equitable because by and large countries pay according to their own purchasing power. The joint costs and corresponding capital investments in pharmaceutical research and development are thus charged in a modulated fashion: a higher than proportional part of the fixed costs is carried into the higher prices charged to wealthier countries. Prices in poor countries or population segments carry no or a lower part of these charges. So, research and development costs are recovered primarily from wealthier markets, allowing poorer markets to benefit from lower price levels.

It is important to strike a balance between the public health concerns and the interest of the patent owner. This balance generally exists within the patent system. Some of the discus- 
sions around patents are based on misunderstandings or misconceptions. Most stakeholders agree that patents form an essential role in stimulating the development of essential medicines by offering incentives for investing in expensive and long-term R\&D. Without patents, the existing anti-AIDS drugs would not have been produced, and new and better medicines that are needed to overcome the increasing resistance of the HIV virus would not be developed. Less appreciated is the fact that the patent system requires significant disclosure of the information leading to the creation of new and similar medicines that compete with each other. Through this quid-pro-quo agreement between society and the inventor, key information on the invention is made available to the public and to other researchers, thus adding to the general body of accessible technical knowledge in the world. Without the patent system, this key technical information would remain unavailable or even secret. As a result, many new product innovators, health researchers and pharmaceutical companies that depend heavily on this information for their work would have to reinvent the wheel.

What is more, patents are not the determining factor in the pricing of medicines. The price of a medicine depends on a number of factors, including the cost of research and development, production, distribution, and the value it brings to the marketplace. Even reducing the price to the costs of basic manufacturing and distribution alone does not guarantee medicines will be within reach of patients in least developed countries. Moreover, this methodology of price setting makes no provision for recouping the cost of R\&D. After all, when the original innovator's patent expires, the protection ends and the product enters into the public domain, which means that anyone can freely use or reproduce the product without having to ask for permission or pay license fees. Importantly, during the patent period, anyone can obtain a patent on an improved invention on the basis of the patent of others. The patent system is designed to allow new entrants to compete with existing patent holders. Patent protection can also be tailored to suit local conditions using the flexibilities in international agreements such as TRIPS so as to maximize access to innovative products. A related problem is that in many developing countries access and affordability is significantly affected by high taxes and tariffs. Eliminating the tariffs imposed on medicines and medical devices will therefore have a significant impact on reducing prices. Stakeholders should also recognize the threats from counterfeiting of medicines in the developing world, and ensure that appropriate early warning systems and regulatory procedures are in place and enforced. Counterfeit medicines waste scarce resources and may kill people.

Despite its many advantages, however, the existence of patents is not sufficient in itself to invest in the research and development of medicines which aim it is to combat diseases primarily ruining the lives of thousands of individuals in developing countries. For that purpose, a new and performance-based economic incentive mechanism - named 'Advance Market Commitment' (AMC) - has been designed and introduced to the international 
community. Through the AMC system the more affluent $\mathrm{OECD}$ nations guarantee a viable market by means of binding contracts to purchase a newly developed medical product on behalf of developing countries if it meets predetermined criteria. We extensively tested the concept and the robustness of the AMC system by running a series of computerassisted scenarios. The objective was to measure the impact of key parameters of the 'riskinvestment-incentive' equation governing pharmaceutical $R \& D$ on neglected diseases. We have not only presented evidence that the newly designed economic incentive system, $A M C$, increases the incentive for $R \& D$ into diseases of the poor, but also acts as a supplementary incentive scheme to patents and research grants. Based on these findings, hypotheses have been formulated on how to significantly improve the design of the AMC incentive program. Further experimentation in practice with this mechanism will take place over the coming years since it will be applied to different disease areas. These field experiments may yield anticipated and unanticipated outcomes, some positive and some not so positive. However, we firmly believe that the opportunity for this new incentive tool to succeed is high since it has already gained endorsement among public and private stakeholders. Several countries have announced support for testing the new approach. The first AMC pilot case, announced in February 2007, is now being applied to a novel pneumococcal vaccine.

We recommend that governments not seek to own or control the disposition of intellectual property developed by contestants in the course of seeking the AMC incentive (in full or part depending on being first on the market with a better product to capture market share). The exception would be if the winner(s) of the AMC choose(s) not to put the winning innovation into commercial practice within a reasonable time period, and/or if the firm declines to supply developing country markets long-term at low cost after the AMC fund has been depleted. In that case, the winner would be required to have entered into good faith negotiations with other manufacturers for a license to be awarded under terms and conditions typical for the industry. We counsel against requirements that AMC winners make the intellectual property underlying their innovation available to the world at no cost or on concessionary terms. At the extreme, such a requirement will most likely discourage potential entrants from participating in innovative activities for fear that if they win, they lose control over their innovations. We do recommend that governments and private sector decision-makers not only embrace the challenge of finding novel cures for developing world diseases, but regard this as an opportunity to explore new modes of research and innovation support that may prove valuable for developing countries and would-be innovators. In that regard, we have examined a number of alternative innovation systems to stimulate and reward innovation, and to lower the barrier to more collaborative and less competitive efforts. 
Potential alternative approaches include creating open access enterprises and patent pools, and de-coupling the rewards for invention from the subsequent pricing of the products. The problem with awards however lies in determining what fair compensation really means and how the prize is calculated. Due to political pressure, the intrinsic value of the new medicine is likely to be undervalued and the payback diminished by politicians. A controversial alternative is the patent buy-out system, in which governments purchase the patent rights of the innovator(s). While there are difficulties in this system related to the problem of (not) knowing how much to pay and to which innovator, under which conditions, and by which government - the chief shortfall in patent buy-outs is that they basically do nothing to change the incentive for the individual researcher and/or firm. Ironically, in a IP buyout system the original innovator or firm is actually discouraged from further carrying out his/her own project and, in effect is stopped short by governments to serve the ultimate customer and patient - unless of course he/she is prepared to buy his/her own patent. In our opinion, patent buy-outs are thus ineffective as a solution because they do not create an incentive for innovation-driven entrepreneurs. They are likely to act as a disincentive, and may actually discourage investment in complex, risky and lengthy $R \& D$ projects. What is more, innovators will likely try to pass on the risk of final product testing - and finding out it does not work well in humans - to the government after the medical award has been received. As a final point, we are more optimistic about the fiercely debated concept of 'patent pooling' and 'open-source innovation', especially if applied in upstream pharmaceutical R\&D. These concepts warrant further theoretical and practical research by scholars and practitioners interested in accelerating medical innovation in the area of neglected diseases.

The findings and implications in relation to public policy and corporate strategy can be summarized as follows:

1) Healthcare issues were initially not included in the G8 macro-economic agenda, but have become central to discussions at the international forum, especially in the context of international development goals as summarized in the MDGs to reduce poverty.

Access to health services and products is one of the world's most pressing social challenges. The difference in the worldwide level of health care stems from differences in the availability of international financial, human, and scientific resources to fight illnesses and epidemics. The health crisis that predominantly affects Africa, Asia, and Latin America can only be overcome by a concerted effort between governments and non-governmental agencies. The G8 has been paying more attention in the new millennium to global health issues, adopting bolder plans and greater financial commitments to support efforts to implement the United Nations MDGs. Ill health has been proven to be expensive for both the individual and society as a whole. It is often a result of poverty but can also be a cause of poverty. For patients it means loss of quality of life, loss of earnings and shortened life expectancy. It 
places a great burden on families - the need to care for sick relatives can reduce attendance at work or at school. For governments, employers and tax payers it represents increased healthcare costs and loss of workforce productivity. Diseases such as HIV/AIDS, tuberculosis, malaria, and looming epidemics like avian flu grossly impede nations economically and socially, and are a threat to sustainable development. These epidemics continue to predominantly affect developing countries causing human tragedy, deepening the poverty level and reversing the relatively small gains in life expectancy made over the last 30 years. Although medical-scientific breakthroughs are by no means the answer to all problems for low-income countries, they will without doubt help achieve the MDGs to reduce poverty through the delivery of better health for all, which leads to increased productivity, economic growth and improved trade. MDG health strategies must aim at intensifying efforts in medical research, upgrading methods of preventing and treating diseases, and developing or improving health care delivery infrastructures.

2) Infectious diseases account for $7 \%$ of the burden of diseases in affluent countries, but $68 \%$ in Africa. More than 6 million deaths annually are caused by three conditions alone: Malaria, TB, and HIV/AIDS - almost all victims live in the developing world. These deserve to be prioritized.

If infectious (communicable) diseases throughout the developing world were reduced to levels comparable to those in industrialized countries, much of the global difference in life expectancy and mortality would disappear. The range of products existing today are not effective enough to tackle the killer infectious diseases, nor sufficiently robust to newly emerging drug-resistant strains to offer a rapid, sustainable solution in fighting these illnesses through treatment and prevention. Disease prevention can however play a critically important role in reducing the global disease burden and the economic costs of ill health. Immunization plays a major role and is the cornerstone of public health programs around the world. From a health economist's perspective, immunization of a population cohort is not purely a health sector issue. It has resonance for wider macro-economic planning and for long-term socioeconomic progress due to the positive external effects it provides to the rest of the community. Such prophylactic products to shield populations from diseases and that have the potential to stop for instance the ever expanding HIV/AIDS pandemic do not yet exist, and no long-term, life-saving inoculation against malaria is available either. Before any powerful preventative medicines and improved therapeutic drugs to combat diseases like HIV/AIDS, TB, and malaria can be developed, significant scientific, technical and financial obstacles must be overcome. Without intensive efforts from basic scientific research through technical product development, new innovative medicines needed primarily in the developing world may be considerably delayed. Much of the advanced scientifictechnical knowledge, experience and expertise required for being successful in research, development and production of medicines of high-quality, safety and efficacy is residing in the private sector. Mobilization of these industrial resources is needed especially for the 
downstream stages of product development and engineering, as well as for the scaling up of manufacturing capacity. These critical stages happen to be the more costly activities and require the ability to manage wide-ranging resources, that is, high-tech infrastructure, highly skilled people, and the indispensable risk capital to invest in complex pharmaceutical projects of long duration.

3) The economics of new medicines discovery, development and delivery are challenging. Developing a new medicine can take on average 7 to 20 years - assuming success at each stage of the process - and each R\&D project may cost several hundreds of million US dollars.

Pharmaceutical R\&D is a risky and expensive proposition despite all the modern tools available and the progress made in biological, chemical and physical science and technology. It usually takes between 7 and 20 years to develop and produce a novel preventive or therapeutic medicine, and this endeavor may cost up to US\$1 billion in capital outlay. Fundamental biomedical science and research leading to the discovery of new mechanisms at the cellular and molecular level increasingly require the use of more sophisticated and expensive tools like genetic mapping, molecular biology and engineering, nanotechnology and proteomics. Developing a chemical or biological pharmaceutical 'lead' compound to the point of scientific 'proof of concept' - that is, proving that the compound under investigation has the intrinsic ability to cure, or if it is a vaccine to stimulate protection from a target disease or condition - remains a high risk proposition. Public private partnerships between specialized laboratories at universities, public institutions and industry are often needed to elucidate these scientific mechanisms. For some high priority diseases, and in particular those prevalent in the least developed countries, basic data are not available, and the scientific uncertainty is increased by a range of factors including dearth of information on the pathogenesis of the disease, or the lack of animal models that accurately mimic the human response. Publicly funded 'basic' research that is often carried out by universities and research institutions is therefore a vitally important component in the underpinning of the more applied work that is undertaken by private-sector pharmaceutical and biotech companies. The findings of any basic discovery should be made available as a public good through free information and knowledge sharing. This in turn creates a foundation for further product design and development, clinical testing, industrial production, and delivery. Moving progressively along the product pipeline, that is, from an 'upstream' scientific idea to the 'downstream' development and production of a pharmaceutical compound is a process that entails scientific uncertainty, unpredictable timelines, and substantial development costs, with the potential for failure at each stage of this protracted pathway. Finally, the transfer of expertise and technology provided by transnational companies operating in developing countries is just as important to sustain supply. Businesses should consider making a considerable development-related investment by transferring technology and 
management expertise that helps improve local staff qualifications. This enables a basis to be established for effective economic and social development.

4) The pharmaceutical and life sciences industry has a business model that heavily relies on incentives provided by limited market exclusivity resulting from intellectual property protection. Nonetheless, IP rules are not the fundamental barrier to medicine access.

We have argued that robust IP protection is essential to incentivize pharmaceutical $R \& D$. Pharmaceutical and biotech R\&D for the most part takes place in the industrialized countries and emerging economies. Quite understandably, there is an increasing volume of $R \& D$ and manufacturing in specifically those countries that have created a favorable economic and regulatory environment. We recommend to encourage pharmaceutical and biotech foreign direct investment (FDI). This can start with transnational firms that already play a significant role in trade and technology transfer via the interaction of the parent firm and affiliates. Through productivity enhancing applications of new technologies, these investments have positive effects on the national economy. The reality however is that trade and investments are often hampered by opaque and bureaucratic processes and by the difficulty of properly enforcing contractual claims. Cooperation should promote better governance in areas pertaining to the economy, such as a functioning fiscal and customs administration system, clear private property rights and an independent and effective judiciary. Contrary to popular belief, the prevailing IP rules are not the fundamental barrier to access to medicines. Of the 325 medicines on the WHO's Essential Medicines List, over $95 \%$ are off patent and yet one-third of the world's population has no reliable access to these medicines. India, for example, has the best developed industry of generics in the world and until recently had no IP protection for pharmaceutical products. Yet, access to antiviral drugs to combat HIV/AIDS in India is arguably not any better than in Africa. Lack of healthcare infrastructure and resources are the key problems; and this is where the focus should be, rather than on IP. Even so, reports from NGOs continue to overstate the importance of IP in access to medicines and fail to recognize the importance of IP as an incentive to biomedical $R \& D$. Abolishing patents may represent a significant disincentive, and act as a deterrent for attracting much needed private investments. Similarly, compulsory licensing is another attempt to weaken intellectual property rights. Compulsory licenses are a legitimate policy option, but LDC governments should not resort to it as a routine policy tool or for local commercial advantage. Rather than unilaterally using compulsory licenses to increase access to medicines, we believe it would be more effective to engage in a dialogue with industry and stakeholders to find sustainable ways to address health supply issues, if needed through voluntary licensing. As a last resort, there is the Doha Declaration on the TRIPS Agreement and Public Health that allows developing countries to take measures to limit IPR, including for emergency and public health priority purposes. Each member is free to determine the grounds upon which compulsory licenses 
are granted, and the Declaration clarifies that each member has the right to determine what constitutes a national emergency or other circumstance of extreme urgency. The Declaration provides the least developed countries with an extension of their transition period for protecting and enforcing the patents and rights with respect to pharmaceutical products until January 2016.

5) Building up pharmaceutical and biotech production capacity, in addition to conducting multi-country and multi-population clinical trials, carries a high fixed cost and represents a major sunk cost to innovation-driven manufacturers of health products.

Building up production capacity takes time and occurs only when manufacturers perceive relatively low risk. Due to the complexity and scale of new medicines development, pharmaceutical and in particular biological manufacturing facilities require large investments early on. Manufacturers must allocate the necessary funds years before a new compound is projected to enter the market, and often before data is available that shows the effectiveness of the product. At times producers must make investment decisions before a new product's potential market is assured, or even before its clinical efficacy and safety have been established to a level sufficient for marketing licensure. Once a pharmaceutical or biological manufacturing facility has been built, its production capacity is relatively fixed. It is difficult to quickly scale-up and expand the production of an existing medicine, and even more difficult to change totally the focus of a facility, as changes to the production process must be validated and approved by a range of regulatory authorities. Scaling up product filling lines can take anywhere from two to five years. Clinical testing in humans and particularly multi-country and multi-population clinical trials represent the single largest incremental cost manufacturers face when bringing a new medicine to the market, be it in the industrialized or developing world. Clinical testing programs in humans constitute a higher risk, because their costs are sunk, not flexible, and cannot be recouped. In research-based companies, every phase in clinical trials in humans (Phases I, II, III) is often a 'go/no go' decision point, and can be pivotal in a firm's resource allocation and multi-pronged decision-making process with regard to capital budgeting. As soon as the new medicine is licensed for general use, information concerning potential adverse reactions continues to be collected, and must be reported to both the authorized national centers of pharmacovigilance, and to the original manufacturer of the product. Additional studies are conducted to monitor any rare or previously unseen side effects of the medicine that may not have surfaced during previous field trials. Clearly, the wider the coverage in a given population, the more likely rare reactions will appear. For this reason, post-marketing surveillance is deemed essential by authorities. It is recommended that equally stringent procedures are followed by all manufacturers, because they guarantee the use of high-quality, safe and effective medicines around the world. 
6) Companies use a formal decision process for managing projects based on a 'stageand-gate' approach. Real-option valuation methods are recommended to guide the allocation of resources in a project. Assessment methods based on decision tree analysis offer advantages over other methods.

Pharmaceutical and biotech companies, faced with increasing development costs and global pressure on pricing, must make difficult choices regarding which products in their pipeline to pursue with the limited resources they are able to mobilize. Given the long development timelines and high risk of failure, companies feel compelled to select products that are likely to generate real market and consumer demand, and for that reason may offer a higher return on their capital investment or ability to attract venture capital. As pointed out before, effective intellectual property protection through patents enables inventors, research-based MNCs and local firms alike, to recoup their investment through a limited period of exclusive marketing rights. While guaranteeing intellectual property rights is an important and necessary incentive mechanism for stimulating private investment in pharmaceutical $R \& D$, they are not expected to trigger investment in itself. A more comprehensive risk management process is needed. Therefore, the multinational companies, as well as the mid-size companies and even the smaller biotech start-ups, follow a strategic portfolio process. This includes continuously measuring and optimising value and risk for each opportunity across the pipeline. Limited resources - staff, equipment, and capital - will force them to make tradeoffs. We have provided evidence that companies and investors of risk capital are likely to accept a number of key risk factors when examining the decision and extent of financing for a new research and development project. In this formal process, the independent risk factors have been clustered into the following three categories: (1) Technical Risk Factors - including pharmaceutical project parameters such as the likelihood of success in conducting clinical trials, seeking regulatory approval, and scaling up production capacity; (ii) Market Risk Factors - including the size of the market, expected market penetration, and market competition; and (iii) Capital Risk Factors -depending principally on the correct selection of time discount factors, which then become the hurdle rates used by investors to appropriately reflect the capital investment risk of either the project, business unit, or industry respectively.

7) We constructed an R\&D 'risk-investment' model that explains the cause-effect relationship between a new medicine project's independent variables (technical, market, and financial risks), and the dependent outcome (the decision to invest, or not to invest).

Decisions to invest in pharmaceutical $R \& D$ are complex and based on a variety of considerations. We designed a management decision model to compare a number of investment strategies with their respective risk factors in order to calculate the expected return-oninvestment outcome under uncertainty. Besides the scientific risks inherent in the development of the new medicine, market considerations play an important role at each stage of 
the process. A candidate pharmaceutical product moves progressively from discovery to testing, licensing, production, distribution, and delivery. Given the irreversible nature of this R\&D process and associated investment decisions, as well as the uncertainty of the market environment in developing countries, we recommend using a stochastic model rather than a deterministic model for informed decision-making. The method uses computer simulation modeling to assist corporate executives and public policymakers in carrying out a risk-adjusted investment appraisal. This evaluation method provides real options to bail out of the project if at a certain point in the R\&D process this looks opportune, accordingly reducing the risk by cutting potential losses. The method can be applied to any new medicine research and development project, including $R \& D$ projects aimed at serving industrialized and established market economies only, as well as those projects targeting primarily, or even exclusively, the least developed countries in the world. For this reason the proposed decision-support tool enables decision makers to compare a number of geographic strategies at a worldwide scale with their respective risk factors and investment outcomes. To gain supplementary insight into the dynamics of the interaction between the different variables of the model, we have scrutinized the dimensions of each cluster of key risk factors (i.e. technical, market and financial), and placed each of them separately under the microscope. Although the miscellaneous risk factors are considered to be independent, in combination they have the capability to collectively predict a firm's decision to invest (or alternatively not to invest) in a particular pharmaceutical $R \& D$ project. The investment scenarios and decisions points can be visualized using the decision tree analysis technique in combination with Monte Carlo risk assessment. Eventually the 'risk-investment' model, as proposed, is designed as one single analytical framework that incorporates the influence of public funded incentive systems. These incentive systems - termed 'push' and 'pull' - have a positive influence on the key parameters underpinning a firm's decision to invest in risky, complex and expensive R\&D projects. We recommend that both private and public sector policymakers use this integrated risk-adjusted model to evaluate the effect of different economic incentive schemes. Several incentives mechanisms are currently being designed and will be further developed in the near future, with the objective to stimulate greater involvement of the private sector in the development of novel medicines for use in the developing world.

8) For diseases prevalent in the developing world, lack of credible markets is one of the major barriers to entry for MNCs and local companies alike. This is true, regardless of whether these firms have a broad or narrow scope in managing $R \& D$ portfolios.

In order to shape a social contract between businesses and the community, private companies must work with other stakeholders to address the important problems that society faces. We urge companies to treat corporate social responsibility (CSR), not as a luxury, but as a true responsibility. On the other hand, this in itself will not be enough to increase access to medicines for diseases mostly endemic in the developing world. A sustainable 
commitment from the private sector to provide these medicines to the developing world has hitherto been compromised by the potential of inadequate returns. In the case of neglected diseases of the poor in LDCs, the limiting purchasing power of governments and the expected poor returns on investment make attracting venture capital for the private sector particularly difficult. The problem of private companies to develop medicines for diseases that are prevalent mostly in the developing world is sometimes referred to as 'market failure'. Instead of being an economic 'market failure', it actually represents an affordability problem. In spite of the vast number of sufferers in the developing world, these countries do not represent a sufficiently attractive market that allows transnational or even local pharmaceutical or biotechnology companies to recover the initial investments, let alone make a profit on these programs. Many of the companies operating in this space frequently use public supported grants to initiate this type of $R \& D$, but their funding often runs out as products progress through the increasingly more expensive stages of development (encompassing clinical testing, registration, manufacturing, distribution and delivery). While external financial support that is made available through direct 'push' funding,may reduce the cost and risk of pharmaceutical product development, and has so far been the driving force behind the increase in $R \& D$ output, it will once again in itself not lead innovators and research-driven companies to allocate sufficient resources to guarantee the development, distribution and marketing of products for LDC markets. Both multinational and local firms may face many demands and unmet needs, but they will not pursue $R \& D$ projects for the developing world unless they are seen as significant or reliable opportunities. If the demand is uncertain or too small, the opportunity cost of allocating scarce resources from other project teams is too great, particularly when large investments are needed to tackle complex diseases of the poor worldwide.

9) The risk and uncertainties related to the inexistence of markets in LDCs are strongly affecting the development and availability of new medicines for these areas. This state of affairs can be altered by 'technology-push' and 'market-pull' incentives.

Over the last few years both governments and the public are increasingly focusing on the need to improve access to medicines which has led to the discussion of a wider range of potential public policy measures to improve incentives for $R \& D$ in neglected therapeutic areas. To that end, a critical analysis has been performed of the advantages and drawbacks of some existing and new public incentive mechanisms that are expected to stimulate pharmaceutical R\&D on LDC-diseases. Historically, the public sector preferred to invest in 'push' incentive mechanisms, particularly those stimulating basic research and some early product development. Less work had been done around 'pull' incentive mechanisms that are to create a viable market which, in turn, would attract investment. We have argued that intellectual property rights (IPR) conferring copyright, patent or trademark protection in theory provide an essential incentive for private sector investment in pharmaceutical research and development. However, this measure in itself is not enough. Therefore, 
promising new ideas about novel incentive schemes need to be thoroughly evaluated and tested. For instance, special public purchase funds to help develop preventative and therapeutic medicines against HIV/AIDS, malaria and TB may resolve the problem, at least partially. Under such an external funding scheme, governments would guarantee to buy vaccines and drugs for developing countries, at subsidized prices, from any firm that develops a safe and effective breakthrough product that meets pre-determined specifications. This scheme would provide private sector investors with the financial incentive that it is now missing. Through this commitment, donor governments would incur the expenditure, only if and when a medical product that is proven safe and effective has been successfully developed. Another economic incentive system that has generated great interest relies on extending the period of intellectual property protection. This scheme entails granting companies exclusive rights to market one of their existing products over a longer period. It has been termed 'roaming exclusivity', which means transferable patents and therefore offers little advantage to SME firms that have a limited, or no, commercial product portfolio. Other more classic 'push' incentive mechanisms like, for instance, tax credits on R\&D remain very important. They are also complementary to novel economic 'pull' incentive schemes that aim to stimulate and accelerate R\&D - the latest of which is the Advanced Market Commitment (AMC).

10) Comprehensive public pledges are needed to implement a novel incentive system termed Advance Market Commitment. This system catalyzes industry investment and can significantly stimulate pharmaceutical and biotech R\&D on developing-country diseases.

An Advance Market Commitment (AMC) is a new economic incentive for research-based companies to take on the risks associated with bringing promising medicines from the laboratory to the poorest populations. By definition, an AMC for a medicine against a disease affecting primarily the developing world is a commitment by governments from more wealthy countries to finance the purchase of a medicine not yet available up to an agreed subsidized price, if and when an appropriate product has been developed. A twostage pricing model is proposed. Initially the subsidized price will be paid by donor governments with a relatively small co-payment from the developing country that uses the product. In the second stage, after the product's research and development costs have been recovered, a lower, more affordable, so-called tail price would be paid by the developing country. Although the AMC is essentially a public health financing tool, the approach greatly helps to replicate market forces. In other words, the system makes money available only if companies or other institutions succeed in producing the desired medicines. As in any other business, private companies will have to decide individually if they are able and willing to take on the risks of making the large investments that are needed to take a candidate medicine through the various development stages, satisfy all regulatory requirements, and deliver a safe and effective product that generates sufficient revenue to justify its 
initial capital outlay. Of the different 'pull' incentive mechanisms for stimulating $R \& D$, advance market commitments (AMC), if designed properly, has the intrinsic potential to meet the goals of (i) creating a market 'pull' incentive for commercial investment in R\&D for until now neglected therapeutic areas; and 2) ensuring rapid uptake of, and affordable access to, new medicines in developing countries, the moment the product has been marketed; as well as 3) introducing market and price competition among suppliers while leaving space for the development of improved second or third generation products. Indepth interviews and roundtable discussions with key stakeholders, including senior executives of leading pharmaceutical and biotech companies, have indicated that an accurate design of AMC programs is a prerequisite for ensuring wide-ranging acceptance and adoption by stakeholders. Therefore, we recommend that the AMC economic incentive system is made a critical component of a package of incentives to attract public and private investment in endemic disease categories.

11) The AMC offers an incentive for accelerating the early and late-stages of $R \& D$ provided that the remaining design-issues are resolved. We developed an integrated 'risk-investment-incentive' model to calculate the minimum size of the AMC subsidy.

The size of the incremental AMC subsidy that is required depends on the global disease prevalence. If an illness is prevalent in rich and poor countries, a system of tiered pricing can be applied where the joint costs of research and development are largely paid for by the industrialized countries. In the case of a characteristic tropical disease like malaria, the investment will have to be regained by the developing country markets, and consequently a larger fund would need to be created. To become an effective incentive system, we recommend that a number of currently outstanding issues with regard to AMC design are addressed. We have proposed solutions for: (1) adequately calculating the minimum size of the AMC subsidy needed in view of the market uncertainties; (2) determining the longterm pricing policy, that is, the price applied during the post-AMC supply period; (3) incorporating variances in attitudes toward risk-taking between individual firms; and 4) ensuring compatibility with voluntary differential pricing to achieve equity in world-wide health and development. In order to factor in the different risks and uncertainties, and determine the threshold level for an AMC fund, an analytical framework has been developed that assists decision-makers in calculating the 'risk-adjusted' $R \& D$ investment to be made in each of the LDC disease categories. We recommend a 'zero-sum' approach to determine the minimum size of AMC funds that are necessary. The impact of the technical, market and financial variables on any firm's return-on-investment are measured through simulation using stochastic 'Monte Carlo' analysis. Input data for each of the parameters is obtained from triangular estimates made by experts following a Delphi expert consensus process. The model exemplifies how different risk aversion profiles and attitudes practiced by pharmaceutical company executives, in turn, being supervised by their stakeholder investor-boards, influence the selection of $\mathrm{R} \& \mathrm{D}$ projects targeting poverty-related diseases. 
The model can be applied to a range of projects at different stages of development, provided scientific-medical 'proof of concept' has been delivered. From then onwards probability estimates and decision-tree simulation analysis can be used to calculate the subsidy. In true markets, however, the price is agreed through a purchase negotiation and typically reflects the value of the product. Price is usually a function of the quantities purchased and the duration of the agreement. In order to succeed, AMCs have to be complemented with extra commitments by partners and countries to make certain that demand forecasts are translated into actual demand. To allay fears that a special purpose production plant would not be used because demand does not materialize, government donors should commit to buying a specific volume.

12) The world's next pandemic may be sparked by bird flu. This would affect individuals in the developed and developing countries. A public private partnership to support biomedical innovation in this area is needed to anticipate this looming crisis.

Pandemic influenza (flu) has in the past occurred at irregular and unpredictable intervals and has been associated with substantial human suffering, mortality, and huge direct and indirect economic costs. A new virus (H5N1) at the moment kills birds, but is widely seen as the candidate to trigger a pandemic in humans. The WHO stated that a worldwide outbreak is a matter of time and considers this to be one of the largest public health threats. Preventative medicines that avoid, or at least mitigate, the consequences of this infectious disease caused by strains with pandemic potential do not yet exist. In this case, pharmaceutical companies, even more so, must make important decisions about investing in $R \& D$ on an uncertain but possibly dramatic disease. Today, very few companies have the production capacity and required bio-containment facilities to produce virus-derived products. The existing biological production methods and processes are unlikely to deliver enough, and in particular quickly enough, pandemic-strain vaccines to stop a pandemic outbreak when it occurs. Building extra capacity to meet the world's needs would take several years and require huge investments. We have looked into pathways for managing these risks and uncertainties. We propose an integrated framework for pandemic vaccine development based on public-private partnerships. The framework consists of economic 'push' and 'pull' incentive mechanisms to stimulate R\&D and global supply in this area. AMC funding will not help in this case because there is no market for 'pandemic' vaccines before the pandemic takes place. Alternatively, disease prevention strategies can be used that make use of novel product formulations that offer cross-protection against multiple (possible) pandemic strains. If these products are stockpiled or administered prior to any outbreak, they might avert the worst effect of this looming threat. Thus, substantial investment in research, development and manufacturing of pre-pandemic vaccines is essential. If stockpiling or vaccinating high-risk groups in the pre-pandemic era is envisaged, mass-production could be spread over a period of several months and years at a time when there is no panic. Accordingly, production surge capacity becomes far less a constraint. We recommend that 
governments consider actively supporting these prevention-oriented $R \& D$ programs rather than waiting for disaster to strike and having to pay for treatment and economic damage after the event occurred. To guarantee an equitable distribution across countries, governments in the developed and developing world should contribute to building an international strategic stockpile of pre-pandemic vaccines in collaboration with the United Nations.

13) Alternative innovation models that spur interest in R\&D on diseases affecting the developing world have been examined: (i) A Global Medical R\&D Treaty, ii) An IPR Buy-out \& Prize System, (iii) Patent Pooling \& Open-Source Innovation, and (iv) New Public-Private Partnerships.

A Global Medical Research and Development Treaty (MRDT) has been proposed in the literature and at conferences. If such MRDT concept is endorsed it would require that every government sets aside a fixed percentage of its national output to finance globally defined pharmaceutical $R \& D$. But we found no evidence that such a treaty would address and reduce the lack of innovation in the area of neglected diseases. The proposal unnecessarily complicates the matter and is unlikely to be accepted by the majority of stakeholders for reasons that have been explained in the book. In the same way, offering a prize or award would have serious drawbacks in that holding them does not guarantee that a viable, affordable medicine will result. In this scheme, governments, sponsors and politicians would have an active role in picking 'winners' from an early stage onwards and backing them throughout the entire process. In our opinion, the objectives of the proponents of a Prize Award or IPR Buy-out approach would be better served by a system of Advance Market Commitments (AMCs). Furthermore, we recommend that systems based on open innovation and patent pooling deserve much more attention. Patent pools are likely to have the ability to attenuate the monopolistic nature of patents, while creating new opportunities for innovation. The existence of a patent pool to facilitate early $R \& D$ in therapeutic areas of interest to the developing world, would eliminate the need for constant renegotiating of licensing rights since new innovations are made by one or more members of the pool. This would represent a welcome reduction in coordinating costs. However, whereas in principle some corporate risks can be mitigated by using patent pools, this could raise concerns about antitrust. Hence, they should not be treated as a universal remedy to resolving IP issues. Quasi-compulsory patent pools should be regarded with as much caution as the compulsory licensing measures their advocates hope to substitute them for. Lastly, public private partnerships like the 'Innovative Medicines Initiative' (IMI) should be encouraged because they require public and private-sector partners to actively work together. The IMI initiative, as supported by the European Commission in cooperation with the European Pharmaceutical Industry Association advises each of the participants to focus on their core competencies. What is more, it offers a unique opportunity for collaboration between patient organizations, universities, hospitals, regulatory authorities, and pharma- 
ceutical and health technology companies. Of the collaborating partners, the large MNCs will have to fund their own contributions $100 \%$. Furthermore, the initiative is not expected to deliver new medicines per se. The IMI delivers common technical tools that catalyze the innovation process. For that reason it represents a new pharmaceutical and medical innovation paradigm.

In summary, there are a number of promising alternative innovation models that could be used in addition to the proposed AMC 'pull' economic incentive mechanism, particularly in specific areas of the new medicines discovery and development process. However, few of these new incentive mechanisms to support new medicines $R \& D$ investment - if any - are able to replace the patent-based pharmaceutical $R \& D$ process wholesale, especially if patents are used in conjunction with AMC economic incentives and tiered or differential pricing. We therefore strongly advocate using the AMC system in conjunction to tiered piecing wherever possible while respecting IPR as defined under TRIPS. AMC market 'pull' mechanisms are also complementary to existing and more conventional technology 'push' mechanisms that aim to promote early-stage research activities through grants and open innovation. 


\section{SAMENVATTIIIIIN CONCUUSES}

Voor vele ziektes geldt dat hoe meer ze voorkomt in de rijkere landen hoe sneller men een geneesmiddel ertegen zal ontwikkelen. Het gebrek aan de nodige $\mathrm{R} \& \mathrm{D}$ voor ziektes die voornamelijk voorkomen in arme landen is één van de grootste socio-economische problemen in de wereld.

Meer en meer innoverend onderzoek en ontwikkeling (O\&O) wordt gedaan voor aan armoede gebonden 'veronachtzaamde' ziektes. De technische moeilijkheidsgraad om een geneesmiddel te vinden gecombineerd met de geringe koopkracht van armere mensen leidt echter tot een situatie waar de private sector verkiest om zich te richten op lucratievere projecten. De ontwikkeling van nieuwe en verbeterde medicijnen houdt in dat men wetenschappelijke en technische obstakels dient te overwinnen. Zelfs na het nemen van deze horde zal de ontwikkeling van beginfase tot eindfase bijna twintig jaar duren en meerdere zware investeringen vereisen. Nadien dient men het patent te registreren in de landen waar het product zal verdeeld worden. In het traditionele bedrijfskundig model kunnen alle gedane kosten gerecupereerd worden door de verkoop van het product. Investeerders en bedrijven zullen echter steeds een serie van investeringen dienen te doen ongeacht of het product succesvol of onsuccesvol zal blijken te zijn. Deze in het verleden gemaakte kosten vormen dan een risico dat in acht zal genomen worden bij de beslissing tot investeren of niet investeren. Een reëel risico is dat arme landen zelfs niet de marginale kostprijs van het product kunnen betalen. Voeg daaraan toe dat de vraag naar medicatie in deze landen onstabiel is omwille van structurele, budgettaire of administratieve redenen. Dit alles draagt bij tot het ontstaan van een investeringsonvriendelijk klimaat en leidt tot het uitblijven van investeringen in deze sector.

Studies tonen aan dat markt van ontwikkelingsmedicijnen gepercipieerd wordt door zowel de multinationale bedrijven als de plaatselijke farmaceutische en biotechnologische bedrijven als zijnde klein, onstabiel en risicovol. Bedrijven achten het niet waarschijnlijk dat de marktvraag voldoende groot zal zijn om de gedane investeringen terug te verdienen. Private investeringen worden daarenboven ontmoedigd door de mogelijkheid dat politieke druk de bedrijven zal verplichten de nieuw ontwikkelde medicijnen, vaccins of diagnose testen te verkopen aan dumpingprijzen. Het gevolg hiervan is dat vele kinderen en volwassenen in ontwikkelingslanden geen onmiddellijke toegang hebben tot dezelfde nieuwe gezondheids- 
technieken en technologie die in de rijkere landen gebruikt worden. De intrede van deze technieken en technologie gebeurt met een vertraging van 10 tot 15 jaar. De ontdekking, ontwikkeling en implementatie van innoverende medicijnen gericht op gebruik voornamelijk in ontwikkelingslanden is ofwel onbestaande of gebeurt tegen een traag tempo. 'Winwin' oplossingen dienen gevonden te worden om deze problematiek aan te pakken. Men dient echter een duurzame oplossing te vinden voor dit socio-economische probleem, en men mag het vinden van dergelijke oplossing niet toevertrouwen aan louter en alleen de vrijgevigheid van de bedrijfswereld en de filantropische gunsten van derden. De schaal van deze problematiek en de technologische uitdaging zorgen ervoor dat enkel een samenwerkingverband tussen de publieke en de private sector realistische slaagkansen heeft.

In dit boek trachten we een dieper inzicht te ontwikkelen in de farmaceutische $R \& D$ processen en de relevante omgevingsfactoren door ons toe te spitsen op de 'risicoinvestering-stimulans' vergelijking. De nadruk ligt op het causale verband tussen aan de ene kant de interne en externe risicofactoren -technisch, marktgerelateerde en financieel- en aan de andere kant de beslissing om te investeren in de ontdekking, ontwikkeling en productie van nieuwe medicijnen met grote potentiële voordelen voor (voornamelijk) ontwikkelingslanden. De voorbije jaren zijn wij nauw betrokken geweest bij zowel de ontwikkeling als bij het testen van nieuwe publieke incentive systemen die het potentieel hebben om het onderzoek naar malaria, tuberculose, HIV/AIDS en andere tropische ziektes niet alleen te stimuleren en te versnellen maar ook om dit onderzoek aan te vullen. Een geïntegreerd structuurmodel wordt voorgesteld en een analytisch model werd opgesteld om de rekenkundige doelstellingen te bereiken. Om de doelstellingen vooropgesteld in dit boek te bereiken zullen alle betrokken partijen - regeringen van zowel ontwikkelde als van ontwikkelingslanden, nationale en supranationale agentschappen, academici en publieke biomedische ontwikkelingsinstituten, de op ontwikkeling en innovatie gerichte multinationals en plaatselijke farmaceutische/biomedische industrie - dienen samen te werken om op deze manier sterke samenwerkingsakkoorden af te sluiten met als uiteindelijk doel het steunen en sponsoren van de $R \& D$ projecten.

Allereerst vereist dit een anpassing van de denkwijze van zowel de private als van de publieke sectoren. Een beter begrijpen van elkanders standpunt aangevuld door de wil om tot een consensus te komen zal een gunstige invloed hebben op verscheidene belangrijke punten. Een voorbeeld van een van deze punten is de discussie over het stimuleren van zowel de ontwikkeling als van het gebruik van ofwel generische medicijnen ofwel innoverende medicijnen. De simpele waarheid is dat beide nodig zijn. We dienen inderdaad de verspreiding van kwalitatief hoogstaande generische medicijnen te stimuleren om op deze manier ziektes zoals HIV/AIDS beter en goedkoper te kunnen bestrijden. Anderzijds dienen we de ontwikkeling van nieuwe medicijnen te stimuleren. Enkel op die manier kan men het resistent worden van ziektes tegen de bestaande medicatie voorblijven en dus het 
algemeen belang dienen. Ook de generische markt is afhankelijk van nieuwe medicijnen aangezien deze op indirecte wijze hun markt vormt. Dit zal enkel kunnen indien investeerders weten dat ze de kans krijgen om de gedane investeringskosten terug te verdienen -elk succesvol medicijn heeft een gemiddelde ontwikkelingskost van $\$ 800$ miljoen.

Het gebrek aan betaalbare medicatie in ontwikkelingslanden is het gevolg van een gesloten markt, niet van het falen ervan. Op lange termijn betekent het verbeteren van de economische vraag dat de economische ontwikkeling gestimuleerd wordt, dat de belastingstarieven dalen en dat patenten erkend en beschermd worden. Dit te bereiken doel is echter een werk van lange adem. Gefrustreerd door deze langzame progressie wensen anders-globalisten dat ontwikkelingslanden het patentrecht van medicijnen mogen negeren om op deze manier de medicijnen toegankelijker te maken voor meer mensen. Hierop wensen wij wel te wijzen op het feit dat het octrooirecht van cruciaal belang is voor farmaceutische innovatie en dat afbreuk doen aan het patentrecht gelijk staat met het ontnemen van de financiële prikkels om te investeren in R\&D. Voor ziektes die zowel mensen in ontwikkelde landen als in ontwikkelingslanden treft is een verschillend prijsmechanisme ontwikkeld zodat mensen in ontwikkelingslanden medicatie tegen een lagere prijs kunnen aanschaffen. In dit boek tonen wij aan dat de bescherming van de intellectuele rechten gekoppeld aan een verschillend prijsmechanisme voldoende waarborgen biedt voor zowel het stimuleren van innovatie als het dienen van het algemeen belang. Dit prijsmechanisme kan echter spijtig genoeg niet toegepast worden voor medicijnen tegen ziektes die voornamelijk ontwikkelingslanden bestrijdt. Desondanks willen we benadrukken dat het afbouwen of zelfs afschaffen van het patentenrecht zal leiden tot een situatie waar investeerders zich zullen toespitsen op lucratievere markt van andoeningen die enkel en alleen ontwikkelde landen (VSA, Japan en Europa) treft. Het voordeel van het hanteren van verschillende tarieven leidt tot een situatie waarin de meerprijs die gevraagd wordt in ontwikkelde landen de verminderde inkomsten in ontwikkelingslanden zal compenseren. Dit systeem kan echter enkel functioneren indien het systeern van gehanteerde prijzen transparant is en de politieke wil aanwezig is om de verschillende markten van elkaar te scheiden. Het gevaar bestaat dat lokale politieke druk ontstaat die kan leiden tot het eveneens willen hanteren van een lagere prijs zoals die gebruikt wordt in minder bevoordeelde landen. Enkel het bestrijden van namaak en de invoer van de goedkopere medicijnen naar landen met een duurdere prijszetting kan dit systeem van prijsverschillen in stand houden. Zonder deze garantie zal een situatie ontstaan waar mensen uit ontwikkelingslanden geen of minder toegang zullen hebben tot de nodige medicijnen.

Het dient echter gezegd te worden - zonder afbreuk te doen aan het belang van de bescherming van patenten - dat de huidige situatie niet leidt tot het aanmoedigen van het ontwikkelen van medicijnen tegen ziektes die voornamelijk ontwikkelingslanden treffen. Zoals eerder vermeldt is de eenvoudige reden hiervoor dat mensen in ontwikkelingslanden 
de financiële koopkracht niet bezitten om te kunnen voldoen aan de gevraagde prijzen (zelfs rekening houdend met verminderde prijzen). Net om deze situatie te corrigeren is een nieuw financiële constructie opgesteld 'Advance Market Commitment' (AMC) genoemd. Deze constructie werd opgesteld door de donorlanden en betrokken NGOs en creëert een vrije markt door middel van bindende contracten met als doel de aankoop van een nieuw ontwikkeld medicijn indien het aan de vooropgestelde criteria (kwalitatief, kwantitatief,. .) voldoet. In dit boek hebben we via verschillende simulaties de stevigheid en de flexibiliteit van deze constructie getest door middel van het veranderen van verscheidene parameters. Op basis van de resultaten van deze simulaties hebben we verscheidene hypotheses geformuleerd om tot een verbetering te komen van zowel het theoretisch aspect als de praktische kant van de constructie. Naarmate men na verloop van tijd voldoende ervaring heeft opgebouwd met betrekking tot de verscheidene mogelijkheden van de AMC, kan deze constructie ook gebruikt worden om de ontwikkeling van medicijnen tegen andere ziektes te stimuleren. Een evaluatie van AMC na enkele jaren zal onvermijdelijk zowel positieve als sommige minder positieve ervaringen opleveren. Desondanks zijn wij ervan overtuigd dat deze constructie een hoge slaagkans heeft, een optimisme dat wordt gedeeld door de belangenhouders zowel uit de publieke sector als uit de private sector. Verscheidene ontwikkelde landen en privé donors hebben recentelijk hun steun publiekelijk betuigd in februari 2007 en tegelijkertijd een test fase aangekondigd, namelijk het lanceren van een AMC gericht op een pneumokokken vaccin.

We hebben aangetoond dat het hierboven vermeld AMC systeem niet alleen de nodige impulsen zal geven aan de farmaceutische $R \& D$ om onderzoek te doen naar ziektes uit armere landen maar ook kan dienen als supplementair systeem ter bescherming van patenten en onderzoeksbeurzen. We raden ten zeerste af dat overheden invloed uitoefenen op de patenten van innoverende bedrijven die bereid zijn om de nodige medicijnen te ontwikkelen en op die manier het AMC fonds (geheel of gedeeltelijk) te verwerven. Een uitzondering hierop kan zijn de situatie waarin de ontwikkelaar weigert of faalt om na afloop van de AMC het ontwikkelde medicijn tegen een sterk gereduceerde prijs verder aan te bieden in de ontwikkelingslanden. De winnaar zal verplicht zijn in onderhandeling te treden met andere producenten voor het verlenen van een licentie - onder de voorwaarden zoals die doorgaans voorkomen binnen de sector zelf. We raden eventuele clausules af waarin gestipuleerd wordt dat het patent van de winnende innovatie tegen geen of een zeer geringe compensatie publiek goed zou worden. Het toevoegen van dergelijke clausule kan leiden tot het uitblijven van potentiële deelnemers aan de AMC uit schrik om het beste product te ontwikkelen en op die manier alle patentrechten hierop te verliezen.

We stellen eveneens voor dat regeringen en beslissingnemers uir de private sector niet alleen de uitdaging van het zoeken naar geneesmiddelen tegen belangrijke ziektes aangaan, maar dit ook aanschouwen als zijnde een unieke mogelijkheid tot het zoeken naar alternatieve 
vormen van onderzoek en ontwikkeling die ontwikkelingslanden en potentiële investeerders ten goede zou komen. Een reeks van voorstellen ter bevordering van alternatieve innoverende systemen worden in deze thesis bestudeerd om zowel innovatic van nieuwe geneesmiddelen te stimuleren alsook stimuleren van meer samenwerking in plaats van concurrentie tussen de verscheidene sectoren. Sommige van deze voorstellen gaan over de creatie van een vrije toegangspoort tot geneesmiddeltechnologie of het bundelen van een reeks patenten waar iedereen nadien gebruik van kan maken. Andere voorstellen hanteren een andere aanpak zoals het instellen van wedstrijden waar het meest innoverende geneesmiddel een geldprijs wint zodat op deze manier de onderzoekskosten terugbetaald zijn, wat een gunstig effect zou hebben op de uiteindelijk gevormde prijs. Een controversieel alternatief voor het markt georiënteerde pull-mechanisme dat AMC is, is het voorstel om regeringen patenten te laten afkopen van de patenthouders. Hoewel dit op het eerste zicht een waardig alternatief lijkt zorgt het in de praktijk voor dat de oorspronkelijke ontwikkelaar zich-ondanks zijn expertise in de zaak - niet meer zal kunnen bezig houden met de verdere verbetering van het geneesmiddel. Dit zou uiteindelijk in het nadeel zijn van de uiteindelijke consument, namelijk de patiënten. Patenten afkopen is in onze opinie ineffectief als oplossing aangezien het bedrijven niet stimuleert om nieuwe geneesmiddelen te ontwikkelen. Meer zelfs, ze nemen bepaalde stimulansen weg waardoor bedrijven minder snel geneigd zijn om te investeren in de ontwikkeling van nieuwe geneesmiddelen. Daartegenover staat dat de 'open bron' aanpak in R\&D - namelijk collaboratie in plaats van concurrentie- zeker in basis wetenschappelijk-medisch onderzoek gunstige effecten kan hebben. We raden aan dat de alternatieven zoals 'open bron' en het bundelen van patentrechten verder onderzocht en uitgewerkt worden door ieder die verdere innovatie wenst op het gebied van de bestrijding van wereldwijd verzuimde ziektes.

De belangrijkste bevindingen en aanbevelingen uit dit onderzoek kunnen als volgt worden samengevat:

1) Gezondheidsproblemen waren tot voor kort niet op de G8 macro-economische agenda. Nu wordt deze problematiek wel bediscussieerd op internationale fora vooral in de context van ontwikkelingsdoelstellingen zoals deze zijn vastgelegd in de MDGs tot armoedebestrijding.

Besmettelijke aandoeningen blijven wereldwijd de belangrijkste doodsoorzaak, en vele nieuwe of opkomende aandoeningen blijven de gezondheid bedreigen. Elk jaar zorgen besmettelijke aandoeningen, veroorzaakt door virussen en bacteriën, voor $1 / 3^{\text {de }}$ van het wereldwijde sterftecijfer. Ziektes zoals HIV/AIDS, tuberculosis, malaria en nieuwe epidemieën zoals het vogelgriep virus hinderen landen in hun sociaal-economische ontwikkeling en hebben een negatieve invloed op de duurzame internationale ontwikkeling. De epidemieën beïnvloeden voornamelijk ontwikkelingslanden waar als gevolg van dit menselijke leed niet alleen de aanwinsten in de levensverwachting van de voorbije 30 jaar teniet wordt 
gedaan maar ook een verslechtering van de armoede in deze landen als gevolg heeft. De ongelijk verdeelde toegang tot anti-epidemische mogelijkheden en bijgevolg wereldwijd de verschillen in gezondheidszorg en ziektebestrijding vinden hun oorsprong in de verschillende mate waarin landen toegang hebben tot internationale fondsen, wetenschappelijke kennis en mankracht om deze ziektes en epidemieën te bestrijden. Rapporten van zowel gouvernementele als niet-gouvernementele organisaties benadrukken de het feit dat de gezondheidsbedreigingen in Afrika, Azië en Latijns-Amerika enkel en alleen overwonnen kunnen worden door middel van het samenbundelen van alle ter beschikking hebbende middelen. Sedert de eeuwwisseling hecht de G8 meer belang aan deze gezondheidskwesties, steunt ze ambitieuzere projecten en zorgt ze ook voor meer financiële steun om op deze manier de Millennium doelstellingen te helpen bereiken. Deze gezondheidsgerelateerde kwesties worden tegenwoordig samen besproken met andere kwesties zoals voedselveiligheid, biotechnologie, veroudering, sociaal demografische veranderingen, het verband tussen de opwarming van de aarde en de verspreiding van ziektekiemen. Hoewel het vaststaat dat technologische vooruitgang in de farmaceutische en de biotechnologische industrie deze problemen niet volledig zullen oplossen kunnen ze toch rechtstreeks bijdragen tot het bereiken van de Millennium doelstellingen. Het bevorderen van het algemene gezondheidspeil heeft namelijk een positief effect op de economische groei waardoor er minder mensen onder de armoedegrens zullen leven. Strategieën dienen zich te richten op het intensifiëren van onderzoek en ontwikkeling in deze ziektegebieden, het opwaarderen van preventiemethodes in de strijd tegen deze ziektes, en het opbouwen van duurzame gezondheidszorgstructuren.

2) Besmettelijke ziektes vormen slechts $7 \%$ van het totale aantal gemelde ziektegevallen in rijkere landen, in Afrika bedraagt dit percentage $68 \%$. Voornamelijk drie besmettelijke ziektes - malaria, TB en HIV/AIDS - zijn elk jaar verantwoordelijk voor 6 miljoen doden; en bijna alle slachtoffers leven in ontwikkelingslanden.

Indien de besmettelijke ziektes in ontwikkelingslanden gereduceerd zouden worden tot het niveau waarop ze voorkomen in ontwikkelde landen zou het verschillen in levensverwachting en mortaliteitscijfers grotendeels verdwenen zijn. Het huidige arsenaal aan middelen om malaria, TB en de HIV/AIDS pandemie te bestrijden is niet doeltreffend genoeg - of krachtig genoeg om resistent geworden virussen en/of bacteriën voldoende te bestrijdenom een snelle en duurzame oplossing te bieden in de strijd tegen deze dodelijke ziektes. Hoewel een uitgebreidere diagnose, preventie en behandelingsprogramma al in werking is om de ziekte te bestrijden is de enige hoop om deze ziektes uit te roeien het ontwikkelen van een veilig en doeltreffend vaccin. Vaccines die bescherming bieden tegen levensbedreigende ziektes - en die in staat zijn om de nog steeds uitbreidende HIV/AIDS pandemie een halt toe te roepen - bestaan momenteel nog niet, net zo min als er preventieve geneesmiddelen op de markt zijn die een langdurende werking hebben tegenover malaria. Alvorens er vaccines en verbeterde therapeutische middelen op de markt komen voor deze dodelijke 
ziektes, dienen nog verscheidene significante obstakels - zowel van wetenschappelijke als van financiële aard- overwonnen te worden. Zonder intensieve wetenschappelijk-technische inspanningen gaande van basis wetenschappelijk onderzoek tot innovatieve productontwikkeling - waaronder biologisch/chemische moleculair onderzoek, klinische proeven in meerdere landen, nieuwe farmaceutische moleculaire registratie, grootschalige wereldwijde productiemogelijkheden- zal de ontwikkeling van nieuwe geneesmiddelen die van cruciaal belang zijn voor de derde wereld aanzienlijke vertraging oplopen. Veel van de noodzakelijke kennis, ervaring, expertise en andere vaardigheden of elementen die cruciaal zijn in de ontwikkeling van kwalitatief, veilig en efficiënte geneesmiddelen bevindt zich in de private sector. Het gebruik van private en industriële middelen is voornamelijk nodig voor de latere stadia in de ontwikkeling van het geneesmiddel en voor het opwaarderen van de productiecapaciteit. Deze stadia zijn ook de duurste in de ontwikkeling van een geneesmiddel en vereisen allereerst de ervaring om met zulke dure middelen om te gaan. Hieronder wordt verstaan het managen van hoogtechnologische infrastructuur, hoogopgeleid personeel en investeringen in risicovolle projecten met lange duurtijd.

3) De economische gevolgen van de ontwikkeling en op de markt brengen van nieuwe geneesmiddelen is een ware uitdaging. Het kan tussen de 7 en de 20 jaar duren ervan uitgaande dat elk stadium in de ontwikkeling succesvol wordt afgerond; elk R\&D project kan verscheidene honderden miljoenen euro's kosten.

Farmaceutische $R \& D$ is een risicovolle en dure bedoening ondanks alle moderne biologische, chemische en fysische technologie die gebruikt wordt. De ontwikkeling van een geneesmiddel neemt doorgaans tussen de 7 en de 20 jaar in beslag met een globale ontwikkelingskost van $€ 1$ miljard. Fundamenteel biomedisch onderzoek naar het ontwikkelen van nieuwe mechanismen op cellulair en moleculair niveau vereist het gebruik van moderne en steeds gesofisticeerdere hulpmiddelen zoals genomics, moleculaire biologietechnologie, nanotechnologie en proteomics. Door de af te leggen weg tussen het ontwikkelen van een chemische of biologische farmaceutisch beloftevolle component en het leveren van de wetenschappelijk te bewijzen doeltreffendheid van die component blijft het een risicovolle investering. Samenwerking tussen de publieke en de private sector, zoals tussen laboratoria van de publieke en de private sector, zijn dan ook noodzakelijk. Voor sommige ziektes met een hoge prioriteit, en vooral voor deze die voornamelijk voorkomen in ontwikkelingslanden, is er weinig tot geen basis data voorhanden. De wetenschappelijke onzekerheid is in deze gevallen groter door het gebrek aan wetenschappelijke informatie en/of het gebrek aan proefdieren of modellen die de effecten op het menselijke lichaam kunnen simuleren. De weg van theoretisch concept of wetenschappelijke mogelijkheid tot het ontwikkelen en produceren van een nieuwe farmaceutische component is een proces dat wetenschappelijke onzekerheid, onzekere tijdschema's en aanzienlijke onderzoeks-en ontwikkelingskosten met zich meebrengt. Dit alles wordt overschaduwd door het gegeven dat de beloftevolle component elk ontwikkelingsstadium met succes zal moeten doorstaan. Door de overheid gespon- 
sorde wetenschappelijk 'basis' onderzoek dat doorgaans uitgevoerd wordt in universiteiten en onderzoeksinstituten is dan ook van cruciaal belang in het ondersteunen van het meer toegepaste onderzoek dat zich voordoet in de onderzoeksinstituten van farmaceutische en biotechnologische bedrijven. De bevindingen van dit basis onderzoek kan best beschouwd worden als zijnde een publiek goed, met als gevolg het vrij bekend maken en verspreiden van deze informatie. Dit zorgt voor de creatie van een wetenschappelijk platform waarop verder onderzoek en productontwikkeling, klinische testen en industriële productie kan bouwen.

4) De farmaceutische/biotechnologische industrie heeft een model dat hevig steunt op het exclusieve gebruik kunnen maken van het patentrecht om op deze manier de nodige stimulansen te geven voor onderzoek. Exclusief gebruik van patenten geeft de investeerder de mogelijkheid om diens investeringen in onderzoek en ontwikkeling van het nieuwe geneesmiddel te recupereren.

Het merendeel van de R\&D van bedrijven in de farmaceutische en biotechnische sector neemt plaats in de ontwikkelde landen. $E_{r}$ is echter een stijgende tendens merkbaar in R\&D activiteiten in ontwikkelingslanden die een gunstig economisch klimaat hebben geschapen met respect voor de intellectuele rechten. Deze tendens dient aangemoedigd te worden des te meer aangezien multinationale farmaceutische en biotechnische bedrijven een belangrijke rol kunnen spelen in de technologische en economische ontwikkeling van een land wegens de positieve invloed die de wisselwerking tussen het moederbedrijf en de plaatselijke afdeling(en) kan hebben op de productiviteit door middel van het plaatselijk toepassen van nieuwe technologieën. We bevelen aan dat nationale beleidsnormen geïmplementeerd worden met als doel de farmaceutische en biotechnologische investeringsafdelingen te overtuigen van de voordelen van verdere technologietransfers door middel van het aangaan van allianties, samenwerkingen met plaatselijke bedrijven, joint ventures. De succesvolle verhalen uit het verleden maken duidelijk dat een succesvolle samenwerking doorgaans leidt tot een versteviging van de intellectuele rechten. Landen zoals Singapore hebben in een relatieve korte tijdspanne diverse succesvolle beleidsnormen toegepast die gericht zijn op de problematiek aangaande intellectuele rechten en het aantrekken en verder ontwikkelen van $R \& D$ activiteiten van farmaceutische en biotechnische bedrijven. Naarmate de bescherming van intellectuele rechten in sommige landen stilaan op het niveau van dat in ontwikkelde landen begint te bereiken, kan men een geografische spreiding van investeringen in de farmaceutische sector waarnemen, zelfs in het geval van R\&D investeringen. Daarenboven biedt de Doha verklaring met betrekking tot de TRIPS akkoorden antwoord op de vragen die waren gerezen in verband met de draagwijdte van de clausules omtrent patentenbescherming in gevallen die de publieke gezondheid aangaan. De verklaring laat in bepaalde gevallen toe dat intellectuele rechten ingekort worden in zover dat dit nodig blijkt te zijn om het algemeen belang (zoals de publieke gezondheid) te kunnen dienen. Elke lidstaat heeft de bevoegdheid om te onderhandelen over de eventueel gedwon- 
gen verlening van een licentie tot productie van een bepaald geneesmiddel. Ook staat het de lidstaten vrij om te oordelen wanneer het algemeen belang dermate in het gedrang komt dat er dient verwezen worden naar het systeem van gedwongen licentieverlening of andere middelen die het intellectueel eigendomsrecht beknotten. Deze mogelijkheden samen met het recht van een lidstaat om over te gaan tot het toelaten van parallelle import kunnen niet aangevochten worden via het gebruikelijke Wereldhandelsorganisatie disputensysteem. De verklaring erkent echter het belang van intellectuele eigendomsrechten voor de ontwikkeling van nieuwe geneesmiddelen. Met betrekking tot ontwikkelingslanden gaat de verklaring akkoord met het hen verlenen van een langere transitieperiode (tot januari 2016) in verband met het verstevigen van zowel de intellectuele eigendomsrechten als het aanpakken van inbreuken hierop. Ten slotte raden we aan dat de overheid streng optreedt tegen onrechtmatige namaak. Op dit ogenblik bestaat de helft van de beschikbare geneesmiddelen in sommige ontwikkelingslanden uit namaak. Deze producten zijn niet veilig of bevatten in het beste geval geen actieve bestanddelen om de zickte efficiënt te bestrijden.

5) Het opbouwen van farmaceutische en medische biotechnologische productiecapaciteit evenals het voeren van klinische studies in meerdere landen en met meerdere bevolkingsprofielen heeft een hoge kostprijs. Deze kosten worden beschouwd als zijnde verzonken kosten door de door innovatie gedreven producenten van gezondheidsproducten.

Het opbouwen van productiecapaciteit neemt tijd in beslag en gebeurt enkel wanneer producenten het risico van deze investering als laag tot zeer laag aanschouwen. Omwille van zijn complexiteit en grootte vereisen chemisch-farmaceutische en vooral biologischfarmaceutische productiefaciliteiten aanzienlijke investeringen en dit zelfs relatief snel in het opbouwproces. Producenten dienen het budget voorhanden te hebben om een product in voldoende mate te produceren lang voordat klinische proeven kunnen uitwijzen of de onderzochte component succesvol is, laat staan vooraleer het op de markt verschijnt. Niet zelden dienen producenten investeringsbeslissingen te nemen ondanks het gebrek aan informatie omtrent de potentiële markt, de doeltreffendheid van het product of de veiligheid van het product. Eenmaal gebouwd ligt de productiecapaciteit van een chemischfarmaceutisch of biotechnologische productiefaciliteit zo goed als vast. Het is uitermate moeilijk om de productiecapaciteit van een bepaald product aan te passen, laat staan om de totale productielijn te veranderen. Dit is een gevolg van de strikte reglementering van zulke productielijnen. Het opwaarderen van een productielijn kan twee tot vier jaar in beslag nemen. Klinische testen op menselijke proefpersonen en meerbepaald in meerdere landen en met meerdere bevolkingsprofielen zorgen voor de grootste stijgende kost bij producenten die een nieuw geneesmiddel zowel in ontwikkelde landen als in ontwikkelingslanden op de markt willen brengen. Over het algemeen bevatten klinische studies een hoger risico aangezien de verzonken kosten weinig flexibel of zelfs helemaal niet terugvorderbaar zijn (in tegenstelling tot investeringen zoals de aankoop van een R\&D toestel). Gezien de verzon- 
ken kost en de risicostructuur zijn klinische studies in mensen (fase I, II, III) doorgaans een 'Ja/Nee' beslissing voor op onderzoek gebaseerde producenten, en kan dergelijke beslissing een cruciaal obstakel zijn in het toekenningsproces van fondsen binnen het bedrijf en omvat meervoudige beslissingsstappen in zake het investeringsbudget. Zodra het nieuwe geneesmiddel een licentie krijgt om te produceren houdt dit eveneens in dat eventuele neveneffecten gerapporteerd worden aan de bevoegde overheidsdiensten en aan de producenten. Verdere studies zullen moeten gebeuren om verder onderzoek te doen naar eventuele neveneffecten, het kan namelijk zijn dat bepaalde neveneffecten niet tot uiting zijn gekomen tijdens de klinische studies. Aangezien de verspreiding van het geneesmiddel een grotere populatie zal bereiken dan tijdens de klinische studies is de kans groter dat men slechts na verloop van tijd bepaalde neveneffecten zal opmerken en kunnen rapporteren. Omwille van deze reden is het noodzakelijk om eventuele neveneffecten actief op te sporen. Dit opsporen is doorgaans verplicht door de bevoegde nationale overheden. We raden aan dat alle producenten deze procedures volgen aangezien het leidt tot de productie van geneesmiddelen die niet alleen veilig en efficiënt maar tevens van hoogstaande kwaliteit zijn.

6) Bedrijven gebruiken een formeel beslissingsproces voor het begeleiden van R\&D projecten in de ontwikkelingsfase gebaseerd op een 'fase-en-poort' aanpak. Dit houdt een verscheidenheid in van evaluatiemethodes voor de toekenning van schaarse middelen tussen de verschillende projecten in de portfolio. Risico gecorrigeerde beoordelingsmethodes gebaseerd op beslissingsbomen bieden voordelen ten opzichte van andere beoordelingsmethodes.

Geconfronteerd met toenemende ontwikkelingskosten en wereldwijde druk op de prijszetting zorgt ervoor dat multinationale en nationale farmaceutische en biotechnologische producenten verplicht worden om een keuze te maken in hun selectie van producten die kunnen rekenen op de nodige fondsen om verder ontwikkeld te worden. Gezien het hoge falingspercentage en de lange ontwikkelingstermijnen zijn producenten geneigd om te kiezen voor producten waarvan de potentiële markt en de potentiële inkomsten zekerder zijn en daardoor ook een hoger rendement op de investering bieden of de mogelijkheid om nieuw kapitaal aan te trekken in de toekomst. Zoals voordien vermeld zorgen doeltreffende intellectuele rechtenbescherming door middel van patenten ervoor dat investeerders en op onderzoekgebaseerde ondernemingen hun gedane investeringen kunnen recupereren dankzij een gelimiteerde periode waarin ze hun exclusieve marketingrechten kunnen uitoefenen. Hoewel het garanderen van intellectuele eigendomsrechten een belangrijke en noodzakelijke stimulans biedt voor private investeringen in farmaceutische R\&D zorgen zij op zich niet voor de prikkel die leidt tot daadwerkelijk investeren. Farmaceutische multinationale bedrijven zowel als KMO's en zelfs de kleine biotechnologische starterbedrijven volgen doorgaans een strategische portfolio aanpak waarbij ze voortdurend de kosten en baten van elke mogelijkheid in hun R\&D ontwikkelingspijpleiding zullen monitoren en 
aanpassen. Beperkte middelen dwingen hen om regelmatig investeringskeuzes aan te passen. We hebben aangetoond dat private bedrijven en hun investeerders doorgaans een minimum van drie cruciale risicofactoren onderzoeken in hun beslissing om al dan niet en in welke mate zij een nieuw farmaceutisch onderzoek en ontwikkelingsproject zullen financieren. In de evaluatie van farmaceutische $R \& D$ projecten bevelen wij aan dat de onafhankelijke risicofactoren als volgt gecatalogeerd worden: (i) Technische risicofactoren - deze bevatten onder andere parameters zoals de succesratio bij het uitvoeren van klinische testen, het verkrijgen van toestemming van de regelgever, en het opwaarderen van productiecapaciteit; (ii) Markt risicofactoren - deze omvat parameters zoals de marktgrootte, verwachte marktaandeel en concurrentie; en (iii) kapitaal risicofactoren - dit zijn overwegend afhankelijk van de selectie en het correcte gebruik van actuele waardefactoren en de zogehete kapitaalkost die gebruikt worden door investeerders voor hun berekening van het kapitaal investeringsrisico van een respectievelijk project of industrie.

7) We hebben een 'risico-investeringsmodel' ontwikkeld dat het oorzakelijk verband aantoont tussen de onafhankelijke variabelen in een $R \& D$ project (cruciale technische, marktgerelateerde, en financiële risicofactoren), en de daarvan afhankelijke uitkomst (de beslissing van een bedrijf om wel of niet te investeren in het project).

Beslissingen om te investeren in $R \& D$ zijn complex en gebaseerd op een brede waaier van factoren die in acht genomen worden. De methode die wij voorstellen om risico's in te schatten en $R \& D$ investeringschattingen maakt gebruik van computeronderbouwde modellen. In principe kan dit toegepast worden op elke nieuwe projectontwikkeling van een geneesmiddel, onder andere ook voor projecten bedoeld voor overwegend de geïndustrialiseerde en ontwikkelde markten en voor deze projecten die voornamelijk gericht zijn op ontwikkelingslanden. We hebben een beslissingsondersteund kader uitgewerkt dat beleidsnemers en managers toelaat om een reeks van geografische strategieën te vergelijken op wereldwijde schaal met de risicofactoren en investeringsuitkomst van hun project. Om inzicht te verwerven in de dynamiek van de wisselwerking tussen verscheidene variabelen in het model, hebben we de verscheidene risicofactoren apart ontleed en bestudeerd. Hoewel de risicofactoren doorgaans beschouwd kunnen worden als zijnde onafhankelijk, gecombineerd geven ze de mogelijkheid om de beslissing van een bedrijf om wel of niet te investeren in een bepaald farmaceutische $R \& D$ project te voorspellen. Uiteindelijk zal dit geïntegreerde 'risico-investering' beslissingsmodel de incorporatie toelaten alsook het meten van de invloed en weerslag dat publiek gesponsorde stimulanssystemen - 'push \& pull' mechanismen genaamd - hebben op de beslissing van een bedrijf om te investeren in risicovolle, complexe en dure $R \& D$ projecten. We raden dan ook aan dat beleidsnemers van zowel de private als van de publieke sector het voorgestelde model gebruiken bij het evalueren van de effecten van verschillende stimulanssystemen. Verscheidene van deze economische stimulanssystemen worden momenteel ontwikkeld. Ze zullen verder ontwikkeld en getest worden 
met als doel het stimuleren van de betrokkenheid van voornamelijk de private sector in de ontwikkeling van nieuwe geneesmiddelen bedoeld voor gebruik in ontwikkelingslanden.

8) Voor ziektes voornamelijk voorkomend in ontwikkelingslanden is het gebrek aan geloofwaardige marktmogelijkheden een van de voornaamste struikelblokken die deelname van multinationale en plaatselijke bedrijven aan deze markten hindert. Het hanteren van een brede of nauwe kijk op R\&D portefeuilles zorgt hier niet voor een verschil.

We raden aan dat bedrijven hun sociale verantwoordelijkheid als bedrijf niet beschouwen als zijnde een bijkomend gegeven. In de vorming van een sociaal contract tussen de bedrijfswereld en de samenleving dienen bedrijven samen te werken met andere belanghebbenden om samen naar een oplossing voor huidige maatschappelijke problemen te zoeken. In het geval van veronachtzaamde ziektes bij arme mensen zorgen de beperkte aankoopkracht van minder ontwikkelde landen gecombineerd met lage verwachtingsrendementen op investeringen ervoor dat het aantrekken van kapitaalinvesteringen door bedrijven in deze sector een moeilijk gegeven is en blijft. Het probleem van de ontwikkeling van nieuwe en verbeterde geneesmiddelen voor ziektes en aandoeningen die voornamelijk aanwezig zijn in ontwikkelingslanden wordt doorgaans omschreven als zijnde een 'falen van de markt zelve'. Het is echter eerder een probleem van koopkracht. Ondanks het aantal geïnfecteerde personen in ontwikkelingslanden, zorgen ontwikkelingslanden niet voor de creatie van een gunstig marktklimaat, dat toelaat om gedane kosten te recupereren en eventueel zelfs een kleine winst te boeken, om op deze manier multinationale of nationale farmaceutische en biotechnologische bedrijven aan te trekken. Vele bedrijven die toch deze stap zetten worden doorgaans gesubsidieerd, met fondsen uit de publieke sector, in hun R\&D onderzoek. Deze fondsen zijn echter niet voldoende om de kosten te recupereren die in de latere en duurdere fases van de ontwikkeling - zoals klinische testen, registratie, productie, verdeling en levering van de goederen- dienen gemaakt te worden. Hoewel externe financiële steun door middel van 'push' mechanismen een verlaging van de kosten en het risico van het nieuwe farmaceutische product met zich meebrengt - en omwille van die redenen tot dusver de voornaamste stimuleringsmethode was in het onderzoek naar geneesmiddelen tegen verwaarloosde ziektes- zorgt het er niet voor dat innoverende - vooral de meer capabele onderzoeksgerichte- bedrijven voldoende eigen kapitaal zullen investeren om de ontwikkeling, distributie en marketing van deze producten te garanderen. Het zijn de onderliggende wereldwijde markt opportuniteiten die investeringsbeslissingen beïnvloeden die in dit geval echter afwezig zijn. Multinationale bedrijven en plaatselijke biotechnologische bedrijven worden geconfronteerd met een grote vraag en meerdere medische uitdagingen. De beslissing om te investeren in $\mathrm{R} \& \mathrm{D}$ projecten voor ontwikkelingslanden zal dan ook slechts gebeuren indien deze investeringen gezien worden als zijnde significante of betrouwbare alternatieven. Indien de marktvraag onzeker of te klein is zorgt dit automatisch ervoor dat de opportuniteitskosten bij een herverdeling van de beperkte middelen van de technische, 
medische en project-management teams der mate significant zijn dat het onmogelijk is om in dergelijke projecten te investeren; zeker indien grote investeringen nodig zijn om tot een geneesmiddel te komen voor deze doorgaans moeilijke ziektes.

9) Onzekerheid met betrekking tot het ontbreken van markten in de minst ontwikkelde landen hebben een invloed op de ontwikkeling en beschikbaarheid van nieuwe geneesmiddelen in deze regio's. Deze situatie kan veranderd worden door publiek gesponsorde technologie 'push' en/of marktgerelateerde 'pull' stimulans maatregels.

We verrichtten een kritische analyse van de voordelen en nadelen eigen aan de huidige en nieuw ontwikkelde publieke stimulansmechanismen waarvan verwacht wordt dat ze de farmaceutische $R \& D$ naar ziektes uit ontwikkelingslanden zal stimuleren. Historisch gezien geeft de publieke sector de voorkeur aan 'push' mechanismen, voornamelijk deze bedoelt tot het stimuleren van basis onderzoek en de basisstadia van productontwikkeling. Minder onderzoek is tot dusver verricht naar 'pull' mechanismen die gericht zijn op de creatie van een leefbare markt om op deze wijze kapitaalinvesteringen van de private sector aan te trekken. De sterke nadruk die regeringen en de publieke opinie de laatste jaren hebben in verband met het dienen te verbeteren van toegang tor medicijnen heeft voor een discussie gezorgd omtrent een bredere waaier van potentiële aanvullende publieke beleidsnormen die kunnen bijdragen tot het verbeteren van de stimulansen die nodig zijn voor ontwikkelingslanden op het vlak van $R \& D$ in gezondheidsgerelateerde gebieden. We hebben eerder al geargumenteerd dat intellectuele eigendomsrechten - auteursrechten, patenten of octrooien- een noodzakelijke stimulans bieden an de private sector op het gebied van farmaceutisch onderzoek en ontwikkeling. Nochtans is deze maatregel op zich niet voldoende om een blijvende oplossing te bieden aan het probleem. Sommige beloftevolle initiatieven omtrent het bieden van stimuli worden momenteel geëvalueerd, zoals speciale publieke aankoopfondsen die de ontwikkeling van geneesmiddelen tegen HIV/AIDS, malaria en TB steunen. Onder een extern gesponsorde constructie zouden regeringen de garantie geven dat de geneesmiddelen en vaccins voor de ontwikkelingslanden aangekocht zullen worden tegen een gesubsidieerde prijs indien een bedrijf een veilig en doeltreffend product kan leveren dat voldoet aan de vooraf gestelde specificaties. Dit zou de private sector de nodige financiële stimulans bieden die heden ten dage nog niet aanwezig is. De regeringen zullen deze uitgaven echter enkel doen indien een veilig en doeltreffend product volledig ontwikkeld is. Andere voorstellen bedoeld tot het ontwikkelen van nieuwe stimulanskaders worden bestudeerd zowel als alleenstaand project of in combinatie met andere mechanismen. Zoals eerder vermeld, een reeds bestaand en doeltreffend systeem is het systeem van prijsverschillen. Dit systeem zorgt voor het in standhouden van een lagere prijs voor het geneesmiddel in ontwikkelingslanden dankzij de hogere prijs die betaald wordt in ontwikkelde landen. Een ander systeem dat momenteel bestudeerd wordt richt zich op het uitbreiden van de termijn waarbinnen men op basis van zijn intellectueel eigendomsrecht zijn exclusieve verkoopsrechten voor een nieuw geneesmiddel kan overdragen op een ander reeds 
bestaand geneesmiddel. . Naast dit systeem van 'zwervende exclusiviteit' bestaan er uiteraard ook de klassieke systemen van belastingreductie op verkoop en/of $R \& D$ activiteiten.

10) Publieke interventies zijn nodig voor de implementatie van een nieuw financieel stimulans systeem Advance Market Commitment (AMC) genaamd. AMC dient als katalysator voor de investeringen van de industrie en kan aanzienlijke stimulansen leveren voor farmaceutische en biotechnologische R\&D op het vlak van ziektes die voorkomen in ontwikkelingslanden.

AMC is een financiële stimulans voor op onderzoekgebaseerde farmaceutische bedrijven door het risico, eigen aan het ontwikkelen van geneesmiddelen van het laboratorium tot aan de uiteindelijke patiënt, te verminderen. Een AMC voor een bepaalde ziekte die voornamelijk voorkomt in ontwikkelingslanden is een financiële verplichting van de meer gegoede regeringen om de toekomstige aankopen te subsidiëren tegen een vooraf afgesproken subsidie voor een nog niet bestaand geneesmiddel, als en zodra dit geneesmiddel ontwikkeld is en aangekocht zal worden door ontwikkelingslanden. Vaccines worden momenteel geacht als zijnde de beste keuze voor een proefproject van AMC aangezien preventie beter is dan genezing. In onze opinie heeft $A M C$ het potentieel om een belangrijk stimulansmechanisme te worden dat de ontwikkeling van gezondheidsgerelateerde producten voor veronachtzaamde aandoeningen (malaria, HIV/AIDS, TB, bepaalde buikloopziektes en luchtwegeninfecties) in een stroomversnelling te brengen. De aanpak van AMC bootst ook de bewegingen van de vrije markt na aangezien enkel de bedrijven die de gewenste geneesmiddelen ontwikkeld hebben profijt uit de AMC zullen kunnen halen. Net zoals in andere sectoren zullen deze bedrijven de afweging dienen te maken om wel of niet het risico van zulke grote investeringen aan te gaan, ervan uitgaande dat het eindproduct niet alleen veilig en doeltreffend genoeg is om op de markt te brengen, maar ook tegen een kostprijs ontwikkeld kan worden die toelaat alle gedane kosten te recupereren. Van de verscheidene 'pull' mechanismen dienend als stimulans voor $R \& D$, heeft AMC - indien nauwkeurig opgebouwd - het voordeel en het intrinsieke potentieel om tegelijkertijd de volgende doelstellingen te bereiken: (i) de creatie van een markt 'pull' stimulans voor verdere commerciële investeringen in $R \& D$ in daarvoor verwaarloosde therapeutische gebieden; (ii) het verwezenlijken van een snelle en betaalbare toegang tot nieuwe geneesmiddelen in ontwikkelingslanden zodra het product ontwikkeld is; (iii) het introduceren van markt en prijsconcurrentie tussen producenten samen met het laten van voldoende ruimte voor de introductie van verbeterde tweede- of derde generatie producten. We bevelen daarom aan dat het AMC stimulanssysteem een belangrijke component vormt van een bredere samenstelling van initiatieven om meer publieke en private investeringen aan te trekken in de hierboven vermelde endemische ziektecategorieën. Verregaande interviews en discussies met meerdere belanghebbende partijen inclusief bedrijfsleiders en kaderpersoneel van de belangrijkste farmaceutische en biotechnologische bedrijven hebben aangetoond dat een accuraat ontwerp van deze programma's van uiterst cruciaal belang is om de diverse 
belanghebbenden - namelijk sponsorlanden, regeringen van ontwikkelingslanden, patiënten uit ontwikkelingslanden en de gezondheidssector in zowel de geïndustrialiseerde als de opkomende landen- aan boord te krijgen.

11) AMC biedt een stimulans aan voor de versnelling van componenten in begin- of zelfs in latere stadia van ontwikkeling op voorwaarde dat de huidige ontwerpproblemen opgelost zijn. Om de minimale grootte van de subsidie te berekenen hebben we een geïntegreerd 'risico-investering-stimulans' model ontworpen.

De grootte van het AMC fonds dat nodig zal zijn is afhankelijk van de wereldwijde spreiding van de ziekte in kwestie. Indien deze ziekte voldoende aanwezig is in zowel rijkere als in armere landen dan kan een systeem van prijsverschillen worden toegepast waarbij het merendeel van de ontwikkelingskosten door patiënten in de rijkere landen betaald wordt. In het geval van tropische ziektes zoals malaria kan de gedane investering enkel en alleen gerecupereerd worden in de ontwikkelingslanden zelf, wat betekent dat een groter fonds nodig zal zijn. Om tot een efficiënt stimulanssysteem te komen raden wij aan dat volgende zaken veranderd worden:

1. het berekenen van de minimum grootte van de AMC subsidie die nodig is in aanmerking nemende de onzekerheid die heerst bij producenten omtrent de markt;

2. het bepalen van de lange termijn prijs, namelijk de prijs die zal aangerekend worden na afloop van de AMC;

3. het incalculeren van variabelen in de risiconemende houding van bedrijven;

4. het waarborgen van de compatibiliteit met het internationaal aanvaarde systeem van prijsverschillen tussen landen om op deze manier een evenwicht te garanderen tussen gezondheid en ontwikkeling.

Om met deze factoren en onzekerheden rekening te houden en om de instapdrempel voor een AMC fonds dat doeltreffend is in het stimuleren van $R \& D$ te berekenen, dient een aangepast kader ontwikkeld te worden. We hebben een kwantitatief model geconstrueerd dat beleidsnemers assisteert bij het berekenen van risico aangepaste investeringen die gemaakt dienen te worden in elk van de ziektecategorieën in ontwikkelingslanden. De 'nulsom' operatieaanpak die wij voorstellen zorgt voor op feiten gebaseerde beslissingsmethodes. Het laat beleidsmakers toe om de grootte van AMC fondsen te berekenen die nodig zijn om R\&D onderzoek te stimuleren naar ziektes die elk jaar miljoenen mensen treft in ontwikkelingslanden. De impact van technische, marktgerelateerde en financiële variabelen op het rendement van een investering kan door een bedrijf berekend worden door gebruik te maken van de 'Monte Carlo' analyse gecombineerd met computersimulaties. Deze methode houdt rekening met de impact van variaties in het hiervoor vermelde $R \& D$ project en diens beslissingsparameters. Invoer data voor elk van deze parameters wordt verkregen door meetkundige schattingen van experts naar aanleiding van een Delphi 
consensus proces. Het model toont eveneens aan hoe verschillende risicoaversieve profielen en houdingen zoals getoond door beleidsmakers van de geraadpleegde farmaceutische en biotechnologische bedrijven - die op hun beurt onderworpen zijn aan het toezicht door belangenpartijen en investeerders - een rol kunnen spelen in de selectie van R\&D projecten gericht op armoedegerelateerde ziektes. Het analytische model kan toegepast worden op vergevorderde projecten en op nieuwe projecten op voorwaarde dat wetenschappelijke data voorhanden is. Zodra dit geleverd wordt kan men probabiliteitsschattingen en beslissingsboom-simulatie analyses gebruiken.

12) De volgende pandemie die de wereld zal treffen kan veroorzaakt worden door het vogelgriepvirus. Dit virus zal zowel individuen in ontwikkelde als in ontwikkelingslanden treffen. Een publiekprivate samenwerking om onderzoek te verrichten in dit gebied is nodig om deze dreigende wereldwijde crisis te verhinderen.

Influenza pandemieën hebben zich in het verleden voorgedaan op onregelmatige en onvoorspelbare intervallen. Ze worden geassocieerd met verregaande menselijk lijden, sterftes en hebben een zware directe en indirecte economische kost. Een nieuw virus ( $\mathrm{H} 5 \mathrm{~N} 1)$ doodt op dit ogenblik voornamelijk vogels maar wordt doorgaans beschouwd als zijnde een kandidaat voor het veroorzaken van een menselijke pandemie. De Wereldgezondheidsorganisatie heeft bevestigd dat een uitbraak slechts een kwestie van tijd is en beschouwt dit als zijnde een van de grootste bedreigingen voor de wereldwijde publieke gezondheid en internationale groei. Menselijke vaccines die de gevolgen van influenza, alsook mutaties die eventueel een pandemie zouden kunnen veroorzaken, kunnen vermijden of op zijn minst kunnen verlichten zijn momenteel niet voorhanden. Farmaceutische bedrijven dienen beslissingen te nemen of men wel of nier zal investeren in dergelijk onzeker rampenscenario. Slechts enkele farmaceutische en biotechnologische bedrijven bezitten de productiecapaciteit en onderzoekslaboratoria om onderzoek te doen naar dergelijke vaccines. De huidige productiemethodes en processen laten echter niet toe om voldoende, laat staan snel genoeg, te produceren om een pandemie uitbraak te stoppen in het geval dat die zou uitbreken. Het opbouwen van extra productiecapaciteit om de wereld voldoende te voorzien van dergelijke geneesmiddelen is een werk van lange adem en neemt verscheidene jaren in beslag. We hebben verschillende mogelijkheden onderzocht voor het managen van de risico's en onzekerheden die gepaard gaan met deze globale dreiging. We stellen een economisch en bestuurskader voor met betrekking tot het ontwikkelen van een publiekprivate samenwerking met als doel het ontwikkelen van een vaccin in geval van een pandemie. Dit kader houdt zowel een 'push' als een 'pull' mechanisme in om op deze wijze het $R \& D$ onderzoek van de private sector te stimuleren en versnellen met als einddoel het opbouwen van een voldoende grote geneesmiddelenvoorraad. AMC fondsen kunnen in dit geval niet dienst doen aangezien er momenteel geen markt is voor pandemische vaccins. We besluiten echter door te wijzen op alternatieve strategieën die gebruikt kunnen worden als ziektepreventie. Een publiek gezondheidsbeleid dat gebruikt maakt van nieuwe productformulerin- 
gen zou kunnen geïmplementeerd worden. Deze producten bieden bescherming tegen meerdere (potentielle) pandemische varianten. Indien deze opgeslagen en/of toegediend zouden worden voor het uitbreken van een pandemie, zou dit als gevolg hebben dat de ergste effecten van de dreiging afgewend wordt. Dit vereist echter aanzienlijke investeringen in onderzoek, ontwikkeling en productie van pandemische vaccins. Indien een publiek gezondheidsprogramma gebaseerd op het aanleggen van een reservestock en prevaccinatie van risicogroepen uitgevoerd wordt zodra deze producten op de markt komen, zou de productie verspreid kunnen worden over een langere termijn en deze maatregel vermijdt paniek. Het gevolg is dat de problemen in verband met productiecapaciteit minder ernstig zouden zijn. We raden regeringen aan om deze preventie initiatieven te steunen in plaats van het afwachten tot de dreiging reëel is en de behandelingskosten en economische kosten werkelijkheid worden. Om een evenwichtige verdeling van de producten doorheen de landen te garanderen dienen regeringen in zowel ontwikkelde als in ontwikkelingslanden samen te werken onder andere met de WGO om op deze manier een strategische voorraad van pre-pandemische vaccines aan te leggen.

13) Alternatieve innovatie modellen die mogelijk leiden tot het stimuleren van onderzoek en ontwikkeling van geneesmiddelen voor ontwikkelingslanden werden eveneens bestudeerd. (i) Een wereldwijd medisch onderzoek- en ontwikkelingsverdrag, (ii) Een afkoop van de intellectuele eigendomsrechten en een prijzensysteem, (iii) Het bundelen van patenten, en 'open bron' innovatie (iv) Nieuwe publiekprivate samenwerkingen.

Een antal alternatieve biomedische innovatieve modellen werden geëxamineerd die gericht zijn op het bespoedigen van $R \& D$ voor ziektes die voornamelijk ontwikkelingslanden treffen:

1. Rechtstreekse Financiering : een systeem waarbij de R\&D direct gefinancierd wordt door middel van een wereldwijd belastingsmechanisme wat toelaat een vooraf afgesproken bedrag op te halen;

2. Prijs/Trofee: een systeem waarbij succesvolle innovatieve pogingen beloond worden met een prijs of een erkenning zodra het innovatieve product ontwikkeld is en aan de gemeenschap geschonken wordt;

3. Open Bron/Patentenbundeling, dit zijn systemen die gericht zijn op de samenwerking via vrij toegankelijk $R \& D$ onderzoek vanaf het prille begin van het onderzoek- en ontwikkelingsproject;

4. OdO Samenwerkingsverbond: een waaier van nieuwe samenwerkingsmechanismen en structuren gebaseerd op publiekprivate samenwerkingsakkoorden.

Het juiste evenwicht vinden tussen openheid van basis biomedisch onderzoek en het onderhouden van stimulansen om te kunnen garanderen dat mogelijkheden verder onder- 
zocht en getest zullen worden in een commercieel stadium is een ware uitdaging in elk nieuw systeem ontwerp. Een wereldwijd medisch onderzoek en ontwikkelingsverdrag is voorgesteld geweest in de literatuur en op conferenties. Dit verdrag, zoals het werd voorgesteld, vereist dat elke regering een bepaald percentage van zijn bruto nationaal product opzij zet om op deze manier wereldwijde farmaceutische $R \& D$ voor ontwikkelingsziekten te financieren. Wij hebben geen bewijs gevonden dat het voorgestelde verdrag het gebrek aan $R \& D$ voor verwaarloosde ziektes zou wegwerken. Het zou naar ons inzien de gehele situatie onoverzichtelijker maken en heeft minieme kansen om aanvaard te worden door belanghebbenden zowel in de private als in de publieke sector. Daarbuiten wensen wij eveneens te wijzen op het feit dat het uitreiken van een geldprijs of een erkenning als groot nadeel heeft dat er geen enkele garantie is dat er uiteindelijk een veilig, doeltreffend en haalbaar medicament ontwikkeld zal worden. Regeringen, sponsors en politici dienen actief betrokken te zijn in het gehele proces waaronder het uitkiezen van de 'winnaars' die vanaf het begin en doorheen het proces gesteund dienen te worden. Ons lijkt dat de beoogde doelstellingen van zowel het Prijs/ Trofee en het afkopen van intellectuele eigendomsrechten beter verwezenlijkt kunnen worden door een systeem van Advance Market Commitment (AMC). Daarenboven wensen wij te wijzen op het feit dat systemen gebaseerd op open innovatie en patentenbundeling meer aandacht dienen te krijgen gezien het grote potentieel van een dergelijke aanpak.

Patentenbundelingen hebben de mogelijkheid om het tijdelijke monopolie karakter van patenten te verminderen en toch nog altijd nieuwe mogelijkheden tot innovatie te behouden. Het bestaan van een patentenbundeling die de $R \& D$ in therapeutische gebieden van interesse voor de ontwikkelingslanden vergemakkelijkt zou de nood aan het herhaaldelijk onderhandelen over licentierechten elimineren aangezien nieuwe innovaties door de andere leden in de patentenbundeling verwezenlijkt zullen worden. Dit levert het oorspronkelijke bedrijf een kostenvermindering op. Hoewel sommige bedrijfsrisico's in principe verlicht kunnen worden door het gebruik van zulke patentenbundelingen dient men toch rekening te houden met de antitrust wetgevingen. Deze optie kan dus niet beschouwd worden als een universele oplossing voor intellectuele eigendomsrechtproblemen. Het gebruik van quasi-verplichte patentenbundelingen dient met argusogen bekeken te worden. als ook het idee van verplichte licentie maatregelen. Ten slotte, een ander systeem van publiekprivate samenwerking zoals de 'Innovative Medicines Initiative' (IMI) dienen aangemoedigd te worden. Het IMI initiatief zoals recentelijk voorgesteld door de Europese Commissie in samenwerking met de Europese farmaceutische industrie associatie moedigt de deelnemers aan om zich elk te richten op hun kernactiviteiten. Het biedt een unieke mogelijkheid om samenwerking op te bouwen tussen patiënten organisaties, universiteiten, ziekenhuizen, regelgevende overheden, kleine en grote biofarmaceutische bedrijven en gezondheidstechnologische bedrijven. Van de deelnemende partners dienen de grote multinationale bedrijven hun bijdrage volledig (100\%) zelf te financieren. De fondsen dienen om andere deel- 
nemers te kunnen steunen. Het INI initiatief beongt niet om perse zelf het geneemiddel te ontwikkelen. Het duel in het anteiken van multidis iplinaire werktuigen dic dienen tot verbetering en versndling van het biomedishe innovatieve proces. Vandar het nieuwe medische innovatre paradigma.

In conchusic, van de bovernvermelde dternatieve imnovatic modellen ain sommigen velbelovend in dedgebieden van het medicamenten onderzock on ontwkelingeproces. Weinige en mischien zelfs geen zijn echter in stadt om het patent system te vervangen vomal indien dit gebruikt word samen met het AMC aanmoedigingsystem. en cen gedifferenticerde of verlaagde prijuetting ten voordele van ontwikkelinglanden. Daarenboven is het AMC." 'pull' marktgerichte adnmoedigingmechanisme complementair aan een reeks 'push' mechanismen voor her stimuleren van onderzok in een vroeg stadium door het gebruik van beurzen en open innovatie. 


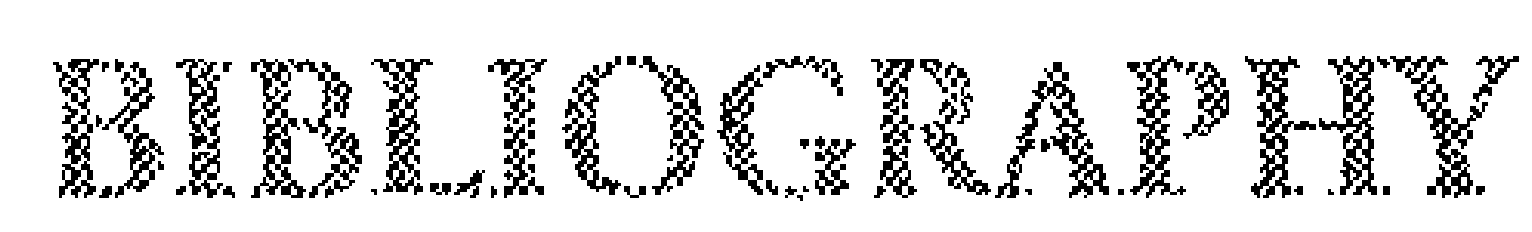

Abbott A. (2005) 'What's in the medicine cabinet?' Nature, 26 May; 435: 407-409.

AEI-Brookings (2005) 'Intellectual Property rights in Frontier Industries: Software and Biotech, Panel Discussion organized by the AEI-Brookings Joint Center, Washington DC, April 30.

Anderson R. and Hanson M. (2005), "Potential Public Health Impact of Imperfect HIV Type 1 Vaccines," Journal of Infectious Diseases 191, no. 1 Supp.: S86-S96; Blower S., Schwartz E., and Mills J., "Forecasting the Future of HIV Epidemics: The Impact of Antiretroviral Therapies and Imperfect Vaccines," AIDS Reviews 5 , no. 2 (2003): 113-125; and Davenport M. et al, "Predicting the Impact of a Nonsterilizing Vaccine against Human Immunodeficiency Virus," Journal of Virology 78, no. 20 (2004): 11340-11351.

Arlington, S., Barnett, S., Davies N., Palo J. (2004) 'Pharma 2010: The threshold innovation', IBM Business Consulting Services. $2^{\text {nd }}$ ed., November, p. 25.

http://www-1.ibm.com/services/us/index.wss/xs/imc/a1001099

Arora A., Fosfuri A., and Gambardella A. (2004) 'Markets for Technology: The Economics of Innovation and Corporate Stratcgy', The MIT Press, Cambridge, Massachusetrs, USA.

Arora A. and Gambardella A. (1994) 'The changing technology of technological change: general and abstract knowledge and the division of innovative labor', Research Policy 23(5): 523-532.

Arrow K. (1962) 'Economic Welfare and the Allocation of Resources for Invention'; in: Nelson R. (1962) (ed.), 'The Rate and Direction of Inventive Activity', Princeton University Press.

Artemiev, E. (974) 'The New Soviet Law on Inventive Activity'. Industrial Property July, 1974: 320-25.

Arundel A. (2002) 'Pharmaceurical Access and Research Incentives: Staying True To TRIPS?'; UNU/INTECH Technology Policy Briefs, Volume 1, Issue 3; hrtp://www.intech.unu.edu/publication/technology_policy/tpbs_2002_2004.php

Attaran A. (2004) 'How do Patents and Economic Policies Affect Access To Essential Medicines in Developing Countries?', Health Affairs, May/June, p155-166.

Attaran A., Gillespie-White L. (2001) 'Do Patents for Antiretroviral Drugs Constrain Access to Aids Treatment in Africa?, Journal of the American Medical Associarion 286, No.15: 1886-1892.

Authentication News (2003) 'Fighting fake pharmaceuticals: small steps. Nigeria atracks fakes', available ar www.authenticationnews.info. Available at www.lowyinstitute.com//Publicationget.asp/I=345

Bale, H. (1999) 'Pharmaceutical Access and Innovation: Challenges and Issues' Presented at International Roundtable on Responses to Globalization: Rethinking Equity and Health, July 12-14, Geneva, Switzerland.

Barder O., Levine R., Kremer M. (2005) 'Making markets for vaccines'; a report from the Center for Global Development, Washington DC hrrp://www.cgdev.org/vaccine 
Barro R. (1997) 'The Determinants of Economic Growth': A Cross-Country Empirical Study', Cambridge, MA: MIT Press.

Bar-Sholam A. and Cook-Deegan R. (2004) "Patents and innovation in cancer therapeutics: lessons from Cellpro", Milbanck Quarterly.

Barton J. (2001) 'Differenciated pricing of patented producs' CMH, a WHO Commission on Macroeconomics and Health, ed. CMH Working paper Series, paper nr. WG4; 2: 23.

Bate R., Porter K. (2008) 'Protecting Patents, Saving lives'; The American, Wednesday, March 5.

Bate R. (2007) 'The War Against Big Pharma'; The American, online at AEI, December 14.

Bate R., Tren R. (2006) 'The WTO and Access to Essential Medicines'; Health Policy Outlook, February 16.

Bate R., Tren R., Urbach J. (2005) 'Still taxed to death: An analysis of taxes and tariffs on medicines, vaccines, and medical devices, online ar $\mathrm{AEI}$, available at www.aei.org:publication 23938 .

Batson A., Ainsworth M. (2001) 'Private investment in AIDS vaccine development: obstacles and solutions', Bullecin of the World Health Organization, 2001, 79 (8).

Baumol W., Bradford D. (1970) 'Optimal departures from marginal cost pricing', Am Econ Rev, 60: 265-83.

Becker G. (1964) 'Human capital: A theorerical and empirical analysis with special reference to education; Third Edition, Chicago and London: The University of Chicago Press.

Bell C., Devarajan S., Gersbach H. (2003) 'Thinking about the Long-run Economic Costs of AIDS'. Wold Bank, October.

Bell C., Lewis M. (2005) 'The Economic Implications of Epidemics Old and New', Center For Global Development, Working Paper 54, February, Washington DC.

Bhagwati J. (2007) 'In Defense of Globalization', Oxford University Press, Inc., New York.

BIAG (2005) 'Patents are not trivial: the case for innovation in research and development within the biomedical industry', Article 5, Biomedical Industry Advisory Group; http://biag.org./index.hrm

BIO Ventures for Global Health (2006) "Advance Market Commitments for vaccines: A new tool in the fight against diseases and poverty", London, December 2. hrtp:/www.bvgh.org/news/report/BVGHReports.asp

Bloom D., Ajay M. (1997) 'Does the AIDS Epidemic Threaten Economic Growth?', Journal of econometrics, 105-124; Bloom D, Ajay M., Rosenberg L., Sevilla J., Steven D., and Weston M. (2004) 'Asia's Economies and the Challenge of AIDS, Asian Development Bank.

Bloom D., Canning D., Jamison D. (2004) "Health, Wealth, and Welfare", Finance and Development, March, Vol. 41, No. 1, pp. 10-15.

Bloom D., Canning D., Weston M. (2003) "The Value of Vaccination", World Economics, Vol. 6, No. 3, JulySeptember.

Boer, P. (2003) 'Risk-adjusted Valuation of R\&D Projects', Research and Technology Management, SepremberOctober, pp. 50-58.

Bonini S., Mendonca L., Oppenheim (2006), 'When Social Issues Become Strategic', The McKinsey Quarterly, Number 2.

Brealey, R., Myers S. (1988) 'Principles of Corporate Finance', 3 ${ }^{\text {rd }}$ ed. New York: McGraw-Hill, 1988, Ch.20, 21.

Brittan I. (1992) 'Brittan speech on pharmaceutical pricing (press release), Brussels: European Commission, 1992 Dec 2.

Bruneton, C. et al (1997), 'The drug trade between European countries and developing countries' Med. Trop. (Mars), 57, 375-379, 1997.

Brunetti A. (1997) "Wading Into Patent Pooling: The Clinton Justice Department is Becoming More Tolerant of High-Tech Patent Sharing Deals, Intellectual Property (Nov.) <http//www.ipmag.com/brunetti.heml).

Burton D. et al (2004) 'Public Health.: A sound rationale needed for phase III HIV-1 vaccine trials', Science, Jan $16 ; 303$ (5656): 316 .

Buse K,, Walt G. (2000) 'Global public-private partnerships, part I: a new development in health?' Bulletin of World Health Organization, pp. 549-61.

Carrin G. (2002) "Social health insurance in developing countries: a continuing challenge", International Social Security Review, Vol. 55. 
Chandler A. (1990) 'Scale and Scope: The Dynamics of Industrial Capitalism', Cambridge MA: Harvard University Press.

Chang-Xiao L. et al (2002), 'Recalling the research and development of new drugs originating from Chinese tradition and herbal drugs', Asian Journal of Drug Metabolism and Pharmacokinerics, No. 2, pp. 136-156, 2002.

Check E. (2005) Is this our best shot? Nature, 26 May; 435: 404-406.

Chesbrough H. (2003) "Open Innovation: The Next Imperative for Creating and Profiting from Technology", Harvard Business School Press.

Chin J. and Grossman G. (1990) 'Intellectual Property Rights and North-South Trade', in Jones R. and Krueger A. (eds.) The Political Economy of International Trade: Essays in Honor of Robert E. Baldwin (pp. 90-107) Cambridge, MA: Basil Blackwell.

Christie C. and Rotstein F. (2007) 'Intellectual Property Research Institute of Australia Working Paper No. 04.07 ISSN 1447-2317, June.

Clark J. et al (2005) "Patent Pools: A Solution to the Problem of Access in Biotechnology Patents?", December 2000, United States Patent Office).

Clark N. (2007) 'Gallois nudges Airbus toward cooperation: 'national pride' caused the A380 strife', International Herald Tribune, Friday, May 18, pp. 9.

Clark N., Perez-Trejo \& Allen P. (1995) Evolutionary Dynamics and Sustainable Development $\Lambda$ Systems Approach, Alderthot: Edward Elgar.

Clarkson K. (1996) 'The effects of research and promotion on rates of return' In: Helm R., editor. Competitive strategies in the pharmaceutical industry. Washington, DC. The American Enterprise Institute Press, 1996.

Clinton W. (2007), "Giving; how each of us can change the world", Published by Alfred A. Knopf, New York, USA.

Cockburn I. (2005a) 'Blurred Boundaries: Tensions Between Open Scientific Resources and Commercial Exploitation of Knowledge in Biomedical Research'; Conference on Advancing Knowledge and the Knowledge Economy, National Academy of Sciences, Washington DC, January 10-11, 2005. http://management.bu.edu/research/highlights.asp

Cockburn I. (2005b) 'State Street Meets the Human Genome Project: Intellectual Property and Bioinformatics' in R. Helm (ed.) Intellectual Property Rights in Frontier Industries: Biotechnology and Software, Washington DC: AEI-Brookings Press, 2005.

Cohen B. and Yamey G. (2005) "A Strategy for Developing an HIV Vaccine", The PloS Medicine Editors, PloS Med 2(1): e35; doi:10.1371/journal.pmed.0020035, published, January 18.

Comstock G., Sjolseth D. (1999) 'Aligning and Prioritizing corporate R\&D', Research Technology Management, May-June, pp19-25.

Cooper, R., et al (2000) 'New Problems, New Solutions: Making Portfolio Management More Effective', Resaearch Technology Management, March-April, pp 18- 33.

Cooper, R, et al (1998) 'Best Practices For Managing R\&D Portfolios', Research Technology Management', JulyAugust, $\mathrm{p} 20,14 \mathrm{p}$.

Copeland, T, Tufano P. (2004) 'A real world way to manage real options', Harvard Business Review, March 2004.

Coriat B., Orsi F., d'Almedia C. (2006) "TRIPS and the international public health controversies: issues and challenges" in "Information, Appropriability and the Generation of Innovative Knowledge" edited by Dosi G., Malerba F., Ramello G., Silva F., Industrial and Corporare Change, Volume 15, Number 6, December.

Cortada J., Fraser, H. (2005) 'Mapping the future in science-intensive industries: Lessons from the pharmaceutical industry', IBM Systems Journal, Vol. 44, No 1, pp. 163-183.

Cortright J., Mayer H. (2002) 'Sign of Life: the growth of biotechnology centers in the US', The Brookings Institution, Center on Urban and Metropolitan Policy.

Crespi G., Geuna A., Verspagen B. (2006) 'University IPRs and Knowledge Transfer, is the IPR ownership model more efficient? SPRU Science and Technology Policy Research, Paper $N^{\circ} 154$, The Freeman Centre, University of Sussex, UK. 
Criscuolo P., 2004) 'R\&D Internationalisation and Knowledge Transfer', Doctoral Dissertation, University of Maastrichr, The Netherlands.

D'Este P. (2002) 'The distinctive patterns of capabilities accumulation and interfirm heterogeneity: the case of the Spanish pharmaceutical industry' in Industrial and Corporate Change, Vol. 11, No. 4, pp. 847-874.

Daems R., Del Giudice G., Rappuoli R. (2005) "Anticipating crisis: Towards a pandemic flu vaccination strategy through alignment of public health and industrial policy", Vaccine 23, 5732-5742.

Danzon P., Nicholson S., Pereira N. S. (2005) "Productivity in pharmaceutical-biotechnology R\&D: the role of experience and alliances" Journal of Health Economics 24, 317 - 339.

Danzon P., Towse A. (2003), 'Differential Pricing for Pharmaceuticals: Reconciling Access, R\&D and Patents', Working Paper 03-7, AEI-Brookings Joint Center For Regulatory Studies; www.aei.brookings.org

Danzon P. and Furukawa M. (2003) "Prices and availability of pharmaceuticals: Evidence from nine countries", Health Affairs, W3: 521-536.

Danzon P. (1998), 'The Economics of Parallel Trade', Pharmacoeconomics 1998. Mar 13 (3).

Danzon P. (1997) 'Pharmaceutical Price Regulation: National Policies versus Global Interests, Washington, D.C.: AEI Press.

Danzon P., Percy A. (1996) 'The effects of price regulation on productivity in pharmaceuticals: studies on income and wealth'; 1996 Mar: Washington, DC.

Davis I. (2005), 'What is the Business of Business', The Mc Kinsey Quarterly, Number 3.

Day G., Reibstein D. (1997), 'Wharton on Dynamic Competitive Strategy', John Wiley \& Sons, Inc., New York, USA.

DeAngelis D (2000) 'Capturing the Option value of R\&D', Research 'Technology Management, July-August, pp. $31-34$.

Deaton A. (2004) 'Health in an Age of Globalization', Research Program in Development Studies, Center for Health and Wellbeing, Princeton University, July.

Deardorff, A. (1992) Welfare Effects of Global Protection', Economica, Vol. 59, pp. 35-51.

Delage G. ((2001), 'Rotavirus vaccine withdrawal in the United States: the role of post-marketing surveillance, The Canadian Journal of Infectious Diseases and Medical Microbiology, November 2001.

De Soto H. (2000) 'The Mystery of Capital: Why Capitalism Triumphs in the West and Fails Everywhere Else', Perseus Books Group, New York.

Desowitz, R. (1991) 'The Malaria Capers: Tales of Parasites and People', New York, W. Norton.

Desrosiers R. (2004) "Prospects for an AIDS Vaccine". Nar Med 10: 221-223.

Desowirz, R. (1991) 'The Malaria Capers: Tales of Parasites and People', New York, W. Norton.

Diamond, J. (1997) 'Guns, Germs and Steel', New York: W.W. Norton Publishing.

DiMasi J., and Grabowski H. (2004) "Patents and R\&D Incentives: Comments on the Hubard and Love Trade Framework for Financing Pharmaceutical R\&D" submission to CIPIH, p5.http://www.biag.org/BIAG/images/articles/art10.pdfp16

DiMasi J., Hansen R., Grabowski H. (2003) 'The price of innovation;: new estimates of drug development costs', Journal of Health Economics, 22 (2003) 151-185.

DiMasi, J. (1995a) 'Success Rates for New Drugs Entering Clinical Testing in the United States', Clinical Pharmacology and Therapeutics, Vol. 58, No 1, July, pp.1-14.

DiMasi,, J. (1995b) 'Trends in Drug Development Costs, Times, and Risks', Drug Information Journal, Vol. 29, pp 375-384.

DiMasi, J., Hansen, R, Grabowski, H., and Lasagna, L. . (July 1991).'Cost of Innovation in the Pharmaceurical Industry', J. Health Econ., Vol: 10, pp107-142.

Diwan, I. and Rodrik, D. (1991) 'Patents, Appropriate Technology, and North-South Trade', Journal of International Economics. 63, 79-90.

DND Working Group (2001), 'Fatal imbalance: The crisis in research and development for drugs for neglected diseases', 2001. 
Dosi et al (2006) "Information, appropriability, and the generation of innovative knowledge four decades after Arrow and Nelson: an introduction"; In "Information, Appropriability and the Generation of Innovative Knowledge"; (Eds.) Dosi G., Malerba F., Ramello G., Silva F., Industrial and Corporare Change, Volume 15, Number 6, December.

Drummond M. (2001) "The use of economic evidence by healthcare decision makers", European Journal of Health Economics, 2:2-3.

Drummond M., O'Brien B., Stoddart G., Torrance G. (1997) 'Methods for the Economic Evaluation of Health Care Programmes', Second edition, Oxford, United Kingdom: Oxford University Press.

Duetsch L. (2002) 'Pharmaceuticals: The critical role of innovation', In: 'Industry studies', third edition, Duetsch L., 2002.

Duetsch L. (2002) 'Pharmaceuticals: The critical role of innovation', In: 'Industry studies', third edition, Duetsch L., 2002.

Dussault G. and Dubois C. (2003) "Human resources for health policies: a critical component in health policies", Human Resources for Health.

Dyer G. (2004), 'A laboratory for globalisation: How India hopes to reshape the world drugs industry', Financial Times, august 18, 2004.

Dykman H. (1964), "Patent Licensing within the Manufacturer's Aircraft Association (MAA), 46 J. PAT. OFF. SOC'Y, 646, 648.

Eisenberg R. (2006) "Patents and data-sharing in public science"; In "Information, Appropriability and the Generation of Innovative Knowledge"; (Eds.)

EMEA (2004), 'Roadmap to 2010: preparing the ground for the future, March 2004.

Eppen G., Gould F., Schmidt C. (1998) 'Quantitative Concepts for Management: decision making without algorithms, $3^{\text {rd }}$ edition.

European Commission (2007) "Trade helps growth"; by the Permanent delegation of the European Commission to the International Organisations in Geneva;

europe.eu/eu/trade_helps_growth.hrm

European Commission. (2005) Pandemic influenza preparedness planning: report on a joint WHO/European Commission workshop, Luxemburg, 2-3 March.

(europa.eu.int/comm/health/ph_threachs/com/Influenza/influenza_en.htm).

European Commission (2005) Towards sufficiency of pandemic influenza vaccines in the EU, Brussels 2005, 22 April.

(europa.eu.int/comm/health/ph_threaths/com/Influenza/influenza_en.htm)

European Vaccine Manufacturcrs. (2005) Influenza pandemic preparedness: EVM Proposal for an action plan between European Vaccine Manufacturers (EVM) and Member States with the support of the European Commission, 2005 (www.evm-vaccines.org).

Etro F. (2007) "Proprietary Software vs. Open Source Software" in "Know IP - The Stockhoim Network's Monthly IPR Journal" Vol. 3: Issue 5, July.

Fauci A. (2003) "HIV and AIDS: 20 years of Science". Nat Med 9: 839-843.

Fauci AS. (2005) Race against time. Nature, 26 May; 435: 423-424.

Farlow A. (2007) "A Global Medical Research And Development Treaty: An answer to global health needs?"; International Policy Press - a division of International Policy Nerwork, London.

Farlow A. (2005), "The Global HIV Vaccine Enterprise, Malaria Vaccines, and Purchase Commitments: What is the Fit? www.biodevelopments.org/innovation

Fauci A. (2008) "US Overhauls Aids Research", Financial Times, Wednesday March 26, p. 8.

Faulkner, T. (1996) 'Applying 'Options Thinking' to R\&D Valuation', Research Technology Management, MayJune, pp 50-56.

Fedson DS. (2005) Preparing for Pandemic Vaccination: An International Policy Agenda for Vaccine Development. Journal of Public Health Policy; 26: 4-2.9.

Fedson DS. (2003) Pandemic influenza and the global vaccine supply. Clin. Infect. Dis.; 36:1552-61. 
Ferguson NM, Cummings DA, Cauchemez S, Fraser C, Riley S, Meeyai A, Lamsirithaworn S, Burke DS. (2005) 'Strategies for containing an emerging influenza pandemic in Southeast Asia'. Nature. (doi:10.1038/nature04017).

Fogel R. (1995) 'The Contribution of Improved Nutrition to the Decline of Mortality Rates in Europe and America' in The Sate of Humanity, ed. Julian L. Simon, Cambridge, MA: Blackwell, 61-71.

Food and Drug Administration (FDA) (2004) 'Innovation, Stagnation: Challenge and Opportunity on the Critical Path to New Medical products', US Department of Health and Human Services, Food and Drug Administration, March 2004.

Furman, Kyle, Cockburn, Hendserson (2005) 'Knowledge spillovers, geographic location, \& the productivity of pharmaceurical research' Forthcoming, Annales d'Economie er de Statistique.

Fuss S. (2008) 'Sustainable Energy Development under Uncertainty', Published by Universitaire Pers Maastricht, ISBN 9789052787077

http://www.merit.unu.edu/training/theses/fuss_ub_thesis.pdf

Galambos L., Sturchi J. (1998) 'Pharmaceurical firms and the transition to biotechnology: A study in strategic innovation'; Harvard Business School Business History Review, 72: 250-278.

Gallo R., Montagner L. (2003) 'Debats et Opinions', Le Figaro, No 18293, 2 June.

Gambardella A., Orsenigo L., Pammoli F. (2000) 'Global Competitiveness in Pharmaceuticals: A European Perspective, Report Prepared for the Directorate General Enterprise of the European Commission, Brussels, Belgium: Enterprise of the European Commission, November.

Garber A. (2000) 'Advances in cost-effectiveness analysis of health interventions; In: Culyer A and Newhouse J, eds.' Handbook of health economics, Vol.1. Amsterdam North Holland; 181-221.

Garnier (2008) 'Rebuilding the R\&D Engine in Big Pharma'; Harvard Business Review, May.

Garrett L. (2007) 'The Challenge of Global Health', Foreign Affairs, January/ February, http://www.foreignaffairs.org/2007

Garrett L. (2005) 'The Lessons of HIVIAIDS'; in 'The Next Pandemic?', Foreign Affairs, Volume 84, Number 4, July/ August, 51-64.

GATB (2002-2003), Global Alliance for TB Drug Development 'The Economics of TB Drug Development', October, 2001.

Gerdil C. (2003) The annual production cycle for influenza vaccine. Vaccine;21:1776-9.

Ghosh R. and Soete L. (2006) "Information and Intellectual Propercy: The Global Challenges", in "Information, Appropriability and the Generation of Innovative Knowledge" edited by G. Dosi, F. Malerba, G. Ramello, F. Silva; Industrial and Corporate Change, Volume 15, Number 6, December.

Ghosh R. and Glott R (2005) "The Open Source Community as an environment for skills development and employment generation" Proceeddings of the European Academy of Management (EURAM) Conference, Munich, 4-7 May. Available at http://flosspols.org/deliverables/FLOSSPOLS-D10-

skils\%20survey_interim_report-revision-FINAL.pdf, version prepared for the European Commission.

Ghosh R. (ed.) (2005), CODE: Collaborarive Ownership and the Digital Economy, MIT Press: Cambridge, MA.

Ghosh R., Glott R., Krieger B., Robles G. (2002) "Free/Libre/Open Source Software Study: Survey of Developers, MERIT/Institute of Infonomics for the European Commission FLOSS Project. Available at http://flossproject.org/report/.

Gilchrist M., Fraser H., Van Dyck W. (2005) 'Transforming Industrialization: A new paradigm for pharmaceurical development' IBM Business Consulting Services.

Gilpin R. (2001) 'Global Political Economy: Understanding the International Economic Order'; Princeton University Press, Princeton, New Jersey.

Gilpin R. (2000) 'The Challenge of Global Capitalism: The World Economy in the 21 1 st Century", Princeton University Press, Princeton, New Jersey.

Global Forum for Health Research (2002), 'The Report on Health Research 2001-2002'. Switzerland, April.

Goklany I. (1995) 'Strategies to Enhance Adaptability: Technological Change, Sustainable Growth and Free Trade', Climate Change 30: 427-49. 
Gostin L. (2006) Medical countermeasures for pandemic influenza: Ethics and the law. JAMA, February 1, Vol 295, No 5.

Grabowski H. (2005) 'Encouraging The Development Of Ncw Vaccines', Health $\Lambda$ ffairs, Volume 24, Number 3 , May/June, pp. 697-700.

Grabowski, H., Vernon J. and DiMasi J. (2002) 'Returns on Research and Development for 1990s New Drug Introductions, PharmacoEconomics, Vol. 20, Suppl 3: pp11-29.

Grabowski, H. and Vernon J. (2000) 'Effective parent life in pharmaceuticals', Int. J. Technology Management, Vol. 19, Nos 1-2.

Grabowski,H. and Vernon J. (1996) 'Longer patents for increased generic competition: The Waxman-Hatch Act after one decade', PharmacoEconomics, Vol.10, Suppl 2, pp 110-123.

Gringle R., Bahamon C. (2003) "Promoting effective antimalarial strategies while ensuring good pharmaceutical and commodity management", Management Sciences for Health, Volume 12, Number 1, p. 1-3).

Grossman, M. (1972), 'On the concept of health capital and the demand for health'; Journal of Political Economy, 80(2): 223-255.

Haffner, M, Whitley, J., Moses M. (2002) 'Two decades of orphan product development', Nature Rev. Drug Discov., 1, 821-825 (2002).

Hehme N., Engelmann H., Knuzel W., Neumeier E., Sanger R. (2002) ,Pandemic preparedness lessons learnt from H2N2 and H9N2 candidate vaccines' Med. Microbiol. Immunol. (Berl); 191:203-08.

Heller M. and Eisenberg R. (1998) "Can parents deter innovation? The anticommons in biomedical research", Science, 280, 698-701.

Hellman T. (2005) 'The role of Patents for Bridging the Science to Market Gap', NBER Working Paper $\mathrm{N}^{\circ} 11460$.

Henderson, R. and Cockburn I. (1996) 'Scale, Scope and Spillovers: Determinants of Research Productivity in the Pharmaceutical Industry', RAND Journal of Economics. Vol. 27, no. 1, pp 32-59.

Henderson R. and Cockburn I. (1994) 'Measuring competence? Exploring firm effects in pharmaceutical research' Strategic Management Journal 15 (Winter Special Issue): 63-84.

Higgins, R. (1998) 'Analysis for Financial Management', Irwin/McGraw-Hill, USA.

Hippel von E. (2004) "Democratizing Innovation", MIT Press: Cambridge, MA.

Hirschy, M., and Pappas, J.L. (1998) 'Fundamentals of Managerial Economics' The Dryden Press. htrp://www.aei-brookings.org/events/page.php?id=129; accessed on 11 Nov. 2005.

Hollis A. (2006) "Determining Rewards in a Prize Fund", Drug Development, 8 July.

Hubbard T., Love J., 2004 'A New Trade Framework For Global Healthcare R\&D' PloS Biology, February, 2004; 2(2): 147-150.

Hughes, F., (1945) 'Soviet Invention Awards'. Economic Journal June-Seprember, 1945: $291-97$.

Hughes, F., (1946) 'Incentive for Soviet Initiative'. Economic Journal September, 1946: 415-25.

Hull, T. G. (1963) 'Disease Transmitted from Animals to Man', (5ch Edition.) Springfield, Illinois.

Hulse-Post DJ, Sturm-Ramirez KM, Humberd J, Seiler P, Govorkova EA, Krauss S, Scholtissek C, Puthavathana P, Buranathai C, Nguyen TD, Long HT, Naipospos TSP, Chen H, Ellis TM, Guan Y, Peiris JSM, Webster RG. (2005) 'Role of domestic ducks in the propagation and biological evolution of highly pachogenic $\mathrm{H} 5 \mathrm{~N} 1$ influenza viruses in Asia. PNAS 2005, Proceedings of the National Academy of Sciences of the United States of America; July 26, vol 102, no.30:10682-10687.

Iademarco MF, Castro KG (2003) 'Epidemiology of tuberculosis'; Seminars in respiratory infections 18 (4), 22540. PMID 14679472

IAVI/ International Aids Vaccine Initiative (2000), AIDS Vaccines for the World: Preparing Now to Assure Access, An IAVI Blueprint, June, New York.

IFPMA (2007) International Federation of Pharmaceutical Manufacturers \& Associations; 'Research and Development: Quick facts',

http://www.ifpma.org/Issues/index.php?id=421

IFPMA (2003) 'Patents, patients and developing countries: Harmony or discord?, Speech by Harvey E. Bale, hrtp://wwww.ifpma.org/News/SpeechDetail.aspx 
IFPMA (2005) 'TRIPS amendment permanently resolves export compulsory license issue', 06 December 2005; http://www.ifpma.org/News/NewsReleaseDetail.

IFPMA (2005) 'Impact of India's Adoption of TRIPS: Access to medicines in the developing world', Article 8, Biomedical Industry Advisory Group; http://biag.org./index.hem

IFPMA (2004), 'The Pharmaceutical Innovation Platform', International Federation of Pharmaceutical Manufacturers Associations, Geneva, October 2004.

IFPMA (2004) 'International Pharmaceutical Manufacturers Associations', http://www.ifpma.org/Issues/issues_research.aspx

IFPMA (2003), 'Research and Development', http://www.ifpma.org/Issues_corp.aspx

Institute of Medicine (1997) "America's Vital Interest in Global Health", National Academy of Sciences, National Academy Press, Washington DC.

IPPPH (2002) 'Initiative on Public-Private Partnerships for Health' http://www.ippph.org

Iren T., Gerhardsen S. (2007) EPO event highlights: Long-term scenarios for IP system" Intellectual Property Watch, May 2007, Vol.4, No.5, p.4-5.

Jack A. 2005) Drug groups set sights on bird flu vaccine. Financial Times, August 16: 19-24.

Jaffe, A. and Lerner J. (2001) 'Privatizing R\&D: Patent Policy and the Commercialization of National Laboratory Technologies', The RAND Journal of Economics. Vol. 32, no. 1.

Jensen and Thursby (2001) 'Proofs and Prototypes for Sale: The Tale of University Licensing', p.3, in National Instituces of Health.

Katz JM. (2004) 'Preparing for the next influenza pandemic'. ASM News; 70, 9:412-419.

Ketter, H. Towse, A. (2002) 'Public private partnerships for research and development: medicines and vaccines for diseases of poverty'; Office of Health Economics, London.

Kettler H. et al (2001) 'Building local research and development capacity for prevention and cure of neglected diseases: the case for India. Bul. World Health Organization, 79, 742-747, 2001.

Kettler H. (2000) 'Narrowing the gap between provision and need for medicines in developing countries', OHE, London, UK.

Kettler, H. (1998) 'Competition through Innovation, Innovation through Competition', OHE, London, UK.

Kremer M, Glennerster R. (2004) Strong Medicine: Creating Incentives for Pharmaceutical Research on Neglected Diseases. Princeton University Press.

Klausner R., Fauci A., Corey L., Nabel G., Gayle H., et al (2003) "The need for a global HIV/AIDS vaccine enterprise", Science 300: 2036-2039.

Knowledge Ecology International (2007) "IGWG Briefing Paper on Patent Pools", KEI Research Note 2007:3(1), January

Kremer M, Glennerster R. (2004) Strong Medicine: Creating Incentives for Pharmaceutical Research on Neglected Diseases. Princeton University Press, 2004.

Kremer, M. (2000) 'Creating markets for new vaccines. Part I: Rationale, Parr II: Design Issues, Harvard University, 2000.

Kremer, M. (1999b) 'Pre-commirments to Purchase New Vaccines Parr II: Design Issues', Harvard University.

Kumarasamy N. (2004) "Generic antiretroviral drugs - will they be the answer to HIV in the developing world?" The Lancet, vol 364.

Kumra G. (2006) 'One business commitment to society: An interview with the president of the Novartis Foundation for Sustainability Development, The McKinsey Quarterly, August.

Laffont J., Tirole J. (1993) 'A theory of incentives in procurement and regulation', Cambridge: MIT press.

Lanjouw, J. (2002) 'Intellectual Properry and the Availability of Pharmaceuticals in Poor Countries'. Working Paper No. 5, Center for Global Development, April 2002.

Lanjouw, J. and Cockburn I. (2001) 'New Pills for Poor People?' Empirical Evidence After GATT', World Development. Vol. 29, no. 2, pp. 265-89.

Lichtenberg F. (1998) 'Pharmaceutical innovation, mortality reduction, and economic growth' National Bureau of Economic Research, Working paper 6569, May. 
Loch, C., Bode-Greuel K.(2001) 'Evaluating growth options as sources of value for pharmaceutical research projects', R\&D Management 31, 2, 2001, Blackwell Publishers Ltd.

Longini IM, Nizam A, Xu S, Ungchusak K, Hanshaoworakul W, Cummings DA, Halloran E. Containing pandemic influenza at the source. Science(xpress) 2005; 3 August.

Love J. and Hubbard T. (2007) "The Big Idea: Prizes to Stimulate R\&D for new Medicines", Knowledge Ecology International, KIA Research Paper 2007:1

Love J. and Hubbard T. (2004) "A New Trade Framework for Global Healthcare R\&D", PLOS Biology, June 25, 2(2):e52 DOI:10.1371/journal.pbio.0020052.

Lumby, S., Jones C. (2001) 'Investment Appraisal and Financial Decisions', Thomson Learning, London, UK.

Lundvall B. (1992) "Innovation as an Interactive Process: From User-Producer Interaction to the National System of Innovation" in Giovanni Dosi, Christopher Freeman, Richard Nelson, Gerald Silverberg and Luc Soete, eds., Technical Change and Economic Theory, Pinter Publishers, UK, pp. 349-369.

MacKenzie D. (2005) US flu vaccine trials may be effort wasted. New Scientist; March 26 (Magazine issue 2492).

Maes, E. (2002), Value-based Pricing of Pharmaceutical Innovations, Unpublished Doctoral Dissertation, Maastricht School of Management, The Necherlands.

Mani S. (2000) 'Policy instruments for stimulation of R\&D in the enterprise sector. The contrasting cxperiences of two MNC dominated economies from South East Asia, The United Nations University, INTECH, Maastricht.

Mani S. (1999) 'Public innovation policies and developing countries in a phase of economic liberalisation', Discussion Paper Series, Institute for New Technologies, The United Nations University, INTECH, Maastricht.

Mansfield, E. (1999) 'Managerial Economics: Theory, $\Lambda$ pplications, and Cases', W.W. Norton \& Company, Inc.

Mansfield, E. (1986) 'Patents and Innovation: An empirical study', Management Science, Vol. 32, No 2, pp173181.

Maponga C., Ondari C. (2003) 'The quality of antimalarials: A study in selected African countries' World health Organization, Department of Essential Drugs and Medicines Policy, May.

Marchant N. 'Risk and return in the pharmaceutical industry', Office of Health Economics, August 1999, London.

Maurer S., Rai A., Sali A. (2004) 'Finding Cures for Tropical Diseases: Is Open Source an Answer', PloS Medicine, Dec. 2004.

McArthur, W. (1999) "Intellectual Property Rights and the Pharmaceutical Industry", The Fraser Institute, pp. 85-104.

Mc Grath, R, Mac Millan I. (2000) 'Assessing Technology Projects Using Real Options Reasoning', Research Technology Management, July-August, pp 35-49.

McDonough E., Spital F. (2003) 'Managing Project Portfolios', Research Technology Management, May - June, pp 40-46.

McGuigan, J.R., Moyer, R. C., Harris F.H. deB (1999) 'Managerial Economics: Applications, Strategy, and Tactics, South-Western College Publishing.

McKibbin W., Sidorenko A. (2005) 'Global macroeconomic consequenses of pandemic influenza' Sydney: The Lowy Institute.

McLauchlin A. (2005) EU braced for crisis as flu pandemic threatens. European Voice; 28 July- 31 August.

Merges, R. (1999) "Institutions for Intellectual Property Transactions: The Case for Patent Pools (August), www.law.berkeley.edu/institutes/bcit/pubs/merges>.

Microcredit Summit Campaign (2005) "State of the Microcredir Summit Campaign Report 2005"; http//www.microcreditsummit.org/pubs/reports/socr02_en.pdf.

Milne, C., Kaitin K., Ronchi E. (2001) 'Orphan drug laws in the United States and Europe: Incentives for the research and development of medicines for neglected diseases, Tufrs Centre, OECD, December, 2001.

Ministry of Health, Labour and Welfare (2002) 'Pharmaceutical Industry Vision', Action Plan, 30 August 2002.

MMV (2003), 'Medicines for Malaria Venture, Annual Report, 2002.

Monto AS. (2005) The threat of an avian influenza pandemic. N. Engl. J. Med.; January 27; 352; 4: 323-325. 
Morgan M, Henrion M. (1990) 'Uncertainty. A Guide to Dealing with Uncertainty in Quantitative Risk and Policy Analysis; Cambridge University Press.

Morris A., Stevens P., Gelder van A. (2005) 'Incentivising Research and Development for the Diseases of Poverty', International Policy Network, London, UK.

Morris, P., Teisberg E., Kolbe, L. (1991) 'When Choosing R\&D Projects, Go With the Long Shots', Research Technology Managennent, January-February, pp. 35-40.

Mowery D., Sampat B. (2001) 'University patents and patent policy debates in the USA, 1925-1980'; Industrial and Corporate Change, 10(3): 781-814.

Mrazek, M. et al (2003), 'Stimulating pharmaceutical research for neglected diseases', Health Policy (New York) $64,75-88,2003$.

MSF (2001) Medecins Sans Frontiers Access to Essential Medicines Campaign: Fatal imbalance, the crisis in research and development for drugs for neglected diseases, 2001.

Muraskin W. (1999) 'Vaccines for developing countries; who will pay?, The Albert Sabin Vaccine Institute Colloquium ar Cold Spring Harbor, December 5-7, 1999.

Myers S. (1996) 'Measuring pharmaceutical risk and the cost of capital'. In: Sussex J., TBC

Myers S., Howe C. (1997) 'A life-cycle financial model of pharmaceutical R\&D'. working paper; program on the pharmaceutical industry, Massachusetts Institute of Technology, Cambridge (MA): MIT.

Mytelka L. (2003) 'Pathways and Policies to (Bio) Pharmaceutical Innovation Systems in Developing Countries', International Workshop: Building (Bio) Pharmaceutical Systems in Developing Countries, INTECH, Maastricht, 26-27 February.

Mytelka L. (2003) 'Building (Bio)Pharmaccutical Innovation Systems in Developing Countries: A Framework for Analysis', International Workshop: Building (Bio) Pharmaceutical Systems in Developing Countries, INTECH, Maastricht, 26-27 February.

Mytelka L. (2002); UNU/INTECH Technology Policy Briefs, Volume 1, Issue 3, 2002.

Mytelka L. (1999a) 'Competition, Innovation and Competitiveness: A framework for Analysis" in L.K. Mytelka (ed.) Competition, Innovation and Competitiveness in Developing Countries, Paris: OECD Development Centre, pp.15_32.

Naik G., Whalen J. (2004) 'Sanofi-Aventis marriage could spark merger fever', Wall Street Journal Europe, Vol. XXII No. 60, Tuesday, April 27, 2004.

National Institutes of Health (NIH) (2001) 'A Plan to Ensure Taxpayer Interests are Protected," NIH Response to the Conference Report Request for a Plan to Ensure Taxpayers' Interests are Protected, July 2001. http://www.nih.gov/news/070101wyden.htm> (1 September 2001)

National Academy of Sciences (2007) 'Innovation Inducement Prizes: Committee on the Design of an National Science Foundation Innovation Prize; National Research Council; ISBN 978-0-309-66834-7.

Nature (2007) 'An Audience with Paul Herrling: Why has Novartis recently decided to have R\&D presence in China?, Nature, March, p.180.

Nelson R (2006) "Reflections on "The Simple Economics of Basic Scientific Research": looking back and looking forward; In "Information, Appropriability and the Generation of Innovative Knowledge"; (Eds.) Dosi G., Malerba F., Ramello G., Silva F.; Industrial and Corporate Change, Volume 15, Number 6, December.

Nelson R. (1993) "The Simple Economics of Basic Scientific Research" Journal of Political Economy, June, 1959 reproduced in N. Rosenberg (ed.) The economics of technological change" U.K.: Pinguin, pp. 148-163.

Nelson R., and Winter S. (1982) An Evolutionary Theory of Economic Change", Harvared University I'ress, Cambridge, Ma.

Newton D., Pearson A. (1994) 'Application of Option Pricing Theory to R\&D', R\&D Management, 24, 1, pp.83-89.

New York 'Times (2007) 'The Soul of a New Vaccine', Health, Research, December 11.

Nichols, N. (2000) 'Scientific Management at Merck: An interview with CFO Judy Lewent', Harvard Business Review, January-February, 1994. 
Nicholson KG, Colegate AE, Podda A, Stephenson I, Wood J, Ypma E, Zambon MC. (2001) Safety and antigenicity of non-adjuvanted and MF59-adjuvanted influenza A/Duck/Singapore/97 (H5N3) vaccine: a randomized trial of two potential vaccines against $\mathrm{H} 5 \mathrm{~N} 1$ influenza. The Lancer;357:1937-1943

Nightingale, P. (2000) 'Economies of scale in experimentation; knowledge and technology in pharmaceutical R\&D', Industrial and Corporate Change 9(2):315-359.

Nightingale, P., Paul, M. (2004) 'The myth of the biorech revolution' Trends in Biotechnology Vol. 22, Issue 11, November: 564-569.

Nordhaus W. (1969) 'Invention, Growth and Welfare: A Theoretical Treatment of Technological Change', Cambridge, Mass.

Nordhaus W. (1972) 'The Optimum Life of a Patent: Reply'; The American Economic Review, Vol. 62, No. 3 (June), pp. 428-431.

Nossal, G. (2000), 'Modern medicine and global communicable diseases: new partnerships for progress', Aust NZ J. med. 30, 267-271, 2000.

Nwaka, S., Ridley, R. (2003) 'Virtual drug discovery and development for neglected diseases through publicprivate partnership', Nature Reviews - Drug Discovery, 2, November, 2003.

Obstfeld M, Rogoff K. (1996) "Foundations of Internarional Macroeconomics"; Cambridge: MIT Press, 473.

Olcay M., Laing R. (2005) 'Pharmaceutical Tariffs: What is Their Effect on Prices, Protection of Local Industry and Revenue Generation? (study, Commission on Intellectual Property Rights, Innovation and Public Health; World Health Organization, May, Geneva.

Osterholm MT. (2005) 'A weapon the world needs.' Nature 2005, 26 May; 435: 417-418.

PhRMA (2003), 'Dramatic Growth of Research and Development', Pharmaceutical Research and Manufacturers of America, Washington DC, USA.

PhRMA (2003), 'Incentives to Discover New Medicines: Pharmaceutical Patents', Pharmaceutical Research and Manufacturers of America, Washington DC, USA.

PhRMA (2003), 'Increased Length and Complexity of the Research and Development Process', Pharmaceutical Research and Manufacturers of America, Washington DC, USA.

Pindyck R. (1991) 'Irreversibility, Uncertainty and Investment', Journal of Economic Literature, 29 (3), 11101148.

Pindyck R. (1993) 'Investments of Uncertain Cost', Journal of Financial Economics, 34, 53-76.

Pisano G. (2006) 'Science Business: The Promise, The Reality, and The Future of Biocech'; Harvard Business School Press, Boston, Massachusetts.

Plahre, J. (2005) 'Tiered pricing of vaccines: a win-win-win situation, not a subsidy', Center for Technology, Innovation, and Culture (TIK-Centre), University of Oslo, Norway, http://infectionthelancet.com, Vol 5 january 2005.

Podda A, Del Giudice G. (2004) 'MF59 adjuvant emulsion' In: Levine MM et al, editors. New Generation Vaccines, $3^{\text {rd }}$ Edition, New York, Marcel Dekker, 2004, 225-235.

Pogge T. (2005) "A New Approach to Pharmaceurical Innovations" Online Opinion, 21 June.

Poisal J. and Chulis G. (2000) "Medicare beneficiaries and drug coverage", Health Affairs, 19(2).

Polt W., Rammer C., Gassler H. (2001) 'Benchmarking industry-science relations: the role of framework conditions. In Science and Public Policy, vol. 28, no 4, August 2001, pp 247-258.

Pomerance L. Bioshield (2005) Slow progress. AAAS Center for Science, Technology, and Congress, S\&T Newsletter; August. (www.aaas.org/spp/cstc/stc/index.shtml).

Porter M. et al (2002) 'The Global Competitiveness Report 2002-2002', Oxford University Press, New York, Oxford.

Prahalad C.K. (2006) "The Fortune at the Bottom of the Pyramid"; Wharton School Publishing.

PriceWaterhouseCoopers (2001) 'The Critical Role of R\&D in the Development of New Drugs' (Washington, DC: PWC).

PricewaterhouseCoopers (2007) "Gearing up for a global gravicy shift: growth, risk and learning in the Asia pharmaceutical market", PricewaterhouseCoopers. 
Pritchett L. and Summers H. (1996) 'Wealthier is Healthier'. Journal of Human Resources, 31:841-68.

Ramsey F. (1927) 'A contribucion to the theory of taxation', Econ J; 37: 47-61.

Rawlins M. (2004) 'Cutting costs of drug development? Nature Reviews Drug Discovery, Vol. 3, No 4, April 2004.

Reekie W. (2002) 'The development trilemma and the South African response' in Granville, B. 'The economics of essential medicines', pp. 161-177, The Royal Institute of International Affairs.

Reich, M. (2000), 'The global drug gap', Science, 287, 1979-1981, (2000).

Reiss T. and Hinze S. (2000) 'Innovation process and techno-scientific dynamics', in 'Changing innovation in the pharmaceutical industry', A. Jungmittag, G. Reger and T. Reiss (Eds.), Berlin, Springer.

Remme J. et al (2002), 'Strategic emphasis for tropical disease research: $\Lambda$ TDR perspective', Trends Parasitol., 18,421-426, 2002.

Research \& Development (R\&D) Scoreboard (2002) http://www.innovation.gov.uk/projects/rd_scoreboard/analysis/analysis

Ridley D., Grabowski H., and Moe J. (2006), 'Developing drugs for developing countries', Health Affairs, 25, no. 2: 313-324.

Ridley R. (2002) 'Medical need, scientific opportunity and the drive for antimalarial drugs, Nature, Vol 415, 7 february.

Roberts I. (1994) 'Evaluating R\&D Investments', Scrip Magazine, pp 16-18, 1994.

Ross B. (1991) 'Managing R\&D as an Opportunity Center.' Portland International Conference on Management of Engineering and Technology, pp. 149-152.

Rozek R. (2000) "The effects of compulsory licensing on innovation and access to healthcare", NERA, September.

Sachs J. (2005) "The End of Poverty: Economic Possibilities for Our Time", Pinguin Books, USA.

Sachs J. (1999) 'Helping the World's Poorest', The Economist, August 14, 16-22.

Saleh K. and Ibrahim M. (2005) "Are essential medicines in Malaysia accessible, affordable and available?" Pharmacy World \& Science, 27:6 442-446.

Salinsky E. (2004) 'Tick-tock: Preparing for the next influenza pandemic', Washington DC, National Health Policy Forum, 2004, NHPF Background Paper; August 27

Sampath, P. (2005) "Regulating Bioprospecting: Institutions for Drug Research, Access and Benefit-Sharing'; United Nations University Press.

Samuels G. (1999) 'Managing Risk - the Pfizer Approach'. In: Sussex J., Marchant N. 'Risk and rerurn in the pharmaceutical industry', Office of Healch Economics, August 1999, London.

Samuelson P. (1954) "The Pure Theory of Public Expenditures", Review of Economics and Statistics, vol. 36, no. 4, November, p. 387-89)

Schwartz B, Gellin B. (2005) Vaccination strategies for an influenza pandemic. Journal of Infectious Diseases, 15 April; 191: JID editorial commentary.

Scherer F. (1993), "Pricing, profits and technological progress in the pharmaceutical industry", Journal of Economic perspectives, 7(3),97-115.

Scherer, F. (1980), "Industrial Market Structure and Economic Performance". Houghton Mifflin: Boston.

Schmokler J. (1962) 'Economic Sources of Inventive Activity', Journal of Economic History, Vol.22, p.1-10.

Schmokler J. (1966) 'Invention and Economic Growth', Cambridge (Mass.): Harvard University Press.

Schumpeter J. (1942) 'Capitalism, Socialism, and Democracy', New York: Harper and Brothers.

Schweitzer S. (1997) 'Pharmaceutical Economics and Policy', Oxford University Press, New York.

SCRIP (2003), 'Indian drug research at fraction of global costs', Scrip, No. 2863, 2 July 2003.

Sender, G. (1994) 'Option Analysis at Merck', Harvard Business Review, 72, January-February, pp. 90-99.

Shapiro R. (2007) "Remarks to the CSIS Forum on Intellectual Property Rights: Implications for Economic Development", April 4, Washington DC.

Shavell S. and van Ypersele T. (2001) "Rewards versus Rights", Journal of Law and Economics vol. 44: 525-547. Previously published as Discussion Paper No. 246. "Rewards versus Intellectual Properry Rights", Harvard Law School, Olin Center for Law, Economics \& Business, 1998. 
Scherer F. (1972) 'Nordhaus' Theory of Optimal Patent Life: A Geometrical Reinterpretation', Amer. Econ. Rev., Junc, 62, 428-30.

Sherwood R. (2000) "The economic importance of judges" Federal Circuit Bar Journal, 9(4):619-633.

Shorr C. (2000) "Eliminating World Poverty: Making Globalisation Work for the Poor"; White Paper on International Development - Presented to Parliament by the Secretary of State for International Development by Command of Her Majesty, London, UK, December.

Simon J. et al (2005) "Managing severe acure respiratory syndrome (SARS) intellectual property rights: the possible role of patent pooling. WHO Bulletin, Volume 83, Number 9, September, 641-720).

Smart, S., Megginson, W., Gitman, L. (2004) 'Corporate Finance', South-Western, a division of 'Thomson Learning.

Smith R., MacKellar L. (2007) 'Global public goods and the global health agenda: problems, priorities and potential'; Globalization and health, 22 September http://www.globalizationandhealth.com/content/3/1/9

Soete L. (2008) "Science, Technology and Development: Emerging Concepts and Visions"; United Nations University (UNU-MERIT) Working Papers; \# 2008-001, January.

Spilker, B.and Cuatrecasas, P., (1990) 'Inside the Drug Industry', Prous Science Publishers, Barcelona.

Stephenson I, Bugarini, Nicholson KG, Podda A, Wood JM, Zambon MC, Katz JM. (2005) Cross-reactivity to highly pathogenic avian influenza $\mathrm{H} 5 \mathrm{~N} 1$ viruses after vaccination with nonadjuvanted and MF59-adjuvanted influenza A/Duck/Singapore/97 (H5N3) vaccine: A porential priming strategy. Journal of Infectious Diseases, 15 April; 191: 1210-1215.

Stephenson I, Nicholson KG, Colegate A, Podda $\Lambda$, Wood J, Ypma E, Zambon M. (2003) Boosting immunity to influenza H5N1 with MF59-adjuvanted H5N3 A/Duck/Singapore/97 vaccine in a primed human population. Vaccine; 21: 1687-1693.

Stephenson I, Nicholson KG, Gluck R, Mischler R, Newman RW, Palache AM, Verlander NQ, Warburton F, Wood JM, Zambon MC. (2003) Safety and antigenicity of whole virus and subunit influenza A/Hong Kong/1073/99 (H9N2) vaccine in healthy adults: phase I randomized trial. The Lancet, 13 December; 362: $1959-1966$.

Stevens P. (2007) "Fighting the Diseases of Poverty", International Policy Press; a division of International Policy Network, London.

Stevens P. (2007) 'If It Ain't Broke, Why Break It?, Investor's Business Daily, 7 November.

Stevens P. (2006) Fake drugs and weak states breed a hidden pandernic. European Voice, February 23-March 1, pp. 9.

Stevens P. (2005) "Free Trade For Betrer Health"; International Policy Network, London, UK www.policynetwork.net

Stevens P., Gelder van A. (2005) 'Incentivising Research and Development For The Diseases Of Poverty', International Policy Press, London, UK.

Stiglizz, J. (2006) "Making Globalization Work", W.W. Norton \& Company, Inc., 500 Fifth Avenue, New York, N.Y. 10110 , www.wwnorton.com.

Stiglitz J., Charlton A. (2005) "Fair Trade For All: How Trade Can Promote Development", Oxford University Press, Inc., New York.

Stiglitz J. (2005) "A willing world can end child poverty"; The Stare of the World's Children", United Nations Children's Fund, 2004, pp.96-97.

Stiglitz J. (2003) 'Globalization, Technology, and Asian Development', Asian Development Review, vol. 20, no 2, pp 1-18.

Stiglitz J. (2003) 'Knowledge As a Public Good'; Case Studies: Knowledge and Information, pp. 308- 325.

Stiglitz J. (2002) 'Comperition and Competitiveness in A New Economy', in Heinz Handler and Christina Berger (eds.), Vienna: Austrian Federal Ministry for Economic Affairs and Labour, pp. 11-12.

Stiglizz J., Wallsten S. (1999) 'Public-Private Technology Partnerships: Promises and Pitfalls', American Behavioral Scientist, Vol. 43, No. 1, September, pp. 52-73.

Stoehr K. (2005) 'Avian influenza and pandemics: Research needs and opportunities'. N. Engl. J. Med.; January 27; 352; 4: 405-407. 
Stoehr K. (2004) 'Will vaccines be available for the next influenza pandemic?' Science, 24 December; 306: 21952196

Stover J., Bollinger L., Hecht R, Williams C., and Roca E. (2007), 'The Impact Of An AIDS Vaccine In Developing Countries: A New Model and Initial Results,' Health Affairs 26, no. 4: 1147-1158; 10.1377/hlthaff.26.4.1147]

Stover J. and Bollinger L. (2006), "The Impact of an AIDS Vaccine in Developing Countries: A New Model and Preliminary Results," Policy Research Working Paper no. 8 (New York: IAVI, October).

Stover J. and Bollinger L. (2005), "A Revicw of the Literature on the Impact of AIDS Vaccines," Policy Research Working Paper no. 5 (New York: International AIDS Vaccine Initiative).

Suh, J. (2000) 'Koreas Innovation System: Challenges and New Policy Agenda', The United Nations Universiry, INTECH, Maastricht.

Suhrcke M., McKee M., Sauto Arce R., Tsolova S., Mortensen J. (2005) 'The contribution of health to the economy of the European Union'; Luxembourg: Office of Official Publications of the European Community, ISBN 92-894-9829-3

Sully R. (1999) 'Managing Risk - Glaxo Wellcome Approaches'. In: Sussex J., Marchant N. 'Risk and return in the pharmaceutical industry', Office of Health Economics, August 1999, London.

Sung L. Pelto D. (1998) "Greater Predictability May Result in patent Pools As the Federal Circuit Refines Scope of Biotech Claims, Use of Collective Rights Becomes Likely", NLJ (Jun. 22), reprinted ar http//www.ljx.com/patents/0622pools.html.)

Sykes, R. (2000) 'New Medicines: The Practice of Medicine and Public Policy', The Nutfield Trust, The Stationery Office, London, 2000.

Tam J. (2003) 'SARS slashes FDI inflows by 62 per cent' The Standard: Greater China's Business Newspaper, 1 October.

Teeling Smith, G. (1992) 'Innovation and Competition in Medicine: A Schumpecarian analysis of the pharmaceutical industry and the NHS, Office of Health Economics, London, UK.

Thomas L. (1996) 'Industrial policy and international competitiveness in the pharmaceutical industry'. In Helms RB, editor. Competitive strategies in the pharmaceutical industry. Washington, DC: The American Enterprise Institute Press, 1996.

Tollman P., Altshuler J., Flanagan A., Steiner M. (2001) 'A Revolution in R\&D: How Genomics and Genetics are transforming the Biopharmaceutical Industry', November 2001, www.bcg.com

Towse A., Renowden O. (2004) 'Estimates of the medium term financial resource needs for development of pharmaceuticals to combat neglected diseases; IPPH Workshop 'Combating diseases associated with poverty: strategies for product development and the potential role of public-private partnerships', London, 15-16 April, 2004.

Treanor JJ, Wilkinson BE, Masseoud F, Hu-Primmer J, Battaglia R, O'Brien D, Wolff M, Rabinovich G, Blackwelder W , Katz JM. (2001) Safety and immunogenicity of a recombinant hemagglutinin vaccine for H5 influenza in humans. Vaccine, 8 February; 19:1732-1737.

Tremonti G. (2005) "Advance Market Commitments for vaccines: A new tool in the fight against disease and poverty", London, December 2.

Trigeorgis L. (1999) 'Real options: Managerial Flexibility and Strategy in Resource Allocation, $4^{\text {th }}$ edition, MIT Press, Cambridge, MA.

Trigeorgis, L. (1993) 'Topics in Real Options and Applications', Financial Management, Autumn, pp. 202-224.

Trouiller, P. et al (2002), 'Drugs development for neglected diseases: a deficient market and a public health policy failure', Lancet, 359, 2188-2194 (2002).

Trouiller, P. et al (2001), 'Drugs for neglected diseases: a failure of the market and public health failure', Trop. Med. Int. Health, 6, 945-951 (2001).

Tsang KWT, Eng P, Liam CK, Shim Y, Lam WK. H5N1 influenza pandemic: contingency plans. The Lancet 2005, August 13; 366: 533-534.

Tufts Center for the Study of Drug Development (2004) 'Outlook 2004', p.4. http://csdd.tufts.edu//nfoServices/OutlookPDFs/Outlook2004.pdf 
UNAIDS (2004) 'Report on the Global AIDS Epidemic'; Geneva, UNAIDS.

UNDP (2001) Unired Nations Development Programme, 'Human Development Report 2001: Making new technologies work for human development',

Ungchusak K, Auewarakul P, Dowell SF, Kitphati R, Auwanit W, Puthavathana P, Uiprasertkul M, Boonnak K, Pittayawonganon $C$, Cox N, Zaki SR, Thawatsupha $P$, Chittaganpitch M, Khontong R, Simmerman JM, Chunsutthiwat S. Probable Person-to-Person Transmission of Avian Influenza A (H5N1). N. Engl. J. Med. 2005; Jan, 27;352:333-340.

US Congress, Office of Technology Assessment (1993) 'Pharmaceutical R\&D: Costs, and Rewards, OTA-H-522. US Government Printing Office, Washington, DC.

Warhurst A. (2005) "Future roles of business in sociery: the expanding boundaries of corporate responsibility and a compelling case for partnership"; Futures, Vol. 37, Issues 2-3, March-April, pp. 151-168.

Washington Times (2005) "Vaccine Vacillation", Washington Times, 13 June.

Watal J. (2007) "The WTO, IPRs and access to medicines", in "Healthy IPRs" edited by Pugatch M., Jensen $\Lambda$, The Stockholm Network, London.

Webber D. (2003) 'Encouraging Pharmaceutical R\&D in Developing Countries', International Federation of Pharmaceutical Manufacturers Association, IFPMA, February 2003, Geneva, Switzerland.

Webber D., Kremer M., (2001) 'Perspectives on stimulating industrial research and development for neglected infectious diseases', Bulletin of the World Health Organization, 2001, 79 (8).

Webber D., Kremer M., (2001) 'Perspectives on stimulating industrial research and development for neglected infectious diseases', Bulletin of the World Healch Organization, 2001, 79 (8).

WHA. (2003) Prevention and control of influenza pandemics and annual epidemics, World Health Assembly Resolution WHA56.19, Geneva: World Health Organization, 2003.

(www.who.int./csr/disease/avian_influenza/en/).

Wheeler C., Berkley, S. (2001), 'Inicial lessons from public-privare partnerships for drug and vaccine development', Bulletin of the World Health Organisation, 79(8), 2001.

Williams B. et al. (2002) 'Estimates of world-wide distribution of child deaths from acute respiratory infections'; Lancet Infect. Dis.; 2: 25-32

Winslade J. and Hutchinson, D.R. (1993) 'Dictionary of Clinical Research'. Brookwood Medical Publications Ltd., Surrey, UK

Winston W., Albright C. (2001) 'Practical Management Science', Duxbury Thomson Learning.

World Bank (1993) 'World Development Report: Investing in Health'. New York: Oxford University Press.

World Economic Forum Global Health Initiative (2005), 'Business and HIV/AIDS: Commitment and Action?', htcp://www.weforum.org/pdf/Initiatives/GHI_Reporc_2005_Final.pdf

World Health Organization (2006) 'Stop TB Partnership' (hrtp://www.stoptb.org/)

World Health Organization (2005) Influenza pandemic preparedness and response. Execurive Board $115^{\text {th }}$ Session Agenda item 4.17; Geneva, Switzerland, 20 January, (www.who.int./csr/disease/avian_influenza/en/).

World Health Organization (2004) Vaccines for pandemic influenza: Informal meeting of WHO, influenza vaccine manufacturers, national licensing agencies, and government representatives on influenza pandemic vaccines. Geneva, Switzerland, 11-12 November 2004. (www.who.int./cst/disease/avian_influenza/en/).

World Health Organization. (2004) Informal consultation on influenza pandemic preparedness in countries with limited resources. Kuala Lumpur, Malaysia, 23-25 June. (www.who.int./csr/disease/avian_influenza/en/).

World Health Organization (2004) 'Avian influenza update: Implications of $\mathrm{H} 5 \mathrm{Nl}$ infections in pigs in China', WHO Department of Communicable Disease Surveillance and Response, Geneva, Switzerland, August 27. (www.who.int./csr/disease/avian_influenza/en/).

World Health Organization (2002) 'Genomics and the World Health: Report of the Advisory Committee on Health Research', Geneva.

World Health Organization (2001) "Macroeconomics and Health: Investing in Healch for Economic Development. Report of the Commission of Macroeconomics and Health"; Geneva: World Health Organization, Geneva, Switzerland. 
World Health Organization (1999) 'The World Health Report 1999. Geneva; and the World Health Report 2000, Geneva, Available : http://www.who.int/aboutwho/en/promoting/nutrition.htm.

Yamane H. (2007), "The Convention on Biodiversity (CBD) and Inrellectual Property Rights"; in M. Pugatch $e t$ al "Healthy IPRs; a forward look at pharmaceutical intellectual property", Stockholm Network, London).

Yarney G. (2002), 'Public sector must develop drugs for neglected diseases', BMJ 324, 698, 2002.

Yuthavong Y. (2001), 'Development and production of drugs for neglected diseases in endemic countries: A key to solving the medicines crisis', MSF/DND Working Group, Geneva, August 2001.

Zon van A. and Muysken J. (2003) "Health as a Principal Determinant of Economic Growth"; MERIT Research Memoranda, 2003-021.

Zon van A. and Muysken J. (1997) "Health, education and endogenous growth" (RM1997-009), UNU-MERIT, Maastricht, The Netherlands.

Zucker L., Darby M., Brewer M. (1998) 'Intellectual human capital and the birth of U.S. Biotechnology Enterprises', American Economic Review, March 1998; 88(1): 290-306.

Zumla A., Grange J. (2001) 'Multidrug resistance tuberculosis - can the tide be turned?', Lancet Infectious Diseases, Vol. 1, 2001. 